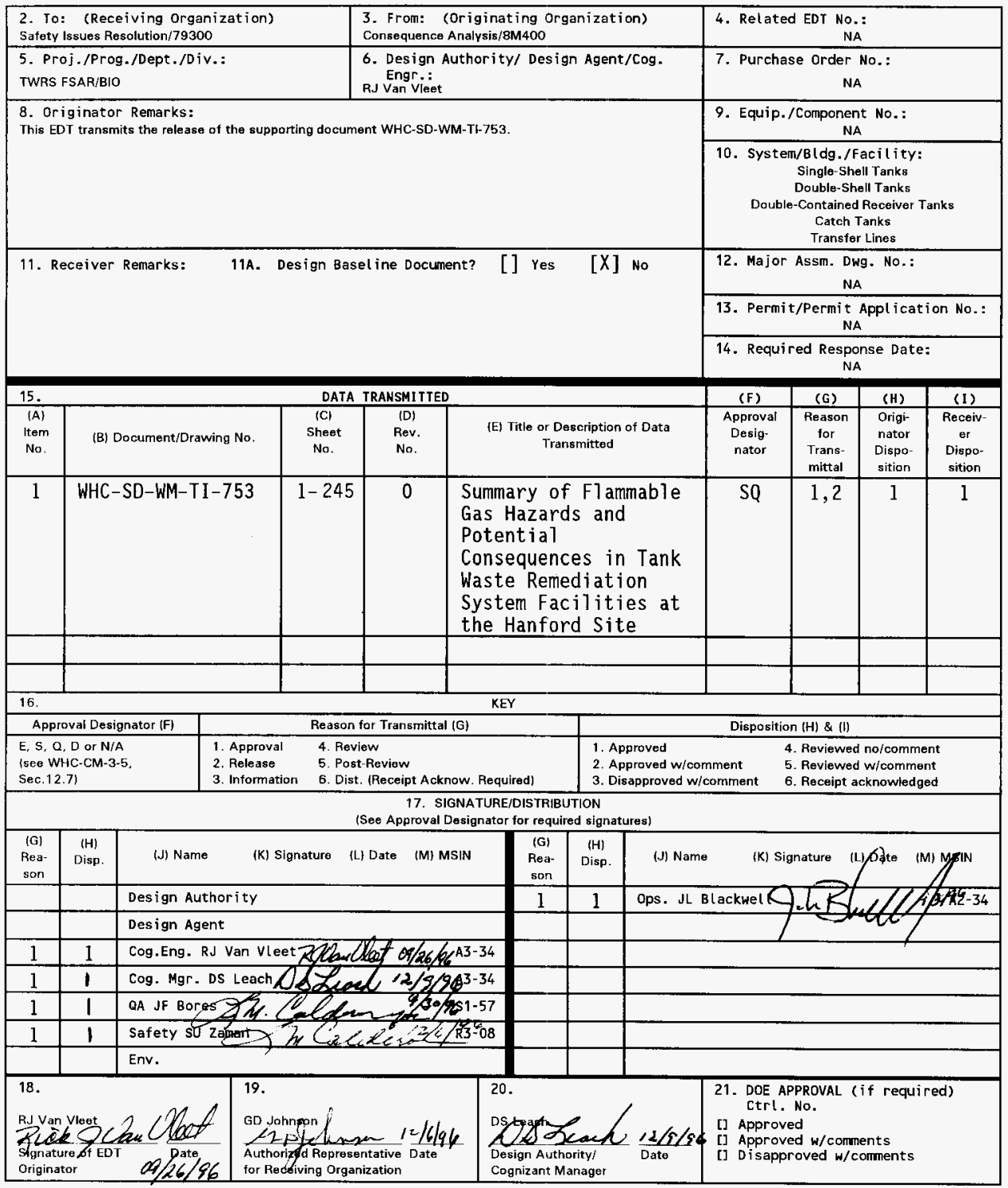




\section{Summary of Flammable Gas Hazards and Potential Consequences in Tank Waste Remediation Facilities at the Hanford Site}

RJ Van Vleet

Westinghouse Hanford Company, Richland, WA 99352

U.S. Department of Energy Contract DE-AC06-87RL10930

$\begin{array}{llll}\text { EDT/ECN: } & 619405 & \text { UC: } 2030 \\ \text { Org Code: } & 8 M 400 & \text { Charge Code: } & \text { N2158 } \\ \text { B\&R Code: } & \text { EW3120072 } & \text { Total Pages: } & 245\end{array}$

Key Words: flammable gas, deflagrations, detonations, dome failure, toxic exposures, radiological exposures, dose consequences, single-shell tanks, SSTs, double-shell tanks, DSTs, double-contained receiver tanks, DCRTs, catch tanks, transfer lines

Abstract: This document provides a summary of the flammable gas program since 1992. It provides the best understanding of generation, retention, release of flammable gases. It gives a composition for each of the flammable gas tanks, calculates postulated concentrations in the event of a release, calculates the pressure obtained during a burn, and provides radiological and toxicological consequences. Controls from the analysis are found in WHC-SD-WM-SAR-067.

TRADEMARK DISCLAIMER. Reference herein to any specific comercial product, process, or service by trade name, trademark, manufacturer, or otherwise, does not necessarily constitute or imply its endorsement, recommendation, or favoring by the United States Government or any agency thereof or its contractors or subcontractors.

Printed in the United States of America. To obtain copies of this document, contact: WHC/BCS Document Control Services, P.O. Box 1970, Mailstop H6-08, Richland WA 99352, Phone (509) 372-2420; Fax (509) 376-4989.
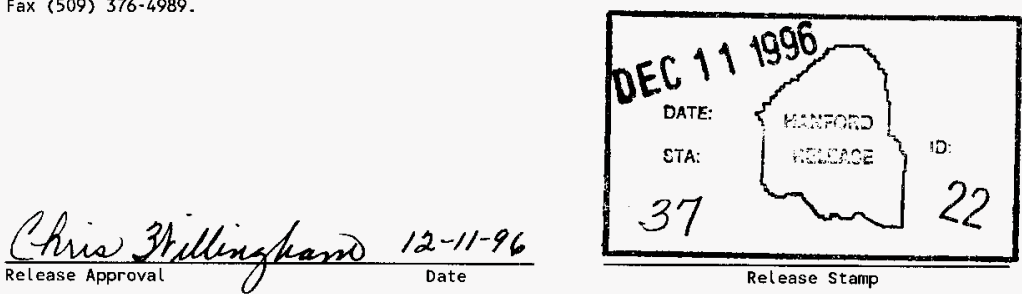

Approved for Public Release 


\section{SUMMARY OF} FLAMMABLE GAS HAZARDS AND POTENTIAL CONSEQUENCES IN TANK WASTE REMEDIATION SYSTEM FACILITIES AT THE HANFORD SITE 
LECAL DISCLAMER

This report was prepared as an account of work sponsored by an egency of the United States Government. Noither the

United States Government nor any egeney thereol, nor any of their employees, nor any of their contractors, subcontractors or their omployees, makes any warranty, express or implied. or assumes any legal liability or responsibility for the accuracy, completeness, or any third party's use or the results of such use of any information, apparatur, product, or process disclosed, or represents that its use would not infringe privately owned rights. Reference herein to eny epecific commercial product, process, or service by trade neme, tredemark, manufacturer, or otherwise, does not necessarily constitute or imply its endorsement, recommendation, or favoring by the United States Government or any gegney thereof or its contractors or subcontractors. The views and opinions of euthors expressed herein do not necesserily state or reflect those of the United States Government or any egency thereof.

This report has been reproduced from the best available copy.

Printed in the United States of America

DISCLM-2.CHP (1-91) 


\section{CONTENTS}

1.0 PURPOSE AND ARRANGEMENT ............................. 1

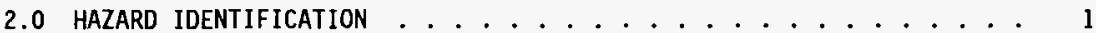

2.1 DESCRIPTION OF THE METHODOLOGY . . . . . . . . . . . . . . . 2

2.2 IDENTIFICATION OF THE SPECTRUM OF POTENTIAL ACCIDENTS . . . . . 2

2.3 IDENTIF ICATION OF THE UNIQUE AND REPRESENTATIVE

FLAMMABLE GAS ACCIDENTS ................. 5

3.0 TANK WASTE REMEDIATION SYSTEM FACILITIES DESCRIPTION . . . . . . . 5

3.1 SINGLE-SHELL TANK DESIGN . . . . . . . . . . . . . . . . 12

3.2 DOUBLE-SHELL TANK DESIGN ................. 12

3.3 DOUBLE-CONTAINED RECEIVER TANK AND TRANSFER LINE DESIGN . . . 18

3.4 CATCH TANK DESIGN . . . . . . . . . . . . . . . . 25

4.0 FLAMMABLE GAS PHENOMENA ............... . . 25

4.1 PHENOMENOLOGY OF TANK GAS GENERATION, RETENTION AND RELEASE . . 25

4.1.1 Single-Shel1 Tanks Gas Generation .......... 28

4.1.2 Double-Shel1 Tank Gas Generation............ 39

4.1.3 Double-Contained Receiver Tanks ............ 43

4.1.4 Catch Tanks .................. 45

4.2 SLURRY GAS COMPOSITIONS .................... . . . 45

4.2.1 Actual Sampling Data . . . . . . . . . . . . . . 46

4.2.2 Simulated Waste Data . . . . . . . . . . . . . 48

4.2.3 Real Waste Data ................. 49

4.2.4 Final Safety Analysis Report Methodology for
Released Slurry Gas Compositions . . . . . 49

4.3 LOCAL, GLOBAL, AND SUBSURFACE DEFLAGRATIONS/DETONATIONS . . . . 54

4.3.1 Estimates of Retained-Gas Volumes . . . . . . . . . 54

4.3.2 Bureau of Mines Flammability Tests . . . . . . . . . . . 54

4.3.3 Local Deflagrations/Detonations . . . . . . . . . 56

4.3.4 Global Deflagrations/Detonations in

Double- and Single-Shell Tanks ............ 61

4.3.5 Global Deflagrations/Detonations in

Double-Contained Receiver Tanks and

Catch Tanks ................ . . 70

4.3.6 Subsurface Deflagrations/Detonations . . . . . . . . 72

4.3.7 0ther Deflagrations and Detonations . . . . . . . 72

5.0 POTENT IAL CONSEQUENCES AND FREQUENCIES . . . . . . . . . . . . 74

5.1 CALCULATED ANNUAL FREQUENCY OF DEFLAGRATION . . . . . . 74

5.1.1 Deflagration Rate When Ignition Source Exists

Prior to Gas Release Event ........... . . . 75

5.1.2 Deflagration Rate When Ignition Source

Develops After a Gas Release Event . . . . . . . . . . 76

5.1.3 Discussions of the Various Potential

Ignition Sources Related to Controls . . . . . . . . 77

5.2 INTERNAL STATIC PRESSURE LIMITS . . . . . . . . . . . . . . 78

5.3 FAILURE MECHANISMS . . . . . . . . . . . . . . . . . . . . 79

5.4 SOURCE TERM ......................... 81 
CONTENTS (cont)

5.5 RADIOLOGICAL CONSEQUENCES ............. 82

5.5.1 Radiological Consequence Calculation Methodology $\therefore 83$

5.6 TOXICOLOGICAL CONSEQUENCES . . . . . . . . . . . . 87

5.6.1 Toxicological Consequence Calculation Methodology . . 87

5.6.2 Peak Concentration Calculation Methods for

Solid and Liquid Toxic Chemical Releases . . . . . . 89

5.7 ACCIDENT SCENARIOS ................... 93

5.7.1 Double-She11 Tank Accident Scenarios . . . . . . 93

5.7 .2 Single-Shell Tank Accident Scenarios . . . . . . 95

5.7.3 Double-Contained Receiver Tank Evaluation

Basis Accident Scenario . . . . . . . . . . 98

5.7 .4 Analysis Methodology . . . . . . . . . . 100

5.8 COMPARISON WITH RISK GUIDELINES $\ldots \ldots \ldots$

5.8.1 Evaluation Basis Accidents . . . . . . . . 101

5.8.2 Evaluation Basis Earthquake ............ 104

5.8.3 Beyond Evaluation Bas is Accident . . . . . . . . . . 107

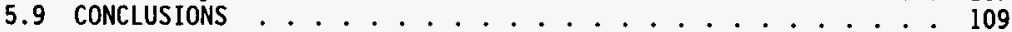

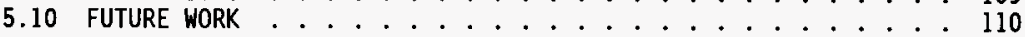

6.0 REFERENCES . . . . . . . . . . . . . . . . 112

APPENDICES

A HEADSPACE CHARACTERIZATION PROGRAM DATAFILE ......... A-1

B STANDARD HYDROGEN MONITORING SYSTEM GRAB SAMPLE ANALYSIS DATAFILE ............... B-1

C SLURRY GAS COMPOSITIONS . . . . . . . . . . . . . . . . c c-1

D ADIABATIC BURN DATA ............... . . . . . . .

F WASTE TANK VENTILATION SYSTEM WASTE MATERIAL ACCUMULATIONS $\because$ F-1

G DEFLAGRATION CONSEQUENCES ............... G-1

H PEER REVIEW CHECKLISTS ................. 


\section{LIST OF FIGURES}

1200 East Area . . . . . . . . . . . . . . . . . . 13

2200 West Area . . . . . . . . . . . . . . . . . . . . 14

3 General Single-Shell Tank Configurations . . . . . . . . . . . 15

4 Nominal Equipment for Single-Shell Tanks . . . . . . . . . . 16

5 General Double-She11 Tank Configurations . . . . . . . . . . 17

6 Nominal Equipment for Double-Shell Tanks . . . . . . . . . . . 19

7 General Configuration of 244-A and 244-S . . . . . . . . . . . 20

8 General Configuration of 244-BX, 244-CR, 244-TX, and 244-U ..... 21

9 General Configuration of Different Types of Encased Transfer Lines ...................... 24

10 General Configuration of 241-EW-151. . . . . . . . . . . . . 27

11 Schematic of Spherical and Dendritic Bubbles . . . . . . . . . . 31

12 Schematic of Other Bubble Retention Mechanisms . . . . . . . . . . 32

13 Schematic of Bubble Retention in Settled Silica . . . . . . . . . 33

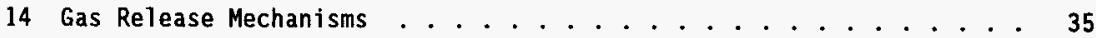

15 Axial Temperature Profile of a Double-Shell Tank . . . . . . . . . 41

16 Buoyant Plume Released from the Waste . . . . . . . . . . . . 59

17 Nonbuoyant Plume Released from the Waste . . . . . . . . . . . 60 


\section{LIST OF TABLES}

1 Analyzed Accidents and the Represented Hazardous Conditions . . . . 6

2 Active Double-Contained Receiver Tanks . . . . . . . . . . . . 22

3 Active Catch Tanks . . . . . . . . . . . . . . . . 26

4 Gas Compositions for the Released Slurry Gas in Tank 241-5Y-101 . . 47

5 Retained-Gas Sampler Results from Tank 241-AW-101 . . . . . . . . . . 48

6 Estimated Compositions for Released Slurry Gas and Lower Flammability Limits . . . . . . . . . . . . . . . . . 52

7 Best Estimates of Retained-Gas Volumes and Headspace Volumes . . . . 55

8 Potential Hydrogen Concentrations Achieved in Local Gas-Release Events ....................... 62

9 Potential Hydrogen Concentrations Achieved in Local Gas-Release Events Involving Larger Releases.................... . 65

10 Potential Hydrogen Concentrations Achieved in Global Gas-Release Events..................... 71

11 Annual Deflagration Rate in Tanks with Flammable Gas . . . . . . . . 75

12 Radiological Risk Guidelines . . . . . . . . . . . . . . . 83

13 Site Boundary Distances for Tank Farms . . . . . . . . . . . . . . 84

14 Centerline Atmospheric Dispersion Coefficients . . . . . . . . . . 86

15 Chronic Annual Average Atmospheric Dispersion Coefficients for 200 Area Tank Farms .................. . 86

16 Parameters used to Calculate Dose Consequences . . . . . . . . . 88

17 Release Durations for Which the Maximum Puff $\chi / Q$ Values Were Used ..................... 89

18 Sum-of-Fractions of Risk Guidelines for a Unit Release . . . . . . . 93

19 Consequences and Frequencies for Double-Shell Tank Deflagrations without Controls ................. 102

20 Consequences and Frequencies for Double-Shell Tank Deflagrations with Controls .................. 102 


\section{LIST OF TABLES (cont)}

21 Consequences and Frequencies without Controls for Single-Shell Tank Deflagrations and Double-Contained Receiver Tank Burns . . . . . . . . . . . 103

22 Consequences and Frequencies with Controls for Single-Shell Tank Deflagrations and Double-Contained Receiver Tanks . . . . . . . . . . 103

23 Consequences and Frequencies for a Seismic Event without Controls . . 106

24 Accidents Conditions Beyond the Evaluation Basis ......... 108 
WHC-SD-WM-TI-753 REV 0

This page intentionally left blank.

viii 


\section{SUMMARY OF FLAMMABLE GAS HAZARDS AND POTENTIAL CONSEQUENCES IN TANK WASTE REMEDIATION SYSTEM FACILITIES AT THE HANFORD SITE}

\subsection{PURPOSE AND ARRANGEMENT}

The purpose of this document is to provide a concise, yet thorough, summary of the hazards associated with the generation, retention (or storage), and release of flammable gases resulting from waste storage operations in the Tank Waste Remediation System facilities at the U.S. Department of Energy's Hanford Site and to calculate the possible consequences and estimate the frequencies of these hazardous conditions. The results of this analysis will be used to support the results reported in the Tank Waste Remediation System Final Safety Analysis Report.

The summary presented herein begins with descriptions of the hazards and the facilities where the waste is stored and progresses through discussions of analyses, modeling, and testing of possible gas generation, retention, and release mechanisms; discussions of the compositions of the flammable gases that appear to be present in the tank wastes, based on analyses of actual gas samples collected from the tanks and gas generation simulations performed to date; and studies of potential natural and intrusive activities that may result in the deflagration of these gases. The summary concludes with projections of the consequences under both unmitigated and mitigated conditions if these deflagrations were to occur.

It should be noted, however, that the methodology used in this analysis is not intended to be a worst-case analys is (in which conservatism on top of conservatism is applied). Consequence analyses were performed only at the beginning of structural failure of the tank. Releases from larger deflagrations or detonations were not modeled because the computer codes are not robust or stable in this area. However, estimates for the higher consequences were developed and are presented in Sections 5.8.2 and 5.8.3. Many of the parameters used for calculations in this document are more "best estimates" for "normal" releases (i.e., more average in nature). As discussed in the text in Sections 4.1.1.2.2, 4.1.1.2.3, 4.1.1.2.4, 4.1.2.2.2, 4.1.2.2.3, $4.2,4.2 .4,4.3 .1,5.3$, and 5.4 and in Appendix D, variations in the key parameters used in the calculations could lead to large variations in the postulated consequences (failure of the tank and radiological and toxicological consequences that could be much higher than those reported in Section 5.8.1, and the number and type of tanks which could exceed risk acceptance guidelines could vary greatly).

\subsection{HAZARD IDENTIFICATION}

The methods used to identify the hazards that are analyzed in this document are described in this section. These hazards were assessed to evaluate the potential internal, external, and natural phenomena events that 
can affect the public, workers, or the environment due to the uncontrolled release of hazardous materials. Sabotage and terrorism were not included. Single and multiple failures (equipment and human errors) were considered as well as common-cause failures.

\subsection{DESCRIPTION OF THE METHODOLOGY}

A summary of the methodology used to perform the Tank Waste Remediation System hazard analysis is presented in this section. The hazard analysis is a systematic and predominantly qualitative evaluation of the spectrum of risks to the public, workers, and environment. It consists of the following activities:

- Hazard identification. Hazardous materials, energy sources, natural phenomena, common cause, and external events associated with facility design, processes, and operations are identified. The results of the hazard identification process provide information used during the hazard evaluation for identifying potential hazardous conditions.

- Hazard topography. Representative hazard evaluations are performed, and the results of the evaluations are mapped to the appropriate Tank Waste Remediation System facility. This activity ensures comprehensive coverage of hazardous conditions.

- Hazard evaluation. Hazardous conditions are identified, and their frequency and consequence are qualitatively assessed. The frequency and consequence estimates provide a basis for selection of the accidents that require a more detailed, quantitative analysis.

- Accident selection. Hazardous conditions identified by the hazard evaluation are used to select candidate accidents for more detailed quantitative analysis. The accidents selected to be analyzed encompass the range of hazardous conditions identified by the hazard evaluations.

- Control identification. Safety-class and safety-significant structures, systems, and components as well as technical specification requirements and other controls required to protect the public, workers, and the environment are identified.

More details can be found in WHC-SD-WM-TI-759, Hazard Evaluations for the Tank Waste Remediation System Final Safety Analysis Report (Niemi 1996a); and WHC-SD-WM-TI-773, Hazard Analysis Results Report (Niemi 1996b).

\subsection{IDENTIFICATION OF THE SPECTRUM OF POTENTIAL ACCIDENTS}

The hazard evaluation tables documented in Niemi (1996a) contain descriptions of causes of hazardous conditions. Each hazardous condition is assessed to determine a qualitative frequency of occurrence and consequence. 
The likelihood assessments are made in occurrences per year. The general criteria used for likelihood assessments are as follows.

F3 The hazardous condition based on the cause(s) postulated has occurred or is likely to occur (anticipated).

F2 The hazardous condition based on the cause(s) postulated is foreseeable (unlikely).

F1 The hazardous condition based on the cause(s) postulated is perhaps possible (extremely unlikely).

Fo The hazardous condition based on the cause(s) postulated is considered too improbable to warrant further consideration (beyond extremely unlikely).

The consequence category assessments address potential impacts on health and safety, and the environment. The general criteria for consequence assessments of impacts on health and safety are as follows.

S3 Based on the material at risk and cause(s) postulated, sufficient material and release energy exist to impact a receptor at the Hanford Site boundary.

S2 Based on the material at risk and cause(s) postulated, sufficient material and energy exist to impact a receptor approximately $100 \mathrm{~m}$ from the source of the material.

S1 Based on the material at risk and cause(s) postulated, the release is confined to the facility where it occurred.

So Based on the material at risk and cause(s) postulated, material release is insufficient to affect facility workers.

The consequence category assessments also address potential impacts on the environment. The general criteria for consequence assessments of impacts on the environment are as follows.

E3 Al1 \$3 hazardous conditions or significant leaks from large storage tanks occur.

E2 A11 S2 hazardous conditions or liquid releases or leaks outside facility boundaries occur.

E1 Postulated releases not included in E3 or E2 occur.

EO No release is postulated.

Two standard techniques were used for the Tank Waste Remediation System hazard evaluation: hazards and operability studies and preliminary hazard analysis. See Niemi (1996a) for more details. The results of the hazard evaluation led to selection of the final set of accidents. These accidents, which represent all S3 and S2 hazardous conditions, are as follows. 
NOTE: Only some of these deal with the flammable gas hazards, see Section 2.3 for more detail.

- In-tank fuel fire or deflagration

- Mixing of incompatible material, causing tank pressurization

- Flammable gas deflagration in double-shell tanks

- Flammable gas deflagration in single-shell tanks

- Organic solvent fire/organic salt-nitrate reaction

- High wind

- Lightning

- Seismic event

- Tank failure due to excessive load

- Tank failure due to vacuum or degradation

- Spray leak from within structure or from overground waste transfer 1 ines

- Spray leak from underground waste transfer lines

- Tank bump

- Surface leak resulting in a pool

- Subsurface leak remaining subsurface

- Nuclear criticality

- High-efficiency particulate air filter failure resulting from exposure to high temperature or pressure

- Fire in contaminated area

- Waste transport vehicle accident

- Caustic spray leak

- Unfiltered release

- Subsurface leak resulting in a pool

- Evaporator dump

- Mixing of incompatible material resulting in toxic vapor generation

- Leak from rail car or tank trailer 
WHC-SD-WM-TI-753 REV 0

- Unplanned excavation or drilling in pond/ditch/crib

- Sodium fire

- Aboveground structure failure

- Steam intrusion from interfacing systems.

\subsection{IDENTIFICATION OF THE UNIQUE AND REPRESENTATIVE FLAMMABLE GAS ACCIDENTS}

Only some of the potential accidents listed in Section 2.2 deal with flammable gas hazards. The analyzed accident and the hazardous conditions that are encompassed by the analyzed flammable gas accidents are presented in Table 1. Further details can be found in WHC-SD-WM-TI-773 (Niemi 1996b). The table contains headings which give a unique identification number, the material at risk, the hazardous condition, the cause, and an estimate of frequency, consequence, and potential impact to the environment (if applicable). The table also indicates the analyzed accident and then immediately below this lists the represented hazardous conditions that are covered by the analyzed accident.

\subsection{TANK WASTE REMEDIATION SYSTEM FACILITIES DESCRIPTION}

Described in this section are the design features of the underground storage tanks and transfer lines comprising the Tank Waste Remediation System facilities that are pertinent to the assessments of the flammable gas hazards and consequences discussed in Sections 3.0 and 4.0. The waste tank design features described are for the single-shell, double-shell, double-contained receiver, and catch tanks used to store the radioactive liquid and solid wastes that were generated during past reactor fuel reprocessing operations at the Hanford Site. The transfer line design features described are for the concrete-encased, pipe-in-pipe, and direct-buried pipe 1 ines used to transfer wastes between these tanks.

The underground storage tanks and associated transfer lines are located in the 200 East and 200 West Areas of the Hanford Site, except for the cross-site transfer line, which runs between the 200 East and 200 West Areas through the 600 Area of the Hanford Site. The tanks in each in the 200 East and West Areas are grouped in clusters, designated as "tank farms." There are 18 tank farms, each of which contains from 2 to 18 tanks of similar design.

Between 1943 and 1964, 149 single-shell tanks were built. Sixty-six of the single-shell tanks are grouped into six tank farms in the 200 East Area (241-A, 241-AX, 241-B, 241-BX, 241-BY, and 241-C). The remaining 83 singleshe 11 tanks are grouped into 6 tank farms in the 200 West Area (241-S, 241-SX, 241-T, 241-TX, 241-TY, and 241-U). 
Table 1. Analyzed Accidents and the Represented Hazardous Conditions. (6 sheets)

\begin{tabular}{|c|c|c|c|c|c|}
\hline 10 & Material at risk & Hazardous condition & Cause & Frequency & $\begin{array}{c}\text { Safety } \\
\text { consequence }\end{array}$ \\
\hline \multicolumn{6}{|c|}{ 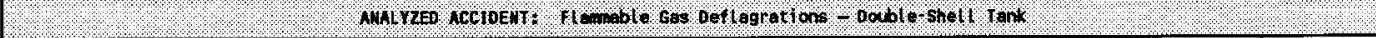 } \\
\hline $1 \mathrm{TK}-10-\mathrm{b}$ & DST tank inventory & $\begin{array}{l}\text { Release of radiaactive material from } \\
\text { in-tank fire or explosion due to } \\
\text { intrusive activity (dome collapse) }\end{array}$ & Spark from equipment or tools & F3 & 53 \\
\hline \multicolumn{6}{|c|}{ Represented Hazardous Conditions } \\
\hline 102AW-02-PRES01 & DST tank contents & $\begin{array}{l}\text { Release of radioactive aerosols from } \\
102-A H \text { tank due to fire-explosion in } \\
\text { waste tank (dome collapse) }\end{array}$ & $\begin{array}{l}\text { F lammable concentration of gases in } \\
\text { tank vapor space with spark source }\end{array}$ & F2 & s3 \\
\hline I-242A-1-FLH-A & $\begin{array}{l}\text { Aerosols and other } \\
\text { radioactive material } \\
\text { from TK-AH-102. }\end{array}$ & $\begin{array}{l}\text { Rel ease of radioactive material fron } \\
\text { feed tank IK-AH-102 due to } \\
\text { fire/explosion caused by igniting } \\
\text { hydrogen gas when pump is damaged and } \\
\text { becomes an ignition source from dead } \\
\text { heading. }\end{array}$ & $\begin{array}{l}\text { Failure of valves to regulate (go } \\
\text { closed), making pump fail and } \\
\text { creating ignition source } \\
\text { AND } \\
\text { sufficient hydrogen accumulation for } \\
\text { fire/explosion }\end{array}$ & F2 & s3 \\
\hline$I-242 A-1-F L W-B$ & $\begin{array}{l}\text { Aerosols and other } \\
\text { radioactive material } \\
\text { from TK-AH-102. }\end{array}$ & $\begin{array}{l}\text { Release of radioactive material from } \\
\text { feed tank tK-Au- } 102 \text { due to } \\
\text { fire/explosion caused by igniting } \\
\text { hydrogen gas when pump is damaged and } \\
\text { becomes an ignition source. }\end{array}$ & $\begin{array}{l}\text { Failure of feed pump, making pump } \\
\text { fail and causing ignition source } \\
\text { AND } \\
\text { sufficient hydrogen accumulation for } \\
\text { fire/explosion }\end{array}$ & F2 & 53 \\
\hline$I-242 A-1-F L W-C$ & $\begin{array}{l}\text { Aerosols and other } \\
\text { radioactive material } \\
\text { from TK-AW-102. }\end{array}$ & $\begin{array}{l}\text { Reiease of radioactive materiai from } \\
\text { feed tank TK-AU- } 102 \text { due to } \\
\text { fire/explosion caused by igniting } \\
\text { hydrogen gas when pump is damaged and } \\
\text { becomes an ignition source from dead } \\
\text { heading. }\end{array}$ & $\begin{array}{l}\text { Plugged tine, which fails pump and } \\
\text { causes ignition source } \\
\text { AND } \\
\text { sufficient hydrogen accumulation for } \\
\text { fire/explosion }\end{array}$ & F2 & s3 \\
\hline$I-242 A-1-F L W-D$ & $\begin{array}{l}\text { Aerosols and other } \\
\text { radioactive material } \\
\text { from TK-AN-102. }\end{array}$ & $\begin{array}{l}\text { Release of radioactive materiat from } \\
\text { feed tank IK-AU-102 due to } \\
\text { fire/explosion caused by igniting } \\
\text { hydrogen gas when pump is damaged and } \\
\text { becomes an ignition source. }\end{array}$ & $\begin{array}{l}\text { Pump plugged, which fails pump and } \\
\text { causes ignition source } \\
\text { AND } \\
\text { sufficient hydrogen accumnlation for } \\
\text { fire/explosion }\end{array}$ & F2 & s3 \\
\hline$I-242 A-1-F L W-E$ & $\begin{array}{l}\text { Aerosols and other } \\
\text { radioactive material } \\
\text { from TK-AW-102. }\end{array}$ & $\begin{array}{l}\text { Release of radioactive material from } \\
\text { feed tank tK-AW-102 due to } \\
\text { fire/explosion caused by igniting } \\
\text { hydrogen gas when pump is damaged and } \\
\text { becones an ignition source from pump } \\
\text { cavitation. }\end{array}$ & $\begin{array}{l}\text { Empty feed tank, wich fails pump } \\
\text { and causes ignition source } \\
\text { ANo } \\
\text { sufficient hydrogen accumlation for } \\
\text { fire/explosion }\end{array}$ & $F 2$ & 53 \\
\hline ITK-11 & Tank inventory & $\begin{array}{l}\text { Release of radioactive material from } \\
\text { in-tank fire or explosion due to } \\
\text { intrusive activity (dome collapse) }\end{array}$ & $\begin{array}{l}\text { Ignition of tank vapors by } \\
\text { lightning, range fire, or seismic } \\
\text { event }\end{array}$ & $F 2$ & 53 \\
\hline
\end{tabular}


Table 1. Analyzed Accidents and the Represented Hazardous Conditions. (6 sheets)

\begin{tabular}{|c|c|c|c|c|c|}
\hline ID & Material at risk & Hazardous condition & Cause & Frequency & $\begin{array}{c}\text { Safety } \\
\text { consequence }\end{array}$ \\
\hline XS-26-PRESO2 & DST tank contents & $\begin{array}{l}\text { Release of radioact ive aerosols from } \\
102-5 Y \text { tank due to flammable gas } \\
\text { fire-expl osion (dome coll lapse) }\end{array}$ & $\begin{array}{l}\text { Accumulation of ftammable gases in } \\
\text { vapor space and spark source }\end{array}$ & $F 2$ & s3 \\
\hline 102AW-03-LEVE01 & DSI tank contents & $\begin{array}{l}\text { Release of radioactive aerosols from } \\
102-\text { AW tank due to fire-explosion in } \\
\text { annulus }\end{array}$ & $\begin{array}{l}\text { fl ammable concentration of gases in } \\
\text { annulus vapor space due to waste } \\
\text { leak into annulus and spark source }\end{array}$ & F2 & $\$ 2$ \\
\hline 102AW-03-LEVE02 & $\begin{array}{l}\text { Liquid radioactive } \\
\text { waste teaked into } \\
102-A W \text { annulus }\end{array}$ & $\begin{array}{l}\text { Release of radioactive aerosols from } \\
\text { 102-AH tank due to fire-explosion in } \\
\text { annulus }\end{array}$ & $\begin{array}{l}\text { Fl ammable concentration of gases in } \\
\text { annut us vapor space due to waste } \\
\text { mistransfer into annulus and spark } \\
\text { source }\end{array}$ & $F 2$ & s2 \\
\hline $1 T K-F R-13$ & $\begin{array}{l}\text { OST \& SST tank } \\
\text { liquid held in flex } \\
\text { receiver }\end{array}$ & $\begin{array}{l}\text { Release of radioact ive } \\
\text { aerosols/vapors from flex receiver } \\
\text { due to buildup and ignition of } \\
\text { flammable gas in receiver }\end{array}$ & $\begin{array}{l}\text { Hydrogen gas buildup in tank/riser } \\
\text { that travels into receiver } \\
\text { AND } \\
\text { ignition source (spark from } \\
\text { hercul ite or equipment) }\end{array}$ & FI & s2 \\
\hline & & ALYZEO ICCIDENT + Ylemnable Gas Deflag & rattons - singlesshell tank & & 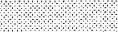 \\
\hline XS-01-FLONO3 & $\begin{array}{l}\text { SST and DCRT tank } \\
\text { contents }\end{array}$ & $\begin{array}{l}\text { Release of l iquids, sol ids, and/or } \\
\text { vapors from SST due to dome collapse } \\
\text { and DCRI pressurization caused by } \\
\text { fl ammable gas explosion/fire } \\
\text { propagating from DCRT to SST }\end{array}$ & $\begin{array}{l}\text { Filling of pipel ine connecting SST } \\
\text { and DCRT with flammable gas; loss of } \\
\text { ventilation flow in OCRT so that a } \\
\text { flamable gas atmosphere is ignited } \\
\text { by the ventilation out let heater }\end{array}$ & $\$ 2$ & s3 \\
\hline \multicolumn{6}{|c|}{ Represented Hazardous Conditions } \\
\hline ITK-08 & Tank inventory & $\begin{array}{l}\text { Release of radioactive material from } \\
\text { in-tank fire or explosion due to } \\
\text { intrusive activity (dome coll lapse) }\end{array}$ & $\begin{array}{l}\text { Exothermic reaction of incompatible } \\
\text { materials in tank }\end{array}$ & F3 & $\$ 3$ \\
\hline ITK-09 & Tank inventory & $\begin{array}{l}\text { Release of radioactive material from } \\
\text { in-tank fire or explosion due to } \\
\text { intrusive activity (dome coll apse) }\end{array}$ & $\begin{array}{l}\text { Failure to bond components or } \\
\text { incorrect bonding }\end{array}$ & F3 & s3 \\
\hline ITK-10-a & SST tank inventory & $\begin{array}{l}\text { Release of radioactive material from } \\
\text { in-tank fire or explosion due to } \\
\text { intrusive activity (dome collapse) }\end{array}$ & Spark from equipment or tools & $F 3$ & $\$ 3$ \\
\hline $106 \mathrm{C}-01 \mathrm{I}$ & Tank inventory & $\begin{array}{l}\text { Release of radioactive and/or } \\
\text { hazardous material from } C-106 \text { tank } \\
\text { due to possible dome collapse caused } \\
\text { by tank high pressure }\end{array}$ & Fire in waste tank & F2 & s3 \\
\hline $106 \mathrm{C}-01 \mathrm{~J}$ & Tank inventory & $\begin{array}{l}\text { Release of radioactive and/or } \\
\text { hazardous materiat from } c-106 \text { tank } \\
\text { due to high pressure in tank and } \\
\text { possible done collapse }\end{array}$ & Explosion/fire in waste tank & F2 & $\mathbf{s 3}$ \\
\hline
\end{tabular}


Table 1. Analyzed Accidents and the Represented Hazardous Conditions. (6 sheets)

\begin{tabular}{|c|c|c|c|c|c|}
\hline ID & Material at risk & Hezardous condition & Cause & Frequency & $\begin{array}{c}\text { Safety } \\
\text { consequience }\end{array}$ \\
\hline $106 \mathrm{C}-01 \mathrm{Ma}$ & Tank inventory & $\begin{array}{l}\text { Release of radioactive and/or } \\
\text { hazardous material from c-106 tank } \\
\text { due to flammable gas explosion/fire } \\
\text { in tank caused by high tenperature in } \\
\text { the tank (dome collapse) }\end{array}$ & Chemical reaction in tank & f2 & s3 \\
\hline $106 C-02 A$ & Tank inventory & $\begin{array}{l}\text { Release of radioactive and/or } \\
\text { hazardous material from c-106 tank } \\
\text { due to dome col lapse caused by } \\
\text { ignition of high flammable-gas } \\
\text { content in tank }\end{array}$ & High waste temperature & F2 & s3 \\
\hline $106 \mathrm{C}-02 \mathrm{~B}$ & Tank inventory & $\begin{array}{l}\text { Release of radioactive and/or } \\
\text { hazardous material from c-106 tank } \\
\text { due to ignition of high ftanmable-gas } \\
\text { content in tank and possible dome } \\
\text { collapse }\end{array}$ & Ventilation system failure & $F 2$ & s3 \\
\hline $106 C-02 C$ & Tank inventory & $\begin{array}{l}\text { Release of radioactive and/or } \\
\text { hazardous material from C- } 106 \text { tank } \\
\text { due to dome collapse caused by } \\
\text { ignition of high flammable-gas } \\
\text { content in tank }\end{array}$ & Tank burp, release of trapped gas & $F 2$ & s3 \\
\hline $106 C-04 A$ & Tank inventory & $\begin{array}{l}\text { Release of radioactive and/or } \\
\text { hazardous material from } \mathrm{C}-106 \text { tank } \\
\text { due to tank damage caused by } \\
\text { flamable gas explosion/fire because } \\
\text { of high flammable-gas content in the } \\
\text { tank (dome collapse) }\end{array}$ & $\begin{array}{l}\text { High f lammable-gas content due to } \\
\text { chemica! reaction in sludge layer }\end{array}$ & $F 2$ & s3 \\
\hline $106 \mathrm{C}-04 \mathrm{~B}$ & Tank inventory & $\begin{array}{l}\text { Release of radioactive and/or } \\
\text { hazardous material from C-106 tank } \\
\text { due to explosion/fire caused by } \\
\text { ignition of flammable gas released } \\
\text { from radiolysis in tank sludge }\end{array}$ & $\begin{array}{l}\text { Radiolysis in sludige layer, allowing } \\
\text { release of trapped gas to vapor } \\
\text { space }\end{array}$ & $F 2$ & s3 \\
\hline $106 C-13 A$ & Tank inventory & $\begin{array}{l}\text { Release of radioactive and/or } \\
\text { hazardous material from C-106 tank } \\
\text { due to possible done collapse, tank } \\
\text { damage caused by high temperature }\end{array}$ & $\begin{array}{l}\text { Propagation of fire in } \mathrm{C}-105 \text { into } \\
\text { tank C-106 }\end{array}$ & F2 & 53 \\
\hline $1145 x-05 . b .1$ & $\begin{array}{l}\text { Radiaactive material } \\
\text { contained in the } \\
\text { tank (this tank has } \\
\text { a dry crust which } \\
\text { may be composed of } \\
\text { easily disturbed } \\
\text { desty material) }\end{array}$ & $\begin{array}{l}\text { Radioactive aerosols from Tank } \$ X-114 \\
\text { waste released to atmosphere due to } \\
\text { flammable-gas ignition resulting in } \\
\text { dome collapse }\end{array}$ & $\begin{array}{l}\text { Radiolysis creating bubbles of gases } \\
\text { in waste }\end{array}$ & F2 & 53 \\
\hline
\end{tabular}


Table 1. Analyzed Accidents and the Represented Hazardous Conditions. (6 sheets)

\begin{tabular}{|c|c|c|c|c|c|}
\hline 10 & Material at risk & Hazardous condition & Cause & Frequency & $\begin{array}{c}\text { Safety } \\
\text { consequence }\end{array}$ \\
\hline XS-01-FLON02 & SST tank contents & $\begin{array}{l}\text { Release of liquids, solids, and/or } \\
\text { vapors from SST due to dome coll lapse } \\
\text { caused by flammable-gas burn }\end{array}$ & $\begin{array}{l}\text { Loss of pump prime, resulting in } \\
\text { overheated pump that ignites } \\
\text { flammable gas }\end{array}$ & $F 2$ & s3 \\
\hline XS-13-PRESO2 & cr contents & $\begin{array}{l}\text { Release of radioactive aerosols from } \\
241-U \text { - } 301 B \text { CT due to fire-explosion } \\
\text { of flamable gas }\end{array}$ & $\begin{array}{l}\text { Buil ldup of } f \text { lammable gas in CT } \\
\text { AND } \\
\text { spark source }\end{array}$ & $F 2$ & $\mathbf{\$ 3}$ \\
\hline $1145 x-04 . b .3 b$ & $\begin{array}{l}\text { Radioactive aerosols } \\
\text { contained in tank } \\
\text { head space }\end{array}$ & $\begin{array}{l}\text { Radioactive aerosols released from } \\
\text { head space of tank Sx- } 114 \text { to } \\
\text { atmosphere through exhaust HEPA } \\
\text { filter due to flarmable gas ignition } \\
\text { in the headspace (dome collapse) }\end{array}$ & $\begin{array}{l}\text { Flammable gas explosion/fire in sx- } \\
114 \text {. } \\
\text { (Note: sx- } 114 \text { is NOT currently } \\
\text { identified as a Flamable Gas Watch } \\
\text { list tank\} } \\
\text { Requires spark to be present }\end{array}$ & F1 & 53 \\
\hline $1145 x-06 . a .1 b$ & $\begin{array}{l}\text { Radicactive material } \\
\text { contained in the } \\
\text { tank (this tank has } \\
\text { a dry crust wich } \\
\text { may be composed of } \\
\text { easily disturbed } \\
\text { dusty material) }\end{array}$ & $\begin{array}{l}\text { Release of radioactive aerosols from } \\
\text { tank } 5 x-114 \text { waste to atmosphere as a } \\
\text { result of a dome collapse }\end{array}$ & $\begin{array}{l}\text { Deflagration of } H^{2} \\
\text { (impl ies gas generation } \\
\text { AMD } \\
\text { a Spark) }\end{array}$ & $F 1$ & s3 \\
\hline $\begin{array}{l}\text { 102AW-01-FLOW } \\
\text { 102AH-02-PRES }\end{array}$ & DST tank contents & $\begin{array}{l}\text { Release of liquids, solids, and/or } \\
\text { vapors from } 102-A 4 \text { tank due to dome } \\
\text { collapse caused by chemical reaction } \\
\text { of incompatible wastes }\end{array}$ & $\begin{array}{l}\text { Misrout ing to destination other than } \\
\text { intended creates chemical } \\
\text { incompatibility }\end{array}$ & $F O$ & s3 \\
\hline 102s-04.e3 & Tank contents & $\begin{array}{l}\text { Release of radioactive aerosols } \\
\text { contained in tank } 5-102 \text { vapor space } \\
\text { to atmosphere due to generation of } \\
\text { excessive heat leading to dome } \\
\text { collapse }\end{array}$ & $\begin{array}{l}\text { Addition of incompatible } \\
\text { waste/chemical (misroute) }\end{array}$ & FO & s3 \\
\hline $1145 x-05 . d$ & $\begin{array}{l}\text { Radioactive material } \\
\text { contained in tank } \\
\text { head space }\end{array}$ & $\begin{array}{l}\text { Radioact ive aerosols released from } \\
\text { Tank } 5 x-114 \text { head space to atmosphere } \\
\text { due to local ized explosion/fire of } \\
\text { flamable gas }\end{array}$ & $\begin{array}{l}\text { Core sampl ing through a pocket of } \\
\text { gas large enough to exceed local LFL } \\
\text { AND } \\
\text { a Spark, resulting in local } \\
\text { explosion/fire }\end{array}$ & F3 & $\$ 2$ \\
\hline ITK-10-I & Material inside MISF & $\begin{array}{l}\text { Release of radioactive or toxic } \\
\text { material from facility due to } \\
\text { in-facility fire or explosion during } \\
\text { intrusive activity }\end{array}$ & $\begin{array}{l}\text { Ignition source provided by spark } \\
\text { from equipment or tools }\end{array}$ & F3 & $\$ 2$ \\
\hline$N P-15$ & $\begin{array}{l}\text { Inventory in } \\
\text { isolated or } \\
\text { abandoned equipment }\end{array}$ & $\begin{array}{l}\text { Radioactive and hazardous material } \\
\text { release from isolated or abandoned } \\
\text { equipment due to fire }\end{array}$ & $\begin{array}{l}\text { Hydrogen-producing chemical } \\
\text { reactions in isolated or abandoned } \\
\text { equipment }\end{array}$ & F3 & $\$ 2$ \\
\hline
\end{tabular}


Table 1. Analyzed Accidents and the Represented Hazardous Conditions. (6 sheets)

\begin{tabular}{|c|c|c|c|c|c|}
\hline 10 & Material at risk & Hazardous condition & Cause & Erequency & $\begin{array}{c}\text { Safety } \\
\text { consequence }\end{array}$ \\
\hline $106 C \cdot 04 A 3$ & Tank atmosphere & $\begin{array}{l}\text { Release of radioactive and/or } \\
\text { hazardous materiat from } \mathrm{C} / 06 \text { tank due } \\
\text { to ftammable-gas content of the waste } \\
\text { causing an exothermic reaction in } \\
\text { waste tank }\end{array}$ & $\begin{array}{l}\text { High flammable-gas content in tank } \\
\text { sludge layer due to chemical } \\
\text { reaction }\end{array}$ & $F 2$ & s2 \\
\hline 244AR-01.C.09 & $\begin{array}{l}\text { Radioactive and } \\
\text { toxic material } \\
\text { contained in tank }\end{array}$ & $\begin{array}{l}\text { Release of radioactive aerosols from } \\
\text { vessel headspace into canyon } \\
\text { atmosphere due to flammable-gas } \\
\text { ignition }\end{array}$ & $\begin{array}{l}\text { Ignition of flamable gas that has } \\
\text { collected in piping and tank dome }\end{array}$ & F2 & s2 \\
\hline 244AR-03.a.04 & $\begin{array}{l}\text { Radioactive material } \\
\text { contained in the } \\
\text { tank }\end{array}$ & $\begin{array}{l}\text { Release of radioactive aerosols into } \\
\text { cell due to ignition of flammable gas } \\
\text { in } 244-A R \text { Vault tank headspace }\end{array}$ & $\begin{array}{l}\text { Explosion/fire due to ignition of } \\
\text { accumulated flamable gas }\end{array}$ & F2 & s2 \\
\hline BND-02 & $\begin{array}{l}\text { Surface } \\
\text { contamination in } \\
\text { pits and risers }\end{array}$ & $\begin{array}{l}\text { Release of radioactive aerosols from } \\
\text { tank due to ignition of combustibles } \\
\text { during preparation for bonding }\end{array}$ & $\begin{array}{l}\text { Sparks from drilling holes for } \\
\text { bonding attachments when flammable } \\
\text { gases of materials are present }\end{array}$ & F2 & $\$ 2$ \\
\hline ITK-08-I & Material inside MISF & $\begin{array}{l}\text { Release of radioactive or toxic } \\
\text { material from facility due to in- } \\
\text { facility fire or explosion during } \\
\text { intrusive activity }\end{array}$ & $\begin{array}{l}\text { Exothermic reaction of incompatible } \\
\text { materials in facility }\end{array}$ & F2 & $\$ 2$ \\
\hline IIK-09-I & Material inside MISF & $\begin{array}{l}\text { Release of radioactive or toxic } \\
\text { material from facility due to in- } \\
\text { facility fire or explosion during } \\
\text { intrusive activity }\end{array}$ & $\begin{array}{l}\text { Failure to bond components or } \\
\text { incorrect bonding }\end{array}$ & 52 & $\mathbf{s 2}$ \\
\hline RSR-06-I & Material inside MISF & $\begin{array}{l}\text { Release of radioactive or toxic } \\
\text { material from facility due to in- } \\
\text { facility fire or explosion during } \\
\text { riser removal activity }\end{array}$ & $\begin{array}{l}\text { Failure to bond components or } \\
\text { incorrect bonding, allowing } \\
\text { electrostatic spark }\end{array}$ & F2 & 52 \\
\hline $\begin{array}{l}\text { XS-03-LEVE01 } \\
\text { XS-21-LEVE } \\
(244-S \text { DCRT) }\end{array}$ & OCRT tank contents & $\begin{array}{l}\text { Release of combustion products from } \\
244-\text { IX OCRT due to flamable gas burn } \\
\text { in tank atmosphere }\end{array}$ & $\begin{array}{l}\text { Evaporation of DCRI contents, } \\
\text { causing decreased ability of waste } \\
\text { to retain flammable gases } \\
\text { AND } \\
\text { spark source }\end{array}$ & $\mathrm{F} 2$ & $\$ 2$ \\
\hline $\begin{array}{l}\text { XS-03-PRESO1 } \\
\text { XS-21-PRES } \\
\text { (244-S DCRT) }\end{array}$ & DCRT tank contents & $\begin{array}{l}\text { Release of liquid aerosols from } \\
244-\text { TX-DCRT due to flammable gas burn } \\
\text { in tank atmosphere }\end{array}$ & $\begin{array}{l}\text { Loss of ventilation flow with } \\
\text { accumul ation of flammole gas } \\
\text { AND } \\
\text { spark source }\end{array}$ & $F 2$ & $s 2$ \\
\hline $\begin{array}{l}\text { XS-03-TEMPO3 } \\
\text { XS-21-TEMP } \\
\text { (244-S-DCRT) }\end{array}$ & DCRT tank contents & $\begin{array}{l}\text { Release of liquid aerosols from } \\
244-T X-D C R T \text { due to flamable gas } \\
\text { burn-explosion/fire in tank } \\
\text { atmosphere }\end{array}$ & $\begin{array}{l}\text { Buildyp of gases, loss of } \\
\text { ventilation } \\
\text { AND } \\
\text { spark source }\end{array}$ & $F 2$ & s2 \\
\hline
\end{tabular}


Table 1. Analyzed Accidents and the Represented Hazardous Conditions. (6 sheets)

\begin{tabular}{|l|l|l|l|l|l|}
\hline ID & Material at risk & Hazardous condition & Cause & Frequency & $\begin{array}{c}\text { Safety } \\
\text { consequence }\end{array}$ \\
\hline XS-41B-LEVE01 & $\begin{array}{l}\text { Vent station CT } \\
\text { contents }\end{array}$ & $\begin{array}{l}\text { Release of radioactive aerosols from } \\
\text { vent station CT due to flammable gas } \\
\text { fire or explosion in nozzle pit }\end{array}$ & $\begin{array}{l}\text { Failure to empty CT, with buildup of } \\
\text { flammable gas in nozzle pit plus } \\
\text { ignition source }\end{array}$ & F2 \\
\hline XS-41C-LEVE01 & $\begin{array}{l}\text { Vent station CT } \\
\text { inventory }\end{array}$ & $\begin{array}{l}\text { Release of radioactive aerosols from } \\
\text { vent station CT due to flammable gas } \\
\text { fire or explosion in CT pit }\end{array}$ & $\begin{array}{l}\text { Leak of CT with buildap of flammable } \\
\text { gas in CT pit plus ignition source }\end{array}$ & F2 & s2 \\
\hline 244AR-02.a.03 & $\begin{array}{l}\text { Radioactive material } \\
\text { contained in vessel }\end{array}$ & $\begin{array}{l}\text { Release of radioactive liquid in the } \\
\text { form of aerosols contained in a cell } \\
\text { to the exterior of the 244-AR } \\
\text { facility due to ignition of flammable } \\
\text { gas }\end{array}$ & Explosion/fire from hydrogen buildup & F1 & S2 \\
\hline
\end{tabular}


Between 1968 and 1986, 28 double-shell tanks were built. Twenty-five of the double-shell tanks are grouped into five tank farms in the 200 East Area (241-AN, 241-AP, 241-AW, 241-AY, and 241-AZ). The remaining three double-shell tanks are grouped into one tank farm in the 200 West Area (241-SY).

Figures 1 and 2 show the 200 East and 200 West Areas and their respective tank farms.

\subsection{SINGLE-SHELL TANK DESIGN}

In single-shell tank designs, waste confinement is achieved by a reinforced concrete shell with a liner of mild carbon steel covering the bottom and the sidewalls.

There are two series of single-shell tank designs-100 series and 200 series. Early 100-series single-she11 tanks are $22.86 \mathrm{~m}(75 \mathrm{ft})^{1}$ in diameter and are constructed to hold a liquid volume of $2,006,200 \mathrm{~L}$ $(530,000 \mathrm{gal})$ of waste. Later 100 -series single-she11 tanks, of the same diameter, are constructed to hold a liquid volume of $2,869,300 \mathrm{~L}(758,000 \mathrm{gal})$ and $3,785,400 \mathrm{~L}(1,000,000 \mathrm{gal})$ of waste. There are 16 smaller 200-series single-shell tanks, called receiver tanks, with a diameter of $6.1 \mathrm{~m}$ (20 ft) and a liquid-holding capacity of $208,200 \mathrm{~L}(55,000 \mathrm{gal})$. Figure 3 shows the general configuration of these different tank designs. Figure 4 shows the nominal equipment for a single-shell tank.

\subsection{DOUBLE-SHELL TANK DESIGN}

Each double-shell tank consists of three concentric structures, as shown in Figure 5. The outmost structure is a reinforced concrete tank, designed to sustain soil loads, dead loads, Tive loads, and temperature gradients generated by the radioactive wastes contained within the tank (Koontz 1986).

The reinforced concrete tank is lined with a carbon-steel 1 iner, referred to as the secondary tank. The inner, free-standing, completely enclosed carbon-steel tank is referred to as the primary tank. An annular space, or annulus, separates the two steel tanks. The primary tank is designed to contain the radioactive waste materials. The secondary steel tank is designed to contain any liquid leakage from the primary tank until the tank contents can be transferred to available storage space (Koontz 1986). This design meets the intent of double containment for hazardous material storage required by the Resource Conservation and Recovery Act of 1976.

${ }^{1}$ The tanks were built using English units. Most conversions in this document take the English measurement and convert it to the corresponding metric value. 
Figure 1. 200 East Area.

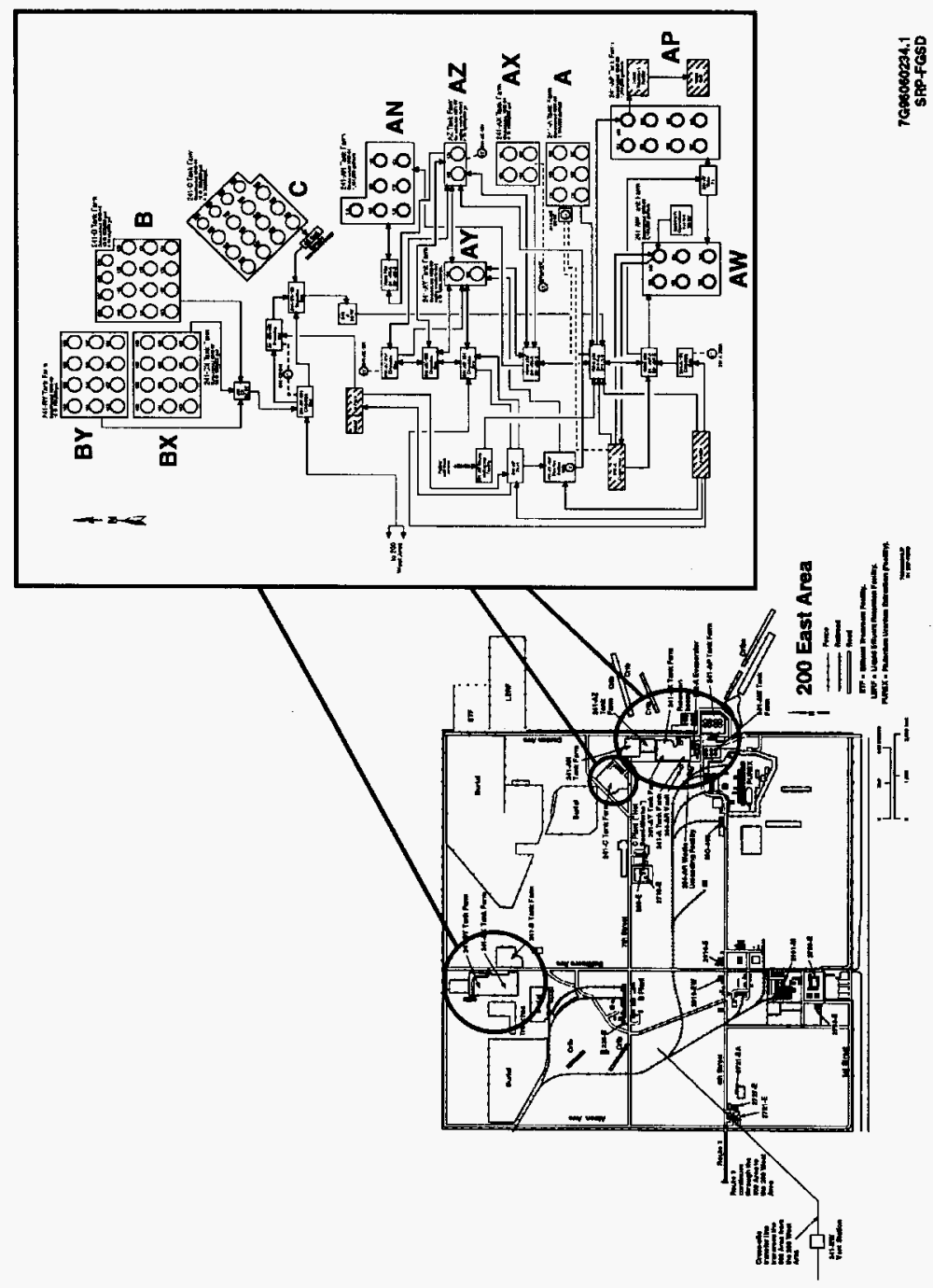




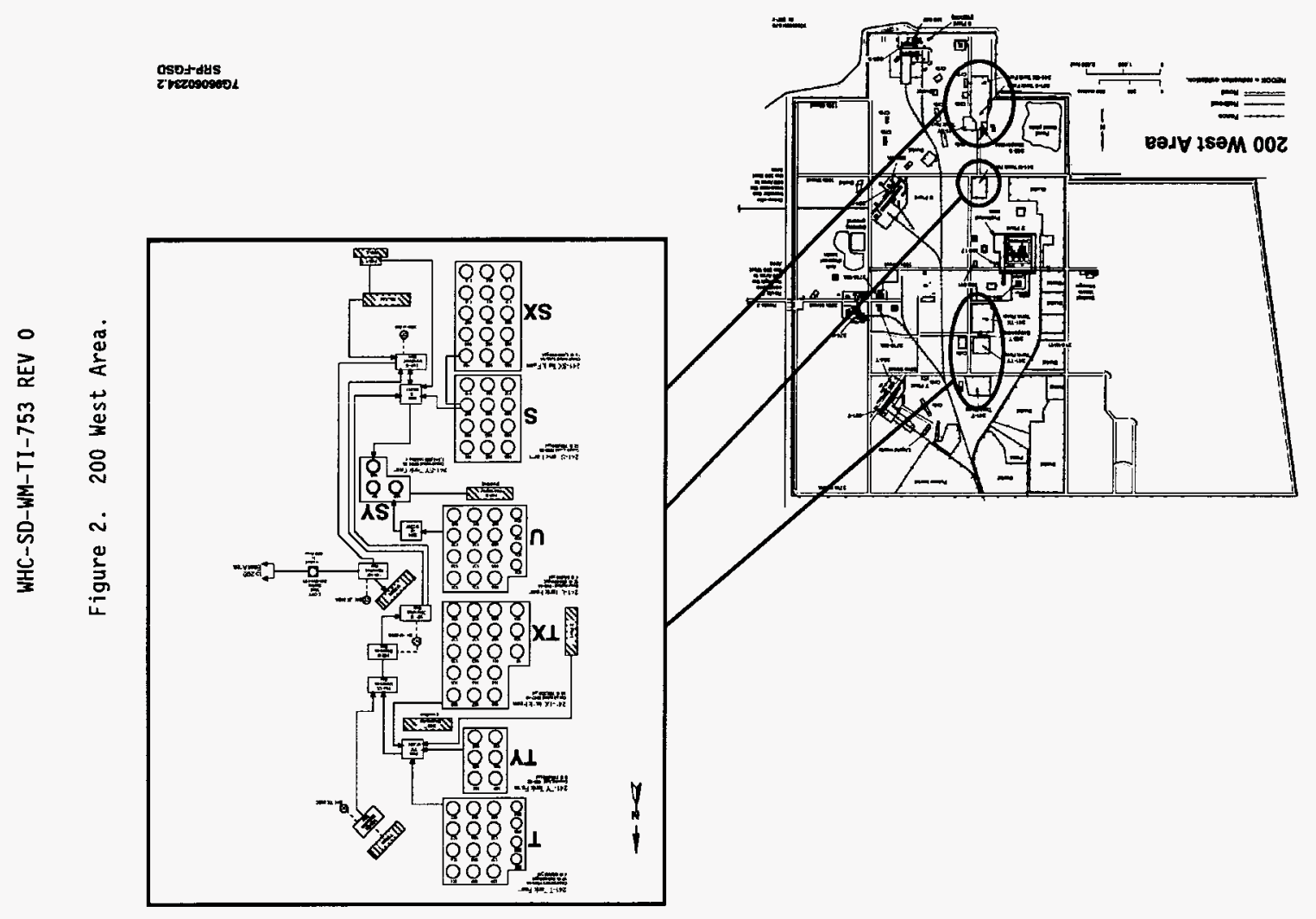



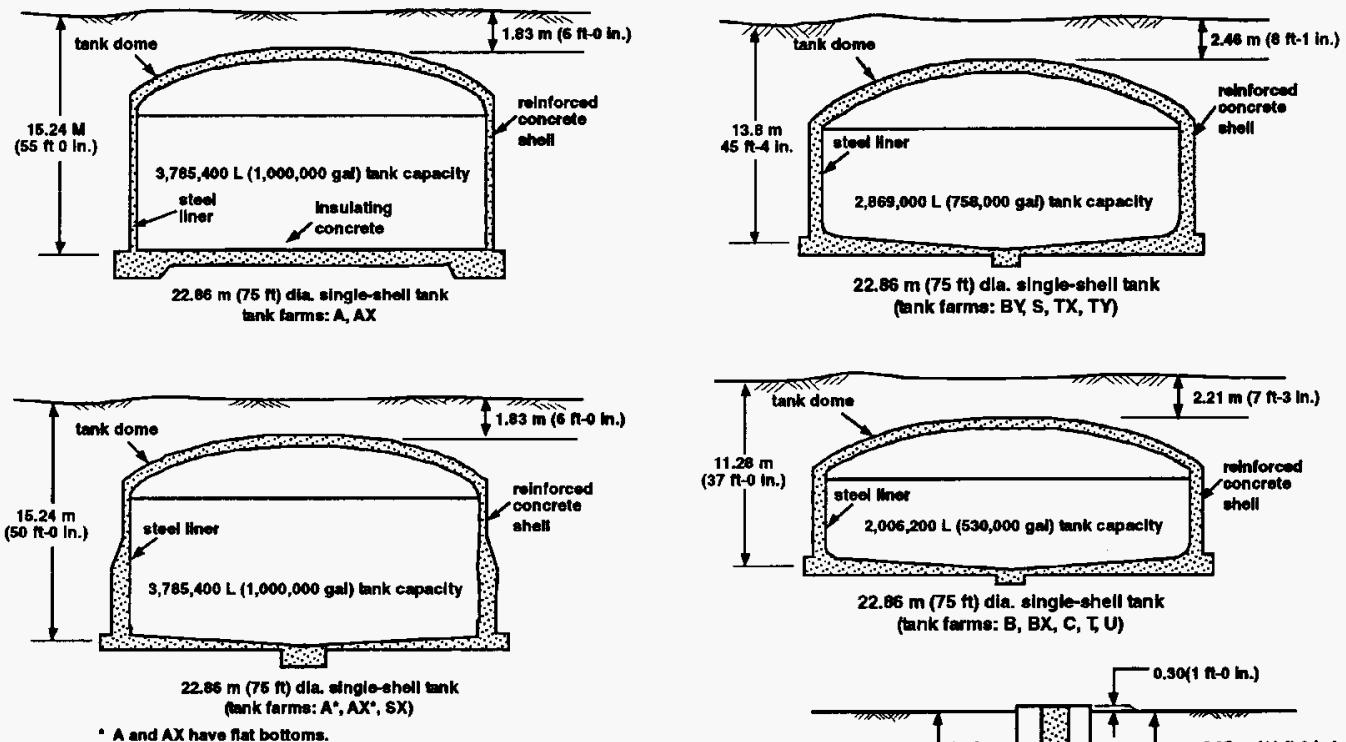

(tank farms: $B, B X, C, T, U$ )

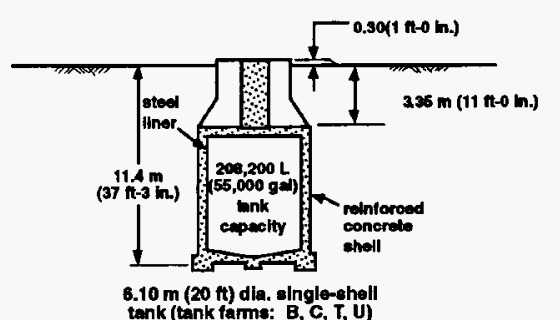

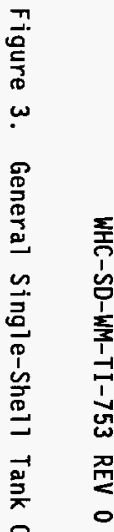

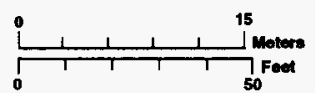




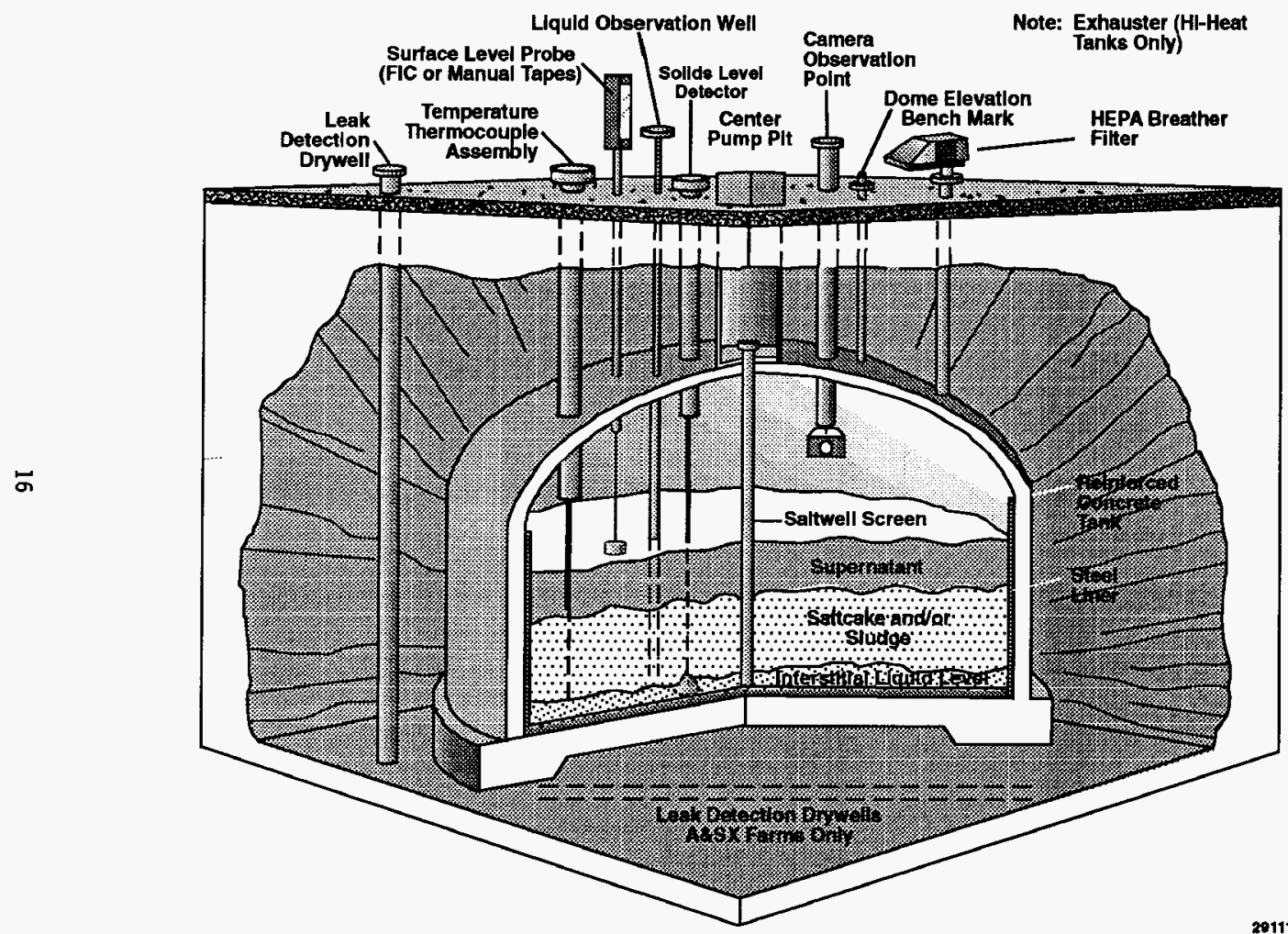

Note: Exhauster (HI-Heat
Tanks Only)

Observation

Dome Elevatlon

etectlon $\checkmark 1$

卌

ำ

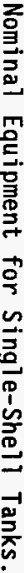

20111046.20
SRP-FGSD 
Figure 5. General Double-Shell Tank Configurations.

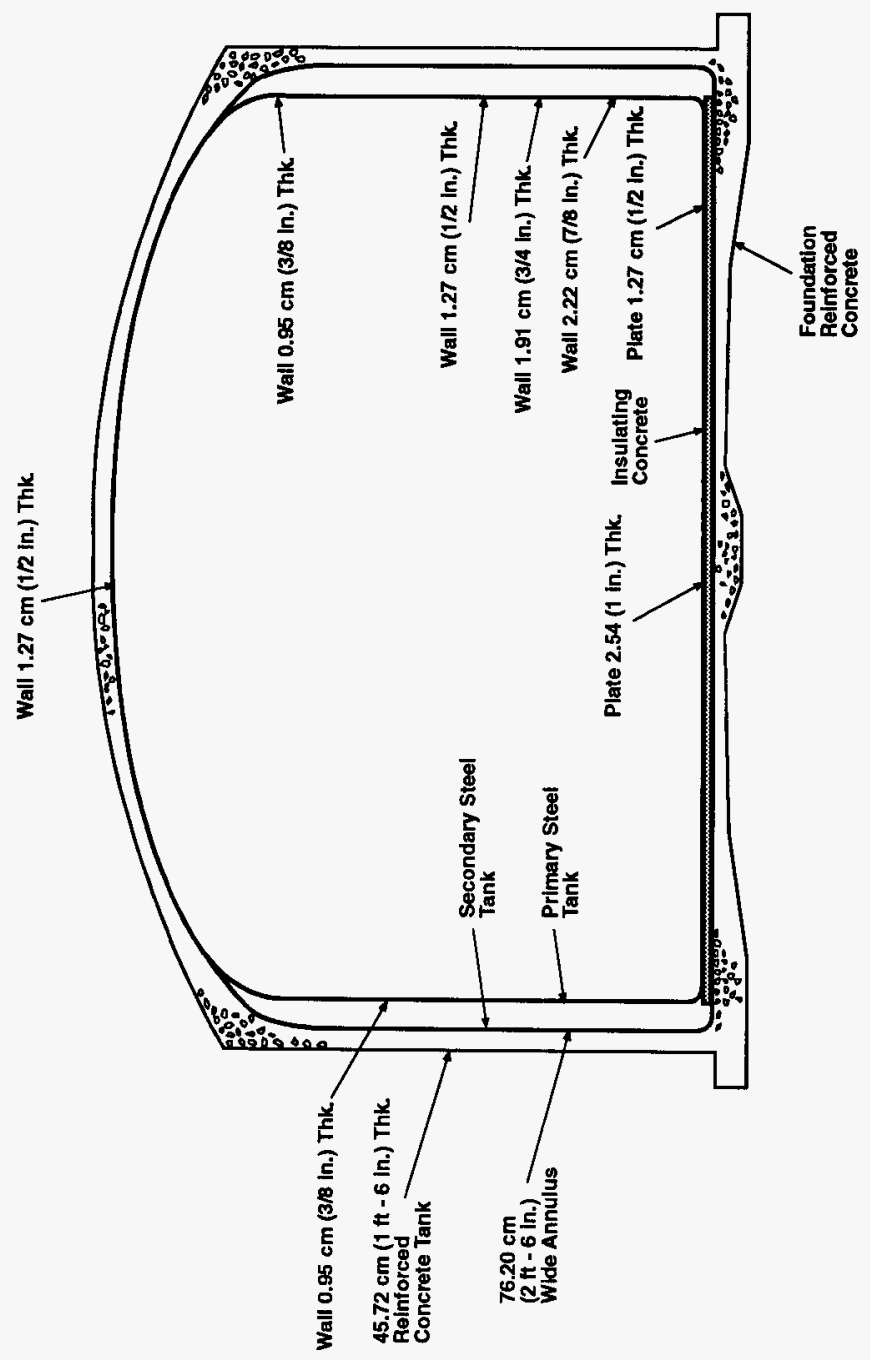


The free-standing primary tanks are $22.86 \mathrm{~m}(75 \mathrm{ft})$ in diameter and $14 \mathrm{~m}$ ( $46 \mathrm{ft}$ ) high at the dome crown. These tanks are designed to hold a liquid volume of $4,392,000 \mathrm{~L}(1,160,000 \mathrm{gal})$, except for the 241-AY and 241-AZ tanks, which are designed to hold a total liquid volume of $3,785,400 \mathrm{~L}$ $(1,000,000 \mathrm{gal})$. The operating liquid volumes (corresponding to waste volumes) for these tanks are lower than the design volumes.

Both the primary tank and the annulus are actively ventilated by separate ventilation systems. The annulus ventilation system routes air from the bottom-center of the secondary tank through slots in the insulating concrete to the annulus. The primary ventilation system draws air from the tank through a riser into the exhaust lines. Leakage into the tank (in-leakage) through the pump-pit and risers provides the make-up air to the primary tank. Except for the 241-SY, 241-AN and 241-AW tank farms, inlets on the primary tank are unfiltered.

Figure 6 shows the nominal equipment for a double-shell tank.

\subsection{DOUBLE-CONTAINED RECEIVER TANK AND TRANSFER LINE DESIGN}

A double-contained receiver tank is a short-term waste storage facility that consists of an underground reinforced concrete structure that typically contains three interconnected compartments: (1) a filter pit, (2) a pump pit, and (3) a vault in which a catch tank is installed. Typically, an instrumentation pit is located above the vault, but it is not interconnected with the vault. There are seven active double-contained receiver tanks (244-A, 244-BX, 244-CR, 244-S, 244-TX, 244-U, and 241-A-350). Shown in Figures 7 and 8 are the two most common double-contained receiver tank configurations. Additional information about the active double-contained receiver tanks is provided in Table 2.

The double-contained receiver tank is used for interim storage of liquid waste and as a valve pit for waste transfer operations. Components for mixing steam and water for backflushing and decontaminating the tanks are located in a nearby flush pit. At Hanford, the term "lift station" has been used synonymously with double-contained receiver tank.

The residence time for storage of wastes in double-contained receiver tanks may vary from a few days to several years. In recent years the primary use of double-contained receiver tanks has been to receive single-shell tank liquid wastes during the process of interim stabilization of the waste by salt-well jet pumping. (A salt well is a long cylinder with a screen section at the bottom that is placed in the waste tank through a tank riser and into which pumping equipment is placed to facilitate pumping of tank waste fluids.)

The facilities designated as double-contained receiver tanks were built from several designs. In every design, the double-contained receiver tank contains a catch tank (primary containment) that is enclosed in a concrete vault (secondary containment), and the vault and tank are served by a common 
Figure 6. Nominal Equipment for Double-She11 Tanks.

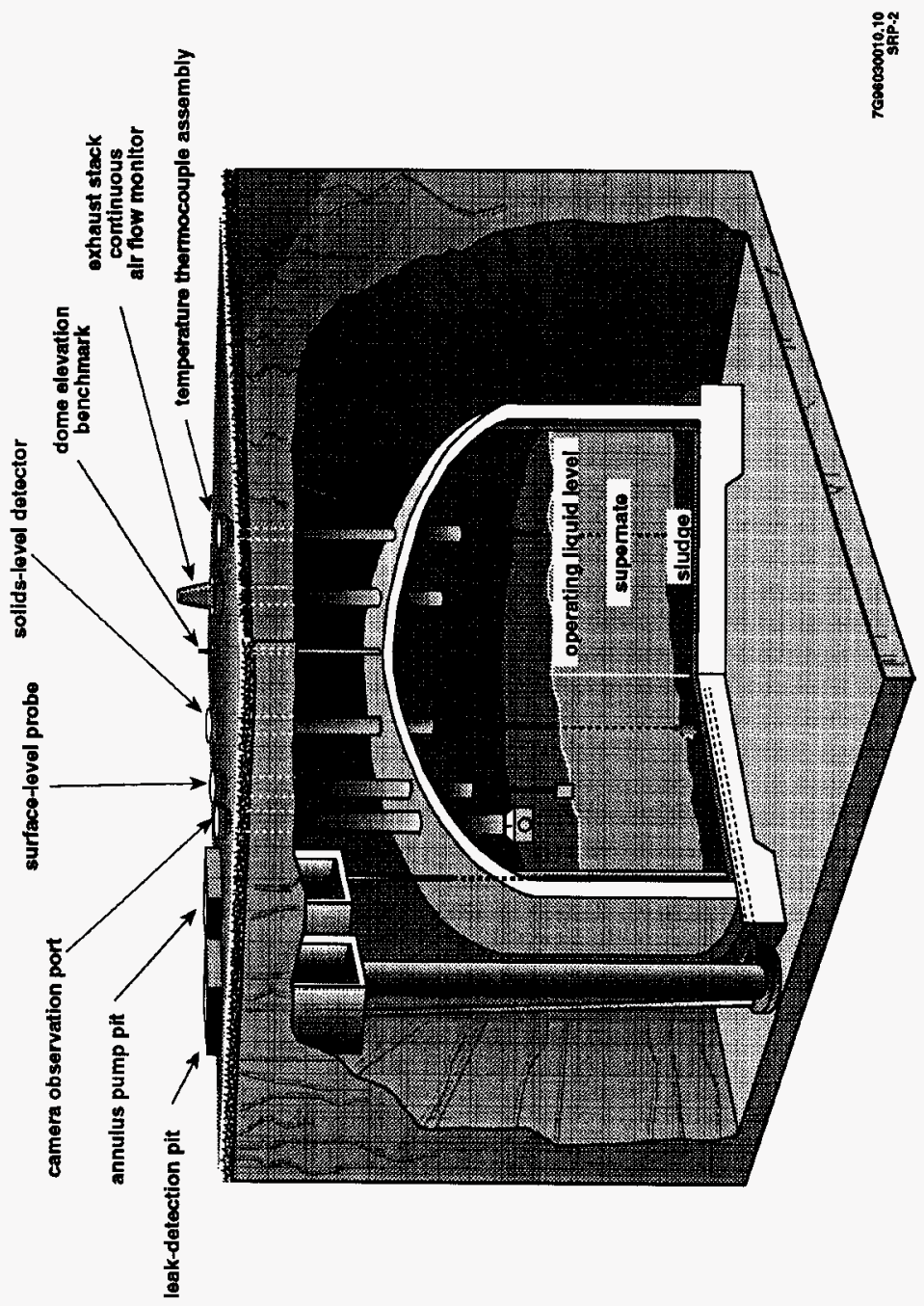


Figure 7. General Configuration of 244-A and 244-S.

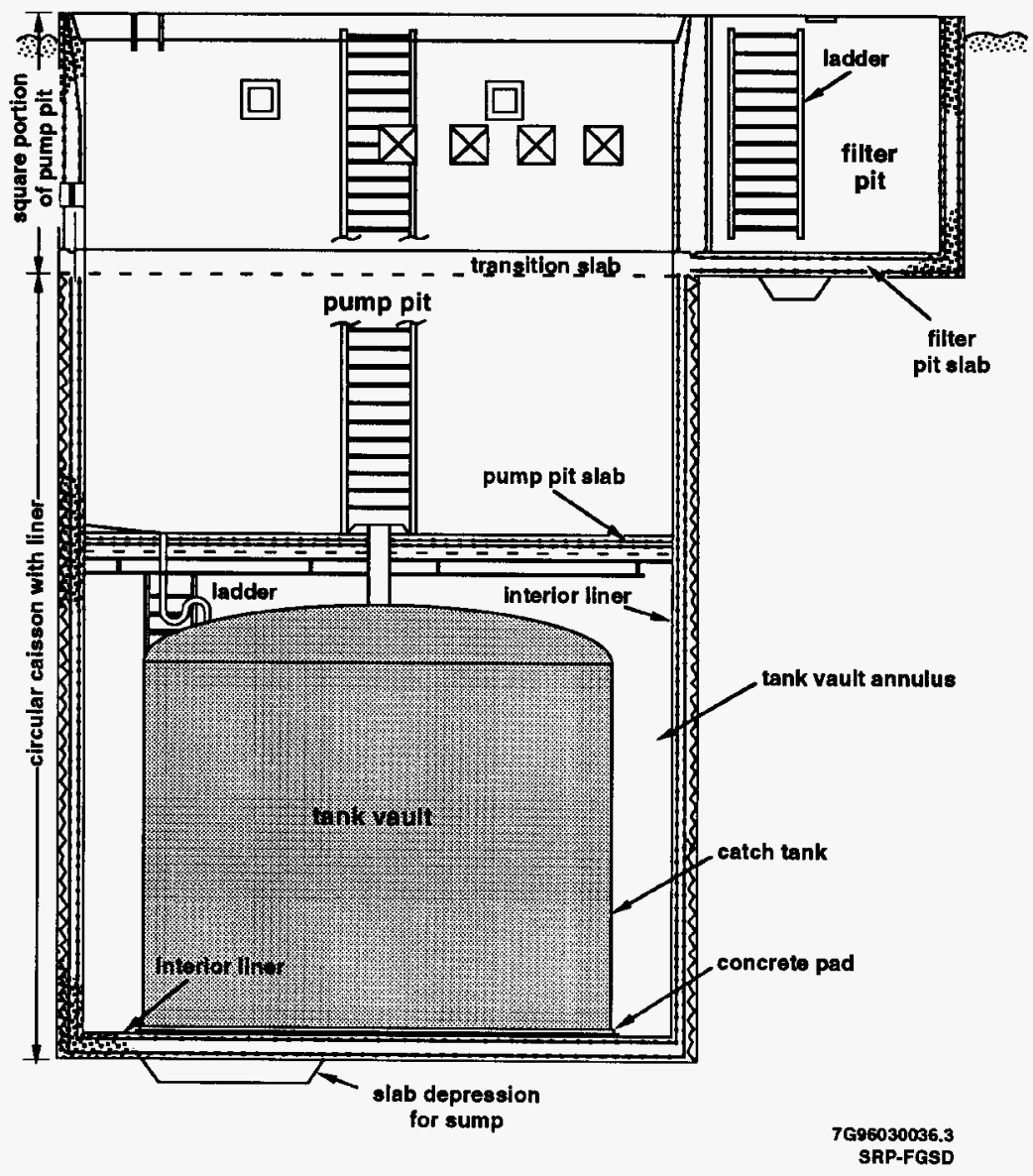


WHC-SD-WM-TI-753 REV 0

Figure 8. General Configuration of 244-BX, 244-CR, 244-TX, and 244-U.

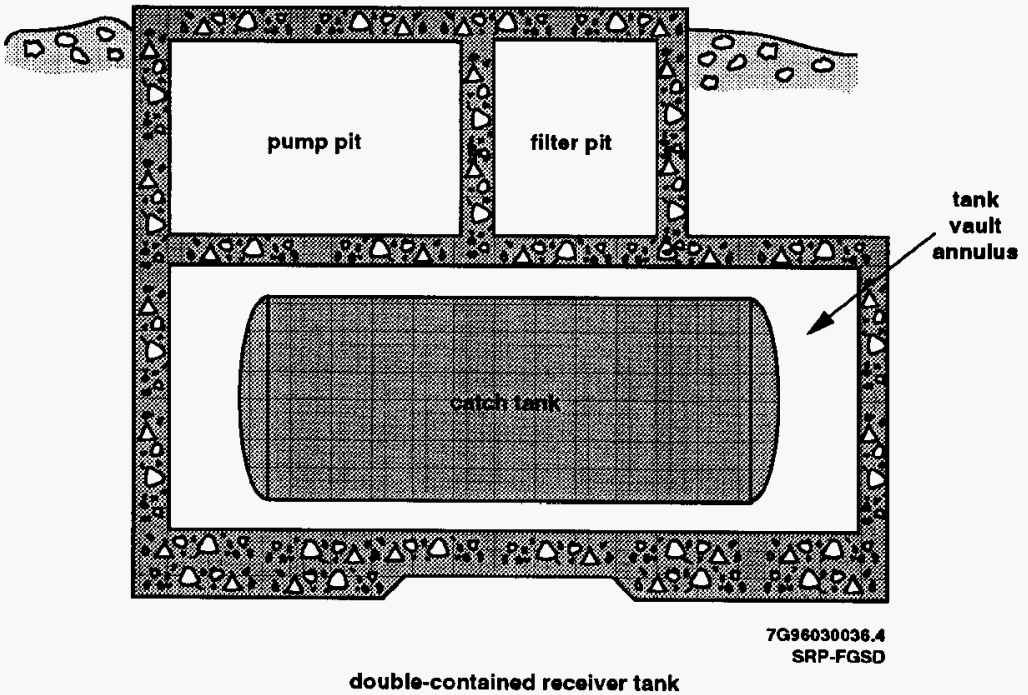


Table 2. Active Double-Contained Receiver Tanks.

\begin{tabular}{|c|c|c|c|c|c|}
\hline Tank number & Location & Use & $\begin{array}{l}\text { Tank design } \\
\text { capacity (L) }\end{array}$ & $\begin{array}{l}\text { Vault design } \\
\text { capacity (L) }\end{array}$ & $\begin{array}{c}\text { Operation } \\
\text { date }\end{array}$ \\
\hline 244-BX & 200 East & $\begin{array}{l}\text { Receives 241-B and 241-BY tank } \\
\text { farm salt well liquids. }\end{array}$ & 117,350 & 321,760 & 1981 \\
\hline 244-CR & 200 East & $\begin{array}{l}\text { Receives } 241-C \text { tank farm salt } \\
\text { we } 11 \text { liquids. }\end{array}$ & 56,780 & 172,170 & 1952 \\
\hline 244-TX & 200 West & $\begin{array}{l}\text { Receives 241-T tank farm salt } \\
\text { well liquids and miscellaneous } \\
\text { Plutonium Finishing Plant wastes. } \\
\text { Serves as the Plutonium Finishing } \\
\text { Plant transfer line drain. }\end{array}$ & 117,350 & 321,760 & 1981 \\
\hline $244-U$ & 200 West & $\begin{array}{l}\text { Not yet in service. Will receive } \\
241-U \text { tank farm salt well } \\
\text { liquids. Will serve as the drain } \\
\text { for the transfer line to } 241-S Y \\
\text { tank farm. }\end{array}$ & 117,350 & 321,760 & - \\
\hline $241-A-350$ & 200 East & $\begin{array}{l}\text { Receives drainage from } 241-A \text { tank } \\
\text { farm. Provides for routing } \\
\text { 207-A Retention Basin waste to } \\
\text { tank 241-AW-102. }\end{array}$ & 3,030 & 23,730 & 1978 \\
\hline
\end{tabular}


ventilation exhaust system. Each catch tank has instrumentation to monitor several tank parameters (e.g., tank temperature, weight factor, and specific gravity) and ports for drawing samples and introducing materials to achieve chemical balance in the tanks.

At the 244-A and 244-S facilities, the catch tank, the pump and filter pits, and the tank vault annulus are vented via one ventilation exhaust system. Outside air, at a rate of about $2.83 \mathrm{~m}^{3} / \mathrm{min}\left(100 \mathrm{ft}^{3} / \mathrm{min}\right)$, is supplied to the vault annulus after passing through an electrical heater, a pre-filter, and a high-efficiency particulate air filter. Because no provision was made to provide filtered air to the catch tank, any fresh air in-leakage is through risers and transfer lines. A $4.67-\mathrm{m}^{3} / \mathrm{min}\left(165-\mathrm{ft}^{3} / \mathrm{min}\right)$ capacity fan exhausts air from the facility via an electrical heater and one of two parallel high-efficiency particulate air filtering systems.

At the 244-BX, 244-TX, and 244-U facilities, the catch tank and the tank vault annulus are vented via one ventilation exhaust system. Outside air, at a rate of about $3.54 \mathrm{~m}^{3} / \mathrm{min}\left(125 \mathrm{ft}^{3} / \mathrm{min}\right)$, is supplied to the vault annulus after passing through an electrical heater, a prefilter, and a high-efficiency particulate air filter. Because no provision was made to provide filtered air to the tank, any fresh air in-leakage is through risers and transfer 1 ines. A $7.08-\mathrm{m}^{3} / \mathrm{min}\left(250-\mathrm{ft}^{3} / \mathrm{min}\right)$ capacity rotary exhauster exhausts air from the facility via two of three parallel high-efficiency particulate air filtering systems.

At the 244-CR facility, the pump pits, the four tank vaults, and four catch tanks are vented via one ventilation exhaust system. Filtered outside air is supplied to the pump pits and tank vaults via an inlet header and subheaders. Since no provision was made to provide filtered air to the tanks, any fresh air in-leakage is through risers and transfer lines. One of two $122-\mathrm{m}^{3} / \mathrm{min}\left(4,200-\mathrm{ft}^{3} / \mathrm{min}\right)$ capacity fans exhausts air from the facility via a single high-efficiency particulate air filtering system.

At the 241-A-350 facility, which is a lift station located southeast of tank 241-A-106 in the 241-A tank farm, the catch tank is located within the pump pit. The tank has an approximate capacity of $3,030 \mathrm{~L}(800 \mathrm{gal})$, and is passively ventilated.

Transfer lines connect the single-shell tanks to the double-contained receiver tank and from the double-contained receiver tank to the double-shell tanks. Shown in Figure 9 are the general configurations of the two types of encased transfer lines: concrete-encased transfer lines and pipe-within-a-pipe (pipe-in-pipe) transfer lines. Another type of transfer line, the direct-buried transfer line, is not encased. It is simply a bare carbon-steel pipe buried in the ground.

The concrete-encased pipe consists of a primary pipe, or pipes, that is encased in a concrete trough with concrete coverblocks. The trough and blocks are used for secondary confinement. The width of the trough varies depending upon the number of primary pipes it contains. Either the coverblocks are precast and placed on top of the trough, or the trough is covered with a steel plate and the concrete is poured in place. Test risers are provided at various locations along the encasement. These risers are routinely monitored for contamination and moisture. 
Figure 9. General Configuration of Different Types of Encased Transfer Lines.
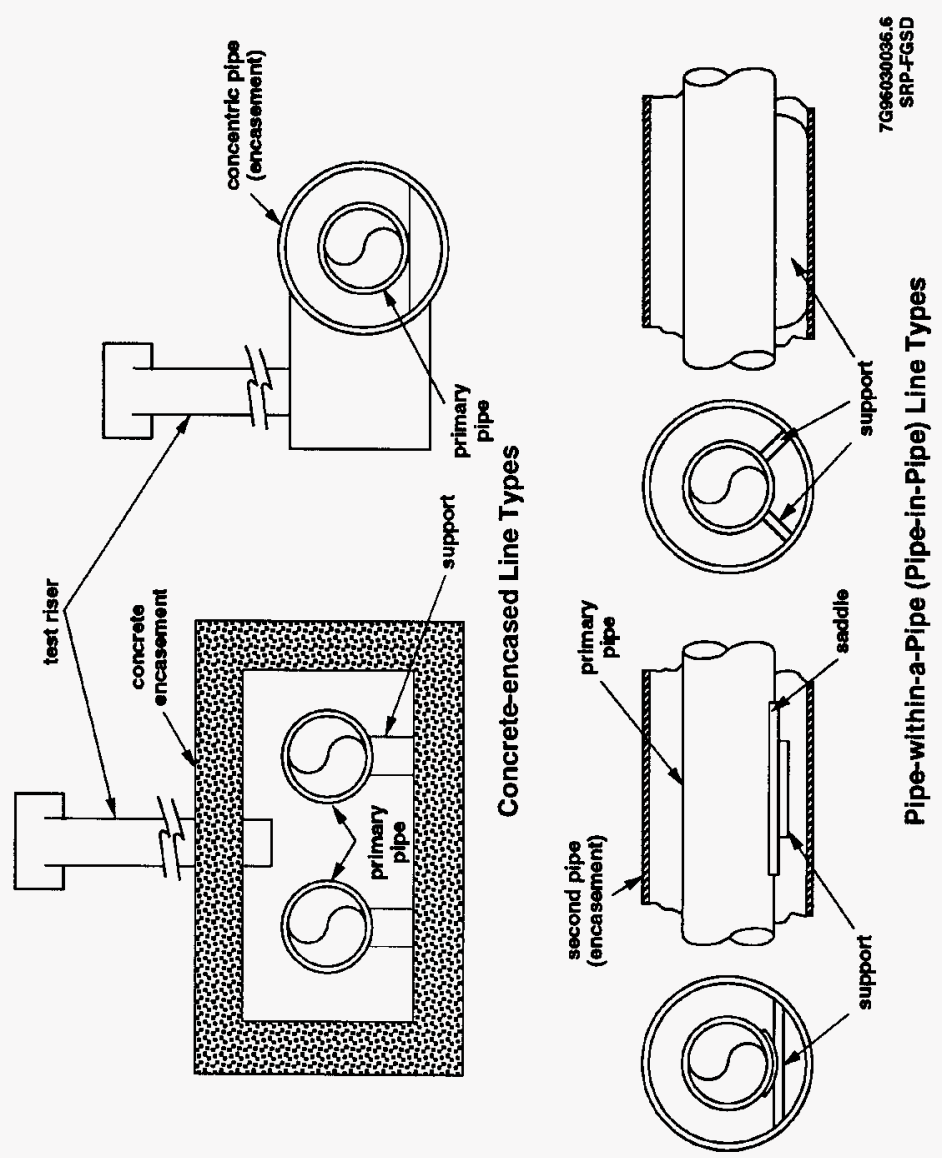
WHC-SD-WM-TI-753 REV 0

In the pipe-in-pipe encasement design, the encasement surrounds the primary pipe with a second pipe or pipe line encasement. This pipe-in-pipe design provides better leak confinement than concrete, and the encasement may be pressure tested to ensure its integrity.

\subsection{CATCH TANK DESIGN}

Catch tanks are underground storage tanks used to collect small amounts of waste drained from diversion boxes; valve pits; diverter stations; tank farm stacks, ventilation condensate systems and instrument buildings; and other double-shell tank equipment. They are also used to collect precipitation and run-off within the tank farms. Most catch tanks look like the primary tanks in double-contained receiver tanks (see Figures 7 and 8 ). Newly replaced catch tanks are housed in subsurface concrete pits to provide secondary confinement for the waste. 0lder catch tanks are simply buried in the ground.

The waste in frequently used catch tanks is pumped into double-shell tanks via diversion boxes and underground pump-out lines. A pump is installed in the catch tank to pump the liquid waste to the associated double-shell tank. When necessary, overground lines and a tank truck are used when the waste in less frequently used catch tanks is pumped out. The contents of the catch tanks are sampled and chemically adjusted, if necessary, before the waste is transferred out of the tank. In some cases, steam and water jets are used to assist in the removal of catch tank waste.

Table 3 provides additional information on the active catch tanks. Catch tank 241-EW-151, 1isted in Table 3, is part of the cross-site transfer system and is located in the 600 Area of the Hanford Site. Figure 10 shows the configuration of this catch tank.

\section{0 flammable gas phenomena}

\subsection{PHENOMENOLOGY OF TANK gas geNERATION, RETENTION AND RELEASE}

Reviewed in this section are the studies (analyses, tests, modeling, etc.) performed by Pacific Northwest National Laboratory, Los Al amos National Laboratory, and others to determine the answers to the following postulated questions regarding the generation, retention, and release of fiammable gases for the various tank wastes:

- Are flammable gases being generated by radiolysis, organic degradation, and corrosion in the waste tanks?

- Are these gases being retained in the single-shell tank and doubleshell tank wastes or are they being steadily released to the headspace of these tanks? 
Table 3. Active Catch Tanks.

\begin{tabular}{|c|c|c|c|}
\hline Area & $\begin{array}{l}\text { Catch } \\
\text { tank }\end{array}$ & $\begin{array}{c}\text { Maximum capacity } \\
(L)\end{array}$ & Use \\
\hline \multirow[t]{5}{*}{200 West } & $241-S-304$ & 23,850 & $\begin{array}{l}\text { Drainage from } D B-241-S-151 \text { and } \\
\text { precipitation and run-off }\end{array}$ \\
\hline & $241-\mathrm{TX}-302-B$ & 44,670 & $\begin{array}{l}\text { Drainage from } \mathrm{DB}-241-\mathrm{TX}-155 \text { and } \\
\text { precipitation and run-off }\end{array}$ \\
\hline & $241-T X-302-C$ & 66,930 & $\begin{array}{l}\text { Drainage from DB- } 241-T X-154 \text { and } \\
\text { precipitation and run-off }\end{array}$ \\
\hline & $241-U-301-B$ & 133,530 & $\begin{array}{l}\text { Drainage from } D B-241-U-151 \text {, } \\
D B-241-U-152, D B-241-U-153 \text {, and } \\
D B-241-U-252\end{array}$ \\
\hline & $241-U X-302-A$ & 66,934 & $\begin{array}{l}\text { Drainage from DB-24l-UX-154, } \\
291-U \text { stack, and precipitation } \\
\text { and run-off }\end{array}$ \\
\hline \multirow[t]{6}{*}{200 East } & $241-A-302-A$ & 31,940 & Orainage from DB-241-A-151 \\
\hline & $241-A-417$ & 167,315 & $\begin{array}{l}\text { Drainage from } 241-A Y / 241-A Z \\
\text { ventilation condensate system and } \\
\text { possibly steam condensate from } \\
241-A X-501 \text { valve pit and } \\
241-A Z-154\end{array}$ \\
\hline & $241-A X-152$ & 41,640 & $\begin{array}{l}\text { Drainage from } 241-A X-152 \text { diverter } \\
\text { station, DB-241-AX-155, AY-501 } \\
\text { and 702-A seal pot }\end{array}$ \\
\hline & $241-A Z-151$ & 45,050 & $\begin{array}{l}\text { Drainage from } D B-241-A Z-152, A Z \\
\text { ventilation loop seals, leak } \\
\text { detection pits, } 801-A Z \\
\text { Instrumentation Building, and } \\
\text { precipitation and run-off }\end{array}$ \\
\hline & $241-A Z-154$ & 3,290 & $\begin{array}{l}\text { Condensate from TK-241-AZ-101 and } \\
-102 \text { steam coils and } \\
\text { precipitation and run-off }\end{array}$ \\
\hline & 241-ER-311 & 67,002 & $\begin{array}{l}\text { Drainage from DB-241-ER-151 and } \\
\text { DB-241-ER-152 }\end{array}$ \\
\hline 600 Area & $241-E W-151$ & 16,050 & $\begin{array}{l}\text { Vent station for cross-site } \\
\text { transfers }\end{array}$ \\
\hline
\end{tabular}

NOTE: Leaks in pump pits or transfer lines drain back to catch tanks. Therefore, the material in the tank could be tank waste.

$\mathrm{DB}=$ diversion box. 
Figure 10. General Configuration of 241-EW-151.

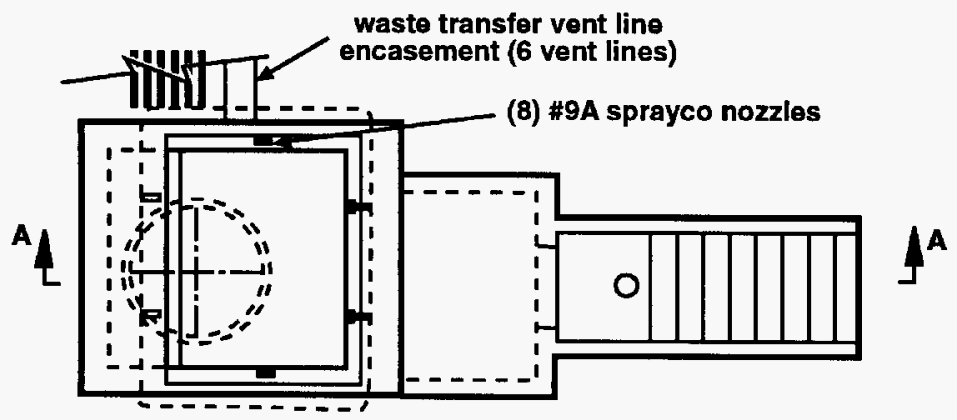

Plan View

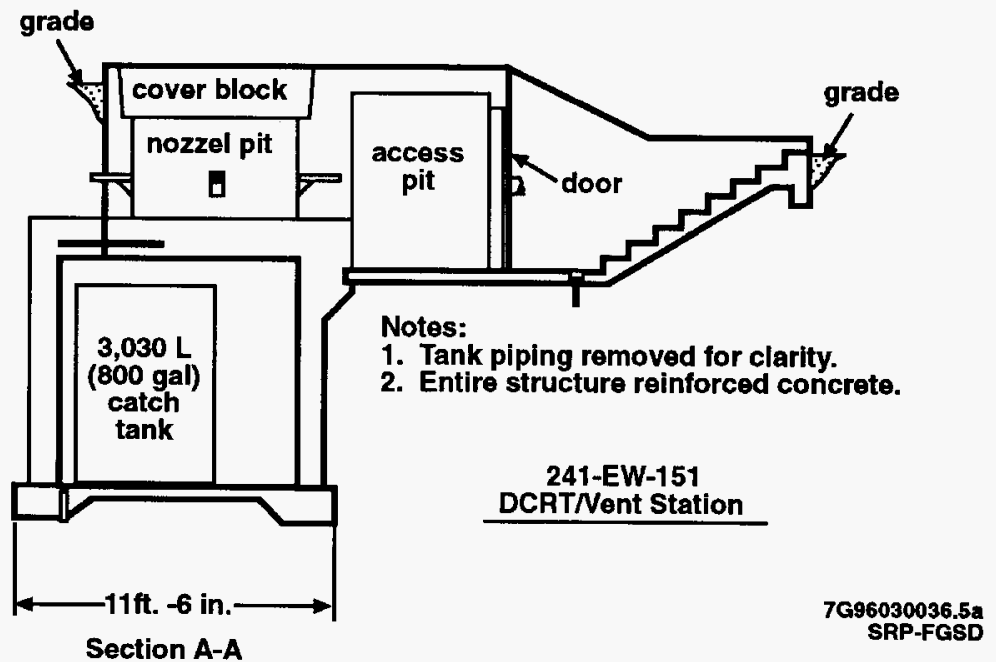

DCRT = double-contained receiver tank 
- If the gases are being retained in the tank waste, what phenomena or mechanisms might be causing this?

- Also, how might they be released, transported to the surface of the tank waste, and released into the tank headspace?

The general conclusions reached, as a result of the previously mentioned studies and the slurry gas compositions studies and calculations discussed in Section 4.2, are (1) that flammable gases are being generated in the tank waste as a result of radiolysis, organic degradation, and corrosion (although corrosion is not considered to be a major contributor to this gas generation) and (2) that these gases either are being steadily released into the tank headspace of the tanks or are being retained by various mechanisms in certain types of tank waste, with the potential for sudden release to the tank headspace as a result of natural occurrences or intrusive activities. Specific conclusions reached regarding flammable gas generation, retention, and releases in single-shell tanks and double-shell tanks are discussed at the beginning of each of the following sections. The conclusions reached regarding double-contained receiver tanks and catch tanks are that the gases generated in these tanks, and those resulting from single-shell tank pumping or from chemicals introduced into the tanks, are being released steadily into the headspace of these tanks.

\subsubsection{Single-She11 Tanks Gas Generation}

The conclusions reached from the studies reviewed in this section are that all 149 single-shell tanks produce flammable gases (for example, hydrogen, ammonia, and methane) because of radiolysis, organic degradation, and corrosion. Similar mechanisms produce nitrous oxide (a good oxidizer) and nitrogen. Production of these gases does not create a problem when the gases are constantly released from the waste and are subsequently removed from the tank through the ventilation systems (either passive or active). However, in some tanks, properties of the waste cause retention of flammable gas.

4.1.1.1 Steady-State Gas Releases. Heubach (1996) calculated the steadystate concentrations of hydrogen present in the waste tanks and used this information to indirectly account for the presence of the other flammable gases in the tanks. The lower flammability limit (LFL) for these gases was then calculated as a function of the various flammable gases and the oxidizers known to be present in the tanks. Then, a conservative value for this lower flammability limit was chosen on the basis of the results seen to date in monitoring the tanks. The lower flammability limit for the flammable gas mixture was 4.5 vol\%. The concentration of hydrogen (the only flammable gas the standard hydrogen-monitoring system detects) in this mixture's lower flammability limit was calculated to be $2.5 \%$. Twenty-five percent of this value is $0.625 \%$ or $6,250 \mathrm{ppm}$. Heubach (1996) used these two values $(0.625 \%$ and $2.5 \%$ ) to identify waste tanks that have the potential to be $>25 \%$ of the lower flammability limit or $>100 \%$ of the lower flammability limit.

The hydrogen generation rates were calculated for radiolysis and the breakdown of organics. Although corrosion of the walls also produces hydrogen, it is an insignificant portion of the total hydrogen generation rate (Heubach 1996). A large fraction of the waste tanks are ventilated passively 
by barometric pressure changes (Crippen 1993). The calculated values in Heubach (1996) do not take credit for other ventilation mechanisms that cannot be quantified and verified. An example of these mechanisms is flow between the cascade lines in single-shel1 tanks. There is no current method for determining if the cascade line is open, partially open, or plugged. There also is no current method for determining the flow rate in the cascade line. In addition, determining if flow in the lines exists all the time or only sporadically is difficult. Therefore, it is expected that the values calculated for steady-state hydrogen concentrations in Heubach (1996) are conservative and that the actual measured values for these concentrations in the waste tanks would be lower. In fact, the hydrogen concentrations in the tanks that have been sampled to date have been lower (sometimes much lower) than the calculated values. Brown (1996) reports that the average measured steady-state concentrations in the 22 single-shell tanks that have permanent gas monitors range from a low of $6 \mathrm{ppm}$ in tank 241-SX-101 to $1042 \mathrm{ppm}$ in tank 241-A-101.

Heubach (1996) calculated that a total of 117 single-shell tanks sould exceed $25 \%$ of the lower flammability limit and that 51 could eventually reach, or exceed, $100 \%$ of the lower flammability limit. These 51 tanks are 241-A-101, 241-A-104, 241-AX-101, 241-AX-104, 241-B-203, 241-BY-104, 241-BY-105, 241-BY-106, 241-BY-108, 241-BY-110, 241-BY-111, 241-C-103, 241-C-105, 241-C-106, 241-C-107, 241-C-201, 241-S-101, 241-S-102, 241-S-106, 241-S-107, 241-S-108, 241-S-109, 241-S-110, 241-S-111, 241-S-112, 241-SX-101, 241-SX-102, 241-SX-103, 241-SX-104, 241-SX-105, 241-SX-106, 241-SX-108, 241-SX-109, 241-SX-110, 241-SX-111, 241-SX-114, 241-T-203, 241-T-204, 241-TX-105, 241-TX-110, 241-TX-112, 241-TX-113, 241-TX-115, 241-TX-116, 241-TX-117, 241-U-103, 241-U-105, 241-U-106, 241-U-108, 241-U-109, and 241-U-204.

4.1.1.2 Single-Shel1 Tank Gas Release Events. The retention mechanisms for flammable gases, the release mechanisms for these gases, and other types of gas release events are discussed in the following subsections. Currently, there are 42 single-shell tanks that are identified by Hodgson et al. (1996) as having the potential for gas release events: 241-A-101, 241-A-103, 241-AX-101, 241-AX-103, 241-BX-107, 241-BY-101, 241-BY-102, 241-BY-103, 241-BY-105, 241-BY-106, 241-BY-109, 241-C-104, 241-C-107, 241-S-102, 241-S-103, 241-S-105, 241-S-106, 241-S-107, 241-S-109, 241-S-111, 241-S-112, $241-\mathrm{SX}-101,241-\mathrm{SX}-102,241-\mathrm{SX}-103,241-\mathrm{SX}-104,241-\mathrm{SX}-105,241-\mathrm{SX}-106$, 241-SX-109, 241-T-110, 241-TX-102, 241-TX-111, 241-TX-112, 241-TX-113, 241-TX-115, 241-U-102, 241-U-103, 241-U-105, 241-U-106, 241-U-107, 24l-U-108, and $241-\mathrm{U}-109$.

4.1.1.2.1 Single-Shell Tank Gas Retention Mechanisms. Recent studies (Gauglitz et a1. 1994, 1995, 1996) have been conducted by Pacific Northwest National Laboratory on the mechanisms of gas bubble retention in sludges and slurries (except for salt-cake studies, which are not yet complete).

Depending on the physical properties of the waste material and the depth at which the gas is being retained, or trapped, gas bubbles have been observed to displace the waste material (spherical bubbles) or to branch between the waste particles (dendritic bubbles). It is believed that spherical bubbles are retained in the waste because of the yield strength of the waste material whereas the dendritic bubbles are retained by capillary forces in the waste 
material. Figure 11 is a schematic of these spherical and dendritic bubbles. other bubble-retention mechanisms also have been postulated. Figure 12 is a schematic of other bubble-retention mechanisms.

Bubble retention in noncohesive particles (settled silica) has been investigated in a laboratory experiment conducted to simulate sludge behavior. Three distinct regimes of bubble retention were observed. In the upper regions of the sludge simulant, spherical bubbles were observed to displace the sludge particles. In the middle region, the sludge fractured, and gas was observed to collect in large bubbles. In the lower region, dendritic bubbles were observed to branch between the individual sludge particles. Figure 13 is a schematic of the bubble retention observed in settled silica.

Bubble retention in cohesive particles (kaolin clay) also has been investigated in a laboratory experiment. The clay-based simulated sludges used in the experiment were ductile pastes. In this experiment, bubbles were essentially spherical and, therefore, were retained by viscous (yield stress) retention. As the spherical bubbles grew in size, they formed interconnected tunnels. These tunnels were larger in size than those formed in the settled silica. In order to compare the laboratory results with what was occurring in the tank waste, a few core samples were collected from the tanks. These samples were $x$-rayed after they were removed from the waste sampler drill string used to collect the samples. The $x$-rays showed structures in some of the waste samples that were similar to, but in some cases larger in scale than, those observed in the laboratory studies. However, these structures were not observed in all waste samples x-rayed.

For bubbles retained in particulate simulated waste, the morphology of the retained bubble depends on a dimensionless grouping called the Bond number that is a ratio of gravitational forces to surface tension (Gauglitz et al. 1996). The Bond number defines the transition between bubbles that displace particles (round bubbles) and bubbles that finger between the particles (dendritic bubbles) composing the particulate media. Bubble retention is also observed in sludges where the particle size is sufficiently small that the bubbles never finger between the particles and the primary mechanism of growth is bubbles displacing the sludge. When surface tension dominates, the bubble shape is round. When the sludge strength dominates, the bubbles grow by displacing the weakest sludge adjacent to the bubble. In this case, if any small nonuniformity exists in the sludge strength, the bubbles will follow that path and evolve into some dendritic shape.

In addition to these experiments, recent push-mode sampling campaigns have been conducted to monitor the concentration of flammable gas in the waste sampler drill string (only after it has been sitting without a sampler for some period of time). In three instances, the gas concentrations in the drill string were found to be well over the lower flammability limit. This provides further evidence that gas does exist in the tank wastes. The gas in the drill string may have been a result of direct release of gas bubbles or simply of diffusion.

4.1.1.2.2 Single-Shell Tank Natural Release Mechanisms. Plausible natural mechanisms for the rapid release of large amounts of flammable gas from the waste in single-shell tanks are the subject of much speculation. 
Figure 11. Schematic of Spherical and Dendritic Bubbles.

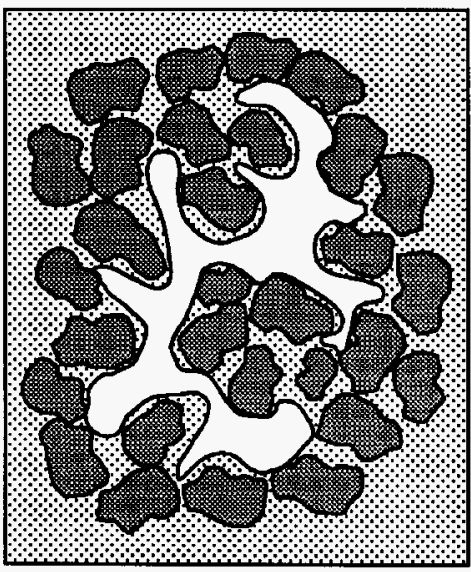

dendritic-waste bubble fingering between particles

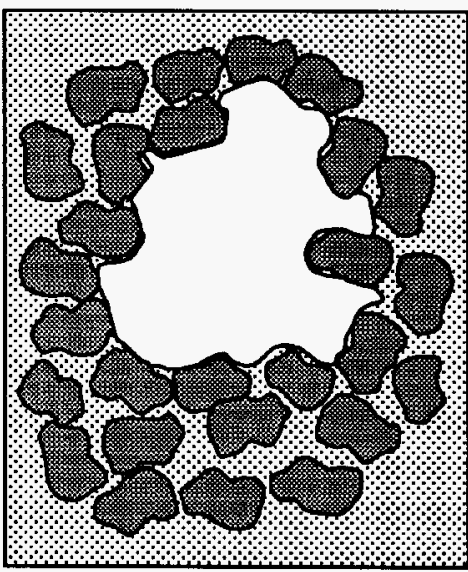

spherical bubble displacing waste particles

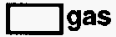

iliquid

solid particles

7G96030036.7 SRP-FGSD 
Figure 12. Schematic of 0ther Bubble Retention Mechanisms.

yield strength retention (viscous)

armored bubbles

bubble attachment

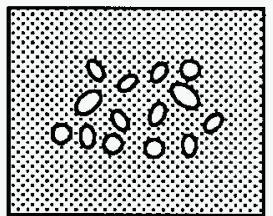

aggregates
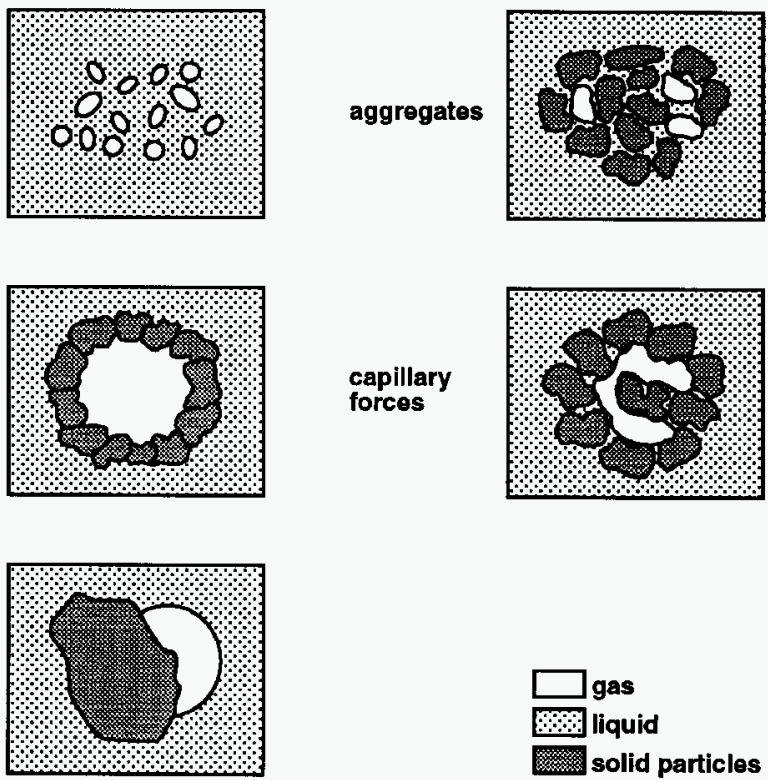

capillary forces $\square$ gas

liquid

solid particles

7g96030036.8 
Figure 13. Schematic of Bubble Retention in Settled Silica.

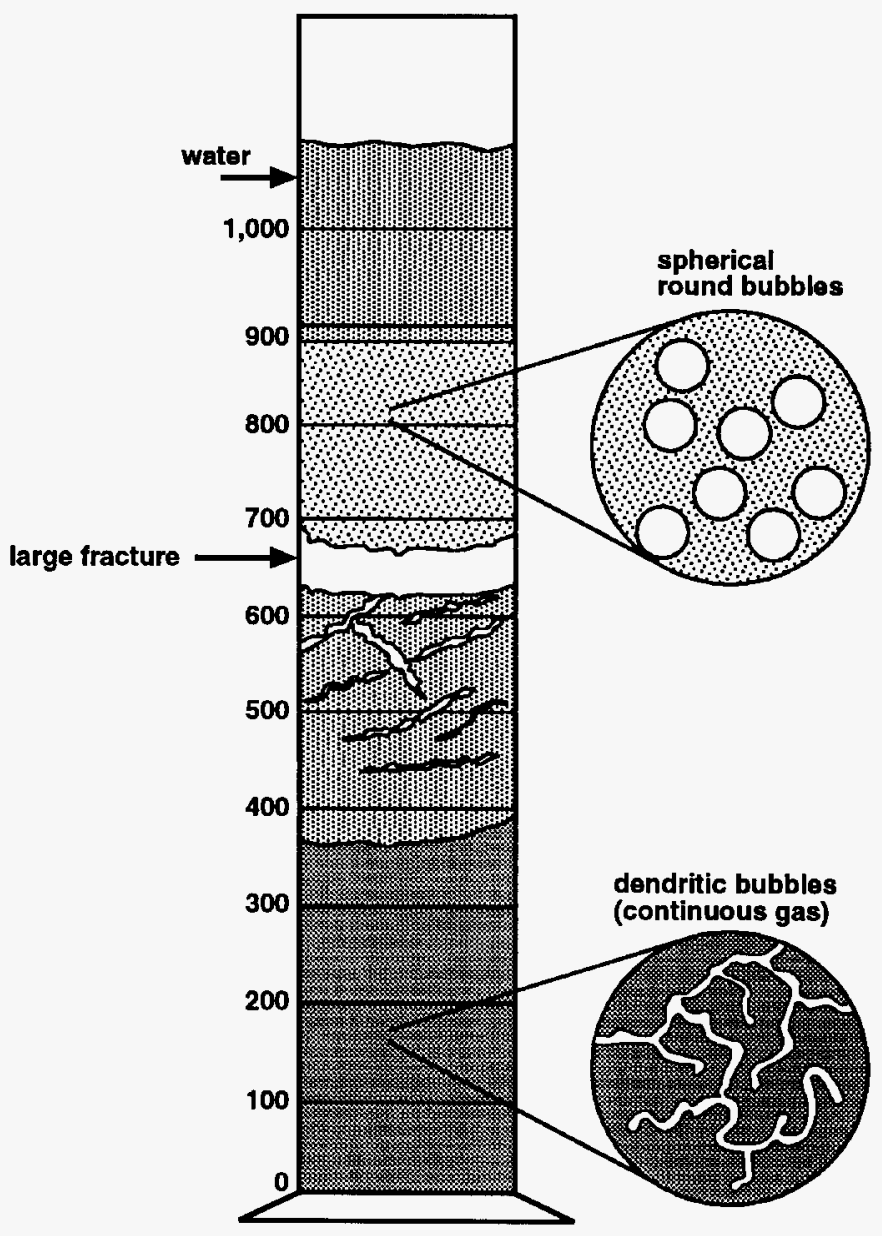

Units depicted in milliliters.

$7 G 96030036.9$

SRP-FGSD 
Some of the natural mechanisms that might cause a large, rapid release of retained flammable gas (Allemann et al. 1995) are as follows:

- Local bubble releases

- Mud pot, fumarole or chimney releases

- Fracture of "dry" sludge releases

- Dryout of salt cake releases

- Rollover.

These mechanisms are explained in more detail in the following paragraphs. Figure 14 illustrates some of the release mechanisms.

4.1.1.2.2.1 Local Bubble Release Mechanism. In sludge that has a yield strength similar to that of the waste in tank 241-SY-101, the 1argest gas bubble that could be retained has an estimated diameter of $1 \mathrm{~m}(3.28 \mathrm{ft})$ (Allemann et al. 1995). Multiple bubbles might be released if a bubble at some depth in the waste begins to rise. This is because the bubble would collect other bubbles that are above it. The affected area would be conical in shape, with its apex at the original location of the initiating bubble. This could be viewed as a vertical cascade of bubbles. A similar cascade might occur if a local pressure sink penetrated one bubble. The resulting collapse would draw in surrounding bubbles which might also collapse. Additional work by the European Study Group (Oxford 1996) indicates that the maximum bubble size in the tank waste should only be on the order of $10 \mathrm{~cm}$. This bubble size is highly dependent upon the yield strength of the waste material. Above this size, the bubble would be in motion and would eventually be released from the tank waste.

4.1.1.2.2.2 Chimney Release Mechanism. Gas retained as dendritic bubbles has been observed to form a finely distributed, connected phase some distance under the sludge surface. At some point, a crack, channel, or chimney is opened to the surface, and the pressurized gas is suddenly provided with a path to the surface. The path may be either naturally occurring or made by an intrusive activity. This type of release could result in a relatively large release of gas to the tank headspace. Preliminary calculations (Allemann et al. 1995) indicate that the opening of a chimney (also called mudpot or fumarole) to an interconnected dendritic bubble region could produce a significant flow rate of gas over several hours. As the release continued, lateral forces in the waste would tend to close the chimney and the release would stop. Allemann et al. (1995) postulates that a flow rate of $28 \mathrm{~m}^{3} / \mathrm{h}\left(1,000 \mathrm{ft}^{3} / \mathrm{h}\right)$ for 10 hours could occur.

The European Study Group (0xford 1996) has also investigated dendritic bubble structures at the request of the Pacific Northwest National Laboratory. This work on dendritic bubbles, concluded that dendritic bubbles would grow in the horizontal direction. This is because the stress on the waste is expected to be anisotropic, i.e., the normal horizontal stress exerted by the bubbles exceeds the normal vertical stress. The dendritic bubble would, therefore, continue to grow until it reached the critical height of $10 \mathrm{~cm}$. At the critical height, the bubble would become mobile and would migrate to the top of the waste and be released. This means that the dendritic bubbles would not be interconnected across the diameter of the tank. Thus, the released gas 
Figure 14. Gas Release Mechanisms. (sheet 1 of 2) Rollover

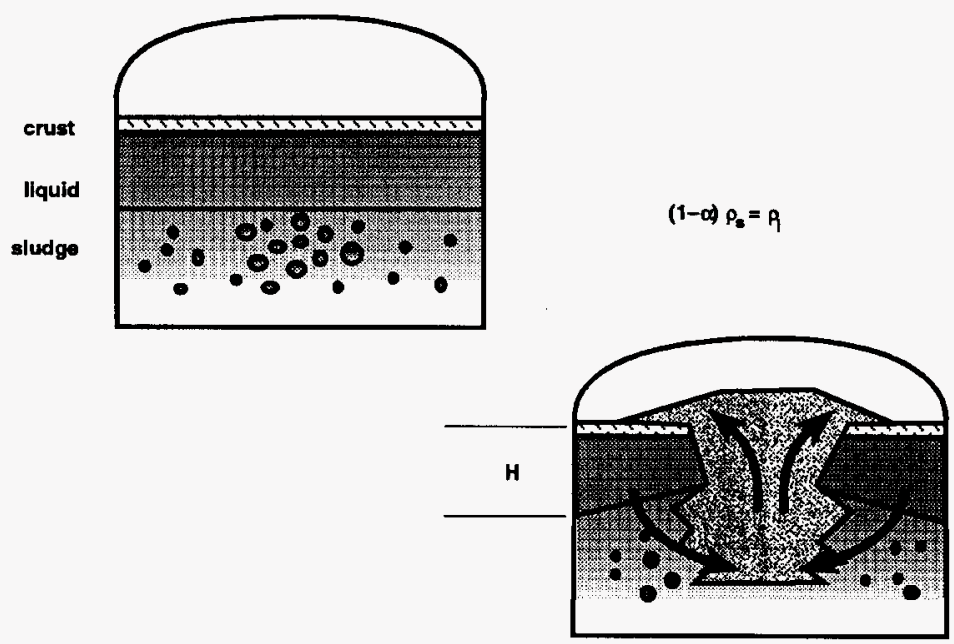

Chimney

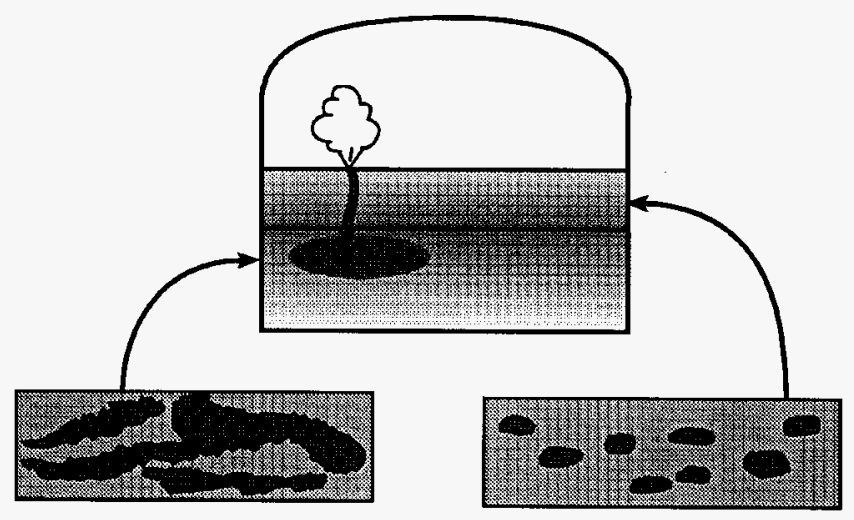

7G96030036.12 SAP-FQSD 


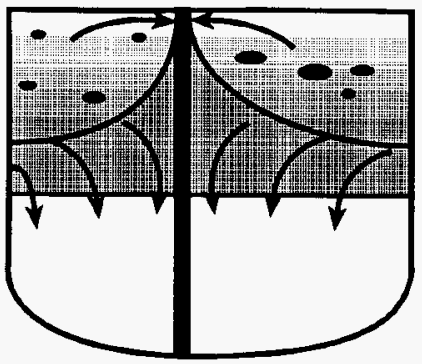

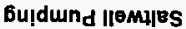
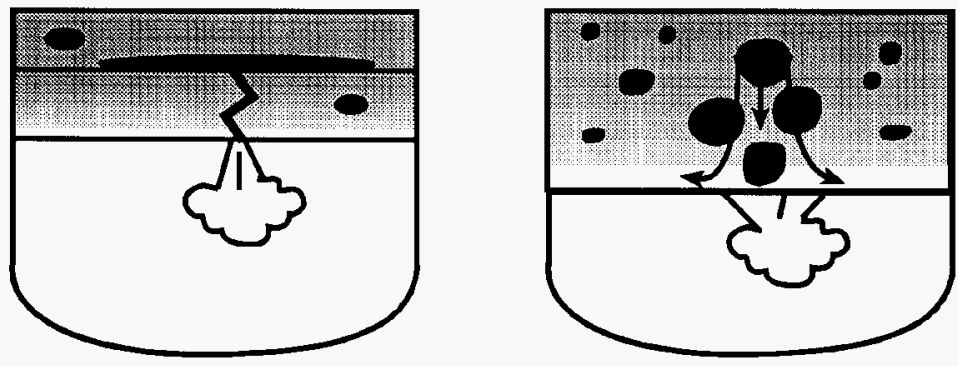

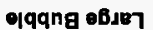

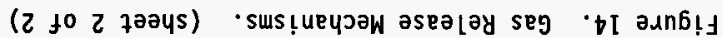

0 А 
volume estimate of $283 \mathrm{~m}^{3}$ by Allemann et al. (1995) would not occur. The release would involve a smaller volume of the tank and would release a smaller volume of the retained gas.

4.1.1.2.2.3 Fracture of "Dry" Sludge Release Mechanism. In the fracture of "dry" sludge mechanism theory proposed to account for the large, rapid release of retained flammable gas, the gas is considered to have migrated to a pressurized layer between the sludge and a wet salt-cake cap. The sudden breaking of this cap could release the gas to the tank headspace in a large quantity. According to Allemann et al. (1995), this mechanism does not appear likely, because the cap must be either impervious or highly resistant to flow for gas to collect there.

4.1.1.2.2.4 Dryout of Salt Cake Release Mechanism. Another mechanism proposed for the rapid release of large amounts of retained flammable gas is the dryout of salt cake. Because of the excess pressure observed to be required to move gas into wet salt cake in the laboratory, gas could be retained between the sludge and salt cake layers, forming a layer under the wet salt cake at a pressure dependent on the weight of the salt cake layers above the gas. A "gasket" made up of wet salt-cake solids would form a seal that would prevent the gas from escaping. As the wet seal is eliminated through salt-cake dryout, gas might transpire through the dry salt cake at a relatively high rate until the gas pressure is relieved. However, this mechanism does not appear likely because the cap must be impervious or highly resistant to flow for gas to collect below it (Allemann et al. 1995).

\subsection{Rollovers in Single-Shell Tanks. A number of previous} studies have investigated bubble retention in both simulated waste and actual tank waste (Gauglitz et al. 1994, 1995; Rassat and Gauglitz 1995; Bredt et al. 1995; Bredt and Tingey 1996). All of these studies involved the growth of bubbles in settled solids submerged beneath a liquid supernatant layer. The presence of the supernatant layer allowed for buoyancy-induced rollovers; however, the rollovers were on a very small scale. In one experiment reported by Bredt and Tingey (1996), very 1ittle supernatant liquid was present. During this experiment, the supernatant liquid was observed to sink downward as the sludge containing bubbles rose. Although this was a buoyancy-induced rollover, it was lethargic and the sludge did not appear to release the gas bubbles. Because the single-shell tanks do not usually contain a supernatant layer (or at most a very small one), similar behavior would be expected. That is, there would be no buoyancy-induced rollovers in single-shell tanks, or if there are, they would be very lethargic ones in which small amounts of gas would be released.

4.1.1.2.2.6 Summary of Single-Shell Tank Natural Release Mechanisms. As the previous discussion indicates, the predominant mechanism for natural release of flammable gases in single-shell tanks is the chimney release mechanism. This type of release would be expected to release a small fraction of the retained gas in the single-shell tank. Natural releases of flammable gas in single-shell tanks can range from essentially zero up to possib 7 y $47 \%$ for salt cake containing interstitial liquid (Allemann et al. 1994). Therefore, a parametric analysis of the release fraction is done, see Appendix D. See Section 4.3.1 for retained gas volume estimates. 
4.1.1.2.3 Single-Shell Tank Intrusive Release Mechanisms. Gas release events in single-shell tanks could also be induced by waste-intrusive activities. These include, but are not limited to the following:

- Core sampling (either push- or rotary-mode)

- Installation of equipment (e.g., thermocouple trees, liquid observation wells, salt well screens)

- Interim stabilization (i.e., pumping the liquids off)

- Sluicing (i.e., removing the solids).

Most of these activities would introduce a "chimney," as discussed previously. This "chimney" would allow any intersected iarge gas bubbles and any intersected interconnected dendritic pockets of gas to be released. However, as discussed previously, the release would be much smaller than the total gas volume of the tank. As stated in Section 4.1.1.2.2.6, the maximum natural release of flammable gases in single-shell tanks is assumed to be $\leq 10 \%$. This is considered an upper bound for natural or activity-induced releases.

Some tanks could have a gas concentration gradient across the waste. This phenomenon could occur in tanks that have been partially interim stabilized or completely stabilized. In these tanks, the volume of liquid, a prime generator of the hydrogen, would be <189,271 L $(50,000$ gal) of drainable liquid or 18,927 L (5,000 gal) of supernatant liquid (Hanlon 1996). In either case, the flammable gases would still be produced by the liquids and the highest concentration would be near the liquid-to-solid interface. From the interface, flammable gases would diffuse through the waste and would be steadily released into the tank headspace. Thus, portions of the waste could contain flammable gas concentrations. These tanks would not be capable of releasing significant quantities of gas. The waste in single-shell tanks can be considered a porous media. Recent experiments on detonations in porous media (Makris 1993) show that deflagrations and detonations can occur in porous media with porosity ranging from 30 to $40 \%$ and pore diameters as small as fractions of a millimeter. In laboratory experiments (Gauglitz et al. $1994,1995,1996)$ with simulated waste, the waste developed porosities up to $50 \%$ and had pore diameters of fractions of a millimeter up to several millimeters in diameter.

\subsection{0ther Types of Single-She11 Tank Gas Release Events.} An earthquake could induce sufficient excitation of the waste in a tank to release retained gas. During the earthquake, the waste would undergo a periodic motion that could cause stresses to exceed the yield stress of the waste and gas to be released. In essence, the waste could become liquefied by the seismic event, thus freeing the retained gas. Ongoing work at Pacific Northwest National Laboratory (Reid et al. 1996) indicates that earthquakes postulated for the Hanford 200 East and 200 West Areas would cause the retained gases to be released. Reid et al. postulate that the 100-year earthquake could cause waste with low yield strength to release gas and that the 1000-year earthquake will cause waste with higher yield strength to release. The release fractions could range from $50 \%$ to nearly all of the retained gas being released. This gas would be released from the waste over a 
short time frame (minutes to hours). Since most of the single-shell tanks are passively ventilated, the gas released into the tank headspace would remain at high gas concentrations (capable of supporting deflagrations and in some cases detonations) for a long period of time.

Several other mechanisms could cause gas release events to occur. These mechanisms are an organic pool fire (Cowley and Postma 1996), an organic solids fire (Meachem et al. 1996), and a diesel or gasoline fire in the tank. These mechanisms could cause a rapid pressurization of the tank headspace. Because all these materials (organic pools, organic solids, diesel or gasoline) require oxygen to burn, the fires will be self-extinguished because of the limited oxygen in the tank headspace (Cowley and Postma 1996). Once the fire is extinguished, the tank will cool and then produce a vacuum (Cowley and Postma 1996). This rapid pressurization and depressurization is postulated to cause nearly all of the retained gas in the tank to be released. The release would take place over a short period of time (minutes to hours). The released gas would be at concentrations capable of supporting deflagrations and in some cases detonations. The released gas could be ignited by the hot tank, movement of equipment due to the gas release event, electrostatic sparks, etc. Note: the flammable gases typically have an oxidizer, nitrous oxide, released at the same time.

The potential of burning subsurface gas has also been investigated (Nakayama and Vogt 1996). According to a European Study Group (Oxford 1996) report, the gas retention mechanisms described previously could result in large bubbles of about $10 \mathrm{~cm}$ in diameter and dendritic elliptical structures $2 \mathrm{~m}$ long by $6 \mathrm{~cm}$ in height. The report (Nakayama and Vogt 1996) indicates that, if one bubble is ignited by a waste-intrusive activity or if lightning strikes the tank and the bubble is located next to the tank wall or an installed piece of equipment, the resulting shock waves could cause autoignition by pressurization of nearby bubbles, or the shock waves may cause stresses to exceed the yield stress and the entire inventory of gas could be released. Nakayama and Vogt (1996) indicate that nearly all of the retained gas would be released from the waste in a short period of time (minutes to hours). The released gas would be at concentrations capable of supporting deflagrations and in some cases detonations. The released gases could be ignited by movement of equipment due to the gas release event, electrostatic sparks, etc.

\subsubsection{Double-She11 Tank Gas Generation}

The conclusions reached from the studies presented in this section are that al1 28 double-shel1 tanks produce flammable gases (for example, hydrogen, ammonia, and methane) because of radiolysis, organic degradation, and corrosion. Similar mechanisms produce nitrous oxide (a good oxidizer) and nitrogen. Production of these gases does not create a problem when the gases are constantly released from the waste and are subsequently removed from the tank through the active ventilation systems. However, in some tanks, properties of the waste cause retention of flammable gas.

4.1.2.1 Steady-State Gas Releases. Heubach (1996) calculates that, without active ventilation, the gas concentrations in a total of 24 double-shell tanks would be $>25 \%$ of the lower flammability limit and that the gas concentrations 
in 20 of these tanks would eventually reach, or exceed, $100 \%$ of the lower flammability limit. These 20 double-shell tanks are 241-AN-101, 241-AN-102, 241-AN-103, 241-AN-104, 241-AN-105, 241-AN-107, 24l-AP-101, 241-AP-102, 241-AP-106, 241-AP-107, 241-AW-101, 241-AW-104, 241-AW-105, 241-AW-106, 241-AY-101, 241-AY-102, 241-AZ-101, 24I-AZ-102, 241-SY-101 and 241-SY-103. A summary of Heubach (1996) can be found in Section 4.1.1.1.

4.1.2.2 Double-She11 Tank Gas Release Events. The retention mechanisms for flammable gases, the release mechanisms for these gases, and other types of gas release events are discussed in the following subsections. Currently, 9 double-shell tanks are identified by Hodgson et al. (1996) as having the potential for gas release events: 241-AN-103, 241-AN-104, 241-AN-105, 241-AN-107, 241-AW-101, 241-AW-104, 241-AY-101, 241-SY-101 and 241-SY-103.

4.1.2.2.1 Double-Shell Tank Gas Retention Mechanisms. The waste in double-shell tanks has been observed to form two distinct layers an upper convective layer and a lower, or bottom, nonconvective layer. The upper convective layer is assumed to be mobile and to remain mixed as a result of convective motion. Consequently, gases generated in this layer are assumed to be released steadily. The lower, or bottom, nonconvective layer is assumed not to convect (move) and to retain all of the gas that is generated in this region until a rollover occurs. The characteristics of the convective and nonconvective layers are inferred from the observed axial temperature profiles in the tanks. Figure 15 is an illustration of this type of axial temperature profile. The existence of these two layers has been confirmed by use of the void fraction instrument, the ball rheometer and core samples. A flat temperature profile in the convective layer is assumed to indicate convective mixing whereas an almost parabolic temperature profile in the nonconvective layer is assumed to represent conductive heat transport. The convective and nonconvective layers are virtually the same, except that the nonconvective layer have more solids than the convective layer.

On the basis of preliminary measurements taken with a void fraction instrument in the double-shell tanks, the convective layer appears to contain very little of the retained gas. The majority of this gas appears to be retained in the nonconvective layer. Several mechanisms have been postulated to explain this observed gas retention phenomenon. These mechanisms are schematically represented in Figure 12 .

4.1.2.2.2 Double-Shell Tank Gas Release Mechanisms. Several mechanisms have been proposed to explain the generation, retention, and release of gas in the double-shell tanks (Babad et a1. 1991, 1992). Although some uncertainty exists regarding these proposed mechanisms, the existing data suggests that a rollover of the nonconvective layer occurs periodically, which releases the retained gas in these tanks. Figure 14 shows an illustration of the rollover mechanism.

The chemical reactions occurring in the double-shell tanks that result in gas generation have not been fully characterized. However, it is known that the reactions involve the organics present in the waste and are assisted by the radiation emanating from the radioactive materials present in the waste. In the convective layer, the motion of the tank fluid brings the gas generated in that layer up to the surface, where it can be released; as a result, the gas does not accumulate in the fluid layer. However, in the 
Figure 15. Axial Temperature Profile of a Double-Shell Tank.

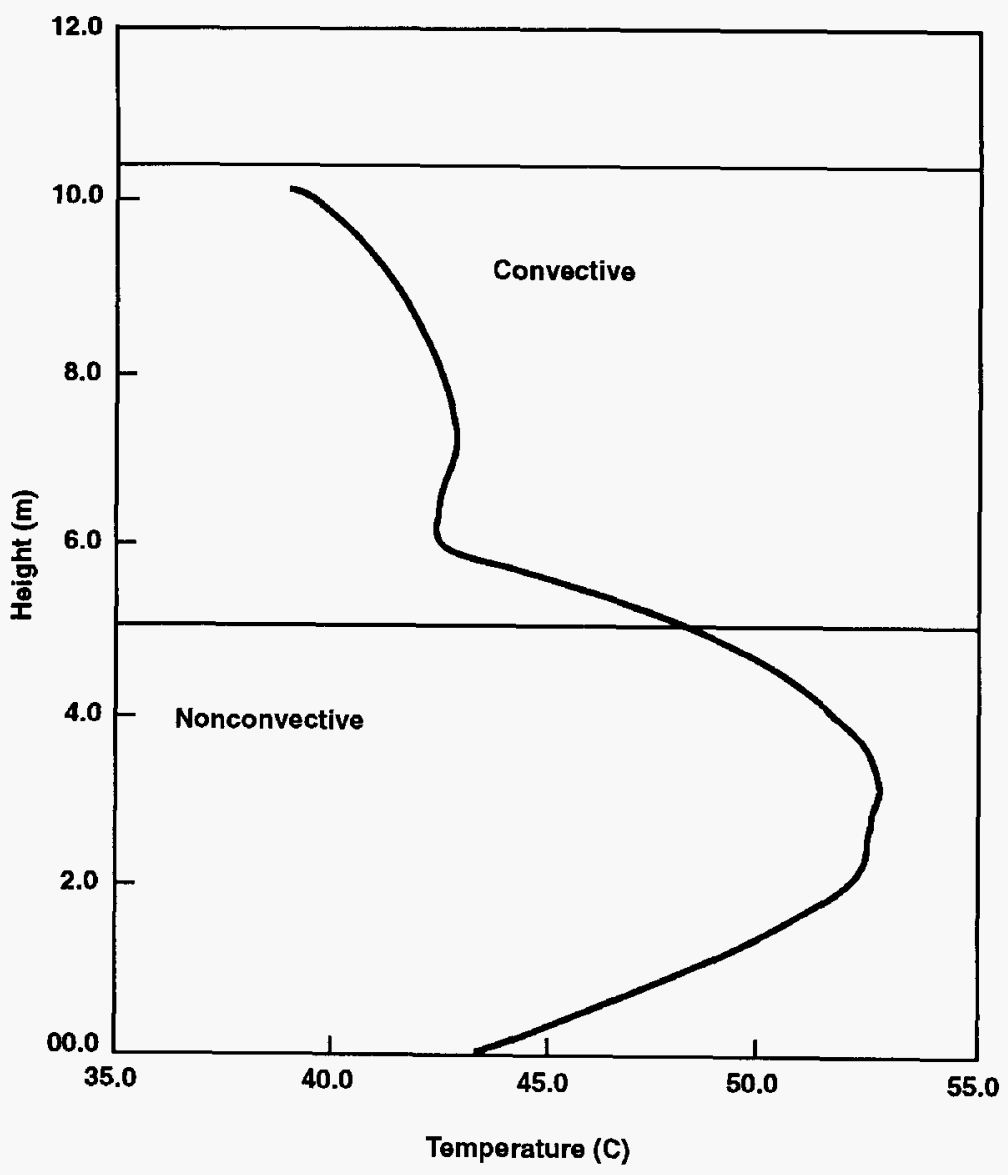


nonconvective layer, the waste does not move; therefore, most of the gas formed in that layer is retained. As gas accumulates, the nonconvective layer becomes less dense because of the retained gas. Also, the temperature rises because radiolytic decay heat is produced faster than it is being conducted away. The rise in temperature has several possible consequences: the accumulated gas expands, further decreasing the density; the viscosity of the material decreases; some of the solid material redissolves at the warmer temperature; and the chemical reaction rates may increase. As a result of some, or all, of these consequences, the nonconvective layer reaches a critical density and becomes buoyant. When this happens, the hydrostatic head decreases, the pressure on the accumulated gas drops, and the bubbles expand. This causes instability, and the lower region of the nonconvective layer rolls over to the top (this is termed a Rayleigh-Taylor instability). When the nonconvective layer reaches the surface, the gas in it is released. The size of the cohesive mass of nonconvective waste material that rises to the tank waste surface is probably dependent on the previous history of various regions of the nonconvective layer (Babad et al. 1992).

Eventualiy, enough of the accumulated gas in the nonconvective layer is released so that the density of solids in this layer increases and the solids settle out. The solids form a new nonconvective layer on the bottom of the tank, and the cycle begins again. This phenomenon was clearly exhibited in tank 24l-SY-101 prior to the installation of the mixer pump. Video photography showed that some rollover events in the tank involved the entire nonconvective layer whereas other events only involved portions of this layer. Calculated release fractions (Stewart 1996, Summary of Gas Retention and Release Behavior in Hanford Single-Shell Waste Tanks) indicate that approximately $50 \%$ of the retained gas was released.

Other double-shell tanks also exhibit rollover behavior, although to a lesser extent than observed in tank 241-SY-101. In fact, observed phenomena in these tanks (e.g., small level drops, no changes in temperature profiles, small or nonexistent pressure increases) indicate that these other doubleshell tanks do not experience rollovers events involving the entire nonconvective layer of the tank and may experience only partial rollover events.

A proposed theory of partial rollover that can explain many of the quantitative and qualitative observations to date is called the "gob theory" (Allemann et a1. 1993). This theory proposes that a portion of the nonconvective layer (or "gob") retains enough of the gas being produced in the waste so that the gob breaks loose from the nonconvective layer. That is, the buoyancy force in that portion of the nonconvective layer has achieved a value that overcomes the cohesive forces and the viscosity of the waste in the nonconvective layer. The gob then rises rapidly to the top of the tank and almost instantly releases the gas in it (Allemann et al. 1993). This release is due either to the large bubbles coalescing or to the gas expanding and coalescing because the motion (rapid rise) of the gob has reduced the strength of the nonconvective material. After this initial release, more gas percolates (fizzes) out of the gob at a slower rate until the amount of gas left in it can no longer hold it afloat. The gob then begins to sink, and the remaining gas is recompressed by hydrostatic pressure. 


\subsection{Other Types of Double-She11 Tank Gas Release Events.} An earthquake could induce sufficient excitation of the waste in a tank to release retained gas. During the earthquake, the waste would undergo a periodic motion, which could cause stresses to exceed the yield stress of the waste and gas to be released. In essence, the waste could become liquefied by the seismic event, thus, freeing the retained gas. Ongoing work at Pacific Northwest National Laboratory (Reid et al. 1996) indicates that earthquakes postulated for the Hanford 200 East and 200 West Areas would cause the retained gases to be released. They postulate that the 100-year earthquake could cause waste with low yield strength to release gas and that the 1000-year earthquake will cause waste with higher yield strength to release. The release fractions could range from $50 \%$ to nearly all of the retained gas being released. This gas would be released over a short time frame (minutes to hours). Because the double-shell tanks are actively ventilated, the gas released into the tank headspace would remain at high concentrations (capable of supporting deflagrations and in some cases detonations) for short periods of time (a few hours to a few days), assuming the tank ventilation system was still functioning. If the ventilation system fails and remains off, the high concentrations could remain in the tanks for a longer period of time.

The potential of burning subsurface gas has also been investigated (Nakayama and Vogt 1996). According to a European Study Group (0xford 1996) report, the gas retention mechanisms described previously could result in large bubbles of about $10 \mathrm{~cm}$ in diameter and dendritic eliptical structures $2 \mathrm{~m}$ long by $6 \mathrm{~cm}$ in height. The report (Nakayama and Vogt 1996) indicates that, if one bubble is ignited by a waste-intrusive activity or if 1 ightning strikes the tank and the bubble is located next to the tank wall or an installed piece of equipment, the resulting shock waves could cause autoignition by pressurization of nearby bubbles, or the shock waves may cause stresses to exceed the yield stress and the entire inventory of gas could be released. Nakayama and Vogt (1996) indicate that nearly all of the retained gas would be released from the waste in a short period of time (minutes to hours). The released gas would be at concentrations capable of supporting deflagrations and in some cases detonations. The released gases could be ignited by movement of equipment due to the gas release event, electrostatic sparks, etc.

\subsubsection{Double-Contained Receiver Tanks}

4.1.3.1 Steady-State Releases. The wastes stored in the double-contained receiver tanks contain both radioisotopes and chemical compounds that can be broken down by radiolysis. The gaseous products of radiolys is in these tanks are released into the tank headspace. One of the main gases produced is hydrogen, which is generated by the radiolysis of water and of certain organic compounds present in the waste.

Other gases that might be generated in the tank waste include methane, ammonia, nitrous oxide, carbon monoxide, oxygen, and the vapors of volatile organic species. Hydrogen, methane, ammonia, and the organic vapors can act as fuels for combustion. oxidizers (oxygen in the headspace air and radiolytically-generated oxygen and nitrous oxide) are also present. Therefore, a combustive reaction (e.g., a deflagration or detonation) in the primary tank headspace is a potential hazard. 
Heubach (1996) has calculated that the 7 double-contained receiver tanks would exceed both $25 \%$ of the lower flammability limit and $100 \%$ of the 1 ower flammability limit without active ventilation. These double-contained receiver tanks are 244-A, 244-BX, 244-S, 244-TX, 244-U, and 244-CR.

4.1.3.2 Transferred-In Gas. Waste transferred into the double-contained receiver tank contains both dissolved gas and small bubbles of gas. The dissolved gas is mainly ammonia, while the bubbies of gas are composed of hydrogen, nitrous oxide, and methane. Recent studies (Norton and Pederson 1994) on ammonia indicate that, if the water content of the waste is 40 weight $\%$ and if the temperature is $50{ }^{\circ} \mathrm{C}\left(122^{\circ} \mathrm{F}\right)$, the concentration of ammonia in the waste is estimated to be 0.6 weight \%. The quantity of gas retained in bubbles has also been estimated to be $<0.01$ weight $\%$ (Kidder 1996).

Peurrung and Gauglitz (1996) modeled salt-well pumping as multiphase flow in porous media. The results of this modeling, which was focused on singleshell tanks, is included here because the liquids pumped out of these tanks are transferred into the double-contained receiver tanks addressed in this section. (A laboratory study, still in an early stage, of gas release as a result of draining liquid from porous media, will be used to confirm the model results.) Both one-dimensional and two-dimensional modeling was conducted by Peurrung and Gauglitz (1996). The results of this modeling show that, although most of the soluble gas (ammonia) would be removed with the pumped fluid and transferred to the double-contained receiver tank, a large quantity of this gas could be volatilized and released into the headspace of the tank being pumped. Instantaneous releases of this gas are projected to be as high as $181 \mathrm{~m}^{3} /$ day $\left(6,400 \mathrm{ft}^{3} / \mathrm{day}\right)$. Also, essentially all of the insoluble gas (hydrogen, methane, and nitrous oxide) is projected to be released in the single-shell tank, but very little of the gas is projected to be released in the salt well itself or transferred to the double-contained receiver tank.

Another study (Siciliano 1996) states that the maximum bound for ammonia concentrations in the double-contained receiver tanks would be 22 vol\% and that the maximum released volume for this gas would be $10.3 \mathrm{~m}^{3}$ (364 $\left.\mathrm{ft}^{3}\right)$. Siciliano also states that the presence of insoluble gas in the tanks is expected to have no effect on ammonia solubility. The main effect of this insoluble gas would be to produce gas bubbles in the waste. These bubbles could potentially be released in a short time if the waste were disturbed. The bubbles could also be the driving force behind a rapid gas release, as is the case when a convection layer rollover event occurs. The specific implication of having insoluble gas present when ammonia is released is that, when the insoluble gas forms bubbles in the waste, a fraction of the gas in the bubbles will be ammonia. This fraction is determined by the Henry's law constant for the system. When the bubbles are released, the ammonia inside them can escape into the primary tank headspace. This mechanism is already included in the calculations for the maximum bound for ammonia concentrations (Siciliano 1996).

4.1.3.3 Gas Produced by Chemical Adjustment. Sodium hydroxide and sodium nitrate are added, as needed, to the double-contained receiver tanks to adjust the chemistry of the waste. This causes a gas release (i.e., the amino compounds in the low-pH waste become free ammonia when the $\mathrm{pH}$ is raised by addition of these chemicals). 
Calculations (Heubach and Siemer 1996) indicate that an injection of 19-molar sodium hydroxide at a rate of $1 \mathrm{~L} / \mathrm{h}$ for 25 hours will produce an ammonia concentration of $50 \%$ in the primary tank headspace of the doublecontained receiver tank. The lower flammability limit for ammonia is $15 \%$ in dry air and $15.95 \%$ in humid air (see Appendix $E$ of this report). It should be noted that the injection rate of sodium hydroxide into the receiver tanks is higher than $1 \mathrm{~L} / \mathrm{h}$ at the tank farms.

\subsubsection{Catch Tanks}

4.1.4.1 Steady-State Releases. The wastes stored in the catch tanks may contain both radioisotopes and chemical compounds that can be broken down by radiolysis (see Table 3 for the types of waste each catch tank may contain). The gaseous products of this radiolys is are released into the tank headspace. One of the main gases produced is hydrogen, which is generated by the radiolysis of water and of certain organic compounds. All catch tanks are passively ventilated except for two near the aging waste facility tanks. These two actively ventilated catch tanks will become passively ventilated with the ventilation upgrade to the aging waste facility tanks.

Other gases that might be generated in the waste include methane, ammonia, nitrous oxide, carbon monoxide, oxygen, and the vapors of volatile organic species. Hydrogen, methane, ammonia and the organic vapors can act as fuels for combustion. Oxidizers (oxygen in the headspace air, and radiolytically generated oxygen and nitrous oxide) are also present. Therefore, a combustive reaction (e.g., a deflagration or detonation) in the tank headspace is a potential hazard.

4.1.4.2 Transferred-In Gas. Waste transferred into the catch tank contains both dissolved gas and bubbles of gas. The dissolved gas is mainly ammonia whereas the bubbles of gas are composed of hydrogen, nitrous oxide, and methane. Recent studies (Norton and Pederson 1994) on ammonia indicate that if the water content of the waste is 40 weight \% and if the temperature is $50{ }^{\circ} \mathrm{C}\left(122{ }^{\circ} \mathrm{F}\right)$, the concentration of ammonia in the waste is estimated to be 0.6 weight $\%$. The quantity of gas retained in bubbles has been estimated to be $<0.01$ weight \% (Kidder 1996).

4.1.4.3 Gas Produced by Chenical Adjustment. Sodium hydroxide and sodium nitrate are added, as needed, to the catch tanks to adjust the chemistry of the waste before it is transferred to the double-shell tanks. This causes a gas release (i.e., the amino compounds in the low-pH waste become free ammonia when the $\mathrm{pH}$ is raised by the addition of these chemicals).

\subsection{SLURRY GAS COMPOSITIONS}

Identified in this section are the slurry gas compositions calculated for waste tanks suspected of retaining significant amounts of flammable gas (as a result of phenomena that may be occurring within these tanks) that could pose hazards to site personnel and the public if the deflagrations or detonations discussed later in Section 4.3 were to occur. Slurry gas is defined as the retained gases that are released from the waste during natural or induced gas-release events. The composition of the released slurry gas may be different 
than the composition of the retained gases due to differences in solubility and release mechanisms. The gas compositions are derived from headspace sampling data (see Sections 4.2.1.2, 4.2.4 and Appendix C). Also identified in this section are the slurry gas compositions calculated for waste tanks that are suspected to produce steady-state releases of flammable gas but that are poorly ventilated, thus posing the same hazards stated previousiy.

The results of the analysis of actual gas samples collected from the previously described waste tanks by several methods are discussed in this section. Historical data from waste tank 24l-SY-101 is also provided for comparison purposes, along with the results of waste simulation studies performed for waste tanks 241-SY-101 and 241-SY-103. The section concludes with a presentation of results from the calculations performed; the actual sampling data (including the data for 241-SY-101) are used to determine the slurry gas compositions of the waste tanks suspected of retaining significant amounts of flammable gas and those poorly ventilated tanks suspected of producing steady-state releases of flammable gas.

These results indicate that slurry gas compositions are unique for each of the waste tanks analyzed and are significantly different from tank 241-SY-101 and that some tank gases are richer in certain fuel values (i.e., percent of methane present), thus requiring smaller amounts of released gas to produce a similar burn than previously proposed for tank 241-SY-101. These results also indicate that the $25 \%$ and $100 \% 10$ wer flammability 1 imit values established in earlier documentation (Sherwood 1995) for controlling certain tank farm operations activities are al so supported by the data collected and analyzed for these additional waste tanks.

\subsubsection{Actual Sampling Data}

4.2.1.1 Headspace Sampling Data. As part of the characterization of the waste tanks, headspace sampling has been performed on a number of single-shell tanks. The headspace samples have been collected using SUMMA ${ }^{2}$ canisters. Analysis of these samples indicates that flammable gases (hydrogen, ammonia, and methane) are present in most single-shell tanks. The results from all tanks sampled to date are summarized in Appendix $A$. These data show the results for 46 waste tanks and support the gas generation data for singleshell tanks (see Section 4.1.1) in that they indicate tank waste generates hydrogen, ammonia, methane and nitrous oxide.

4.2.1.2 Grab Sampling Data from Standard Hydrogen Monitoring Systems. As part of the strategy for resolution of the flammable-gas unreviewed safety question, standard hydrogen-monitoring systems were placed in service on 6 double-shel1 tanks and on 22 single-shel1 tanks. Part of the effort to ensure that the monitoring systems were functioning correctly was to collect grab samples from the tanks, analyze the samples, and compare the results with what was measured at the same time by the standard hydrogen-monitoring systems placed on these tanks. Since this baselining activity was completed, periodic grab samples have been collected and analyzed on a continuing basis. The analyses to date of the grab samples collected from the tanks are provided in Appendix B.

${ }^{2}$ SUMMA is a registered trademark of Moletrics, Inc., Cleveland, Ohio. 
The analyses of the grab samples indicate that nitrous oxide is a major component of the gases found in the headspace of a large number of Hanford waste tanks. These data were obtained from mass spectrometry analysis of the grab samples. Some of the tanks gave very high hydrogen-to-nitrous-oxide ratios, particularly tank 24l-AW-101 which has a 3:1 ratio. Because these samples were highly diluted with air, information on the concentration of nitrogen, expected to be a major constituent, could not be obtained.

Considerable scatter in the calculated hydrogen-to-nitrous-oxide ratios was at least partially due to very low measures of absolute concentrations of these gases in the headspace.

4.2.1.3 Historic Data from Tank 241-SY-101. Sampling data obtained for tank 241-SY-101 indicate that hydrogen composed less than a third of the released gases from tank. Nitrous oxide, nitrogen, and ammonia are other important gas components. Gas composition information for tank 241-SY-101 is more extensive than for any other waste tank at the Hanford Site. Table 4 presents a best estimate and a conservative estimate of the gas compositions for the slurry gas released during rollover events in tank 241-SY-101 (LANL 1995). These rollover events consist of the exchange of solids in the nonconvective layer at the bottom of the tank with the fluids in the convective layer at the top of the tank (bottom to top). This phenomenon is postulated to occur (see Section 4.1.2.2.2) because the solids are buoyed up, or become buoyant, because of the retained gas, rise either to the surface or to a point below the surface of the waste, and release a portion or all of their retained gas to the tank headspace.

Table 4. Gas Compositions for the Released Slurry Gas in Tank 241-SY-101.

\begin{tabular}{|l|c|c|}
\hline \multicolumn{1}{|c|}{ Component } & $\begin{array}{c}\text { Best estimate, } \\
\text { mole \% }\end{array}$ & $\begin{array}{c}\text { Conservative } \\
\text { estimate, mole } \%\end{array}$ \\
\hline Hydrogen & 28.77 & 31.41 \\
\hline Nitrous oxide & 24.45 & 26.69 \\
\hline Ammonia & 10.95 & 14.95 \\
\hline Nitrogen & 32.82 & 23.51 \\
\hline Methane & 0.35 & 0.53 \\
\hline Carbon monoxide & 0.25 & 0.50 \\
\hline Water & 2.40 & 2.40 \\
\hline
\end{tabular}

SOURCE: LANL, 1995, A Safety Assessment for Proposed Pump Mixing Operations to Mitigate Episodic Gas Releases in Tank 241-SY-101: Hanford Site, Richland, Hashington, LA-UR-92-3196, Rev. 14, Los Alamos National Laboratory, Los Alamos, New Mexico.

4.2.1.4 Retained-Gas Sampler Data. Analysis of gas samples collected with a retained-gas sampler from tank 241-AW-101 (Shekarriz et al. 1996) showed nitrogen to be among the principal components of the gases retained in the tank waste, with hydrogen composing less than half of the total gases present. Avoidance of large-scale dilution of the sampled gases with air is among the 
important advantages of using the retained-gas sampler to collect gas samples from the waste tanks. Observed hydrogen-to-nitrous-oxide ratios in the gas samples analyzed from tank 242-AW-101 remained quite high, similar to analyses of grab samples collected from the headspace in the tank. Table 5 lists the measured concentrations observed in the gas samples obtained from tank 241-AW-101 with the retained-gas sampler. However, one must be somewhat cautious about these results because the presence of oxygen (Shekarriz et al. 1996) in the samples probably indicates contamination of the samples with air. (An investigation is in progress to determine whether or not this oxygen was introduced into the gas samples by leakage of the retained-gas sampler or was due to subsequent handling and analysis of the samples collected.) Even considering some dilution of these samples with air, at least half of the nitrogen concentrations 1 isted in Table 5 are believed to have been present in the core samples collected from tank 241-AW-101 with the retained-gas sampler. It must be noted that the data in Table 5 are "raw data" that have not been manipulated. The retained-gas sampler results are a direct measurement of the stored gases in the waste. Thus, the results will be biased high on ammonia (because of the extraction processes) and perhaps other gases, too. Also, because the samples were not immediately analyzed and were not maintained at tank temperature, the entire chemistry of the retained gases could have changed. The correlation between what is stored in the tank and what gets released is also not known at this time.

Table 5. Retained-Gas Sampler Results from Tank 241-AW-101.

\begin{tabular}{|c|c|c|c|c|}
\hline $\begin{array}{c}\text { Sample } \\
\text { designation }\end{array}$ & $\begin{array}{c}\text { Hydrogen, } \\
\text { mole \% }\end{array}$ & $\begin{array}{c}\text { Nitrous } \\
\text { oxide, mole } \%\end{array}$ & $\begin{array}{c}\text { Nitrogen, } \\
\text { mole } \%\end{array}$ & $\begin{array}{c}\text { Calculated } \\
\mathrm{H}_{2} / \mathrm{N}_{2} \mathrm{O}\end{array}$ \\
\hline AW 101-8J1 & 8.3 & 0.83 & 41.0 & 10.0 \\
\hline AW 101-17J1 & 17.8 & 2.89 & 49.0 & 6.2 \\
\hline AW 101-19J1 & 33.1 & 3.87 & 42.4 & 8.6 \\
\hline AW 101-21J1 & 24.2 & 5.6 & 50.4 & 4.3 \\
\hline
\end{tabular}

\subsubsection{Simulated Waste Data}

In laboratory studies of gas generation with simulated wastes (Ashby et al. 1992, 1993, 1994; Barefield et a1. 1995; Bryan et al. 1992, 1994; Delegard 1980; Meisel et a1. 1991, 1993), nitrous oxide and nitrogen were observed to be the primary components of the gases generated in addition to hydrogen. Typical nitrous-oxide-to-hydrogen ratios observed in these studies ranged from $5: 1$ to 20:1 when hydroxyethylethylenediamine triacetic acid and ethylenediamine tetraacetic acid were used as the organic components of the waste simulant. Greater relative amounts of hydrogen were obtained when sodium citrate and sodium glycolate were present. The relative yields of hydrogen, nitrogen, and nitrous oxide were observed in these laboratory studies to be sensitive to many factors, including the identity and concentration of organic components in the waste simulant; the concentrations of hydroxide, nitrite, chromium and aluminate ions in the simulant; the temperatures simulated; and the radiation dose and dose rates simulated. 
Under simulated thermal conditions assumed to be present in the waste tanks, the primary oxidant observed was the nitrite ion. Therefore, some form or forms of reduced nitrogen (i.e, either nitrous oxide or molecular nitrogen, or both of these forms) are expected to always be produced as organics are oxidized in the tank waste.

Nitrous oxide and molecular nitrogen were observed in the study to be produced both thermally and radiolytically; however, the mechanism for their formation is not well understood. Most of the nitrogen observed in these products is believed to be derived from the nitrite ion. However, neither nitrous oxide nor nitrogen can be formed in the absence of organic components.

Hydrogen is known to be produced by the direct radiolysis of water and by abstraction of a hydrogen atom from an organic molecule by a hydrogen radical. A direct correlation between hydrogen generation rates and the concentration of carbon-hydrogen and nitrogen-hydrogen bonds was established in the Meisel et al. (1993) study with simulated wastes. Meisel concluded that hydrogen generation by radiolysis is inhibited in Hanford wastes by efficient capture of the hydrated electron by the nitrate ion.

Part of the retained gas will consist of water vapor. The partial pressure of water over solutions of concentrated electrolytes is lower than for pure water. The results of laboratory studies using waste simulants (Norton and Pederson 1994) indicate that the water vapor pressure should be $<0.05 \mathrm{~atm}$. at $50^{\circ} \mathrm{C}\left(122{ }^{\circ} \mathrm{F}\right)$, and if the total pressure is $\sim 2 \mathrm{~atm}$., water vapor should compose $2.5 \%$ of the retained-gas volume.

\subsubsection{Real Waste Data}

Recent laboratory gas generation studies using actual waste samples (Person 1996, Bryan et al. 1996) have also yielded data about the gases being generated in tank wastes. The methodology used in these studies allows overall waste behavior to be established without first exhaustively characterizing all of the waste components. The analysis of thermally-induced gas generation during these studies, using tank 241-5Y-103 samples, indicates that hydrogen, nitrous oxide, and nitrogen are the primary products of this gas-generation process in tank wastes. Hydrogen was observed to compose less than half of the product gases (in the tank waste samples studied) over the temperature range of $60^{\circ} \mathrm{C}$ to $120^{\circ} \mathrm{C}\left(140^{\circ} \mathrm{F}\right.$ to $\left.248^{\circ} \mathrm{F}\right)$. Lower temperatures were observed to favor the formation of nitrogen whereas higher temperatures were observed to favor the production of nitrous oxide in these tank wastes. Similar results were obtained for composite waste samples from tank 241-SY-101. Further laboratory studies are needed to establish both the rates of gas generation for these complex waste mixtures and the stoichiometry of the product gases.

\subsubsection{Final Safety Analysis Report Methodology for Released Slurry Gas Compositions}

A large body of gas composition data has been obtained (see Appendix C) for many of the waste tanks by using mass spectrometry analys is methodology. Most of this data corresponds to mass spectrometry analyses of grab samples 
collected from the headspace in the tanks. As such, the samples are highly diluted with air, which precludes obtaining meaningful data on the nitrogen, oxygen, or carbon dioxide concentrations present in the waste tank gases. However, the concentrations of hydrogen, nitrous oxide, methane, and various minor components were able to be determined from the mass spectrometry analyses performed. Ammonia concentrations were also determined from these analyses and included in the Appendix $C$ data. However, because ammonia tends to adsorb onto the stainless steel walls of the sampling tubes, sampling container, mass spectrometer, and associated vacuum equipment used in these analyses, the ammonia concentrations identified in Appendix $C$ are generally believed to be less reliable.

There are no direct measurements of the released slurry gas compositions in any of the Hanford waste tanks. Therefore, the released slurry gas compositions for these tanks must be inferred from tank headspace gas concentration data. As previously discussed in Section 4.2.1.2, headspace grab samples were collected and analyzed by using mass spectrometry as a means of baselining the data collected from the standard hydrogen-monitoring systems installed on some of the single-shell tanks and double-shell tanks. The grab sample data collected (see Appendix B) have been used to identify the slurry gas composition for each of the sampled tanks. Only the noncondensable gas species present in the slurry gases are identified in the grab sample data provided in Appendix B because the noncondensable gas species of interest in the tank wastes are not very soluble in the waste. Consequently, the masstransfer effects of the noncondensable gas species are expected to be negligible. Likewise, provided that all the gas species are generated in constant proportions independent of the location, the surface diffusion effects when the gases are released from the waste are expected to be small.

The methodology for deriving the released slurry gas compositions for the tank wastes was to use the hydrogen data in Appendix B to obtain an average and standard deviation for these compositions. Then, the ratios between the nitrous oxide and hydrogen and the methane and hydrogen that may be present in the tank wastes were calculated, along with their averages and standard deviations. The average hydrogen value, plus two standard deviations, was then used to calculate the amount of nitrous oxide and methane that may be present in the waste. Appendix $C$ provides additional details on the derivation of the released slurry gas compositions for the tank wastes.

Because data was not available on the amount of nitrogen present in the released slurry gas (except for a very few tanks) and because the amount of this gas present is highly dependent on waste tank temperature and waste chemistry, a simplifying assumption was made that $20 \%$ nitrogen was present in the released slurry gas. To determine the effects of this assumption, a calculation was performed to compare the pressure differences for a released slurry gas composition with $20 \%$ nitrogen and a released slurry gas composition with $0 \%$ nitrogen (see Appendix $C$ ). The calculated gauge pressure for released slurry gas compositions with $0 \%$ nitrogen was only 11 to $21 \%$ higher (depending on the remaining gas constituents) than the pressure for released slurry gas compositions with $20 \%$ nitrogen added. These small variations in gas pressure of $20 \%$ ( 0.2 times) are not considered significant for the purpose of tank gas composition analysis because variations in other slurry gas parameters (such as the volume of the gas and how much material is entrained from the tank) can result in gas pressure increases of from $200 \%$ to $3600 \%$ (2 to 36 times). 
Ammonia is known to be soluble in the tank waste. However, the amount of ammonia present in the released slurry gas or released due to mass transport phenomena associated with the gas release event is not well characterized. Therefore, in the data provided in Appendix D, a constant value of $15 \%$ was chosen for the amount of ammonia that could be present in the waste. This value was chosen because of several factors. One factor was that the same value was chosen for tank 241-SY-101 (LANL 1995). In recent work at the Los Alamos National Laboratory (Pasamehmetoglu 1996) on rotary-mode core sampling of the tank wastes and on interim stabilizing of the tanks, the value chosen for ammonia has ranged as high as 50\%. However, al though ammonia is not routinely monitored in the tank farms, no measured data exist to support that high a value, and operational experience during the performance of the types of activities analyzed by Los Alamos National Laboratory does not appear to support it. Twenty-three vapor exposure events involving 40 workers at the Hanford Site have occurred between July 1987 and February 1995. During these events, workers have reported $i 11$ effects including headaches, burning sensation in nose and throat, nausea, and impaired pulmonary function while working around waste tanks at the Hanford project. Musty and foul odors, including the smell of ammonia, have been reported to emanate from several single-shelled tanks (Meacham et al. 1996). Ten of these occurrences, involving 18 workers, were linked to C Tank Farm. In particular, tank 241-C-103 was implicated with six of the reported occurrences. The occupational limit for ammonia is $25 \mathrm{ppm}$ while a concentration of $500 \mathrm{ppm}$ is considered immediately dangerous to life and health.

To determine the effect of ammonia on the calculated final gas pressures in the tanks after deflagration, ammonia levels in the released slurry gas were varied (by calculation) from the $15 \%$ value chosen (see Appendix $C$ for details) to a lower value of $10 \%$ and to a higher value of $20 \%$ of the slurry gas. The results of these variations were that the final gauge pressure was lowered by $\sim 2$ to $12 \%$ for $10 \%$ ammonia in the slurry gas and was raised by $\sim 2$ to $11 \%$ for $20 \%$ ammonia in the slurry gas. These sma11 variations in gas pressure of $10 \%$ ( 0.1 times) are not considered significant for the purpose of tank gas composition analysis because variations in other released slurry gas parameters (such as the volume of the gas and how much material is entrained from the tank) can result in gas pressure increases of from $200 \%$ to $3600 \%$ (2 to 36 times).

Table 6 lists estimated compositions for released slurry gas for the waste tanks for which monitoring data is available. The table also lists the calculated values of (1) the lower flammability limit (see Appendix $C$ for details) for a total mixture of the gases listed for each tank and (2) the hydrogen concentration at the mixture lower flammability limit for each tank. The calculated concentration for hydrogen at the mixture lower flammability limit is useful because the only flammable-gas species being monitored in these tanks is hydrogen (the standard hydrogen-monitoring systems are specifically designed to monitor for hydrogen only). It should be noted that the current flammability limit values used in the tank farms is a lower flammability limit of $4.5 \%$ (Sherwood 1995) for a mixture of gases. The hydrogen concentration at this lower flammability limit is $2.5 \%(25,000 \mathrm{ppm})$, and $25 \%$ of this hydrogen concentration is $0.6250 \%(6,250 \mathrm{ppm})$. A comparison of these limits with the limits determined for slurry gas compositions, which are based upon actual measurements of hydrogen levels in the waste tanks, shows that these 1 imits $(2.5 \%$ and $0.6250 \%)$ are still bounding, except for one tank. 
Table 6. Estimated Compositions for Released Slurry Gas and Lower Flammability Limits. (2 sheets)

\begin{tabular}{|c|c|c|c|c|c|c|c|c|c|}
\hline \multirow[t]{2}{*}{ Tank } & \multirow[t]{2}{*}{$\underset{\text { mole }}{\mathrm{H}_{2}} \%$} & \multirow[t]{2}{*}{$\begin{array}{c}\mathrm{N}_{2} \mathrm{O} \\
\text { mote } \%\end{array}$} & \multirow[t]{2}{*}{$\underset{\text { mole }}{\mathrm{CH}_{4}}$} & \multirow[t]{2}{*}{${ }_{\text {mole }}^{\mathrm{NH}_{3}}$} & \multirow[t]{2}{*}{${ }_{\text {mole }}^{\mathrm{N}_{2}} \%$} & \multicolumn{2}{|c|}{$\begin{array}{c}\text { Total mixture } \\
\text { LFL }\end{array}$} & \multicolumn{2}{|c|}{$\begin{array}{c}\text { Hydrogen } \\
\text { concentration } \\
\text { at LFL }\end{array}$} \\
\hline & & & & & & $100 \%$ & $25 \%$ & $100 \%$ & $25 \%$ \\
\hline AN-103 & 60 & 5 & 0 & 15 & 20 & 4.69 & 1.17 & 3.75 & 0.9373 \\
\hline AN-104 & 55 & 10 & 0 & 15 & 20 & 4.75 & 1.19 & 3.73 & 0.9318 \\
\hline AN-105 & 52 & 13 & 0 & 15 & 20 & 4.79 & 1.20 & 3.71 & 0.9281 \\
\hline AN-107 & \multicolumn{9}{|c|}{ No monitoring data } \\
\hline AW-101 & 48 & 17 & 1 & 15 & 20 & 4.85 & 1.21 & 3.66 & 0.9148 \\
\hline AW-104 & \multicolumn{9}{|c|}{ No monitoring data } \\
\hline AY-101 & \multicolumn{9}{|c|}{ No monitoring data } \\
\hline SY-101 & 31 & 27 & 1 & 15 & 26 & 5.24 & 1.31 & 3.51 & 0.8769 \\
\hline SY-103 & 30 & 20 & 2 & 17 & 31 & 5.43 & 1.36 & 3.35 & 0.8377 \\
\hline A-101 & 54 & 10 & 1 & 15 & 20 & 4.76 & 1.19 & 3.68 & 0.9199 \\
\hline A-103 & \multicolumn{9}{|c|}{ No monitoring data } \\
\hline$A X-101$ & 55 & 7 & 3 & 15 & 20 & 4.76 & 1.19 & 3.59 & 0.8964 \\
\hline$A X-103$ & 30 & 31 & 4 & 15 & 20 & 5.28 & 1.32 & 3.21 & 0.8030 \\
\hline $\mathrm{BX}-107$ & \multicolumn{9}{|c|}{ No monitoring data } \\
\hline BY-101 & \multicolumn{9}{|c|}{ No monitoring data } \\
\hline BY-102 & \multicolumn{9}{|c|}{ No monitoring data* } \\
\hline BY-103 & 45 & 18 & 1 & 15 & 20 & 4.89 & 1.22 & 3.60 & 0.9011 \\
\hline BY -105 & \multicolumn{9}{|c|}{ No monitoring data } \\
\hline$B Y-106$ & 27 & 37 & 1 & 15 & 20 & 5.42 & 1.35 & 3.42 & 0.8540 \\
\hline BY-109 & 46 & 16 & 3 & 15 & 20 & 4.89 & 1.22 & 3.51 & 0.8770 \\
\hline C-104 & \multicolumn{9}{|c|}{ No monitoring data ${ }^{*}$} \\
\hline$C-106$ & 41 & 0 & 24 & 15 & 20 & 4.98 & 1.25 & 2.56 & 0.6400 \\
\hline C-107 & \multicolumn{9}{|c|}{ No monitoring data } \\
\hline$S-101$ & \multicolumn{9}{|c|}{ No monitoring data } \\
\hline$S-102$ & 37 & 28 & 1 & 15 & 20 & 508 & 1.27 & 3.56 & 0.8912 \\
\hline$S-103$ & \multicolumn{9}{|c|}{ No monitoring data" } \\
\hline$S-105$ & \multicolumn{9}{|c|}{ No monitoring data* } \\
\hline S-106 & \multicolumn{9}{|c|}{ No monitoring data } \\
\hline S-107 & 57 & 8 & 0 & 15 & 20 & 4.72 & 1.18 & 3.73 & 0.9336 \\
\hline$S-108$ & 65 & 0 & 0 & 15 & 20 & 4.64 & 1.16 & 3.77 & 0.9420 \\
\hline
\end{tabular}


Table 6. Estimated Compositions for Released Slurry Gas and Lower Flammability Limits. (2 sheets)

\begin{tabular}{|c|c|c|c|c|c|c|c|c|c|}
\hline \multirow[t]{2}{*}{ Tank } & \multirow[t]{2}{*}{$\underset{\text { mole } \%}{\mathrm{H}_{2}}$} & \multirow[t]{2}{*}{$\underset{\text { mole } \%}{\mathrm{~N}_{2} \mathrm{O}}$} & \multirow[t]{2}{*}{${ }_{\text {mole }}^{\mathrm{CH}_{4}} \%$} & \multirow[t]{2}{*}{$\operatorname{mole}_{3}^{\mathrm{NH}_{3}} \%$} & \multirow[t]{2}{*}{$\underset{\text { mole }}{\mathrm{N}_{2}} \%$} & \multicolumn{2}{|c|}{ Total mixture } & \multicolumn{2}{|c|}{$\begin{array}{c}\text { Hydrogen } \\
\text { concentration } \\
\text { at LFL }\end{array}$} \\
\hline & & & & & & $100 \%$ & $25 \%$ & $100 \%$ & $25 \%$ \\
\hline S-109 & \multicolumn{9}{|c|}{ No monitoring data } \\
\hline$S-110$ & 56 & 9 & 0 & 15 & 20 & 4.73 & 1.18 & 3.73 & 0.9336 \\
\hline$S-111$ & 37 & 10 & 18 & 15 & 20 & 5.05 & 1.26 & 2.68 & 0.6697 \\
\hline$S-112$ & 42 & 17 & 6 & 15 & 20 & 4.96 & 1.24 & 3.33 & 0.8314 \\
\hline $5 X-101$ & 44 & 0 & 21 & 15 & 20 & 4.94 & 1.24 & 2.69 & 0.6734 \\
\hline $5 X-102$ & 21 & 36 & 8 & 15 & 20 & 5.61 & 1.40 & 2.63 & 0.6578 \\
\hline $5 x-103$ & 41 & 16 & 8 & 15 & 20 & 4.98 & 1.25 & 3.20 & 0.7993 \\
\hline $5 x-104$ & 33 & 0 & 32 & 15 & 20 & 5.11 & 1.28 & 2.13 & 0.5313 \\
\hline $5 X-105$ & 44 & 0 & 21 & 15 & 20 & 4.94 & 1.24 & 2.70 & 0.6747 \\
\hline SX-106 & 30 & 29 & 6 & 15 & 20 & 5.27 & 1.32 & 3.06 & 0.7655 \\
\hline SX-109 & 35 & 14 & 16 & 15 & 20 & 5.10 & 1.28 & 2.70 & 0.6743 \\
\hline $\mathrm{T}-104$ & 65 & 0 & 0 & 15 & 20 & 4.64 & 1.16 & 3.77 & 0.9420 \\
\hline $\mathrm{T}-110$ & 65 & 0 & 0 & 15 & 20 & 4.64 & 1.16 & 3.77 & 0.9420 \\
\hline $\mathrm{TX}-102$ & \multicolumn{9}{|c|}{ No monitoring data } \\
\hline TX-111 & \multicolumn{9}{|c|}{ No monitoring data ${ }^{*}$} \\
\hline $\mathrm{TX}-112$ & \multicolumn{9}{|c|}{ No monitoring data ${ }^{*}$} \\
\hline $\mathrm{TX}-113$ & \multicolumn{9}{|c|}{ No monitoring data } \\
\hline $\mathrm{TX}-115$ & \multicolumn{9}{|c|}{ No monitoring data* } \\
\hline $\mathrm{U}-102$ & \multicolumn{9}{|c|}{ No monitoring data" } \\
\hline $\mathrm{U}-103$ & 24 & 40 & 1 & 15 & 20 & 5.54 & 1.39 & 3.36 & 0.8412 \\
\hline $\mathrm{U}-105$ & 15 & 49 & 1 & 15 & 20 & 6.24 & 1.56 & 3.10 & 0.7754 \\
\hline $\mathrm{U}-106$ & \multicolumn{9}{|c|}{ No monitoring data" } \\
\hline $\mathrm{U}-107$ & 21 & 43 & 1 & 15 & 20 & 5.73 & 1.43 & 3.29 & 0.8225 \\
\hline $\mathrm{U}-108$ & 27 & 36 & 2 & 15 & 20 & 5.40 & 1.35 & 3.27 & 0.8182 \\
\hline $\mathrm{U}-109$ & 26 & 38 & 1 & 15 & 20 & 5.47 & 1.37 & 3.40 & 0.8508 \\
\hline
\end{tabular}

*Tanks with no monitoring data are included in this table, because they are addressed in the f lammable-gas unreviewed safety question; however, these tanks do not have monitoring equipment installed yet.

LFL $=$ lower flammability limit. 
That tank is 241-SX-104, where the calculated mixture lower flammability limit is 4.96 , the hydrogen concentration at this lower flammability limit is $2.16 \%(21,600 \mathrm{ppm})$, and $25 \%$ of this hydrogen concentration is $0.5394 \%$ $(5,394 \mathrm{ppm})$.

\subsection{LOCAL, GLOBAL, AND SUBSURFACE DEFLAGRATIONS/DETONATIONS}

Addressed in this section is the potential for deflagration (i.e., propagation of a flame at a rate below the speed of sound) or detonations (i.e., propagation of a flame at a rate above the speed of sound) to occur in localized regions of the waste tank headspace, in the global region (total headspace volume) of the waste tanks, or in subsurface regions (below the surface of the tank waste) if the concentrations of flammable gases in these regions were ignited by some credible natural occurrence or intrusive activity. Also addressed in this section is the credibility of these deflagrations and detonations occurring in other locations of the tank farm systems (e.g., process pits and transfer lines).

The estimates of the retained-gas volumes in the tanks and the studies conducted on possible deflagration or detonation of this gas to date are summarized in this section to support the conclusions to date on these subjects. These conclusions are that deflagrations appear to be credible events in single-shell tanks and double-shell tanks, and if enough gas is released from the tank waste in a short period of time, detonations appear to be credible events in a few single-shell tanks and double-shell tanks. Deflagrations of gas under the waste surface are also considered credible events that could cause release of nearly all of the retained gas in the tanks. Similarly, earthquakes could also cause anywhere from $50 \%$ to nearly all of the retained gas to be released from the waste and ignited in the tank headspace, resulting in deflagrations or detonations, depending on the hydrogen concentrations present in the headspace.

\subsubsection{Estimates of Retained-Gas Volumes}

The estimates for the volumes of retained gas in the waste tanks that are used in this section are from Hodgson et al. (1996). These values were determined by using average, or best estimate, parameters. As such, they should be considered the average value of the retained gas in the tanks. A conservative estimate of the retained gas would likely be twice as large as the reported volume; however, this conservatism is not used herein. Table 7 lists the estimated retained-gas volumes and the tank headspace volumes from Hodgson et a1. (1996) for various tanks.

\subsubsection{Bureau of Mines Flammability Tests}

The Pittsburgh Research Center of the U.S. Bureau of Mines has studied the flammability of various mixtures of hydrogen, nitrous oxide, and air (Cashdollar et a). 1992). More than 280 tests using electric sparks and stronger pyrotechnic ignitors were performed in a $120-\mathrm{L}$ spherical chamber. 
Table 7. Best Estimates of Retained-Gas Volumes and Headspace Volumes.

\begin{tabular}{|c|c|c|c|c|c|}
\hline Tank & $\begin{array}{c}\text { Retained } \\
\text { gas } \\
(\mathrm{scm})\end{array}$ & $\begin{array}{l}\text { Headspace } \\
\qquad\left(\mathrm{m}^{3}\right)\end{array}$ & Tank & $\begin{array}{c}\text { Retained } \\
\text { gas } \\
\text { (scm) }\end{array}$ & $\begin{array}{l}\text { Headspace } \\
\qquad\left(\mathrm{m}^{3}\right)\end{array}$ \\
\hline AN- 103 & 641 & 1717 & $S-106$ & 808 & 2197 \\
\hline AN-104 & 320 & 1321 & S-107 & - & 2543 \\
\hline AN-105 & 397 & 1024 & $S-108$ & - & 2268 \\
\hline AN-107 & - & 1328 & $S-109$ & 447 & 2256 \\
\hline$A W-101$ & 299 & 1065 & $S-110$ & - & 2510 \\
\hline AW-104 & 150 & 1083 & $S-111$ & 466 & 1938 \\
\hline AY-101 & 34 & 1759 & $S-112$ & - & 2005 \\
\hline $5 Y-101$ & 551 & 1032 & $5 X-101$ & 56 & 3152 \\
\hline$S Y-103$ & 119 & 2514 & SX-102 & 386 & 2865 \\
\hline & 8 & & $5 x-103$ & 673 & 2393 \\
\hline$A-101$ & 130 & 1224 & SX-104 & - & 2591 \\
\hline A-103 & 102 & 3349 & $S X-105$ & - & 2357 \\
\hline$A X-101$ & - & 1886 & $5 X-106$ & 266 & 2813 \\
\hline$A X-103$ & - & - & $5 x-109$ & - & 3896 \\
\hline BX-107 & 122 & 1933 & $T-104$ & - & 1458 \\
\hline BY -101 & 266 & 3165 & $T-110$ & - & 1655 \\
\hline BY -102 & - & 2933 & $T X-102$ & 175 & 3209 \\
\hline BY -103 & - & 2529 & $T X-111$ & 179 & 2652 \\
\hline BY -105 & 183 & 2322 & TX-112 & 511 & 1594 \\
\hline BY-106 & - & 1432 & $\mathrm{TX}-113$ & 242 & 1814 \\
\hline BY-109 & - & 2746 & $T X-115$ & 297 & 1985 \\
\hline$C-104$ & 30 & 2296 & $\mathrm{U}-102$ & 272 & 1821 \\
\hline$C-106$ & - & 2372 & $U-103$ & 303 & 1448 \\
\hline$C-107$ & 5 & 2296 & $U-105$ & 209 & 1619 \\
\hline$S-101$ & 138 & 2380 & $\mathrm{U}-106$ & 41 & 2381 \\
\hline S-102 & 608 & 1924 & $U-107$ & 184 & 1693 \\
\hline$S-103$ & 256 & 2961 & $\mathrm{U}-108$ & - & 1456 \\
\hline$S-105$ & 120 & 2412 & U-109 & 215 & 1473 \\
\hline
\end{tabular}

SCM = standard cubic meters . 
The results of these tests indicate that, below $20 \%$ hydrogen, there is no significant difference in the flammability data for hydrogen-air mixtures and for 1:1 or 3:2 ratios of hydrogen-nitrous oxide-air mixtures (Cashdollar et a1. 1992). At higher hydrogen concentrations, the hydrogen-nitrous oxide-air mixtures are more hazardous, with higher maximum pressures and rates of pressure rise (Cashdollar et al. 1992). Therefore, small amounts of nitrous oxide (relative to air) do not appear to have much effect on the flammability of retained gases. This would be the situation in a tank that has experienced a gas-release event with the entire tank headspace becoming we11 mixed before ignition occurs. However, high concentrations of nitrous oxide (relative to air) could markedly increase the explosion hazard. This appears to be substantiated by an experiment by Cashdollar (1992) who states "a stoichiometric mixture of hydrogen with nitrous oxide appears to have detonated when initiated with a spark." This explosion hazard could exist for subsurface ignition events or for local releases in the waste tanks that have not become wel1 mixed before ignition occurs.

Some tests conducted by the U.S. Bureau of Mines were made at an elevated temperature of $54{ }^{\circ} \mathrm{C}\left(129.2^{\circ} \mathrm{F}\right)$. These tests al so included added water vapor. The data obtained from these tests were not significantly different from those obtained at ambient temperature, with no water vapor (dry)

(Cashdollar et al. 1992).

The issue raised concerning the potential for ignition of ammonia gas in the gas mixtures was also tested (Cashdollar et al 1992). Mixtures of $1: 1$ ratios of hydrogen to nitrous oxide in air, with small amounts of ammonia added, were tested in the 120- $L$ spherical chamber with the spark ignition source. Ammonia is a fuel with its own lean flammability limit of $15 \%$ in air (Coward and Jones 1952, Zabetakis 1965). It is not as flammable as hydrogen, but the data show that addition of ammonia to the equimolar hydrogen-nitrous oxide mixture in air results in the lowering of the downward propagation limit for hydrogen by about $0.5 \%$ for each $1 \%$ of ammonia added. In the equimolar hydrogen-nitrous oxide mixtures, the downward propagation limit occurs at $8 \%$ hydrogen (Cashdollar et a1. 1992). Thus, for example, adding $4 \%$ ammonia lowers the downward propagation 1 imit to $6 \%$ hydrogen.

\subsubsection{Local Deflagrations/Detonations}

Modeling of local deflagrations/detonations has been conducted for various local release scenarios (Antoniak and Recknagle 1995, 1996a, 1996b; Recknagle and Michener 1995; Thurgood 1996; Heard 1996; Plys et al. 1996; Beyler and Thorne 1996). The following paragraphs summarize these modeling efforts.

4.3.3.1 Local Deflagrations. Antoniak and Recknagle (1995) modeled a 28- $\mathrm{m}^{3}$ $\left(1,000-\mathrm{ft}^{3}\right)$ release of hydrogen in 60 seconds from a localized area in tank 241-AW-101. They used a fully three-dimensional model that simulates airflow into and out of the tank, heat transfer by convection (both forced and natural), conduction, buoyancy, and diffusion. The active ventilation on this tank was also modeled in this simulation. The modeling showed that the peak concentration in the dome reached $30 \%$ hydrogen, which dissipated to $8 \%$ within 2 minutes and to $3 \%$ within 2 hours. A video made from the numerical 
simulation showed that the buoyant gases collected in the apex of the tank and remained flammable for nearly 2 hours.

Recknagle and Michener (1995) modeled different size releases into the tank headspace of tank 241-AY-101 over an 80-minute release period. This modeling showed that $6.8 \mathrm{~m}^{3}\left(240 \mathrm{ft}^{3}\right)$ of hydrogen brought the well-mixed headspace concentration to $0.4 \%, 31 \mathrm{~m}^{3}\left(1,090 \mathrm{ft}^{3}\right)$ of hydrogen yielded $1.8 \%$, and $141 \mathrm{~m}^{3}\left(4,980 \mathrm{ft}^{3}\right)$ of hydrogen gave a hydrogen concentration of $8 \%$. This study did not look at the localized concentrations in the tank headspace.

Antoniak and Recknagle (1996a) modeled a gas release event that occurred in tank 24l-AN-105 on October 21, 1995, The best fit to the measured data obtained from this modeling was $14.2 \mathrm{~m}^{3}\left(500 \mathrm{ft}^{3}\right)$ of hydrogen released in 10 minutes from a localized area. The measured peak from the standard hydrogen monitoring system was $1.6 \%$ hydrogen whereas the calculated peak resulting from the modeling was $1.7 \%$ hydrogen. Note: The modeling only attempted to calculate what the standard hydrogen-monitoring system should be reading and not the highest concentration in the dome.

Antoniak and Recknagle (1996b) updated an earlier analyses for singleshell tank 241-S-108 and double-shel1 tank 241-SY-101. In the earlier analyses, the dome was initially modeled as quiescent with no ventilation flow. This modeling established an initial (thermal buoyancy-driven) flow field in the tank headspace and looked at various ventilation flow rates. The presence of an established flow field simulating convective heat flow was calculated to have a relatively small, short-term effect on hydrogen concentrations. Ventilation airflow rate was determined to have a similarly small effect on peak hydrogen concentrations.

Thurgood (1996) investigated the effects of two postulated flammable-gas releases (the release of gas from a dendritic structure and the release of large 1-m bubbles) during salt-well pumping. The analysis focused on the pump pit concentrations. Note: The European Study Group (1996) indicates that 1-m bubbles cannot exist; however, $10-\mathrm{cm}$ bubbles can. The results indicated that the pump pit would approach the lower flammability limit from the release of flammable gas from a dendritic region. Pump pit concentrations exceeding the lower flammability limit (but only lasting for a few seconds) can occur as the result of multiple releases of large bubbles.

Heard (1996) performed analyses on the effects of igniting small volumes of flammable gas. The thrust of the analysis was to calculate the volume of flammable gas that, if burned, would result in a pressure that would cause the failure of the inlet high-efficiency particulate air filter or the exhaust high-efficiency particulate air filter. It is calculated that burning $2.12 \mathrm{~m}^{3}$ $\left(75 \mathrm{ft}^{3}\right)$ of flammable gas will cause the inlet filter to fail whereas the exhaust filter would not fail until 5.38 to $8.5 \mathrm{~m}^{3}\left(190\right.$ to $\left.300 \mathrm{ft}^{3}\right)$ of flammable gas is burnt. It must be noted that Heard's analys is is specific to tank 241-SY-101 and the SY farm ventilation system.

4.3.3.2 Local Detonations. Plys et al. (1996) looked at the potential for gas plumes in the tanks to detonate. They looked at two cases that could arise in the tanks: (1) lighter than air buoyant plumes (where the mole fraction of hydrogen is large) and (2) heavier-than-air nonbuoyant plumes (where the mole fraction of nitrous oxide is large). 
For the buoyant plume, the release gas rises from the waste and mixes with the air in the tank headspace. Figure 16 shows a schematic of the buoyant plume. To calculate the amount of hydrogen in the explosive region of a buoyant plume release, the Taylor entrainment mixing concept was used. An equation was developed giving the mass fraction of the released gas as a function of the distance from the release opening. The modeling results showed that a small release of $9.6 \mathrm{~m}^{3}$ of hydrogen over a short period of time (2 minutes) produces a very small volume of gas $\left(0.273 \mathrm{~m}^{3}\right)$ in the detonable range. The modeling results also showed that the volume of gas in the plume that is flammable is also small $\left(2.82 \mathrm{~m}^{3}\right)$.

The modeling results also presented a parametric analysis that looked at the effect of plume travel distance, plume composition, and tank headspace composition. Two plume compositions were considered: pure hydrogen and a stoichiometric mixture of hydrogen and nitrous oxide. The gas analys is showed that concentration in the pure hydrogen plume becomes lower than the lower flammability 7 imit of $4 \%$ hydrogen in air at $5.5 \mathrm{~m}(18 \mathrm{ft}$ ). If the dome is less than $5.5 \mathrm{~m}$ above the waste, the plume will turn and move parallel to the dome. If the buoyant plume persists for a period of time, the tank will begin to fill with flammable gases from the top down. For the stoichiometric hydrogen and nitrous oxide plume, the analysis shows gas concentration becomes less than the lower explosive limit of $8 \%$ hydrogen-nitrous oxide in air at $5.2 \mathrm{~m}$. Plys et al. (1996) argues that, in either case, the plume is a free, unconfined cloud and that a detonation or deflagration-to-detonation transition is considered extremely unlikely to beyond extremely unlikely. It is noted that deflagrations could still occur and could have postcombustion pressures that are nonnegligible (Plys et al. 1996).

Plys et al. (1996) also looked at nonbuoyant plumes. Modeling of these plumes indicated that, unless the release momentum is high, the plume will not rise significantly above the surface of the waste before the upward flow within the plume stops and the flow reverses direction. Figure 17 shows the behavior of a heavier-than-air plume. A heavier-than-air plume will result whenever the mole fraction of nitrous oxide is high (i.e., when the ratio of the plume density to that of the tank atmosphere is 1.52 or greater) (Plys et al. 1996). Due to the low Froude number, the plume entrains very little air from the tank headspace over the maximum height that the plume rises to. Some entrainment of air will occur as the plume spreads radially although the rate of entrainment is usually less than that measured for buoyant plumes because the stable density stratification causes turbulence damping (Plys et al. 1996).

An example of a nonbuoyant plume was also modeled by Plys et al. (1996). This modeling showed that, if the release occurs in the center of the tank, if the flow rate is $0.1 \mathrm{~m}^{3} / \mathrm{s}$, if the hydrogen concentration in the released gas is $20 \%$, and if the upper bound entrainment coefficient is used, the plume will reach the side wall in 48.7 seconds (a total gas release of $4.87 \mathrm{~m}^{3}$ ). If the plume continues, the hydrogen concentration in the layer will increase and ultimately exceed the lower flammability limit. (Note: Plys et a1. (1996) states that, if the lower bound entrainment coefficient were used, the plume would be flammable at all times.) The long term dilution of the dense gas layer occurs by molecular diffusion. Again, the amount of gas that is at 
Figure 16. Buoyant Plume Released from the Waste.

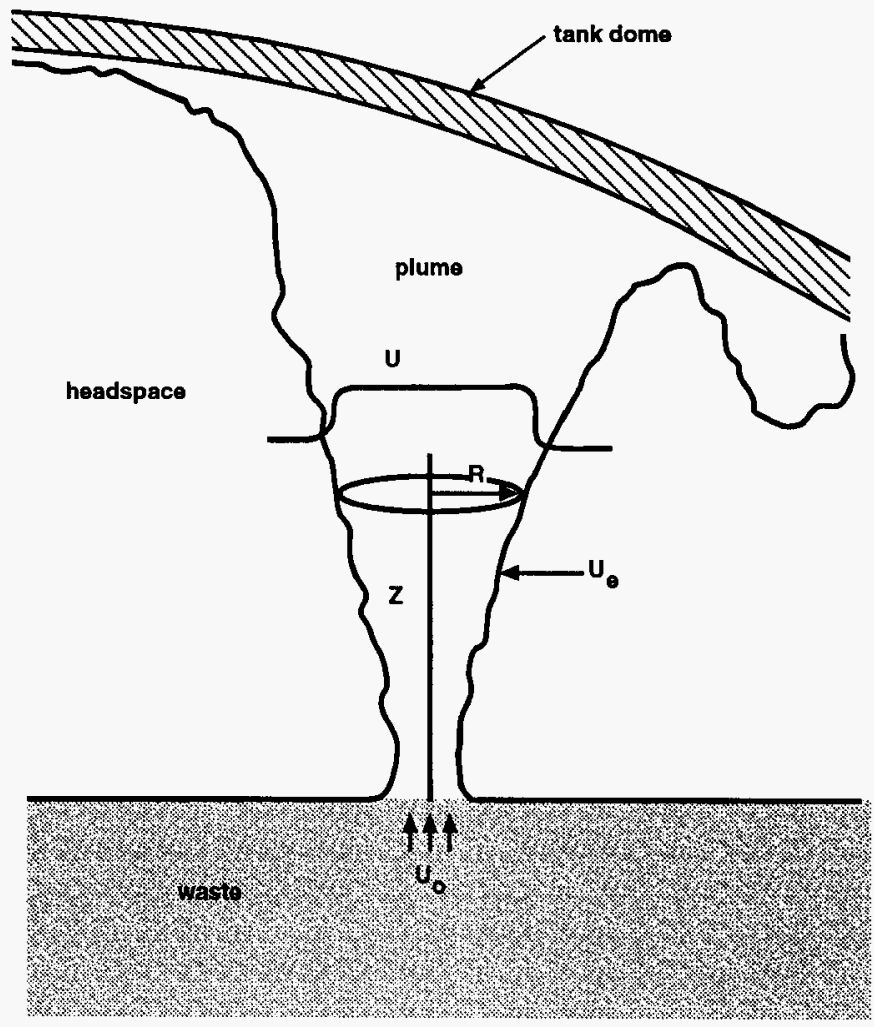

$R$ = radius of the plume

$U$ = top-hat velocity in the plume

$U_{e}=$ entrainment velocity

$U_{0}=$ velocity of slurry gas as it exits the waste

$Z$ = height above the waste 


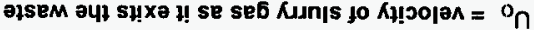

$$
\begin{aligned}
& \text { snịped }=\quad \mathbf{U} \\
& \text { әכeds peaY awop yue? u! sese6 to Kusuep }=\infty_{d} \\
& \text { se6 Kun|s to Ki!suap = } d \\
& \text { әu!! น!!M sn!peג u! әбиечэ }=\frac{1 p}{\forall p}
\end{aligned}
$$

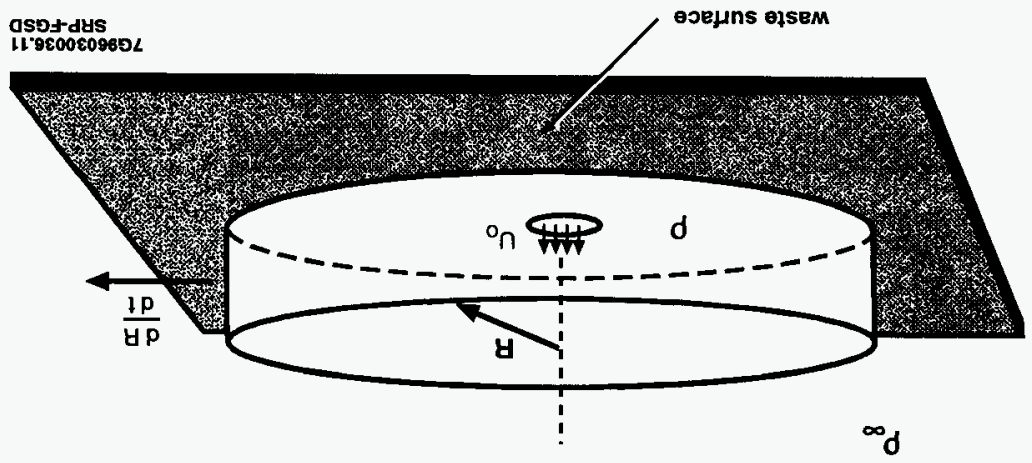

esedspeey

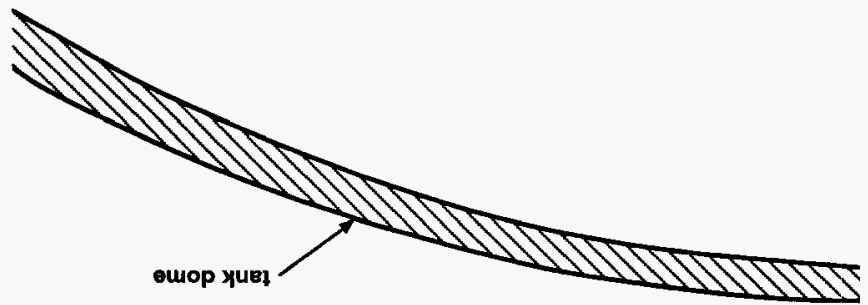

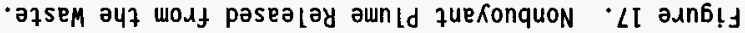

0 АЭУ $\varepsilon S L-I L-W M-O S-כ H M$ 
concentrations high enough to support detonations is smal1, and the flammablegas layer is too small to support a deflagration-to-detonation transition. However, the deflagration itself may be capable of damaging the tank dome (Plys et al. 1996).

Beyler and Roby (1996) also addressed local gas releases. They suggested that the classic two-layer model should be used to model to the situation. In this model, the buoyant plume causes a layer of flammable gases to develop in the top of the tank. As the plume continues, the tank is filled with flammable gases from the top down. The method used was originally developed for rectangular geometries, i.e., without dome curvature effects included. Plume entrainment measurements were surveyed (Beyler and Roby 1996), and an entrainment constant that is a function of the buoyant release which depends on the molecular weight and volume of gas that is released. Table 8 is derived using the two-layer model. Hydrogen concentrations in Table 8 were calculated for double-shell and single-shell tanks after an assumed local release of $10 \%$ of the retained-gas in a two-minute time frame. The tank headspace volumes (see Table 7) were used to calculate the equivalent headspace heights (assuming rectangular geometry with a surface area of $410 \mathrm{~m}^{3}$ ) in Table 8. The gas compositions (see Table 6) were used to calculate the average molecular weight of the released gas in Table 8 . An equation was then used to calculate the predicted buoyant layer interface height, the buoyant layer depth (difference between the equivalent tank headspace height and the buoyant layer interface height), and the hydrogen volume fraction in the layer and in the well-mixed (or well-stirred) tank. For comparison purposes, the hydrogen concentration at the lower flammability limit (from Table 6) is listed in the last column of Table 8 . Similar calculations were done for release of $50 \%$ and $100 \%$ of the retained gas. Table 9 presents the results. Notations are provided to indicate if the 1 ayer or the we11-mixed concentrations are flammable or detonable or if a deflagration-to- detonation transition is possible.

\subsubsection{Global Deflagrations/Detonations in Double- and Single-Shell Tanks}

Global deflagrations have been modeled since 1990 . These models have mostly concentrated on tank 241-SY-101 (LANL 1995); however, some of them did look at other tanks (Fox et al. 1993, Fox and Stepnewski 1994, Spore et al. 1994, Schlosser 1996a, 1996b).

\subsubsection{Global Deflagrations. In the Los Alamos National Laboratory} (LANL 1995) analysis, proposed accident scenarios concerning the installation, operation, and removal of the mixer pump were analyzed. Los Alamos National Laboratory used computer codes HMS and TRAC for the thermal-hydraulic analysis, which simulated the injection and mixture of the release gases within the tank dome space, the combustion of the flammable gases, and the resulting gas transport through the various leak paths of the tank. The predicted parameters of interest were the tank 241-SY-101 dome pressures and vapor temperatures and the radioactive waste material and toxic gases released to the atmosphere. The results of the pressure response of the tank were used as input for the structural analysis of the tank. The entrainment and transport of waste material and toxic gases were used for the radiological and toxicological consequence analysis. 
Table 8. Potential Hydrogen Concentrations Achieved in Local Gas-Release Events. ${ }^{\text {(3 sheets) }}$

\begin{tabular}{|c|c|c|c|c|c|c|c|c|c|}
\hline \multirow{2}{*}{ Tank } & \multirow{2}{*}{$\begin{array}{l}\text { Retained } \\
\text { gas volume } \\
\text { (scm) }\end{array}$} & \multirow{2}{*}{$\begin{array}{l}\text { Headspace } \\
\text { vol } \mathrm{l}^{3} \mathrm{me} \\
\left(\mathrm{m}^{\prime}\right)\end{array}$} & \multirow{2}{*}{$\begin{array}{l}\text { Equivalentrit } \\
\text { headspace } \\
\text { height (m) }\end{array}$} & \multirow{2}{*}{$\begin{array}{c}\text { Release gas } \\
\text { average } \\
\text { molecular weight }\end{array}$} & \multirow{2}{*}{$\begin{array}{l}\text { Interface } \\
\text { height (m) }\end{array}$} & \multirow{2}{*}{$\begin{array}{l}\text { Layer } \\
\text { depth (m) }\end{array}$} & \multicolumn{3}{|c|}{ Volume fraction } \\
\hline & & & & & & & $\begin{array}{c}\text { Layer } \\
\text { hydrogen }\end{array}$ & $\begin{array}{c}\text { Well stirred } \\
\text { hydrogen }\end{array}$ & $\begin{array}{l}\text { Hydrogen at lower } \\
\text { flamnabi lity limit }\end{array}$ \\
\hline \multicolumn{10}{|c|}{ Double-shell tank } \\
\hline AN-103 & 641 & 1,717 & 4.19 & 11.6 & 3.16 & 1.03 & $0.091^{4,9}$ & 0.022 & 0.037 \\
\hline AN-104 & 320 & 1,321 & 3.22 & 13.8 & 2.70 & 0.52 & $0.082^{f}$ & 0.013 & 0.037 \\
\hline$A N-105$ & 397 & 1,024 & 2.50 & 15.1 & 2.15 & 0.35 & $0.142^{f, g, h}$ & 0.020 & 0.037 \\
\hline$A N-107^{b}$ & $\cdots$ & 1,328 & 3.24 & & & & & & \\
\hline AH-101 & 229 & 1,065 & 2.60 & 16.6 & 2.30 & 0.30 & $0.089^{f}$ & 0.010 & 0.037 \\
\hline$A U-104^{C}$ & 150 & 1,083 & 2.64 & 4.3 & 2.15 & 0.49 & $0.063^{f}$ & 0.012 & 0.038 \\
\hline$A Y-101^{c}$ & 34 & 1,759 & 4.29 & 4.3 & 3.60 & 0.69 & 0.010 & 0.002 & 0.038 \\
\hline$s Y-101$ & 551 & 1.032 & 2.52 & 22.4 & 2.24 & 0.28 & $0.151^{f, 9, h}$ & 0.017 & 0.035 \\
\hline SY -103 & 119 & 2,514 & 6.13 & 21.2 & 5.35 & 0.78 & 0.011 & 0.001 & 0.034 \\
\hline \multicolumn{10}{|c|}{ single-shell tank } \\
\hline A-101 & 130 & 1,224 & 2.99 & 13.8 & 2.63 & 0.35 & $0.049^{f}$ & 0.006 & 0.037 \\
\hline$A-103^{C}$ & 102 & 3,349 & 8.17 & 4.3 & 5.68 & 2.49 & 0.008 & 0.003 & 0.038 \\
\hline$A x-101^{d}$ & $\cdot-$ & 1,886 & 4.60 & 13.0 & & & & & \\
\hline$A x-103^{d}$ & -. & -- & 0.00 & 23.1 & & & & & \\
\hline $8 x-107^{c}$ & 122 & 1,933 & 4.71 & 4.3 & 3.58 & 1.14 & 0.022 & 0.005 & 0.038 \\
\hline$B y-101^{c}$ & 266 & 3,165 & 7.72 & 4.3 & 4.84 & 2.88 & 0.019 & 0.007 & 0.038 \\
\hline$B Y-102^{b}$ & $\cdot-$ & 2,933 & 7.15 & & & & & & \\
\hline $8 Y-103^{d}$ & $-\cdot$ & 2,529 & 6.17 & 17.4 & & & & & \\
\hline BY $-105^{C}$ & 183 & 2,322 & 5.66 & 4.3 & 4.00 & 1.67 & 0.023 & 0.007 & 0.038 \\
\hline$B Y-106^{d}$ & -- & 1,432 & 3.49 & 25.2 & & & & & \\
\hline$B Y-109^{d}$ & $\cdots$ & 2,746 & 6.70 & 16.6 & & & & & \\
\hline C- $104^{c}$ & 30 & 2,296 & 5.60 & 4.3 & 4.59 & 1.01 & 0.006 & 0.001 & 0.038 \\
\hline$c-106^{d}$ & $\cdot \cdot$ & 2,372 & 5.79 & 12.8 & & & & & \\
\hline$c-107^{c}$ & 5 & 2,296 & 5.60 & 4.3 & 5.00 & 0.60 & 0.002 & 0.000 & 0.038 \\
\hline
\end{tabular}


Table 8. Potential Hydrogen Concentrations Achieved in Local Gas-Release Events. ${ }^{a}$ ( 3 sheets)

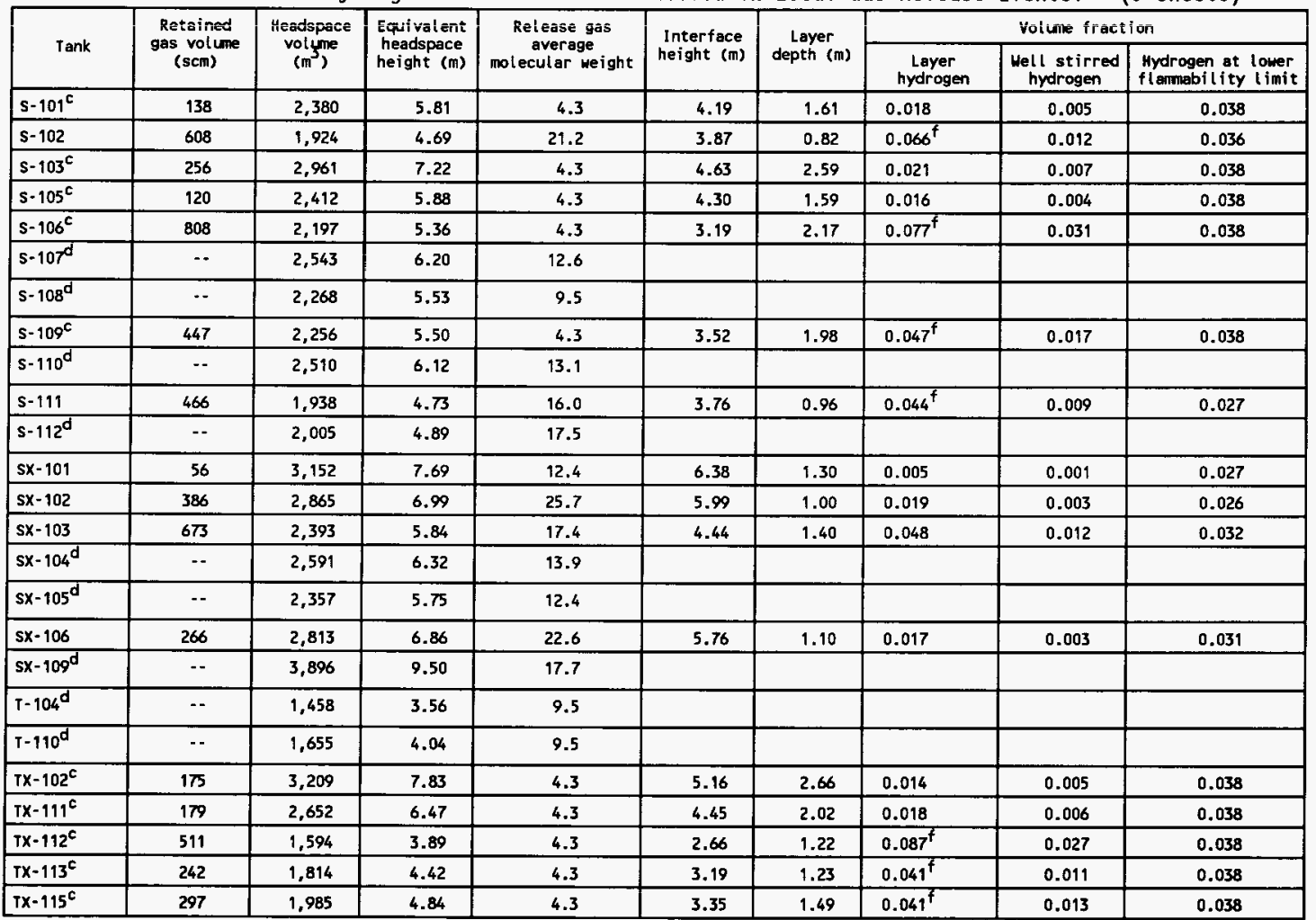


Table 8. Potential Hydrogen Concentrations Achieved in Local Gas-Release Events. ${ }^{\text {(3 sheets) }}$

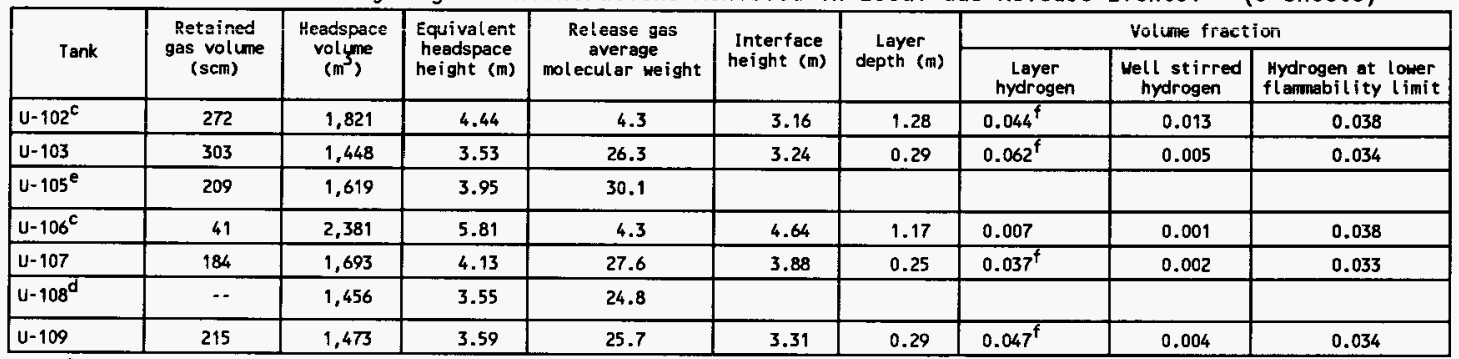

${ }^{a}$ Tank release gas volume was assumed to be $10 \%$ of the volume calculated by Hodgson et al. (1996).

Wo retained gas volume AND no monitoring data.

cho monitoring data so a composition of $85 \%$ hydrogen and $15 \%$ ammonia was assumed.

No retained gas volume.

Heavier than air gas mixture.

Flammable on the basis of the hydrogen equivalent lower flamability limit (see the last column).

Detonable on the bas is of hydrogen equivalent detonable limits of $8 \%$ for tanks where the hydrogen and nitrous oxide concentrations are compapable and $11 \%$ for those tanks with little or no nitrous oxide (Beyler and Roby 1996).

on the basis of the geometry classes, the hydrogen concentration that will result in a deflagration-to-detonation transition will be taken as $8 \%$ for tanks where the hydrogen and nitrous oxide concentrations are comparable and $14 \%$ for those tanks with little or no nitrous oxide (Beyler and Roby 1996). 
Table 9. Potential Hydrogen Concentrations Achieved in Local Gas-Release Events Involving Larger Releases. ( 3 sheets)

\begin{tabular}{|c|c|c|c|c|c|c|c|}
\hline \multirow{2}{*}{ Tank } & \multirow{2}{*}{$\begin{array}{l}\text { Retained } \\
\text { gas volume } \\
\text { (scm) }\end{array}$} & \multirow{2}{*}{$\begin{array}{l}\text { Headspace } \\
\text { volume } \\
\left(\mathrm{m}^{3}\right)\end{array}$} & \multicolumn{2}{|c|}{$50 \%$ release of retained gas volume } & \multicolumn{2}{|c|}{$100 \%$ release of retained gas volume } & \multirow{2}{*}{$\begin{array}{l}\text { Hydrogen at } \\
\text { lower } \\
\text { flammability } \\
\text { L imit }\end{array}$} \\
\hline & & & $\begin{array}{l}\text { Layer hydrogen } \\
\text { volume fraction }\end{array}$ & $\begin{array}{l}\text { Well stirred } \\
\text { hydrogen volume } \\
\text { fraction }\end{array}$ & $\begin{array}{l}\text { Layer hydrogen } \\
\text { volume fraction }\end{array}$ & $\begin{array}{l}\text { Well stirred } \\
\text { hydrogen volume } \\
\text { fraction }\end{array}$ & \\
\hline \multicolumn{8}{|c|}{ Double-shell tank } \\
\hline$A N-103$ & 641 & 1,717 & $0.306^{a, b}, c$ & $0.112^{a, b}$ & $0.526^{\mathrm{a}, b, c}$ & $0.223^{a, b, c}$ & 0.037 \\
\hline AN-104 & 320 & 1,321 & $0.264^{a, b, c}$ & $0.066^{a}$ & $0,442^{a, b, c}$ & $0.132^{a, b}$ & 0.037 \\
\hline AN-105 & 397 & 1,024 & $0.452^{a, b, c}$ & $0.100^{a}$ & $0.753^{a, b, c}$ & $0.200^{a, b, c}$ & 0.037 \\
\hline AN- $107^{f}$ & -- & 1,328 & & & & & \\
\hline$A H-101$ & 229 & 1,065 & $0.279^{a, b, c}$ & $0.051^{a}$ & $0.461^{a, b, c}$ & $0.102^{a}$ & 0.037 \\
\hline$A H-104^{e}$ & 150 & 1,083 & $0.206^{a, b, c}$ & $0.059^{\mathrm{a}}$ & $0.348^{a, b, c}$ & $0.118^{a, b}$ & 0.038 \\
\hline$A Y-101^{e}$ & 34 & 1,759 & 0.033 & 0.008 & 0.055 & 0.016 & 0.038 \\
\hline$s \gamma-101$ & 551 & 1,032 & $0.472^{a, b, c}$ & $0.084^{a, b}$ & $0.779^{a, b, c}$ & $0.168^{a, b, c}$ & 0.035 \\
\hline$s \gamma-103$ & 119 & 2,514 & 0.035 & 0.007 & $0.058^{\mathrm{a}}$ & 0.014 & 0.034 \\
\hline \multicolumn{8}{|c|}{ Single-shell tank } \\
\hline$A-101$ & 130 & 1,224 & $0.152^{a, b, c}$ & 0.029 & $0.252^{a, b, c}$ & $0.057^{a}$ & 0.037 \\
\hline$A-103^{e}$ & 102 & 3,349 & 0.029 & 0.013 & $0.051^{a}$ & 0.026 & 0.038 \\
\hline$A x-101^{f}$ & -- & 1,886 & & & & & \\
\hline$A X-103^{f}$ & $\cdots$ & $\cdots$ & & & & & \\
\hline$B x-107^{e}$ & 122 & 1,933 & $0.075^{a}$ & 0.027 & $0.128^{a, b}$ & $0.054^{\mathrm{a}}$ & 0.038 \\
\hline$B Y-101^{e}$ & 266 & 3,165 & $0.069^{a}$ & 0.036 & $0.123^{a, b}$ & $0.071^{\mathrm{a}}$ & 0.038 \\
\hline$B Y-102^{d}$ & $\cdots$ & 2,933 & & & & & \\
\hline$B Y-103^{f}$ & -. & 2,529 & & & & & \\
\hline BY $-105^{e}$ & 183 & 2,322 & $0.079^{\mathrm{a}}$ & 0.033 & $0.137^{a, b}$ & $0.067^{a}$ & 0.038 \\
\hline BY $-106^{f}$ & -- & 1,432 & & & & & \\
\hline$B Y-109^{f}$ & $\cdots$ & 2,746 & & & & & \\
\hline$c-104^{e}$ & 30 & 2,296 & 0.020 & 0.005 & 0.033 & 0.011 & 0.038 \\
\hline
\end{tabular}


Table 9. Potential Hydrogen Concentrations Achieved in Local Gas-Release Events Involving Larger Releases. (3 sheets)

\begin{tabular}{|c|c|c|c|c|c|c|c|}
\hline \multirow{2}{*}{ Tank } & \multirow{2}{*}{$\begin{array}{l}\text { Retained } \\
\text { gas volume } \\
\text { (scm) }\end{array}$} & \multirow{2}{*}{$\begin{array}{c}\text { Headspace } \\
\text { vot yme } \\
\left(m^{3}\right)\end{array}$} & \multicolumn{2}{|c|}{$50 x$ release of retained gas volume } & \multicolumn{2}{|c|}{$100 \%$ release of retained gas volume } & \multirow{2}{*}{$\begin{array}{l}\text { Hydrogen at } \\
\text { lower } \\
\text { flammabil ity } \\
\text { limit }\end{array}$} \\
\hline & & & $\begin{array}{l}\text { Layer hydrogen } \\
\text { volume fraction }\end{array}$ & $\begin{array}{l}\text { Well stirred } \\
\text { hydrogen volune } \\
\text { fraction }\end{array}$ & $\begin{array}{l}\text { Layer hydrogen } \\
\text { volume fraction }\end{array}$ & $\begin{array}{l}\text { Well stirred } \\
\text { hydrogen volume } \\
\text { fraction }\end{array}$ & \\
\hline$c-106^{f}$ & $-\cdot$ & 2,372 & & & & & \\
\hline $\mathrm{c}-107^{e}$ & 5 & 2.296 & 0.005 & 0.001 & 0.009 & 0.002 & 0.038 \\
\hline s-101 ${ }^{e}$ & 138 & 2,380 & $0.061^{a}$ & 0.025 & $0.106^{\mathrm{a}}$ & $0.049^{\mathrm{a}}$ & 0.038 \\
\hline s-102 & 608 & 1,924 & $0.214^{a, b, c}$ & $0.058^{\mathrm{a}}$ & $0.360^{a, b, c}$ & $0.116^{a, b, c}$ & 0.036 \\
\hline$s-103^{e}$ & 256 & 2,961 & $0.074^{\mathrm{a}}$ & 0.037 & $0.130^{a, b}$ & $0.074^{\mathrm{a}}$ & 0.038 \\
\hline $\mathrm{s}-105^{\mathrm{e}}$ & 120 & 2,412 & $0.053^{\mathrm{a}}$ & 0.021 & $0.093^{\mathrm{a}}$ & $0.042^{\mathrm{a}}$ & 0.038 \\
\hline s-106 & 808 & 2,197 & $0.283^{a, b, c}$ & $0.156^{a, b, c}$ & $0.508^{a, b, c}$ & $0.313^{\mathrm{a}, \bar{b}, \mathrm{c}}$ & 0.038 \\
\hline$s-107^{f}$ & $-\cdot$ & 2,543 & & & & & \\
\hline$s-108^{f}$ & $-\cdot$ & 2,268 & & & & & \\
\hline $\mathrm{s}-109^{\mathrm{e}}$ & 447 & 2,256 & $0.168^{a, b, c}$ & $0.084^{a}$ & $0.298^{a, b, c}$ & $0.168^{a, b, c}$ & 0.038 \\
\hline$s-110^{f}$ & -- & 2,510 & & & & & \\
\hline s-111 & 466 & 1,938 & $0.145^{a, b, c}$ & $0.045^{a}$ & $0.246^{a, b, c}$ & $0.090^{a, b}$ & 0.027 \\
\hline$s-112^{f}$ & -- & 2,005 & & & & & \\
\hline sx-101 & 56 & 3,152 & 0.015 & 0.004 & 0.025 & 0.008 & 0.027 \\
\hline $5 x-102$ & 386 & 2,865 & $0.062^{a}$ & 0.014 & $0.103^{a, b, c}$ & $0.028^{a}$ & 0.026 \\
\hline $5 x-103$ & 673 & 2,393 & $0.161^{a, b, c}$ & $0.058^{a}$ & $0.276^{a, b, c}$ & $0.115^{a, b}$ & 0.032 \\
\hline$s x-104^{f}$ & $-\cdot$ & 2,591 & & & & & \\
\hline $5 x-105^{f}$ & -- & 2,357 & & & & & \\
\hline $5 x-106$ & 266 & 2,813 & $0.056^{a}$ & 0.014 & $0.094^{a, b, c}$ & 0.028 & 0.031 \\
\hline $5 x-109^{f}$ & $\cdot$ & 3,896 & & & & & \\
\hline$T-104^{f}$ & -- & 1,458 & & & & & \\
\hline$T-110^{f}$ & $\cdots$ & 1,655 & & & & & \\
\hline$I X-102^{e}$ & 175 & 3,209 & $0.048^{a}$ & 0.023 & $0.085^{a}$ & $0.046^{\mathrm{a}}$ & 0.038 \\
\hline
\end{tabular}


Table 9. Potential Hydrogen Concentrations Achieved in Local Gas-Release Events Involving Larger Releases. (3 sheets)

\begin{tabular}{|c|c|c|c|c|c|c|c|}
\hline \multirow{2}{*}{ Tank } & \multirow{2}{*}{$\begin{array}{l}\text { Retained } \\
\text { gas vol ume } \\
\text { (scm) }\end{array}$} & \multirow{2}{*}{$\begin{array}{l}\text { Headspace } \\
\text { volyme } \\
\left(m^{3}\right)\end{array}$} & \multicolumn{2}{|c|}{$50 x$ release of retained gas volume } & \multicolumn{2}{|c|}{$100 \%$ release of retained gas volume } & \multirow{2}{*}{$\begin{array}{l}\text { Hydrogen at } \\
\text { lower } \\
\text { flammabil ity } \\
\text { l imit }\end{array}$} \\
\hline & & & $\begin{array}{l}\text { Layer hydrogen } \\
\text { volume fraction }\end{array}$ & $\begin{array}{l}\text { Well stirred } \\
\text { hydrogen volume } \\
\text { fraction }\end{array}$ & $\begin{array}{l}\text { Layer hydrogen } \\
\text { volume fraction }\end{array}$ & $\begin{array}{l}\text { Well stirred } \\
\text { hydrogen volume } \\
\text { fraction }\end{array}$ & \\
\hline$T X-111^{e}$ & 179 & 2,652 & $0.064^{\mathrm{a}}$ & 0.029 & $0.112^{\mathrm{a}}$ & $0.057^{a}$ & 0.038 \\
\hline $\mathrm{TX}-112^{\mathrm{e}}$ & 511 & 1,594 & $0.303^{a, b, c}$ & $0.136^{a, b}$ & $0.530^{a, b, c}$ & $0.273^{a, b, c}$ & 0.038 \\
\hline $\mathrm{TX}-113^{\mathrm{e}}$ & 242 & 1,814 & $0.140^{\mathrm{a}, \mathrm{b}, \mathrm{c}}$ & $0.057^{8}$ & $0.242^{a, b, c}$ & $0.114^{a, b}$ & 0.038 \\
\hline$T X-115^{e}$ & 297 & 1,985 & $0.144^{a, b, c}$ & $0.064^{a}$ & $0.252^{a, b, c}$ & $0.127^{a, b}$ & 0.038 \\
\hline $\mathrm{u}-102^{\mathrm{e}}$ & 272 & 1,821 & $0.152^{a, b, c}$ & $0.063^{\mathrm{a}}$ & $0.264^{a, b, c}$ & $0.127^{a, b}$ & 0.038 \\
\hline$u-103$ & 303 & 1,448 & $0.191^{a, b, c}$ & 0.025 & $0.312^{a, b, c}$ & $0.051^{a}$ & 0.034 \\
\hline$U-105^{9}$ & 209 & 1,619 & & & & & \\
\hline $\mathrm{u}-106^{\mathrm{e}}$ & 41 & 2,381 & 0.024 & 0.007 & $0.041^{\mathrm{a}}$ & 0.015 & 0.038 \\
\hline$u-107$ & 184 & 1,693 & $0.113^{a, b, c}$ & 0.012 & $0.184^{a, b, c}$ & 0.023 & 0.033 \\
\hline$U-108^{f}$ & - & 1,456 & & & & & \\
\hline$U-109$ & 215 & 1,473 & $0.144^{a, b, c}$ & 0.019 & $0.236^{a, b, c}$ & $0.038^{8}$ & 0.034 \\
\hline
\end{tabular}

aflamable on the bas is of the hydrogen equivalent lower flamability limit (see the last column).

Detonable on the basis of hydrogen equivalent detonable limits of $B \%$ for tanks where the hydrogen and nitrous oxide concentrations are comparable and $11 x$ for those tanks with little or no nitrous oxide (Beyler and Roby 1996).

$\varepsilon_{\text {on }}$ the basis of the geometry classes, the hydrogen concentration that will result in a deflagration-to-detonation transition will be taken as $\mathbf{B X}$ for tanks where the hydrogen and nitrous oxide concentrations are comparable and $14 \%$ for those tanks with little or no nitroys oxide (Beyler and Roby 1996).

No retained gas volume AND no monitoring data.

No monitoring data so a composition of $85 \%$ hydrogen and $15 \%$ amnonia was assumed.

No retained gas volume.

Heavier than air gas mixture. 
The two computer codes, HMS and TRAC, were combined numerically at the physical representation of the boundary to the tank. That is, the HMS code provided the TRAC code with the pressures, temperatures, and gas composition at computational cells adjacent to the physical connections for the ventilation system and the inlet filter. The TRAC code used these values to compute the flow rates throughout the entire system, excluding tank 241-SY-101. The corresponding TRAC velocities, representing the response of the ventilation system, were used as inflow or outflow boundary conditions for HMS. The combination was accomplished in a simultaneously explicit manner that proved to be extremely stable and robust (LANL 1995).

Los Alamos National Laboratory (LANL 1995) modeled three basic gasburning scenarios assocjated with installation, operation and removal of the mixer pump. These are a release and burning of 113,245 , and $297 \mathrm{~m}^{3}(4000$, 8640 , and $10,480 \mathrm{ft}^{3}$ ) of gas. They analyzed these burning scenarios with the ventilation system on, the ventilation system off, openings in the tank (corresponding to the multiport riser), no openings, top-down gas burning, and bottom-up gas burning. The largest gas release $(297 \mathrm{~m})$ causes the tank to fail. It corresponds to the largest naturally occurring gas release in the tank. The burning of $245 \mathrm{~m}^{3}$ of gas does not exceed tank structural criteria. That is, the pressure reaches $414 \mathrm{kPa}$ (60 psi), the tank liner tears in the transition region of the dome, and there is extensive concrete cracking and rebar yielding throughout the dome of the tank, but the tank has not failed below the water line. The burning of $113 \mathrm{~m}^{3}$ of gas corresponds to the maximum burning that could occur during pump replacement, specifically during removal of the mixer pump. This burning does not cause the pump to be ejected from the tank; however, large amounts of waste are entrained by the pump and exit through the annular region in the riser from which the pump is being removed.

Fox et a1. (1993) modeled deflagrations in tank 241-SY-103. This modeling was authored before it was determined that 1 arge amounts of ammonia can be released at the same time as a natural gas release. It was also thought that the gas releases in this tank occurred over a long period of time (one to several days). Therefore, the analysts used a volume of gas corresponding to the maximum one-day drop. They then released it and found that, if the release was coming off the entire surface, then only a short distance above the waste was flammable. They also restricted the release to a smaller area and looked at local gas burning.

Fox and Stepnewski (1994) modeled deflagrations in double-she11 tanks 241-AW-101, 241-AN-103, 241-AN-104, 241-AN-105, and 241-SY-103. This modeling added ammonia to the slurry gas. However, the slurry gas used was essentially the same as the tank 241-SY-101 slurry gas (see Table 6 for current estimates of slurry gas composition). In addition, because releases occurring over long periods of time were still postulated in this report, only the maximum one-day drop (and corresponding release gas volume) was modeled. On the basis of the modeling results, Fox and Stepnewski concluded that burning of a plume in a double-shell tank will not cause the tank to fail.

Spore et al. (1994) modeled six double-shell tanks (241-AN-103, 241-AN-104, 241-AN-105, 241-AW-101, 241-SY-101, and 241-SY-103). In order to get a ranking, the same set of assumptions were used to model the tanks. A Rayleigh-Taylor instability model was used to determine the amount of gas released from each tank. Although tank specific depths were defined for the 
nonconvective layers, all waste densities used in the analysis and the gas void fraction used in the modeling were from tank 241-SY-101. Spore et al. also calculated the pressure and headspace temperature that resulted from the gas burns. Two cases were analyzed, one using a derivative of the 241-SY-101 gas composition and the other using $100 \%$ hydrogen as the slurry gas. From the results of this modeling, it was concluded that a gas release and burn in tanks 241-AN-103 and 241-SY-103 would not exceed their structural limits (because the volume of gas released was smal1) but that a release and burn in the other tanks modeled would exceed their structural limits.

Schlosser (1996a, 1996b) looked at single-shell tanks and double-shell tanks that fall under the flammable-gas unreviewed safety question. Schlosser was trying to extend the safety basis for activities that had been done in tank 241-SY-101 to other flammable gas double-shell tanks and single-shell tanks. In order to not use a slurry gas composition based on tank 241-SY-101 or to use $100 \%$ hydrogen, an effort was made to evaluate a range of compositions and to set monitoring limits on a limiting basis. Schlosser only covered deflagrations in the tanks. It was concluded from this modeling that double-shell tanks are bounded by the tank 241-SY-101 analys is but that single-shell tanks will fail structurally if burning of the gas is supportable (either a local or global burn).

4.3.4.2 Global Detonations. Los Alamos National Laboratory (LANL 1995) assessed the potential of a detonation in tank 241-SY-101. The Los Alamos National Laboratory analysis (see Appendix D of LANL 1995) used a mixture and geometry classification system developed by Sandia National Laboratory in conjunction with a series of gas-burning tests (where the gas composition was $38.5 \%$ hydrogen, $30.3 \%$ nitrous oxide, $31.2 \%$ nitrogen) to develop estimates of the likelihood of a deflagration-to-detonation transition. The conclusion drawn from this modeling was that a deflagration-to-detonation transition was extremely unlikely to beyond extremely unlikely for the tank headspace, which is considered an open, unconfined volume with very few obstacles.

A detonation in the ventilation system was also considered unlikely. On the basis of all the considerations, Los Alamos National Laboratory (LANL 1995) concluded that a deflagration-to-detonation transition is possible but unlikely for the integrated waste tank headspace volume and ventilation system.

Plys et al. (1996) looked at global (tank headspace) detonations. This work was intended to cover both double-shell tanks (including aging-waste facility tanks) and single-shell tanks. Plys et a1. (1996) reviewed the work Los Alamos National Laboratory (LANL 1995) had done on detonation in tank 241-SY-101 and concluded that the results would be applicable to all other tanks. That is, the tank dome head-space is an open, unconfined volume with very few obstacles (even when the air lift circulators are considered in aging-waste facility tanks); therefore, deflagration-to-detonation transition is possible but unlikely (Plys et al. 1996).

Beyler and Thorne (1996) also suggested a model to look at the potential for global detonations for nine double-shell tanks. This model used the information from Hodgson et a1. (1996) for the retained gas volume, assumed that $50 \%, 75 \%$, and $100 \%$ of the retained gas could be released, coupled with the gas composition developed in Table 6 , to determine whether a global detonation was possible. Three of the tanks they evaluated do not have gas 
composition data. For these tanks, they assumed a mixture of $85 \%$ hydrogen and $15 \%$ ammonia. The results of the assessment, which are shown in Table 10 , indicate that two of the tanks listed could have detonable gas concentrations and one of the tanks listed could have a deflagration-to-detonation transition (Note: this tank is tank 24l-SY-101 which now has a operating mixer pump to prevent large uncontrolled gas release events) with $50 \%$ release of retained gas; 3 could have detonable concentrations and 2 could have deflagration-todetonation transition with $75 \%$ release of retained gas; and 5 could have detonable concentrations and 3 could have deflagration-to-detonation transition with $100 \%$ release of retained gas.

\subsubsection{Global Deflagrations/Detonations in Double-Contaîned Receiver Tanks and Catch Tanks}

Stahl and Coles (1992) studied hydrogen accumulation in double-contained receiver tanks as part of a larger study on interim stabilization of non-watch 1 ist tanks. Their evaluation concluded that the primary receiver vessel would be the most likely location for hydrogen to accumulate because this is the place that the hydrogen is generated and no design provisions were made to provide filtered airflow through the primary receiver vessel from the ventilation system. It was al so concluded that potential ignition sources existed within the primary receiver vesse1, and that fires (deflagrations) or explosions (detonations) were credible given this condition. It should be noted that other flammable gases (principally methane and ammonia) and other oxidizers (nitrous oxide) were not considered in this study. Also not considered were gases (bubbles and dissolved) transferred into the primary receiver tank and gases generated in the primary receiver tank when chemical adjustments are made to the waste (see Sections 4.1.3.2 and 4.1.3.3).

Double-contained receiver tanks were also evaluated for detonation potential by Plys et al. (1996). As explained in the description of the double-contained receiver tanks (see Section 3.3), there is no engineered flow inlet into the primary vessel; also, as described in Section 4.1 .3 of this report, there are three mechanisms for flammable gases to be produced or introduced into the double-contained receiver tanks. Plys et at. modeled two situations, one without active or passive ventilation flow and one with passive ventilation flow. In both cases, if enough time is allowed to pass (approximately 1 year) the flammable gas concentration in the double-contained receiver tank will be at detonable limits. However, according to Plys et al. (1996), the buildup is slow and the required ignition energy is low enough that it is reasonable to suppose flammable-gas ignition (i.e., a deflagration) would occur prior to buildup to such high concentrations.

Double-contained receiver tanks have a level-measuring system that employs dip tubes. Three dip tubes make up the system. One tube is in the tank headspace, and two tubes are in the waste (one near the bottom of the primary vessel and the other one located a short distance above the bottom). The differential pressure between the tubes is converted into a level measurement. The difference between the backpressure on the lower tube and the atmospheric (reference) tube is used to calculate the level in the tank. 
Table 10. Potential Hydrogen Concentrations Achieved in Global Gas-Release Events.

\begin{tabular}{|c|c|c|c|c|c|c|}
\hline \multirow[b]{2}{*}{ Tank } & \multirow[b]{2}{*}{$\begin{array}{l}\text { Retained gas } \\
\text { volume }(\mathrm{scm})\end{array}$} & \multirow[b]{2}{*}{$\begin{array}{l}\text { Headspace } \\
\text { volume }\left(m^{3}\right)\end{array}$} & \multicolumn{3}{|c|}{$\begin{array}{c}\text { Well-mixed headspace hydrogen volume } \\
\text { fraction }\end{array}$} & \multirow{2}{*}{$\begin{array}{c}\text { Hydrogen volume } \\
\text { fraction at the } \\
\text { lower } \\
\text { flammability } \\
\text { limit }\end{array}$} \\
\hline & & & $\begin{array}{l}\text { Release of } \\
50 \% \text { of the } \\
\text { retained gas } \\
\text { volume }\end{array}$ & $\begin{array}{l}\text { Release of } \\
75 \% \text { of the } \\
\text { retained gas } \\
\text { volume }\end{array}$ & $\begin{array}{l}\text { Release of } \\
100 \% \text { of the } \\
\text { retained gas } \\
\text { volume }\end{array}$ & \\
\hline$A N-103$ & 641 & 1,717 & $0.112^{\mathrm{a}, \mathrm{b}}$ & $0.167^{a, b, c}$ & $0.223^{a, b, c}$ & 0.037 \\
\hline AN-104 & 320 & 1,321 & $0.066^{\mathrm{a}}$ & $0.099^{\mathrm{a}}$ & $0.132^{a, b}$ & 0.037 \\
\hline AN-105 & 397 & 1,024 & $0.100^{\mathrm{a}}$ & $0.150^{\mathrm{a}, \mathrm{b}}$ & $0.200^{a, b, c}$ & 0.037 \\
\hline AN- 107 & -- & 1,328 & -- & -- & -- & -- \\
\hline$A W-101$ & 229 & 1,065 & $0.051^{a}$ & $0.077^{\mathrm{a}}$ & $0.102^{\mathrm{a}}$ & 0.037 \\
\hline$A W-104^{d}$ & 150 & 1,083 & $0.059^{a}$ & $0.088^{\mathrm{a}}$ & $0.118^{a, b}$ & 0.038 \\
\hline$A Y-101^{d}$ & 34 & 1,759 & 0.008 & 0.012 & 0.016 & 0.038 \\
\hline$S Y-101^{e}$ & 551 & 1,032 & $0.084^{a, b, c}$ & $0.126^{a, b, c}$ & $0.168^{a, b, c}$ & 0.035 \\
\hline SY-103 & 119 & 2,514 & 0.007 & 0.011 & 0.014 & 0.034 \\
\hline
\end{tabular}

Flammable, on the basis of the hydrogen equivalent lower flammability limit (see the last column).

Detonable, on the basis of hydrogen equivalent detonable limits of $8 \%$ for tanks where the hydrogen and nitrous oxide concentrations are comparable and $\mathbf{1 1 X}$ for those tanks with Little or no nitrous oxide (Beyler and Roby 1996).

Con the basis of the geometry classes, the hydrogen concentration that will result in a deflagration-to-detonation transition uas assumed to be $8 \%$ for tanks where the hydrogen and nitrous oxide concentrations are comparable and $14 \%$ for those tanks with little or no nitroys oxide (Beyler and Roby 1996).

No monitoring data so a composition of $85 \%$ hydrogen and $15 \%$ ammonia was assumed.
erepump gas volume was used. 
This is then corrected for specific gravity by utilizing the backpressure difference between the two lower tubes, which are a known vertical distance apart. All three dip tubes, operating together, provide on average flow of $3.5 \times 10^{-5} \mathrm{~m}^{3} / \mathrm{s}\left(4.5 \mathrm{ft}^{3} / \mathrm{h}\right)$. The flow through the three dip tubes can be adjusted from 0 to $7.9 \times 10^{-5} \mathrm{~m}^{3} / \mathrm{s}\left(0\right.$ to $\left.10 \mathrm{ft}^{3} / \mathrm{h}\right)$. Calculations show that flow through the dip tubes is enough to maintain the headspace of the doublecontained receiver tank below $25 \%$ of the lower flammability 1 imit for flammable gases generated by radiolysis and organic decomposition.

Peurrung and Gauglitz (1996) investigated the effects of transferred gases (insoluble and soluble) during salt well pumping (see Section 4.1.3). The maximum ammonia concentration due to soluble ammonia coming out of solution due to mass transfer was estimated by Siciliano (1996) to result in a $22 \mathrm{vol} \%$ of ammonia in the double-contained receiver tank.

Heubach and Siemer (1996) have studied how quickly catch tanks can reach flammable and detonable concentrations. Bounding calculations show that, if the catch tank is filled with waste to the operating level at which catch tanks are pumped ( $80 \%$ of capacity), the catch tank will reach $25 \%$ of the lower flammability limit after $\sim 1$ day, the lower flammability limit in $\sim 4$ days, and the detonable limit after 15 days. NOTE: These times are calculated by upon a generic single-shell tank liquid source term; see Cowley (1996).

\subsubsection{Subsurface Deflagrations/Detonations}

Due to the gas retention mechanisms in single-shell tanks (see Section 4.1.1.2.1), there is a potential for the burning of subsurface gas. The burning of subsurface gas, in itself, would not cause the tank to fail. However, the shock wave from the burned gas could cause the waste to liquefy and release all its gas (Nakayama and Vogt 1996). The shock wave from the burnt gas could also be sufficient to compress surrounding bubbles enough for the gas to autoignite. This would cause a propagating event through the tank waste. The result would be that, eventually, all of the retained gas in the tank would be released and ignited over a short period of time. Nakayama and Vogt (1996) also postulates that the combustion gases would rise through the waste and would cause surface waves when released to the tank headspace. The wave movement is estimated to have a velocity of $6 \mathrm{~m} / \mathrm{s}$, which could cause equipment to bang into other equipment, into the riser the equipment is installed in, or into the wall of the tank. This would produce the ignition source for the flammable gases in the tank headspace and could cause a global deflagration or, in some cases, a detonation.

\subsubsection{Other Deflagrations and Detonations}

Plys et a1. (1996) also looked at detonations occurring in pump pits. Tank pits exchange gases with the tank headspace through leakage around riser covers and pit drains. Two types of releases from the tank waste were evaluated, global releases and local releases. Plys et al. (1996) state that "since the pump pit hydrogen concentration would necessarily be below the headspace value, a detonation in the pit is clearly impossible (beyond extremely unlikely)." This assumes that the pump pit is in communication with the tank headspace and the atmosphere. It was also concluded a deflagration- 
to-detonation transition is extremely unlikely to beyond extremely unlikely. However, deflagrations in tank pits could still occur.

The physical potential for a detonation in a double-shell tank annulus was also investigated by Plys et a 1 . (1996). In order for a detonation to happen, waste must have accumulated in the annulus and caused the annulus ventilation flow to fail. Ventilation for the annulus enters at the bottom center of the tank and flows through channels in the refractory concrete through the annulus, then out the annulus exhaust ventilation ducting. Thus, waste in the annulus would plug the channels in the refractory concrete, causing a ventilation failure. It has been determined that there are two scenarios for waste to enter the annulus. One is a breach of the primary liner (through corrosion, defects in the construction techniques, drop of equipment, etc.). The other is through a mistransfer accident. Plys et al. (1996) indicate that in this configuration, the gas concentration would buildup and could eventually (around a year) reach detonable concentrations. However, Plys et al. conclude that "...given the small energies needed to ignite gas mixtures, a deflagration would occur before a detonation became a concern."

Nakayama and Vogt (1996) evaluated the potential for a deflagration in the transfer lines. During salt well pumping, very small flow rates ranging from 0.19 to $19 \mathrm{~L} / \mathrm{min}(0.05$ to $5 \mathrm{gal} / \mathrm{min})$ are used. This rate is insufficient to fill the transfer 1 ines. Salt well pumping a single-shell tank can take several months to several years, depending on the amount of pumpable liquids in the tank. Peurrung and Gauglitz (1996) showed that a significant amount of soluble gas (ammonia) would be transferred to the double-contained receiver tank and that some insoluble gas (hydrogen, methane, and nitrous oxide) would also be transferred. The maximum concentration of ammonia in the doublecontained receiver tank is estimated to be $22 \%$ (Siciliano 1996). This percentage is also thought to bound the maximum concentration of ammonia in the transfer line. Nakayama and Vogt (1996) calculated that a deflagration in the transfer line would cause an increase in pressure of $1,455 \mathrm{kPa}$ (211 psi). Because most of the transfer 1 ines are made of Schedule 40 carbon steel pipes, it was determined that this would not cause a rupture of the transfer 1 ine and that there would be no consequences.

Nakayama and Vogt (1996) also evaluated flammable-gas collection in installed equipment. This has recently become a concern because flammable conditions have been measured in the waste sampling drill string and in liquid observation wells. Flammable gases could also collect in instrument trees. Nakayama and Vogt (1996) calculated that gas ignitions in the drill string (representative of the other equipment) would cause ejection of the drill string (a conclusion thought to hold for instrument trees and stainless steel liquid observation wells). However, some of the liquid observation wells are made of fiberglass or a Teflon ${ }^{3}$-type material. If a ignition were to occur in one of these wells, rapid disassembly of the well is likely to happen.

${ }^{3}$ Teflon is a trademark of E.I. du Pont de Nemours \& Company. 


\subsection{POTENTIAL CONSEQUENCES AND FREQUENCIES}

The results of frequency calculations for flammable gas release events and subsequent ignition of these gases in the waste tanks are presented in this section. The resulting potential radiological and toxicological consequences to onsite and offsite receptors are also presented. Studies summarized herein predict how the tanks might fail following this event and release waste material to surrounding areas. Calculations indicate the potential consequences to onsite and offsite receptors that could result from these tank failures. Then, these calculated results are compared with the risk guidelines established for Tank Waste Remediation System facilities operations. The conclusions are that the risk to site personnel and the public, to some degree, is outside of the risk guidelines established, even if the prudent and feasible mitigating actions are taken.

\subsection{CALCULATED ANNUAL FREQUENCY OF DEFLAGRATION}

One of three basic methods is used to calculate the deflagration rate (events per year or annual frequency). The method selected depends upon which of the following three relationships exists between the gas release event and the ignition source:

- An ignition source exists undetected prior to a gas release event

- An ignition source develops after a gas release event

- A common cause exists between the occurrence of a gas release event and the existence of an ignition source.

The ignition source contributions to the annual deflagration rate calculations were based on "order-of-magnitude" estimates obtained from the best available information and informed engineering judgement. These values are considered good "order-of-magnitude" estimates with which to identify the appropriate likelihood categories for deflagrations in the tanks and to indicate the impacts of basic controls that might be used to mitigate these deflagrations.

For the Final Safety Analysis Report, unmitigated refers to taking no credit for active systems and administrative controls. Mitigated accident are evaluated assuming that active systems and administrative controls (including the Technical Specification Requirements) are in place. The term mitigated refers to a mitigation of risk. That is, features that are mitigative (lower the consequences) and preventative (lower the frequency) contribute toward mitigation of the risk. In the rest of this document, mitigated and unmitigated will be used interchangeably with the phrases "with controls" and "without controls," respectively.

The current information presented herein, based on the work of Powers and Sawtelle (1996), is for normal storage, instrument maintenance and repair, and installation activities. Mixer pump operation, rotary-mode core sampling, and salt-well pumping are addressed in detail in other reports and are not included herein. Results from Powers and Sawtelle (1996) are summarized in 
Table 11. The information in the table is briefly explained in the following paragraphs. More details can be found in Powers and Sawtelle (1996).

\subsubsection{Deflagration Rate When Ignition Source Exists Prior to Gas Release Event}

For ignition sources that can exist undetected prior to a gas release event, the deflagration rate is a gas release event rate combined with a probability that the ignition source exists during the period of time between failure detection [Deflagration rate = gas release event rate * probability of ignition from ignition source].

Table 11. Annual Deflagration Rate in Tanks with Flammable Gas.

\begin{tabular}{|c|c|c|c|c|}
\hline \multirow{2}{*}{ Category } & \multicolumn{2}{|c|}{ Unmitigated } & \multicolumn{2}{|c|}{ Mitigated } \\
\hline & SST & DST & SST & DST \\
\hline Normally installed equipment & $\mathrm{U}$ & A & EU & EU \\
\hline Activity external to tank & U & U & EU & EU \\
\hline Natural phenomena & $\mathrm{U}$ & $\mathbf{U}$ & $\mathbf{U}$ & U \\
\hline Intrusive activities & A & A & $\mathbf{U}$ & U \\
\hline COMBINED LIKELIHOOD & A & A & $\mathbf{U}$ & U \\
\hline
\end{tabular}

The method for calculating gas release event rates is based on gas retention rates and volumes of flammable gases that, if burned, result in hazardous consequences. The rate of gas retention can be used to calculate how often "large" gas releases might occur by noting that the gas has to exist in the waste before it can be released from the waste. The retention rate of gas is estimated from level rise (noting that certain assumptions were made about the pressure at which the gas is held in the waste). The volumes of flammable gases that, if burned, can result in dome damage have been calculated.

Calculations of gas release event rates are constructed as a combination of two gas release rates. The first is an "intrinsic" release rate and the second is a rate of seismically induced gas release. The seismically induced releases are hypothetical. For double-shell tanks, the intrinsic releases modeled are the observed rollovers. For single-shell tanks, the intrinsic releases are hypothesized releases that have not yet been observed.

The method for calculating the probability of ignition for each identified ignition source involves understanding how each piece of equipment could fail and produce an ignition possibility, or what phenomena could occur that would result in the production of an ignition possibility. Once the 
equipment failures or phenomena that could produce an ignition possibility are postulated, probabilities that represent these failures or phenomena are calculated.

Where applicable, three types of calculations are performed relative to each potential ignition source. First, a calculation is performed or number assumed that represents the unmitigated possibility of an ignition source. This means that equipment is off-the-shelf or of a standard design with no particular consideration for ignition source reduction, and no controls are implemented to limit the number of activities or methods so that the number of possible ignition sources would be reduced. Second, a calculation is performed or a number assumed that represents the mitigated possibility of an ignition source. This means that equipment is designed to industrial standards for flammable gas (hydrogen) environments according to National Fire Protection Association requirements for Class 1, Division 1 or 2, group locations. Also, controls are in place to limit the number of activities and implement other methods (in addition to industry standards for flammable gas environments) to reduce the number of ignition sources. Third, if applicable, controls are designed with human factors considerations to maximize compliance.

\subsubsection{Deflagration Rate When Ignition Source Develops After a Gas Release Event}

For ignition sources that develop after a gas release event, the deflagration rate is an ignition source existence rate per year combined with the proportion of time that the tank headspace is in the hazardous condition [deflagration rate = ignition rate * probability that the headspace is hazardous ].

The method for calculating ignition source rates has the same basis as that described in Section 4.1.1 for calculating the ignition source probabilities. The ignition sources that develop after a gas release event must be identified, the mechanisms of failure causing an ignitor to exist must be understood, and the average rate at which a potential ignition source can be capable of producing an ignition source is represented on a per year basis. The same three types of calculations (unmitigated, mitigated, and mitigated with human factors considerations) are made as appropriate as discussed in Section 4.1.1.

The method for calculating the proportion of time the tank headspace is in a hazardous condition is based on gas retention rates and volumes of flammable gases that, if burned, result in hazardous consequences. The proportion of time varies as a function of the volume of an individual 
release. Thus the proportion of time the tank headspace is in a hazardous condition is represented by the formula

$$
\text { POT }=\left(f_{\text {sm }} * \tau_{\text {sm }}\right)+\left(f_{\text {int }} * \tau_{\text {int }}\right)
$$

where

$$
\begin{aligned}
\text { POT }= & \text { proportion of time } \\
f_{\mathrm{sm}}= & \text { frequency of gas release related to a seismic event } \\
\tau_{\mathrm{sm}}= & \text { duration for which the tank headspace contains a hazardous amount } \\
& \text { of flammable gas related to a seismic event } \\
f_{\text {int }}= & \text { frequency of gas release related to an intrinsic release } \\
\tau_{\text {int }}= & \text { duration for which the tank headspace contains a hazardous amount } \\
& \text { of flammable gas related to an intrinsic release. }
\end{aligned}
$$

The retention rate of gas is estimated from level rise (noting that certain assumptions were made about the pressure at which the gas is held in the waste). The volumes of flammable gases that, if burned, can result in dome damage have been calculated.

\subsubsection{Discussions of the Various Potential Ignition Sources Related to Controls}

The various potential ignition sources will be discussed in the categories represented in Table 11 .

5.1.3.1. Normally Installed Equipment. The equipment normally installed in the tanks includes temperature, level, pressure, and hydrogen monitoring equipment that is reasonably well designed and the contribution of which to the ignition probability, either individually or in combination, is minor. These pieces of installed equipment contribute to annual deflagration rates that are in the beyond-extremely-unlikely range. Only a few potential ignition sources contribute to making the combined unmitigated annual deflagration rate fall into the anticipated (for double-shell tanks) or unlikely (for single-shell tanks) categories. These are the high-level sensing probe in the double-shell tanks, the video camera and lights in tank 241-AN-107, the pump pit leak detectors, and the nonconductive components (such as fiberglass or Teflon ${ }^{4}$-type liquid observation wells and riser sleeves made of plastic-type materials).

For single-shell tanks, mitigating the ignition source posed by the use of nonconductive materials reduces the combined annual deflagration rate to at least the extremely unlikely category.

For double-shell tanks, mitigating the ignition sources posed by the tank high-level sensing probe, video camera and lights, pump pit leak detectors, and use of nonconductive components reduces the combined annual deflagration rate to at least the extremely unlikely category.

\footnotetext{
${ }^{4}$ Teflon is a trademark of E.I. du Pont de Nemours \& Company.
} 
5.1.3.2. Activity External to Tank. The potential ignition sources that originate outside the tank are the use of transfer pumps (for double-shell tanks only), vehicle fuel fires, hot chips from drilling, hot slag from welding, sparks from grinding, electrical equipment, greenhouse fires, and brush fires. The combined annual rate of deflagration falls into the uni ikely range for the unmitigated case for both single-shell tanks and double-shell tanks.

The combined annual deflagration rate for potential ignition source activities external to the tank under the mitigated case is at least extremely unlikely. Hot drilling chips are the largest contributors for single-shell tanks. Transfer pump operation and electrical equipment are the largest contributors for double-shell tanks.

5.1.3.3 Adjacent Tank Fire. A tank fire propagating to an adjacent tank has an annual deflagration rate in the unlikely category for the unmitigated case. When mitigation is applied to the various potential ignition sources that contribute to the adjacent tank fire, the annual deflagration rate is at least extremely unlikely.

5.1.3.4 Natural Phenomena. The combined lightning and seismic event contributions cause the natural phenomena annual deflagration rate to be in the unlikely category for both unmitigated and mitigated cases. Low pressure associated with thunderstorms is assumed to trigger a gas release event and simultaneously produce lightning that ignites the gas. An earthquake is assumed to cause a gas release event and to cause a spark that ignites the gas to be generated from moving equipment.

5.1.3.5 Intrusive Activities. In the unmitigated case, the combined annual deflagration rate is in the anticipated category for intrusive activities. In the mitigated case for single-shell tanks, the rate can be reduced to the unlikely category by good grounding/bonding. In the mitigated case for double-shell tanks, the rate could be reduced to the unlikely category if a method were available to adequately ground/bond the waste addition piping at the discharge end.

5.1.3.6 Combination of Ignition Sources. The combined likelihood for the unmitigated case for all potential ignition sources discussed in Sections 4.1.3.1 to 4.1.3.5 is in the anticipated category because of the intrusive activities. The combined likelihood for the mitigated case is in the unlikely category for single-shell tanks and the anticipated category because of the intrusive activities (primarily because a method to adequately ground/bond waste addition piping is lacking).

\subsection{INTERNAL STATIC PRESSURE LIMITS}

A DELPHI session of national experts was held on April 8-9, 1996 (Han and Beavers 1996). This group established a condensed description of reference tank fallures and modes. As a result, the failure limiting loads and modes incorporated information obtained from that meeting.

The static internal pressure limits established by Han and Beavers (1996) for the tanks for onset of failure are $76 \mathrm{kPa}$ (11 psig) for single-shell tanks 
and $312 \mathrm{kPa}$ (45.3 psig) for double-shell tanks. These are essentially the same limits that were developed earlier (Julyk 1994 and LANL 1995).

\subsection{FAILURE MECHANISMS}

Han and Beavers (1996) state that, if a single-shell tank experiences an internal static pressure of $76 \mathrm{kPa}$ (11 psig), concrete cracks would probably develop in the center region of the dome. Some of the air within the tank would probably escape through these cracks; therefore, the internal pressure could not build up to the level that would cause a section of the dome to be blown outward, thereby causing concrete debris and soil to fall back into the tank. Pieces of concrete on the inside face of the dome may lose bond with the rebar and fall into the tank as a result of excessive compressive forces from the post-event soil load (i.e., soil reimpact would cause spalling of the concrete). Rebar in the tank wall below the haunch region would be overstressed but would not cause the dome to collapse.

Han and Beavers (1996) also state that when a double-shell tank experiences an internal static pressure of $312 \mathrm{kPa}(45.3 \mathrm{psig})$, failure at the top of the dome would result. This would happen because of a weld failure of the liner at the connection of the $1.27 \mathrm{~cm}(1 / 2 \mathrm{in}$.) riser insert plate to the $0.95 \mathrm{~cm}(3 / 8 \mathrm{in}$.$) plate. The thinner plate is in the center of the dome and$ extends outward for a radius of $175 \mathrm{~cm}(5.75 \mathrm{ft})$. The static internal pressure would result in a liner tear along the periphery of this weld. The failure would most likely result in the thinner plate being bent upward (like the top of a soup can), thereby creating a hole $350.5 \mathrm{~cm}$ (11.5 ft) in diameter. Significant portions of concrete and soil would fall back into the tank.

Because some of the calculated pressures (see Appendix $C$ ) for the deflagrations exceeded these static internal pressure limits (sometimes by significant amounts), additional information was developed (Han 1996). This additional information is summarized in the following paragraphs.

All 100 Series single-shell tanks are $22.86 \mathrm{~m}(75 \mathrm{ft})$ in diameter. The waste storage capacity of these tanks is determined by the height of the tank wall. The transient pressures in the various single-shell tanks would have the same dynamic effect. The pressures would result in the same uplift force because the projected areas (area of the domes) are the same. The maximum internal pressure used in the single-shell tank design was $51.7 \mathrm{kPa}$ (7.5 psig), which is based on the existing structural analysis. Because soil pressures were the only significant loads accounted for at the time of construction, the rebar in the dome was provided mainly to resist the soil overburden on the tank dome and lateral soil pressure on the cylindrical wall. The rebar quantity in the dome is therefore 7 ight. Also, only a minimum amount of vertical rebar was provided for in the wall.

Two areas in the single-shell tanks are potentially vulnerable to the high transient pressure load associated with deflagration. These areas are the upper wall region and the central dome region. Han (1996) performed calculations showing that the required rebar area for the transient pressure load of $607 \mathrm{kPa}$ ( $88 \mathrm{psig}$ ) was greater than the available rebar by a factor of 3 . He concluded that the rebar will fail in tension in both the dome and 
the upper wall. If dynamic factors are considered, the affected rebar area would be even larger. The entire dome would likely be blown away (Han 1996).

Han (1996) also looked at double-shell tanks under a more severe pressure loading of $973 \mathrm{kPa}$ (141 psig). He analyzed both the overall structural stability of the tank and the dome failure mode. In terms of the overall structural stability, Han states that the primary tank could be stretched under the high-pressure 1oad. Because the secondary concrete tank is not tied to the concrete foundation, the pressure acting on the dome would become an uplift force on the concrete tank. Assuming the primary tank dome does not fail at this pressure, the uplift force would be transmitted through the dome, haunch, wall, and secondary liner to the base of the concrete wall. Because there are no dowels in the concrete, the uplift force would be carried by the secondary liner at the base. The calculation demonstrated that the secondary liner (which is anchored in the concrete wall with studs and structural steel angles) could fail in tension and cause the concrete tank to uplift.

The dome failure mode for the $973 \mathrm{kPa}$ (141 psig) static internal pressure loading on double-shel1 tanks was also investigated (Han 1996). Under the pressure load, the dome would expand outward in the radial direction. At locations where expansion is constrained, high strain would be developed in the steel plate, particularly in the transition seams between liner plates and insert plates and between penetrations and stiffeners. Concrete would crack under tension. The most likely section in which a crack or tear would be initiated is at the transition seam between the $1.27 \mathrm{~cm}(1 / 2 \mathrm{in.}$ ) riser insert plate and the $0.95 \mathrm{~cm}$ ( $3 / 8 \mathrm{in.})$ plate. As soon as the seam cracked as a result of the dynamic pressure, the crack would propagate along the seam line until the entire insert plate was bent up or blown away. Because of ripping and tearing of the plate along the failed edge, the remaining portion of the steel plate would be damaged at certain weakened locations. Some radial cracks would also develop farther out toward the haunch region. Concrete above the steel liner would be shattered and the rebar would be significantly deformed. The overburdened soil would be blown away. The dome opening caused by the event could reach to the region of the dome rebar transition zone at a radius of $8.23 \mathrm{~m}(27 \mathrm{ft}$ ) from the centerline of the tank (i.e., the remaining dome would open like a tulip). The portion of the dome beyond the rebar transition zone and the haunch would remain in place, and rebar would be exposed in certain areas after the event.

Wagenblast (1996) evaluated the structural response of double-contained receiver tanks and catch tanks to internal pressurization events. He looked at a rapid internal pressurization up to $827 \mathrm{kPa}(120 \mathrm{psi})$. The internal pressurization reached in the double-contained receiver tank should be no greater than the internal pressure reached in a single-shell tank. This is because only single-shell tank waste is transferred through double-contained receiver tanks and the gas generated by the waste, while in the doublecontained receiver tank, should have the same constituents and the same ratios as when the gas was in the tank. As long as the gas composition stays the same, the pressure from burning the gas will be the same, regardless of the tank volume the gas is in. That is, a $30 \%$ mixture of hydrogen in air in a $100-L$ volume will give the same pressure as a $30 \%$ mixture of hydrogen in air in a $10,000-\mathrm{L}$ volume. 
The conclusion that Wagenblast (1996) reached was that, for the 244-BX, 244. TX, 244-U, and 244-S vaults, the primary vessel would rupture and the vault would $f a i l$ at an overpressure of half that analyzed (i.e., at $414 \mathrm{kPa}$, or $60 \mathrm{psi}$. This conclusion would be true for all catch tanks with wall thicknesses of $0.64 \mathrm{~cm}(1 / 4 \mathrm{in.})$. The $244-C R$ and $244-\mathrm{A}$ primary vessels and vaults would withstand the $827 \mathrm{kPa}$ (120 psi) pressurization, but both would fail at $1,200 \mathrm{kPa}$ (174 psi). This conclusion is also true for catch tanks with wall thicknesses of $0.95 \mathrm{~cm}(3 / 8 \mathrm{in.})$.

Nakayama and Vogt (1996) looked at the structural response of transfer lines to sudden internal pressures. They concluded that, because the maximum pressure they calculated for a burn was $1,455 \mathrm{kPa}$ (211 psi) and because most transfer lines are Schedule 40 carbon steel pipes, the pipe would withstand the overpressurization with no damage. This is also true of the Schedule $10 \mathrm{~S}$ stainless steel pipes.

\subsection{SOURCE TERM}

The amount of respirable material that would be ejected from the tank and available for transport as a result of the preceding study results is documented in this section. The tanks covered are single-shell tanks, doubleshell tanks, double-contained receiver tanks, and catch tanks.

\section{As discussed in Section 3.3.4, the entrainment from the waste has been modeled. This modeling was originally done for double-shell tanks (LANL 1995), but has also been extended to single-shell tanks (Pasamehmetoglu 1996).} For the single-shell tanks, the total mass loading of the headspace would consist of the preexisting waste in the headspace (because of that normally found in the headspace plus an extra amount because of the gas release event), estimated to be $0.2 \mathrm{l}(0.35 \mathrm{~kg})$, and the waste entrained by the $\mathrm{flame}$ front sweeping over the waste surface at $45 \mathrm{~m} / \mathrm{s}$, estimated to be $3.30 \mathrm{~L}(5.45 \mathrm{~kg})$. However, using the data from Table 8 , a flame speed of $45 \mathrm{~m} / \mathrm{s}$ cannot be supported. At most the $f 1$ ame speed will be $10 \mathrm{~m} / \mathrm{s}$. Adjusting the entrained amount gives $2.69 \mathrm{~kg}$. This is the mass of waste in the headspace that consists of small particles $(\leq 10 \mu \mathrm{m})$. Only a portion $(\sim 75 \%)$ of this waste would be transported from the tank due to the pressure blowdown. The total waste available for transport to the onsite and offsite receptors is estimated to be $1.38 \mathrm{~L}$ of respirable material.

Los Alamos National Laboratory (LANL 1995) had also estimated the amount of waste that would be released from the double-shell tanks. The total mass loading of the headspace would consist of the preexisting waste in the headspace gases, estimated to be $0.39 \mathrm{~L}(0.64 \mathrm{~kg})$, and the waste entrained by the flame front sweeping over the waste surface, estimated to be $3.30 \mathrm{~L}$ $(5.45 \mathrm{~kg})$. This is the mass of waste in the headspace that consists of sma11 particles $(\leq 10 \mu \mathrm{m})$. Again, only a portion $(-75 \%)$ of this waste would be transported from the tank because of the pressure blowdown. The total waste available for transport to the onsite and offsite receptors is estimated to be $2.76 \mathrm{~L}$ of respirable material.

Los Alamos National Laboratory (LANL 1995) also estimated the amount of waste that would be released during the pump ejection scenario (see section 3.3.4). This event is postulated to occur during removal of the mixer 
pump. Estimates based on modeling are that a total of $7.74 \mathrm{~L}(12.77 \mathrm{~kg})$ of respirable-size particles of waste material is entrained by the hot gases sweeping past the waste-covered pump. This additional material would be in addition to the $2.94 \mathrm{~L}$ of total waste discussed in the preceding paragraph. Thus, the total waste available for transport to the onsite and offsite receptors would be $10.68 \mathrm{~L}$ of respirable material.

A review of waste entrainment literature (NUREG 1982, Iversen 1984) shows that one of the important parameters for determining how much material is entrained from the waste is the speed of the flame front. For some of the larger burns that result in higher dome pressures than those calculated by Los Alamos National Laboratory (LANL 1995 and 1996), the flame-front speed can be estimated (NUREG 1989). This higher flame-front speed is estimated to be $600 \mathrm{~m} / \mathrm{s}$. Empirical equations (Iversen 1984), relating the entrainment to the flame-front velocity, show a functional relationship involving the square of the velocity. If all the other parameters involved remain the same (such as the surface area of the tank, the radius of the tank, the density of the waste material, etc.) then the only parameter that changes is flame-front velocity. Thus, the amount of material that would be entrained can be larger by a factor of 36 (if it varies as the square of the velocity). The amount of material released is directly proportional to the consequences. Thus, if the material released increases by a factor of 36 , the dose consequence would also increase by a factor of 36 .

In an earlier study (WSRC 1993), the amount of material resuspended from the rupture of the primary vessel of a tank with a liquid surface was analyzed. The release calculations are based on data on liquid entrainment from small scale breaks in piping containing stratified layers of air and water. This data fits the geometry of most double-contained receiver tanks (cylindrical) with a layer of liquid waste and a layer of gas above it. The release would then occur because the flammable gases burn and cause the vessel to fail. This analysis yields $18.28 \mathrm{~L}$ of respirable material (assumed to be $5 \%$ single-she1l tank solids and $95 \%$ single-she11 1iquids).

\subsection{RADIOLOGICAL CONSEQUENCES}

The radiological consequence calculation methods common to the analyses of operational accidents, natural phenomena, and external events selected for further analysis in Section 2.3 are summarized in this section.

Accident consequences are combined with the accident frequency and compared with the risk evaluation guidelines as shown in Table 12 . For comparison with the risk evaluation guidelines, the radiological and toxicological consequences of accidents must be calculated at the location of the maximum onsite and maximum offsite individuals. The maximum onsite and offsite individuals are defined in WHC-CM-4-46, Nonreactor Facility Safety Analysis Manual (WHC 1996), as follows.

- Maximum onsite individual. The hypothetical onsite receptor located at the distance and direction from the point of release at which the maximum dose occurs. This distance shall be at least $100 \mathrm{~m}$. 
- Maximum offsite individual. The hypothetical receptor at or beyond the Site boundary, with the maximum factor for atmospheric dilution, for which offsite consequences are calculated.

Table 12. Radiological Risk Guidelines.

\begin{tabular}{|c|c|c|c|}
\hline \multirow{2}{*}{ Frequency category } & $\begin{array}{c}\text { Frequency range } \\
\left(\mathrm{yr}^{-1}\right)\end{array}$ & \multicolumn{2}{|c|}{$\begin{array}{c}\text { Effective dose equivalent } \\
\text { (mSv) }\end{array}$} \\
\cline { 3 - 4 } & $10^{0}$ to $10^{-2}$ & Onsite & Offsite \\
\hline A (anticipated) & $10^{-2}$ to $10^{-4}$ & 50 & 1 \\
\hline$U$ (unlikely) & $10^{-4}$ to $10^{-6}$ & 100 & 5 \\
\hline $\begin{array}{c}\text { EU (extremely } \\
\text { unlikely) }\end{array}$ & & & 40 \\
\hline
\end{tabular}

NOTE: The information in this table is from WHC (1996).

For tank farm facilities, the maximum onsite individual is located at $100 \mathrm{~m}$. The distances from tank farm facilities to the Hanford Site boundary are shown in Table 13.

For tank farm facilities, the maximum atmospheric dilution factor occurs at the site boundary at a distance of either $8.7 \mathrm{~km}$ to the north-north-west or $8.8 \mathrm{~km}$ to the north, depending on the release and the duration.

\subsubsection{Radiological Consequence Calculation Methodology}

5.5.1.1. Exposure Pathways. Two potential radiological exposure pathways (interral and external) are associated with releases of radioactive materials. The total effective dose equivalent calculated for an individual is equal to the sum of the dose contributions from these two exposure pathways.

5.5.1.2 Internal Exposure Pathway. Internal exposure pathways include inhalation and ingestion. The inhalation pathway is the major internal exposure pathway for tank farm accidents. Exposure by means of the inhalation pathway occurs when an accident results in a release of airborne radioactive material that is transported downwind and inhaled by the maximum onsite and offsite individuals or when radioactive materials that have been deposited on the ground become suspended and are subsequently inhaled. The dose contribution from inhalation of resuspended materials is orders of magnitude less than that from inhalation of airborne radioactive materials during plume passage. Because resuspension dose contribution is minor, it is not included in consequence calculations for the maximum onsite individual. The resuspension dose is included in consequence calculations for the maximum offsite individual as an artifact of the ingestion dose calculations, i.e., the GENII computer program (PNL 1988) used to calculate the ingestion dose automatically calculates a resuspension dose.

Exposure via the ingestion pathway occurs when radioactive material that has been deposited offsite is ingested by any of the following methods: eating crops on which radioactive materials have deposited; eating crops grown in, or animals raised on, contaminated soil; or drinking contaminated water. Depending on the type of tank waste involved, the dose contribution from the 
ingestion of contaminated food during a 24-hour period can account for up to $20 \%$ of the total effective dose equivalent. Therefore, the dose contribution from the ingestion of contaminated foods for 24 hours is included in offsite consequence calculations. The 24-hour duration is based on the premise that the maximum offsite individual can be notified and appropriate interdiction taken within 24 hours of the start of the accident.

Table 13. Site Boundary Distances for Tank Farms.

\begin{tabular}{|c|c|}
\hline Transport direction & Distance (m) \\
\hline S & 15,360 \\
\hline SSW & 15,640 \\
\hline SW & 13,875 \\
\hline WSW & 11,100 \\
\hline W & 11,100 \\
\hline WNW & 11,100 \\
\hline NW & 11,440 \\
\hline NNW & 8,690 \\
\hline N & 8,760 \\
\hline NNE & 10,610 \\
\hline NE & 10,680 \\
\hline ENE & 10,530 \\
\hline$E$ & 12,630 \\
\hline ESE & 18,730 \\
\hline SE & 22,440 \\
\hline SSE & 19,960 \\
\hline
\end{tabular}

NOTES: Site boundary distances are based on the minimum distance from the nearest tank farm (or associated waste transfer (ines) to the Hanford site boundary. The site boundary is assumed to be the near bank of the Columbia River to the north and the east.

The information in this table is from Van Keuren and Savino (1996).

5.5.1.3 External Exposure Pathway. External exposure pathways include submersion, ground shine, and direct exposure from a concentrated radioactive source, such as a pool formed from a spill of liquid radioactive material.

Submersion refers to the external dose received by a person located in the plume of airborne radioactive material during plume passage. In general, for the radionuclides present in tank waste, the submersion dose is orders of magnitude less than the inhalation dose. For example, assuming an airborne release of $1 \mathrm{~L}$ of respirable single-shell tank liquids, the GENII computer program calculates a submersion dose of $3 \times 10^{-5} \mathrm{~Sv}\left(3 \times 10^{-3} \mathrm{rem}\right)$ versus an 
inhalation dose of $1.2 \times 10^{-1} \mathrm{~Sv}\left(1.2 \times 10^{1}\right.$ rem). Because its contribution is minor, the submersion dose is not included in consequence calculations.

Ground shine refers to the external dose received by a person standing on ground contaminated by radioactive materials deposited during plume passage. The ground shine dose is orders of magnitude less than the inhalation dose and, therefore, it is not included in consequence calculations for the maximum onsite individual. The ground shine dose is included in consequence calculations for the maximum offsite individual as an artifact of the ingestion dose calculation.

Given an airborne respirable source term, the doses from the inhalation and ingestion pathways are calculated by the following formulas:

For the offsite and the onsite receptor, inhalation dose consequences are as follows:

$$
D_{i n h}(S v)=Q \frac{X}{Q^{\prime}} B_{r} U L D_{i n h}
$$
follows:

For only the offsite receptor, ingestion dose consequences are as

$$
\mathrm{D}_{\text {ing }}(\mathrm{Sv})=Q \frac{X}{Q^{\prime}} U \mathrm{LD}_{\mathrm{ing}}
$$

where

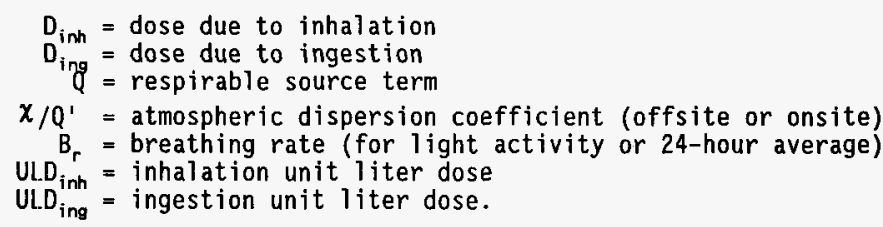

For the inhalation pathway, the dose calculated is the 50-year committed effective dose equivalent defined as the dose received by the individual during a 50-year period following the uptake. For the maximum onsite indiviclual, this dose must be combined with that resulting from external exposure (if any) to yield the total effective dose equivalent. For the ingestion pathway, the dose calculated is the committed effective dose equivalent from ingestion plus the dose due to external exposure (e.g., ground shine). Combining the ingestion dose with the inhalation dose yields the total effective dose equivalent for the maximum offsite individual.

The atmospheric dispersion coefficient $\left(X / Q^{\prime}\right)$ represents the dilution of an airborne contaminant caused by atmospheric turbulence resulting from wind speed and atmospheric stability conditions. $\chi / Q^{\prime}$ values applicable to tank farm accident analyses have been calculated and are documented in WHC-SD-WM-SARR-016, Tank Waste Compositions and Atmospheric Dispersion Coefficients for Use in Safety Analysis Consequence Assessments (Van Keuren 
and Savino 1996). The $\chi / Q^{\prime}$ values applicable to ground-level releases are shown in Table 14. The values shown are the $99.5 \%$ sector-dependent $\chi / Q$ 's as defined by Regulatory Guide 1.145, Atmospheric Dispersion Models for Potential Accident Consequence Assessments at Nuclear Power Plants (NRC 1982), with the exception of the onsite bounding integrated $\chi / Q^{\prime}$, which is a $95 \%$ sectorindependent value.

The bounding integrated $\chi / Q^{\prime}$ values shown in Table 14 are used for release durations up to 1 hour. For release durations between 1 and 2 hours, the integrated $X / Q^{\prime}$ with plume meander values is used. Plume meander accounts for enhanced horizontal spreading of the plume as it meanders over a large area during light wind and relatively stable atmospheric conditions. Plume meander corrections were made in accordance with the empirical model given in Regulatory Guide 1.145 (NRC 1982). As recommended in the guide, for release durations greater than 2 hours a logarithmic interpolation is made between the acute bounding $\chi / Q^{\prime}$ with plume meander and the chronic annual average $\chi / Q^{\prime}$ values given in Table 15 .

Table 14. Centerline Atmospheric Dispersion Coefficients.

\begin{tabular}{|l|c|c|c|}
\hline Maximum individual & $\begin{array}{c}\text { Bounding } \\
\text { integrated } \chi / Q^{\prime} \\
\left(\mathrm{s} / \mathrm{m}^{3}\right)\end{array}$ & $\begin{array}{c}\text { Bounding } \\
\text { integrated } \chi / Q^{\prime} \\
\left(\mathrm{s} / \mathrm{m}^{3}\right) \text { with } \mathrm{PM}^{\mathrm{a}}\end{array}$ & $\begin{array}{c}\text { Maximum puff } \\
\chi / Q\left(1 / \mathrm{m}^{3}\right)\end{array}$ \\
\hline $\begin{array}{l}\text { Onsite } \\
\text { sector and distance }\end{array}$ & $\begin{array}{c}3.41 \mathrm{E}-02 \\
\mathrm{E} 100 \mathrm{~m}\end{array}$ & $\begin{array}{c}1.13 \mathrm{E}-02 \\
\mathrm{ESE} 100 \mathrm{~m}\end{array}$ & $\begin{array}{c}9.85 \mathrm{E}-03 \\
\mathrm{E} 100 \mathrm{~m}\end{array}$ \\
\hline $\begin{array}{l}\text { Offsite } \\
\text { sector and distance }\end{array}$ & $\begin{array}{c}2.83 \mathrm{E}-05 \\
\mathrm{~N} 8,760 \mathrm{~m}\end{array}$ & $\begin{array}{l}2.12 \mathrm{E}-05 \\
\mathrm{~N} 8,760 \mathrm{~m}\end{array}$ & $\begin{array}{c}1.14 \mathrm{E}-07 \\
\mathrm{NNW} 8,690 \mathrm{~m}\end{array}$ \\
\hline
\end{tabular}

NOTE: The information in this table is from Van Keuren and Savino (1996).

auclear Regulatory Commission Regulatory Guide 1.145 (HRC 1982) plume meander correction applied.

Table 15. Chronic Annual Average Atmospheric Dispersion Coefficients for 200 Area Tank Farms.

\begin{tabular}{|l|c|}
\hline \multicolumn{1}{|c|}{ Maximum individual } & $\begin{array}{c}\text { Integrated } \\
\chi / Q^{\prime} \\
\left(\mathrm{s} / \mathrm{m}^{3}\right)\end{array}$ \\
\hline $\begin{array}{l}\text { Onsite } \\
\text { sector and distance }\end{array}$ & $4.03 \mathrm{E}-04$ \\
\hline $\begin{array}{l}\text { Offsite } \\
\text { sector and distance }\end{array}$ & $\mathrm{ESE} 100 \mathrm{~m}$ \\
\hline
\end{tabular}

NOTE: The information in this table is from Van Keuren and Savino (1996). 
Breathing rate $\left(B_{r}\right)$ values used to calculate the radiological consequences of accidents are taken from Report of the Task Group on Reference Man (ICRP 1975). For the maximum onsite individual, the light activity breathing rate is used, i.e., $3.3 \times 10^{-4} \mathrm{~m}^{3} / \mathrm{s}$. For the maximum offsite individual, the light activity breathing rate is used because the offsite receptor is assumed to be working.

The inhalation unit liter dose $\left(U L D_{i n h}\right)$ represents the dose associated with the hypothetical inhalation of $1 \mathrm{~L}$ of waste. The ingestion unit liter dose $\left(U L D_{\text {ing }}\right)$ represents the dose associated with the hypothetical ingestion of fruits and vegetables, inadvertent soil ingestion, ground shine, and the inhalation of resuspended material for a $1-L$ release of waste and an $\chi / Q^{\prime}$ value of 1. As described in WHC-SD-WM-SARR-037, Development of Radiological Concentrations and Unit Liter Doses for TWRS FSAR Radiological Consequence Calculations (Cowley 1996), unit liter doses have been developed on the basis of the concentration of radionuclides present in tank waste as determined from tank waste characterization data. Although more than 150 radionuclides are stored in the waste tanks, the unit liter doses are based on the concentrations of 22 predominant radionuclides, 11 of which constitute more than $99 \%$ of the inhalation and ingestion doses (refer to table $^{3}-7$ ). These

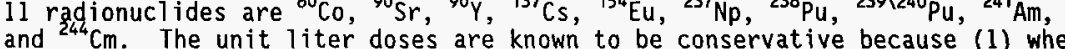
compared with isotope production data from reactor operations, individual isotope unit liter doses have a weighted average about 58 times the production-based values; (2) high points of sample distributions were selected versus average values; and (3) statistical analysis has shown that the probability of finding a higher value for a radionuclide in the sample database is less than $4 \%$ with $95 \%$ confidence.

The inhalation and ingestion unit liter doses for different waste types are presented in Table 16. The inhalation unit liter doses were calculated by Cowley (1996) by using dose conversion factors published in EPA-520/1-88-020, Limiting Values of Radionuclide Intake and Air Concentration and Dose Conversion Factors for Inhalation, Submersion, and Ingestion (EPA 1988). The ingestion unit liter doses were calculated by Cowley (1996) by using the GENII (Napier et al. 1988) computer program.

The consequences reported in Section 5.8 were calculated by using doubleshell tank liquids for the double-shell accidents, aging waste facility liquids for the aging waste accident, single-shell tank solids for the singleshell tank accident, and $5 \%$ single-shell tank solids and $95 \%$ single-shell tank liquids for the double-contained receiver tank accident.

\subsection{TOXICOLOGICAL CONSEQUENCES}

\subsubsection{Toxicological Consequence Calculation Methodology}

5.6.1.1 Exposure Pathways. The toxicological source terms resulting from tank farm accidents consist of liquid and solid particulates and gases.

Evaluation of the effects caused by chemical exposure is based on the airborne pathway only because the toxicological risk evaluation guidelines are based on 
the chemical concentration at the location of the maximum onsite and offsite individuals. External exposure to the skin and eyes was considered in the development of the risk evaluation guidelines for corrosives and irritants.

Table 16. Parameters used to Calculate Dose Consequences.

\begin{tabular}{|c|c|c|}
\hline \multicolumn{3}{|c|}{$\chi / Q^{\prime}$ Values } \\
\hline Location & Continuous $\left(\mathrm{s} / \mathrm{m}^{3}\right)$ & Puff $\left(1 / \mathrm{m}^{3}\right)$ \\
\hline Onsite & $3.4 \times 10^{-2}$ & $9.9 \times 10^{-3}$ \\
\hline Offsite & $2.8 \times 10^{-5}$ & $1.1 \times 10^{-7}$ \\
\hline \multicolumn{3}{|c|}{ Standard man breathing rate } \\
\hline Breathing rate & $3.3 \times 10^{-4}$ & $\mathrm{~m}^{3} / \mathrm{s}$ \\
\hline \multicolumn{3}{|c|}{ Unit liter doses } \\
\hline Waste type & Inhalation $(\mathrm{Sv} / \mathrm{L})$ & Ingestion $\left(\mathrm{Sv} \mathrm{m}^{3}\right) /(\mathrm{s} \mathrm{L})$ \\
\hline All liquids & $1.2 \times 10^{4}$ & 0.11 \\
\hline All solids & $1.9 \times 10^{6}$ & 8.20 \\
\hline SST liquids & $1.1 \times 10^{4}$ & 0.05 \\
\hline SST solids & $2.2 \times 10^{5}$ & 4.10 \\
\hline DST liquids & $6.1 \times 10^{3}$ & 0.07 \\
\hline DST solids & $5.3 \times 10^{5}$ & 0.48 \\
\hline AWF liquids & $1.4 \times 10^{3}$ & 0.09 \\
\hline AWF solids & $1.7 \times 10^{6}$ & 8.10 \\
\hline
\end{tabular}

*An onsite continuous release is defined as a ground-level release of a duration longer than $3.5 \mathrm{~s}$ and an offsite continuous release is defined as a release that occurs for more than $420 \mathrm{~s}$ (Van Keuren and Savino 1996). If the release times are shorter, the release is treated as a puff.

AWF = aging waste facility.

DST = double-shell tank.

SST = single-shell tank.

5.6.1.2 Exposure Calculation Methods. Toxicological consequence calculations for both the maximum onsite and offsite individuals assume a 1-hour exposure period. The 1-hour exposure period was selected because the toxicological risk evaluation guidelines are based on Emergency Response Planning Guideline values, which are defined in terms of up to a 1-hour exposure.

The calculation method for chemical exposure is based on the use of Emergency Response Planning Guides for risk evaluation. For comparison with the Emergency Response Planning Guide 1imits, the peak concentration must be calculated. Equations used in WHC-SD-WM-SARR-011, Toxic Chemical Considerations for Tank Farm Releases (Van Keuren et al. 1996), to calculate peak concentrations of individual chemicals are presented in the following subsections for solid and Tiquid, gaseous, and total particulate chemical releases. 


\subsubsection{Peak Concentration Calculation Methods for Solid and Liquid Toxic Chemical Releases}

The peak concentration is of concern for chemical releases. For a continuous release, the integrated $\chi / Q^{\prime}$ was used. For instantaneous or short-duration releases, the maximum puff $\chi / Q^{\prime}$ was used. Significant windward diffusion can occur for release durations for which the plume travel time is long in comparison with the release duration. Hence, the use of the integrated $p l$ ume $X / Q^{\prime}$ values for deriving peak air concentration for an instantaneous release is overly conservative. (A release is essentially instantaneous when its duration is much less than the plume travel time to the maximum onsite/offsite individual). Maximum puff $\chi / Q$ values were used for the release durations shown in Table 17 . The values in this table are derived by dividing the puff $\chi / Q$ into the continuous release $\chi / Q$. The results of the puff and continuous release models are equal at the times specified in Table 17. Using the puff model for longer times or the continuous release model for shorter times is overly conservative.

Table 17. Release Durations for Which the Maximum Puff $\chi / Q$ Values Were Used.

\begin{tabular}{|c|c|}
\hline \multicolumn{1}{|c|}{ Release } & Duration \\
\hline Onsite receptor ground-level release & $\leq 3.5 \mathrm{~s}$ \\
\hline Offsite receptor ground-level release & $\leq 420 \mathrm{~s}$ \\
\hline
\end{tabular}

NOTE: The information in this table is from Van Keuren and Savino (1996).

The integrated plume $\chi / Q^{\prime}$ values (without plume meander) are used for release durations longer than those shown in Table 17. For a continuous release of solid or liquid toxic materials, the peak concentration was calculated by using the following equation:

where

$$
C\left(m g / m^{3}\right)=Q^{\prime}(m g / s) \times \frac{X}{Q^{\prime}}\left(s / m^{3}\right)
$$

\footnotetext{
$C=$ peak concentration

$Q^{\prime}=$ toxic material release rate

$\chi / Q^{\prime}=$ continuous release atmospheric dispersion coefficient.
} 
The puff release $\chi / Q^{\prime}$ was used for an instantaneous release of solid or liquid toxic materials. The following equation was used to calculate the peak concentration for an instantaneous release of solid or liquid toxic material:

$$
C\left(\mathrm{mg} / \mathrm{m}^{3}\right)=Q(\mathrm{mg}) \times \frac{X}{Q}\left(1 / \mathrm{m}^{3}\right)
$$

where

$$
\begin{aligned}
C & =\text { peak concentration } \\
Q & =\text { toxic material released } \\
X / Q & =\text { puff release atmospheric dispersion coefficient } .
\end{aligned}
$$

\subsubsection{Peak Concentration Calculation Methods for Gaseous Toxic Chemical} Releases. The equations provided here calculate the peak concentration from gaseous toxic material releases. The equations include corrections for the fact that the standard Gaussian equations assume a point release with zero source volume. The correction is necessary because the equations, which are based on a point release, grossly overestimate peak concentrations as the volume released or the volumetric release rate increases or as the distance to the receptor decreases. Because the source concentration is fixed, the peak concentration approaches the source concentration as the volume released or the volumetric release rate increases. The peak concentration also approaches the source concentration as the source to maximum onsite/offsite individual distance decreases. The equations given here provide the correct peak concentrations for both small and large gaseous toxic material releases. The GENII computer code uses this model to correct the $\chi / Q^{\prime}$ for nonzero source volumes (Napier et al. 1988).

The peak concentration for gaseous releases of toxic materials at the receptor depends on the source concentration, the $\chi / Q^{\prime}$ value, and the volume or volumetric flow rate of the release. For a cont inuous release of gaseous toxic materials, the peak concentration was calculated by using the following equation:

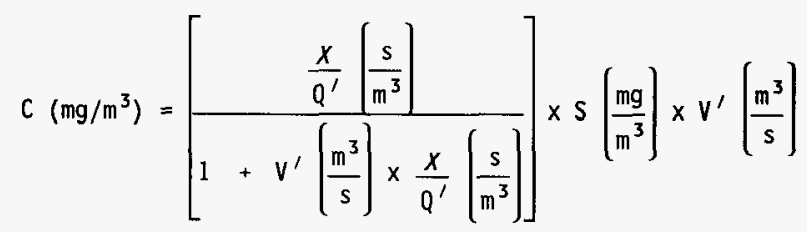

where

$$
\begin{aligned}
C & =\text { peak concentration } \\
S & =\text { gaseous toxic material source concentration } \\
\chi / Q^{\prime} & =\text { continuous release atmospheric dispersion coefficient } \\
V^{\prime} & =\text { volume release rate of gaseous source. }
\end{aligned}
$$


For an instantaneous release of gaseous toxic materials, the puff release $x / Q$ was used to calculate the peak concentration as shown in the following equation:

$$
C\left(\mathrm{mg} / \mathrm{m}^{3}\right)=\left[\frac{\frac{x}{Q}\left(\frac{1}{\mathrm{~m}^{3}}\right)}{1+V\left(\mathrm{~m}^{3}\right) \times \frac{x}{Q}\left(\frac{1}{\mathrm{~m}^{3}}\right)}\right] \times s\left[\frac{\mathrm{mg}}{\mathrm{m}^{3}}\right) \times v\left(\mathrm{~m}^{3}\right)
$$

where

$$
\begin{aligned}
C & =\text { peak concentration } \\
S & =\text { gaseous toxic material source concentration } \\
\chi / Q & =\text { puff release atmospheric dispersion coefficient } \\
V & =\text { volume of gaseous source released. }
\end{aligned}
$$

\subsubsection{Peak Concentration Methods for Total Particulates. For a puff} release of tank material, the total particulate concentration at the maximum onsite/offsite individual is given by the following equation:

$$
C=\rho 10^{6} Q \frac{X}{Q}
$$

where

$C=$ concentration at the maximum onsite/offsite individual $\left(\mathrm{mg} / \mathrm{m}^{3}\right)$

$Q=$ release amount $(\mathrm{L})$

$\chi / Q=$ puff atmospheric dispersion coefficient $\left(1 / \mathrm{m}^{3}\right)$

$\rho=$ density of source material $\left(\mathrm{g} / \mathrm{cm}^{3}\right)$.

The constant $10^{6}$ is a unit conversion and results from multiplying by a factor of 1,000 to convert liters to cubic centimeters and by another factor of 1,000 to convert grams to milligrams. Densities of $1.6 \mathrm{~g} / \mathrm{cm}^{3}$ and $1.1 \mathrm{~g} / \mathrm{cm}^{3}$ $\left(100 \mathrm{lb} / \mathrm{ft}^{3}\right.$ and $\left.69 \mathrm{lb} / \mathrm{ft}^{3}\right)$ are assumed for the tank solids and liquids, respectively. This calculation is very conservative because it assumes all material released is in the form of small particles that would be transported to the exposed individual. In practice, a significant fraction of the released material would be deposited near the release point. 
Following is the formula for the concentration from a continuous release of particulates.

$$
C=\rho 10^{6} Q^{\prime} \frac{X}{Q^{\prime}}
$$

where

$C=$ concentration at the maximum onsite/offsite individual $\left(\mathrm{mg} / \mathrm{m}^{3}\right)$

$Q^{\prime}=$ release amount $(L / S)$

$\chi / Q^{\prime}=$ continuous release atmospheric dispersion coefficient $\left(\mathrm{s} / \mathrm{m}^{3}\right)$

$\rho=$ density of source material.

In calculating peak concentrations, a unit release of tank waste with chemical concentrations based on best available tank waste characterization data was assumed (Van Keuren et al. 1996). These peak concentrations were then used to calculate sum-of-fraction values (refer to Section 3.4.1.2(3)).

When calculating peak concentration, a distinction must be made between continuous and instantaneous (or "puff") releases due to differences in atmospheric dispersion modeling. A release is essentially instantaneous when its duration is much less than the plume travel time to the maximum onsite and offsite receptors. Releases are modeled as puffs for the release durations in Table 17. For release durations greater than those shown in Table 17, the continuous release model is used. Puff release atmospheric dispersion coefficients are provided in Table 14. The atmospheric dispersion coefficients applicable to a continuous release are the bounding integrated values presented in Table 14.

Radiological risk evaluation guidelines are quantified in terms of the total effective dose equivalent which can be determined and summed for all types and energies of radiation. In contrast, toxicological risk evaluation guidel ines are specific to the biological impacts of individual chemicals. To account for exposure to all chemicals contained in a release, sum-of-fraction values were calculated by Van keuren et al. (1996).

The method for comparing toxicological consequences with the risk evaluation guidelines is as follows.

1. Determine the frequency range of the accident.

2. Determine the type of material being released (i.e., single-shell tank solids, single-shell tank 1iquids, etc.).

3. Determine whether the release is continuous or instantaneous (i.e., a puff).

4. Determine the release quantity or release rate (i.e., the airborne source term). This determination is performed in the same manner as for radioactive materials. 
5. Multiply the release quantity or release rate determined in step 4 by the appropriate value from Table 18 . Products less than or equal to 1 indicate that the risk evaluation guidelines have been met.

Table 18. Sum-of-Fractions of Risk Guidelines for a Unit Release.

\begin{tabular}{|c|c|c|c|c|}
\hline \multirow{2}{*}{ Tank waste type } & \multirow{2}{*}{$\begin{array}{c}\text { Maximum } \\
\text { individual }\end{array}$} & \multicolumn{3}{|c|}{ Accident frequency, $1 /$ year } \\
\hline & & 1 to $10^{-2}$ & $10^{-2}$ to $10^{-4}$ & $10^{-4}$ to $10^{-6}$ \\
\hline Single-shell liquids (s/L) & Onsite & $9.6 \times 10^{3}$ & $7.5 \times 10^{2}$ & $2.0 \times 10^{2}$ \\
\hline Single-shell liquids (s/L) & Offsite & $8.0 \times 10^{0}$ & $8.0 \times 10^{0}$ & $6.2 \times 10^{-1}$ \\
\hline Single-shell solids (s/L) & Onsite & $4.0 \times 10^{4}$ & $2.1 \times 10^{3}$ & $1.0 \times 10^{3}$ \\
\hline Single-shell solids (s/L) & Offsite & $9.4 \times 10^{1}$ & $3.3 \times 10^{1}$ & $1.7 \times 10^{1}$ \\
\hline Double-she11 liquids (s/L) & Onsite & $1.0 \times 10^{4}$ & $7.5 \times 10^{2}$ & $2.1 \times 10^{2}$ \\
\hline Double-shell liquids (s/L) & Offsite & $8.4 \times 10^{0}$ & $8.4 \times 10^{0}$ & $6.2 \times 10^{-1}$ \\
\hline Double-shell solids (s/L) & Onsite & $1.8 \times 10^{4}$ & $3.3 \times 10^{3}$ & $6.3 \times 10^{2}$ \\
\hline Double-shell solids (s/L) & Offsite & $1.9 \times 10^{2}$ & $1.5 \times 10^{1}$ & $2.8 \times 10^{0}$ \\
\hline Gas Release $\left(\mathrm{s} / \mathrm{m}^{3}\right)$ & Onsite & $7.7 \times 10^{1}$ & $9.4 \times 10^{0}$ & $1.9 \times 10^{0}$ \\
\hline Gas Release $\left(\mathrm{s} / \mathrm{m}^{3}\right)$ & Offsite & $6.6 \times 10^{-2}$ & $6.6 \times 10^{-2}$ & $8.1 \times 10^{-3}$ \\
\hline
\end{tabular}

NOTE: Aging waste facility tank information is contained in the double-shell liquids and doubleshell solids sum-of-fractions of risk guidel ines for a unit release.

Units of sum- of-fractions follow the tank waste type.

\subsection{ACCIDENT SCENARIOS}

The following accident scenarios are developed from those identified in Section 2.3. Consequences are reported in Section 5.8. The word "deflagration" is used in the accident scenarios; however, a detonation potentially could result in the same end state.

\subsubsection{Double-Shell Tank Accident Scenarios}

5.7.1.1 Deflagration in the Headspace. Flammable gases of concern (e.g., hydrogen, ammonia, methane) are produced in the tank waste by three principal means: radiolysis, organic decomposition, and corrosion. Nitrous oxide, an oxidizer, is also produced by radiolysis. Radiolysis is the process by which chemical molecules are dissociated due to radiation. For example, radiolysis causes water molecules to break apart into hydrogen and oxygen. Radiolysis a) so affects other chemical species in the tank. Organic decomposition also produces hydrogen and other flammable gases. The organic molecules breakdown principally by thermal reactions. Corrosion of the steel primary tank produces hydrogen only; no other gas products are formed (Strachan 1994). 
Experimental work and computer modeling at Pacific Northwest National Laboratory indicates that retention mechanisms exist in double-shell tanks. The current understanding of this phenomena requires the presence of two layers of waste in the tank: one layer principally composed of settled solids and a supernatant layer. Gases are generated in both layers; however, the gas in the supernatant layer is continuously released. The gas in the settled solids layer is retained. The gases buildup until the density of the settled solids layer becomes equal to the density of the supernatant layer. A perturbation to the system can cause an inversion of the layers. This type of event is called a gas release event and causes the sudden release of the flammable gases into the headspace. Current estimates of the average or best estimate expected volume of retained gases in double-shell tanks range from 0 to 641 standard $\mathrm{m}^{3}$ (0 to $22,627 \mathrm{scf}$ ) (Hodgson et al. 1996).

The release can occur naturally (the tank is in storage mode) or as a result of intrusive activities in the tank (the tank is in active mode). Tank 241-SY-101 had large natural releases approximately every 100 days. As part of the mitigation strategy for this tank, releases were induced by several mechanisms: water lancing, air lancing, and currently, mixer pump operation. Other operations in the tank could also induce gas release events. These include, but are not limited to, equipment installation and removal, core sampling, use of the void fraction instrument, and use of the ball rheometer.

The releases could be local or global. A local release occurs when gas is released over a small portion of the waste surface. The plume can also be buoyant: or nonbuoyant and may also lead to stratified regions in the tank. That is, a buoyant plume could lead to a layer of flammable gases at the apex of the dome. A nonbuoyant plume could lead to a pancake layer of flammable gases on the waste surface. Thus, the local release can cause a portion of the headspace to be above the lower flammability limit. As determined from the permanent hydrogen monitoring systems (which have recently been installed), plume releases seem to be typical of the releases in tanks 241-SY-103, 241-AN-103, 24I-AN-104, 241-AN-105, and 241-AW-101. In a global release, gas is released from the entire (or nearly entire) surface of the waste. This is the type of release seen in tank 241-SY-101. Global releases may also have occurred in tanks 241-SY-103, 241-AN-103, 241-AN-104, 241-AN-105, and 241-AW-101.

The volume of gas introduced by the gas release event may be enough to make a portion or all of the headspace flammable, i.e., above the lower flammability limit. If the release occurs over a small area of the waste surface, i.e., a local release, only a portion of the headspace may be flammable. This is a transient condition and because of diffusion, convection, and the ventilation, flammable concentrations will be short lived.

Hydrogen, a major constituent of the flammable gases, ignites with a very small energy source: only $0.017 \mathrm{~mJ}$ to $0.1 \mathrm{~mJ}$ is required (Fisher 1986, Dufresne and Karwat 1988). Installed equipment in the tank or ventilation system, activities being conducted in the tank, human errors, or natural phenomena (such as earthquakes or lightning) provide ignition sources. A deflagration occurs. Current analyses (LANL 1995) show that large volumes of gas must be released and ignited to generate a pressure pulse larger than the calculated internal static pressure $1 \mathrm{imit}$ of $312 \mathrm{kPa}$ (45 psig). This 
WHC-SD-WM-TI-753 REV 0

pressure is well above the pressure required to cause failure of the inlet high-efficiency particulate air filter and the exhaust prefilters and highefficiency particulate air filters. The release amounts from the filters will also contribute toward calculation of the consequences.

Structural analysis of the tank indicates that the riser plate, a $3.7 \mathrm{~m}$ (12 ft) diameter plate in the top center of the dome, would tear along the weld at this pressure. This plate would lift up and provide pressure relief for the tank. However, the tank remains sound below the water line.

5.7.1.2 Deflagration in the Annulus. Waste may enter the annulus from a leak of the primary tank or by a mistransfer into the annulus. If enough waste enters the annulus, the annulus ventilation system will fail because the annulus ventilation air is supplied from the bottom center of the secondary tank. The air proceeds through channels in the refractory concrete pad that separates the primary tank from the secondary tank. The air is then exhausted from the annulus by the annulus ventilation system. If enough waste enters the annulus, it will fill the channels in the refractory concrete and prevent the annulus from being ventilated. Flammable gases will then build up in the annulus. Installed equipment in the annulus or annulus ventilation system, activities being conducted in the annulus, human errors, or natural phenomena (such as earthquakes or lightning) provide ignition sources. A deflagration occurs.

5.7.1.3 Deflagration During Pump Removal. The mixer pump in tank 241-SY-101 is used to induce periodic small gas releases in the tank as a means of preventing larger uncontrolled releases from occurring. Mixer pumps may be placed in other double-shell tanks and aging waste facility tanks in the future. Removal of the mixer pump presents a unique flammable gas hazard because the removal effort could serve as a release mechanism for the residual retained gas and as an ignition source. Removal of the pump also provides a direct release path to the environment.

5.7.1.4 Subsurface Deflagration. As discussed above, flammable gases are retained in double-shell tank wastes. A subsurface deflagration can be postulated due to the retention mechanisms, i.e., the ignition of a subsurface bubble by an intrusive activity (like core sampling) or natural phenomena, for example, lightning. This phenomenon has been analyzed (Nakayama and Vogt 1996). This analysis concludes that the pressure pulse from the bubble that ignites will be transmitted by the fluid and that oscillations of the bubble as it expands and contracts will send waves through the waste. Nakayama and Vogt (1996) state "this may lead to a release of significant volume of the subsurface gas into the headspace." The subsequent ignition of the gases in the headspace and its associated consequences are considered to be similar to the events that could happen during a seismic event because similar release fractions can be obtained. The consequences from seismic events are discussed in Sections 5.8.2 and 5.8.3.

\subsubsection{Single-She11 Tank Accident Scenarios}

5.7.2.1 Single-Shell Tank Headspace Deflagration. Flammable gases of concern (e.g., hydrogen, ammonia, methane) are produced in the tank waste by three principal means: radiolysis, organic decomposition, and corrosion. Nitrous 
oxide, an oxidizer, is also produced by radiolysis. Organic decomposition also produces hydrogen and other flammable gases. Corrosion of the steel primary tank produces hydrogen on $7 y$; no other gas products are formed (Strachan 1994).

Experimental work at Pacific Northwest National Laboratory indicates that retention mechanisms exist in two single-shell simulants (one simulating sludge and one salt cake). For bubbles retained in particulate simulated waste, the morphology of the retained bubble depends on a dimensionless grouping called the Bond number that is a ratio of gravitational forces to surface tension (Gauglitz et a1. 1996). The Bond number defines the transition between bubbles that displace particles (round bubbles) and bubbles that finger between the particles (dendritic bubbles) composing the particulate media. Bubbles are also retained in sludges where the particle size is sufficiently small that the bubbles never finger between the particles and the primary mechanism of growth is bubbles displacing the sludge. When surface tension dominates, the bubble shape is round. When the sludge strength dominates, the bubbles grow by displacing the weakest sludge adjacent to the bubble. In this case, if any small nonuniformity exists in the sludge strength, the bubbles will follow that path and evolve into some dendritic shape.

A number of previous studies have investigated bubble retention in both simulated waste and actual tank waste (Gauglitz et al. 1994, 1995; Rassat and Gauglitz 1995, Bredt et a1. 1995, Bredt and Tingey 1996). A11 of these studies involved the growth of bubbles in settled solids submerged beneath a liquid supernatant layer. The presence of the supernatant layer allowed for buoyancy-induced rollovers; however, the rollovers were on a very small scale. In one experiment reported by Bredt and Tingey (1996), very 1ittle supernatant liquid was present. During this experiment, the supernatant liquid was observed to sink downward as the sludge-containing bubbles rose. Although this was a buoyancy-induced rollover, it was lethargic and the sludge did not appear to release the gas bubbles. Because the single-shell tanks do not usually contain a supernatant layer (or at most a very small one), similar behavior would be expected. That is, no buoyancy-induced rollovers would be expected to occur in single-shell tanks. Any such rollovers that did occur would be very lethargic ones that would release small amounts of gas.

Gas retained as dendritic bubbles has been observed to form a finely distributed, connected phase some distance under the sludge surface. At some point, a crack, channel, or chimney is opened, and the pressurized gas is suddenly provided with a path to the surface. The path may be either naturally occurring or made by an intrusive activity. This type of release could result in a release of gas to the tank dome headspace.

The release can occur naturally (the tank is in storage mode) or as a result of waste-intrusive activities in the tank (the tank is in active mode). The releases could be local or global. A local release occurs when gas is released over a small portion of the waste surface. The plume can also be buoyant or nonbuoyant and may also lead to stratified regions in the tank. That is, a buoyant plume could lead to a layer of flammable gases at the apex of the dome. A nonbuoyant plume could lead to a pancake layer of flammable gases on the waste surface. Thus, the local release can cause a portion of the headspace to be above the lower flammability limit. A plume release is 
the type of release that would be anticipated from the single-shell tank waste. A global release is one in which gas is being released from the entire (or nearly entire) surface of the waste. This type of release may occur in single-shell tanks during earthquakes. To date, no releases, plume or global, in the single-shell tanks have been detected by the recently installed permanent hydrogen monitors.

Current analyses (LANL 1995) show that small volumes of gas must be released and ignited to generate a pressure pulse larger than the calculated internal static pressure 1 imit of $76 \mathrm{kPa}$ (11 psig). Fox and Stepnewski (1994) show that ignition of $\sim 24 \mathrm{~m}^{3}\left(850 \mathrm{ft}^{3}\right)$ of hydrogen for a headspace of $991 \mathrm{~m}^{3}$ $\left(35,000 \mathrm{ft}^{3}\right)$ to $55 \mathrm{~m}^{3}\left(1943 \mathrm{ft}^{3}\right)$ of hydrogen for a headspace of $2,407 \mathrm{~m}^{3}$ $\left(85,000 \mathrm{ft}^{3}\right)$ can generate a pressure pulse larger than the calculated internal static pressure limit. This pressure is well above the pressure required to cause failure of the inlet high-efficiency particulate air filter and the exhaust prefilters and high-efficiency particulate air filters. The release amounts from the filters will also contribute toward calculation of the consequences.

A very small energy source can ignite hydrogen, a major constituent of the flammable gases: only $0.017 \mathrm{~mJ}$ to $0.1 \mathrm{~mJ}$ is required (Fisher 1986, Dufresne and Karwat 1988). Installed equipment in the tank or ventilation system, activities being conducted in the tank, human errors, or natural phenomena (such as earthquakes or lightning) provide ignition sources. A deflagration occurs.

Han and Beavers (1996) state that when a single-shell tank experiences an internal static pressure of $76 \mathrm{kPa}$ (11 psig), concrete cracks would probably develop in the center region of the dome. The air within the tank would escape through these cracks; therefore, the internal pressure could not build up to the level that would cause a section of the dome to be blown outward, which in turn would cause concrete debris and soil to fall back into the tank. The release would also occur through the opening for the inlet filter, through open risers in the central pump pit, and through the opening for the exhauster (if the tank is equipped with an active ventilation). Pieces of concrete on the inside face of the dome may lose bond with the rebar and fall into the tank due to excessive compressive forces from the postevent soil load (i.e., soil reimpact would cause spalling of the concrete). Rebar in the tank wall below the haunch region would be overstressed but would not cause the dome to collapse.

5.7.2.2 Transfer Line Deflagration. Flammable gases are introduced into the transfer line during salt well pumping. The flow rate during salt well pumping is very low, typically 0.19 to $19 \mathrm{~L}$ per minute $(0.05$ to $5 \mathrm{gal}$ per minute). This leaves a "headspace" in the transfer line, i.e., the transfer line is not completely full of liquids. Pumping a single-shell tank can take an extended period of time (months to years). Gases can be introduced into the headspace of the transfer line by three processes: transfer with singleshel1 tank waste, production in the transfer line by radiolysis and organic decomposition, or transfer from the double-contained receiver tank.

The concentration of flammable gases in the transfer lines has never been measured. The analys is done here assumes that the concentrations reached allow a deflagration to occur. For mixtures with nearly equal amounts of 
nitrous oxide and hydrogen, this concentration is below 8 vol\% hydrogen. For mixtures with little nitrous oxide, this limit is below 11 vol\% hydrogen. A very small energy source can ignite hydrogen, a major constituent of the flammable gases: only $0.017 \mathrm{~mJ}$ to $0.1 \mathrm{~mJ}$ is required. No ignition sources are known to be present in the transfer lines; however, natural phenomena (such as earthquakes or lightning) could provide an ignition source. The double-contained receiver tank could also provide an ignition source. A deflagration occurs in the transfer line. The resulting pressure is $1,462 \mathrm{kPa}(211 \mathrm{psia})$. The burst pressure for $5.1 \mathrm{~cm}$ (2 in.) Schedule 40 pipe is $57.9 \mathrm{MPa}(8,400 \mathrm{psia})$ for Schedule $40 \mathrm{pipe}$ and $51.7 \mathrm{MPa}(7,500 \mathrm{psia})$ for Schedule 10S. A detonation has a hypothetical maximum pressure of $2.83 \mathrm{MPa}$ (411 psia) (NUREG 1983). Bodurtha (1980) states "Equipment designed to $3.5 \mathrm{MPa}$ (508 psi) ... usually will be adequate to contain a detonation ... for flammable gases in air at atmospheric pressures." Therefore, the transfer line remains intact.

5.7.2.3 Subsurface Deflagration. As discussed above, flammable gases are retained in double-shell tank wastes. A subsurface deflagration can be postulated due to the retention mechanisms, i.e., the ignition of a subsurface bubble by an intrusive activity (like core sampling) or natural phenomena, for example, lightning. This phenomenon has been analyzed (Nakayama and Vogt 1996). This analysis concludes that the pressure pulse from the bubble that ignites will be transmitted by the fluid and that oscillations of the bubble as it expands and contracts will send waves through the waste. Nakayama and Vogt (1996) state "this may lead to a release of significant volume of the subsurface gas into the headspace." The subsequent ignition of the gases in the headspace and its associated consequences are considered to be similar to the events that could happen during a seismic event because similar release fractions can be obtained. The consequences from seismic events are discussed in Sections 5.8.2 and 5.8.3.

\subsubsection{Double-Contained Receiver Tank Evaluation Basis Accident Scenario}

Flammable gases can be introduced into the headspace of a doublecontained receiver tank or catch tank by three processes: transfer with single-shell tank waste, production in the tank during storage by radiolysis and organic decomposition, or production by chemical adjustment of the singleshell tank waste before transfer into a double-shell tank.

Peurrung and Gauglitz (1996) modeled salt-well pumping as multiphase flow in porous media. (The results of this modeling, which was focused on singleshell tanks, are included here because the 1 iquids pumped out of these tanks are transferred into the double-contained receiver tanks addressed in this section.) Peurrung and Gauglitz conducted both one-dimensional and twodimensional modeling. The results of this modeling show that most of the soluble gas (ammonia) would be removed with the pumped fluid and transferred to the double-contained receiver tank. Essentially all of the insoluble gas (hydrogen, methane, and nitrous oxide) is projected to be released in the single-shell tank, and very little of the insoluble gas is projected to be released in the salt well itself or transferred to the double-contained receiver tank. 
Flammable gases of concern (e.g., hydrogen, ammonia, methane) are produced in the tank waste by three principal means: radiolysis, organic decomposition, and corrosion. Nitrous oxide, an oxidizer, is also produced by radiolysis. Organic decomposition also produces hydrogen and other flammable gases. Corrosion of the steel primary tank produces hydrogen only; no other gas products are formed (Strachan 1994). These gases are cont inuously released because no submerged settled solids are present to retain the gas.

Sodium hydroxide and sodium nitrate are added, as needed, to the doublecontained receiver tanks to adjust the waste chemistry. This adjustment causes a gas release (i.e., the amino compounds in the low pH waste become free ammonia when the $\mathrm{pH}$ is raised by addition of these chemicals).

Calculations (Heubach and Siemer 1996) indicate that an injection rate of $1 \mathrm{~L} / \mathrm{h}$ for 25 hours of 19-molar sodium hydroxide will produce an ammonia concentration of $50 \%$ in the primary tank headspace of the double-contained receiver tank.

Stahl and Coles (1992) studied hydrogen accumulation in double-contained receiver tanks as part of a larger study on interim stabilization of nonwatchlist tanks. They concluded that the primary receiver vessel would be the most likely location for hydrogen to accumulate because this is the place where the hydrogen is generated, and no design provisions were made to provide airflow through the primary receiver vessel from the primary ventilation system. Some airflow is provided by the dip-tube system.

Stahl and Coles (1992) also concluded that potential ignition sources existed within the primary receiver vessel and that fires (deflagrations) or explosions (detonations) were credible given this condition. A very small energy source can ignite hydrogen, a major constituent of the flammable gases: only $0.017 \mathrm{~mJ}$ to $0.1 \mathrm{~mJ}$ is required. Installed equipment in the doublecontained receiver tank or ventilation system or natural phenomena (such as earthquakes or lightning) provide an ignition source and combustion occurs.

Wagenblast (1996) evaluated the structural response of double-contained receiver tanks and catch tanks to internal pressurization events. He looked at a rapid internal pressurization up to $827 \mathrm{kPa}(120 \mathrm{psi})$. The internal pressurization reached in the double-contained receiver tank should be no greater than the internal pressure reached in a single-shell tank because only single-shell tank waste is transferred through double-contained receiver tanks and the gas generated by the waste, while in the double-contained receiver tank, should have the same constituents and the same ratios as when it was in the single-shell tank. As long as the gas composition remains the same, the pressure from burning the gas will be the same, regardless of the tank volume the gas is in.

The conclusion that Wagenblast (1996) reached was that for the 244-BX, 244-TX, 244-U, and 244-S vaults, the primary vessel would rupture and the vault would fail at an overpressure of half that analyzed (i.e., at $414 \mathrm{kPa}$, or $60 \mathrm{psi}$ ). This conclusion would be true for all catch tanks with wall thicknesses of $0.64 \mathrm{~cm}$ (1/4 in.). The 244-CR and 244-A primary vessels and vaults would withstand the $827 \mathrm{kPa}$ (120 psi) pressurization, but both would fail at $1,200 \mathrm{kPa}$ (174 psi). This conclusion is also true for catch tanks with wall thicknesses of $0.95 \mathrm{~cm}(3 / 8 \mathrm{in.})$. 


\subsubsection{Analys is Methodology}

For double-shell tanks and single-shell tanks, three flammable gas accident consequence end states, all of which are credible, are presented in Section 5.8 of this report. The three end states, which are related to the structural response of the tank dome to pressures generated by the burning of flammable gas, are:

(1) cracking of the dome

(2) collapse of the dome into the tank

(3) dome loss (i.e., blow out).

The first accident end state was selected as the evaluation basis accident. Although so designated for dome response, the scenario presented should not be construed as a representative flammable gas deflagration. The postulated accident, i.e., a flammable gas deflagration that generates sufficient pressure to cause the dome to crack (based upon a dynamic analysis for double-shell tanks and a static analysis for single-shell tanks), challenges the functional design requirements that were originally established for the waste tanks and provides an initial basis for the selection of safety structures, systems, and components and technical safety requirements for the Tank Waste Remediation System Final Safety Analysis Report. In addition, the analysis provides an initial basis for the selection of technical safety requirements and other controls for the prevention of flammable gas accidents. Final control selection considered the frequency and consequences of a 11 three end states.

The second accident end state results from a deflagration that generates sufficient pressure to cause a tank dome collapse that leads to debris falling into the tank. This represents an intermediate consequence between the two extremes (i.e., dome cracking and dome loss). Although there are other potential initiating events, this second accident end state is presented in light of a discussion of the evaluation basis earthquake since a seismic event has the potential to release significant quantities of retained gas.

The third accident end state results from a detonation that generates sufficient pressure to destroy and displace the dome structure. This third, postulated accident, representing the upper bound of potential consequences, is presented in the discussion of a beyond evaluation basis event because it is considered a less likely but more severe event than either the evaluation basis accident or evaluation basis earthquake analyses.

For double-contained receiver tanks, the calculation is presented in two end states. The first is an evaluation basis accident of a detonation where the source term consists of $5 \%$ single-shell tank solids and $95 \%$ single-shell liquids. The second is a beyond evaluation basis accident with $33 \%$ singleshell tank solids and $67 \%$ single-shell tank 1 iquids.

The uncertainties associated with the quantities of flammable gas retained in the tanks, the gas release mechanisms, the relative mixtures of the released gases, and the quantities of flammable gas that might be released in a gas release event are such that it is not possible to demonstrate that the frequency of any of these three postulated representative accidents is 
beyond extremely unlikely. The frequency classification of each postulated accident is discussed in Section 5.8 where the accident consequences are presented.

\subsection{COMPARISON WITH RISK GUIDELINES}

\subsubsection{Evaluation Basis Accidents}

The consequences for the postulated accidents in double-shell tanks are presented below in Table 19 (without controls) and in Table 20 (with controls). The consequences for the postulated accidents in single-shell tanks and double-contained receiver tanks are presented in Table 21 (without controls) and Table 22 (with controls). The evaluation basis earthquake is discussed in Section 5.8.2.

\subsubsection{Comparison with Guidelines for Double-Shell Tanks.}

\subsection{Comparison with Radiological Guidelines-Scenarios without} Controls. All onsite radiological doses from accidents without controls are well above the onsite evaluation guidelines. All offsite radiological doses from accidents without controls are well below the offsite evaluation guidelines.

\subsection{Comparison with Radiological Guidelines-Scenarios with} Controls. The onsite doses from all accidents with controls are above the onsite evaluation guidelines. All offsite radiological doses from accident with controls are well below the offsite evaluation guidelines.

\subsection{Comparison with Toxicological Guidelines-Scenarios without} Controls. All onsite toxicological sum-of-fractions are well over 1 for the accidents without controls at the onsite receptor location. The toxicological consequences therefore exceed the onsite risk evaluation guidelines. With one exception, the offsite toxicological sum-of-fractions for the double-shell and aging waste facility tank headspace deflagration accidents without controls are all less than 1 and hence meet the risk guidelines. However, the offsite toxicological sum-of-fractions for the deflagration during pump removal without controls slightly exceeds the risk guidelines.

\subsection{Comparison with Toxicological Guidelines-Scenarios with} Controls. The onsite toxicological sum-of-fractions for the double-shell tank deflagration accident with controls, the aging waste facility tank deflagration accident with controls, and the pump removal from a double-shell tank with controls are over 1 and hence exceed the onsite risk guidelines. However, the offsite toxicological sum-of-fractions for the deflagration accidents with controls are a11 less than 1 and hence meet the risk guide 1 ines. 
Table 19. Consequences and Frequencies for Double-Shell Tank Deflagrations without Controls.

\begin{tabular}{|c|c|c|c|c|c|c|c|c|c|}
\hline \multirow{4}{*}{ Accident } & \multicolumn{8}{|c|}{ Consequences } & \multirow{4}{*}{ Frequency } \\
\hline & \multicolumn{4}{|c|}{ Radiological, Sv (rem) } & \multicolumn{4}{|c|}{ Toxicological } & \\
\hline & \multicolumn{2}{|c|}{ Onsite } & \multicolumn{2}{|c|}{ offsite } & \multicolumn{2}{|c|}{ Onsite } & \multicolumn{2}{|c|}{ offsite } & \\
\hline & $\begin{array}{c}\text { Calculated } \\
\text { dose }\end{array}$ & $\begin{array}{c}\text { Risk } \\
\text { guidel ine }\end{array}$ & $\begin{array}{l}\text { Calculated } \\
\text { dose }\end{array}$ & $\begin{array}{c}\text { Risk } \\
\text { guidel ine }\end{array}$ & $\begin{array}{l}\text { Calculated } \\
\text { sof }\end{array}$ & $\begin{array}{c}\text { Risk } \\
\text { guidel ine }\end{array}$ & $\begin{array}{c}\text { Calculated } \\
\text { Sof }\end{array}$ & $\begin{array}{c}\text { Risk } \\
\text { guidel ine }\end{array}$ & \\
\hline $\begin{array}{l}\text { Double-Shell Tank Deflagration } \\
\text { in the Headspace }\end{array}$ & $\begin{array}{l}1.9 E-01 \\
(1.9 E+01)\end{array}$ & $\begin{array}{l}5.0 E-03 \\
(5.0 \mathrm{E}-01)\end{array}$ & $\begin{array}{l}1.6 \mathrm{E}-04 \\
(1.6 \mathrm{E}-02)\end{array}$ & $\begin{array}{l}1.0 E-03 \\
(1.0 E-01)\end{array}$ & 1,100 & 1 & 0.94 & 1 & Anticipated \\
\hline $\begin{array}{l}\text { Aging Waste Facility Tank } \\
\text { Deflagration in the Headspace }\end{array}$ & $\begin{array}{l}4.4 E-02 \\
(4.4 E+00)\end{array}$ & $\begin{array}{l}5.0 E-03 \\
(5.0 E-01)\end{array}$ & $\begin{array}{l}4.0 E-05 \\
(4.0 E-03)\end{array}$ & $\begin{array}{l}1.0 \mathrm{E}-03 \\
(1.0 \mathrm{E}-01)\end{array}$ & 820 & 1 & 0.70 & 1 & Anticipated \\
\hline
\end{tabular}

soF $=$ sum-of-fractions.

Table 20. Consequences and Frequencies for Double-She11 Tank Deflagrations with Controls.

\begin{tabular}{|c|c|c|c|c|c|c|c|c|c|}
\hline \multirow{4}{*}{ Accident } & \multicolumn{8}{|c|}{ Consequences } & \multirow{4}{*}{ Frequency } \\
\hline & \multicolumn{4}{|c|}{ Radiological, sv (rem) } & \multicolumn{4}{|c|}{ Toxicological } & \\
\hline & \multicolumn{2}{|c|}{ Onsite } & \multicolumn{2}{|c|}{ offsite } & \multicolumn{2}{|c|}{ Onsite } & \multicolumn{2}{|c|}{ offsite } & \\
\hline & $\begin{array}{l}\text { Calculated } \\
\text { dose }\end{array}$ & $\begin{array}{l}\text { Risk } \\
\text { guidel ine }\end{array}$ & $\begin{array}{l}\text { Calculated } \\
\text { dose }\end{array}$ & $\begin{array}{c}\text { Risk } \\
\text { guidel ine }\end{array}$ & $\begin{array}{c}\text { Calculated } \\
\text { sof }\end{array}$ & \begin{tabular}{|c|} 
Risk \\
guidel ine
\end{tabular} & $\begin{array}{c}\text { Calculated } \\
\text { SOF }\end{array}$ & $\begin{array}{c}\text { Risk } \\
\text { guidel ine }\end{array}$ & \\
\hline $\begin{array}{l}\text { Double-Shell Tank Deflagration in } \\
\text { the Headspace }\end{array}$ & $\begin{array}{l}1.9 \mathrm{E}-01 \\
(1.9 \mathrm{E}+01)\end{array}$ & $\begin{array}{l}5.0 \mathrm{E}-02 \\
(5.0 \mathrm{E}+00)\end{array}$ & $\begin{array}{l}1.6 E-04 \\
(1.6 E-02)\end{array}$ & $\begin{array}{l}5.0 \text { E-03 } \\
(5.0 \text { E-01) } \\
\end{array}$ & 130 & 1 & 0.94 & 1 & Unlikely \\
\hline $\begin{array}{l}\text { Aging Waste Facility Tank } \\
\text { Deflagration in the Headspace }\end{array}$ & $\begin{array}{l}4.4 E-02 \\
(4.4 E+00)\end{array}$ & $\begin{array}{l}5.0 \mathrm{E}-02 \\
(5.0 \mathrm{E}+00)\end{array}$ & $\begin{array}{l}4.0 \mathrm{E}-05 \\
(4.0 \mathrm{E}-03)\end{array}$ & $\begin{array}{l}5.0 \mathrm{E}-03 \\
(5.0 \mathrm{E}-01)\end{array}$ & 93 & 1 & 0.70 & 1 & Unlikely \\
\hline
\end{tabular}

SOF = sum- of-fractions. 
Table 21. Consequences and Frequencies without Controls for Single-Shell Tank Deflagrations and Double-Contained Receiver Tank Burns.

\begin{tabular}{|c|c|c|c|c|c|c|c|c|c|}
\hline \multirow{4}{*}{ Accident } & \multicolumn{8}{|c|}{ Consequences } & \multirow{4}{*}{ F: equency } \\
\hline & \multicolumn{4}{|c|}{ Radiological, Sv (rem) } & \multicolumn{4}{|c|}{ Toxicological } & \\
\hline & \multicolumn{2}{|c|}{ Onsite } & \multicolumn{2}{|c|}{ offsite } & \multicolumn{2}{|c|}{ Onsite } & \multicolumn{2}{|c|}{ offsite } & \\
\hline & $\begin{array}{l}\text { Calculated } \\
\text { dose }\end{array}$ & $\begin{array}{c}\text { Risk } \\
\text { guideline }\end{array}$ & $\begin{array}{l}\text { Calculated } \\
\text { dose }\end{array}$ & $\begin{array}{c}\text { Risk } \\
\text { guidel ine }\end{array}$ & $\begin{array}{l}\text { Calculated } \\
\text { Sof }\end{array}$ & $\begin{array}{c}\text { Risk } \\
\text { guideline }\end{array}$ & $\begin{array}{l}\text { Calculated } \\
\text { SOF }\end{array}$ & $\begin{array}{c}\text { Risk } \\
\text { guideline }\end{array}$ & \\
\hline $\begin{array}{l}\text { Single-Shell Tank } \\
\text { Deflagration in the } \\
\text { Headspace }\end{array}$ & $\begin{array}{l}3.4 E+00 \\
(3.4 E+02)\end{array}$ & $\begin{array}{l}5.0 E-03 \\
(5.0 E-01)\end{array}$ & $\begin{array}{l}3.0 E-03 \\
(3.0 E-01)\end{array}$ & $\begin{array}{l}1.0 \mathrm{E}-03 \\
(1.0 \mathrm{E}-01)\end{array}$ & 1,600 & 1 & 1.8 & 1 & Ant : cipated \\
\hline $\begin{array}{l}\text { Doubie-Contained Receiver } \\
\text { Tank Burn }\end{array}$ & $\begin{array}{l}4.4 E+00 \\
(4.4 E+02)\end{array}$ & $\begin{array}{l}5.0 E-03 \\
(5.0 E-01)\end{array}$ & $\begin{array}{l}3.8 E-03 \\
(3.8 E-07)\end{array}$ & $\begin{array}{l}1.0 E-03 \\
(1.0 E-01)\end{array}$ & 1,000 & 1 & 1.1 & 1 & Ant:c:pated \\
\hline
\end{tabular}

SOF $=$ sum of fractions.

Table 22. Consequences and Frequencies with Controls for Single-Shell Tank Deflagrations and Double-Contained Receiver Tanks Burns.

\begin{tabular}{|c|c|c|c|c|c|c|c|c|c|}
\hline \multirow{5}{*}{ Accident } & \multicolumn{9}{|c|}{ necetret lalles duris. } \\
\hline & \multicolumn{8}{|c|}{ Consequences } & \\
\hline & \multicolumn{4}{|c|}{ Radiologicat, SV (rem) } & \multicolumn{4}{|c|}{ roxicological } & \\
\hline & \multicolumn{2}{|c|}{ Onsite } & \multicolumn{2}{|c|}{ offsite } & \multicolumn{2}{|c|}{ Onsite } & \multicolumn{2}{|c|}{ offsite } & \multirow{2}{*}{ Frequency } \\
\hline & $\begin{array}{l}\text { Calculated } \\
\text { Dose }\end{array}$ & $\begin{array}{l}\text { Risk } \\
\text { Guidel ine }\end{array}$ & $\begin{array}{l}\text { Calculated } \\
\text { Dose }\end{array}$ & $\begin{array}{l}\text { Risk } \\
\text { Guideline }\end{array}$ & $\begin{array}{l}\text { Calculated } \\
\text { sof }\end{array}$ & $\begin{array}{l}\text { Risk } \\
\text { Guidel ine }\end{array}$ & $\begin{array}{l}\text { Calculated } \\
\text { Sof }\end{array}$ & $\begin{array}{l}\text { Risk } \\
\text { Guideline }\end{array}$ & \\
\hline $\begin{array}{l}\text { Single-Shell Iank Deflagration in } \\
\text { the Headspace }\end{array}$ & $\begin{array}{c}3.4 E+00 \\
(3.4 E+02)\end{array}$ & $\begin{array}{l}5.0 E-02 \\
(5.0 E+00)\end{array}$ & $\begin{array}{l}3.0 E-03 \\
(3.0 E-01)\end{array}$ & $\begin{array}{l}5.0 E-03 \\
(5.0 E-01)\end{array}$ & 300 & 1 & 1.3 & 1 & Unl ikely \\
\hline Double-Contained Receiver Tank Burn & $\begin{array}{l}4.4 \mathrm{E}+00 \\
(4.4 \mathrm{E}+02)\end{array}$ & $\begin{array}{l}1.0 E-01 \\
(1.0 E+01)\end{array}$ & $\begin{array}{l}3.8 E-03 \\
(3.8 E-01)\end{array}$ & $\begin{array}{l}4.0 E-02 \\
(4.0 E+00)\end{array}$ & 22 & 1 & 0.13 & 1 & $\begin{array}{l}\text { Extremely } \\
\text { Untikely }\end{array}$ \\
\hline
\end{tabular}

SOF $=$ sum of fractions. 


\subsubsection{Comparison with Guidelines for Single-She11 Tanks.}

5.8.1.2.1 Comparison with Radiological Guidelines-Scenarios without controls. All radiological doses from accidents without controls are well above both the offsite and onsite evaluation guidelines.

5.8.1.2.2 Comparison with Radiological Guidelines Scenarios with controls. The onsite radiological dose from single-shell tank deflagration accident with controls is above both the onsite evaluation guidelines. However, the offsite radiological dose is below the offsite guidelines.

5.8.1.2.3 Comparison with Toxicological Guidelines Scenarios without controls. All toxicological sum-of-fractions are over 1 for accidents without controls at the onsite and offsite receptor locations.

5.8.1.2.4 Comparison with Toxicological Guidelines-Scenarios with controls. The onsite and offsite sum-of-fractions from single-she 11 tank deflagration accidents with controls are above both the offsite and onsite evaluation guidelines.

\subsubsection{Comparison with Guidelines for Double-Contained Receiver Tanks.}

\subsection{Comparison with Radiological Guidelines Scenarios without} Controls. All radiological doses for accident without controls are well above both the offsite and onsite evaluation guidelines for anticipated events.

\subsection{Comparison with Radiological Guidelines-Scenarios with} Controls. The offsite doses from the deflagration in a double-contained receiver tank are less than the offsite evaluation guidelines. However, the onsite doses from the deflagration in a double-contained receiver tank are above the onsite evaluation guidelines.

5.8.1.3.3 Comparison with Toxicological Guidelines Scenarios without controls. All toxicological sum-of-fractions are over 1 for accidents without controls at the onsite and offsite receptor locations.

\subsection{Comparison with Toxicological Guidelines-Scenarios with} controls. The offsite sum-of-fractions from the deflagration in a doublecontained receiver tank with controls are less than the offsite evaluation guidelines. However, the onsite sum-of-fractions from the deflagration in a double-contained receiver tank with controls are above the onsite evaluation guidelines.

\subsubsection{Evaluation Basis Earthquake}

A seismically-induced gas release event and deflagration occurs in a single-shell tank and in a double-shell tank. The seismic excitation of the tank sludge is assumed to result in the release of entrained gases to the tank head space in quantities in excess of the reference cases considered in the evaluation basis accident. Ignition of the flammable gases is assured from seismically-initiated mechanical or electrical sparks. Deflagrations occur and cause tank pressures to exceed the ultimate strength of the tank domes resulting in a single-shell tank and double-shell tank dome collapse. 
The conditional probability of a deflagration resulting from the seismic events is not well understood and is conservatively assumed unity. Therefore, the seismically induced accidents are assigned the same frequency as the initialing event frequency (i.e., that of the evaluation basis earthquake) and thus fall in the "unlikely" frequency category.

The source terms without controls for the flammable gas deflagrations are developed in Section 5.4. The source term for flammable gas deflagrations depends on the amount of gas released from the waste in the seismic event. The amount of gas released is not well understood but would depend an magnitude and duration of the seismic event. For purposes of this assessment, the seismic event is assumed to have a source term comparable to the cases summarized in Section 5.4 for double-shell tanks $(2.76 \mathrm{~L})$ and a larger source term for single-shell tanks $(2.62 \mathrm{~L}$ that corresponds to a flame front speed of $45 \mathrm{~m} / \mathrm{s}$ ), with an additional source component is added to account for the collapse of the dome. WHC-SD-WM-CN-051, The Effects of Load Drop, Uniform Load, and Concentrated Loads of waste Tanks, analyzes the release from a collapsed dome in which the tank overburden is credited with reducing the respirable particles by a factor of 10 . Because some of the overburden may be expelled by the deflagration, this factor was not credited and an additional $3.8 \mathrm{~L}$ of respirable waste is released. Note that even a larger source term is assessed for a beyond evaluation basis flammable gas detonation.

Assessments of the onsite and offsite radiological and toxicological exposures for deflagrations in a double-shell tank and an single-shell tank without dome collapse are given in the evaluation basis accident. Adding consequences from the dome collapse results in consequences as illustrated in Table 23. A case with greater consequences is assessed for a beyond evaluation basis flammable gas detonation.

\subsubsection{Comparison with Guidelines for Double-Shell Tanks.}

5.8.2.1.1 Comparison with Radiological Guidelines. The onsite radiological dose is above the onsite evaluation guidelines for unlikely events. The offsite radiological dose is below the offsite evaluation guideline for unlikely events.

5.8.2.1.2 Comparison with Toxicological Guidelines. All toxicological sum-of-fractions are over 1 at the onsite and offsite receptor locations.

\subsubsection{Comparison with Guidelines for Single-Shell Tanks.}

5.8.2.2.1 Comparison with Radiological Guidelines. The radiological doses are above both the offsite and onsite evaluation guidelines for unlikely events.

5.8.2.2.2 Comparison with Toxicological Guidelines. All toxicological sum-of-fractions are over 1 at the onsite and offsite receptor locations. 
Table 23. Consequences and Frequencies for a Seismic Event without Controls.

\begin{tabular}{|c|c|c|c|c|c|c|c|c|c|}
\hline \multirow{4}{*}{ Accident } & \multicolumn{8}{|c|}{ Consequences } & \multirow{4}{*}{ Frequency } \\
\hline & \multicolumn{4}{|c|}{ Radiological, Sv (rem) } & \multicolumn{4}{|c|}{ Toxicological } & \\
\hline & \multicolumn{2}{|c|}{ Onsite } & \multicolumn{2}{|c|}{ Offsite } & \multicolumn{2}{|c|}{ Onsite } & \multicolumn{2}{|c|}{ offsite } & \\
\hline & $\begin{array}{c}\text { Calculated } \\
\text { dose }\end{array}$ & $\begin{array}{c}\text { Risk } \\
\text { guidel ine }\end{array}$ & $\begin{array}{c}\text { Calculated } \\
\text { dose }\end{array}$ & $\begin{array}{l}\text { Risk } \\
\text { guidel ine }\end{array}$ & $\begin{array}{c}\text { Calculated } \\
\text { SOF }\end{array}$ & $\begin{array}{c}\text { Risk } \\
\text { guidel ine }\end{array}$ & $\begin{array}{c}\text { Calculated } \\
\text { sof }\end{array}$ & $\begin{array}{c}\text { Risk } \\
\text { guidel ine }\end{array}$ & \\
\hline $\begin{array}{l}\text { Double-shell tank deflagration } \\
\text { with dome collapse }\end{array}$ & $\begin{array}{l}4.5 E-01 \\
(4.5 E+01)\end{array}$ & $\begin{array}{l}5.0 E-02 \\
(5.0 E+00)\end{array}$ & $\begin{array}{l}3.9 E-04 \\
(3.9 E-02)\end{array}$ & $\begin{array}{l}5.0 \text { E-03 } \\
(5.0 \text { E-01) } \\
\end{array}$ & 140 & 1 & 1.1 & 1 & Unl ikely \\
\hline $\begin{array}{l}\text { Single-shell tank deflagration } \\
\text { with dome collapse }\end{array}$ & $\begin{array}{l}16 E+00 \\
(16 E+02)\end{array}$ & $\begin{array}{l}5.0 \mathrm{E}-02 \\
(5.0 \mathrm{E}+00)\end{array}$ & $\begin{array}{l}1.4 E-02 \\
(1.4 E+00)\end{array}$ & $\begin{array}{l}5.0 \mathrm{E}-03 \\
(5.0 \mathrm{E}-01)\end{array}$ & 830 & 1 & 2.2 & 1 & Unlikely \\
\hline
\end{tabular}
Sof $=$ sum of fractions. 


\subsubsection{Beyond Evaluation Basis Accident}

A detonation is possible if the flammable gases, mixed with sufficient oxidant, exceed a specific concentration. This concentration is $8 \%$ hydrogen in those cases in which the volume fraction of hydrogen and nitrous oxide were similar and $11 \%$ hydrogen for those cases that had little nitrous oxide. Scenarios can be postulated with deflagration-to-detonation transitions but their consequences are less than, or similar to, detonations without transitions. As summarized below, there are three cases in which tank detonations might be possible.

In the first case, the gas release occurs over a small area of the surface via some waste intrusion mechanism. The analysis assumed flammable gas was released through this small area and rose to the dome without much entrainment of the surrounding air. There, the gas spread out radially. Since the initial concentration of flammable gases was large and there was little entrainment, the hydrogen concentration at the apex of the dome was also large. It was assumed that gas was ignited prior to diffusing significantly and a detonation occurred.

The second case involves a global detonation. In this case, it was assumed that a roll-over or other tank wide disturbance occurred and caused a gas release event. The release was postulated to occur at a rate much greater than the ventilation flow rate. Ignition was postulated to occur prior to significant gas venting due to the resulting pressure differential (about 30 to $50 \mathrm{kPa}$ ) between the dome and the atmosphere. Under these assumptions, and assuming significant nitrous oxide is al so released, a detonation may be possible.

In the third case, the ventilation system is assumed to fail in a doublecontained receiver tank. If the failure persists for about 15 days, the concentration of flammable gas could exceed the detonatable limit.

The frequency of a deflagration with controls is in the unlikely frequency category. A detonation is estimated to be no greater than "extremely unlikely" because of the specific requirements that must be realized concerning the quantity of gas released, the timing of the ignition and the lack of entrainment of air during the release.

As a result of a detonation, the assumed tank dome failure mode corresponds to a large portion of the dome tearing and being expelled by the internal tank pressure. Other postulated failure modes are less severe.

The consequences of a detonation are obtained by assuming that the mechanism for radionuclide release is similar to a deflagration. In a deflagration, radionuclides are resuspended from the surface of the waste by the high velocity gas flow over it. Using this same model but increasing the gas flow velocity to that representative of a detonation results in a release. Material resuspension correlations were studied and it was found that the quantity resuspended was a function of the square of the velocity. The frequency of a deflagration with controls is in the unlikely frequency category. A detonation is estimated to be no greater than "extremely unlikely" because of the specific requirements that must be realized 
concerning the quantity of gas released, the timing of the ignition, and the lack of entrainment of air during the release.

Because the gas velocity over the surface increases by a factor of 6 for a detonation, the consequences of a detonation exceed those of a deflagration by a factor of 36 . The results of the beyond evaluation basis flammable gas detonation are summarized in Table 24 for the case with the largest consequences, i.e., a postulated detonation in an single-shell tank. The best estimate radiological doses for the larger releases are partially offset by the use of a 50th percentile meteorology. The toxicological consequences are partially compensated for by the larger acceptable release for the lower frequency class. Comparable cases can be postulated for double-shell tank and aging waste tanks if the detonation releases a liquid-solid mixture rather than a Tiquid-only release.

Table 24. Accidents Conditions Beyond the Evaluation Basis.

\begin{tabular}{|c|c|c|}
\hline Accident description & $\begin{array}{c}\text { Frequency } \\
\text { category }\end{array}$ & Best estimate consequences ${ }^{a}$ \\
\hline $\begin{array}{l}\text { Detonation of flammable } \\
\text { gases in a single-shell } \\
\text { tank }\end{array}$ & $\begin{array}{l}\text { Extremely } \\
\text { unlikely }\end{array}$ & $\begin{array}{l}\text { Radiological onsite (Sv): } \\
39 \\
\text { Radiological offsite (SV): } \\
3.4 \times 10^{-02} \\
\text { Toxicological onsite (SOF): } \\
500 \\
\text { Toxicological offsite (SOF): } \\
8.2\end{array}$ \\
\hline $\begin{array}{l}\text { Detonation of flammable } \\
\text { gases in a double- } \\
\text { contained receiver tank }\end{array}$ & $\begin{array}{l}\text { Extremely } \\
\text { unlikely }\end{array}$ & $\begin{array}{l}\text { Radiological onsite (Sv): } \\
2.7 \\
\text { Radiological offsite (Sv): } \\
2.4 \times 10^{-03} \\
\text { Toxicological onsite (SOF): } \\
42 \\
\text { Toxicological offsite (SOF): } \\
5.5 \times 10^{-01}\end{array}$ \\
\hline
\end{tabular}

Based on 36 times the reference deflagration and average meteorology (i.e., a dose reduction factor of 6 for 50 percent meteorology).

bonly single-shell tank results are presented, because the addition of solids to the source term from double-shell and aging waste facility tanks is bounded by this case.

SOF $=$ sum of fraction.

The above radiological and toxicological consequences would be reduced if credit were taken for plume rise due to momentum and buoyancy of the released material. Fallout of the entrained particulate during travel to the onsite and offsite receptor would further reduce the consequences.

\subsubsection{Comparison with Guidelines for Single-Shell Tanks.}

5.8.3.1.1 Comparison with Radiological Guidelines. The onsite radiological dose is above the onsite evaluation guidelines for extremely 
unlikely events. The offsite radiological dose is below the offsite evaluation guideline for extremely unlikely events.

5.8.3.1.2 Comparison with Toxicological Guidelines. The toxicological sum-of-fractions are over 1 at the onsite and offsite receptor locations.

\subsubsection{Comparison with Guidelines for Double-Contained Receiver Tanks.}

5.8.3.2.1 Comparison with Radiological Guidelines. The onsite radiological dose is above the onsite evaluation guidelines for extremely unlikely events. The offsite radiological dose is below the offsite evaluation guideline for extremely unlikely events.

5.8.3.2.2 Comparison with Toxicological Guidelines. The toxicological sum-of-fraction is over 1 at the onsite receptor location. The toxicological sum-of-fraction at the offsite receptor locations is within the offsite guideline.

\subsection{CONCLUSIONS}

This analysis used the best available knowledge and understanding of the flammable gas tanks to evaluate potential consequences from a release, ignition, and subsequent burn. As discussed in the text, there is a continuum of credible accidents, and consequences corresponding to three end states have been provided. Variations in the key parameters used in the calculations lead to Targe variations in the postulated consequences (see Section 5.8). The number of tanks that can reach or exceed the consequences presented here may change depending on the selected end state (i.e., the evaluation basis accident, the evaluation basis earthquake, or the beyond evaluation basis accident). This analysis does not provide a justification for the removal of controls on tanks with flammable gas hazards.

As discussed earlier, steady-state concentrations can build-up over periods of time when there is little or no ventilation. To prevent this hazard from occurring, flammable gas monitoring and ventilation must be protected by controls. The consequences from an ignition and burn of a flammable concentration due to steady-state build-up will not be any different than the consequences due to a gas release event.

of the nine double-shell tanks evaluated, six are able to achieve layer concentrations that are flammable (see Table 8). In addition, onTy three double-shell tanks have retained gas volumes large enough that a $50 \%$ release and burn could cause dome failure (see Appendix D). Of these three tanks, tank 24l-SY-101 already has a mixer pump to mitigate gas releases and the other two double-shell tanks are not currently having gas release events that release $50 \%$ of their retained gas. If a $100 \%$ release and burn is postulated, 5 double-shell tanks could experience dome failure.

of the single-shell tanks evaluated, 12 could potentially achieve layer concentrations that are flammable (see Table 8 ) if $10 \%$ of the retained gas was released from a local area in a two minute time frame. In terms of a global release, of the single-shell tanks evaluated, only 3 would achieve pressures due to an ignition and burn that could cause dome failure if $10 \%$ to $15 \%$ of the 
retained gas is released; 6 if approximately $30 \%$ of the retained gas is released; 9 if $40 \%$ to $45 \%$ of the retained gas is released; and 11 if $100 \%$ of the retained gas is released. However, during the time that hydrogen monitoring equipment has been on the tanks, no gas release events of any size has been seen on a single-shell tank.

of the 7 double-contained receiver tanks and 12 catch tanks that were analyzed, all of them could reach flammable conditions if the generation rate is high and there is little or no ventilation flow. Prudent controls have been developed in the Tank Waste Remediation System Final Safety Analysis Report.

Of the transfer lines analyzed, no consequences were calculated because the pressures from burns were well within the burst pressures of the transfer lines. However, valves and/or jumpers were not evaluated. The failure of these pieces of equipment would cause either a spray leak in a pit or a pool leak. These accidents are analyzed in the Tank Waste Remediation System Final Safety Analysis Report.

For several of the postulated accidents, the estimated frequency and calculated consequences exceed the risk guidelines when evaluated with identified controls. The identified suite of controls is sufficient to reduce the consequences of the accidents to less than the $0.25 \mathrm{SV}$ (25 rem) offsite dose siting guideline in DOE 6430.1A. Although the short-term risk of Tank Waste Remediation System operations with the controls identified in the Final Safety Analysis Report is judged to be acceptable, actions are required to address the intermediate or long-term risk of Tank Waste Remediation System operations, especially for postulated accidents that exceed risk guidelines. The actions include improvements to the accident consequences analysis methodology, improvements in the characterization of the tank wastes, and improvements to Tank Waste Remediation System design and operational safety. Implementation of these actions provides either (1) a better estimate or understanding of Tank Waste Remediation System risks or (2) additional preventive or mitigative controls to reduce the risk of postulated accidents. Because of their potential cost and time to implement and the need for further study (e.g., technical issues, cost benefit), it is not feasible to either make commitments to specific improvements or implement these actions before submittal of the Final Safety Analysis Report.

In conclusion, it is thought that the flammable gas short-term risk during continued operation of the Tank Waste Remediation System facilities is small when the controls identified in the Technical Safety Requirements are in place and followed (the Technical Safety Requirements will be issued with the final safety analysis report).

\subsection{FUTURE WORK}

The methodology used in this analysis was not intended to be a worst-case analysis (in which conservatism on top of conservatism is applied). Consequence analyses were performed only at the beginning of structural failure of the tank. Many of the parameters used for calculations in this document are more "best estimates" for "normal" releases (i.e., more average in nature). These calculations still result in failure of the tank dome and 
severe consequences. Additional work is needed to provide more definitive analysis of worst-case accident scenarios.

More definitive conclusions on flammable gas deflagrations/detonations can be made if additional work is done in several areas. The following is a general 1 ist of the areas where more work should be done:

- Gas compositions can be improved by additional gas monitoring and retained gas sampling. Additional work on gas generation experiments can lead to a better understanding of the amount of nitrogen and ammonia that can occur during steady-state conditions, gas release events, and during waste intrusive or waste disturbing activities.

- Retained gas volumes can be improved by employing other techniques (retained gas sampling, void fraction instrument, etc.) to independently calculate the volume of stored gas in the tanks.

- Release fractions can be improved by further laboratory studies, historical research, and continued monitoring. Ammonia releases due to other mechanisms (such as water additions, chemical adjustments) in addition to during gas release events need to be studied.

- Dynamic modeling of the response of the tank to larger deflagrations and detonations should be attempted. If computer modeling is not feasible, then physical experiments should be considered.

- Laboratory studies and modeling of the compositions and geometries that can lead to detonations within Tank Waste Remediation System facilities need to continue.

- Modeling of the entrainment and release of waste material would lead to better estimates of the radiological and toxicological consequences. This may entail physical experimentation in scale models.

Integration between this topical report and the Fire Hazards Analysis (WHC-SD-WM-FHA-020, Tank Farms Fire Hazards Analysis) has been a prerogative. However, the schedules for release of the two documents has not coincided. Therefore, the information used in the documents may be different because of changes in the knowledge base concerning flammable gas. Efforts have been ongoing to ensure that both the topical author and the fire hazards analysis author have the best available information. As the above work is conducted, integration efforts should continue, and both documents updated accordingly. 


\subsection{REFERENCES}

Al lemann, R. T. et al., 1993, Assessment of Gas Accumulation and Retention Tank 241-SY-101, WHC-EP-0576, Rev. 0, Westinghouse Hanford Company, Richland, Washington.

Allemann, R. T. et al., 1995, A Discussion of Some Mechanisms for Sudden Gas Release from Single-Shel7 Tanks at Hanford, PNL-WTS-101095, Pacific Northwest Laboratory, Richland, Washington

Antoniak, Z. I., and K. P. Recknagle, 1995, Modeling of Post-GRE Spatial and Temporal Hydrogen Concentrations in Tank 241-AW-101, WTSFG95.27, Pacific Northwest Laboratory, Richland, Washington.

Antoniak, Z. I., and K. P. Recknagle, 1996a, Modeling of Post-GRE Spatial and Temporal Hydrogen Concentrations in Tank 241-AN-105 Dome, WTSFG95.56, Pacific Northwest National Laboratory, Richland, Washington.

Antoniak, Z. I., and K. P. Recknagle, 1996b, Modeling Hydrogen Plume Concentrations in Single and Double-Shell Tank Domes, TWSFG96.12, Pacific Northwest National Laboratory, Richland, Washington.

Ashby, E. C. et al., 1992, Gas Generation and Retention in Tank 241-SY-101: A Summary of Laboratory Studies, Tank Data, and Information Needs, PNL-8124, Pacific Northwest Laboratory, Richland, Washington.

Ashby, E. C. et al., 1993, "Concerning the Formation of Hydrogen in Nuclear Waste Quantitative. Generation of Hydrogen via a Cannizzaro Intermediate," J. American Chemical Society, Vol. 115, p. 1171.

Ashby, E. C. et al., 1994, Synthetic Waste Chemical Mechanism Studies, WHC-EP-0823, Westinghouse Hanford Company, Richland, Washington. (Work performed at the Georgia Institute of Technology.)

Babad, H. et al., 1991, Evaluation of the Generation and Release of Flammable Gases in Tank 241-SY-101, WHC-EP-0517, Westinghouse Hanford Company, Richland, Washington.

Babad, H. et a1., 1992, Understanding of Cyclic Venting Phenomena in Hanford Site High-Level Waste Tanks: The Evaluation of Tank 241-SY-101, WHC-SA-1364-EP, Westinghouse Hanford Company, Richland, Washington.

Barefield, E. K. et a1., 1995, Mechanisms of Gas Generation from Simulated SY Tank Farm Wastes: FY 1994 Progress Report, PNL-10822, Pacific Northwest Laboratory, Richland, Washington. (Work performed at the Georgia Institute of Technology.)

Beyler, C. L., and R. Roby, 1996, Deflagration and Detonation Hazards in Hanford Tank Farm Facilities, Hughes Associates, Inc., Baltimore, Maryl and.

Bodurtha, F. T., 1980, Industrial Explosion Prevention and Protection, McGraw-Hill Book Company, New York, New York. 
Bredt, P. R., and S. M. Tingey, 1996, The Effect of Di7ution on the GasRetention Behavior of Iank 24J-SY-103 Waste. PNL-10893, Pacific Northwest National laboratory. Richland, Washington.

Bredt, P. R. et a7., 1995, The Effect of Dilution on the Gas Retention Behavior of Tank 241-SY-101 Waste, PNL-10781, Pac ific Northwest Laboratory, Richland, Washington.

Brown, R. G., 1996, Compilation of Hydrogen Data for 22 Single Shell Flammable Gas Watch List Tanks, WHC-SD-WM-ER-576, Rev. 0, Westinghouse Hanford Company, Richland, Washington.

Bryan, S. A., and L. R. Pederson, 1994, Composition, Preparation, and Gas Generation Results from Simulated Wastes of Tank 241-SY-101, PNL-10075, Pacific Northwest Laboratory, Richland, Washington.

Bryan, S. A. et a1., 1992, Slurry Growth, Gas Retention, and Flammable Gas Generation by Hanford Radioactive Waste Tanks, PNL-8169, Pacific Northwest Laboratory, Richland, Washington.

Bryan, S. A. et al., 1996, Gas Generation from Tank 241-SY-103 Waste, PNL-10978, Pacific Northwest National Laboratory, Richland, Washington.

Cashdol1ar, K. L. et a1., 1992, Laboratory Flammability Studies of Mixtures of Hydrogen, Nitrous Oxide, and Air, WHC-SD-WM-ES-219, Rev. 0., Westinghouse Hanford Company, Richland, Washington.

Coward, H. F., and G. W. Jones, 1952, Limits of Flammability of Gases and Vapors, Bureau of Mines Bulletin 503.

Cowley. W. L., 1996, Development of Radiological Concentration and Unit Liter Doses for Tank Waste Remediation Systein Final Safety Analysis Report Radiological Consequence Calculations, WHC-SD-WM-SARR-037, Rev. 0, Westinghouse Hanford Company, Richland, Washington.

Cowley, W. L., and A. K. Postma, 1996, Analysis of Consequences of Postulated Solvent Fires in Hanford Site Waste Tanks, WHC-SD-WM-CN-032, Rev. OA, Westinghouse Hanford Company, Richland, Washington.

Crippen. M. 0., 1993, Barometric Pressure Variations, WHC-EP-0651, Westinghouse Hanford Company, Richland, Washington.

Delegard, C., 1980, Laboratory Studies of Complexed Waste Slurry Volume Growth in Tank. 241-SY-101, RHO-LD-124, Rockwell International, Richland, Washington.

Dufresne, J., and H. Karwat, 1988, "Hydro- and Gasdynamic Aspects of Hydrogen Behavior in PWR Containments," in NURETH-4 Proceedings Fourth International Topical Meeting on Nuclear Reactor Thermal-Hydraulics, vol. 2 .

EPA, 1988, Limiting Values of Radionuclide Intake and Air Concentration and Dose Conversion Factors for Inhalations, Submersion, and Ingestion, U.S. Environmental Protection Agency, Washington D.C. 
Fischer, M., 1986, "Safety Aspects of Hydrogen Combustion," in Hydrogen Energy Systems, International Journal Hydrogen Energy, Vol. II, No.9, pp. 593-601.

Fox, G. L., Jr., and D. D. Stepnewski, 1994, Hazard Assessments of Double-Sheil Flammable Gas Tanks, WHC-SD-WM-SAR-064, Rev. 0, Westinghouse Hanford Company, Richland, Washington.

Fox, G. L., Jr. et al., 1993, Tank 241-SY-103 Hazard Assessment, WHC-SD-WM-SAR-061, Rev. 0, Westinghouse Hanford Company, Richland, Washington.

Gauglitz, P. A. et al., 1994, Mechanisms of Gas Bubble Retention, PNL-10120, Pacific Northwest Laboratory, Richland, Washington.

Gauglitz, P. A. et al., 1995, Gas Bubble Retention and Its Effect on Waste Properties: Retention Mechanisms, Viscosity, and Tensile and Shear Strengths, PNL-10740, Pacific Northwest Laboratory, Richland, Washington.

Gauglitz, P. A. et al., 1996, Gas Bubble Retention and Release from Simulated Single-Shell Tank Waste, TWSFG96.7, Pacific Northwest National Laboratory, Richland, Washington.

Han, F. C., 1996, "Hydrogen Deflagration Pressure Load," (DSI to R. M. Marusich, June 3), Westinghouse Hanford Company, Richland, Washington.

Han, F. C., and J. E. Beavers, 1996, Limiting Loads and Failure Modes of Waste Storage Tanks, (DSI to R. M. Marusich, April 5), Westinghouse Hanford Company, Richland, Washington.

Hanlon, B. M., 1996, "Waste Tank Summary Report for Month Ending May 31, 1996," WHC-EP-0182-99, Westinghouse Hanford Company, Richland, Washington.

Heard, F. J., 1996, Waste Tank 241-SY-101 Dome Airspace and Ventilation System Response to a Flammable Gas Plume Burn, WHC-SD-WM-ER-515, Rev. 0, Westinghouse Hanford Company, Richland, Washington.

Heubach, E. C., 1996, Topical Report on Steady-State Flammable Gas Generation in Waste Tanks, Draft, WHC-SD-WM-SARR-015, Rev. 1, Westinghouse Hanford Company, Richland, Washington.

Heubach, E. C., and J. M. Siemer, 1996, Calculation Notes for Steady-State Hydrogen and Ammonia Accumulation in Selected Tank Vapor Spaces, $W H C-S D-W M-C N-034$, Rev. 0, Westinghouse Hanford Company, Richland, Washington.

Hodgson, K. M. et al., 1996, Evaluation of Hanford Tanks for Trapped Gas, WHC-SD-WM-ER-526, Rev. 1, Westinghouse Hanford Company, Richland, Washington.

ICRP, 1975, Report of the Task Group on Reference Man, Publication 23, International Commission on Radiological Protection. 
Iversen, J. D., 1984, Particulate Entrainment by Wind, ISU-ERI-Ames-85010, Department of Aerospace Engineering, Iowa State University, Ames, Iowa.

Julyk, L. J., 1994, Static Internal Pressure Capacity of Hanford Single-Shell Waste Tanks, WHC-SD-WM-TI-623, Rev 0, Westinghouse Hanford Company, Richland, Washington.

Kidder, R. J., 1996, Safety Assessment for Initial Retrieval Systems Project W-211, WHC-SD-W211-PSAD-001, Rev. 0, Westinghouse Hanford Company, Richl and, Washington.

Koontz, R. L., 1986, Double-Shell Tank Farm Facility Safety Analysis Report, WHC-SD-WM-SAR-016, Rev. 1, Westinghouse Hanford Company, Richl and, Washington.

LANL, 1995, A Safety Assessment for Proposed Pump Mixing Operations to Mitigate Episodic Gas Re7eases in Tank 241-SY-101: Hanford Site, Richland, Washington, LA-UR-92-3196, Rev. 14, Los Alamos National Laboratory, Los Alamos, New Mexico.

Makris, A., 1993, The Propagation of Gaseous Detonations in Porous Media, Department of Mechanical Engineering, MCGi1l University, Montreal, Quebec, Canada.

Meacham, J. E., A. B. Webb, J. M. Grigsby, P. G. Heasler, J. J. Toth, J. L. Bryant, M. G. Plys, S. J. Lee, and P. M. Daling, 1996, Preliminary Safety Criteria for the Organic Watch List Tanks at the Hanford Site, WHC-SD-WM-SARR-033, Rev. 1, Westinghouse Hanford Company, Richland, Washington.

Meise1, D. et al., 1991, Radiation Chemistry of Synthetic Waste, ANL-91/40, Argonne National Laboratory, Argonne, Illinois.

Meise7, D. et al., 1993, Radiolytic and Radiolytically Induced Generation of Gases from Synthetic Wastes, PNL-93/43, Argonne National Laboratory, Argonne, Illinois.

Nakayama, P. I., and D. Vogt, 1996, Detonation Analyses to Support the Flammable Gas Program and Tank Farm Final Safety Analysis Report, Jason Associates Corporation, San Diego, California.

Napier, B. A., R. A. Peloguin, J. U. Ramsde11, and D. L. Strenge, 1988, GENII - The Hanford Environmental Radiation Dosimetry System, PNL-6584, vols. 1-3, Pacific Northwest Laboratory, Richland, Washington.

Niemi, B. J., 1996a, Hazard Evaluations for the Tank Waste Remediation System Final Safety Analysis Report, WHC-SD-WM-TI-759, Westinghouse Hanford Company, Richland, Washington.

Niemi, B. J., 1996b, Hazard Analysis Results Report, WHC-SD-WM-TI-773, Westinghouse Hanford Company, Richland, Washington. 
Norton, J. D., and L. R. Pederson, 1994, Ammonia in Simulated Hanford DoubleShell Tank Wastes: Solubility and Effects on Surface Tension, PNL-10173, Pacific Northwest Laboratory, Richland, Washington.

NRC, 1982, Atmospheric Dispersion Models for Potential Accident Consequence Assessments at Nuclear Power Plants, Regulatory Guide 1-145, Nuclear Regulatory Commission, Washington D.C.

NUREG, 1982, Accident Generated Particulate Materials and Their Characteristics $A$ Review of Background Information, NUREG/CR-2651, Pacific Northwest Laboratory, Richland, Washington.

NUREG, 1983, Light Water Reactor Hydrogen Manual, NUREG/CR-2726, Sandia National Laboratories, Albuquerque, New Mexico.

NUREG, 1989, The Effect of Obstacles and Transverse Venting on Flame Acceleration and Transition to Detonation for Hydrogen-Air Mixtures at Large Scale, NUREG/CR-5275, Sandia National Laboratory, Albuquerque, New Mexico.

Oxford, 1996, 29th European Study Group with Industry, Mathematical Institute, Oxford University, Oxford, England.

Pasamehmetoglu, K., 1996, A Safety Assessment of Rotary Mode Core Sampling in Flammable Gas Single-Shell Tanks: Hanford Site, Richland, Washington LA-UR-96-35, WHC-SD-WM-SAD-035, Rev. 0, Los Alamos Nationál Laboratory, Los Alamos, New Mexico.

Person, J. C., 1996, Effects of Oxygen Cover Gas and NaOH Dilution on Gas Generation in Tank 241-SY-101 Waste, WHC-SD-WM-DTR-043, Westinghouse Hanford Company, Richland, Washington.

Peurrung, L. M., and P. A. Gauglitz, 1996, Gas Release During Salt Well Pumping: Model Predictions from the STOMP Hydrology Simulator, TWSFG96.14, Pacific Northwest National Laboratory, Richland, Washington.

Plys, M. et al., 1996, Detonation Potential for Selected Hanford Tank Farm Applications, FAI/96-29, Fauske \& Associates, Inc., Burr Ridge, Illinois.

Powers, T. B., 1996, Tank Farm Deflagration Rate Due to Various Ignition Sources, WHC-SD-WM-CN-041, Rev. 0, Westinghouse Hanford Company, Richland, Washington.

Powers, T. B., and G. R. Sawtelle, 1996, Tank Farm Deflagration Rates due to Various Ignition Sources, WHC-SD-WM-CN-041, Rev. 0, Westinghouse Hanford Company, Richland, Washington.

Rassat, S. D., and P. A. Gauglitz, 1995, Bubble Retention in Synthetic sludge: Testing of Alternative Gas Retention Apparatus, PNL-10661, Pacific Northwest Laboratory, Richland, Washington.

Recknagle, K. P., and T. E. Michener, 1995, Modeling of Gas Release from Sludge Layer in Tank 241-AY-101, PNL-FG:112495, Pacific Northwest National Laboratory, Richland, Washington. 
Reid, H. C. et al., 1996, Waste Tank Sludge Vielding Estimates with Design Base Earthquake Spectrum Shock Analysis, (a presentation at the Quarterly Technical Review), Pacific Northwest National Laboratory, Richland, Washington.

Resource Conservation and Recovery Act of 1976, 42 U.S.C. 6901 et seq.

Schlosser, R. L., 1996a, Safety Basis for Activities in Double-Shell Flammable Gas Watch List Tanks, WHC-SD-WM-SARR-002, Rev. 1, Westinghouse Hanford Company, Richland, Washington.

Schlosser, R. L., 1996b, Safety Basis for Activities in Single-Shell Flammable Gas Watch List Tanks, WHC-SD-WM-SARR-004, Rev. 1, Westinghouse Hanford Company, Richland, Washington.

Shekarriz, R., et al., 1996, Preliminary Retained Gas Sampler Measurements for Hanford Waste Tank 241-AW-101, TWS-MIT-052596, Pacific Northwest Nationa] laboratory, Richl and, Washington.

Sherwood, D. J., 1995, Flammable Gas Tank Safety For Gas Sampling and Monitoring, WHC-SD-WM-ES-346, Rev. 0, Westinghouse Hanford Company, Richland, Washington.

Siciliano, 1996, Ammonia Studies Results for FY-96 Safety Analysis, WHC-SD-WM-CN-042, Rev. 0, Westinghouse Hanford Company, Richland, Washington.

Spore, J. et a1., 1994, Double-Shell Tank Bounding Analysis, LA-UR-94-2088, Rev. 0, Los Alamos National Laboratory, Los Alamos, New Mexico.

Stah1, S. M., and G. A. Coles, 1992, Safety Study of Interim Stabilization of NonWatchlist Single-Shell Tanks, WHC-SD-WM-RPT-048, Rev. 0, West inghouse Hanford Company, Richland, Washington.

Stewart, C. W., 1996, Summary of Gas Retention and Release Behavior in Hanford Single-Shel7 Waste Tanks (external memo to W. H. Meader, TWRS Interim Stabilization, October 3), Pacific Northwest National Laboratory, Richland, Washington.

Strachan, 1994, Status and Integration of the Gas Generation Studies Performed for the Hydrogen Safety Program - FY 1993 Annual Report, PNL-9459, Pacific Northwest Laboratory, Richland, Washington.

Thurgood, M. J., 1996, Evaluation of Hydrogen Release During Saltwell Pumping for Tanks T107, S110, and S108, WHC-SD-WM-ER-571, Rev. 0, Westinghouse Hanford Company, Richland, Washington.

Van Keuren, J. C., and A. V. Savino, 1996, Tank Waste Compositions and Atmospheric Dispersion Coefficients for use in Safety Analysis Consequence Assessments, WHC-SD-WM-SARR-016, Rev. 2, Westinghouse Hanford Company, Richland, Washington. 
Van Keuren, J. C., J. S. Davis, and M. L. Dentler, 1996, Toxic Chemical Considerations for Tank Farm Releases, WHC-SD-WM-SARR-011, Rev. 2, Westinghouse Hanford Company, Richland, Washington.

Wagenblast, G. R., 1996, "Structural Assessments of Accident Loads for FSAR," (interoffice memorandum J. P. Strehlow, May 29), ICF Kaiser Hanford Company, Richland, Washington.

WHC, 1995, Interim Chapter 3.0 Hazard and Accident Analysis, WHC-SD-WM-SAR-065, Rev. 0, Westinghouse Hanford Company, Richland, Washington.

WHC, 1996, Nonreactor Facility Safety Analysis Manua7, WHC-CM-4-46, Westinghouse Hanford Company, Richland, Washington.

WHC-SD-WM-CN-051, 1996, The Effects of Load Drop, Uniform Load, and Concentrated Loads on Waste Tanks, Rev. 1, Westinghouse Hanford Company, Richland, Washington.

WHC-SD-WM-FHA-020, 1996, Tank Farms Fire Hazards Analysis, Rev. 0, Westinghouse Hanford Company, Richland, Washington.

WSRC, 1993, Consequences of a Hydrogen Deflagration in a Waste Tank (U), WSRC-TR-93-445, Westinghouse Savannah River Company, Savannah River, South Carolina.

Zabetakis, M. G., 1965, Flammability Characteristics of Combustible Gases and Vapors, Bureau of Mines Bullet in 627 . 
WHC-SD-WM-TI-753 REV 0

\section{APPENDIX A}

HEADSPACE CHARACTERIZATION

PROGRAM DATAFILE

A-1 
WHC-SD-WM-TI-753 REV 0

This page intentionally left blank.

A-2 


\section{APPENDIX A}

\section{HEADSPACE CHARACTERIZATION \\ PROGRAM DATAFILE}

This appendix contains the data to date collected by the tank headspace sampling program. Samples were taken from the tank in SUMMA canisters using heated vapor probes (to prevent condensation of vapors on the tube surface). The SUMMA canisters were then sent to Oregon State University for analyses. The results of the analyses are shown on the following spreadsheet pages.

Data for 46 tanks is data reported in the following pages. This data is from single-point-in-time sampling. The data shows that the flammable gases of interest (hydrogen, methane, ammonia) and nitrous oxide, an oxidizer, are produced in a large number of the sampled tanks. For example, 46 of the 46 sampled tanks have ammonia.

Column B provides the chemical species name, column $C$ gives the Chemical Abstract Services number, column $D$ gives the mean concentration calculated from all the data on that chemical species, column $F$ tells how many tanks the chemical species has been observed in, and columns $G$ and $H$ give the maximum and minimum measured concentrations of the chemical species. 
WHC-SD-WM-TI-753 REV 0

This page intentionally left blank. 


\begin{tabular}{|c|c|c|c|c|c|c|}
\hline & B & $\overline{\mathbf{C}}$ & $\bar{D}$ & $\mathbf{F}$ & $\mathbf{G}$ & $\mathrm{H}$ \\
\hline 1 & TANK CHEMICALS & CAS \# & $\begin{array}{c}\text { Mean } \\
\text { (mg/m3) }\end{array}$ & $\begin{array}{c}\text { Number of } \\
\text { tanks }\end{array}$ & $\begin{array}{c}\text { Maximum } \\
\text { (mg/m3) }\end{array}$ & $\begin{array}{r}\text { Minimum } \\
(\mathrm{mg} / \mathrm{m} 3)\end{array}$ \\
\hline 2 & Carbon dioxide & $124-38-9$ & $3.85 E+02$ & 37 & $2.80 \mathrm{E}+03$ & $6.61 E-01$ \\
\hline 3 & Nitrogen oxide (N2O) & $10024-97-2$ & $4.30 \mathrm{E}+02$ & 39 & $1.72 \mathrm{E}+03$ & $7.33 E+00$ \\
\hline 4 & Ammonia & $7664-41-7$ & $1.51 \mathrm{E}+02$ & 46 & $7.93 \bar{E}+02$ & 1.14E-01 \\
\hline 5 & 1-Butanol & $71-36-3$ & $7 . \overline{45 \mathrm{E}+00}$ & 45 & $1.90 \mathrm{E}+02$ & $2.03 \mathrm{E}-03$ \\
\hline 6 & Butanal & $123-72-8$ & $5.37 \mathrm{E}+00$ & 35 & $1.57 \mathrm{E}+02$ & $1.59 \mathrm{E}-03$ \\
\hline 7 & Hydrogen & $1333-74-0$ & $2.08 \mathrm{E}+01$ & 27 & $6.82 \mathrm{E}+01$ & $8.69 \mathrm{E}-01$ \\
\hline 8 & Tridecane & $629-50-5$ & $2.80 E+00$ & 42 & $3.28 \mathrm{E}+01$ & $1.63 \mathrm{E}-03$ \\
\hline 9 & 2-Propanone & $67-64-1$ & $268 \mathrm{E}+00$ & 46 & $2.57 \bar{E}+01$ & $2.66 \mathrm{E}-02$ \\
\hline 10 & Dodecane & $112-40-3$ & $1.85 \mathrm{E}+00$ & 42 & $2.41 \bar{E}+01$ & 3.97E-04 \\
\hline 11 & Carbon monoxide & $630-08-0$ & $2.70 \mathrm{E}+00$ & 14 & $1.94 \bar{E}+01$ & $1.25 \mathrm{E}-01$ \\
\hline 12 & 3-Buten-1-ol & $627-27-0$ & $9.16 \mathrm{E}+00$ & 2 & $1.82 \mathrm{E}+01$ & $7.70 E-02$ \\
\hline 13 & Methane, trichlorofluoro- & $75-69-4$ & $1.36 \mathrm{E}+00$ & 46 & $1.79 \mathrm{E}+01$ & $3.88 E-03$ \\
\hline 14 & Pentane, 2-methyl- & $107-83-5$ & $1.88 \mathrm{E}+00$ & 15 & $1.51 E+01$ & 1.25E-03 \\
\hline 15 & Tetradecane & $629-59-4$ & $1.51 \mathrm{E}+00$ & 37 & $1.47 \mathrm{E}+01$ & 1.61E-03 \\
\hline 16 & Tridecane, 7-methyl- & $26730-14-3$ & $1.90 \mathrm{E}+00$ & 11 & $1.18 \mathrm{E}+01$ & $4.61 E-03$ \\
\hline 17 & Undecane & $1120-21-4$ & $8.60 \mathrm{E}-01$ & 38 & $1.13 \mathrm{E}+01$ & $3.20 E-04$ \\
\hline 18 & Dodecane, 4,6-dimethyl- & $61141-72-8$ & $3.07 E+00$ & 7 & $9.60 \mathrm{E}+00$ & $2.68 \mathrm{E}-02$ \\
\hline 19 & Ethanol & $64-17-5$ & 1.07E+00 & 30 & $9.44 \mathrm{E}+00$ & $2.14 \mathrm{E}-03$ \\
\hline 20 & Hexane & $110-54-3$ & $6.34 \mathrm{E}-01$ & 40 & $8.66 \mathrm{E}+00$ & $3.20 \mathrm{E}-04$ \\
\hline 21 & Methane & $74-82-8$ & $2.54 \mathrm{E}+00$ & 12 & $8.59 \mathrm{E}+00$ & 4.77E-02 \\
\hline 22 & Furan, tetrahydro- & $109-99-9$ & $6.84 \mathrm{E}-01$ & 30 & $8.53 \mathrm{E}+00$ & $1.58 \mathrm{E}-03$ \\
\hline 23 & Naphthalene, decahydro-2-methyl- & $2958-76-1$ & $1.05 E+00$ & 12 & $8.31 E+00$ & $4.23 \mathrm{E}-03$ \\
\hline 24 & Butane, 2-methyl- & $78-78-4$ & $1.46 E+00$ & 7 & $7.89 \mathrm{E}+00$ & $3.52 \mathrm{E}-03$ \\
\hline 25 & Undecane, 2,6-dimethyl- & $17301-23-4$ & $122 E+00$ & 18 & $7.53 E+00$ & $2.42 \mathrm{E}-03$ \\
\hline 26 & Dodecane, $2,6,10$-trimethyl- & $3891-98-3$ & $8.61 E-01$ & 10 & $7.34 \mathrm{E}+00$ & $2.75 E-03$ \\
\hline 27 & Cyclopropane, ethyl- & $1191-96-4$ & $2.57 \mathrm{E}+00$ & 5 & $7.32 \mathrm{E}+00$ & $1.25 \mathrm{E}-03$ \\
\hline 28 & Acetonitrile & 75-05-8 & $5.10 E-01$ & 44 & $5.40 \mathrm{E}+00$ & 4.27E-03 \\
\hline 29 & Dodecane, $2,7,10$-trimethyl- & $74645-98-0$ & $1.17 E+00$ & 5 & $5.30 \bar{E}+00$ & $7.10 \mathrm{E}-03$ \\
\hline 30 & 2-Propanol & $67-63-0$ & $4.57 \mathrm{E}-01$ & 26 & $5.25 E+00$ & $4.62 \mathrm{E}-03$ \\
\hline 31 & Undecane, 4,6-dimethy|- & $17312-82-2$ & $1.91 \mathrm{E}+00$ & 3 & $5.20 E+00$ & $1.40 \mathrm{E}-02$ \\
\hline 32 & 3-Buten-2-ol & $598-32-3$ & $1.60 \mathrm{E}+00$ & 5 & $4.80 \mathrm{E}+00$ & $9.25 \mathrm{E}-02$ \\
\hline 33 & Phosphoric acid tributyl ester & $126-73-8$ & $9.85 E-01$ & 18 & $4.76 \mathrm{E}+00$ & $5.35 E-04$ \\
\hline 34 & 1-Propanol & $71-23-8$ & 4.12E-01 & 28 & $4.71 \mathrm{E}+00$ & $6.62 \mathrm{E}-03$ \\
\hline 35 & Undecane, 3-methyl- & $1002-43-3$ & $9.83 E-01$ & 11 & $4.68 E+00$ & $9.22 \mathrm{E}-03$ \\
\hline 36 & Methano! & $67-56-1$ & $1.42 \mathrm{E}+00$ & 25 & $467 E+00$ & $6.40 \mathrm{E}-02$ \\
\hline 37 & 1-Hexene & $592-41-6$ & $7.57 \mathrm{E}-01$ & 10 & $4.56 \mathrm{E}+00$ & $8.09 E-03$ \\
\hline 38 & Methane, dichloro- & $75-09-2$ & 2.63E-01 & 30 & $4.56 \mathrm{E}+00$ & $3.85 E-04$ \\
\hline 39 & Undecane, 2-methyl- & $7045-71-8$ & $1.26 E+00$ & 12 & $4.55 \mathrm{E}+00$ & $7.50 \mathrm{E}-04$ \\
\hline 40 & Undecane, 3,8-dimethyl- & $17301-30-3$ & $1.62 \mathrm{E}+00$ & 5 & 4.17E+00 & $1.90 \mathrm{E}-03$ \\
\hline 41 & 1-Propene, 2-rnethyl- & $115-11-7$ & $3.64 \mathrm{E}-01$ & 29 & 4.12E+00 & $2.95 \mathrm{E}-03$ \\
\hline 42 & Pentadecane & $629-62-9$ & $5.01 \mathrm{E}-01$ & 24 & $4.05 \mathrm{E}+00$ & 2.67E-03 \\
\hline 43 & Decane & $124-18-5$ & $2.77 E-01$ & 35 & $4.04 E+00$ & $5.67 \mathrm{E}-04$ \\
\hline 44 & Heptane & $142-82-5$ & $3.07 \mathrm{E}-01$ & 38 & $3.96 E+00$ & $2.67 \mathrm{E}-04$ \\
\hline 45 & Dodecane, $2,6,11$-trimethyl- & $31295-56-4$ & 8.77E-01 & 7 & $3.61 \mathrm{E}+00$ & $1.64 \mathrm{E}-02$ \\
\hline 46 & 2-Butanone & $78-93-3$ & $5.09 E-01$ & 34 & $3.56 \mathrm{E}+00$ & $\uparrow .65 \mathrm{E}-02$ \\
\hline 47 & Undecane, 6-methyl- & $17302-33-9$ & $9.22 E-01$ & 10 & $3.54 \mathrm{E}+00$ & 1.08E-02 \\
\hline 48 & Cyclohexane, 2-butyl-1,1,3-trimethyi- & $54676-39-0$ & $5.17 \mathrm{E}-01$ & 13 & $3.41 E+\infty 0$ & $9.97 \mathrm{E}-04$ \\
\hline 49 & 3-Undecene, 2-methyl-, $(Z)$ - & $74630-48-1$ & $1.69 E+00$ & 2 & $3.28 \mathrm{E}+00$ & $9.79 \mathrm{E}-02$ \\
\hline 50 & Undecane, 2,10-dimethyl- & $17301-27-8$ & $4.85 \mathrm{E}-01$ & 12 & $3.28 \mathrm{E}+00$ & 1.46E-03 \\
\hline 51 & Decane, 2,5 -dimethyl- & $17312-50-4$ & 1.12E+00 & 3 & $3.15 \mathrm{E}+00$ & $5.09 \mathrm{E}-02$ \\
\hline 52 & Tetradecane, 4-methyl- & $25117-24-2$ & $8.13 \mathrm{E}-01$ & 4 & $3.13 \mathrm{E}+00$ & $2.06 \mathrm{E}-03$ \\
\hline 53 & Octane, 2,3,7-trimethyl- & $62016-34-6$ & $1.86 E+00$ & 3 & $3.05 \mathrm{E}+00$ & $1.53 \mathrm{E}=02$ \\
\hline
\end{tabular}




\begin{tabular}{|c|c|c|c|c|c|c|}
\hline & $\mathbf{B}$ & C & $\bar{D}$ & $F$ & $\mathbf{G}$ & $\mathbf{H}$ \\
\hline 1 & TANK CHEMICALS & CAS \# & $\begin{array}{c}\text { Mean } \\
(\mathrm{mg} / \mathrm{m} 3)\end{array}$ & $\begin{array}{c}\text { Number of } \\
\text { tanks }\end{array}$ & $\begin{array}{c}\text { Maximum } \\
(\mathbf{m g} / \mathbf{m} 3)\end{array}$ & $\begin{array}{c}\text { Minimum } \\
\text { (mg/m3) }\end{array}$ \\
\hline 54 & Nonane, 2,6-dimethyl- & $17302-28-2$ & $7.09 \mathrm{E}-01$ & 10 & $3.02 \mathrm{E}+00$ & $2.02 \mathrm{E}-03$ \\
\hline 55 & Dodecane, 2-methyl- & $1560-97-0$ & $1.36 \mathrm{E}+00$ & 3 & $2.97 \mathrm{E}+00$ & 3.59E-02 \\
\hline 56 & Dodecane, 2-methyl-8-propyl- & $55045-07-3$ & $1.00 \mathrm{E}+00$ & 8 & $2.89 \mathrm{E}+00$ & $1.35 \mathrm{E}-02$ \\
\hline 57 & Undecane, 5-methyl- & $1632-70-8$ & $5.72 \mathrm{E}-01$ & 10 & $2.85 \mathrm{E}+00$ & $2.20 \mathrm{E}-03$ \\
\hline 58 & 1, 个'-Biphenyl & $92-52-4$ & $1.22 \mathrm{E}+00$ & 3 & $2.76 \mathrm{E}+00$ & $4.38 \mathrm{E}-03$ \\
\hline 59 & Cyclohexane, (4-methylpentyl)- & $61142-20-9$ & $1.06 \mathrm{E}+00$ & 5 & $2.69 \mathrm{E}+00$ & $2.56 \mathrm{E}-03$ \\
\hline 60 & Cyclododecane & $294-62-2$ & $6.91 \mathrm{E}-01$ & 7 & $2.66 \mathrm{E}+00$ & $1.89 \mathrm{E}-03$ \\
\hline 61 & Octane, 2-cyclohexyl- & $2883-05-8$ & $2.64 \mathrm{E}+00$ & 1 & $2.64 \mathrm{E}+00$ & $2.64 \mathrm{E}+00$ \\
\hline 62 & 1-Pentene, 2-methyl- & $763-29-1$ & $6.77 \mathrm{E}-01$ & 5 & $2.61 \mathrm{E}+00$ & $7.30 \mathrm{E}-02$ \\
\hline 63 & 1-Pentene, 4-methyi- & $691-37-2$ & $5.52 \mathrm{E}-01$ & 6 & $2.54 \mathrm{E}+00$ & $2.86 \mathrm{E}-03$ \\
\hline 64 & Dodecane, 2,5-dimethyl- & $56292-65-0$ & $4.30 \mathrm{E}-01$ & 7 & $2.54 \mathrm{E}+00$ & $9.85 \mathrm{E}-03$ \\
\hline 65 & Pentane, 3-methyl- & $96-14-0$ & $5.94 \mathrm{E}-01$ & 8 & $2.50 \mathrm{E}+00$ & $8.20 \mathrm{E}-03$ \\
\hline 66 & Oxirane, ethenyl- & $930-22-3$ & $8.46 \mathrm{E}-01$ & 3 & $2.50 \bar{E}+00$ & $1.81 \mathrm{E}-02$ \\
\hline 67 & Cyclopropane, butyl- & $930-57-4$ & $6.54 \mathrm{E}-01$ & 4 & $2.46 \mathrm{E}+00$ & $6.64 \mathrm{E}-03$ \\
\hline 68 & Nonane, 3,7-dimethyl- & $17302-32-8$ & $6.48 \mathrm{E}-01$ & 5 & $2.41 \mathrm{E}+00$ & $8.25 \mathrm{E}-02$ \\
\hline 69 & Undecane, 4,7-dimethyl- & $17301-32-5$ & $1.07 \mathrm{E}+00$ & 3 & $2.32 \mathrm{E}+00$ & $4.54 \mathrm{E}-02$ \\
\hline 70 & 6-Tridecene, 7-methyl- & $24949-42-6$ & $1.04 \mathrm{E}+00$ & 5 & $2.28 \mathrm{E}+00$ & $1.79 \mathrm{E}-02$ \\
\hline 71 & Furan, 2,5-dihydro- & $1708-29-8$ & $7.78 \mathrm{E}-01$ & 3 & $2.25 E+00$ & $2.17 \mathrm{E}-02$ \\
\hline 72 & Phosphonic acid, butyl-, dibutyl ester & $78-46-6$ & $4.14 \mathrm{E}-01$ & 14 & $2.23 \mathrm{E}+00$ & $5.58 \mathrm{E}-05$ \\
\hline 73 & Undecane, 4-methyl- & $2980-69-0$ & $5.86 \mathrm{E}-01$ & 12 & $2.23 \mathrm{E}+00$ & $1.34 \mathrm{E}-03$ \\
\hline 74 & Benzene & $71-43-2$ & $1.15 \mathrm{E}-01$ & 42 & $2.21 \mathrm{E}+00$ & $3.95 \mathrm{E}-04$ \\
\hline 75 & Decane, 6-ethyl-2-methyl- & $62108-21-8$ & $2.20 \mathrm{E}+00$ & 1 & $2.20 \mathrm{E}+00$ & $2.20 \mathrm{E}+00$ \\
\hline 76 & Tridecane 4,8-dimethyl- & $55030-62-1$ & $5.59 \mathrm{E}-01$ & 9 & $2.19 \mathrm{E}+00$ & $1.10 \mathrm{E}-02$ \\
\hline 77 & Methane, tetrachloro- & $56-23-5$ & $3.24 \mathrm{E}-01$ & 8 & $2.18 \mathrm{E}+00$ & $6.86 \mathrm{E}-04$ \\
\hline 78 & 2-Tridecanone & $593-08-8$ & $6.80 \mathrm{E}-01$ & 4 & $2.16 \mathrm{E}+00$ & $8.33 \mathrm{E}-03$ \\
\hline 79 & Tetradecanoic acid & $544-63-8$ & $2.17 \mathrm{E}-01$ & 17 & $2.13 \mathrm{E}+00$ & $7.45 \mathrm{E}-03$ \\
\hline 80 & Ethanol, 2-(tetradecyloxy)- & $2136-70-1$ & $2.11 \mathrm{E}+00$ & 1 & $2.11 \mathrm{E}+00$ & $2.11 \mathrm{E}+00$ \\
\hline 81 & Undecane, 2,4-dimethyl- & $17312-80-0$ & $3.51 \mathrm{E}-01$ & 8 & $2.09 \mathrm{E}+00$ & $1.03 \mathrm{E}-02$ \\
\hline 82 & 2-Nonanone & $821-55-6$ & 2.13E-01 & 16 & $2.07 E+00$ & $1.95 \mathrm{E}-03$ \\
\hline 83 & Decane, 2-methyl- & $6975-98-0$ & $3.99 \mathrm{E}-01$ & 11 & $2.07 \mathrm{E}+00$ & $5.11 \mathrm{E}-03$ \\
\hline 84 & Hexadecanoic acid & $57-10-3$ & 2.09E-01 & 23 & $2.07 \mathrm{E}+00$ & 1.60E-03 \\
\hline 85 & Cyclopentane, methyl- & $96-37-7$ & 6.11E-01 & 4 & $2.05 \mathrm{E}+00$ & $9.64 E-02$ \\
\hline 86 & Tridecane, 2-methyl- & $1560-96-9$ & $3.72 E-01$ & 17 & $2.05 \mathrm{E}+00$ & $2.89 \mathrm{E}-03$ \\
\hline 87 & 1-Propene & $115-07-1$ & 7.04E-01 & 20 & $2.02 \bar{E}+00$ & $5.33 \mathrm{E}-02$ \\
\hline 88 & 1-Butene & 106-98-9 & 4.59E-01 & 16 & $2.02 \mathrm{E}+00$ & $1.00 \mathrm{E}-03$ \\
\hline 89 & 4-Undecene, 4-methyl- & $61142-40-3$ & $1.42 \mathrm{E}+00$ & 2 & $1.99 \mathrm{E}+00$ & $8.64 \mathrm{E}-01$ \\
\hline 90 & Nitrogen oxide (NO) & $10102-43-9$ & 4.52E-01 & 26 & $1.96 \mathrm{E}+00$ & $1.00 \mathrm{E}-01$ \\
\hline 91 & Heptane, 2,3,5-trimethyl- & $20278-85-7$ & $1.94 E+00$ & 1 & $1.94 \mathrm{E}+00$ & $1.94 \mathrm{E}+00$ \\
\hline 92 & Heptane, 2,3,6-trimethyl- & $4032-93-3$ & $9.50 \mathrm{E}-01$ & 2 & $1.90 \mathrm{E}+00$ & 3.85E-03 \\
\hline 93 & Tridecane, 5-propyl- & $55045-11-9$ & $4.95 \mathrm{E}-01$ & 4 & $1.87 \mathrm{E}+00$ & $2.33 \mathrm{E}-03$ \\
\hline 94 & 2-Pentanone & $107-87-9$ & $2.23 \mathrm{E}-01$ & 39 & $1.81 \mathrm{E}+00$ & $2.20 \mathrm{E}-04$ \\
\hline 95 & Dodecane, 4-methyl- & $6117-97-1$ & $3.15 \overline{\mathrm{E}}-01$ & 14 & $1.81 E+00$ & $8.74 \mathrm{E}-04$ \\
\hline 96 & 1-Pentene, 3,4-dimethyl- & $7385-78-6$ & $9.12 \mathrm{E}-01$ & 2 & $1.76 \bar{E}+00$ & $6.25 \mathrm{E}-02$ \\
\hline 97 & 1.1'-Biphenyl, 2-methyl- & $643-58-3$ & 9.27E-01 & 2 & $1.76 \mathrm{E}+00$ & 9.55E-02 \\
\hline 98 & Dodecane, 3-methyl- & $17312-57-1$ & $1.05 \mathrm{E}+00$ & 5 & $1.75 \mathrm{E}+00$ & $2.60 \mathrm{E}-02$ \\
\hline 99 & Butane & $106-97-8$ & $6.09 \mathrm{E}-01$ & 24 & $1.75 \mathrm{E}+00$ & $6.23 \mathrm{E}-02$ \\
\hline 100 & Hexane, 3-methyl- & $589-34-4$ & $7.02 \mathrm{E}-01$ & 6 & $1.69 E+00$ & $8.09 \mathrm{E}-03$ \\
\hline 101 & Propane, 2-methyl- & $75-28-5$ & $4.12 \mathrm{E}-01$ & 11 & $1.68 \mathrm{E}+00$ & $1.65 \mathrm{E}-02$ \\
\hline 102 & 5-Undecanone, 2-methyl- & $50639-02-6$ & $3.16 \mathrm{E}-01$ & 10 & $1.67 \mathrm{E}+00$ & $1.70 \mathrm{E}-03$ \\
\hline 103 & Furan & $110-00-9$ & $5.89 \mathrm{E}-01$ & 3 & $1.66 \mathrm{E}+00$ & $5.17 \mathrm{E}-02$ \\
\hline 104 & Octane & $111-65-9$ & $1.52 \mathrm{E}-01$ & 41 & $1.66 \mathrm{E}+00$ & $1.64 E-04$ \\
\hline 105 & Propane & $74-98-6$ & $4.36 \mathrm{E}-01$ & 26 & $1.63 \mathrm{E}+00$ & $6.23 \mathrm{E}-02$ \\
\hline
\end{tabular}


WHC-SD-WM-TI-753 REV 0

\begin{tabular}{|c|c|c|c|c|c|c|}
\hline & B & c & D & $\mathbf{F}$ & 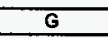 & H \\
\hline 1 & TANK CHEMICALS & CAS \# & $\begin{array}{c}\text { Mean } \\
(\mathrm{mg} / \mathrm{m} 3)\end{array}$ & $\begin{array}{c}\text { Number of } \\
\text { tanks }\end{array}$ & $\underset{(\mathrm{mg} / \mathrm{m} 3)}{\text { Maximum }}$ & $\begin{array}{r}\text { Minimum } \\
(\mathrm{mg} / \mathrm{m} 3)\end{array}$ \\
\hline 106 & Nonanal & $124-19-6$ & $9.34 \mathrm{E}-02$ & 21 & $1.62 \mathrm{E}+00$ & $1.60 \mathrm{E}-03$ \\
\hline 107 & Cyclopropane, 1-pentyl-2-propyl- & $41977-33-7$ & $1.61 \mathrm{E}+00$ & 1 & $1.61 \mathrm{E}+00$ & $1.61 \mathrm{E}+00$ \\
\hline 108 & Hexadecane & $544-76-3$ & $2.34 E-01$ & 24 & $1.60 \mathrm{E}+00$ & $1.34 \mathrm{E}-03$ \\
\hline 109 & 1-Hexene, 5-methyl- & $3524-73-0$ & 5.45E-01 & 3 & $1.58 \mathrm{E}+00$ & $2.81 E-\overline{02}$ \\
\hline 110 & Pentane & $109-66-0$ & 5.36E-01 & 17 & $1.57 \mathrm{E}+00$ & $6.50 \mathrm{E}-02$ \\
\hline 111 & Benzene, dimethyl- & $1330-20-7$ & $1.57 \mathrm{E}+00$ & 1 & $1.57 \mathrm{E}+00$ & $1.57 \mathrm{E}+00$ \\
\hline 112 & Benzenesulfonamide, $\mathrm{N}$-butyl- & $3622-84-2$ & 1.35E-01 & 37 & $1.54 \mathrm{E}+00$ & $3.51 \mathrm{E}-03$ \\
\hline 113 & 1-Undecene, 4-methyl- & $74630-39-0$ & $9.20 \mathrm{E}-01$ & 3 & $1.54 \mathrm{E}+00$ & $3.50 \mathrm{E}-03$ \\
\hline 114 & 1-Butene, 3-methyl- & $563-45-1$ & 4.54E-01 & 4 & $1.53 \mathrm{E}+00$ & $5.33 \mathrm{E}-02$ \\
\hline 115 & 5-Undecene & $4941-53-1$ & $3.47 \mathrm{E}-01$ & 9 & $1.50 \mathrm{E}+00$ & $1.05 \mathrm{E}-03$ \\
\hline 116 & Tridecane, 4-methyl- & $26730-12-1$ & $3.60 \mathrm{E}-01$ & 12 & $1.50 \mathrm{E}+00$ & $2.15 \mathrm{E}-03$ \\
\hline 117 & 1,3-Pentadiene, 2-methyl- & $1118-58-7$ & $5 . \overline{48 E-01}$ & 4 & $1.47 \mathrm{E}+00$ & $4.63 \mathrm{E}-02$ \\
\hline 118 & Cyclohexane, butyl- & $1678-93-9$ & 4.44E-01 & 4 & $1.45 E+00$ & $2.72 \mathrm{E}-02$ \\
\hline 119 & 1-Propene, 2-fluoro- & $1184-60-7$ & $8.41 \mathrm{E}-01$ & 3 & $1.42 E+00$ & $6.88 \mathrm{E}-02$ \\
\hline 120 & Undecane, 5,5-dimethyl- & $17312-73-1$ & $1.42 \mathrm{E}+00$ & 1 & $1.42 E+00$ & $1.42 \bar{E}+00$ \\
\hline 121 & Naphthalene, decahydro-1,2-dimethyl- & $3604-14-6$ & $1.41 \mathrm{E}+00$ & 1 & $1.41 \mathrm{E}+00$ & $1.41 \mathrm{E}+00$ \\
\hline 122 & 3-Dodecanone & $1534-27-6$ & $2.63 \mathrm{E}-01$ & 11 & $1.38 \mathrm{E}+00$ & $1.20 \mathrm{E}-02$ \\
\hline 123 & Cyclobutane, methyl- & $598-61-8$ & $1.38 \mathrm{E}+00$ & 1 & $1.38 \mathrm{E}+00$ & $1.38 \mathrm{E}+00$ \\
\hline 124 & Benzene, pentyl- & $538-68-1$ & $1.38 \mathrm{E}+00$ & 1 & $1.38 \mathrm{E}+00$ & $1.38 \mathrm{E}+00$ \\
\hline 125 & 2-Heptanone, 6-methyl- & $928-68-7$ & $2.84 \mathrm{E}-01$ & 21 & $1.37 E+00$ & 2.40E-03 \\
\hline 126 & Naphthalene, decahydro-2,6-dimethyl- & $1618-22-0$ & $5.05 \mathrm{E}-01$ & 5 & $1.37 \mathrm{E}+00$ & $3.13 \mathrm{E}-02$ \\
\hline 127 & 1-Octadecanol & $112-92-5$ & $5.03 \mathrm{E}-01$ & 3 & $1.36 \mathrm{E}+00$ & $5.31 \mathrm{E}-02$ \\
\hline 128 & Decane, 2,6,7-trimethyl- & $62108-25-2$ & 4.13E-01 & 4 & $1.35 \mathrm{E}+00$ & $1.57 \mathrm{E}-02$ \\
\hline 129 & Undecane, 5-ethyl- & $17453-94-0$ & 4.24E-01 & 5 & $1.35 E+00$ & $1.23 \mathrm{E}-02$ \\
\hline 130 & Hexane, 2 -methyl- & $591-76-4$ & $3.99 \mathrm{E}-01$ & 6 & $1.34 \mathrm{E}+00$ & $4.43 \mathrm{E}-02$ \\
\hline 131 & 2-Pentene, (Z)- & $627-20-3$ & $3.70 \mathrm{E}-01$ & 4 & $1.32 E+00$ & $2.15 \mathrm{E}-02$ \\
\hline 132 & 3-Heptanone & $106-35-4$ & $2.02 \mathrm{E}-01$ & 29 & $1.28 \mathrm{E}+00$ & $5.60 \mathrm{E}-04$ \\
\hline 133 & Cyclopropane, octyl- & $1472-09-9$ & $6.24 \mathrm{E}-01$ & 2 & $1.24 \mathrm{E}+00$ & $3.95 \mathrm{E}-03$ \\
\hline 134 & $\begin{array}{l}2 \mathrm{H}-\text { Pyran-2-one, tetrahydro-5,6-dimethyl-, } \\
\text { trans- }\end{array}$ & $24405-16-1$ & 3.19E-01 & 4 & $1.21 \mathrm{E}+00$ & $1.11 \mathrm{E}-02$ \\
\hline 135 & Cyclotetrasiloxane, octamethyl- & $556-67-2$ & $9.49 \mathrm{E}-02$ & 33 & $1.15 \mathrm{E}+00$ & $1.95 \mathrm{E}-03$ \\
\hline 136 & 1-Heptene & $592-76-7$ & $2.71 \mathrm{E}-01$ & 7 & $1.13 \mathrm{E}+00$ & $2.02 \mathrm{E}-02$ \\
\hline 137 & Cyclohexane, methyl- & $108-87-2$ & 3.03E-01 & 7 & $1.13 E+00$ & $4.10 \mathrm{E}-02$ \\
\hline 138 & Heptane, 3-ethyl-5-methyl- & $52896-90-9$ & $5.67 \mathrm{E}-01$ & 2 & $1.13 \bar{E}+00$ & $4.88 \mathrm{E}-03$ \\
\hline 139 & Naphthalene, decahydro-, trans- & $493-02-7$ & $2.74 \mathrm{E}-01$ & 11 & $1.10 \mathrm{E}+00$ & $1.43 \mathrm{E}-03$ \\
\hline 140 & 5-Undecene, $(E)-$ & $764-97-6$ & $5.94 \mathrm{E}-01$ & 2 & $1.10 \mathrm{E}+00$ & $9.30 \mathrm{E}-02$ \\
\hline 141 & Decane, 3-methyl- & $13151-34-3$ & $3.49 \mathrm{E}-01$ & 9 & $1.09 \mathrm{E}+00$ & $1.14 \mathrm{E}-02$ \\
\hline 142 & Nonane & $111-84-2$ & $9.47 E-02$ & 42 & $1.07 \mathrm{E}+00$ & $2.29 \mathrm{E}-04$ \\
\hline 143 & 1-Hexanol, 2-ethyl- & $104-76-7$ & $7.28 \mathrm{E}-02$ & 28 & $1.05 E+00$ & $1.94 \mathrm{E}-03$ \\
\hline 144 & Hexane, 2,3-dimethyl- & $584-94-1$ & $3.67 \mathrm{E}-01$ & 3 & $1.05 \mathrm{E}+00$ & $1.43 \mathrm{E}-02$ \\
\hline 145 & Tridecane, 3-ethyl- & $13286-73-2$ & $4.84 \mathrm{E}-01$ & 3 & $1.05 \mathrm{E}+00$ & $1.35 \mathrm{E}-01$ \\
\hline 146 & Benzene, 1,4-dimethy:- & $106-42-3$ & $1.11 \mathrm{E}-01$ & 13 & $1.05 \mathrm{E}+00$ & $6.85 \mathrm{E}-04$ \\
\hline 147 & Cyclohexane, 1-propenyl- & $5364-83-0$ & $1.03 E+00$ & 1 & $1.03 \mathrm{E}+00$ & $1.03 \mathrm{E}+00$ \\
\hline 148 & Cyclohexane, 1-(cyclohexylmethyl)-2-ethyl-, cis & $54934-93-9$ & $3.49 \mathrm{E}-01$ & 3 & $1.01 \mathrm{E}+00$ & 5.57E-03 \\
\hline 149 & Decane, $2,3,7$-trimethyl- & $62238-13-5$ & $\overline{5} . \overline{32 E-01}$ & 2 & $1.01 \mathrm{E}+00$ & $5.73 \mathrm{E}-02$ \\
\hline 150 & Cyclotrisiloxane, hexamethyl- & $541-05-9$ & $9.95 E-02$ & 35 & $9.93 \mathrm{E}-01$ & $2.27 \mathrm{E}-03$ \\
\hline 151 & Tridecane, 6-methyl- & $13287-21-3$ & $1.22 \mathrm{E}-01$ & 11 & $9.74 \mathrm{E}-01$ & $1.95 \mathrm{E}-03$ \\
\hline 152 & Decane, 1,1'-oxybis- & $2456-28-2$ & $3 . \overline{27}-01$ & 3 & $9.71 \mathrm{E}-01$ & $1.70 \mathrm{E}-03$ \\
\hline 153 & Undecane, 2,3-dimethyl- & $17312-77-5$ & $6.39 \mathrm{E}-01$ & 3 & $9.67 \mathrm{E}-01$ & $170 \mathrm{E}-01$ \\
\hline 154 & Butanenitrile & $109-74-0$ & $8.84 \mathrm{E}-02$ & 40 & $9.62 \mathrm{E}-01$ & $8.15 \mathrm{E}-04$ \\
\hline 155 & Octanal & 124-13-0 & $7.98 \mathrm{E}-02$ & 19 & $9.62 \mathrm{E}-01$ & $2.12 \mathrm{E}-03$ \\
\hline
\end{tabular}




\begin{tabular}{|c|c|c|c|c|c|c|}
\hline & B & C & D & $\bar{F}$ & $\mathbf{G}$ & $\mathrm{H}$ \\
\hline 1 & TANK CHEMICALS & CAS \# & $\begin{array}{c}\text { Mean } \\
(\mathrm{mg} / \mathrm{m} 3)\end{array}$ & $\begin{array}{l}\text { Number of } \\
\text { tanks }\end{array}$ & $\begin{array}{l}\text { Maximum } \\
(\mathrm{mg} / \mathrm{m} 3)\end{array}$ & $\begin{array}{l}\text { Minimum } \\
(\mathrm{mg} / \mathrm{m} 3)\end{array}$ \\
\hline 156 & 3-Tridecanone & $1534-26-5$ & $1.81 \mathrm{E}-01$ & 14 & $9.58 \mathrm{E}-01$ & $1.06 \mathrm{E}-02$ \\
\hline 157 & Tridecane, 3-methyl- & $6418-41-3$ & $3.04 \mathrm{E}-01$ & 7 & $9.52 \mathrm{E}-01$ & $8.66 \mathrm{E}-03$ \\
\hline 158 & 1-Octene & $111-66-0$ & $2.07 \mathrm{E}-01$ & 6 & $9.21 \mathrm{E}-01$ & $4.00 \mathrm{E}-03$ \\
\hline 159 & Pentanal & $110-62-3$ & $2.52 \mathrm{E}-01$ & 9 & $9.16 \mathrm{E}-01$ & 1.10E-02 \\
\hline 160 & Octadecane, 2-methyl- & $1560-88-9$ & $4.57 \mathrm{E}-01$ & 2 & $9.11 \mathrm{E}-01$ & $3.01 \mathrm{E}-03$ \\
\hline 161 & Benzene, (1-methylpentyl)- & $6031-02-3$ & $8.93 \mathrm{E}-01$ & 1 & $8.93 E-01$ & $8.93 \mathrm{E}-01$ \\
\hline 162 & 1-Hexadecene & 629-73-2 & $2.02 \mathrm{E}-01$ & 5 & 8.93E-01 & $1.29 \mathrm{E}-02$ \\
\hline 163 & Decane, 5-methyl- & 13151-35-4 & $3.94 \mathrm{E}-01$ & 5 & $8.88 E-01$ & $1.09 \mathrm{E}-02$ \\
\hline 164 & Undecane, 6,6-dimethyl- & $17312-76-4$ & $8.85 \mathrm{E}-01$ & 1 & $8.85 \mathrm{E}-01$ & $8.85 \mathrm{E}-01$ \\
\hline 165 & 6-Tridecanone & $22026-12-6$ & 1.69E-01 & 8 & 8.75E-01 & $4.82 \mathrm{E}-03$ \\
\hline 166 & Benzene, 1-methyl-2-propyl- & $1074-17-5$ & $8.68 \mathrm{E}-01$ & 1 & $8.68 \mathrm{E}-01$ & $8.68 \mathrm{E}-01$ \\
\hline 167 & Nitrous acid, methyl ester & $624-91-9$ & $4.02 \mathrm{E}-01$ & 6 & $8.67 \mathrm{E}-01$ & $1.46 \mathrm{E}-02$ \\
\hline 168 & 2-Heptanone & $110-43-0$ & $9.93 E-02$ & 42 & $8.63 \mathrm{E}-01$ & $3.60 \mathrm{E}-04$ \\
\hline 169 & Undecane, 2,8-dimethyl- & $17301-25-6$ & $7.14 \mathrm{E}-01$ & 2 & 8.47E-01 & $5.80 \mathrm{E}-01$ \\
\hline 170 & Benzene, methyl- & $108-88-3$ & $1.23 \mathrm{E}-01$ & 43 & $8.44 \mathrm{E}-01$ & $3.17 \mathrm{E}-04$ \\
\hline 171 & Cyclohexane, 1,1,3-trimethyl- & $3073-66-3$ & $1.87 \mathrm{E}-01$ & 9 & $8.15 \mathrm{E}-01$ & $4.10 \mathrm{E}-03$ \\
\hline 172 & 3-Undecanone & $2216-87-7$ & $2.35 \mathrm{E}-01$ & 5 & $7.99 \mathrm{E}-01$ & $1.22 \mathrm{E}-02$ \\
\hline 173 & Dodecane, 6-methyl- & $6044-71-9$ & $2.04 \mathrm{E}-01$ & 4 & 7.95E-01 & 1.19E-03 \\
\hline 174 & 4-Nonanone & $4485-09-0$ & $3.97 \mathrm{E}-01$ & 2 & $7.89 \mathrm{E}-01$ & 4.40E-03 \\
\hline 175 & Decane, 4-methyl- & $2847-72-5$ & $1.92 \mathrm{E}-01$ & 13 & $7.82 \mathrm{E}-01$ & $7.00 \mathrm{E}-04$ \\
\hline 176 & Benzene, 1,2-dimethyl- & $95-47-6$ & $1.20 \mathrm{E}-01$ & 12 & $7.82 \mathrm{E}-01$ & $4.74 E-04$ \\
\hline 177 & 1-Heptene, 3-methyl- & $4810-09-7$ & $7.81 \mathrm{E}-01$ & 1 & $7.81 \mathrm{E}-01$ & $7.81 \mathrm{E}-01$ \\
\hline 178 & Ethene, tetrachloro- & $127-18-4$ & $6.70 \mathrm{E}-02$ & 23 & $7.72 \mathrm{E}-01$ & $7.40 \mathrm{E}-04$ \\
\hline 179 & Cyclopentane, 1,3-dimethyl-2-(1-methylethyl)- & $32281-85-9$ & $2.43 \mathrm{E}-01$ & 5 & $7.61 \mathrm{E}-01$ & $7.40 \mathrm{E}-03$ \\
\hline 180 & $\begin{array}{l}\text { Cyclohexane, 1,1,3-trimethyl-2-(3- } \\
\text { methylpentyl)- }\end{array}$ & $54965-05-8$ & 2.13E-01 & 4 & 7.44E-01 & $8.00 \mathrm{E}-03$ \\
\hline 181 & 5-Undecene, 7-methyl-, (E)- & $74630-66-3$ & $7.43 \mathrm{E}-01$ & 1 & $7.43 E-01$ & 7.43E-01 \\
\hline 182 & 1-Heptene, 6-methyl- & $5026-76-6$ & $4.52 \mathrm{E}-01$ & 2 & 7.40E-01 & 1.63E-01 \\
\hline 183 & 6-Dodecanone & $6064-27-3$ & $1.38 \mathrm{E}-01$ & 6 & $7.38 \mathrm{E}-01$ & $1.60 \mathrm{E}-03$ \\
\hline 184 & 2-Hexanone & $591-78-6$ & $8.94 \mathrm{E}-02$ & 42 & $7.30 E-01$ & $2.23 E-04$ \\
\hline 185 & Hexanal, 3-methyl- & $19269-28-4$ & 4.19E-01 & 3 & $727 \mathrm{E}-01$ & $1.81 \mathrm{E}-03$ \\
\hline 186 & $\begin{array}{l}2(3 \mathrm{H}) \text {-Benzofuranone, 3a,4,5,6-tetrahydro- } \\
3 \mathrm{a}, 6,6 \text {-trimethyl- }\end{array}$ & $16778-26-0$ & $1.79 \mathrm{E}-01$ & 6 & 7.25E-01 & $5.03 E-03$ \\
\hline 187 & Undecane, 3,7-dimethyl- & $17301-29-0$ & $2.17 \mathrm{E}-01$ & 5 & $7.20 \mathrm{E}-01$ & $2.20 \mathrm{E}-02$ \\
\hline 188 & Benzene, (1-methylhexyl)- & $2132-84-5$ & $7.19 E-01$ & 1 & $7.19 E-01$ & $7.19 \mathrm{E}-01$ \\
\hline 189 & 2-Pentene $(E)$ - & $646-04-8$ & $7.14 \mathrm{E}-01$ & 1 & $7.14 \mathrm{E}-01$ & 7.14E-01 \\
\hline 190 & $2(3 \mathrm{H})$-Furanone, dihydro-3,5-dimethyl- & $5145-01-7$ & $6.12 \mathrm{E}-01$ & 2 & $7.11 \mathrm{E}-01$ & $5.14 \mathrm{E}-01$ \\
\hline 191 & Decane, 2,3,6-trimethyl- & $62238-12-4$ & $1.99 E-01$ & 5 & 7.09E-01 & $7.33 \mathrm{E}-03$ \\
\hline 192 & 3-Tetradecene, $(E)$ - & $41446-68-8$ & $2.38 \mathrm{E}-01$ & 3 & 7.08E-01 & $9.23 \mathrm{E}-04$ \\
\hline 193 & Nonane, 4-methyl- & $17301-94-9$ & $1.82 E-01$ & 9 & $7.05 \mathrm{E}-01$ & $1.24 E-02$ \\
\hline 194 & Acetic acid & 64-19-7 & $1.47 \mathrm{E}-01$ & 14 & $6.98 \mathrm{E}-01$ & $1.84 \mathrm{E}-03$ \\
\hline 195 & Nitric acid, propyl ester & $627-13-4$ & $1.03 \mathrm{E}-01$ & 12 & $6.88 \mathrm{E}-01$ & $1.31 E-03$ \\
\hline 196 & 1-Pentene & 109-67-1 & $2.62 \mathrm{E}-01$ & 12 & $6.85 E-01$ & $1.50 \mathrm{E}-02$ \\
\hline 197 & Cyclohexene, 1-ethyl- & 1453-24-3 & $6.82 \mathrm{E}-01$ & 1 & $6.82 \mathrm{E}-01$ & $6.82 \mathrm{E}-01$ \\
\hline 198 & 2-Pentanone, 4-methyl- & $108-10-1$ & $1.54 \mathrm{E}-01$ & 12 & $6.82 \mathrm{E}-01$ & $8.81 \mathrm{E}-03$ \\
\hline 199 & 2-Butanol & $78-92-2$ & $1.49 \mathrm{E}-01$ & 7 & $6.81 \mathrm{E}-01$ & $3.79 \mathrm{E}-03$ \\
\hline 200 & 5-Eicosene, $(E)-$ & $74685-30-6$ & $6.79 \mathrm{E}-01$ & 1 & $6.79 \mathrm{E}-01$ & $6.79 \mathrm{E}-01$ \\
\hline 201 & Acetaldehyde & $75-07-0$ & $1.63 \mathrm{E}-01$ & 16 & $6.76 \mathrm{E}-01$ & $2.30 \mathrm{E}-02$ \\
\hline 202 & Cyclohexane, hexyl- & $4292-75-5$ & $9.44 \mathrm{E}-02$ & 11 & $6.67 \mathrm{E}-01$ & $1.90 \mathrm{E}-03$ \\
\hline 203 & 2-Octanone & $111-13-7$ & $4.87 \mathrm{E}-02$ & 40 & $6.62 \mathrm{E}-01$ & $2.58 \mathrm{E}-04$ \\
\hline 204 & 2-Decene, 4-methyl-, (Z)- & $74630-30-1$ & $3.95 \mathrm{E}-01$ & 2 & $6.62 E-01$ & $1.28 \mathrm{E}-01$ \\
\hline 205 & Cyclopropane, propyl- & $2415-72-7$ & $3.20 \mathrm{E}-01$ & 6 & $6.53 \mathrm{E}-01$ & $3 . \overline{42 \mathrm{E}-02}$ \\
\hline
\end{tabular}




\begin{tabular}{|c|c|c|c|c|c|c|}
\hline & B & $\mathbf{C}$ & D & $\bar{F}$ & $\mathbf{G}$ & $\mathrm{H}$ \\
\hline 1 & TANK CHEMICALS & CAS \# & $\begin{array}{c}\text { Mean } \\
(\mathrm{mg} / \mathrm{m} 3)\end{array}$ & $\begin{array}{c}\text { Number of } \\
\text { tanks }\end{array}$ & $\begin{array}{c}\text { Maximum } \\
(\mathrm{mg} / \mathrm{m} 3)\end{array}$ & $\begin{array}{c}\text { Minimum } \\
(\mathrm{mg} / \mathrm{m} 3)\end{array}$ \\
\hline 206 & 2-Butene & $107-01-7$ & $4.35 \mathrm{E}-01$ & 3 & $6.52 \mathrm{E}-01$ & $1.25 \mathrm{E}-01$ \\
\hline 207 & Cyclopentane & $287-92-3$ & $2.14 \mathrm{E}-01$ & 5 & $6.51 \mathrm{E}-01$ & $3.21 \mathrm{E}-02$ \\
\hline 208 & Benzene, ethenyl- & $100-42-5$ & 1.49E-01 & 5 & $6.46 \mathrm{E}-01$ & $5.25 \mathrm{E}-03$ \\
\hline 209 & Cyclohexane, (3-methylpentyl)- & $61142-38-9$ & $6.46 \mathrm{E}-01$ & 1 & $6.46 \mathrm{E}-01$ & $6.46 \mathrm{E}-01$ \\
\hline 210 & Benzene, 1-propenyl- & $637-50-3$ & $3.59 \mathrm{E}-01$ & 2 & $6.32 \mathrm{E}-01$ & 8.67E-02 \\
\hline 211 & 5-Tetradecene, (E)- & $41446-66-6$ & $3.34 \mathrm{E}-01$ & 2 & $6.31 \mathrm{E}-01$ & $3.67 E-02$ \\
\hline 212 & Heptane, 2-methyl- & $592-27-8$ & $3.83 \mathrm{E}-01$ & 4 & $6.10 \mathrm{E}-01$ & $7.67 \mathrm{E}-02$ \\
\hline 213 & 4-Dodecene, (E)- & $7206-15-7$ & $3.07 \mathrm{E}-01$ & 2 & $6.06 \mathrm{E}-01$ & $6.80 \mathrm{E}-03$ \\
\hline 214 & 4,5-Nonadiene & $821-74-9$ & $6.04 \mathrm{E}-01$ & 1 & $6.04 \mathrm{E}-01$ & $6.04 \mathrm{E}-01$ \\
\hline 215 & 1-Propyne & $74-99-7$ & 4.09E-01 & 3 & $6.04 \mathrm{E}-01$ & $6.49 \mathrm{E}-02$ \\
\hline 216 & Undecane, 2,7-dimethyl- & $17301-24-5$ & $3.08 \mathrm{E}-01$ & 2 & $6.02 \mathrm{E}-01$ & $1.36 \mathrm{E}-02$ \\
\hline$\overline{217}$ & Heptanal & $111-71-7$ & $6.06 \mathrm{E}-02$ & 20 & $5.99 \mathrm{E}-01$ & 1.14E-03 \\
\hline 218 & Benzene, (2-methyl-2-propenyl)- & $3290-53-7$ & $5.92 \mathrm{E}-01$ & 1 & $5.92 \mathrm{E}-01$ & $5.92 \mathrm{E}-01$ \\
\hline 219 & Cyclohexane, 1-methyl-3-propyl- & $4291-80-9$ & $2.53 \mathrm{E}-01$ & 3 & $5.92 \mathrm{E}-01$ & $5.75 \mathrm{E}-03$ \\
\hline 220 & Methanamine, $\mathrm{N}$-(1-methylbutylidene)- & $22431-09-0$ & $1.40 \mathrm{E}-01$ & 5 & $5.83 \mathrm{E}-01$ & $1.82 \mathrm{E}-02$ \\
\hline 221 & Cyclohexane, 1-ethyl-4-methyl-, cis- & $4926-78-7$ & 1.44E-01 & 6 & $5.74 \mathrm{E}-01$ & 4.25E-03 \\
\hline 222 & Cyclohexane, pentyl- & $4292-92-6$ & $1.51 \mathrm{E}-01$ & 16 & $5.73 \mathrm{E}-01$ & $1.56 \mathrm{E}-03$ \\
\hline 223 & Cyclopentane, 1-methyl-3-(2-methylpropyl)- & $29053-04-1$ & $1.56 \mathrm{E}-01$ & 5 & $5.71 \mathrm{E}-01$ & $9.85 \mathrm{E}-03$ \\
\hline 224 & Cyclohexane, 1,5 -diethyl-2,3-dimethyl- & $74663-66-4$ & $5.46 \mathrm{E}-01$ & 2 & $5.71 \mathrm{E}-01$ & $5.22 \mathrm{E}-01$ \\
\hline 225 & Dodecane, 5-methyl- & $17453-93-9$ & $3.87 \mathrm{E}-01$ & 2 & $5.68 \mathrm{E}-01$ & $2.07 \mathrm{E}-01$ \\
\hline 226 & 4-Nonene, 2,3,3-trimethyl-, (Z)- & $63830-68-2$ & $2.94 \mathrm{E}-01$ & 2 & $5.68 \mathrm{E}-01$ & $1.95 \mathrm{E}-02$ \\
\hline 227 & Cyclobutane, ethyl- & $4806-61-5$ & $5.68 \mathrm{E}-01$ & 1 & $5.68 \mathrm{E}-01$ & $5.68 \mathrm{E}-01$ \\
\hline 228 & Heptane, 3-methyl- & $589-81-1$ & $1.15 \mathrm{E}-01$ & 8 & $5.62 \mathrm{E}-01$ & 1.10E-02 \\
\hline 229 & Heptane, 2,6-dimethyl- & $1072-05-5$ & $1.90 \mathrm{E}-01$ & 6 & $5.54 \mathrm{E}-01$ & $2.24 \mathrm{E}-02$ \\
\hline 230 & Benzene, ethyl- & $100-41-4$ & $5.99 \mathrm{E}-02$ & 19 & $5.39 \mathrm{E}-01$ & 4.74E- 04 \\
\hline 231 & Cyclohexane & $110-82-7$ & $1.78 \mathrm{E}-01$ & 9 & $5.30 \mathrm{E}-01$ & $4.17 \mathrm{E}-02$ \\
\hline 232 & Cyclohexane, 1 -methyl-2-pentyl- & $54411-01-7$ & $1.93 \mathrm{E}-01$ & 3 & $5.28 \mathrm{E}-01$ & $1.68 \mathrm{E}-02$ \\
\hline 233 & 9-Hexadecenoic acid & $2091-29-4$ & 1.39E-01 & 12 & $5.20 E-01$ & $1.00 \mathrm{E}-02$ \\
\hline 234 & 3-Decyne & $2384-85-2$ & $2.59 \mathrm{E}-01$ & 2 & $5.14 \mathrm{E}-01$ & $3.67 \mathrm{E}-03$ \\
\hline 235 & Hexanal & $66-25-1$ & $8.59 \mathrm{E}-02$ & 21 & $5.08 \mathrm{E}-01$ & $1.48 \mathrm{E}-03$ \\
\hline 236 & Cyclopropane, 1,1-dimethyl- & $1630-94-0$ & $1.71 \mathrm{E}-01$ & 4 & $5.08 \mathrm{E}-01$ & $2.64 \mathrm{E}-02$ \\
\hline 237 & 1,2-Propanediol & $57-55-6$ & $1.44 \mathrm{E}-01$ & 9 & $5.06 \mathrm{E}-01$ & $1.14 \mathrm{E}-02$ \\
\hline 238 & 3-Hexadecyne & $61886-62-2$ & $5.03 \mathrm{E}-01$ & 1 & $5.03 E-01$ & $5.03 E-01$ \\
\hline 239 & Heptadecane, 7-methyl- & $20959-33-5$ & $5.02 \mathrm{E}-01$ & 1 & $5.02 \mathrm{E}-01$ & $5.02 \mathrm{E}-01$ \\
\hline 240 & Undecane, 4,8-dimethyl- & $17301-33-6$ & 1.17E-01 & 5 & $4.97 \mathrm{E}-01$ & $6.25 \mathrm{E}-03$ \\
\hline 241 & 2-Heptene & $592-77-8$ & $1.24 \mathrm{E}-01$ & 5 & 4.93E-01 & $4.40 \mathrm{E}-03$ \\
\hline 242 & Cyclopentane, 1,2-dimethyl-, trans- & $822-50-4$ & $2.54 \mathrm{E}-01$ & 2 & $4.87 \mathrm{E}-01$ & $2.13 \mathrm{E}-02$ \\
\hline 243 & Tridecane, 5-methyl- & $25117-31-1$ & $1.69 \mathrm{E}-01$ & 3 & $4.82 \mathrm{E}-01$ & $6.93 \mathrm{E}-04$ \\
\hline 244 & 3,4-Nonadiene & $37050-03-6$ & $4.81 \mathrm{E}-01$ & 1 & $4.81 \mathrm{E}-01$ & $4.81 \mathrm{E}-01$ \\
\hline 245 & Cyclohexane, (1-methylpropyl)- & $7058-01-7$ & $2.19 \mathrm{E}-01$ & 3 & $4.76 \mathrm{E}-01$ & $1.35 \mathrm{E}-02$ \\
\hline 246 & Acetic acid ethyl ester & $141-78-6$ & $3.76 \mathrm{E}-01$ & 2 & $4.73 \mathrm{E}-01$ & $2.79 \mathrm{E}-01$ \\
\hline 247 & Benzene, (1-methylethyl)- & $98-82-8$ & 2.53E-01 & 2 & 4.71E-01 & $3.46 \mathrm{E}-02$ \\
\hline 248 & Cyclopentanone, 2-methyl-4-(2-methylpropyl)- & $69770-96-3$ & $4.70 \mathrm{E}-01$ & 1 & 4.70E-01 & $4.70 \mathrm{E}-01$ \\
\hline 249 & Cyclopentane, 1-pentyl-2-propyl- & $62199-51-3$ & $2.01 \mathrm{E}-01$ & 4 & $4.69 \mathrm{E}-01$ & $2.50 \mathrm{E}-03$ \\
\hline 250 & 9H-Fluorene & $86-73-7$ & $4.64 \mathrm{E}-01$ & 1 & $4.64 \mathrm{E}-01$ & $4.64 \mathrm{E}-01$ \\
\hline 251 & Cyclohexane, ethyl- & $1678-91-7$ & $1.55 \mathrm{E}-01$ & 5 & $4.61 \mathrm{E}-01$ & 1.14E-02 \\
\hline$\overline{252}$ & Cyclohexane, 1, 1,3,5-tetramethyl-, cis- & $50876-32-9$ & $1.62 \mathrm{E}-01$ & 3 & $4.59 \mathrm{E}-01$ & 2.30E-03 \\
\hline 253 & Cyclobutane & $287-23-0$ & $2.91 \mathrm{E}-01$ & 3 & $4.51 \mathrm{E}-01$ & $1.65 \mathrm{E}-02$ \\
\hline 254 & Heptane, 4-(1-methylethyl)- & $52896-87-4$ & $2.63 \mathrm{E}-01$ & 2 & 4.43E-01 & $8.32 \mathrm{E}-02$ \\
\hline 255 & Propane, 2,2 '-oxybis- & $108-20-3$ & $4.40 \mathrm{E}-01$ & 1 & 4.40E-01 & 4.40E-01 \\
\hline 256 & Hexadecanoic acid, 1-methylethyl ester & $142-91-6$ & $4.90 \mathrm{E}-02$ & 27 & $4.36 \mathrm{E}-01$ & $1.00 \mathrm{E}-03$ \\
\hline 257 & Hexadecane, 3-methyl- & $6418-43-5$ & $2.18 \mathrm{E}-01$ & 2 & 4.35E-01 & $2.20 \mathrm{E}-03$ \\
\hline
\end{tabular}




\begin{tabular}{|c|c|c|c|c|c|c|}
\hline & B & $\mathbf{C}$ & $\mathbf{D}$ & $\mathbf{F}$ & $\mathbf{G}$ & $\mathbf{H}$ \\
\hline 1 & TANK CHEMICALS & CAS \# & $\begin{array}{c}\text { Mean } \\
(\mathrm{mg} / \mathrm{m} 3)\end{array}$ & $\begin{array}{c}\text { Number of } \\
\text { tanks }\end{array}$ & $\begin{array}{c}\text { Maximum } \\
(\mathrm{mg} / \mathrm{m} 3)\end{array}$ & $\begin{array}{c}\text { Minimum } \\
\text { (mg/m3) }\end{array}$ \\
\hline 258 & 1-Dodecene & $112-41-4$ & 2.23E-01 & 4 & $4.32 \mathrm{E}-01$ & $4.90 E-03$ \\
\hline 259 & Pyridine & $110-86-1$ & $1.30 \mathrm{E}-01$ & 13 & 4.32E-01 & $2.42 \mathrm{E}-02$ \\
\hline 260 & 2-Decene, (E)- & $20063-97-2$ & $4.27 \mathrm{E}-01$ & 1 & 4.27E-01 & 4.27E-01 \\
\hline 261 & Cyclohexane, 1-ethyl-2-propyl- & $62238-33-9$ & 1.93E-01 & 3 & $4.26 \mathrm{E}-01$ & 4.41E-02 \\
\hline 262 & 5-Heptenal, 2,6-dimethyl- & $106-72-9$ & $4.20 \mathrm{E}-01$ & 1 & $4.20 \mathrm{E}-01$ & $4.20 \mathrm{E} \times 01$ \\
\hline 263 & Octane, 3-methyl- & 2216-33-3 & $1.25 \mathrm{E}-01$ & 4 & 4.19E-01 & $2.00 \mathrm{E}-02$ \\
\hline 264 & 1,3-Butadiene & $106-99-0$ & $1.16 \mathrm{E}-01$ & 11 & $4.19 E-01$ & $1.05 E-03$ \\
\hline 265 & Ethene, fluoro- & $75-02-5$ & 4. $12 \mathrm{E}-01$ & 1 & 4.12E-01 & 4.12E-01 \\
\hline 266 & 2-Ocianol & $123-96-6$ & 2.15E-01 & 4 & 4.08E-01 & $2.00 \mathrm{E}-03$ \\
\hline 267 & Heptanenitrile & $629-08-3$ & $2.87 \mathrm{E}-02$ & 34 & 4.07E-01 & $1.46 \mathrm{E}-04$ \\
\hline 268 & Cyclotetradecane & 295-17-0 & 2.18E-01 & 2 & $3.99 \mathrm{E}-01$ & $3.79 \mathrm{E}-02$ \\
\hline 269 & 4-Nonyne & $20184-91-2$ & $3.99 \mathrm{E}-01$ & 1 & $3.99 \mathrm{E}-01$ & $3.99 E-01$ \\
\hline 270 & Tetradecane, 3-methyl- & $18435-22-8$ & $9.20 \mathrm{E}-02$ & 5 & $3.83 \mathrm{E}-01$ & $2.90 E-03$ \\
\hline 271 & 2-Undecene, 8-methyl-, (Z)- & $74630-44-7$ & $2.04 \mathrm{E}-01$ & 2 & $3.77 \mathrm{E}-01$ & $3.13 \mathrm{E}-02$ \\
\hline 272 & Octane, 4-methyl- & $2216-34-4$ & $1.57 \mathrm{E}-01$ & 3 & $3.76 \mathrm{E}-01$ & $2.70 E-02$ \\
\hline 273 & Cyclopropane & $75-19-4$ & $1.77 \mathrm{E}-01$ & 21 & $3.75 \mathrm{E}-01$ & $7.88 E-03$ \\
\hline 274 & 3-octen-2-ol, 2-methyl-, (Z)- & $18521-07-8$ & 1.89E-01 & 2 & $3.74 E-01$ & $3.60 \mathrm{E}-03$ \\
\hline 275 & Cyclohexane, 1,2-diethyl-1-methyl- & $61141-79-5$ & $1.16 \mathrm{E}-01$ & 4 & 3.63E-01 & $5.02 \mathrm{E} \cdot 03$ \\
\hline 276 & Cyclopentane, 1,1,3-trimethyl- & $4516-69-2$ & $1.82 \mathrm{E}-01$ & 2 & $3.57 \mathrm{E}-01$ & $6.87 \mathrm{E}-03$ \\
\hline 277 & 2-Undecanone, 6,10-dimethyl- & $1604-34-8$ & $3.57 \mathrm{E}-01$ & 1 & $3.57 \mathrm{E}-01$ & $3.57 \mathrm{E}-01$ \\
\hline 278 & Pentadecanoic acid & $1002-84-2$ & 4.98E-02 & 11 & $3.56 \mathrm{E}-01$ & $3.00 \mathrm{E}-03$ \\
\hline 279 & Naphthalene, decahydro-1,6-dimethyl- & $1750-51-2$ & $1.34 \mathrm{E}-01$ & 5 & $3.56 \mathrm{E}-01$ & 4.10E-03 \\
\hline 280 & 1-Octanol & $111-87-5$ & $6.76 \mathrm{E}-02$ & 11 & $3.55 \mathrm{E}-01$ & $5.40 E-04$ \\
\hline 281 & 1-Octanol, 2-butyl- & $3913-02-8$ & $190 \mathrm{E}-01$ & 4 & $3.53 \mathrm{E}-01$ & $1.28 \mathrm{E}-02$ \\
\hline 282 & Cyclohexane 1-methyl-4-(1-methylethyl)-, cis- & $6069-98-3$ & $1.22 \mathrm{E}-01$ & 3 & $3.50 \mathrm{E}-01$ & $5.68 \mathrm{E}-03$ \\
\hline 283 & Cyclopentane, (2-methylbutyl)- & $53366-38-4$ & $1.74 \bar{E}-01$ & 2 & $3.45 \mathrm{E}-01$ & 3.00E-03 \\
\hline 284 & Cyclohexane, 1-methyl-3-(1-methylethyl)- & $16580-24-8$ & $3.42 \mathrm{E}-01$ & 1 & $3.42 E-01$ & $3.42 \mathrm{E}-01$ \\
\hline 285 & Cyclohexane, 1,3-dimethyl-, cis- & $638-04-0$ & $1.08 \mathrm{E}-01$ & 4 & $3.42 \mathrm{E}-01$ & $1.25 \mathrm{E}-02$ \\
\hline 286 & 1-Hexene, 3,4-dimethyl- & $16745-94-1$ & $8.80 \mathrm{E}-02$ & 4 & $3.40 \mathrm{E}-01$ & 1.89E-03 \\
\hline 287 & Furan, 2-propyl- & $4229-91-8$ & $3.40 \mathrm{E}-01$ & 1 & $3.40 \mathrm{E}-01$ & $3.40 E \times 01$ \\
\hline 288 & 1-Hexene, 4,5-dimethyl- & $16106-59-5$ & 1.15E-01 & 3 & $3.38 E-01$ & $5.90 \mathrm{E}-04$ \\
\hline 289 & Nonane, 5-butyl- & $17312-63-9$ & $9.35 E-02$ & 4 & 3.37E-01 & 4.10E-03 \\
\hline 290 & Pentadecane, 2-methyl- & $1560-93-6$ & $1.10 \mathrm{E}-01$ & 6 & 3.33E-01 & 3.23E-03 \\
\hline 291 & Undecane, 5,7-dimethyl- & $17312-83-3$ & $1.66 \mathrm{E}-01$ & 2 & 3.31E-01 & $1.19 \mathrm{E}-03$ \\
\hline 292 & Cyclooctane, butyl- & $16538-93-5$ & $3.31 \mathrm{E}-01$ & 1 & $3.31=-01$ & $3.31 \mathrm{E}-01$ \\
\hline 293 & Octane, 2,5-dimethyl- & $15869-89-3$ & 1.71E-01 & 2 & $3.29 E-01$ & $1.36 \mathrm{E}-02$ \\
\hline 294 & Octane, 2,6-dimethyl- & $2051-30-\uparrow$ & 9.55E-02 & 6 & $3.25 E-01$ & 2.19E-02 \\
\hline 295 & 1-Pentadecene & $13360-61-7$ & $8.36 E-02$ & 4 & $3.25 E-01$ & $2.15 E-03$ \\
\hline 296 & Cyclopentane, 1,2-dimethyl-3-(1-methylethyl)- & $489-20-3$ & $3.23 \mathrm{E}-01$ & 1 & $3.23 E-01$ & $3.23 \mathrm{E}-01$ \\
\hline 297 & Naphthalene, 2-butyldecahydro- & $6305-52-8$ & $3.22 \mathrm{E}-01$ & 1 & $3.22 \mathrm{E}-01$ & $3.22 \mathrm{E}-01$ \\
\hline 298 & Naphthalene, decahydro- & $91-17-8$ & $3.20 \mathrm{E}-01$ & 1 & $3.20 E-01$ & $3.20 \mathrm{E}-01$ \\
\hline 299 & 1-Undecene & $821-95-4$ & $1.42 \mathrm{E}-01$ & 4 & $3.19 E-01$ & $4.80 \bar{E}-03$ \\
\hline 300 & Cyclobutane, 1,2-diethyl-, trans- & $19341-98-1$ & $2.03 \mathrm{E}-01$ & 2 & $3.17 E-01$ & $8.82 \mathrm{E}-02$ \\
\hline 301 & Hexadecane, 2,6,10,14-tetramethyl- & $638-36-8$ & $6.10 \mathrm{E}-02$ & 8 & $3.14 \mathrm{E}-01$ & $2.00 \mathrm{E}-03$ \\
\hline 302 & Cyclohexane, (2,2-dimethylcyclopentyl)- & $61142-23-2$ & $1.45 \mathrm{E}-01$ & 4 & $3.13 E-01$ & $2.90 \mathrm{E}-02$ \\
\hline 303 & 2-Hexenoic acid, 2 -hexenyl ester, $(\mathrm{E}, \mathrm{E})$ - & $54845-28-2$ & $3.10 \mathrm{E}-01$ & 1 & $3.10 \mathrm{E}-01$ & 3.10E-01 \\
\hline 304 & Dodecanoic acid & $143-07-7$ & $6.84 E-02$ & 5 & $3.07 E=01$ & $3.57 E-03$ \\
\hline 305 & 2-Hexenal, $(E)$ - & $6728-26-3$ & $1.54 \mathrm{E}-01$ & 2 & $3.07 \mathrm{E}-01$ & $1.29 E-03$ \\
\hline 306 & 3-Heptanol & $589-82-2$ & $8.20 \mathrm{E}-02$ & 10 & $3.05 \mathrm{E}-01$ & $3.34 \mathrm{E}-03$ \\
\hline 307 & Heptanol & $53535-33-4$ & $3.05 \mathrm{E}-01$ & 1 & 3.05E-01 & $3.05 \mathrm{E}-01$ \\
\hline 308 & 3-Hexanone & 589-38-8 & $7.19 \mathrm{E}-02$ & 10 & $2.99 \mathrm{E}-01$ & $6.90 \mathrm{E}-04$ \\
\hline 309 & Nitric acid, ethyl ester & $625-58-1$ & $9.32 \mathrm{E}-02$ & 12 & $2.99 \mathrm{E}-01$ & $5.25 \mathrm{E}-03$ \\
\hline
\end{tabular}




\begin{tabular}{|c|c|c|c|c|c|c|}
\hline & $\overline{8}$ & $\mathrm{C}$ & $\bar{D}$ & $\mathbf{F}$ & $\mathbf{G}$ & $\mathbf{H}$ \\
\hline 1 & TANK CHEMICALS & CAS \# & $\begin{array}{c}\text { Mean } \\
(\mathrm{mg} / \mathrm{m} 3)\end{array}$ & $\begin{array}{l}\text { Number of } \\
\text { tanks }\end{array}$ & $\begin{array}{c}\text { Maximum } \\
(\mathrm{mg} / \mathrm{m} 3)\end{array}$ & $\begin{array}{r}\text { Minimum } \\
(\mathrm{mg} / \mathrm{m} 3)\end{array}$ \\
\hline 310 & 3-Dodecene, (Z)- & $7239-23-8$ & $2.99 \mathrm{E}-01$ & 1 & $2.99 \mathrm{E}-01$ & $2.99 \mathrm{E}-01$ \\
\hline 311 & Formic acid, 2-methylpropyl ester & $542-55-2$ & $2.98 \mathrm{E}-01$ & 1 & $2.98 \mathrm{E}-01$ & $2.98 \mathrm{E}-01$ \\
\hline 312 & Hexacosane & $630-01-3$ & $2.98 \mathrm{E}-01$ & 1 & $2.98 \mathrm{E}-01$ & $2.98 \mathrm{E}-01$ \\
\hline 313 & Decane, 3,8-dimethyl- & $17312-55-9$ & 1.10E-01 & 4 & $2.96 \mathrm{E}-01$ & $1.63 \mathrm{E}-02$ \\
\hline 314 & Cyclopropane, (1-methylethyl)- & $3638-35-5$ & $1.41 \mathrm{E}-01$ & 3 & $2.92 \mathrm{E}-01$ & $4.96 \mathrm{E}-02$ \\
\hline 315 & 2-Hexenal & $505-57-7$ & $1.61 \mathrm{E}-01$ & 2 & $2.92 \mathrm{E}-01$ & 3.00E-02 \\
\hline 316 & 1-Hexadecanol & $36653-82-4$ & $4.98 \mathrm{E}-02$ & 11 & $2.92 \mathrm{E}-01$ & 1.20E-03 \\
\hline 317 & $\begin{array}{l}\text { Cyclohexanone, 5-methyl-2-(1- } \\
\text { methylethylidene)- }\end{array}$ & $15932-80-6$ & 2.90E-01 & 1 & $2.90 \mathrm{E}-01$ & $2.90 \mathrm{E}-01$ \\
\hline 318 & Octane, 6-ethyl-2-methy1- & $62016-19-7$ & $1.67 \mathrm{E}-01$ & 4 & $2.90 \mathrm{E}-01$ & $4.93 \mathrm{E}-02$ \\
\hline 319 & Nitric acid, butyl ester & 928-45-0 & $8.08 \mathrm{E}-02$ & 12 & $2.87 \mathrm{E}-01$ & $2.89 \mathrm{E}-03$ \\
\hline 320 & Acetic acid, butyl ester & $123-86-4$ & $6.15 \mathrm{E}-02$ & 8 & $2.86 \mathrm{E}-01$ & $6.25 \mathrm{E}-03$ \\
\hline 321 & Benzene, 2-propenyl- & $300-57-2$ & $2.85 \mathrm{E}-01$ & 1 & 2.85E-01 & $2.85 \mathrm{E}-01$ \\
\hline 322 & Cyclohexane, cyclopropyl- & $32669-86-6$ & $1.47 E-01$ & 3 & $2.83 \mathrm{E}-01$ & $6.71 E-02$ \\
\hline 323 & Heptane, 2,3-dimethyl- & $3074-71-3$ & $9.20 \mathrm{E}-02$ & 5 & $2.81 \mathrm{E}-01$ & $8.25 \mathrm{E}-03$ \\
\hline 324 & 1-Propanone, 1-phenyl- & 93-55-0 & $2.81 \mathrm{E}-01$ & 1 & $2.81 \mathrm{E}-01$ & $2.81 \mathrm{E}-01$ \\
\hline 325 & Cyclohexane, 2,4-diethyl-1-methyl- & $61142-70-9$ & $1.53 \mathrm{E}-01$ & 4 & $2.80 \mathrm{E}-01$ & $3.75 \mathrm{E}-03$ \\
\hline 326 & 3-Hexene, 3-ethyl-2,5-dimethyl- & $62338-08-3$ & $1.41 \mathrm{E}-01$ & 2 & $2.78 \mathrm{E}-01$ & $3.50 E-03$ \\
\hline 327 & Nitrogen oxide (NO2) & $10102-44-0$ & $1.29 \mathrm{E}-01$ & 3 & $277 \mathrm{E}-01$ & $4.76 \mathrm{E}-03$ \\
\hline 328 & Heptadecane, 9-octyt- & $7225-64-1$ & $2.74 \mathrm{E}-01$ & 1 & $2.74 \mathrm{E}-01$ & $2.74 \mathrm{E}-01$ \\
\hline 329 & 2-Heptanol & $543-49-7$ & $1.36 \mathrm{E}-01$ & 2 & $2.69 \mathrm{E}-01$ & 2.13E-03 \\
\hline 330 & Cyclopentane, 1-hexyl-3-methy|- & $61142-68-5$ & $9.28 \mathrm{E}-02$ & 5 & $2.69 E-01$ & $2.30 \mathrm{E}-03$ \\
\hline 331 & 4-Undecene, 5-methyl-, (Z)- & $74630-69-6$ & $2.67 \mathrm{E}-01$ & 1 & $2.67 E-01$ & $2.67 \mathrm{E}-01$ \\
\hline 332 & Cyclohexane, 1,2-diethyl-3-methy|- & $61141-80-8$ & $1.02 \mathrm{E}-01$ & 3 & 2.67E-01 & $7.17 \mathrm{E}-03$ \\
\hline 333 & Decane 2,3,8-trimethyl- & $62238-14-6$ & $1.08 \mathrm{E}-01$ & 3 & $2.64 E-01$ & $9.00 E-03$ \\
\hline 334 & Hexanenitrile & $628-73-9$ & $2.84 \mathrm{E}-02$ & 34 & $2.61 E-01$ & 4.04E-05 \\
\hline 335 & Cyclohexane, 1,2-dimethyl- & $583-57-3$ & $2.53 \mathrm{E}-01$ & 1 & $2.53 \mathrm{E}-01$ & $2.53 \mathrm{E}-01$ \\
\hline 336 & 2-Butanone, 3-methyl- & $563-80-4$ & $6.83 \mathrm{E}-02$ & 11 & $2.50 \mathrm{E}-01$ & $2.16 \mathrm{E}-03$ \\
\hline 337 & Cyclohexanone & 108-94-1 & $1.11 \mathrm{E}-01$ & 5 & $2.50 \mathrm{E}-01$ & $2.55 \mathrm{E}-02$ \\
\hline 338 & 3-Tetradecene, (Z)- & $41446-67-7$ & $2.49 \mathrm{E}-01$ & 1 & $2.49 E-01$ & $2.49 E-01$ \\
\hline 339 & $\begin{array}{l}\text { Cyclohexane, 1-(cyclohexyimethyl)-2-methyl-, } \\
\text { trans- }\end{array}$ & $54823-94-8$ & $2.48 \mathrm{E}-01$ & 1 & $2.48 \mathrm{E}-01$ & $2.48 \mathrm{E}-01$ \\
\hline 340 & 1,2-Propanediol, (S)- & $4254-15-3$ & $1.57 \mathrm{E}-01$ & 2 & $2.48 \mathrm{E}-01$ & $6.54 \mathrm{E}-02$ \\
\hline 341 & Methane, dichlorofluoro- & $75-43-4$ & $4.89 \mathrm{E}-02$ & 9 & $2.48 \mathrm{E}-01$ & $1.55 \mathrm{E}-03$ \\
\hline 342 & Butane, 1,1'-oxybis- & $142-96-1$ & $8.59 \mathrm{E}-02$ & 4 & $2.48 E-01$ & $7.75 \mathrm{E}-03$ \\
\hline 343 & 2-Propanol, 2-methyl- & $75-65-0$ & $8.83 \mathrm{E}-02$ & 7 & $2.39 \mathrm{E}-01$ & 1.63E-02 \\
\hline 344 & Cyclopentane, (1-methylbutyl)- & $4737-43-3$ & $1.22 \mathrm{E}-01$ & 2 & $2.37 \mathrm{E}-01$ & $7.30 \mathrm{E}-03$ \\
\hline 345 & Undecane, 2,9-dimethyi- & $17301-26-7$ & $1.19 \mathrm{E}-01$ & 2 & $2.36 \mathrm{E}-01$ & $2.04 \mathrm{E}-03$ \\
\hline 346 & Hexane, 3-methoxy- & $54658-01-4$ & $1.22 \mathrm{E}-01$ & 2 & $2.35 \mathrm{E}-01$ & $8.55 \mathrm{E}-03$ \\
\hline 347 & 4-Hepten-3-one, 5-ethyl-2,4-dimethyl- & $22319-29-5$ & $2.34 \mathrm{E}-01$ & 1 & $2.34 \mathrm{E}-01$ & $2.34 \mathrm{E}-01$ \\
\hline 348 & 2-Pentanol, 2-methyl- & $590-36-3$ & $6.15 \mathrm{E}-02$ & 5 & $2.33 \mathrm{E}-01$ & $1.55 \mathrm{E}-03$ \\
\hline 349 & 3-Octanone & $106-68-3$ & $7.95 \mathrm{E}-02$ & 3 & $2.32 \mathrm{E}-01$ & $3.07 \mathrm{E}-03$ \\
\hline 350 & Hexane, 2,5-dimethyl- & $592-13-2$ & $1.03 \mathrm{E}-01$ & 3 & $2.30 \mathrm{E}-01$ & 2.11E-03 \\
\hline 351 & Pentanal, 2-methy!- & $123-15-9$ & $1.27 \mathrm{E}-01$ & 2 & $2.30 \mathrm{E}-01$ & $2.33 \mathrm{E}-02$ \\
\hline 352 & Benzenamine, $\mathrm{N}$-phenyl- & $122-39-4$ & $4.43 \mathrm{E}-02$ & 7 & $2.28 \mathrm{E}-01$ & $4.58 \mathrm{E}-03$ \\
\hline 353 & 1H-Pyrazole, 3-methyl- & $1453-58-3$ & $1.15 \mathrm{E}-01$ & 2 & $2.25 \mathrm{E}-01$ & $4.15 \mathrm{E}-03$ \\
\hline 354 & Heptane, 3,5-dimethyl- & $926-82-9$ & $2.20 \mathrm{E}-01$ & 1 & $2.20 \mathrm{E}-01$ & $2.20 \mathrm{E}-01$ \\
\hline 355 & Pentanenitrile & $110-59-8$ & $2.72 \mathrm{E}-02$ & 38 & $220 \mathrm{E}-01$ & $2.06 \mathrm{E}-04$ \\
\hline 356 & 7-Hexadecene, $(\mathrm{Z})$ - & $35507-09-6$ & $1.46 \mathrm{E}-01$ & 3 & $2.16 \mathrm{E}-01$ & $1.03 \mathrm{E}-02$ \\
\hline 357 & 3-Heptene, $2,2,3,5,5,6,6$-heptamethyl- & $54845-26-0$ & $1.31 \mathrm{E}-01$ & 2 & $2.15 E-01$ & 4.68E-02 \\
\hline 358 & 1-Butene, 2-methyl- & $563-46-2$ & $1.25 \mathrm{E}-01$ & 3 & $2.12 \mathrm{E}-01$ & $5 . \overline{00 E}-02$ \\
\hline 359 & Naphthalene, decahydro-2,3-dimethyl- & $1008-80-6$ & $9.26 \mathrm{E}-02$ & 6 & 2.10 -01 & $6.48 \mathrm{E}-03$ \\
\hline
\end{tabular}




\begin{tabular}{|c|c|c|c|c|c|c|}
\hline & $\mathbf{B}$ & C & $\mathbf{D}$ & $\mathbf{F}$ & $\mathbf{G}$ & $\mathrm{H}$ \\
\hline 1 & TANK CHEMICALS & CAS \# & $\begin{array}{c}\text { Mean } \\
(\mathrm{mg} / \mathrm{m} 3)\end{array}$ & $\begin{array}{c}\text { Number of } \\
\text { tanks }\end{array}$ & $\begin{array}{l}\text { Maximum } \\
(\mathrm{mg} / \mathrm{m} 3)\end{array}$ & $\begin{array}{c}\text { Minimum } \\
(\mathrm{mg} / \mathrm{m} 3)\end{array}$ \\
\hline 360 & Propanenitrile & $107-12-0$ & $5.18 \mathrm{E}-02$ & 40 & $2.09 \mathrm{E}-01$ & $2.25 E-05$ \\
\hline 361 & Cyclohexanone, 3,3,5-trimethyl- & $873-94-9$ & $1.05 \mathrm{E}-01$ & 2 & $2.08 \mathrm{E}-01$ & $1.62 E-03$ \\
\hline 362 & Methanamine, $\mathrm{N}$-methyl-N-nitroso- & $62-75-9$ & $8.66 \mathrm{E}-02$ & 9 & 2.07E-01 & 4.99E-03 \\
\hline 363 & Eicosane & $112-95-8$ & $7.05 \mathrm{E}-02$ & 5 & $2.06 \mathrm{E}-01$ & 7.65E-03 \\
\hline 364 & Cyclohexane, 1,1,2,3-tetramethyl- & $6783-92-2$ & 1.31E-01 & 3 & $2.05 \mathrm{E}-01$ & $8.80 \mathrm{E}-02$ \\
\hline 365 & Butane, 1-chloro- & $109-69-3$ & $6.67 \mathrm{E}-02$ & 5 & 2.04E-01 & 3.10E-03 \\
\hline 366 & 2-Furanacetaldehyde, .alpha.-propyl- & $31681-26-2$ & $2.03 \mathrm{E}-01$ & 1 & 2.03E-01 & 2.03E-01 \\
\hline 367 & Nitric acid, methyl ester & $598-58-3$ & $8.37 \mathrm{E}-02$ & 8 & $2.00 \mathrm{E}-01$ & $1,19 \mathrm{E}-03$ \\
\hline 368 & Decane, 2,4,6-trimethyl- & $62108-27-4$ & $1.11 \mathrm{E}-01$ & 2 & $1.99 \mathrm{E}-01$ & $2.38 \mathrm{E}-02$ \\
\hline 369 & $\begin{array}{l}1 \mathrm{H}-\text { Indene, octahydro- } 2,2,4,4,7,7-\text { hexamethyl-, } \\
\text { trans- }\end{array}$ & $54832-83-6$ & $1.97 \mathrm{E}-01$ & 1 & $1.97 E-01$ & $1.97 \mathrm{E}-01$ \\
\hline 370 & Pyrazine & $290-37-9$ & 7.27E-02 & 14 & 1.95E-01 & $2.48 E-03$ \\
\hline 371 & 3-Buten-2-one & $78-94-4$ & $6.28 \mathrm{E}-02$ & 13 & $1.94 \mathrm{E}-01$ & $2.44 E-03$ \\
\hline 372 & Methane, nitroso- & $865-40-7$ & $1.93 \mathrm{E}-01$ & 1 & $1.93 \mathrm{E}-01$ & 1.93E-01 \\
\hline 373 & Tetradecane, 2,6,10-trimethyl- & $14905-56-7$ & $6.70 \bar{E}-02$ & 4 & $1.93 \mathrm{~F}-01$ & $1.62 \mathrm{E}-02$ \\
\hline 374 & 4-Decene, 3-methyl-, (E)- & $62338-47-0$ & $1.93 E-01$ & 1 & $1.93 \mathrm{E}-01$ & 1.93E-01 \\
\hline 375 & 2-Hexanone, 5-methyl- & $110-12-3$ & $9.44 \mathrm{E}-02$ & 3 & 1.92E-01 & $4.25 \mathrm{E}-02$ \\
\hline 376 & 2-Hexanone, 4-methyl- & $105-42-0$ & $1.16 \mathrm{E}_{\mathrm{n}}-01$ & 2 & $1.90 E-01$ & 4.12E-02 \\
\hline 377 & Hexanal, 2-ethyl- & $123-05-7$ & $1.89 \mathrm{E}-01$ & 1 & $1.89 \mathrm{E}-01$ & $1.89 \mathrm{E}-01$ \\
\hline 378 & Pentanal, 3-methyl- & $15877-57-3$ & 1.14E-01 & 2 & $1.88 \mathrm{E}-01$ & $3.91 E-02$ \\
\hline 379 & Ethane, 1,1,2-trichloro-1,2,2-trifluoro- & $76-13-1$ & $3.72 \mathrm{E}-02$ & 13 & $1.88 \mathrm{E}-01$ & $8.36 \mathrm{E}-04$ \\
\hline 380 & Bicyclo[2.2.1]heptane & $279-23-2$ & $1.04 \mathrm{E}-01$ & 2 & $1.86 \mathrm{E}-01$ & $2.06 \mathrm{E}-02$ \\
\hline 381 & Nitrous acid, butyl ester & $544-16-1$ & $8.46 \mathrm{E}-02$ & 4 & $1.86 \mathrm{E}-01$ & 2. $16 \mathrm{E}-03$ \\
\hline 382 & 1-Pentanol & $71-41-0$ & $5.98 \mathrm{E}-02$ & 10 & $1.85 E-01$ & $4.46 \mathrm{E}-03$ \\
\hline 383 & Cyclohexanone, 2,2,6-trimethyl- & $2408-37-9$ & $9.28 \mathrm{E}-02$ & 2 & $1.85 \mathrm{E}=01$ & $5.25 \mathrm{E}-04$ \\
\hline 384 & Benzene, (1-methylheptyl)- & $777-22-0$ & 1.84E-01 & 1 & $1.84 E-01$ & 1.84E-01 \\
\hline 385 & 2-Undecene, 6-methyl-, (E)- & $74630-61-8$ & $1.81 \mathrm{E}-01$ & 1 & $1.81 E-01$ & 1.81E-01 \\
\hline 386 & Benzene, $1,1^{\prime}$-oxybis- & $101-84-8$ & $9.16 \mathrm{E}-02$ & 2 & $1.81 E-01$ & $2.44 \mathrm{E}-03$ \\
\hline 387 & Octane, 5-ethyl-2-methyl- & $62016-18-6$ & $1.80 \mathrm{E}-01$ & 1 & $1.80 \mathrm{E}-01$ & $1.80 \mathrm{E}-01$ \\
\hline 388 & Aziridine, 2-ethyl- & $2549-67-9$ & $8.89 \mathrm{E}-02$ & 3 & $1.791=-01$ & 1.47E-02 \\
\hline 389 & Methane, oxybis- & $115-10-6$ & $1.08 \mathrm{E}-01$ & 7 & $1.78 \mathrm{E}-01$ & 2.62E-02 \\
\hline 390 & 3-Dodecene, (E) & $7206-14-6$ & $5.12 \mathrm{E}-02$ & 4 & $1.74 \mathrm{E}-01$ & 1.33E-03 \\
\hline 391 & 1-Propanol, 2,2-dimethyl-, nitrate & $926-42-1$ & $5.65 \mathrm{E}-02$ & 4 & $1.72 E-01$ & $2,40 \mathrm{E}-03$ \\
\hline 392 & Cyclohexane, 1-ethyl-4-methyl-, trans- & $6236-88-0$ & $4.85 E-02$ & 4 & $1.71 E-01$ & 4.16E-03 \\
\hline 393 & 2-Pentanol & $6032-29-7$ & $8.99 \mathrm{E}-02$ & 2 & 1.71E-01 & $9.22 \mathrm{E}-03$ \\
\hline 394 & Garbon disulfide & $75-15-0$ & $1.70 \mathrm{E}-01$ & 1 & $1.70 E-01$ & $1.70 \mathrm{E}-01$ \\
\hline 395 & Ethane, 1-chloro-1,1-difluoro- & $75-68-3$ & 1.24E-01 & 2 & $1.68 \mathrm{E}-01$ & $7.90 \mathrm{E}-02$ \\
\hline 396 & 1-Hexanol & $111-27-3$ & $4.80 \mathrm{E}-02$ & 7 & 1.67E-01 & $5.46 \mathrm{E}-03$ \\
\hline 397 & 1-Butanol, 2-methyl- & $137-32-6$ & $9.25 \mathrm{E}-02$ & 2 & $1.62 \mathrm{E}-01$ & 2.30E-02 \\
\hline 398 & Nitric acid, pentyl ester & $1002-16-0$ & $6.48 \mathrm{E}-02$ & 9 & $1.61 E-01$ & $3.62 E-03$ \\
\hline 399 & 2(3H)-Furanone, dihydro- & $96-48-0$ & $5.38 \mathrm{E}-02$ & 5 & 1.61E-01 & $5.70 \mathrm{E}-04$ \\
\hline 400 & Propane, 1-fluoro- & $460-13-9$ & $1.59 \mathrm{E}-01$ & 1 & $159 \mathrm{E}-01$ & $1.59 \mathrm{E}-01$ \\
\hline 401 & 2-Pentanone, 3-methyl- & $565-61-7$ & $6.55 \mathrm{E}-02$ & 6 & $1.58 \mathrm{E}-01$ & $5.55 \mathrm{E}-04$ \\
\hline 402 & 1,3-Butadiene, 2-methyl- & 78.79 .5 & $6.11 \mathrm{E}-02$ & 3 & 1.57E-01 & $8.89 \mathrm{E}-03$ \\
\hline 403 & Cyclopentane, 1-butyl-2-propyl- & $62199-50-2$ & $1.57 E-01$ & 1 & 1.57E-01 & $1.57 \mathrm{E}-01$ \\
\hline 404 & 2-Butene, 2-methyl- & $513-35-9$ & $8.13 E-02$ & 2 & 1.57E-01 & $5.65 E-03$ \\
\hline 405 & 1-Heptanol & $111-70-6$ & $5.76 E-02$ & 9 & $1.57 E-01$ & $5.30 \mathrm{E}-03$ \\
\hline 406 & Oxirane, 2-ethyl-3-propyl-, cis- & $56052-94-9$ & $1.55 \mathrm{E}-01$ & 1 & $1.55 \mathrm{E}-01$ & $1.55 \mathrm{E}-01$ \\
\hline 407 & Octane, 3,5-dimethyl- & $15869-93-9$ & $1.55 \mathrm{E}-01$ & 1 & 1.55E-01 & $1.55 \mathrm{E}-01$ \\
\hline 408 & 1,4-Hexadiene & $592-45-0$ & $7.38 \mathrm{E}-02$ & 3 & $1.55 \mathrm{E}-01$ & $3.31 \mathrm{E}-02$ \\
\hline 409 & 3-Pentanol, 2-methyl- & $565-67-3$ & $7.74 \mathrm{E}-02$ & 2 & $1.54 \mathrm{E}-01$ & $9.90 E-04$ \\
\hline 410 & 3-Tetradecanone & $629-23-2$ & $8.39 E-02$ & 2 & $1.50 \mathrm{E}-01$ & $1.76 \mathrm{E}-02$ \\
\hline
\end{tabular}


WHC-SD-WM-TI-753 REV 0

\begin{tabular}{|c|c|c|c|c|c|c|}
\hline & B & $\mathrm{C}$ & $\bar{D}$ & $\mathbf{F}$ & $G$ & $\vec{H}$ \\
\hline 1 & TANK CHEMICALS & CAS \# & $\begin{array}{c}\text { Mean } \\
(\mathrm{mg} / \mathrm{m} 3)\end{array}$ & $\begin{array}{c}\text { Number of } \\
\text { tanks }\end{array}$ & $\begin{array}{c}\text { Maximum } \\
(\mathbf{m g} / \mathbf{m} 3)\end{array}$ & $\underset{(\mathrm{mg} / \mathrm{m} 3)}{\operatorname{Minimum}}$ \\
\hline 411 & Cyclobutanone & $1191-95-3$ & $1.50 \mathrm{E}-01$ & 1 & $1.50 \mathrm{E}-01$ & $1.50 \mathrm{E}-01$ \\
\hline 412 & Pyridine, 3-methyl- & $108-99-6$ & $4.41 \mathrm{E}-02$ & 4 & $1.50 \mathrm{E}-01$ & $2.26 \mathrm{E}-03$ \\
\hline 413 & Nitric acid, 1-methylethyl ester & $1712-64-7$ & $9.99 \mathrm{E}-02$ & 3 & 1.50E-01 & $4.58 \mathrm{E}-03$ \\
\hline 414 & Cyclohexane, 1,3,5-trimethyl-2-octadecyl- & $55282-34-3$ & 7.44E-02 & 2 & 1.45E-01 & $3.97 \mathrm{E}-03$ \\
\hline 415 & 3-Hepten-2-one, 3-methyl- & 39899-08-6 & 1.44E-01 & 1 & 1.44E-01 & $1.44 \mathrm{E}-01$ \\
\hline 416 & Butane, 2-bromo- & $78-76-2$ & $7.70 E-02$ & 2 & $1.44 \mathrm{E}-01$ & $1.01 \mathrm{E}-02$ \\
\hline 417 & 1,4-Butanediol, dinitrate & $3457-91-8$ & $7.51 \mathrm{E}-02$ & 3 & $1.44 \mathrm{E}-01$ & $6.50 \mathrm{E}-04$ \\
\hline 418 & 4-Nonene, 5-buty|- & $7367-38-6$ & $9.65 \mathrm{E}-02$ & 3 & $1.43 \mathrm{E}-01$ & $1.93 \mathrm{E}-02$ \\
\hline 419 & Acetic acid, methyl ester & $79-20-9$ & $8.44 \mathrm{E}-02$ & 2 & 1.40E-01 & $2.83 \mathrm{E}-02$ \\
\hline 420 & Hexanedioic acid, dioctyl ester & $123-79-5$ & 5.43E-02 & 3 & 1.40E-01 & $6.00 \mathrm{E}-03$ \\
\hline 421 & Bicyclo[4.2.0]octa-1,3,5-triene & $694-87-1$ & 1.39E-01 & 1 & $1.39 \mathrm{E}-01$ & $1.39 \mathrm{E}-01$ \\
\hline 422 & Aziridine, 2-methyl- & $75-55-8$ & $1.38 \mathrm{E}-01$ & 1 & $1.38 \mathrm{E}-01$ & $1.38 \mathrm{E}-01$ \\
\hline 423 & 2-Pentanone, 4,4-dimethyl- & $590-50-1$ & $2.20 \mathrm{E}-02$ & 9 & $1.35 \mathrm{E}-01$ & $1.91 \mathrm{E}-03$ \\
\hline 424 & Cyanamide, dimethyl- & $1467-79-4$ & $1.30 \mathrm{E}-01$ & 1 & $1.30 \mathrm{E}-01$ & $1.30 \mathrm{E}-01$ \\
\hline 425 & 3-Octene $(E)-$ & 14919-01-8 & $1.30 \mathrm{E}-01$ & 1 & $1.30 \mathrm{E}-01$ & $1.30 \mathrm{E}-01$ \\
\hline 426 & $1 \mathrm{H}-1,2,4$-Triazole, 1-ethyl- & $16778-70-4$ & $1.29 \mathrm{E}-01$ & 1 & $1.29 \mathrm{E}-01$ & $1.29 \mathrm{E}-01$ \\
\hline 427 & Benzene, 1,2,4-trichloro- & $120-82-1$ & $1.29 \mathrm{E}-01$ & 1 & 1.29E-01 & $1.29 \mathrm{E}-01$ \\
\hline 428 & 4-Heptanone & $123-19-3$ & $4.88 \mathrm{E}-02$ & 7 & $1.28 \mathrm{E}-01$ & $6.70 \mathrm{E}-04$ \\
\hline 429 & Cyciohexane, octyl- & $1795-15-9$ & $5.32 \mathrm{E}-02$ & 5 & $1.25 \mathrm{E}-01$ & $1.17 \mathrm{E}-02$ \\
\hline 430 & 2-Butene, 2,3-dimethyl- & $563-79-1$ & $1.25 \mathrm{E}-01$ & 1 & $1.25 \mathrm{E}-01$ & $1.25 \mathrm{E}-01$ \\
\hline 431 & Nonane, 2-methyl- & $871-83-0$ & $8.00 \mathrm{E}-02$ & 2 & $1.25 \mathrm{E}-01$ & $3.53 \mathrm{E}-02$ \\
\hline 432 & Propane, 2,2-dimethyl- & $463-82-1$ & $6.86 \mathrm{E}-02$ & 2 & $1.24 \mathrm{E}-01$ & $1.28 \mathrm{E}-02$ \\
\hline 433 & 2-Buten-1-ol, (Z)- & $4088-60-2$ & $6.36 \mathrm{E}-02$ & 2 & $1.22 \mathrm{E}-01$ & $5.25 \mathrm{E}-03$ \\
\hline 434 & 3-Pentanone, 2-methyl- & $565-69-5$ & $3.25 \mathrm{E}-02$ & 4 & 1.21E-01 & 7.57E-04 \\
\hline 435 & 1,5-Hexadiene & $592-42-7$ & 1.20E-01 & 1 & $1.20 \mathrm{E}-01$ & $1.20 \mathrm{E}-01$ \\
\hline 436 & 1,1'-Bicyclohexyl, 2-methyl-, cis- & $50991-08-7$ & 1.17E-01 & 1 & 1.17E-01 & $1.17 \mathrm{E}-01$ \\
\hline 437 & 2-Pentene & $109-68-2$ & $9.18 \mathrm{E}-02$ & 2 & $1.17 \mathrm{E}-01$ & $6.70 \mathrm{E}-02$ \\
\hline 438 & Heptane, 4-methyl- & 589-53-7 & 1. $\overline{15} \overline{\mathrm{E}}-01$ & 1 & $1.15 \mathrm{E}-01$ & $1.15 \mathrm{E}-01$ \\
\hline 439 & 6-Tridecene & $24949-38-0$ & $3.99 \mathrm{E}-02$ & 3 & 1.14E-01 & $1.16 \mathrm{E}-03$ \\
\hline 440 & 4-Octanone & $589-63-9$ & $3.52 \mathrm{E}-02$ & 5 & $1.14 \mathrm{E}-01$ & $5.10 \mathrm{E}-03$ \\
\hline 441 & Pyridine, $1,2,3,6$-tetrahydro- & $694-05-3$ & $6.60 \mathrm{E}-02$ & 2 & 1.13E-01 & $1.91 \mathrm{E}-02$ \\
\hline 442 & $\begin{array}{l}\text { Cyclohexane, 1-(cyclohexylmethyl)-2-methyl-, } \\
\text { cis- }\end{array}$ & $54824-04-3$ & 1.11E-01 & 1 & 1.11E-01 & 1.11E-01 \\
\hline 443 & 5-Undecene, 7-methyl-, (Z)- & $74630-62-9$ & $1.11 \mathrm{E}-01$ & 1 & $1.11 \mathrm{E}-01$ & $1.11 \mathrm{E}-01$ \\
\hline 444 & Cyclopentane, 1-butyl-2-ethyl- & $72993-32-9$ & $6.73 \mathrm{E}-02$ & 2 & $1.10 \mathrm{E}-01$ & $2.51 \mathrm{E}-02$ \\
\hline 445 & 2-Propenenitrile, 2-methyl- & $126-98-7$ & $1.09 \mathrm{E}-01$ & 1 & $1.09 \mathrm{E}-01$ & $1.09 \mathrm{E}-01$ \\
\hline 446 & Cyclohexane, propyl- & $1678-92-8$ & $7.42 \mathrm{E}-02$ & 3 & $1.08 \mathrm{E}-01$ & $4.54 \mathrm{E}-02$ \\
\hline 447 & Methane, dichlorodifluoro- & $75-71-8$ & $3.25 \mathrm{E}-02$ & 12 & 1.08E-01 & 1.08E-03 \\
\hline 448 & Cycloheptane, methoxy- & 42604-04-6 & $1.07 \mathrm{E}-01$ & 1 & 1.07E-01 & $1.07 \mathrm{E}-01$ \\
\hline 449 & Furan, 2,5-diethyltetrahydro- & $41239-48-9$ & $1.07 \mathrm{E}-01$ & 1 & $1.07 \mathrm{E}-01$ & $1.07 \mathrm{E}-01$ \\
\hline 450 & 2-Tetradecanone & $2345-27-9$ & $2.99 \mathrm{E}-02$ & 6 & $1.06 \mathrm{E}-01$ & $5.70 \mathrm{E}-03$ \\
\hline 451 & Octanenitrile & $124-12-9$ & $2.08 \mathrm{E}-02$ & 16 & $1.04 \mathrm{E}-01$ & $2.51 \mathrm{E}-04$ \\
\hline 452 & 3-Pentanone, 2,4-dimethyl- & $565-80-0$ & $1.03 \mathrm{E}-01$ & 1 & $1.03 \mathrm{E}-01$ & 1.03E-01 \\
\hline 453 & Undecane, 3,6-dimethyl- & $17301-28-9$ & $5.12 \mathrm{E}-02$ & 2 & $1.01 \mathrm{E}-01$ & $1.63 \mathrm{E}-03$ \\
\hline 454 & Cyclohexane, 1-methyl-4-(1-methylbutyl)- & $54411-00-6$ & $5.32 \mathrm{E}-02$ & 3 & $1.00 \mathrm{E}-01$ & $1.00 \mathrm{E}-02$ \\
\hline 455 & 2-Heptanone, 4-methyl- & $6137-06-0$ & $7.71 \mathrm{E}-02$ & 3 & $9.95 \mathrm{E}-02$ & $5.00 \mathrm{E}-02$ \\
\hline 456 & 1-Tridecene & $2437-56-1$ & 2.49E-02 & 5 & $9.95 \mathrm{E}-02$ & $2.88 \mathrm{E}-03$ \\
\hline 457 & Undecane, 2,5-dimethyl- & $17301-22-3$ & $9.88 \mathrm{E}-02$ & 1 & $9.88 \mathrm{E}-02$ & $9.88 \mathrm{E}-02$ \\
\hline 458 & Ethanol, 2-butoxy- & $111-76-2$ & $5.39 \mathrm{E}-02$ & 4 & $9.79 \mathrm{E}-02$ & $2.70 \mathrm{E}-03$ \\
\hline 459 & Ethene, $1,1^{1}$-oxybis- & $109-93-3$ & $9.74 \mathrm{E}-02$ & 1 & $9.74 \mathrm{E}-02$ & $9.74 \mathrm{E}-02$ \\
\hline 460 & Cyclopentanone, 3-methyl- & $1757-42-2$ & $6.00 \mathrm{E}-02$ & 2 & $9.60 \mathrm{E}-02$ & $2.40 \mathrm{E}-02$ \\
\hline 461 & Cyclooctane, ethenyl- & $61142-41-4$ & $9.60 \mathrm{E}-02$ & 1 & $9.60 \mathrm{E}-02$ & $9.60 \mathrm{E}-02$ \\
\hline
\end{tabular}




\begin{tabular}{|c|c|c|c|c|c|c|}
\hline & $\mathbf{B}$ & $\mathbf{C}$ & $\mathrm{D}$ & $\bar{F}$ & $\mathbf{G}$ & $\mathrm{H}$ \\
\hline 1 & TANK CHEMICALS & CAS \# & $\begin{array}{l}\text { Mean } \\
(\mathrm{mg} / \mathrm{m} 3)\end{array}$ & $\begin{array}{l}\text { Number of } \\
\text { tanks }\end{array}$ & $\begin{array}{l}\text { Maximum } \\
(\mathrm{mg} / \mathrm{m} 3)\end{array}$ & $\begin{array}{l}\text { Minimum } \\
(\mathrm{mg} / \mathrm{m} 3)\end{array}$ \\
\hline 462 & Butane, 2,2-dimethyl- & $75-83-2$ & $4.00 \mathrm{E}-02$ & 3 & $9.30 \mathrm{E}-02$ & $7.70 \mathrm{E}-03$ \\
\hline 463 & 2-Undecene, 2,5 -dimethyl- & $49622-16-4$ & $9.11 \mathrm{E}-02$ & 1 & $9.11 \mathrm{E}-02$ & 9.11E-02 \\
\hline 464 & Tridecanenitrile & $629-60-7$ & $8.94 \mathrm{E}-02$ & 1 & $8.94 \mathrm{E}-02$ & $8.94 \mathrm{E}-02$ \\
\hline 465 & 2(3H)-Furanone, 5-ethyldihydro- & $695-06-7$ & 1.33E-02 & 9 & 8.91E-02 & $5.20 \mathrm{E}-04$ \\
\hline 466 & Pyridine, 2,5-dimethyl- & $589-93-5$ & 8.87E-02 & 1 & $8.87 E-02$ & 8.87E-02 \\
\hline 467 & Undecane, 3,9-dimethyl- & $17301-31-4$ & $8.84 E-02$ & 1 & $8.84 \mathrm{E}-02$ & $8.84 E-02$ \\
\hline 468 & Benzene, (ethylsulfonyl)- & $599-70-2$ & $8.78 \mathrm{E}-02$ & 1 & $8.78 \bar{E}-02$ & $8.78 \mathrm{E}-02$ \\
\hline 469 & 2-Hexene, $(E)-$ & $4050-45-7$ & $8.75 \mathrm{E}-02$ & 1 & $8.75 E-02$ & $8.75 E-02$ \\
\hline 470 & Phenol & $108-95-2$ & $3.14 \mathrm{E}-02$ & 7 & $8.74 \mathrm{E}-02$ & 6.18E-03 \\
\hline 471 & 3-Penten-2-one, 4-methyl- & $141-79-7$ & 8.64E-02 & 1 & $8.64 E-02$ & 8.64E-02 \\
\hline 472 & Nitric acid, hexyl ester & $20633-11-8$ & $2.90 \mathrm{E}-02$ & 8 & $860 \mathrm{E}-02$ & 1.49E-03 \\
\hline 473 & 1,3-Pentadiene, $(Z)$ - & $1574-41-0$ & $8.44 \mathrm{E}-02$ & 1 & $8.44 \mathrm{E}-02$ & $8.44 \mathrm{E}-02$ \\
\hline 474 & $\begin{array}{l}t \text {-Butanamine, } 1,1,2,2,3,3,4,4,4-\text { nonaftuoro-N,N } \\
\text { bis(nonafluorobutyl)- }\end{array}$ & $311-89-7$ & 8.31E-02 & 1 & 8.31E-02 & 8.31E-02 \\
\hline 475 & 4-Undecanone & $14476-37-0$ & $8.23 \mathrm{E}-02$ & 1 & $8.23 E-02$ & $8.23 \mathrm{E}-02$ \\
\hline 476 & Methane, trichloro- & $67-66-3$ & $2.35 \mathrm{E}-02$ & 8 & $8.18 E-02$ & $5.33 \mathrm{E}-04$ \\
\hline 477 & Furan, 2-methyl- & $534-22-5$ & $8.00 \mathrm{E}-02$ & 1 & $8.00 \mathrm{E}-02$ & $8.00 E-02$ \\
\hline 478 & 3-Buten-2-one, 3-methy|- & $814-78-8$ & $4.07 \mathrm{E}-02$ & 2 & 8.00E-02 & 1.39E-03 \\
\hline 479 & 1-Undecene, 7-methyl- & $74630-42-5$ & 7.97E-02 & 1 & $7.97 E-02$ & $7.97 \mathrm{E}-02$ \\
\hline 480 & Benzene, 1,3-dimethyl- & $108-38-3$ & $3.93 E-02$ & 7 & $7.94 E-02$ & $1.44 \mathrm{E}-02$ \\
\hline 481 & Butanamide & $541-35-5$ & $5.68 \mathrm{E}-02$ & 2 & $7.87 \mathrm{E}-02$ & $3.49 \mathrm{E}-02$ \\
\hline 482 & Cyclohexane, 1-methyl-2-propyl- & $4291-79-6$ & $6.03 \mathrm{E}-02$ & 2 & $7.84 \mathrm{E}-02$ & $4.22 \mathrm{E}-02$ \\
\hline 483 & Butanal, 3-methyl- & $590-86-3$ & $5.10 \mathrm{E}-02$ & 2 & $7.70 \mathrm{E}-02$ & $2.51 \mathrm{E}-02$ \\
\hline 484 & Cyclohexane, 1-methyl-3-penty|- & $54411-02-8$ & $3.26 \mathrm{E}-02$ & 3 & $7.69 \mathrm{E}-02$ & $9.10 \mathrm{E}-03$ \\
\hline 485 & Hexane, 2,4-dimethyl- & $589-43-5$ & 4.04E-02 & 2 & $7.67 \mathrm{E}-02$ & $4.10 \mathrm{E}-03$ \\
\hline 486 & Dodecane, 5,8-diethyl- & $24251-86-3$ & $5.25 E-02$ & 2 & $7.63 \mathrm{E}-02$ & $2.87 \mathrm{E}-02$ \\
\hline 487 & t-Tetradecene & $1120-36-1$ & $2.82 \mathrm{E}-02$ & 3 & $7.49 \mathrm{E}-02$ & $1.61 \mathrm{E}-03$ \\
\hline 488 & Benzonitrile & $100-47-0$ & $2.76 \mathrm{E}-\mathrm{O} 2$ & 3 & $7.47 E-02$ & $2.06 \mathrm{E}-03$ \\
\hline 489 & 2-Furanmethanol, tetrahydro- & $97-99-4$ & 7.45E-02 & 1 & $7.45 E-02$ & 7.45E-02 \\
\hline 490 & Octadecane & $593-45-3$ & $2.05 \mathrm{E}-02$ & 6 & $7.43 \mathrm{E}-02$ & $1.50 \mathrm{E}-03$ \\
\hline 491 & Heptane, 3-ethyl-2-methyl- & $14676-29-0$ & $2.35 \mathrm{E}-02$ & 6 & $7.33 \mathrm{E}-02$ & $1.43 \mathrm{E}-03$ \\
\hline 492 & 2-Butenal & $4170-30-3$ & 4.34E-02 & 4 & $7.22 \mathrm{E}-02$ & $2.17 E-03$ \\
\hline 493 & Cyciohexadecane & $295-65-8$ & $2.75 \mathrm{E}-02$ & 3 & $7.10 \mathrm{E}-02$ & $2.80 \mathrm{E}-03$ \\
\hline 494 & Ethene, 1,1-dichloro- & $75-35-4$ & $1.22 \mathrm{E}-02$ & 22 & $7.06 \mathrm{E}-02$ & $3.50 \mathrm{E}-04$ \\
\hline 495 & 5-Hexen-1-ol & $821-41-0$ & $7.06 \mathrm{E}-02$ & 1 & $7.06 \mathrm{E}-02$ & $7.06 E-02$ \\
\hline 496 & Butane, 2,2,3,3-tetramethyl- & $594-82-1$ & $7.00 E-02$ & 1 & $7.00 \mathrm{E}-02$ & $7.00 \mathrm{E}-02$ \\
\hline 497 & 2,3-Pentanedione & $600-14-6$ & 7.00E-02 & 1 & $7.00 \mathrm{E}-02$ & $7.00 \mathrm{E}-02$ \\
\hline 498 & 2-Butanol, 2-methyl- & $75-85-4$ & $7.00 \mathrm{E}-02$ & 1 & $7.00 \mathrm{E}-02$ & $7.00 E-02$ \\
\hline 499 & 9-Octadecenoic acid (Z)- & $112-80-1$ & $2.48 \mathrm{E}-02$ & 4 & $6.92 \mathrm{E}-02$ & $2.60 \mathrm{E}-03$ \\
\hline 500 & 2-Oxazolidinone, 5-methyl-3-(2-propenyl)- & $55956-20-2$ & $3.05 \mathrm{E}-02$ & 3 & $6.73 \mathrm{E}-02$ & $4.14 E-03$ \\
\hline 501 & 1H-Pyrazole, 4,5-dihydro-5-methyl- & $1568-20-3$ & $6.68 \mathrm{E}-02$ & 1 & $6.68 \mathrm{E}-02$ & $6.68 \mathrm{E}-02$ \\
\hline 502 & Hexadecane, 2-methyl- & $1560-92-5$ & $3.71 \mathrm{E}-02$ & 2 & $6.61 \mathrm{E}-02$ & B.00E-03 \\
\hline 503 & 1,3-Pentadiene, (E)- & $2004-70-8$ & $6.60 \mathrm{E}-02$ & 1 & $6.60 \mathrm{E}-02$ & $6.60 E-02$ \\
\hline 504 & Pentadecane, 3-methyl- & $2882-96-4$ & $6.42 \mathrm{E}-02$ & 1 & $6.42 E-02$ & $6.42 E-02$ \\
\hline 505 & 2-Decanone & $693-54-9$ & 1.73E-02 & 7 & $6.40 \mathrm{E}-02$ & $2.10 \mathrm{E}-03$ \\
\hline 506 & 2-Nonen-4-one & $32064-72-5$ & $6.33 \mathrm{E}-02$ & 1 & $6.33 \mathrm{E}-02$ & $6.33 \mathrm{E}-02$ \\
\hline 507 & Ethane, 1,1,1-trichloro- & $71-55-6$ & $966 \mathrm{E}-03$ & 8 & $6.31 \mathrm{E}-02$ & $7.94 \mathrm{E}-04$ \\
\hline 508 & Benzothiazole, 2-phenyl- & $883-93-2$ & $2.43 \mathrm{E}-02$ & 4 & $6.23 \mathrm{E}-02$ & $2.68 \mathrm{E}-03$ \\
\hline 509 & 3-Butenenitrile & $109-75-1$ & $3.45 \mathrm{E}-\mathrm{O} 2$ & 2 & $6.20 \mathrm{E}-02$ & $6.95 E-03$ \\
\hline 510 & Propane, 2-methyl-2-nitro- & $594-70-7$ & $2.54 \mathrm{E}-02$ & 14 & $6.20 \mathrm{E}-02$ & 5.15E-03 \\
\hline 511 & Oxazole, 4,5-dihydro-2-methyl- & $1120 \cdot 64-5$ & $2.32 \mathrm{E}-02$ & 6 & $6.19 \mathrm{E}-02$ & $2.41 \mathrm{E}-03$ \\
\hline 512 & Pyridine, 2-methyl- & $109-06-8$ & $6.11 \mathrm{E}-02$ & 1 & $6.1 \mathrm{tE}-02$ & $6.11 \mathrm{E}-02$ \\
\hline
\end{tabular}




\begin{tabular}{|c|c|c|c|c|c|c|}
\hline & B & $\mathbf{c}$ & $\mathrm{D}$ & $\mathbf{F}$ & $\mathbf{G}$ & $\mathbf{H}$ \\
\hline 1 & TANK CHEMICALS & CAS \# & $\begin{array}{l}\text { Mean } \\
(\mathbf{m g} / \mathrm{m} 3)\end{array}$ & $\begin{array}{c}\text { Number of } \\
\text { tanks }\end{array}$ & $\begin{array}{c}\text { Maximum } \\
(\mathrm{mg} / \mathrm{m} 3)\end{array}$ & $\begin{array}{c}\text { Minimum } \\
(\mathrm{mg} / \mathrm{m} 3)\end{array}$ \\
\hline 513 & Benzothiazole & $95-16-9$ & $1.72 E-02$ & 4 & $6.10 \mathrm{E}-02$ & $1.15 \mathrm{E}-03$ \\
\hline 514 & Docosane, 7-hexyl- & $55373-86-9$ & $6.08 \mathrm{E}-02$ & 1 & $6.08 \mathrm{E}-02$ & $6.08 \mathrm{E}-02$ \\
\hline 515 & 1,4-Dioxane & $123-91-1$ & $3.41 \mathrm{E}-02$ & 4 & $6.04 \mathrm{E}-02$ & $9.54 \mathrm{E}-03$ \\
\hline 516 & Cyclopropane, 1-ethyl-2-heptyl- & $74663-86-8$ & $6.00 \mathrm{E}-02$ & 1 & $6.00 \mathrm{E}-02$ & $6.00 \mathrm{E}-02$ \\
\hline 517 & Propanenitrile, 2-methyl- & $78-82-0$ & $6.00 \mathrm{E}-02$ & 1 & $6.00 \mathrm{E}-02$ & $6.00 \mathrm{E}-02$ \\
\hline 518 & Ethanone, 1-phenyl- & $98-86-2$ & $1.27 \mathrm{E}-02$ & 12 & $6.00 \mathrm{E}-02$ & $2.40 \mathrm{E}-03$ \\
\hline 519 & Bicyclo[2.2.2]octane, 1,2,3,6-tetramethyl- & $62338-45-8$ & $6.00 \mathrm{E}-02$ & 1 & $6.00 \mathrm{E}-02$ & $6.00 \mathrm{E}-02$ \\
\hline 520 & Formamide, N-butyl- & $871-71-6$ & $5.80 \mathrm{E}-02$ & 1 & $5.80 \mathrm{E}-02$ & $5.80 \mathrm{E}-02$ \\
\hline 521 & Cyclopentanol & $96-41-3$ & $5.80 \mathrm{E}-02$ & 1 & $5.80 \mathrm{E}-02$ & $5.80 \mathrm{E}-02$ \\
\hline 522 & Pentadecane, 2,6,10,14-tetramethyl- & $1921-70-6$ & $1.98 \mathrm{E}-02$ & 5 & $5.74 \mathrm{E}-02$ & $3.78 \mathrm{E}-03$ \\
\hline$\overline{523}$ & Nonane, 5-(2-methylpropyl)- & $62185-53-9$ & $2.95 \mathrm{E}-02$ & 2 & $5.74 \mathrm{E}-02$ & $1.69 \mathrm{E}-03$ \\
\hline 524 & Silane, dimethoxydimethyl- & $1112-39-6$ & $2.78 \mathrm{E}-02$ & 3 & $5.64 \mathrm{E}-02$ & $1.16 \mathrm{E}-02$ \\
\hline 525 & Cyclohexene, 1-pentyl- & $15232-85-6$ & $3.01 \mathrm{E}-02$ & 2 & $5.44 \mathrm{E}-02$ & $5.87 \mathrm{E}-03$ \\
\hline 526 & Nonane, 3-methyl- & $5911-04-6$ & $5.43 \mathrm{E}-02$ & 1 & $5.43 \mathrm{E}-02$ & $5.43 \mathrm{E}-02$ \\
\hline 527 & 2,2'-Bioxepane & $74793-02-5$ & $2.22 \mathrm{E}-02$ & 5 & $5.36 \mathrm{E}-02$ & $2.00 \mathrm{E}-03$ \\
\hline 528 & 1-Hexadecanol, acetate & $629-70-9$ & $2.21 \mathrm{E}-02$ & 3 & $5.36 \mathrm{E}-02$ & $4.50 \mathrm{E}-03$ \\
\hline 529 & Benzene, $(1,1$-dimethylethyl)- & $98-06-6$ & $3.88 \mathrm{E}-02$ & 2 & $5.32 \mathrm{E}-02$ & $2.45 \mathrm{E}-02$ \\
\hline 530 & 2-Propanone, 1,1,1-trifluoro- & $421-50-1$ & $5.20 \mathrm{E}-02$ & 1 & $5.20 \mathrm{E}-02$ & $5.20 \mathrm{E}-02$ \\
\hline 531 & Joxirane & $75-21-8$ & $5.19 \mathrm{E}-02$ & 1 & $5.19 \mathrm{E}-02$ & 5.19E-02 \\
\hline 532 & 2-Butanone, 3,3-dimethyl- & $75-97-8$ & $1.95 \mathrm{E}-02$ & 8 & $5.09 \mathrm{E}-02$ & $2.00 \mathrm{E}-03$ \\
\hline 533 & $\begin{array}{l}\text { Cyclohexane, 1,2,4,5-tetraethyl-, } \\
\text { (1. alpha, 2.alpha , 4 alpha, 5. alph a.)- }\end{array}$ & $61142-24-3$ & $5.07 \mathrm{E}-02$ & 1 & $5.07 \mathrm{E}-02$ & $5.07 \mathrm{E}-02$ \\
\hline 534 & Heptadecane, 3-methyl- & $6418-44-6$ & $5.03 \mathrm{E}-02$ & 1 & $5.03 E-02$ & $5.03 E-02$ \\
\hline 535 & 1-Undecene, 8-methyl- & $74630-40-3$ & $5.02 \mathrm{E}-02$ & 1 & $5.02 \mathrm{E}-02$ & $5.02 \mathrm{E}-02$ \\
\hline 536 & Cyclopentane, 1,2-dimethyl- & $2452-99-5$ & $3.00 \mathrm{E}-02$ & 2 & $5.00 \mathrm{E}-02$ & $9.93 \mathrm{E}-03$ \\
\hline 537 & Acetamide, N, N-dimethyl- & $127-19-5$ & $4.99 \mathrm{E}-02$ & 1 & $4.99 \mathrm{E}-02$ & $4.99 \mathrm{E}-02$ \\
\hline 538 & Furan, 2,3-dihydro- & 1191-99-7 & $2.61 \mathrm{E}-02$ & 4 & $4.92 \mathrm{E}-02$ & $1.55 \mathrm{E}-03$ \\
\hline 539 & Butane, 1-nitro- & $627-05-4$ & $1.94 \mathrm{E}-02$ & 3 & $4.90 \mathrm{E}-02$ & $2.77 \mathrm{E}-03$ \\
\hline 540 & 3-Hexen-2-one & $763-93-9$ & 4. $90 \mathrm{E}-02$ & 1 & $4.90 \mathrm{E}-02$ & $4.90 \mathrm{E}-02$ \\
\hline 541 & Benzenemethanol & $100-51-6$ & $1.65 \mathrm{E}-02$ & 9 & $4.87 \mathrm{E}-02$ & $1.77 \mathrm{E}-03$ \\
\hline 542 & Cyclopropane, 1,2-dimethyl- trans- & $2402-06-4$ & $4.85 \mathrm{E}-02$ & 1 & 4.85E-02 & $4.85 \mathrm{E}-02$ \\
\hline 543 & 1,3-Butadiene, 2,3-dimethyl- & $513-81-5$ & $4.84 E-02$ & 1 & 4.84E-02 & $4.84 \mathrm{E}-02$ \\
\hline 544 & Silane, chlorotrimethyl- & $75-77-4$ & $1.74 E-02$ & 7 & $4.80 \mathrm{E}-02$ & $2.85 \mathrm{E}-03$ \\
\hline 545 & 2-Propenal, 2-methyl- & $78-85-3$ & $2.73 \mathrm{E}-02$ & 2 & $4.75 \mathrm{E}-02$ & $7.08 \mathrm{E}-03$ \\
\hline 546 & Decane 3-cyciohexyl-, 3-cyclohexyl- & $13151-74-1$ & $2.36 \bar{E}-02$ & 3 & $4.75 \mathrm{E}-02$ & $7.38 \mathrm{E}-03$ \\
\hline 547 & Oxazole, 4,5-dimethyl-2-propyl- & $53833-32-2$ & $3.59 \mathrm{E}-02$ & 3 & $4.69 \mathrm{E}-02$ & $2.78 \mathrm{E}-02$ \\
\hline 548 & Bicyclo[3.3.1]nonane & $280-65-9$ & $4.68 \mathrm{E}-02$ & 1 & $4.68 \mathrm{E}-02$ & $4.68 \mathrm{E}-02$ \\
\hline 549 & $1,1^{\prime}$-Bicyclohexyl & $92-51-3$ & $4.62 \mathrm{E}-02$ & 1 & $4.62 \mathrm{E}-02$ & $4.62 \mathrm{E}-02$ \\
\hline 550 & Heptadecane, 2,6,10, 14-tetramethyl- & $18344-37-1$ & $4.56 \mathrm{E}-02$ & 1 & 4.56E-02 & $4.56 \mathrm{E}-02$ \\
\hline 551 & Heptadecane & $629-78-7$ & $1.29 \mathrm{E}-02$ & 14 & $4.53 \mathrm{E}-02$ & $4.30 \mathrm{E}-04$ \\
\hline 552 & 2-Butanol, $(R)$ - & $14898-79-4$ & $4.52 \mathrm{E}-02$ & 1 & $4.52 \mathrm{E}-02$ & $4.52 \mathrm{E}-02$ \\
\hline 553 & Cyclopropane, pentyl- & 2511-91-3 & $2.46 \mathrm{E}-02$ & 2 & $4.47 \mathrm{E}-02$ & $4.50 \mathrm{E}-03$ \\
\hline 554 & Nonanenitrile & $2243-27-8$ & 1.24E-02 & 16 & $4.45 \mathrm{E}-02$ & $2.55 \mathrm{E}-04$ \\
\hline 555 & Propane, 2-isocyanato- & $1795-48-8$ & $4.41 \mathrm{E}-02$ & 1 & $4.41 \mathrm{E}-02$ & 4.41E-02 \\
\hline 556 & 1-Decene & $872-05-9$ & $1.99 \mathrm{E}-02$ & 4 & $4.40 \mathrm{E}-02$ & $1.33 \mathrm{E}-03$ \\
\hline 557 & Benzene, 1 -ethyl-2-methyl- & $611-14-3$ & $4.39 E-02$ & 1 & $4.39 \mathrm{E}-02$ & $4.39 \mathrm{E}-02$ \\
\hline 558 & $2(3 \mathrm{H})$-Furanone, dihydro-5-methyl- & $108-29-2$ & $1.25 \mathrm{E}-02$ & 4 & $4.37 \mathrm{E}-02$ & $1.34 \mathrm{E}-03$ \\
\hline 559 & 4-Piperidinemethanol, 1-methyl- & $20691-89-8$ & 4.28E-02 & 1 & $4.28 \mathrm{E}-02$ & $4.28 \mathrm{E}-02$ \\
\hline 560 & 5-Decanone & $820-29-1$ & 2.19E-02 & 2 & $4.27 \mathrm{E}-02$ & $9.77 \mathrm{E}-04$ \\
\hline 561 & 14-Pentadecenoic acid & $17351-34-7$ & $2.62 \mathrm{E}-02$ & 2 & $4.24 \mathrm{E}-02$ & $1.00 \mathrm{E}-02$ \\
\hline 562 & 3-Pentanone & $96-22-0$ & $1.87 \mathrm{E}-02$ & 4 & $4.22 \mathrm{E}-02$ & $3.23 \mathrm{E}-03$ \\
\hline 563 & Cyclopropane, 1,2-dibutyl- & $41977-32-6$ & $4.21 \mathrm{E}-02$ & 1 & $4.21 \mathrm{E}-02$ & $4.21 \mathrm{E}-02$ \\
\hline
\end{tabular}




\begin{tabular}{|c|c|c|c|c|c|c|}
\hline & B & C & D & $\mathbf{F}$ & $\mathbf{G}$ & $\mathrm{H}$ \\
\hline 1 & TANK CHEMICALS & CAS \# & $\underset{(m g / m 3)}{\text { Mean }}$ & $\begin{array}{l}\text { Number of } \\
\text { tanks }\end{array}$ & $\begin{array}{c}\text { Maximum } \\
(\mathrm{mg} / \mathrm{m} 3)\end{array}$ & $\underset{(\mathrm{mg} / \mathrm{m} 3)}{\text { Minimum }}$ \\
\hline 564 & 5-Undecanone & $33083-83-9$ & $2.61 E-02$ & 2 & $4.04 \mathrm{E}-02$ & $1.17 \mathrm{E}-02$ \\
\hline 565 & 3-Hepten-2-one, 4-methyl- & $22319-25-1$ & $4.01 \mathrm{E}-02$ & 1 & $4.01 \mathrm{E}-02$ & 4.01E-02 \\
\hline 566 & Cyclooctane, 1,4-dimethyl-, cis- & 13151-99-0 & $4.00 \mathrm{E}-02$ & 1 & $4.00 \mathrm{E}-02$ & $4.00 \mathrm{E}-02$ \\
\hline 567 & Tetradecane, 4-ethyl- & $55045-14-2$ & $4.00 \mathrm{E}-02$ & 1 & $4.00 \mathrm{E}-02$ & $4.00 \mathrm{E}-02$ \\
\hline 568 & Furan, 2,5-dimethyl- & $625-86-5$ & $4.00 E-02$ & 1 & $4.00 \mathrm{E}-02$ & $4.00 \mathrm{E}-02$ \\
\hline 569 & Cyclopentane, ethyl- & $1640-89-7$ & $2.49 \mathrm{E}-02$ & 2 & $4.00 \mathrm{E}-02$ & $9.75 \mathrm{E}-03$ \\
\hline 570 & 3-Hexadecene, $(Z)-$ & $34303-81-6$ & $2.10 \mathrm{E}-02$ & 2 & $4.00 \mathrm{E}-02$ & $2.00 \mathrm{E}-03$ \\
\hline 571 & Dodecane, 2-methyl-6-propyl- & $55045-08-4$ & $2.09 \mathrm{E}-02$ & 4 & $4.00 \mathrm{E}-02$ & $5.10 \mathrm{E}-03$ \\
\hline 572 & 1-Propanone, 1-[4-[(trimethylsilyl)oxy]phenyl]-- & $33342-89-1$ & $3.94 \mathrm{E}-02$ & 1 & $3.94 \mathrm{E}-02$ & $3.94 \mathrm{E}-02$ \\
\hline 573 & Heptane, 3-ethyl- & $15869-80-4$ & $3.83 \mathrm{E}-02$ & 1 & $3.83 \mathrm{E}-02$ & $3.83 \mathrm{E}-02$ \\
\hline 574 & 1,1'-Biphenyl, 2-chloro- & $2051-60-7$ & $1.39 \mathrm{E}-02$ & 4 & $3.81 \mathrm{E}-02$ & $1.67 \mathrm{E}-03$ \\
\hline 575 & Butanoic acid, 2-hexenyl ester, (E)- & $5 \overline{3398-83-7}$ & $3.80 \mathrm{E}-02$ & 1 & $3.80 \mathrm{E}-02$ & $3.80 \mathrm{E}-02$ \\
\hline 576 & 2-Hexene, (Z)- & $7688-21-3$ & $3.06 \mathrm{E}-02$ & 2 & $3.80 \mathrm{E}-02$ & $2.32 \mathrm{E}-02$ \\
\hline 577 & 1,2-Benzenedicarboxylic acid, diethyl ester & $84-66-2$ & $1.78 \mathrm{E}-02$ & 9 & $3.80 \mathrm{E}-02$ & $9.05 \mathrm{E}-04$ \\
\hline 578 & Pyridine, 4-methyl- & $108-89-4$ & 2.13E-02 & 3 & $3.73 \mathrm{E}-02$ & $6.62 \mathrm{E}-03$ \\
\hline 579 & $1 \mathrm{H}$-Indene, octahydro-, cis- & $4551-51-3$ & $3.72 \mathrm{E}-02$ & 1 & $3.72 \mathrm{E}-02$ & $3.72 \mathrm{E}-02$ \\
\hline 580 & 3-Hexanol & $623-37-0$ & $3.71 \mathrm{E}-02$ & 1 & $3.71 \mathrm{E}-02$ & $3.71 \mathrm{E}-02$ \\
\hline 581 & $\begin{array}{l}\text { Propanoic acid, 2-methyl-, 1-(1,1-dimethylethyl) } \\
\text { 2-methyl-1,3-propanediyl ester }\end{array}$ & $74381-40-1$ & $1.65 E-02$ & 6 & $3.69 \mathrm{E}-02$ & $4.50 \mathrm{E}-04$ \\
\hline 582 & 2-Pentene, 2,4-dimethyl- & $625-65-0$ & $1.88 \mathrm{E}-02$ & 2 & $3.66 \mathrm{E}-02$ & $1.05 \mathrm{E}-03$ \\
\hline 583 & 1,1'-Biphenyl, 3-chloro- & $2051-61-8$ & $2.15 \mathrm{E}-02$ & 2 & $3.59 \mathrm{E}-02$ & $7.03 E-03$ \\
\hline 584 & 1-Pentanol, 4-methyl-2-propyl- & $54004-41-0$ & $3.51 E-02$ & 1 & $3.51 \mathrm{E}-02$ & $3.51 \mathrm{E}-02$ \\
\hline 585 & Pentane, 1-methoxy- & $628-80-8$ & $3.50 \mathrm{E}-02$ & 1 & $3.50 \mathrm{E}-02$ & $3.50 \mathrm{E}-02$ \\
\hline 586 & 1-Butanamine, N-ethylidene- & $6898-74-4$ & $1.90 \mathrm{E}-02$ & 2 & $3.49 \mathrm{E}-02$ & $3.03 \mathrm{E}-03$ \\
\hline 587 & 2-Hexene, 4,4,5-trimethy|- & $55702-61-9$ & $3.40 \mathrm{E}-02$ & 1 & $3.40 \mathrm{E}-02$ & $3.40 \mathrm{E}-02$ \\
\hline 588 & 1-Octen-3-one & $4312-99-6$ & $3.40 \mathrm{E}-02$ & 1 & $3.40 \mathrm{E}-02$ & $3.40 E-02$ \\
\hline 589 & $\begin{array}{l}\text { Benzeneacetic acid, alpha.,4- } \\
\text { bis[(trimethylsilyl)oxy], methyl ester }\end{array}$ & $55334-40-2$ & $1.90 \mathrm{E}-02$ & 2 & 3.34E-02 & $4.60 E-03$ \\
\hline 590 & Pentane, 2,3-dimethyl- & $565-59-3$ & $1.86 \mathrm{E}-02$ & 2 & $3.28 \mathrm{E}-02$ & $4.40 \mathrm{E}-03$ \\
\hline 591 & Butanoic acid, butyl ester & $109-21-7$ & $1.08 \mathrm{E}-02$ & 5 & 3.27E-02 & 1.20E-03 \\
\hline 592 & 3-Hexanone, 2,5-dimethyl- & $1888-57-9$ & $3.26 \mathrm{E}-02$ & 1 & $3.26 \mathrm{E}-02$ & $3.26 \mathrm{E}-02$ \\
\hline 593 & 2-Propanol, 1-(1-methylethoxy)- & $3944-36-3$ & $3.25 \mathrm{E}-02$ & 1 & $3.25 \mathrm{E}-02$ & $3.25 \mathrm{E}-02$ \\
\hline 594 & 1,3,5,7-Tetraazatricyclo[3,3,1,13,7]decane & $100-97-0$ & $1.44 \mathrm{E}-02$ & 7 & $3.19 \mathrm{E}-02$ & $5.58 \mathrm{E}-03$ \\
\hline 595 & Butane, 2,3-dimethyl- & $79-29-8$ & $3.18 \mathrm{E}-02$ & 1 & $3.18 \mathrm{E}-02$ & $3.18 \mathrm{E}-02$ \\
\hline 596 & 2-Heptene, (E)- & $14686-13-6$ & $1.25 E-02$ & 4 & $3.17 \mathrm{E}-02$ & $1.38 \mathrm{E}-03$ \\
\hline 597 & $\begin{array}{l}\text { Benzoic acid, 2-l(trimethylsilyl)oxyl-, } \\
\text { trimethylsilyl ester }\end{array}$ & $3789-85-3$ & $9.40 \mathrm{E}-03$ & 14 & $3.14 \mathrm{E}-02$ & $8.20 E-04$ \\
\hline 598 & 1-Butene, 3,3-dimethyl- & $558-37-2$ & $3.14 \mathrm{E}-02$ & 1 & $3.14 \mathrm{E}-02$ & $3.14 \mathrm{E}-02$ \\
\hline 599 & 1,2-Pentadiene & $591-95-7$ & $3.13 \mathrm{E}-02$ & 1 & $3.13 \mathrm{E}-02$ & $3.13 \mathrm{E}-02$ \\
\hline 600 & 4-Dodecene & $2030-84-4$ & $3.10 \mathrm{E}-02$ & 1 & $3.10 \mathrm{E}-02$ & $3.10 \mathrm{E}-02$ \\
\hline 601 & Octane, 2,5,6-trimethy|- & $62016-14-2$ & $3.04 \mathrm{E}-02$ & 2 & $3.08 \mathrm{E}-02$ & $3.00 \mathrm{E}-02$ \\
\hline 602 & 5-Tridecanone & $30692-16-1$ & $1.68 \mathrm{E}-02$ & 4 & $3.02 \mathrm{E}-02$ & $1.86 \mathrm{E}-03$ \\
\hline 603 & 1,4-Hexadiene, 4-methyl- & $1116-90-1$ & $3.00 \mathrm{E}-02$ & 1 & $3.00 E-02$ & $3.00 \mathrm{E}-02$ \\
\hline 604 & Cyclopentane, 1-methyl-2-(2-propenyl)-, trans- & 50746-53-7 & $3.00 \mathrm{E}-02$ & 1 & $3.00 \mathrm{E}-02$ & $3.00 \mathrm{E}-02$ \\
\hline 605 & $\begin{array}{l}\text { Cyclopentane, } 1,2,4 \text {-trimethyl- } \\
\text { (1. alpha., 2.alpha. 4 beta.)- }\end{array}$ & $4850-28-6$ & 1.80E-02 & 2 & 3.00E-02 & $6.00 \mathrm{E}-03$ \\
\hline 606 & 3-Heptanone, 6-methyl- & $624-42-0$ & $1.53 \mathrm{E}-02$ & 3 & $3.00 \mathrm{E}-02$ & $4.96 \mathrm{E}-03$ \\
\hline 607 & Hexanedioic acid, mono(2-ethythexyl) ester & $4337-65-9$ & $3.00 \mathrm{E}-02$ & 1 & $3.00 \mathrm{E}-02$ & $3.00 \mathrm{E}-02$ \\
\hline 608 & Benzene, 1,2,4-trimethyl- & 95-63-6! & $1.46 \mathrm{E}-02$ & 4 & $2.99 \mathrm{E}-02$ & $1.34 \mathrm{E}-03$ \\
\hline 609 & Pentane, 2-cyclopropyl- & $5458-16-2$ & $2.91 \mathrm{E}-02$ & 1 & $2.91 \mathrm{E}-02$ & $2.91 \mathrm{E}-02$ \\
\hline 610 & Naphthalene, decahydro-1,5-dimethyl- & $66552-62-3$ & $1.54 \mathrm{E}-02$ & 3 & $2.91 \mathrm{E}-02$ & $7.00 \mathrm{E}-03$ \\
\hline 611 & 2-Pentene, 4-methyl- (E)- & 674-76-0i & $2.86 \mathrm{E}-02$ & 1 & $2.86 \mathrm{E}-02$ & $2.86 \mathrm{E}-02$ \\
\hline
\end{tabular}




\begin{tabular}{|c|c|c|c|c|c|c|}
\hline & $\bar{B}$ & $\mathrm{C}$ & $D$ & $\mathbf{F}$ & $\bar{G}$ & $\bar{H}$ \\
\hline 1 & TANK CHEMICALS & CAS \# & $\begin{array}{c}\text { Mean } \\
(\mathrm{mg} / \mathrm{m} 3)\end{array}$ & $\begin{array}{c}\text { Number of } \\
\text { tanks }\end{array}$ & $\begin{array}{c}\text { Maximum } \\
(\mathrm{mg} / \mathrm{m} 3)\end{array}$ & $\begin{array}{c}\text { Minimum } \\
(\mathrm{mg} / \mathrm{m} 3)\end{array}$ \\
\hline 612 & Benzene, propyl- & $103-65-1$ & $1.38 \mathrm{E}-02$ & $\overline{4}$ & $2.80 E-02$ & $3.25 \mathrm{E}-03$ \\
\hline 613 & 1-Propanol, 2-methyl- & $78-83-1$ & $1.18 \mathrm{E}-02$ & 4 & $2.80 \mathrm{E}-02$ & $1.30 \mathrm{E}-03$ \\
\hline 614 & Decane, 5-propyl- & $17312-62-8$ & $1.74 \mathrm{E}-02$ & 2 & $2.77 \mathrm{E}-02$ & $7.11 \mathrm{E}-03$ \\
\hline 615 & 1,5-Pentanediol, dinitrate & $3457-92-9$ & $1.42 \mathrm{E}-02$ & 3 & $2.76 \mathrm{E}-02$ & $4.00 \mathrm{E}-03$ \\
\hline 616 & 2,5-Pyrrolidinedione, 1-methyl- & $1121-07-9$ & $1.51 \mathrm{E}-02$ & 2 & $2.76 E-02$ & $2.70 \mathrm{E}-03$ \\
\hline 617 & 1,4-Pentadien-3-ol & $922-65-6$ & $2.73 \mathrm{E}-02$ & 1 & $2.73 E-02$ & $2.73 E-02$ \\
\hline 618 & Cyclopentene, 5-hexyl-3,3-dimethyl- & $61142-66-3$ & 2.70E-02 & 1 & $2.70 \mathrm{E}-02$ & $2.70 \mathrm{E}-02$ \\
\hline 619 & 1H-1,2,4-Triazole & $288-88-0$ & $2.67 \mathrm{E}-02$ & 1 & $2.67 \mathrm{E}-02$ & $2.67 \mathrm{E}-02$ \\
\hline 620 & 1,3-Pentadiene & $504-60-9$ & $2.67 \mathrm{E}-02$ & 1 & $267 \mathrm{E}-02$ & $2.67 \mathrm{E}-02$ \\
\hline 621 & 1-Butanol, 2-methyl-, (S)- & $1565-80-6$ & $2.66 \mathrm{E}-02$ & 1 & $2.66 \mathrm{E}-02$ & $2.66 \mathrm{E}-02$ \\
\hline 622 & Tetradecanoic acid, 1-methylethyl ester & $110-27-0$ & 1.07E-02 & 4 & $2.65 \mathrm{E}-02$ & $1.29 \mathrm{E}-03$ \\
\hline 623 & Cyclododecane, ethyl- & $28981-49-9$ & $2.65 \mathrm{E}-02$ & 1 & $2.65 \mathrm{E}-02$ & $2.65 \mathrm{E}-02$ \\
\hline 624 & Naphthalene, 2-methyl- & $91-57-6$ & $2.65 \mathrm{E}-02$ & 1 & $2.65 \mathrm{E}-02$ & $2.65 \mathrm{E}-02$ \\
\hline 625 & Formamide, $\mathrm{N}-(2$-methylpropyl)- & $6281-96-5$ & $2.61 \mathrm{E}-02$ & 1 & $2.61 \mathrm{E}-02$ & $2.61 \mathrm{E}-02$ \\
\hline 626 & Propanoic acid, 2-methyl-, butyl ester & $97-87-0$ & $2.60 E-02$ & 1 & $2.60 \mathrm{E}-02$ & $2.60 \mathrm{E}-02$ \\
\hline 627 & Cyclopentanone, 2,4-dimethyl- & 1121-33-1 & $2.58 \mathrm{E}-02$ & 1 & $2.58 \mathrm{E}-02$ & $2.58 \mathrm{E}-02$ \\
\hline 628 & 1-Butene, 2,3-dimethyl- & $563-78-0$ & $2.58 \mathrm{E}-02$ & 1 & $2.58 \mathrm{E}-02$ & $2.58 \mathrm{E}-02$ \\
\hline 629 & 3 -Heplene & $592-78-9$ & $257 \mathrm{E}-02$ & 1 & $2.57 \mathrm{E}-02$ & $2.57 \mathrm{E}-02$ \\
\hline 630 & 4-Dodecanone, 11-methyl- & $29366-35-6$ & $2.53 \mathrm{E}-02$ & 1 & $2.53 \mathrm{E}-02$ & $2.53 E-02$ \\
\hline 631 & 5-Decanol & $5205-34-5$ & $2.50 \mathrm{E}-02$ & 1 & $2.50 \mathrm{E}-02$ & $2.50 \mathrm{E}-02$ \\
\hline 632 & Methane, chloro- & $74-87-3$ & $7.30 \mathrm{E}-03$ & 11 & $2.46 E-02$ & $2.25 E-04$ \\
\hline 633 & Cyclopentane, (2-methylpropyl)- & $3788-32-7$ & $2.46 \mathrm{E}-02$ & 1 & $2.46 \mathrm{E}-02$ & $2.46 \mathrm{E}-02$ \\
\hline 634 & Dodecane, 4,9-dipropyl- & $3054-63-5$ & $1 . \overline{51 E-02}$ & 2 & $2.44 \mathrm{E}-02$ & $5.90 \mathrm{E}-03$ \\
\hline 635 & 2-Decanone, 5,9-dimethyl- & $33933-82-3$ & $2.43 \mathrm{E}-02$ & 1 & $2.43 \mathrm{E}-02$ & $2.43 \mathrm{E}-02$ \\
\hline 636 & Ethane, chloro- & $75-00-3$ & $2.42 \mathrm{E}-02$ & 2 & $2.42 \mathrm{E}-02$ & $2.42 \mathrm{E}-02$ \\
\hline 637 & 2-Pentene, 5-(pentyloxy)-, $(E)$ - & $56052-85-8$ & $1.41 \mathrm{E}-02$ & 2 & $2.42 \mathrm{E}-02$ & $4.00 \mathrm{E}-03$ \\
\hline 638 & 2-Octadecenal & $56554-96-2$ & $1.27 \mathrm{E}-02$ & 2 & $2.42 \mathrm{E}-02$ & $1.30 \mathrm{E}-03$ \\
\hline 639 & 1H-Pyrazole, 4,5-dihydro-4,5-dimethyl- & $28019-94-5$ & $2.40 \mathrm{E}-02$ & 1 & $2.40 \mathrm{E}-02$ & $2.40 \mathrm{E}-02$ \\
\hline 640 & Pentane, 3-ethyl-2-methyl- & $\mid 609-26-7$ & $2 . \overline{39 E-02}$ & $i$ & $2.39 \mathrm{E}-02$ & $2.39 \mathrm{E}-02$ \\
\hline 641 & Furan, 2-ethyl-5-methyl- & $1703-52-2$ & $2.35 \bar{E}-02$ & 1 & $2.35 \mathrm{E}-02$ & $2.35 \mathrm{E}-02$ \\
\hline 642 & Undecane, 4,4-dimethyl- & $17312-68-4$ & $2.35 \mathrm{E}-02$ & 1 & $2.35 \mathrm{E}-02$ & $2.35 E-02$ \\
\hline 643 & 1-Heptadecanol & $1454-85-9$ & $2.34 \mathrm{E}-02$ & 1 & $2.34 \mathrm{E}-02$ & $2.34 \mathrm{E}-02$ \\
\hline 644 & 3-Heptene, $(E)$ - & $14686-14-7$ & $1.43 \mathrm{E}-02$ & 2 & $2.33 E-02$ & $5 . \overline{33 E}-03$ \\
\hline 645 & 3-Undecene $(E)$ - & $1002-68-2$ & 2.33E-02 & 1 & $2.33 \mathrm{E}-02$ & $2.33 \mathrm{E}-02$ \\
\hline 646 & Thiophene, 2-methoxy-5-methyl- & $31053-55-1$ & $2.33 \mathrm{E}-02$ & 1 & $2.33 E-02$ & $2.33 \mathrm{E}-02$ \\
\hline 647 & 5-Decene, $(\mathrm{E})-$ & $7433-56-9$ & $1.20 \mathrm{E}-02$ & 2 & $2.28 \mathrm{E}-02$ & $1.08 \mathrm{E}-03$ \\
\hline 648 & 1H-Pyrazole, 4,5-dihydro-5-propy|- & $75011-90-4$ & $2.27 \mathrm{E}-02$ & 1 & $2.27 \mathrm{E}-02$ & $2.27 \mathrm{E}-02$ \\
\hline 649 & Decanal & $112-31-2$ & $6.80 \mathrm{E}-03$ & 13 & $2.27 \mathrm{E}-02$ & $1.11 \mathrm{E}-03$ \\
\hline 650 & Cyclohexane, $1, t^{-}-(1-$ methylethylidene $)$ bis- & $54934-90-6$ & $2.25 \mathrm{E}-02$ & 1 & 2.25E-02 & $2.25 \mathrm{E}-02$ \\
\hline 651 & Bicycto[4.1.0]heptane & $286-08-8$ & $2.25 \mathrm{E}-02$ & 1 & $2.25 E-02$ & $2.25 \mathrm{E}-02$ \\
\hline 652 & 3-Decene & $19398-37-9$ & $2.21 \mathrm{E}-02$ & 1 & $2.21 \mathrm{E}-02$ & $2.21 \mathrm{E}-02$ \\
\hline 653 & Cyclohexane, 1,1,2-trimethyl- & $7094-26-0$ & $2.21 \mathrm{E}-02$ & 1 & $2.21 \mathrm{E}-02$ & $2.21 \mathrm{E}-02$ \\
\hline 654 & Heptasiloxane, hexadecamethyt- & $541-01-5$ & $2.20 \mathrm{E}-02$ & 1 & $2.20 \mathrm{E}-02$ & $2.20 \mathrm{E}-02$ \\
\hline 655 & 1-Octene, 7-methyl- & $13151-06-9$ & $2.18 \mathrm{E}-02$ & 1 & $2.18 \mathrm{E}-02$ & $2.18 \mathrm{E}-02$ \\
\hline 656 & Cyclobutanone, 2-ethyl- & $10374-14-8$ & $2.16 \mathrm{E}-02$ & 1 & $2.16 \mathrm{E}-02$ & $2.16 \mathrm{E}-02$ \\
\hline 657 & 2-Dodecene, 4-methyl- & $56851-45-7$ & $2.16 \mathrm{E}-02$ & 1 & $2.16 \mathrm{E}-02$ & $2.16 \mathrm{E}-02$ \\
\hline 658 & 1,1'-Bicyclohexyl, 2-methyl-, trans- & $50991-09-8$ & 2.16E-02 & 1 & $2.16 \mathrm{E}-02$ & 2.16E-02 \\
\hline 659 & Cyclopropanecarbonitrile & $5500-21-0$ & $1.45 \mathrm{E}-02$ & 2 & $2.15 E-02$ & $7.57 \mathrm{E}-03$ \\
\hline 660 & $\begin{array}{l}\text { 3,6-Dioxa-2,4,5,7-tetrasilaoctane, } \\
2,2,4,4,5,5,7,7 \text {-octamethyl- }\end{array}$ & $4342-25-0$ & $2.14 \mathrm{E}-02$ & 1 & $2.14 \mathrm{E}-02$ & $2.14 \mathrm{E}-02$ \\
\hline 661 & 2,7-Octanediol, 2,7-dimethyl- & 19781-07-8 & $2.13 \mathrm{E}-02$ & $i$ & $2.13 \mathrm{E}-02$ & $2.13 \mathrm{E}-02$ \\
\hline 662 & 1-Pentadecanol & $629-76-5$ & $2.13 \mathrm{E}-02$ & 1 & $2.13 \mathrm{E}-02$ & $2.13 \mathrm{E}-02$ \\
\hline
\end{tabular}




\begin{tabular}{|c|c|c|c|c|c|c|}
\hline & B & C & D & $\mathbf{F}$ & $\mathbf{G}$ & $\mathrm{H}$ \\
\hline 1 & TANK CHEMICALS & CAS \# & $\begin{array}{c}\text { Mean } \\
(\mathrm{mg} / \mathrm{m} 3)\end{array}$ & $\begin{array}{l}\text { Number of } \\
\text { tanks }\end{array}$ & $\begin{array}{c}\text { Maximum } \\
(\mathrm{mg} / \mathrm{m} 3)\end{array}$ & $\begin{array}{l}\text { Minimum } \\
\text { (mg/m3) }\end{array}$ \\
\hline 663 & Silanol, trimethyl- & $1066-40-6 !$ & $9.33 \mathrm{E}-03$ & 3 & $2.12 \mathrm{E}-02$ & $2.58 \mathrm{E}-03$ \\
\hline 664 & Cyclohexanone, 3-methyl- & $591-24-2$ & 2. 10E-02 & 1 & $2.10 E-02$ & $2.10 E-02$ \\
\hline 665 & Cyclohexane, 1,1,3,5-tetramethy -, trans- & $50876-31-8$ & 1.17E-02 & 2 & $2.10 \mathrm{E}-02$ & $2.40 E-03$ \\
\hline 666 & Nonanol & $28473-21-4$ & $1.20 \mathrm{E}-02$ & 2 & $2.07 E-02$ & 3.16E-03 \\
\hline 667 & Propane, 1-nitro- & $108-03-2$ & $2.07 \mathrm{E}-02$ & 1 & 2.07E-02 & $2.07 E-02$ \\
\hline 668 & 3-Hexenal, $(Z)$ - & $6789-80-6$ & 2.07E-02 & 4 & $2.07 \mathrm{E}-02$ & 2.07E-02 \\
\hline 669 & Undecane, 3,4-dimethyl- & $17312-7 \overline{8}-6$ & 2.04E-02 & 1 & $2.04 \mathrm{E}-02$ & $2.04 \mathrm{E}-02$ \\
\hline 670 & 4-Heptanone, 3-methyl- & $15726-15-5$ & $2.03 \mathrm{E}-02$ & 1 & 2.03E-02 & $2.03 E-02$ \\
\hline 671 & Benzene, (1-methylpropyl)- & $135-98-8$ & $2.01 \mathrm{E}-02$ & 1 & 2.01E-02 & 2.01E-02 \\
\hline 672 & Benzene, 1,3,5-trimethyl- & $108-67-8$ & $8.44 \mathrm{E}-03$ & 4 & $2.01 E-02$ & $5.36 \mathrm{E}-04$ \\
\hline 673 & $\begin{array}{l}\text { Cyclohexane, 1,3,5-trimethyl-, } \\
\text { (1.alpha.,3.alpha.,5.alpha.)- }\end{array}$ & $1795-27-3$ & $2.00 E-02$ & 1 & $2.00 E-02$ & 2.00E-02 \\
\hline 674 & Cyclopentane, 1,1,3,4-tetramethyl-, cis- & $53907-60-1$ & 2.00E-02 & 1 & $2.00 E-02$ & $2.00 \mathrm{E}-02$ \\
\hline 675 & 4-Octen-3-one & $14129-48-7$ & $9.65 \mathrm{E}-03$ & 3 & $2.00 \mathrm{E}-02$ & $3.00 \mathrm{E}-03$ \\
\hline 676 & Formic acid, butyl ester & $592-84-7$ & $1.90 \mathrm{E}-02$ & 2 & $1.99 \mathrm{E}-02$ & $1.82 \mathrm{E}-02$ \\
\hline 677 & Octane, 2-methy|- & $3221-61-2$ & 1.95E-02 & 1 & $1.95 E-02$ & $1.95 \mathrm{E}-02$ \\
\hline 678 & Benzene, (1.1-dimethylpropyl)- & $2049-95-8$ & 1.93E-02 & 1 & $1.93 E-02$ & $1.93 E-02$ \\
\hline 679 & Cyclopropane, 1,2-dimethyl-3-methylene-, cis- & $4866-55-1$ & 1.92E-02 & 1 & $1.92 \mathrm{E}-02$ & 1.92E-02 \\
\hline 680 & Cyclohexane, diethyl- & $1331-43-7$ & $1.92 \mathrm{E}-02$ & 1 & $1.92 E-02$ & $1.92 \mathrm{E}-02$ \\
\hline 681 & Pyrazine, methyl- & $109-08-0 !$ & $1.04 \mathrm{E}-02$ & 6 & $1.92 \mathrm{E}-02$ & $2.34 \mathrm{E}-03$ \\
\hline 682 & 7-Tetradecene & $10374-74-0$ & 1.15E-02 & 2 & $1.89 \mathrm{E}-02$ & $4.08 \mathrm{E}-03$ \\
\hline 683 & Hexane, 2,2.3-trimethyl- & $16747-25-4$ & $1.89 \mathrm{E}-02$ & 1 & $1.89 E-02$ & $1.89 E-02$ \\
\hline 684 & Cyclohexene, 1-methyl-4-(1-methylethenyl)- & $138-86-3$ & $1.88 \mathrm{E}-02$ & 1 & $1.88 E-02$ & $1.88 \mathrm{E}-02$ \\
\hline 685 & 3-Hexene, $(Z)$ - & $7642-09-3$ & $1.88 \mathrm{E}-02$ & 1 & $1.88 \mathrm{E}-02$ & $1.88 \mathrm{E}-02$ \\
\hline 686 & 1-Pentene, 2,4,4-trimethyl- & $107-39-1$ & $1.87 \mathrm{E}-02$ & 1 & $1.87 \mathrm{E}-02$ & 1.87E-02 \\
\hline 687 & Heptane, 2,5-dimethyl- & 2216-30-0 & $1.80 \mathrm{E}-02$ & 2 & $1.87 \mathrm{E}-02$ & $1.72 \mathrm{E}-02$ \\
\hline 688 & Heptane, 3,3-dimethyl- & $4032-86-4$ & $1.85 \mathrm{E}-02$ & 1 & $1.85 \mathrm{E}-02$ & $1.85 \mathrm{E}-02$ \\
\hline 689 & 2-Nonenal, (E)- & $18829-56-6$ & $9.51 \mathrm{E}-03$ & 3 & $1.84 \mathrm{E}=02$ & $3.60 \mathrm{E}-03$ \\
\hline 690 & Ethane, 1,2-dibromo- & $106-93-4$ & $1.83 E-02$ & 1 & $1.83 E-02$ & $1.83 \mathrm{E}-02$ \\
\hline 691 & 4-Octanone, 3-methyl- & $20754-04-5$ & $1.83 E-02$ & 1 & 1.83E-02 & 1.83E-02 \\
\hline 692 & 3-Decanol & $1565-81-7$ & $1.83 \mathrm{E}-02$ & 1 & $1.83 \mathrm{E}-02$ & 1.83E-02 \\
\hline 693 & 1-Pentyne & $627-19-0$ & $1.83 \mathrm{E}-02$ & 1 & $1.83 \mathrm{E}-02$ & $1.83 E-02$ \\
\hline 694 & 1-Hexene, 5,5-dimethyl- & $7116-86-11$ & $1.02 \mathrm{E}-02$ & 2 & 1.82E-02 & $2.32 E-03$ \\
\hline 695 & 4-Decanone & $624-16-8$ & $1.55 E-02$ & 2 & $1.82 \mathrm{E}-02$ & $1.28 E-02$ \\
\hline 696 & $2,4(3 \mathrm{H}, 5 \mathrm{H})$-Furandione, 3-methyl- & $|192-51-4|$ & $1.80 \bar{E}-02$ & 1 & 1.80E-02 & $1.80 \mathrm{E}-02$ \\
\hline 697 & 2-Undecanone & $112-12-9$ & $1.27 \bar{E}-02$ & 2 & $1.78 \mathrm{E}-02$ & $7.53 E-03$ \\
\hline 698 & Propane, 1-chloro-2,2-dimethyl- & $753-89-9$ & $1.78 E-02$ & 1 & $1.78 \mathrm{E}-02$ & $1.78 \mathrm{E}-02$ \\
\hline 699 & Cyclooctanemethanol, .alpha.,..alpha.-dimethyl- & $16624-06-9$ & $1.76 E-02$ & 1 & $1.76 \mathrm{E}-02$ & $1,76 \mathrm{E}-02$ \\
\hline 700 & 2-Hexenal, 2-ethyl- & $645-62-5$ & $1.75 \mathrm{E}-02$ & 1 & $1,75 \bar{E}-02$ & $1.75 E-02$ \\
\hline 701 & 2-Butenenitrile & $4786-20-3$ & $1.23 E-02$ & 2 & $1.75 \mathrm{E}-02$ & $7.12 \mathrm{E}-03$ \\
\hline 702 & $2(3 \mathrm{H})$-Furanone, dihydro-5-pentyl- & $104-61-0$ & $1.74 \mathrm{E}-02$ & 1 & $1.74 E-02$ & $1.74 E-02$ \\
\hline 703 & Pentanoic acid, hexyl ester & $1117-59-5$ & $1.74 \mathrm{E}-02$ & 1 & $1.74 \mathrm{E}-02$ & $1.74 \mathrm{E}-02$ \\
\hline 704 & Propanoic acid & $79-09-4$ & $8.66 E-03$ & 4 & $1.73 \mathrm{E}-02$ & $1.68 \mathrm{E}-03$ \\
\hline 705 & 3-Hexen-2-one. 5-methyl- & $5166-53-0$ & $1.71 \mathrm{E}-02$ & 1 & $1.71 \mathrm{E}-02$ & 1.71E-02 \\
\hline 706 & Cyclopropane, 1,2-dimethyl-, cis- & $930-18-7$ & $1.70 \mathrm{E}-02$ & 1 & 1.70E-02 & $1.70 \mathrm{E}-02$ \\
\hline 707 & 1,4-Cyclohexanedione & $637-88-7$ & $1.69 E-02$ & 1 & $169 \mathrm{E}-02$ & $1.69 \mathrm{E}-02$ \\
\hline 708 & 9H-Fluoren-9-one & $486-25-9$ & $1.69 \mathrm{E}-02$ & 1 & 1.69E-02 & $1.69 \mathrm{E}-02$ \\
\hline 709 & Ethanone, 1-(2,4,5-trimethylphenyi)- & $2040-07-5$ & $1.66 \mathrm{E}-02$ & 1 & $1.66 \mathrm{E}-02$ & $1.66 \mathrm{E}-02$ \\
\hline 710 & Phenol, 2,6-bis (1,1-dimethylethyl)-4-methyl- & $128-37-0$ & $1.64 E-02$ & 1 & 1.64E-02 & $1.64 \mathrm{E}-02$ \\
\hline 711 & Undecane, 2,2-dimethyl- & $17312-64-0$ & $1.61 E-02$ & 1 & $1.61 \mathrm{E}-02$ & $1.61 \mathrm{E}-02$ \\
\hline 712 & Cyclopropene, 1-butyl-2-ethyl- & $50915-91-8$ & $1.59 \mathrm{E}-02$ & 1 & $1.59 \mathrm{E}-02$ & $1.59 \mathrm{E}-02$ \\
\hline
\end{tabular}


WHC-SD-WM-TI-753 REV 0

\begin{tabular}{|c|c|c|c|c|c|c|}
\hline & $\mathbf{B}$ & $\bar{c}$ & D & $\mathbf{F}$ & $\mathbf{G}$ & $\mathrm{H}$ \\
\hline 1 & TANK CHEMICALS & CAS \# & $\underset{(\mathrm{mg} / \mathrm{m} 3)}{\operatorname{Mean}}$ & $\begin{array}{l}\text { Number of } \\
\text { tanks }\end{array}$ & $\begin{array}{l}\text { Maximum } \\
(\mathrm{mg} / \mathrm{m} 3)\end{array}$ & $\begin{array}{l}\text { Minimum } \\
\text { (mg/m3) }\end{array}$ \\
\hline 713 & Cyclohexane, 1-ethyl-2-methyl-, cis- & $4923-77-7$ & $1.57 \mathrm{E}-02$ & 1 & $1.57 \mathrm{E}-02$ & $1.57 \mathrm{E}-02$ \\
\hline 714 & 1-Butanone, 4-(dimethylamino)-1-phenyl- & 3760-63-2 & $1.57 \mathrm{E}-02$ & 1 & $1.57 \mathrm{E}-02$ & $1.57 E-02$ \\
\hline 715 & Furan, 2-pentyl- & $3777-69-31$ & $1.56 \mathrm{E}-02$ & 1 & $1.56 \mathrm{E}-02$ & $1.56 \mathrm{E}-02$ \\
\hline 716 & Oxirane, 2-methyl-2-pentyl- & $53907-75-8 \mid$ & $1.55 \mathrm{E}-02$ & 1 & $1.55 \mathrm{E}-02$ & $1.55 \mathrm{E}-02$ \\
\hline 717 & Benzene, nitro- & $98-95-3 i$ & $9.35 \mathrm{E}-03$ & 2 & $1.50 E-02$ & $3.66 \mathrm{E}-03$ \\
\hline 718 & Benzenemethanot, alpha., alpha -dimethyl- & $617-94-7$ & 7.91E-03 & 4 & $1.50 \mathrm{E}-02$ & $2.25 E-03$ \\
\hline 719 & 5-Nonanone & $502-56-7 !$ & $9.53 \mathrm{E}-03$ & 3 & $1.50 \mathrm{E}-02$ & $4.80 \mathrm{E}-03$ \\
\hline 720 & Ethane, 1,1,2,2-tetrachloro- & $79-34-5$ & $7.86 \mathrm{E}-03$ & 2 & $1.50 \mathrm{E}-02$ & $7.49 \mathrm{E}-04$ \\
\hline 721 & Benzaldehyde & $100-52-7$ & $8.08 \mathrm{E}-03$ & 3 & $1.48 \mathrm{E}-02$ & $3.51 \mathrm{E}-03$ \\
\hline 722 & Cyclohexene, 1-ethyl-6-ethylidene- & $61141-57-9$ & $8.52 \mathrm{E}-03$ & 2 & $1.47 \mathrm{E}-02$ & $2.35 \mathrm{E}-03$ \\
\hline 723 & Cyclopropane, 1-heptyl-2-methyl- & $74663-91-5$ & $1.46 \mathrm{E}-02$ & 1 & $1.46 \mathrm{E}-02$ & $1.46 \mathrm{E}-02$ \\
\hline 724 & Cyclopentanone, 2,2,5-trimethy|- & $4573-09-5$ & 1.46E-02 & 1 & $1.46 \mathrm{E}-02$ & $1.46 \mathrm{E}-02$ \\
\hline 725 & Benzene, 1-methyl-3-(1-methylethyl)- & $535-77-3$ & $1.45 \mathrm{E}-02$ & 1 & 1.45E-02 & $1.45 \mathrm{E}-02$ \\
\hline 726 & Octane, 3-ethyl-2,7-dimethy|- & $62183-55-5$ & $1.44 \mathrm{E}-02$ & 1 & $1.44 \mathrm{E}-02$ & $1.44 \mathrm{E}-02$ \\
\hline 727 & Furan, tetrahydro-2,4-dimethyl-, trans- & $39168-02-0$ & $1.44 \mathrm{E}-02$ & 1 & $1.44 \mathrm{E}-02$ & $1.44 \mathrm{E}-02$ \\
\hline 728 & Hexane, 2,2,5-trimethyl- & $3522-94-9$ & $1.43 E-02$ & 1 & $1.43 \mathrm{E}-02$ & $1.43 \mathrm{E}-02$ \\
\hline 729 & Pyridine, 5-ethyl-2-methyl- & $104-90-5$ & $9.77 \mathrm{E}-03$ & 2 & $1.43 \mathrm{E}-02$ & $5.25 \mathrm{E}-03$ \\
\hline 730 & $\begin{array}{l}\text { Cyclohexane, 1,2,4-trimethyl-, } \\
\text { (1. alpha, 2.beta , 4. beta.)- }\end{array}$ & $7667-60-9$ & 1.42E-02 & 1 & $1.42 \mathrm{E}-02$ & $1.42 \mathrm{E}-02$ \\
\hline 731 & 6-Dodecanol & $6836-38-0$ & $1.05 E-02$ & 2 & $1.40 \mathrm{E}-02$ & $7.10 \mathrm{E}-03$ \\
\hline 732 & 1-Nonanol & $143-08-8$ & $6.76 E-03$ & 7 & 1.39E-02 & $1.00 \mathrm{E}-03$ \\
\hline 733 & Decane, $2,2,3$-trimethyl- & 62338-09-4 & $1.37 E-02$ & 1 & $1.37 \mathrm{E}-02$ & $1.37 E-02$ \\
\hline 734 & $\begin{array}{l}\text { Benzeneacetic acid, alpha,-hydroxy-, ethyl } \\
\text { ester }\end{array}$ & $774-40-3$ & $1.37 \mathrm{E}-02$ & 1 & $1.37 \mathrm{E}-02$ & $1.37 \mathrm{E}-02$ \\
\hline 735 & Butanethioic acid, S-decyl ester & $2432-55-5$ & $8.37 \mathrm{E}-03$ & 2 & $1.34 \mathrm{E}-02$ & $3.32 \mathrm{E}-03$ \\
\hline 736 & Butanoic acid _... & $107-92-6$ & 1.33E-02 & 1 & 1.33E-02 & 1.33E-02 \\
\hline 737 & 2-Hexenoic acid, 4-methylphenyl ester & $69687-91-8$ & $1.32 \mathrm{E}-02$ & 1 & $1.32 \mathrm{E}-02$ & $1.32 \mathrm{E}-02$ \\
\hline 738 & Benzene, $1,1^{\prime}-(1,4-$ butanediyl)bis- & $1083-56-3$ & $1.30 \mathrm{E}-02$ & 1 & $1.30 \mathrm{E}-02$ & $1.30 \mathrm{E}-02$ \\
\hline 739 & 4-Tetradecanone & $26496-20-8$ & $1.29 \mathrm{E}-02$ & 1 & $1.29 \mathrm{E}-02$ & $1.29 \mathrm{E}-02$ \\
\hline 740 & Heneicosane & $629-94-7$ & $1.29 \mathrm{E}-02$ & 1 & $1.29 \mathrm{E}-02$ & $1.29 \mathrm{E}-02$ \\
\hline 741 & Cyclohexane, (2-ethyl-1-methylbutylidene)- & $74810-41-6 !$ & 1.29E-02 & 1 & $1.29 \mathrm{E}-02$ & $1.29 \mathrm{E}-02$ \\
\hline $7 \overline{42}$ & Benzenesulfonamide, $\mathrm{N}$-ethyl-4-methyl- & $80-39-7$ & 1.27E-02 & 1 & $1.27 \mathrm{E}-02$ & 1.27E-02 \\
\hline 743 & 3-Heptene, 4-propyl- & $4485-13-6$ & $1.26 \mathrm{E}-02$ & 1 & $1.26 \mathrm{E}-02$ & $1.26 \mathrm{E}-02$ \\
\hline $\mathbf{7 4 4}$ & Methylamine, $\mathrm{N}$-(1-methylhexylidene)- & $22058-71-5$ & $1.25 \mathrm{E}-02$ & 1 & $1.25 \mathrm{E}-02$ & $1.25 \mathrm{E}-02$ \\
\hline 745 & Hexadecane, 7,9-dimethyl- & $21164-95-4$ & 5.39E-03 & 3 & $1.24 \mathrm{E}-02$ & $7.03 E-04$ \\
\hline 746 & Pyridine, 2,6-dimethyl- & $108-48-5$ & $1.21 \mathrm{E}-02$ & 1 & $1.21 \mathrm{E}-02$ & $1.21 E-02$ \\
\hline 747 & $1 \mathrm{H}-$ Pyrrole & $109-97-7$ & $1.20 \mathrm{E}-02$ & 1 & $1.20 \mathrm{E}-02$ & $1.20 \mathrm{E}-02$ \\
\hline 748 & Ethane, 1,2-dimethoxy- & $110-71-4$ & $1.20 \mathrm{E}-02$ & 1 & $1.20 \mathrm{E}-02$ & $1.20 \mathrm{E}-02$ \\
\hline 749 & Nonadecane, 9-methyi- & 13287-24-6! & $6.22 \mathrm{E}-03$ & 2 & $1.19 E-02$ & $5.50 \mathrm{E}-04$ \\
\hline 750 & Pyrazine, ethyl- & $13925-00-3$ & $7.35 \mathrm{E}-03$ & 2 & 1.17E-02 & $3.00 \mathrm{E}-03$ \\
\hline 751 & Naphthalene, 2,3-dimethyl- & $581-40-8$ & 1.16E-02 & 1 & $1.16 \mathrm{E}-02$ & 1.16E-02 \\
\hline 752 & Phenol, 3-methyl- & $108-39-4$ & $6.68 \mathrm{E}-03$ & 2 & $1.15 \bar{E}-02$ & $1.87 \mathrm{E}-03$ \\
\hline 753 & Heptane, $2,2,4,6,6$-pentamethyl- & $13475-82-6$ & $8.61 \mathrm{E}-03$ & 2 & $1.15 \mathrm{E}-02$ & $5.77 \mathrm{E}-03$ \\
\hline 754 & 1H-Pyrrole, 2,5-dimethyl- & $625-84-3$ & 1.14E-02 & 1 & $1.14 \mathrm{E}-02$ & $1.14 \mathrm{E}-02$ \\
\hline 755 & 2(3H)-Furanone, dihydro-5-propyl- & $105-21-5$ & $5.44 \mathrm{E}-03$ & 7 & $1.14 \mathrm{E}-02$ & $4.80 E-04$ \\
\hline 756 & $\begin{array}{l}\text { Propanedioic acid, [(trimethylsilyl)oxy]-, } \\
\text { bis(trimethylsilyl) ester }\end{array}$ & $38165-93-4$ & 1.13E-02 & 1 & $1.13 \mathrm{E}-02$ & 1.13E-02 \\
\hline 757 & Naphthalene, 1,7-dimethyl- & $575-37-1$ & $1.12 \mathrm{E}-02$ & 1 & $1.12 \mathrm{E}-02$ & $1.12 \mathrm{E}-02$ \\
\hline 758 & 2-Undecene, 4,5-dimethyl-, $\left[\mathbf{R}^{*}, \mathbf{R}^{*}-(\mathrm{E})\right]-$ & $55170-92-8$ & 1.10E-02 & 1 & $1.10 \mathrm{E}-02$ & $1.10 \mathrm{E}-02$ \\
\hline 759 & Decanenitrile & $1975-78-6$ & $9.01 \mathrm{E}-03$ & 2 & 1.10E-02 & $7.02 E-03$ \\
\hline 760 & 3-Pentanone, 2,2,4-trimethyl- & $5857-36-3$ & $7.45 E-03$ & 2 & $1.09 \mathrm{E}-02$ & $4.00 \mathrm{E}-03$ \\
\hline 761 & Cyclopropane, 1-butyl-2-methyl-, trans- & $38851-70-6$ & $1.09 \mathrm{E}-02$ & 1 & $1.09 \mathrm{E}-02$ & $1.09 \mathrm{E}-02$ \\
\hline
\end{tabular}


WHC-SD-WM-TI-753 REV 0

\begin{tabular}{|c|c|c|c|c|c|c|}
\hline & B & $\mathbf{C}$ & D & $\mathbf{F}$ & $\mathbf{G}$ & $\mathbf{H}$ \\
\hline 1 & TANK CHEMICALS & CAS \# & $\underset{(\mathrm{mg} / \mathrm{m} 3)}{\operatorname{Mean}}$ & $\begin{array}{l}\text { Number of } \\
\text { tanks }\end{array}$ & $\begin{array}{l}\text { Maximum } \\
(\mathbf{m g} / \mathrm{m} 3)\end{array}$ & $\begin{array}{c}\text { Minimum } \\
(\mathrm{mg} / \mathrm{m} 3)\end{array}$ \\
\hline 762 & Cyclobutanone, 2,3,3-trimethyl- & $28290-01-9$ & $1.08 \mathrm{E}-02$ & 1 & $1.08 \mathrm{E}-02$ & $1.08 \mathrm{E}-02$ \\
\hline 763 & Pyridine, 2-ethyl- & 100-71-0 & $5.75 \mathrm{E}-03$ & 2 & $1.08 \mathrm{E}-02$ & $6.70 \mathrm{E}-04$ \\
\hline 764 & 1-Pentanol, 5-methoxy- & $4799-62-6$ & $1.08 \mathrm{E}-02$ & 1 & $1.08 \mathrm{E}-02$ & $1.08 \mathrm{E}-02$ \\
\hline 765 & Benzene, 1-ethyl-4-methyl- & $622-96-8$ & $5.63 \mathrm{E}-03$ & 2 & $1.07 \mathrm{E}-02$ & $5.36 \mathrm{E}-04$ \\
\hline 766 & 7-Oxabicyclo[4.1.0 oheptane, 1-methyl- & $1713-33-3$ & $1.07 \mathrm{E}-02$ & 1 & $1.07 \mathrm{E}-02$ & $1.07 \mathrm{E}-02$ \\
\hline 767 & Hexanoic acid, 2-ethyl-, butyl ester & $68443-63-0$ & 1.07E-02 & 1 & 1.07E-02 & $1.07 \mathrm{E}-02$ \\
\hline 768 & $\begin{array}{l}\text { 1,2-Benzenedicarboxylic acid, butyl 2- } \\
\text { methylpropyl ester }\end{array}$ & $17851-53-5$ & $1.05 \mathrm{E}-02$ & 1 & $1.05 \mathrm{E}-02$ & $1.05 E-02$ \\
\hline 769 & Pentadecane, 8-hexyl- & $13475-75-7$ & $1.05 \mathrm{E}-02$ & 1 & $1.05 \mathrm{E}-02$ & $1.05 \mathrm{E}-02$ \\
\hline 770 & Pentane, 2,4-dimethyl- & 108-08-7 & $1.03 \mathrm{E}-02$ & 1 & $1.03 \mathrm{E}-02$ & $1.03 \mathrm{E}-02$ \\
\hline 771 & Pyrazine, 2,5-dimethyl-3-(3-methylbutyl)- & $18433-98-2$ & $1.01 \mathrm{E}-02$ & 1 & $1.01 \mathrm{E}-02$ & $1.01 \mathrm{E}-02$ \\
\hline 772 & 3-Pentanol, 2,3,4-trimethyl- & $3054-92-0$ & $1.00 \mathrm{E}-02$ & 1 & $1.00 \mathrm{E}-02$ & $1.00 \mathrm{E}-02$ \\
\hline 773 & 5-Undecene, $(\mathrm{Z})$ & $764-96-5$ & $9.89 \mathrm{E}-03$ & 1 & $9.89 \mathrm{E}-03$ & $9.89 \mathrm{E}-03$ \\
\hline 774 & Tetradecane, 4,11-dimethyl- & $55045-12-0$ & $9.05 \mathrm{E}-03$ & 3 & $9.89 \mathrm{E}-03$ & $8.27 \mathrm{E}-03$ \\
\hline 775 & Decane, 5-ethyl-5-methyl- & $17312-74-2$ & $9.88 \mathrm{E}-03$ & 1 & $9.88 \mathrm{E}-03$ & $9.88 \mathrm{E}-03$ \\
\hline 776 & Tridecanol ........ & $26248-42-0$ & $9.65 \mathrm{E}-03$ & 1 & $9.65 \mathrm{E}-03$ & $9.65 \mathrm{E}-03$ \\
\hline 777 & 2-Butenal, $(E)$ - & $123-73-9$ & $9.55 \mathrm{E}-03$ & 1 & $9.55 \mathrm{E}-03$ & $9.55 \mathrm{E}-03$ \\
\hline 778 & 4-Octene, (E)- & $14850-23-8$ & $9.50 \mathrm{E}-03$ & 1 & $9.50 \mathrm{E}-03$ & $9.50 E-03$ \\
\hline 779 & 2-Propen-i-ol & $107-18-6$ & $5.17 \mathrm{E}-03$ & 2 & $9.46 \mathrm{E}-03$ & $8.75 E-04$ \\
\hline 780 & 3-Piperidinecarboxamide, $\mathrm{N}$-methyl- & $51+5-98-0$ & $9.35 \mathrm{E}-03$ & 1 & $9.35 E-03$ & $9.35 \mathrm{E}-03$ \\
\hline 781 & $4 \mathrm{H}-1,2,4-$ Triazol-3-amine, 4-ethyl- & $42786-06-1$ & $9.35 \mathrm{E}-03$ & 1 & 9.35E-03 & $9.35 \mathrm{E}-03$ \\
\hline 782 & Tetradecanoic acid, 12-methyl- (S)- & $5746-58-7 !$ & $7.90 E-03$ & 2 & $9.35 \mathrm{E}-03$ & $6.45 \mathrm{E}-03$ \\
\hline 783 & 2-Hexenedioic acid, bis(trimethylsilyl) ester, (E) & $55494-10-5$ & $9.24 \mathrm{E}-03$ & 1 & $9.24 \mathrm{E}-03$ & $9.24 \mathrm{E}-03$ \\
\hline 784 & 2-Octenal, (E)- & $2548-87-0$ & 9.05E-03 & 1 & $9.05 \mathrm{E}-03$ & $9.05 \mathrm{E}-03$ \\
\hline 785 & 1-Butanol, 3-methyl- & $123-51-3 !$ & $8.99 \mathrm{E}-0.3$ & 1 & $8.99 \mathrm{E}-03$ & $8.99 \mathrm{E}-03$ \\
\hline 786 & 3-Octanol, 6-ethyl- & $19781-27-2$ & 8.93E-03 & 1 & 8.93E-03 & $8.93 \mathrm{E}-03$ \\
\hline 787 & 2,3-Butanediol, 2,3-dimethyl- & $76-09-5$ & $8.90 \mathrm{E}-03$ & 1 & $8.90 E-03$ & $8.90 \mathrm{E}-03$ \\
\hline 788 & 2,5-Furandione, dihydro- & $108-30-5$ & $8.90 \mathrm{E}-03$ & 1 & $8.90 E-03$ & $8.90 E-03$ \\
\hline 789 & 3-Hexanone, 5-methyl- & $623-56-3$ & $8.81 \mathrm{E}-03$ & 1 & $8.81 \mathrm{E}-03$ & $8.81 \mathrm{E}-03$ \\
\hline 790 & 3-Octanol, 3,7-dimethyl-, (.+-)- & $57706-88-4$ & $8.80 \mathrm{E}-03$ & 1 & $8.80 \mathrm{E}-03$ & $8.80 \mathrm{E}-03$ \\
\hline 791 & 1,3-Dioxane, 4,4-dimethyi- & $766-15-4$ & 8.80E-03 & 1 & $8.80 \mathrm{E}-03$ & $8.80 \mathrm{E}-03$ \\
\hline 792 & 1-Nonyne & $3452-09-3$ & $8.75 \mathrm{E}-03$ & 1 & $8.75 \mathrm{E}-03$ & $8.75 E-03$ \\
\hline 793. & Nitric acid, decyl ester & $2050-78-4$ & $8.63 \mathrm{E}-03$ & 1 & $8.63 \mathrm{E}-03$ & $8.63 \mathrm{E}-03$ \\
\hline 794 & 6-Dodecene, (E)- & $7206-17-9$ & $8.50 \mathrm{E}-03$ & 1 & $8.50 \mathrm{E}-03$ & $8.50 \mathrm{E}-03$ \\
\hline 795 & $\begin{array}{l}\text { Cyclopentane, 1,1,3-trimethyl-3-(2-methyl-2- } \\
\text { propenyl)- }\end{array}$ & $74421-09-3$ & $8.50 E-03$ & 1 & 8.50E-03 & $8.50 \mathrm{E}-03$ \\
\hline 796 & $\begin{array}{l}\text { 1,2-Benzenedicarboxylic acid, butyl 2- } \\
\text { ethylhexyl ester }\end{array}$ & 85-69-8 & $8.50 \mathrm{E}-03$ & 1 & 8.50E-03 & 8.50E-03 \\
\hline 797 & 3-Dodecanol & 10203-30-2 & $8.48 \mathrm{E}-03$ & 1 & $8.48 \mathrm{E}-03$ & $8.48 \mathrm{E}-03$ \\
\hline 798 & 1-Butanol, 3-methyl-, nitrate & $543-87-3 i$ & $8.42 \mathrm{E}-03$ & 1 & $8.42 \mathrm{E}-03$ & $8.42 \mathrm{E}-03$ \\
\hline 799 & Tridecane, 2,5-dimethyl- & $56292-66-11$ & $8.40 \mathrm{E}-03$ & 1 & $8.40 \mathrm{E}-03$ & $8.40 \mathrm{E}-03$ \\
\hline 800 & Formamide & $75-12-7$ & $8.39 \mathrm{E}-03$ & 1 & $8.39 \mathrm{E}-03$ & $8.39 \mathrm{E}-03$ \\
\hline 801 & Acetamide & $60-35-5$ & $5.02 E-03$ & 2 & $8.33 \mathrm{E}-03$ & $1.72 \mathrm{E}-03$ \\
\hline 802 & 1H-Azepin-1-amine, $\mathrm{N}$-ethylidenehexahydro- & $75268-01-8$ & $8.33 \mathrm{E}-03$ & 1 & $8.33 \mathrm{E}-03$ & $8.33 \mathrm{E}-03$ \\
\hline 803 & Cyclobutane, $1,1,2,3,3$-pentamethyl- & $57905-86-9$ & $8.30 \mathrm{E}-03$ & 1 & $8.30 \mathrm{E}-03$ & $8.30 E-03$ \\
\hline 804 & Heptane, 2,2,4-trimethyl- & $14720-74-2$ & $8.20 \mathrm{E}-03$ & $i$ & $8.20 \mathrm{E}-03$ & $8.20 \mathrm{E}-03$ \\
\hline 805 & 9-Octadecenoic acid, methyl ester, (E)- & $1937-62-8$ & $8.20 \mathrm{E}-03$ & 1 & $8.20 \mathrm{E}-03$ & $8.20 \mathrm{E}-03$ \\
\hline 806 & 1-Dodecanoi & $112-53-8$ & $4.80 \mathrm{E}-03$ & 3 & $8.20 \mathrm{E}-03$ & $2.20 \mathrm{E}-03$ \\
\hline 807 & Hydrazine, 1,1-dimethyl- & $57-14-7$ & $5.66 \mathrm{E}-03$ & 2 & $8.18 \mathrm{E}-03$ & $3.14 \mathrm{E}-03$ \\
\hline 808 & Benzene, (1-ethy|nonyl)- & $4536-87-2$ & $8.10 \mathrm{E}-03$ & 1 & 8.10E-03 & $8.10 \mathrm{E}-03$ \\
\hline 809 & Cyclohexene & $110-83-8$ & $8.00 \mathrm{E}-03$ & 1 & $8.00 \bar{E}-03$ & $8.00 \mathrm{E}-03$ \\
\hline
\end{tabular}


WHC-SD-WM-TI-753 REV 0

\begin{tabular}{|c|c|c|c|c|c|c|}
\hline & $\mathbf{B}$ & C & D & $\mathbf{F}$ & $\mathbf{G}$ & $\bar{H}$ \\
\hline 1 & TANK CHEMICALS & CAS \# & $\underset{(\mathbf{m g} / \mathbf{m} 3)}{\text { Mean }}$ & $\begin{array}{l}\text { Number of } \\
\text { tanks }\end{array}$ & $\begin{array}{l}\text { Maximum } \\
(\mathrm{mg} / \mathrm{m} 3)\end{array}$ & $\begin{array}{l}\text { Minimum } \\
(\mathrm{mg} / \mathrm{m} 3)\end{array}$ \\
\hline 810 & 1-Hexene, 3,5,5-trimethyl- & $4316-65-8$ & $8.00 E-03$ & 1 & $8.00 \mathrm{E}-03$ & $8.00 \mathrm{E}-03$ \\
\hline 811 & 2-Heptenal, (E)- & $18829-55-5$ & 7.97E-03 & 1 & $7.97 \mathrm{E}-03$ & $7.97 \mathrm{E}-03$ \\
\hline 812 & 1-Propene, 1-nitro-, $(Z)$ & $27675-36-1$ & $7.95 E-03$ & 1 & $7.95 \mathrm{E}-03$ & $7.95 E-03$ \\
\hline 813 & $2(3 H)$-Furanone, 5-ethyldihydro-5-methyl- & $2865-82-9$ & $7.92 \mathrm{E}-03$ & 1 & $7.92 \mathrm{E}-03$ & $7.92 \mathrm{E}-03$ \\
\hline 814 & $\begin{array}{l}\text { Benzeneacetic acid, alpha-hydroxy-, methyl } \\
\text { ester, }(R) \text { - }\end{array}$ & 20698-91-3 & $7.87 \mathrm{E}-03$ & 1 & $7.87 \mathrm{E}-03$ & $7.87 \mathrm{E}-03$ \\
\hline 815 & Dodecanamide, $\mathrm{N}$-(2-hydroxyethyl)- & $142-78-9$ & $7.84 \mathrm{E}-03$ & 1 & $7.84 \mathrm{E}-03$ & $7.84 \mathrm{E}-03$ \\
\hline 816 & 1-Heptadecene & $6765-39-5$ & $7.81 \mathrm{E}-03$ & 1 & $7.81 \mathrm{E}-03$ & $7.81 \mathrm{E}-03$ \\
\hline 817 & $\begin{array}{l}\text { Cyclopropane, 1,1,2-trimethyl-3-(2- } \\
\text { methylpropyl)- }\end{array}$ & 41977-43-9 & $7.75 \mathrm{E}-03$ & 1 & $7.75 \mathrm{E}-03$ & $7.75 \mathrm{E}-03$ \\
\hline 818 & $\begin{array}{l}\text { 2,5-Cyclohexadiene-1,4-dione, 2,6-bis (1,1- } \\
\text { dimethylethyl)- }\end{array}$ & $719-22-2$ & $3.29 E-03$ & 6 & $7.70 \mathrm{E}-03$ & $1.20 \mathrm{E}-03$ \\
\hline 819 & Octane, 3,4-dimethy|- & $15869-92-8$ & $7.67 E-03$ & 1 & $7.67 \mathrm{E}-03$ & $7.67 \mathrm{E}-03$ \\
\hline 820 & $2,5-$ Hexanedione & $110-13-4$ & $7.65 \mathrm{E}-03$ & 1 & $7.65 \mathrm{E}-03$ & $7.65 E-03$ \\
\hline 821 & 4-Heptenal, (Z)- & $6728-31-0$ & $7.30 \mathrm{E}-03$ & 2 & $7.60 \mathrm{E}-03$ & $7.00 \mathrm{E}-03$ \\
\hline 822 & 1,1'-Biphenyl, 3.3'-dichloro- & $2050-67-1$ & $7.53 E-03$ & 1 & $7.53 \mathrm{E}-03$ & $7.53 \mathrm{E}-03$ \\
\hline 823 & 1,4-Pentadiene, 2,3-dimethyl- & $758-86-11$ & $7.52 \mathrm{E}-03$ & 1 & $7.52 \mathrm{E}-03$ & $7.52 \mathrm{E}-03$ \\
\hline 824 & $\begin{array}{l}\text { Cyclohexane, 1-(cyclohexyimethyl)-4-methyl-, } \\
\text { trans- }\end{array}$ & $54823-98-2$ & $7.50 E-03$ & 1 & $7.50 E-03$ & $7.50 \mathrm{E}-03$ \\
\hline 825 & Heptadecane, $2,6,10,15$-tetramethyl- & $54833-48-6$ & $7.50 \mathrm{E}-03$ & 1 & $7.50 \mathrm{E}-03$ & $7.50 \mathrm{E}-03$ \\
\hline 826 & 5-Dodecene, $(\mathrm{Z})-$ & $7206-28-2$ & $7.40 \mathrm{E}-03$ & 1 & $7.40 \mathrm{E}-03$ & $7.40 \mathrm{E}-03$ \\
\hline 827 & Pyridine, 3,4-cimethyl- & $583-58-4$ & 7.14E-03 & 1 & $7.14 \mathrm{E}-03$ & $7.14 \mathrm{E}-03$ \\
\hline 828 & 7-Octen-2-one & $3664-60-6$ & $7.10 \mathrm{E}-03$ & 1 & $7.10 \mathrm{E}-03$ & $7.10 E-03$ \\
\hline 829 & Benzene, (1-pentylheptyl)- & 2719-62-2 & $5.53 \mathrm{E}-03$ & 2 & $7.10 \mathrm{E}-03$ & $3.97 \mathrm{E}-03$ \\
\hline 830 & $\begin{array}{l}\text { Benzeneacetic acid, .alpha.,4- } \\
\text { bis[(trimethylsilyl)oxy]-, trimethylsilyl ester }\end{array}$ & $37148-64-4$ & $5.31 \mathrm{E}-03$ & 2 & $7.05 \mathrm{E}-03$ & $3.56 \mathrm{E}-03$ \\
\hline 831 & 1-Tetradecanol & $112-72-1$ & $4.45 E-03$ & 2 & $7.00 \mathrm{E}-03$ & $1.90 \mathrm{E}-03$ \\
\hline 832 & Cyclohexane, 1,3,5-trimethyl- & $1839-63-0$ & $6.65 \mathrm{E}-03$ & 2 & $7.00 \mathrm{E}-03$ & $6.30 \mathrm{E}-03$ \\
\hline 833 & 2-Heptanone, 3-methyl- & $2371-19-9$ & $5.10 \mathrm{E}-03$ & 2 & $7.00 E-03$ & $3.20 \mathrm{E}-03$ \\
\hline 834 & 5,9-Undecadien-2-one, 6,10-dimethyl-, (Z)- & $3879-26-3$ & $4.78 \mathrm{E}-03$ & 3 & $6.83 \mathrm{E}-03$ & $3.60 \mathrm{E}-03$ \\
\hline $\mathbf{8 3 5}$ & 5-Hepten-2-one, 6-methyl- & $110-93-0$ & $6.80 \mathrm{E}-03$ & 1 & $6.80 E-03$ & $6.80 \mathrm{E}-03$ \\
\hline $\mathbf{8 3 6}$ & Furan, tetrahydro-2.5-dipropyl- & $4457-62-9$ & $6.75 \mathrm{E}-03$ & 1 & $6.75 \mathrm{E}-03$ & $6.75 E-03$ \\
\hline 837 & Cyclohexane, (1-methylethyl)- & $696-29-7$ & $6.60 \mathrm{E}-03$ & 1 & $6.60 \mathrm{E}-03$ & $6.60 \mathrm{E}-03$ \\
\hline 838 & 1H-Pyrazole, i-methyl- & $930-36-9$ & $6.55 \mathrm{E}-03$ & 1 & $6.55 \mathrm{E}-03$ & $6.55 \mathrm{E}-03$ \\
\hline 839 & Octanamide, $\mathrm{N}$-(2-hydroxyethyl)- & $7112-02-9$ & $6.53 \mathrm{E}-03$ & 1 & $6.53 \mathrm{E}-03$ & $6.53 \mathrm{E}-03$ \\
\hline 840 & 2,4-Hexadiene, 3-methyl- & $28823-42-9$ & $6.50 \mathrm{E}-03$ & 1 & $6.50 \mathrm{E}-03$ & $6.50 \mathrm{E}-03$ \\
\hline 841 & 2-Pentanol, 2,3-dimethyl- & $4911-70-0$ & $3.58 \mathrm{E}-03$ & 2 & $6.30 \mathrm{E}-03$ & $8.67 \mathrm{E}-04$ \\
\hline 842 & 1, †'-Biphenyl, 2,2'-dichloro- & $13029-08-8$ & $3.67 \mathrm{E}-03$ & 2 & $6.16 \mathrm{E}-03$ & $1.19 \mathrm{E}-03$ \\
\hline 843 & Benzene, (1-methyidecyl)- & $4536-88-3$ & $5.95 E-03$ & 2 & $6.15 \bar{E}-03$ & $5.75 \mathrm{E}-03$ \\
\hline 844 & 2-Heptanone, 4,6-dimethyl- & $19549-80-5$ & $6.10 \mathrm{E}-03$ & 1 & $6.10 \mathrm{E}-03$ & $6.10 \mathrm{E}-03$ \\
\hline 845 & 2-Propenenitrile & $107-13-1$ & $6.09 \mathrm{E}-03$ & 1 & $6.09 \mathrm{E}-03$ & $6.09 E-03$ \\
\hline 846 & Cyclooctane, 1,5-dimethyl- & $21328-57-4$ & $6.00 \mathrm{E}-03$ & 1 & $6.00 \mathrm{E}-03$ & $6.00 \mathrm{E}-03$ \\
\hline 847 & Cyclopentane, 1,3-dimethyl-, cis- & $2532-58-3$ & $6.00 \mathrm{E}-03$ & 1 & $6.00 \mathrm{E}-03$ & $6.00 \mathrm{E}-03$ \\
\hline 848 & $2(3 \mathrm{H})$-Furanone, dihydro-4,4-dimethyl- & $13861-97-7$ & $5.98 \mathrm{E}-03$ & 1 & $5.98 \mathrm{E}-03$ & $5.98 \mathrm{E}-03$ \\
\hline 849 & 1-Tridecyn-4-ol & $74646-37-0$ & $5.85 \mathrm{E}-03$ & 1 & $5.85 \mathrm{E}-03$ & $5.85 \mathrm{E}-03$ \\
\hline 850 & Benzene, (1-butyloctyl)- & $2719-63-3$ & $5.85 \mathrm{E}-03$ & 1 & $5.85 \mathrm{E}-03$ & $5.85 \mathrm{E}-03$ \\
\hline 851 & Nonane, 4,5-dimethyl- & $17302-23-7$ & $3.67 E-03$ & 2 & $5.75 \mathrm{E}-03$ & $1.60 \mathrm{E}-03$ \\
\hline 852 & 2(3H)-Furanone, 5-hexyldihydro- & $706-14-9$ & $4.40 \mathrm{E}-03$ & 2 & $5.60 \mathrm{E}-03$ & $3.20 \mathrm{E}-03$ \\
\hline 853 & Propanal, 2-methyl- & $78-84-2$ & $5.57 \mathrm{E}-03$ & 1 & $5.57 \mathrm{E}-03$ & $5.57 \mathrm{E}-03$ \\
\hline 854 & 1H-Indole, 2-phenyl- & $948-65-2$ & $5.56 \mathrm{E}-03$ & 1 & $5.56 \mathrm{E}-03$ & $5.56 \mathrm{E}-03$ \\
\hline 855 & 1,3-Benzenediol, 2-methyl- & $608-25-3$ & $5.55 \mathrm{E}-03$ & 1 & $5.55 \mathrm{E}-03$ & $5.55 \mathrm{E}-03$ \\
\hline 856 & Furan, 2,3-dihydro-4-(1-methylpropyl)-, (S)- & $34379-54-9$ & $5.52 \mathrm{E}-03$ & 1 & $5.52 \mathrm{E}-03$ & $5.52 \mathrm{E}-03$ \\
\hline
\end{tabular}


WHC-SD-WM-TI-753 REV 0

\begin{tabular}{|c|c|c|c|c|c|c|}
\hline & B & C & $\mathrm{D}$ & $\bar{F}$ & $\mathbf{G}$ & $\mathrm{H}$ \\
\hline 1 & TANK CHEMICALS & CAS \# & $\underset{(\mathbf{m g} / \mathbf{m} 3)}{\operatorname{Mean}}$ & $\begin{array}{l}\text { Number of } \\
\text { tanks }\end{array}$ & $\begin{array}{l}\text { Maximum } \\
(\mathrm{mg} / \mathrm{m} 3)\end{array}$ & $\begin{array}{l}\text { Minimum } \\
\text { (mg/m3) }\end{array}$ \\
\hline 857 & Decanamide, $\mathrm{N}$-(2-hydroxyethyl)- & $7726-08-1 !$ & $5.43 \mathrm{E}-03$ & 1 & $5.43 \mathrm{E}-03$ & $5.43 E-03$ \\
\hline 858 & 2-Tridecanol & 1653-31-2! & $5.40 \mathrm{E}-03$ & 1 & $5.40 \mathrm{E}-03$ & $5.40 \mathrm{E}-03$ \\
\hline 859 & 1,12-Tridecadiene & $21964-48-7$ & $5.40 \mathrm{E}-03$ & 1 & $5.40 \mathrm{E}-03$ & $5.40 \mathrm{E}-03$ \\
\hline 860 & Cyclohexene, 1-methyl-3-(1-methylethyl)- & $13828-31-4$ & $5.36 \mathrm{E}-03$ & 1 & $5.36 \mathrm{E}-03$ & $5.36 \mathrm{E}-03$ \\
\hline 861 & 2,4-Nonadienal, $\{E, E\}$ - & $5910-87-2 !$ & $5.36 \mathrm{E}-03$ & 1 & $5.36 \mathrm{E}-03$ & $5.36 \mathrm{E}-03$ \\
\hline 862 & 1-Undecanol & $112-42-5$ & $5.31 \mathrm{E}-03$ & 1 & $5.31 \mathrm{E}-03$ & $5.31 \mathrm{E}-03$ \\
\hline 863 & 9-Octadecen-1-ol, (Z)- & $143-28-2$ & $5.30 \mathrm{E}-03$ & 1 & $5.30 \mathrm{E}-03$ & $5.30 \mathrm{E}-03$ \\
\hline 864 & Methane, nitro- & $75-52-5$ & $5.23 \mathrm{E}-03$ & 1 & $5.23 \mathrm{E}-03$ & $5.23 E-03$ \\
\hline 865 & 1,3-Benzenediol, 4-hexy!- & $136-77-6$ & $5.20 \mathrm{E}-03$ & 1 & $5.20 \mathrm{E}-03$ & $5.20 \mathrm{E}-03$ \\
\hline 866 & 1,3-Hexadiene, 3-ethyl-2-methyl-, (Z)- & $74752-97-9$ & $5.20 \mathrm{E}-03$ & 1 & $5.20 \mathrm{E}-0 \overline{3}$ & $5.20 \mathrm{E}-03$ \\
\hline 867 & Benzene, 1 -chloro-4-nitro- & $100-00-5$ & 5.17E-03 & 1 & 5. $17 \mathrm{E}-03$ & $5.17 \mathrm{E}-03$ \\
\hline 868 & 2-Propen-1-one, 3-(2-furanyl)-1-phenyl- & $717-21-5$ & $5.12 \mathrm{E}-03$ & 1 & $5.12 \mathrm{E}-03$ & $5.12 \mathrm{E}-03$ \\
\hline 869 & Benzene, (1-methylethenyl)- & $98-83-9$ & $5.10 \mathrm{E}-03$ & 1 & $5.10 \mathrm{E}-03$ & $5.10 \mathrm{E}-03$ \\
\hline 870 & Dodecanal & $112-54-9$ & $2.77 \mathrm{E}-03$ & 3 & $5.05 \mathrm{E}-03$ & $1.30 \mathrm{E}-03$ \\
\hline 871 & $\begin{array}{l}\text { 3-Cyclohexene-1-carboxaldehyde, 1,3,4- } \\
\text { trimethyl- }\end{array}$ & $40702-26-9$ & $5.02 \mathrm{E}-03$ & 1 & $5.02 E-03$ & $5.02 E-03$ \\
\hline 872 & 1,4-Hexadiene, 2,3-dimethyl- & $18669-52-8$ & $5.01 \mathrm{E}-03$ & 1 & $5.01 \mathrm{E}-03$ & $5.01 \mathrm{E}-03$ \\
\hline 873 & $1,1^{1}$-Biphenyl $2,3,3^{\prime}, 5^{\prime}$-tetrachloro- & $41464-49-7$ & $3.85 \mathrm{E}-03$ & 2 & $4.91 \mathrm{E}-03$ & $2.79 \mathrm{E}-03$ \\
\hline 874 & $\begin{array}{l}\text { 1,2-Benzenedicarboxylic acid, bis(2-ethylhexyl) } \\
\text { ester }\end{array}$ & $117-81-7$ & 4.90E-03 & 1 & 4.90E-03 & $4.90 \mathrm{E}-03$ \\
\hline 875 & Benzene, (1-propylnonyl)- & $2719-64-4$ & $4.20 \mathrm{E}-03$ & 2 & 4.90E-03 & $3.50 \mathrm{E}-03$ \\
\hline 876 & Benzene, (1-butylheptyi)- & $4537-15-9$ & $4.80 \mathrm{E}-03$ & 2 & $4.90 \bar{E}-03$ & $4.70 \mathrm{E}-03$ \\
\hline 877 & 2-Decanol & $1120-06-5$ & $4.81 E-03$ & $\uparrow$ & $4.81 \mathrm{E}-03$ & $4.81 \mathrm{E}-03$ \\
\hline 878 & 2H-Pyran-3(4H)-one, dihydro- & $23462-75-1$ & $4.80 \mathrm{E}-03$ & 1 & $4.80 E-03$ & $4.80 \mathrm{E}-03$ \\
\hline 879 & Nitric acid, heptyl ester & $20633-12-9$ & $3.19 \mathrm{E}-03$ & 2 & $4.78 \mathrm{E}-03$ & $1.59 \mathrm{E}-03$ \\
\hline 880 & Cyclopentane, 1,2,3-trimethyl- & $2815-57-8$ & $4.76 E-03$ & 1 & $4.76 \mathrm{E}-03$ & $4.76 \mathrm{E}-03$ \\
\hline 881 & Octane, 2-chloro- & $628-61-5$ & $4.73 E-03$ & 1 & $4.73 \mathrm{E}-03$ & $4.73 \mathrm{E}-03$ \\
\hline 882 & Cyclobutanone, 3,3-dimethyl- & $1192-33-2$ & $4.72 \mathrm{E}-03$ & 1 & $4.72 \mathrm{E}-03$ & $4.72 \mathrm{E}-03$ \\
\hline 883 & $\begin{array}{l}\text { Propane, 2-[(1,1-dimethylethyl)sulfonyl]-2- } \\
\text { methyl- }\end{array}$ & $1886-75-5$ & $3.87 \mathrm{E}-03$ & 3 & 4.71E-03 & $2.28 \mathrm{E}-03$ \\
\hline 884 & Hexadecanal & $629-80-1$ & $4.69 \mathrm{E}-03$ & 1 & $4.69 \mathrm{E}-03$ & $4.69 \mathrm{E}-03$ \\
\hline 885 & Cyclohexane, 1,1-dimethyl- & $590-66-9 !$ & $4.66 \mathrm{E}-03$ & 1 & $4.66 \bar{E}-03$ & $4.66 \mathrm{E}-03$ \\
\hline 886 & 1-Hexadecanol, 2-methyl- & $2490-48-4$ & $4.60 \mathrm{E}-03$ & 1 & $4.60 \mathrm{E}-03$ & $4.60 \mathrm{E}-03$ \\
\hline 887 & Propanenitrile, 2,2-dimethyl- & $630-18-2$ & $3.38 \mathrm{E}-03$ & 2 & $4.60 \mathrm{E}-03$ & $2.16 \mathrm{E}-03$ \\
\hline 888 & $\begin{array}{l}\text { Propanoic acid, 2-methyl-, 3-hydroxy-2,4,4- } \\
\text { trimethyipentyl ester }\end{array}$ & 74367-34-3 & $2.64 \mathrm{E}-03$ & 3 & 4.60E-03 & $1.61 \mathrm{E}-03$ \\
\hline 889 & 3-Cyclopenten-1-one, 2,3,4-trimethyl- & $83321-16-8$ & $4.47 \mathrm{E}-03$ & 4 & $4.47 \mathrm{E}-03$ & $4.47 \mathrm{E}-03$ \\
\hline 890 & Phenol, 2-methyl- & $95-48-7$ & $4.40 \mathrm{E}-03$ & 1 & $4.40 \mathrm{E}-03$ & 4. 40E-03 \\
\hline 891 & 2-Heptanone, 6-(2-furanyl)-6-methyl- & $51595-87-0$ & $4.35 \mathrm{E}-03$ & 1 & $4.35 \mathrm{E}-03$ & $4.35 \mathrm{E}-03$ \\
\hline 892 & 2-Pentadecanone, 6,10,14-trimethyt- & $502-69-2$ & $4.33 \mathrm{E}-03$ & 1 & $4.33 \mathrm{E}-03$ & 4. $33 \mathrm{E}-03$ \\
\hline 893 & 2-Decenal, $(E)-$ & $3913-81-3$ & $4.26 \mathrm{E}-03$ & 1 & $4.26 \mathrm{E}-03$ & $4.26 \mathrm{E}-03$ \\
\hline 894 & Cyclopropane, 1-butyl-1-methyl-2-propyl- & $41977-34-8$ & $4.25 \mathrm{E}-03$ & 1 & $4.25 \mathrm{E}-03$ & $4.25 \mathrm{E}-03$ \\
\hline 895 & Cyclohexanol 4-(1,1,3,3-tetramethylbutyl)- & $4631-98-5$ & $4.22 \mathrm{E}-03$ & 1 & $4.22 \mathrm{E}-03$ & $4.22 \mathrm{E}-03$ \\
\hline 896 & 2(3H)-Furanone, 5-butyldihydro- & $104-50-7$ & $2.88 \mathrm{E}-03$ & 3 & $4.15 \mathrm{E}-03$ & $3.90 \mathrm{E}-04$ \\
\hline 897 & Octadecanoic acid & $57-11-4$ & 4.10E-03 & 1 & $4.10 \bar{E}-03$ & $4.10 \mathrm{E}-03$ \\
\hline 898 & 1,1'-Bipheny|, 4,4'-dichloro- & $2050-68-2$ & $4.08 \mathrm{E}-03$ & 1 & $4.08 \mathrm{E}-03$ & $4.08 \mathrm{E}-03$ \\
\hline 899 & Hexadecanoic acid, 2,3-dihydroxypropyl ester & $542-44-9$ & 4.00E-03 & 1 & $4.00 \mathrm{E}-03$ & $4.00 \mathrm{E}-03$ \\
\hline 900 & 4-Undecene, $(E)-$ & $693-62-9$ & 4.0OE-03 & 1 & 4.00E-03 & 4.00E-03 \\
\hline 901 & 1-Hexene, 2-methyl- & $6094-02-6$ & $3.90 \bar{E}-03$ & 1 & $3.90 \mathrm{E}-03$ & $3.90 \mathrm{E}-03$ \\
\hline 902 & Hexanoic acid & $142-62-1$ & $3.85 \mathrm{E}-03$ & 1 & $3.85 E-03$ & $3.85 \mathrm{E}-03$ \\
\hline 903 & Pyridine, 2,4-dimethyl- & $108-47-4$ & $3.82 \mathrm{E}-03$ & 1 & $3.82 \mathrm{E}-03$ & $3.82 \mathrm{E}-03$ \\
\hline 904 & 1,1'-Biphenyl, 2,4',5-trichloro- & $16606-02-3$ & $3.80 \mathrm{E}-03$ & 1 & $3.80 \mathrm{E}-03$ & $3.80 \mathrm{E}-03$ \\
\hline
\end{tabular}




\begin{tabular}{|c|c|c|c|c|c|c|}
\hline & B & $\mathrm{C}$ & D & $\mathbf{F}$ & $G$ & $\mathrm{H}$ \\
\hline 1 & TANK CHEMICALS & CAS \# & $\begin{array}{c}\text { Mean } \\
(\mathbf{m g} / \mathbf{m} 3)\end{array}$ & $\begin{array}{l}\text { Number of } \\
\text { tanks }\end{array}$ & $\begin{array}{l}\text { Maximum } \\
(\mathrm{mg} / \mathrm{m} 3)\end{array}$ & $\begin{array}{l}\text { Minimum } \\
(\mathrm{mg} / \mathrm{m} 3)\end{array}$ \\
\hline 905 & Cyclohexanone, 2,6-diethyl- & $16519-68-9$ & $3.80 \mathrm{E}-03$ & 1 & $3.80 \mathrm{E}-03$ & $3.80 \mathrm{E}-03$ \\
\hline 906 & 2-Dodecenal & $4826-62-4$ & $3.70 \mathrm{E}-03$ & 1 & 3.70E-03 & $3.70 \mathrm{E}-03$ \\
\hline 907 & Benzene, 1-butoxy-4-methoxy- & $20743-95-7$ & $3.60 \mathrm{E}-03$ & 1 & $3.60 \mathrm{E}-03$ & $3.60 \mathrm{E}-03$ \\
\hline 908 & Undecanal & $112-44-7$ & $2.17 E-03$ & 3 & $3.60 \mathrm{E}-03$ & $1.40 \mathrm{E}-03$ \\
\hline 909 & 2-Undecanol & $1653-30-1$ & $3.53 \mathrm{E}-03$ & 1 & $3.53 \mathrm{E}-03$ & $3.53 E-03$ \\
\hline 910 & Nonane, 5-propyl- & $998-35-6$ & $3.50 \mathrm{E}-03$ & 1 & $3.50 \mathrm{E}-03$ & $3.50 \mathrm{E}-03$ \\
\hline 911 & 4-Nonene, 5-methyl- & $15918-07-7$ & $3.40 \mathrm{E}-03$ & 1 & $3.40 \mathrm{E}-03$ & $3.40 \mathrm{E}-03$ \\
\hline 912 & $\begin{array}{l}\text { Cyclohexanone, } 2,5 \text {-dimethyl-2-(1- } \\
\text { methylethenyl)- }\end{array}$ & $6711-26-8$ & $3.40 \mathrm{E}-03$ & 1 & $3.40 \mathrm{E}-03$ & $3.40 E-03$ \\
\hline 913 & 3-Hexanone, 4-ethyl- & $6137-12-8$ & $3.35 \mathrm{E}-03$ & 1 & $3.35 \mathrm{E}-03$ & $3.35 \mathrm{E}-03$ \\
\hline 914 & 2-Furanmethanol, tetrahydro-5-methyl-, trans- & $54774-28-6$ & $3.34 \mathrm{E}-03$ & 1 & $3.34 \mathrm{E}-03$ & $3.34 \mathrm{E}-03$ \\
\hline 915 & Cyclohexane, 1,2,3-trimethyl- & $1678-97-3$ & $2.94 \mathrm{E}-03$ & 2 & $3.29 \mathrm{E}-03$ & $2.60 \mathrm{E}-03$ \\
\hline 916 & Phenol, (1,1-dimethylethyl)-4-methoxy- & $250+3-16-5$ & $3.20 \mathrm{E}-03$ & 1 & $3.20 \mathrm{E}-03$ & $3.20 \mathrm{E}-03$ \\
\hline 917 & Hexadecanamide & $629-54-9$ & $3.20 \mathrm{E}-03$ & 1 & $3.20 \mathrm{E}-03$ & 3.20E-03 \\
\hline 918 & 2-Cyclohexen-1-one, 4-ethyl-3,4-dimethyl- & $17622-46-7$ & $3.15 \mathrm{E}-03$ & 1 & $3.15 \mathrm{E}-03$ & 3.15E-03 \\
\hline 919 & 2-Heptanol, 2-methyl- & $625-25-2$ & $3.15 \mathrm{E}-03$ & 1 & $3.15 \mathrm{E}-03$ & $3.15 \mathrm{E}-03$ \\
\hline 920 & Phenol, 4-propyl- & $645-56-7$ & $3.11 \mathrm{E}-03$ & 1 & $3.11 \mathrm{E}-03$ & $3.11 \mathrm{E}-03$ \\
\hline 921 & Undecane, 6-ethyl- & $17312-60-6$ & $3.10 \mathrm{E}-03$ & 1 & $3.10 \mathrm{E}-03$ & $3.10 \mathrm{E}-03$ \\
\hline 922 & Furan, 3-(1,1-dimethylethy)-2,3-dihydro- & $34314-82-4$ & $3.00 \mathrm{E}-03$ & 1 & $3.00 \mathrm{E}-03$ & $3.00 \mathrm{E}-03$ \\
\hline 923 & 1-Pentanol, 5-amino- & $2508-29-4$ & $2.55 \mathrm{E}-03$ & 2 & $2.98 \mathrm{E}-03$ & $2.13 \mathrm{E}-03$ \\
\hline 924 & Heptanoic acid, butyl ester & $5454-28-4$ & $2.96 E-03$ & 1 & $2.96 \mathrm{E}-03$ & $2.96 \mathrm{E}-03$ \\
\hline 925 & 2-Dodecanone & $6175-49-1$ & $2.95 \mathrm{E}-03$ & 1 & $2.95 \mathrm{E}-03$ & $2.95 \mathrm{E}-03$ \\
\hline 926 & 2-Furanmethanol, tetrahydro-, acetate & $637-64-9$ & $2.95 \mathrm{E}-03$ & 1 & $2.95 \mathrm{E}-03$ & 2.95E-03 \\
\hline 927 & Decane, 2,4-dimethyl- & $2801-84-5$ & $2.92 \mathrm{E}-03$ & 1 & $2.92 \mathrm{E}-03$ & $2.92 \mathrm{E}-03$ \\
\hline 928 & 1H-Inden-1-one, 2,3-dihydro-3,3-dimethyl- & $26465-81-6$ & $2.90 \mathrm{E}-03$ & 1 & $2.90 \mathrm{E}-03$ & $2.90 \mathrm{E}-03$ \\
\hline 929 & Naphthalene & $91-20-31$ & $2.90 \mathrm{E}-03$ & 1 & $2.90 \mathrm{E}-03$ & $2.90 \mathrm{E}-03$ \\
\hline 930 & Nonane, 3-methyl-5-propyl- & $31081-18-2$ & $1.90 \mathrm{E}-03$ & 2 & $2.90 \mathrm{E}-03$ & 9.10E-04 \\
\hline 931 & Decanoic acid & $334-48-5$ & $2.75 E-03$ & 2 & $2.90 E-03$ & $2.60 E-03$ \\
\hline 932 & Acetonitrile, hydroxy- & $107-16-4$ & $2.86 \mathrm{E}-03$ & 1 & $2.86 \mathrm{E}-03$ & $2.86 \mathrm{E}-03$ \\
\hline 933 & 2-Hexanol, 5-methyl- & $627-59-8$ & $2.85 \mathrm{E}-03$ & 1 & $2.85 \mathrm{E}-03$ & $2.85 \mathrm{E}-03$ \\
\hline 934 & Butyric acid, ester with p-hydroxybenzonitrile & $29052-10-6$ & $2.80 E-03$ & 1 & $2.80 \mathrm{E}-03$ & $2.80 \mathrm{E}-03$ \\
\hline 935 & 11, 1'-Biphenyl, 4-chloro- & $2051-62-9$ & $2.80 \mathrm{E}-03$ & 1 & $2.80 \mathrm{E}-03$ & $2.80 \mathrm{E}-03$ \\
\hline 936 & Hydrazine, methyl- & $60-34-4$ & $2.77 \mathrm{E}-03$ & 1 & $2.77 \mathrm{E}-03$ & $2.77 \mathrm{E}-03$ \\
\hline 937 & 1-Pentyn-3-ol, 3,4-dimethyl- & $1482-15-1$ & $2.74 \mathrm{E}-03$ & 1 & $2.74 \mathrm{E}-03$ & $2.74 \mathrm{E}-03$ \\
\hline 938 & 1,1'-Biphenyl, 2,2'-diethyl- & $13049-35-9$ & $2.07 \mathrm{E}-03$ & 4 & $2.69 E-03$ & $1.60 \mathrm{E}-03$ \\
\hline 939 & Cyclohexane, 1-(1,5-dimethylhexyl)-4-methy|- & $29799-19-7$ & $2.36 \mathrm{E}-03$ & 2 & $2.68 \mathrm{E}-03$ & $2.03 \mathrm{E}-03$ \\
\hline 940 & 2H-Pyran-2-one, 6-hexyltetrahydro- & $710-04-3$ & $2.68 \mathrm{E}-03$ & 1 & $2.68 \mathrm{E}-03$ & $2.68 \mathrm{E}-03$ \\
\hline 941 & Hexadecanoic acid, butyl ester & $111-06-8$ & $2.64 \mathrm{E}-03$ & 1 & $2.64 \mathrm{E}-03$ & $2.64 \mathrm{E}-03$ \\
\hline 942 & 1.1'-Biphenyl, 2,4,4'-trichloro- & $7012-37-5$ & $2.61 \mathrm{E}-03$ & 1 & $2.61 E-03$ & $2.61 \mathrm{E}-03$ \\
\hline 943 & 2H-Pyran-2-one, tetrahydro-6,6-dimethyl- & $2610-95-9$ & $2.60 \mathrm{E}-03$ & 1 & $2.60 \mathrm{E}-03$ & $2.60 \mathrm{E}-03$ \\
\hline 944 & Isothiazole & $288-16-4$ & $2.55 \mathrm{E}-03$ & 2 & $2.60 \mathrm{E}-03$ & $2.50 \mathrm{E}-03$ \\
\hline 945 & Nonadecane & $629-92-5$ & $2.22 \mathrm{E}-03$ & 3 & $2.60 E-03$ & $1.50 \mathrm{E}-03$ \\
\hline 946 & 1-Pentene, 4,4-dimethyl- & $762-62-9$ & $2.54 \mathrm{E}-03$ & 1 & $2.54 \mathrm{E}-03$ & $2.54 \mathrm{E}-03$ \\
\hline 947 & 7-Tetradecene. (Z)- & $41446-60-0$ & $2.52 \mathrm{E}-03$ & 1 & $2.52 \mathrm{E}-03$ & $2.52 \mathrm{E}-03$ \\
\hline 948 & Decane, 2,3,5-trimethyl- & $62238-11-3$ & $2.51 \mathrm{E}-03$ & 1 & $2.51 \mathrm{E}-03$ & $2.51 \mathrm{E}-03$ \\
\hline 949 & 1,1'-Biphenyl, 2,3,4',6-tetrachloro- & $52663-58-8$ & $1.54 \mathrm{E}-03$ & 2 & $2.48 \mathrm{E}-03$ & $5.90 \mathrm{E}-04$ \\
\hline 950 & 2(3H)-Furanone, 5-ethenyldihydro-5-methyl- & $1073-11-6$ & $2.47 \mathrm{E}-03$ & 1 & $2.47 \mathrm{E}-03$ & $2.47 \mathrm{E}-03$ \\
\hline 951 & 1,3-Benzodioxol-2-one, hexahydro-, trans- & $20192-66-9$ & $2.43 \mathrm{E}-0.3$ & 1 & $2 . \overline{43 \mathrm{E}-03}$ & $2.43 \mathrm{E}-03$ \\
\hline 952 & Propanenitrile, 3-amino- & $151-18-8$ & $2.43 \mathrm{E}-03$ & 1 & $2.43 \mathrm{E}-03$ & $2.43 \mathrm{E}-03$ \\
\hline 953 & 4-Undecanol & $4272-06-4$ & $2.41 \mathrm{E}-03$ & 1 & $2.41 \mathrm{E}-03$ & $2.41 \mathrm{E}-03$ \\
\hline 954 & 2-Fentene 2-methoxy- & $61142-47-0$ & $2.41 \mathrm{E}-03$ & 1 & $2.41 \mathrm{E}-03$ & $2.41 \mathrm{E}-03$ \\
\hline 955 & Cyclohexanone, 4-hydroxy-4-methyl- & $17429-02-6$ & $2.40 \mathrm{E}-03$ & 1 & $2.40 \mathrm{E}-03$ & $2.40 \mathrm{E}-03$ \\
\hline
\end{tabular}




\begin{tabular}{|c|c|c|c|c|c|c|}
\hline & 官 & c & D & $F$ & $\mathbf{G}$ & $\mathrm{H}$ \\
\hline 1 & TANK CHEMICALS & CAS \# & $\begin{array}{c}\text { Mean } \\
\text { (mg/m3) }\end{array}$ & $\begin{array}{c}\text { Number of } \\
\text { tanks }\end{array}$ & $\begin{array}{c}\text { Maximum } \\
(\mathrm{mg} / \mathrm{m} 3)\end{array}$ & $\begin{array}{l}\text { Minimum } \\
(\mathrm{mg} / \mathrm{m} 3)\end{array}$ \\
\hline 956 & $\begin{array}{l}\text { Cycichexanecarboxylic acid, 2-(1,1- } \\
\text { dimethylethyl }) \text {-, trans- }\end{array}$ & $27392-16-1$ & $2.40 \mathrm{E}-03$ & 1 & $2.40 E-03$ & $2.40 E-03$ \\
\hline 957 & Undecane 3-ethyl- & $17312-58-2$ & $2.40 \mathrm{E}-03$ & 1 & $2.40 \mathrm{E}-03$ & $2 . \overline{40 E-03}$ \\
\hline 958 & Oxirane, (1-methylbutyi)- & $53229-39-3$ & $2.36 \mathrm{E}-03$ & 1 & $2.36 \mathrm{E}-03$ & $2.36 \mathrm{E}-03$ \\
\hline 959 & Benzamide, N-methyl- & $613-93-4$ & $2.30 E-03$ & 1 & $2.30 E-03$ & 2.30E-03 \\
\hline 960 & 3-Hexyne-2,5-diol, 2,5-dimethyl- & $\{42-30-3 \mid$ & $2.28 \mathrm{E}-03$ & 1 & $2.28 \mathrm{E}-03$ & $2.28 \mathrm{E}-03$ \\
\hline 961 & Formic acid, meihyl ester & $107-31-3$ & $2.24 \mathrm{E}-03$ & 1 & $2.24 \mathrm{E}-03$ & $2.24 \mathrm{E}-03$ \\
\hline 962 & Cyclohexane, (2-ethyl-1-methyl-1 -butenyl)- & $74810-42-7$ & $2.23 E-03$ & 1 & $2.23 E-03$ & $2.23 \mathrm{E} .03$ \\
\hline 963 & Hexanoic acid, anhydride & $2051-49-2$ & $2.20 \mathrm{E}-03$ & 1 & $2.20 \mathrm{E}-03$ & $2.20 \mathrm{E}-03$ \\
\hline 964 & Hexanoic acid, 2-ethyl- & 149-57-5 & $2.20 \mathrm{E}-03$ & 1 & $2.20 \mathrm{E}-03$ & $2.20 \mathrm{E}-03$ \\
\hline 965 & Cyclohexanol & $108-93-0$ & $2.20 E-03$ & 1 & $2.20 \mathrm{E}-03$ & $2.20 \mathrm{E}-03$ \\
\hline 966 & Undecanenitrile & $2244-07-7$ & $2.19 E-03$ & 1 & $2.19 \mathrm{E}-03$ & $2.19 \mathrm{E}-03$ \\
\hline 967 & Cyclopentane, 2-thyl-1,1-dimethyl- & $54549-80-3$ & $2.17 \mathrm{E}-03$ & 1 & $2.17 \mathrm{E}-03$ & $2.17 \mathrm{E}-03$ \\
\hline 968 & Nitric acid, 2-methylpropyl ester & $543-29-3$ & 2.17E-03 & 1 & $2.17 \mathrm{E}-03$ & $2.17 \mathrm{E}-03$ \\
\hline 969 & Nonane, 2-methyl-5-propyl- & $31081-17-1$ & $2.16 \mathrm{E}-03$ & 1 & $2.16 \mathrm{E}-03$ & $2.16 \mathrm{E}-03$ \\
\hline 970 & Cycloheptane, 1,3-dimethoxy-, trans- & $29887-79-4$ & $2.10 \mathrm{E}-03$ & 1 & $2.10 \mathrm{E}-03$ & $2.10 \mathrm{E}-03$ \\
\hline 971 & Hexane, $2,3,3$-trimethyl- & $16747-28-7$ & $2.06 \mathrm{E}-03$ & 1 & $2.06 \mathrm{E}-03$ & $2.06 \mathrm{E}-03$ \\
\hline 972 & Decane 4-cyclohexyl-, 4-cyclohexyl- & $1315-75-2$ & $2.00 \mathrm{E}-03$ & 1 & 2.00E-03 & $2.00 \mathrm{E}-03$ \\
\hline 973 & Heptadecane, 8-methyl- & $13287-23-5$ & $2.00 \mathrm{E}-03$ & 1 & $2.00 E-03$ & $2.00 \mathrm{E}-03$ \\
\hline 974 & Cyclohexane, decyl- & $1795-16-0$ & $2.00 E-03$ & 1 & $2.00 \mathrm{E}-03$ & $2.00 \mathrm{E}-03$ \\
\hline 975 & Benzaldehyde, 3-phenoxy- & $39515-5 t-0$ & $2.00 E-03$ & 1 & $2.00 \mathrm{E}-03$ & $2.00 \mathrm{E}-03$ \\
\hline 976 & Silane, fluorotrimethyl- & $420-56-4$ & $1.96 \mathrm{E}-03$ & 1 & $1.96 \mathrm{E}-03$ & $1.96 \mathrm{E}-03$ \\
\hline 977 & Tridecanal & $10486-19-8$ & $1.90 \mathrm{E}-03$ & 1 & $1.90 \mathrm{E}-03$ & $1.90 \mathrm{E}-03$ \\
\hline 978 & 1-Decanol & $112-30-1$ & $1.90 \mathrm{E}-03$ & 1 & $1.90 E-03$ & $1.90 \mathrm{E}-03$ \\
\hline 979 & 1-Octadecene & $112-88-9$ & $1.90 \mathrm{E}-03$ & 1 & $1.90 \mathrm{E}-03$ & $1.90 \mathrm{E}-03$ \\
\hline 980 & Hexanedioic acid, bis(1-methyipropyl) ester & $38447-22-2$ & $1.90 \mathrm{E}-03$ & $t$ & $1.90 \mathrm{E}-03$ & $1.90 \mathrm{E}-03$ \\
\hline 981 & 1-Decene, 5-methyl- & $54244-79-0$ & $1.88 \mathrm{E}-03$ & 1 & $1.88 E-03$ & $1.88 \mathrm{E}-03$ \\
\hline 982 & Decane, 2,2,6-trimethyl- & $62237-97-2$ & $1.87 \mathrm{E}-03$ & 1 & $1.87 \mathrm{E}-03$ & $1.87 \mathrm{E}-03$ \\
\hline 983 & Pyrazine, 2,5-dimethyl- & $123-32-0$ & 1.87E-03 & 1 & $1.87 \mathrm{E}-03$ & $1.87 \mathrm{E}-03$ \\
\hline 984 & 1-Octadecyne & $629-89-0$ & $1.86 \mathrm{E}-03$ & 1 & $1.86 \mathrm{E}-03$ & $1.86 \mathrm{E}-03$ \\
\hline 985 & 1,1'-Biphenyl, 2,3,4-trichlora- & $55702-46-0$ & $1.85 \mathrm{E}-03$ & 1 & $1.85 \mathrm{E}-03$ & $1.85 \mathrm{E}-03$ \\
\hline 986 & 1-Pyrrolidinamine, 2-(methoxymethyl)-, (S)- & 59983-39-0. & 1.80E-03 & 1 & $1.80 \mathrm{E}-03$ & $1.80 \mathrm{E}-03$ \\
\hline 987 & Octadecane, 2,0 -dimethyl- & $75163-97-2$ & $1.80 \mathrm{E}-03$ & 1 & $1.80 \mathrm{E}-03$ & $1.80 \mathrm{E}-03$ \\
\hline 988 & Ethanone, $1-(3-$-methylphenyl)- & $585-74-0$ & $1.79 \mathrm{E}-03$ & 1 & $1.79 \mathrm{E}-03$ & $1.79 \mathrm{E}-03$ \\
\hline 989 & Tetradecane, 5-methyl- & $25117-32-2$ & $1.72 \mathrm{E}-03$ & 1 & $1.72 \mathrm{E}-03$ & $1.72 \mathrm{E}-03$ \\
\hline 990 & 3,4-Undecadiene-2, 10 -dione, 6,6-dimethyl- & $52588-78-0$ & $1.70 \mathrm{E}-03$ & 1 & $1.70 \mathrm{E}-03$ & $1.70 \mathrm{E}-03$ \\
\hline 991 & 2-Pyrrolidinone & $616-45-5$ & $1.58 \mathrm{E}-03$ & 1 & $1.58 \mathrm{E}-03$ & $1.58 \mathrm{E}-03$ \\
\hline 992 & $1 \mathrm{H}$-Imidazoie, 2-methyl- & $693-98-1$ & $1.57 \mathrm{E}-03$ & 1 & $1.57 \mathrm{E}-03$ & $1.57 \mathrm{E}-03$ \\
\hline 993 & Cyclopropane, 1-ethyl-2-pentyl- & 62238-08-8 & $1.55 \mathrm{E}-03$ & 1 & $1.55 \mathrm{E}-03$ & $1.55 \mathrm{E}-03$ \\
\hline 994 & Acetic acid, oxo-, butyl ester & $6295-06-3$ & $1.45 \mathrm{E}-03$ & 1 & $1.45 \mathrm{E}-03$ & $1.45 E-03$ \\
\hline 995 & Decane, 2,6,8-trimethyl- & $62108-26-3$ & $1.43 \mathrm{E}-03$ & 1 & $1.43 \mathrm{E}-03$ & $1.43 \mathrm{E}-03$ \\
\hline 996 & Nitric acid, nonyl ester & $20633-13-0$ & $1.38 \mathrm{E}-03$ & 1 & $1.38 \mathrm{E}-03$ & $1.38 \mathrm{E}-03$ \\
\hline 997 & Butanoic acid, 1-methylpropyt ester & $819-97-6$ & $1.37 \mathrm{E}-03$ & 1 & $1.37 \mathrm{E}-03$ & $1.37 \mathrm{E}-03$ \\
\hline 998 & Tetradecane, 6,9-dimethyl- & $55045-13-11$ & $1.35 \mathrm{E}-03$ & 1 & $1.35 \mathrm{E}-03$ & $1.35 \mathrm{E}-03$ \\
\hline 999 & Phenol, 4-11,1-dimethylethyl)- & $98-54-4$ & $1.33 \mathrm{E}-03$ & 1 & $1.33 \mathrm{E}-03$ & $1.33 \mathrm{E}-03$ \\
\hline 1000 & Octanal, 7-hydroxy-3,7-dimethyl- & $107-75-5$ & $1.32 \mathrm{E}-03$ & 1 & $1.32 \mathrm{E}-03$ & $1.32 \mathrm{E}-03$ \\
\hline 1001 & Undecane, 3,5-dimethyl- & $17312-81-1$ & $1.30 E-03$ & 1 & $1.30 \mathrm{E}-03$ & $1.30 \mathrm{E}-03$ \\
\hline 1002 & 1-Nonadecene & $18435-45-5$ & $1.30 \mathrm{E}-03$ & 1 & $1.30 \mathrm{E}-03$ & $1.30 \mathrm{E}-03$ \\
\hline 1003 & Cyclohexanol, 4-methyl-1-(1-methylethyl)- & $470-65-5$ & $1.2 \mathrm{gE}-03$ & 1 & $1.29 \mathrm{E}-03$ & $1.2 \mathrm{gE}-03$ \\
\hline 1004 & Acetamide, $\mathrm{N}$-methyi- & $79-16-3 i$ & $1.21 \mathrm{E}-03$ & 1 & $1.21 \mathrm{E}-03$ & $1.21 \mathrm{E}-03$ \\
\hline 1005 & Butanoic acid, hexylester & $2639-63-6$ & $1.20 \mathrm{E}-03$ & 1 & $1.20 \mathrm{E}-03$ & $1.20 \mathrm{E}-03$ \\
\hline 1006 & 1,4-Butanediamine & $110-60-1$ & $1.19 \mathrm{E}-03$ & 1 & $1.19 \mathrm{E}-03$ & $1.19 \mathrm{E}-03$ \\
\hline
\end{tabular}


WHC-SD-WM-TI-753 REV 0

\begin{tabular}{|c|c|c|c|c|c|c|}
\hline & $\mathbf{B}$ & C & D & $\mathbf{F}$ & $\mathbf{G}$ & $\mathrm{H}$ \\
\hline 1 & TANK CHEMICALS & CAS \# & $\begin{array}{c}\text { Mean } \\
(\mathrm{mg} / \mathrm{m} 3)\end{array}$ & $\begin{array}{l}\text { Number of } \\
\text { tanks }\end{array}$ & $\begin{array}{l}\text { Maximum } \\
(\mathrm{mg} / \mathrm{m} 3)\end{array}$ & $\begin{array}{l}\text { Minimum } \\
(\mathrm{mg} / \mathrm{m} 3)\end{array}$ \\
\hline 1007 & Hexadecanol & $29354-98-1$ & 1.10E-03 & 1 & 1.10E-03 & $1.10 E-03$ \\
\hline 1008 & 1,1'-Biphenyl, 2,3-dichloro- & $16605-91-7$ & $1.08 \mathrm{E}-03$ & 1 & $1.08 E-03$ & $1.08 \mathrm{E}-03$ \\
\hline 1009 & Propane, 2-ethoxy-2-methyl- & $637-92-3$ & $1.07 \mathrm{E}-03$ & 1 & $1.07 E-03$ & 1.07E-03 \\
\hline 1010 & Cycloheptanol, 1-methyl- & $3761-94-2$ & $101 \mathrm{E}-03$ & 1 & $1.01 \mathrm{E}-03$ & $1.01 \mathrm{E}-03$ \\
\hline 1011 & 1,12-Dodecanediol & $5675-51-4$ & $1.00 \mathrm{E}-03$ & 1 & $1.00 \mathrm{E}-03$ & $1,00 \mathrm{E}-03$ \\
\hline 1012 & 2-Heptadecanone & $2922-51-2$ & 7.65E-04 & 2 & $1.00 E-03$ & 5.30E-04 \\
\hline 1013 & 1,1'-Biphenyl, 2,5-dichloro- & $34883-39-1$ & 9.87E-04 & 1 & $9.87 \mathrm{E}-04$ & 9.87E-04 \\
\hline 1014 & $\begin{array}{l}\text { Ethanone, } \uparrow-(5,6,7,8 \text {-tetrahydro }-3,5,5,6,8,8- \\
\text { hexamethyl-2- naphthalenyl)- }\end{array}$ & $1506-02-1$ & $9.79 E-04$ & 1 & 9.79E-04 & $9.79 E-04$ \\
\hline 1015 & 1-Decanol, 2-ethyl- & $21078-65-9$ & $9.50 E-04$ & 1 & $9.50 \mathrm{E}-04$ & $9.50 \mathrm{E}-04$ \\
\hline 1016 & 5,9-Undecadien-2-one, 6,10-dimethyl-, (E)- & $3796-70-1$ & $7.30 E-04$ & 1 & $7.30 \mathrm{E}-04$ & 7.30E-04 \\
\hline 1017 & 2-Hexanone, 6-methoxy- & $29006-00-6$ & $6.65 E-04$ & 1 & $6.65 \mathrm{E}-04$ & $6.65 E-04$ \\
\hline 1018 & 2-Hexanol, 2,3-dimethyl- & 19550-03-9 & $6.50 \mathrm{E}-04$ & 1 & $6.50 \mathrm{E}-04$ & $6.50 \mathrm{E}-04$ \\
\hline 1019 & Pyridine, 2,3,6-trimethyl- & $1462-84-6$ & $6.45 \mathrm{E}-04$ & 1 & $6.45 \mathrm{E}-04$ & $6.45 \mathrm{E}-04$ \\
\hline 1020 & 2-Nonene, $(E)$ - & $6434-78-2$ & $635 \mathrm{E}-04$ & 1 & $6.35 \mathrm{E}-04$ & $6.35 \mathrm{E}-04$ \\
\hline 1021 & Cyclopentanone, 3,4-dimethyl-, trans- & $19550-73-3$ & $6.30 \mathrm{E}-04$ & 1 & $6.30 \bar{E}-04$ & $6.30 \mathrm{E}-04$ \\
\hline 1022 & 1-Pyrrolidinecarboxaldehyde & $3760-54-1$ & $6.00 E-04$ & 1 & $6.00 \mathrm{E}-04$ & $6.00 \mathrm{E}-04$ \\
\hline 1023 & 2-Undecene, $(Z)$ - & $821-96-5$ & 5.97E-04 & 1 & $5.97 E-04$ & 5.97E-04 \\
\hline 1024 & Cyclopentane, 1-ethyl-3-methyl-, cis- & $2613-66-3$ & 5.80E-04 & 1 & $5.80 E-04$ & $5.80 E-04$ \\
\hline 1025 & Butanamide, N-hexyl- & $10264-17-2$ & 4.30E-04 & 1 & $4.30 \mathrm{E}-04$ & 4.30E-04 \\
\hline
\end{tabular}


WHC-SD-WM-TI-753 REV 0

This page intentionally left blank. 
WHC-SD-WM-TI-753 REV 0

APPENDIX B

STANDARD HYDROGEN MONITORING SYSTEM

GRAB SAMPLE ANALYSIS DATAFILE 
WHC-SD-WM-TI-753 REV 0

This page intentionally left blank.

B-2 


\section{APPENDIX B}

\section{STANDARD HYDROGEN MONITORING SYSTEM GRAB SAMPLE ANALYSIS DATAFILE}

This appendix contains the data taken to date using the grab sampling capabilities of the standard hydrogen monitoring systems installed on selected single- and double-shell tanks. The sample was collected in the field and sent to the PNL for analyses. The results of the analyses are shown on the following spreadsheet pages.

Averages of the hydrogen concentrations were found and standard deviations were calculated. Ratios of nitrous oxide to hydrogen and methane to hydrogen were also calculated. Standard deviations were found for these ratios also. Results that were 0 (zero) or errors (division by zero) were not used when calculating the standard deviations. 
WHC-SD-WM-TI-753 REV 0

This page intentionally left blank. 


\begin{tabular}{|c|c|c|c|c|c|c|c|c|c|c|c|c|c|c|c|c|c|c|c|c|c|c|c|c|c|}
\hline Sample ID & LRB & Sample Time & Recetved & Analyzed & Reported & dit tot & dit lab & Ar & & $\mathrm{CO2}$ & & CO & & $\mathrm{He2}$ & & $\mathrm{H} \mathbf{2}$ & & CH4 & & N2 & & 02. & & $\mathrm{~N} 2 \mathrm{O}$ & \\
\hline & & & & & & & & moles: & est proce & $\operatorname{man} x$ & estprose & moliex & estpras & molos & estprose & molok & mt proce & molox & stprest & molnox & ext preste & motex & menex & moles & extprece \\
\hline AN-103-1102-94-140 & 55413 & $11 / 2941400$ & $11 / 10 / 94$ & $11 / 90 / 94$ & $11 / 19 / 94$ & 8 & 1 & 0.95 & 0.02 & 0.034 & 0.002 & & $<.01$ & & $<.001$ & 0.0077 & 0.0004 & & $<.009$ & 78.1 & 0.4 & 20.9 & 0.4 & & $<.001$ \\
\hline AN-103-1110.94-085 & 55413 & $11 / 10 / 94850$ & $11 / 10 / 94$ & $11 / 10 / 94$ & $11 / 41 / 94$ & 1 & 1 & 0.95 & 0.02 & 0.032 & 0,002 & & $<.01$ & & $<.001$ & 0.0034 & 0.0002 & & $<.001$ & 78.1 & 0.4 & 20.9 & 0.4 & & $<.001$ \\
\hline AN-103-1116-94-140 & & $1 1 \longdiv { 1 6 9 4 1 4 0 0 }$ & $12 / 194$ & $12 / 2 / 94$ & $12 / 5 / 94$ & 18 & 4 & 0.94 & 0.02 & 0.033 & 0.002 & & $<.01$ & & $<.001$ & $0.008 i$ & 0.0008 & & $<.001$ & 77.9 & 0.4 & 21.1 & 0.4 . & 0.0006 & 0.0001 \\
\hline AN-103-1122-94-103 & & $11 / 229941030$ & $12 / 194$ & $12 / 234$ & $12 / 5 / 94$ & 13 & 4 & 0.94 & 0.02 & 0.033 & 0.002 & & $<.01$ & & 5.001 & 0.0022 & 0.0002 & & $<.001$ & 779 & 0.4 & 21.1 & 0.4 & & $<.0005$ \\
\hline AN-103-1130-94-150 & 6 & 11/30194 15:05 & $12 / 1 / 94$ & $12 / 2 / 94$ & $12 / 5 / 94$ & 4 & 4 & 0.94 & 0.02 & 0.030 & 0.002 & & $<.07$ & & $<.001$ & 0.023 & 0.002 & & $<.001$ & 77.9 & 0.4 & 21.1 & 0.4 & 0.0014 & 0.0004 \\
\hline AN-103-1207-94-155 & 6 & $127 / 9415.55$ & 12/15/94 & $12 / 16 / 94$ & $12 / 6 / 94$ & 8 & 1 & 0.93 & 0.02 & 0.033 & 0.002 & & $<.01$ & & 5,001 & 0.001 & 0.0005 & & $<.001$ & 78.0 & 0.4 & $2+.1$ & 0.4 & & $<.0005$ \\
\hline AN-103-1214-94-140 & & $12 / 14 / 941400$ & $12 / 15 / 94$ & $12 / 16 / 94$ & $12 / 46194$ & 1 & 1 & 0.94 & 0.02 & 0,028 & 0.002 & & $<.07$ & & $<.001$ & 0.0025 & 0.0001 & & $<.001$ & 78.0 & 0.4 & 24.1 & 0.4 & & $<, 0005$ \\
\hline AN-103-1221-94-095 & 6 & $12 / 21 / 94950$ & $4 / 595$ & $175 / 95$ & $1 / 6 / 95$ & 16 & 1 & 0.95 & 0.02 & 0035 & 0.002 & & $<01$ & & $<.001$ & 0.012 & 0.001 & & $<.001$ & 78.1 & 0.4 & 20.9 & 0.4 & & $<.001$ \\
\hline AN-103-0104-94-140 & ह & $1 / 4 / 951400$ & 1/5/95 & $1 / 5 / 95$ & $1 / 6995$ & 1 & 1 & 0.94 & 0.02 & 0.037 & 0.002 & & $<01$ & & $<.001$ & 0.0024 & 0.0001 & & $<.001$ & 78.1 & 0.4 & 20.9 & 0.4 & & $<.001$ \\
\hline TK-103-AN-1, 2/29/9 & 6 & $2 / 29 / 968: 20$ & $2 / 29 / 96$ & $3 / 1 / 196$ & $3 / 1996$ & 1 & 1 & 0.94 & 0.02 & 0.035 & 0.002 & & $<.01$ & & $<.001$ & 0.0015 & 0.0003 & & $<.001$ & 78.1 & 0.4 & 21.0 & 0.4 & & $\leq 0005$ \\
\hline TK-103-AN-2, 2/29/9 & 6 & $2 / 29 / 968.20$ & $2 / 29 / 96$ & $3 / 1 / 96$ & $3 / 1 / 96$ & 1 & 1 & 0.94 & 0.02 & 0.034 & 0.002 & & 0.01 & & 5.001 & 0.0013 & 0.0003 & & $<.001$ & 78.0 & 0.4 & 21.0 & 0.4 & & $<.0005$ \\
\hline TK-103-AN-1 & 6 & $3 / 27 / 9614.40$ & $3 / 28196$ & $3 / 28 / 96$ & 329,96 & 1 & 1 & 0.95 & 0.02 & 0.038 & 0.002 & & $<.01$ & & $<.001$ & 0.0022 & 0.0003 & & $<009$ & 77.9 & 0.4 & 21.1 & 0.4 & & $<0005$ \\
\hline TK-1C3-AN-2 & 6 & \begin{tabular}{|l|}
$3 / 2796614.40$ \\
\end{tabular} & $3 / 28 / 96$ & $3 / 28 / 96$ & $3 / 29 / 96$ & 1 & 1 & 0.95 & 0.02 & 0.036 & 0.002 & & $<.01$ & & 5.001 & 0.0023 & 0.0003 & & $<.001$ & 77.9 & 0.4 & 211 & 0.4 & & .0005 \\
\hline & & & & & & & & & & & & & & & & & & & & & & & & & \\
\hline & & & & & & & & & & & & & & & & & & & & & & & & & \\
\hline & & & & & & & & & & & & & & & & n20m2 & & ch4m2 & & & & & & & \\
\hline & & & & & & & & & & & & & & & & 0 & & 0 & & & & & & & \\
\hline & & & & & & & & & & & & & & & & & & 0 & & & & & & & \\
\hline & & & & & & & & & & & & & & & & 0.0741 & & o & & & & & & & \\
\hline & & & & & & & & & & & & & & & & & & 0 & & & & & & & \\
\hline & & & & & & & & & & & & & & & & 0.0609 & & 0 & & & & & & & \\
\hline & & & & & & & & & & & & & & & & 0 & & 0 & & & & & & & \\
\hline & & & & & & & & & & & & & & & & 0 & & 0 & & & & & & & \\
\hline & & & & & & & & & & & & & & & & 0 & & D & & & & & & & \\
\hline & & & & & & & & & & & & & & & & 0 & & 0 & & & & & & & \\
\hline & & & & & & & & & & & & & & & & 이 & & 0 & & & & & & & \\
\hline & & & & & & & & & & & & & & & & 0 & & of & & & & & & & \\
\hline & & & & & & & & & & & & & & & & 0 & & 0 & & & & & & & \\
\hline & & & & & & & & & & & & & & h12 & & o & & D & & & & & & & \\
\hline & & & & & & & & & & & & & avg & 0.005 & & 0.0675 & & NAB & Exclude & $s$ the $0 \mathrm{a}$ & ind \#livio & points & & & \\
\hline & & & & & & & & & & & & & sidd der & 0.006 & & 0.0093 & & NA & & & & & & & \\
\hline & & & & & & & & & & & & & $A+2 S D$ & 0.018 & & 0.0261 & & NA & & & & & & & \\
\hline
\end{tabular}




\begin{tabular}{|c|c|c|c|c|c|c|c|c|c|c|c|c|c|c|c|c|c|c|c|c|c|c|c|c|c|}
\hline Sample to & LRB & Sample Time & Received & Analyzedi & Reported & det tot & dt lab & Ar & & $\mathrm{CO} 2$ & & co & & $\mathrm{He} 2$ & & Hz & & CH4 & & N2 & & 02 & & $\mathrm{N2O}$ & \\
\hline$A A-104-110204-140$ & 55413 & & & & & & & molex & est prece & molox & sostprece & molex & 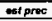 & moter & estpones & moles & eot proce & molot & ent proce & molew & $=0$ ostor & $\operatorname{mos} \theta x$ & est pros & molim $\%$ & sest procec \\
\hline AN-104-1102-94-14O & 55413 & $11 / 2 / 9414: 05$ & $11 / 10 / 94$ & $11 / 10 / 94$ & $11 / 1194$ & 8 & 1 & 0.95 & 002 & 0.033 & 0.002 & & 5.01 & & 5.001 & 0.0047 & 0.0002 & & $<001$ & 78.2 & 04 & 20.9 & 0.4 & & $<001$ \\
\hline AN-104-1109-94-151 & 56413 & 11/9/94 15:10 & $11 / 10 / 94$ & $11 / 10 / 94$ & $11 / 11 / 94$ & 1 & $t$ & 0.95 & 0.02 & 0.026 & 0.002 & & $<.01$ & & $<.001$ & 0.0154 & 0.0008 & & $<001$ & 78.1 & 0.4 & 20.0 & 0.4 & 0.0019 & 0.0009 \\
\hline $4 \mathrm{~N}+104-1116-94-140$ & & $19 / 16 / 9414: 05$ & $12 / 1 / 94$ & $12 / 2 / 94$ & $12 / 5 / 94$ & 18 & 4 & 0.94 & 0.02 & 0.031 & 0.002 & & $<.01$ & & $<.001$ & 0.0059 & 0.0006 & & $<.001$ & 77.9 & 0.4 & 21.1 & 04 & 0.0007 & 0.0002 \\
\hline $\mathrm{AN}-104 \cdot 1122 \cdot 94 \cdot 103$ & & 11/222194 10:35 & $12 / 1 / 94$ & $122 / 294$ & $12 / 5 / 94$ & 13 & 4 & 0.94 & 0.02 & 0.034 & 0.002 & & $<.01$ & & $<.001$ & 0.0032 & 0.0003 & & $<.001$ & 78.0 & 0.4 & 21.1 & 0.4 & 0.0005 & 0.0001 \\
\hline AN-104-1130-94-151 & 6 & $1 4 \longdiv { 3 0 / 2 4 1 5 : 1 0 }$ & $12 / 1 / 94$ & $12 / 2 / 54$ & $12 / 5 / 94$ & 4 & 4 & 0.94 & 0.02 & 0.032 & 0.002 & & $<.04$ & & $<.001$ & 0.0067 & 0.0007 & & $<001$ & 77.9 & 0.4 & 21.1 & 0.4 & 0.0008 & 100002 \\
\hline AN-104-1207-94-155 & 6 & $12 / 7 \% 415.55$ & $12 / 15 / 94$ & $12 / 16 / 94$ & $12 / 16 / 94$ & 8 & 1 & 0.94 & 0.02 & 0.035 & 0.002 & & $<.01$ & & $<.001$ & 0.0052 & 0.0001 & & $<.001$ & 78.0 & 0.4 & 21.0 & 0.4 & 0.0008 & 0.0003 \\
\hline AN-104-1214-94-140 & & $12 / 14 / 941405$ & $12 / 15 / 94$ & $12 / 16 / 94$ & $12 / 16 / 94$ & 1 & 1 & 0.94 & 0.02 & 0.033 & 0.002 & & $<.04$ & & $<.001$ & 0.0058 & 0.0001 & & $<.001$ & 780 & 04 & 210 & 0.4 & 0.001 & 0.0003 \\
\hline AN-104-1221-94-095 & 6 & $12 / 21 / 94955$ & $1 / 5 / 95$ & $1 / 5 / 95$ & $16 / 95$ & 16 & 1 & 0.94 & 0.02 & 0.036 & 0.002 & & 0.01 & & .001 & 0.0066 & 0.0001 & & $<.001$ & 78.2 & 04 & 20.8 & 0.4 & & $<001$ \\
\hline AN-104-0404-94-145 & 6 & $9 / 499514: 50$ & $1 / 5 / 95$ & $1 / 5 / 95$ & $1,6 / 95$ & 1 & 1 & 0.94 & 0.02 & 0.038 & 0.002 & & $<.01$ & & $<.001$ & 0.0062 & 0.0001 & & $<.001$ & 78.1 & 0.4 & 20.9 & 0.4 & & $<<01$ \\
\hline TK-104-AN-1, $2 / 29 \mathrm{~g}$ & 6 & 2279966825 & 229996 & $3 / 1 / 1 / 6$ & $3 / 1 / 96$ & 1 & 1 & 0.94 & 0.02 & 0.034 & 0.002 & & $<.01$ & & 5.001 & $\mid 0.0027$ & 0.0003 & & $<.001$ & 780 & 04 & 210 & 0.4 & & $<0005$ \\
\hline TK-104-AN-2, $2 / 2919$ & 6 & $2 / 29 / 968.25$ & $2 / 29 / 96$ & $3 / 106$ & $3 / 196$ & 1 & 1 & 0.94 & 0.02 & \begin{tabular}{|l|}
0.033 \\
\end{tabular} & 0.002 & & $<.01$ & & $<.001$ & 0.0025 & $\begin{array}{l}0.0003 \\
0.000\end{array}$ & & $<.001$ & 78.0 & 0.4 & 210 & 0.4 & & $<.0005$ \\
\hline TK-104-AN-1 & 6 & $3 / 27 / 9614: 40$ & $3 / 28 / 96$ & $3 / 28 / 96$ & $3 / 29 / 96$ & 1 & 1 & 0.95 & 002 & 0.034 & 0.002 & & $<.01$ & & 5001 & 0.0049 & 0.0003 & & $<001$ & 77.9 & 0.4 & 212 & 0.4 & 0.0008 & 0.0004 \\
\hline FK-104-AN-2 & $\underline{6}$ & $3 / 27 / 16614: 40$ & $3 / 28 / 166$ & $3 / 28 / 86$ & $3 / 29 / 06$ & 1 & 1 & 0.95 & 0.02 & 0.034 & 0.002 & & $<.01$ & & $<.001$ & $0.005 t$ & 0.0003 & & $<.001$ & 77.8 & 0.4 & 21.2 & 0.4 & 0.0008 & 0.0004 \\
\hline & & & & & & & & & & & & & & & & & & & & & & & & & \\
\hline & & & & & & & & & & & & & & & & & & & & & & & & & \\
\hline & & & & & & & & & & & & & & & & n2o/h2 & & $\cot 4 / 2$ & & & & & & & \\
\hline & & & & & & & & & & & & & & & & & & 0 & & & & & & & \\
\hline & & & & & & & & & & & & & & & & 0.1234 & & 0 & & & & & & & \\
\hline & & & & & & & & & & & & & & & & 0.1186 & & 0 & & & & & & & \\
\hline & & & & & & & & & & & & & & & & 0.1563 & & 0 & & & & & & & \\
\hline & & & & & & & & & & & & & & & & 0.1194 & & 0 & & & & & & & \\
\hline & & & & & & & & & & & & & & & & 0.1538 & & 0 & & & & & & & \\
\hline & & & & & & & & & & & & & & & & 0.1724 & & 0 & & & & & & & \\
\hline & & & & & & & & & & & & & & & & 0 & & 0 & & & & & & & \\
\hline & & & & & & & & & & & & & & & & 0 & & 0 & & & & & & & \\
\hline & & & & & & & & & & & & & & & & 0 & & 0 & & & & & & & \\
\hline & & & & & & & & & & & & & & & & 0 & & 0 & & & & & & & \\
\hline & & & & & & & & & & & & & & & & 0.1633 & & 0 & & & & & & & \\
\hline & & & & & & & & & & & & & & $\mathrm{h2}$ & & 0.1569 & & 0 & & & & & & & \\
\hline & & & & & & & & & & & & & avg & 0.006 & & 0.1455 & & NA & Exclude & sthe 0 & oints & & & & \\
\hline & & & & & & & & & & & & & std dev & 0.003 & & 0.0215 & & NA & & & & & & & \\
\hline & & & & & & & & & & & & & $A+2 \mathrm{SO}$ & \begin{tabular}{|l|}
0.012 \\
\end{tabular} & & \begin{tabular}{|l|l|}
0.1886 \\
\end{tabular} & & NA & & & & & & & \\
\hline
\end{tabular}




\begin{tabular}{|c|c|c|c|c|c|c|c|c|c|c|c|c|c|c|c|c|c|c|c|c|c|c|c|c|c|}
\hline Sample ID & LRB & Sample Time & Received & Analyzed & Reported & dt lot: & detab & Ar & & $\mathrm{CO} 2$ & & co & & He2 & & H2 & & $\mathrm{CH} 4$ & & N2 & & 02 & & N2O & \\
\hline & & & & & & & & molos & $=0$ & moras & $=0$ persec & ore & 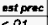 & modex & metarnes & molnx & eet pores & molex $x$ & estprect & dot & stper & ove & 0 apro & molex & $\mid$ \\
\hline AN-105-1102-94-1410 & 55413. & 11/2/94 14:40 & 11/10/94 & 11/10/94 & 11/11/94 & 8 & & 095 & 0.02 & 0.023 & 0.002 & & $<01$ & & $<.001$ & 0.0101 & 0.0005 & & $<.001$ & & 0.42 & & 0.4 & & 0,0009 \\
\hline AN-105-1109-94-1505 & 55413 & 11/9/9415:05 & $11 / 10 / 94$ & $11 / 10 / 94$ & $11 / 11 / 94$ & 1 & & 0.95 & 0.02 & 0.019 & 0.002 & & $<01$ & & $<.001$ & 0.022 & 0.001 & & $<.001$ & 78.1 & 0.42 & 20.9 & 0.4 & 0.0031 & 0.0006 \\
\hline$A N-105-1116-94-1410$ & & $11 / 16 / 9414: 10$ & $12 / 1 / 94$ & $12 / 2 / 94$ & $1215 / 94$ & 18 & & 0.95 & 0.02 & 0.035 & 0.002 & & $<.01$ & & $<.001$ & 0.0096 & 0,0005 & & $<.004$ & 78.2 & 0.42 & 20.8 & 0.4 & 0.002 & 0.0005 \\
\hline AN-105-1122-94-1040 & $6:$ & $11 / 22 / 94$ 10:40 & $12 / 1 / 94$ & $12 / 2 / 94$ & $12 / 5 / 94$ & 13 & 4 & 0.94 & 0.02 & 0.027 & 0.002 & & $\angle 01$ & & $<.009$ & 0.0098 & 0.0005 & & $<.001$ & 78.0 & 0.42 & 21.0 & 0.4 & 0.002 & 0.0005 \\
\hline AN-105-1130-94-1515 & 6. & $11 / 30 / 9415: 15$ & $12 / 1 / 94$ & $12 / 2 / 94$ & $12 / 5 / 94$ & 4 & & 0.94 & 0.02 & 0.029 & 0.002 & & $<.01$ & & $<, 001$ & 0.0114 & 0,0005 & & $<.001$ & 78.0 & 0.42 & 21.0 & 0.4 & 0.002 & 0.0005 \\
\hline AN-105-1207-94-1400 & 6 & $127 / 9494: 00$ & $12115 / 94$ & $12 / 16194$ & $12 / 16 / 94$ & 8 & 1 & 0.94 & 0.02 & 0.031 & 0.002 & & $<01$ & & $<000$ & 0.0069 & 0,0001 & & $<.001$ & 78.0 & 0.42 & 21.0 & 0.4 & 0.0014 & 0.0003 \\
\hline $\mathrm{AN}-105-1214-94-1405$ & 6 & $12 / 44 / 9414: 05$ & $\$ 2115 / 94$ & $12 / 46 / 94$ & $12 / 16 / 94$ & 1 & 1. & 0.94 & 0.02 & 0.018 & 0.002 & & $<.01$ & & $<001$ & 0.0173 & 0.004 & & $<.001$ & 78.0 & 0.42 & 21.0 & 0.4 & 0.0026 & 0.0003 \\
\hline AN-105-0823-95-0835T & E) & $8 / 23 / 958: 35$ & 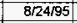 & $8 / 24 / 95$ & $8 / 24 / 95$ & 1 & & 0.94 & 0.02 & 0.032 & 0.002 & & $<01$ & & $<\infty$ & & $<0005$ & 0.0002 & 0.0001 & 78.0 & $0.4 \sqrt{2}$ & 21.0 & 0.4 & & $<0005$ \\
\hline$A \mathrm{AN}-105-0823-95-0835 \mathrm{~B}$ & है & $8 / 23 / 958: 35$ & $8: 24 / 95$ & $8 / 24 / 95$ & $8 / 24 / 95$ & if & 0 & 0.94 & 0.02 & 0.031 & 0.002 & & $<.01$ & & $<.001$ & & $<0005$ & 0.0003 & 0.0002 & 78.0 & 0.42 & 21.1 & 0.4 & & $<0005$ \\
\hline AN-105-0823-95-0840 & 6 & 8/23/95: B:40 & $8 / 24 / 95$ & $8 / 24 / 95$ & $8 / 24 / 95$ & 1 & 0 & 094 & 0.02 & 0.029 & 0.002 & & $<.01$ & & $<.001$ & 0.08 & 0.004 & 0.0005 & 0.0002 & 77.9 & 0.42 & 21.1 & 0.4 & 0.0039 & 0.0005 \\
\hline TK-105-AN-1，2/29/9683 & 6 & 2229/96 8:30 & $2 / 29 / 96$ & $3 / 1 / 96$ & $3 / 1 / 96$ & 1 & 1 & 0.94 & 0.02 & 0.041 & 0.004 & & $<.01$ & & $<.001$ & 0.004 & 0.0004 & & $<.001$ & 78.0 & 0.42 & 21.0 & 0.4 & 0.0008 & 0.0005 \\
\hline TK-105-AN-1 & 6 & $3 / 2799614: 40$ & $3 / 28 / 96$ & $3 / 28 / 96$ & $3 / 29 / 96$ & 1 & 1 & 0.95 & 0.02 & 0.038 & 0.002 & & $<.09$ & & $<.001$ & 0.004 & 0.0003 & & $<.001$ & 77.8 & 0.42 & 21.2 & 0.4 & 0.0008 & 0.0004 \\
\hline \multirow[t]{20}{*}{ TK-105-AN-2 } & 6 & $3 / 27 / 9614: 40$ & $3 / 28 / 96$ & $3 / 28 / 96$ & $3 / 29 / 96$ & 1 & & 0.95 & 0.02 & 0.038 & 0.002 & & $<.01$ & & $<, 001$ & 0.0059 & 0,0003 & & $<.001$ & 77.9 & $0.4 \sqrt{2}$ & 21.1 & 0.4 & 0.0008 & 0.0004 \\
\hline & & & & & & & & & & & & & & & & & & & & & & & & & \\
\hline & & & & & & & & & & & & & & & & & & & & & & & & & \\
\hline & & & & & & & & & & & & & & & & $n 20 / m^{2}$ & & $\operatorname{ch} 4 \pi 2$ & & & & & & & \\
\hline & & & & & & & & & & & & & & & & 0.1881 & & 0 & & & & & & & \\
\hline & & & & & & & & & & & & & & & & 0.1409 & & 0 & & & & & & & \\
\hline & & & & & & & & & & & & & & & & 0.2083 & & 은 & & & & & & & \\
\hline & & & & & & & & & & & & & & & & 0.2041 & & 0 & & & & & & & \\
\hline & & & & & & & & & & & & & & & & 0.1754 & & 0 & & & & & & & \\
\hline & & & & & & & & & & & & & & & & 0.2029 & & 0 & & & & & & & \\
\hline & & & & & & & & & & & & & & & & 0.1503 & & 0 & & & & & & & \\
\hline & & & & & & & & & & & & & & & & \#DIVIOT: & & FDI/0! & & & & & & & \\
\hline & & & & & & & & & & & & & & & & 0.0488 & & 0.0063 & & & & & & & \\
\hline & & & & & & & & & & & & & & & & 0.2 & & 0 & & & & & & & \\
\hline & & & & & & & & & & & & & & & & 0.1667 & & a & & & & & & & \\
\hline & & & & & & & & & & & & & & & & 0.2 & & 0 & & & & & & & \\
\hline & & & & & & & & & & & & & & $h_{2}$ & & 0.1356 & & 0 & & & & & & & \\
\hline & & & & & & & & & & & & & & 0.016 & & 0.1684 & & NA & Exclued & is ail 0 & and & Hcivis & points & & \\
\hline & & & & & & & & & & & & & sta dev & 0.022 & & 0.0457 & & NA & & & & & & & \\
\hline & & & & & & & & & & & & & $A+2 S D$ & 0.06 & & 0.2598 & & $\mathrm{NA}$ & & & & & & & \\
\hline
\end{tabular}




\begin{tabular}{|c|c|c|c|c|c|c|c|c|c|c|c|c|c|c|c|c|c|c|c|c|c|c|c|c|c|}
\hline Sample ID & LRB & Sample Time & Received & Analyzed; & Reponted & dof toit & det tiab & Ar & moles & $\mathrm{CO2}$ & & co & & $\begin{array}{ll}\text { He2 } \\
\end{array}$ & & $\mathrm{H}_{2}$ & & $\mathrm{CH}_{4}$ & & & & 02 & & & \\
\hline AW-101.0928.94 133 & & 928.18 13:35 & 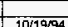 & 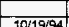 & 100094 & & & matox & entponot & motax & 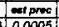 & & 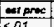 & molex. & atponect & $\operatorname{matax}$ & metprest & moinex & $=0$ & motex & etpriof: & neatex: & ipmost & matex & \\
\hline & 554 & & $\frac{10 / 191949}{10 / 19994}$ & & 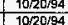 & $\frac{21}{21}$ & & $\frac{0.94}{0.53}$ & $\left|\frac{0.02}{0.02}\right|$ & \begin{tabular}{|l|}
$\mid 0.0063$ \\
0.002
\end{tabular} & $\mid \frac{0.0005}{10.0055}$ & & $\frac{1.01}{<.01}$ & & $\frac{0.001}{<001}$ & 0.047 & $\mid 0.0008$ & & $\mid \begin{array}{l}\mid<.001 \\
<\infty\end{array}$ & $\begin{array}{l}78.1 \\
78.1\end{array}$ & \begin{tabular}{|l|}
0.4 \\
\end{tabular} & 20.9 & 0.4 & $8 E-04$ & $\frac{0.00}{0.00}$ \\
\hline & & 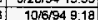 & 年 & 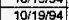 & 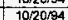 & 14. & & 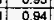 & 0.02 & 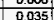 & 1. & & 00 & & 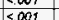 & 年 & (2) & & 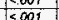 & 78 & 0.4 & $-\frac{20.0}{200}$ & $\begin{array}{l}0.4 \\
0.4\end{array}$ & $\frac{9 E-04}{5=04}$ & $\frac{0.00}{0.00}$ \\
\hline & & $10,6 / 949: 18$ & & & & & & 0.93 & $\frac{0.02}{0.02}$ & 然 & 50.002 & & $<.01$ & & $\frac{00 \%}{5.09}$ & 0.001 & $\frac{100003}{0.003}$ & & & $\frac{10}{78}$ & & 20.9 & & & \\
\hline$A N \bar{N}-101-102$ & 55413 & \begin{tabular}{|l|l|l|l|l|l} 
& $15: 30$
\end{tabular} & $10127 / 194$ & 1027794 & 10028194 & $\frac{7}{6}$ & & 0.93 & 0.02 & 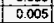 & 5 & & 5.01 & & $\frac{.001}{5.001}$ & 0.296 & $\mid$\begin{tabular}{|l|l|} 
\\
\end{tabular} & 0.003 & 30.0003 & 77.9 & 0.4 & $\mid \frac{20.9}{20.9}$ & 0.4 & \begin{tabular}{|l|}
$\mid 3 E-0409$ \\
0.009 \\
\end{tabular} & \\
\hline AW-101-1021-.54 & 55413 & $310 / 21 / 9475: 30$ & 1027994 & 10,2794 & & & & 0.83 & 0.02 & 0.005 & 0.0005 & & $<.01$ & & $<.001$ & 0.298 & 0.003 & 0.003 & 0.0003 & 77.8 & 0.4 & 21.0 & 0.4 & \begin{tabular}{|l|l|} 
& 0.009 \\
\end{tabular} & \\
\hline$\frac{A N-1}{A M-10}$ & 555413 & \begin{tabular}{l|l}
$10 / 279948: 41$ \\
13074
\end{tabular} & $\frac{1027194}{11401094}$ & $\frac{10 / 2794}{111404}$ & $\frac{1028 / 94}{101 / 194}$ & 1) & & 0.93 & 0.02 & +2 & $<.001$ & & 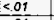 & & $<.001$ & 0.024 & 0,0002 & & $<.001$ & 780 & 0.4 & 211 & 0.4 & & \\
\hline 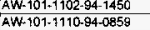 & $\begin{array}{l}\mid 55413 \\
55413\end{array}$ & $\begin{array}{l}11 / 2 / 2414450 \\
31 / 10 / 948: 59\end{array}$ & 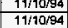 & 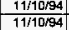 & $\frac{11111 / 94}{11 / 11 / 94}$ & $\begin{array}{l}4 \\
4\end{array}$ & & $\begin{array}{l}0.95 \\
0.55 \\
\end{array}$ & -0.02 & \begin{tabular}{|l|}
0.022 \\
0.019 \\
\end{tabular} & $\begin{array}{l}0.002 \\
0.02 \\
\end{array}$ & & $\frac{0.01}{0.09}$ & & $<.001$ & 0.017 & $\left|\begin{array}{|c|c|c|c|}\mid 0.0099 \\
0.002\end{array}\right|$ & & $\mid \frac{\mid, 001}{<001}$ & $\begin{array}{l}78.3 \\
78.1 \\
\end{array}$ & \begin{tabular}{|l|}
0.4 \\
0.4
\end{tabular} & 20.7 & \begin{tabular}{|l|}
0.4 \\
0.4 \\
\end{tabular} & $\ldots$ & $\frac{c \infty 01}{6001}$ \\
\hline$A W=0101.1716-94-1435$ & & 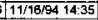 & $121 / 94$ & $12 / 2 / 94$ & 12515194 & 18 & & 0.94 & 0.02 & \begin{tabular}{|l|l|}
0.017 \\
\end{tabular} & 0.002 & & $\frac{.01}{209}$ & & < & 0.038 & $\mid 0.004$ & & $\frac{1.001}{6.01}$ & $\frac{78.19}{779}$ & \begin{tabular}{|l|}
.4 .4 \\
\end{tabular} & $\frac{20.9}{21.1}$ & $\begin{array}{l}0.41 \\
0.4\end{array}$ & & $\frac{5.00}{0.00}$ \\
\hline & & & & & & & & 4 1) 0.94 & & & 0.002 & & $\frac{.01}{100}$ & & $\frac{1007}{x .001}$ & & 0.002 & & $\times .001$ & $\overline{77.9}$ & & $\frac{21.1}{21.1}$ & 0.4 & & 2.000 \\
\hline-1335 & & $311 / 30404$ 13:35 & 121794 & 125294 & 1235.94 & aी & & 年 & 0.024 & 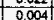 & $\mid \begin{array}{l}1 \\
0.0006\end{array}$ & & 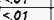 & & $\frac{2.001}{<.001}$ & 0.001 & $\frac{1002}{0.009}$ & & & & 0.4 & 210 & 0.4 & 0 & \\
\hline 1508 & & $\begin{array}{l}5.27 / 5415: 08 \\
\end{array}$ & $122 / 15 / 94$ & $121 / 6 / 1 / 44$ & $121 / 16 / 94$ & 8 & & 0.94 & 0.02 & 0.025 & 0.002 & & $<.01$ & & $\begin{array}{c}\tau .001 \\
\end{array}$ & 0.012 & 0.0005 & & $<001$ & $\overline{781}$ & 04 & 209 & 0.4 & SE-04 & \\
\hline & & $12214 / 94$ 14:45 & 12/155/94 & 12/1/194 & 12/16/\%94 & & & 0.54 & 0.02 & 0.022 & 0.002 & & 5.01 & & $\begin{array}{c}x .001 \\
\end{array}$ & 0.026 & 0.001 & & & 78.0 & 0.4 & & 0.4 & 6E-04 & \\
\hline (1907) & & 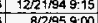 & & 1/131955 & 1/13/95 & 23 & & 0.54 & 0.02 & 0.009 & 0.0009 & & $<.07$ & & $\frac{x .001}{x .001}$ & 0.04 & 0.001 & & 5.001 & 78.1 & $\frac{0.4}{0.4}$ & 20 & 0.4 & EE-04 & 0.00 \\
\hline 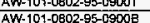 & & $\frac{8,2959900}{82959000}$ & $\frac{8 / 2,95}{8 / 295}$ & $8 / 2795$ & $8 / 3 / 95$ & $\frac{1}{1}$ & & 0.94 & -0.022 & $\begin{array}{l}0.025 \\
0.0289 \\
\end{array}$ & \begin{tabular}{|l|l|}
0.002 \\
0.002
\end{tabular} & & $=0.01$ & & $\frac{x .001}{x .001}$ & 0.285 & 0.006 & 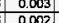 & 1) & $\frac{778}{777}$ & $\frac{0.4}{0.4}$ & 21.0: & 0.4 & 0.005 & \\
\hline$\frac{\pi-1}{101-A}$ & & 1218958.25 & 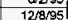 & 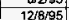 & 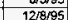 & 0 & & 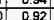 & 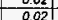 & 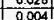 & $\begin{array}{l}40.002 \\
0.001\end{array}$ & & $=01$ & & $\frac{1}{2001}$ & | & 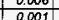 & & & $\frac{7.1}{782}$ & & & & 0.005 & $\begin{array}{l}\frac{0.00}{<.00} \\
<.00\end{array}$ \\
\hline & & $12: 18958: 25$ & & & & 0 & & $\frac{2.29}{0.92}$ & $=0.02$ & & 80.05 & & $<01$ & & $\frac{601}{2001}$ & 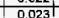 & $\frac{0.001}{0.001}$ & & $<001$ & $\frac{7.2}{781}$ & $\frac{0.4}{0.4}-2$ & . & 0.4 & & . 00 \\
\hline$\frac{51500}{1500}$ & & $2: 2779615: 00$ & $7 / 96$ & 222796 & $2 / 28 / 96$ & & & 0.91 & 0.02 & & $<.01$ & & $<0 \%$ & & $x .001$ & $2.96 \mid$ & 0.06 & & $<.001$ & $\frac{\pi 74}{774}$ & 0.4 & 28.5: & 0.4 & 0.236 & 0.0 \\
\hline W 101.8 .81 & 6 & & $3 / 22196$ & $3 / 2296$ & $3 / 22 / 96$ & 3 & & 4.1 & 0.1 & & 8.01 & & $<.01$ & & $<.001$ & 8.3 & 0.2 & 0.21 & 0.02 & 41 & & 5. & 0.1 & 0.8 & \\
\hline $\begin{array}{l}A W 101822 \\
A W 101-833\end{array}$ & & & $\frac{3 / 225995}{3 / 25 / 969}$ & $\frac{322996}{3 / 25596}$ & $\begin{array}{l}3 / 225966 \\
3 / 25 / 96\end{array}$ & $\mid$ & & $\begin{array}{c}\frac{0.94}{7733} \\
\end{array}$ & $\frac{0.02}{0.4}$ & 0038 & $\frac{1.1}{0.004}$ & & $\frac{0.01}{<.01}$ & & $\frac{<.001}{<001}$ & \begin{tabular}{r|r|}
2.49 \\
0021
\end{tabular} & $\frac{0.05}{0.001}$ & & $\begin{array}{l}0.05 \\
<<005\end{array}$ & $\begin{array}{r}9.5 \\
199\end{array}$ & $\frac{0.2}{0.4}$ & $\frac{0.76}{83}$ & $\frac{0.02}{0.7}$ & \begin{tabular}{|c|}
0.45 \\
0009
\end{tabular} & \begin{tabular}{|l|}
0.0 \\
0.00 \\
\end{tabular} \\
\hline & & & & & & & & & & & & & & & & & & & & & & & & & \\
\hline & & & & & & & & & & & & & & & & 220/h2 & & ctaAM2: & & & & & & & \\
\hline & & & & & & & & & & & & & & & & o.017| & & & & & & & & & \\
\hline & & & & & & & & & & & & & & & & 0.417 & & of & & & & & & & \\
\hline & & & & & & & & & & & & & & & & 0.385 & & of & & & & & & & \\
\hline & & & & & & & & & & & & & & & & $\frac{0.031}{0.031}$ & & $\frac{0.01}{0.11}$ & & & & & & & \\
\hline & -3 & & & & & & & & & & & & & & & 0 & & & & & & & & & \\
\hline & & & & & & & & & & & & & & & & & & & & & & & & & \\
\hline & & & & & & & & & & & & & & & & 0.026 & & & & & & & & & \\
\hline & & & & & & & & & & & & & & & & & & & & & & & & 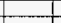 & \\
\hline & & & & & & & & & & & & & & & & $\begin{array}{l}0.034 \\
0.042\end{array}$ & & of & & & - & & & & \\
\hline & & & & & & & & & & & & & & & & & & of & & & & & & & \\
\hline & & & & & & & & & & & & & & & & $\mid \begin{array}{c}0.02 \\
0.016\end{array}$ & & 0.009 & & & & & & & \\
\hline & & & & & & & & & & & & & & & & 0.016 & & 0.008 & & & & & & & \\
\hline & & & & & & & & & & & & & & & & & & & & & & & & & \\
\hline & & & & & & & & & & & & & & & & 0.08 & & of & & $\ldots+2+2$ & & & & -1 & \\
\hline & & & & & & & & & & & & & & & & & & & & & & & & & \\
\hline & & & & & & & & & & & & & & & & $\begin{array}{l}0.181 \\
0.006\end{array}$ & & 0.104 & & & & & & & \\
\hline & & & & & & & & & & & & & & 0.035 & & 0.079 & & 0.009 & Excludes & as all the 0 & Opoints & and the & RGS data & & \\
\hline & & & & & & & & & & & & & 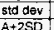 & 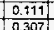 & & \begin{tabular}{|l|}
0.137 \\
0.352
\end{tabular} & & \begin{tabular}{|l|}
0.001 \\
0.012
\end{tabular} & & & & & & & \\
\hline
\end{tabular}




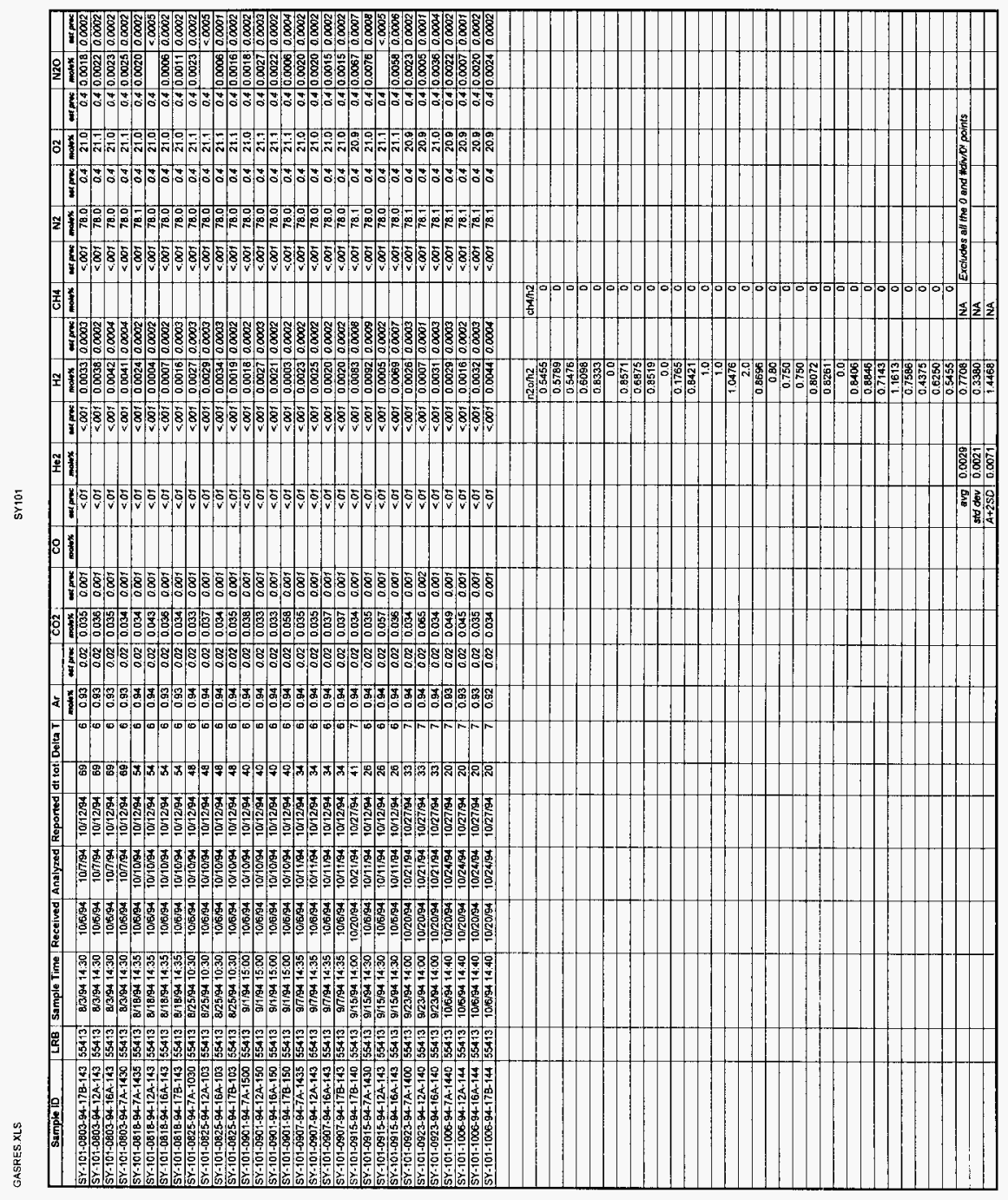




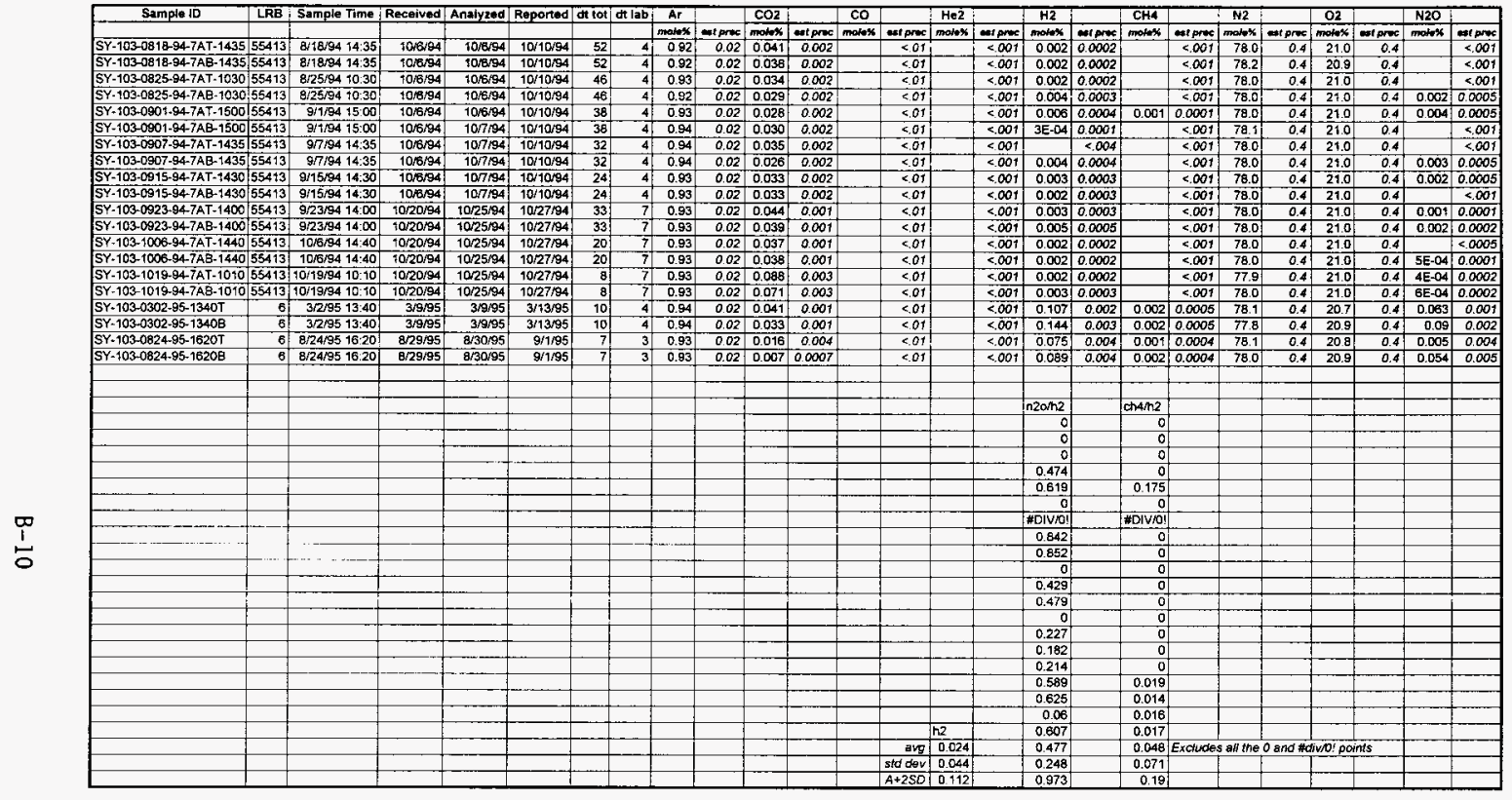




\begin{tabular}{|c|c|c|c|c|c|c|c|c|c|c|c|c|c|c|c|c|c|c|c|c|c|c|c|c|c|}
\hline & & & & & & & $\begin{array}{l}z 910^{\circ} \\
+82000^{\circ}\end{array}$ & & \begin{tabular}{|l|l|}
8810 \\
$\varepsilon 100$
\end{tabular} & & \begin{tabular}{|l|l|l|l}
$661^{\circ}$ \\
$\varepsilon+0^{\circ}{ }^{\prime}$
\end{tabular} & 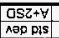 & & & - & & -5 & - & - & & & & & & \\
\hline & & & & & & & $\begin{array}{l}16000^{\circ} \\
500^{\circ}\end{array}$ & & $\begin{array}{ll}1910 \\
\end{array}$ & & $8 z 110$ & & & & & & & & & & & & & & \\
\hline & & & & & & & $\begin{array}{l}550+0^{\circ} 0 \\
8000^{\circ}\end{array}$ & & $\frac{8910}{2910}$ & & & & & & & & & & & & & & & & \\
\hline & & & & & & & $\begin{array}{l}950000 \\
95000\end{array}$ & & $\frac{210}{1910}$ & & & & & & & & & & & & & & & & \\
\hline & & & & & & & 16000 & & 2910 & & & & & & & & & & & & & & & & \\
\hline & & & & & & & artóo & & 981.0 & & & & & & & & & & & & & & & & \\
\hline & & & & & & & $\frac{1950}{5500^{\circ}}$ & & 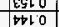 & & & & & & & & & & & & & & & & \\
\hline & & & & & - & & 89000 & & 8410 & & & & & & & & & & & & & & & & \\
\hline & & & & & & & & & 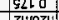 & & & & & & & & & & & & & & & & \\
\hline & & - & & & - & & 20,1040 & & & & & & & & & & & & & & & & & & \\
\hline & & & & & & & & & & & & & & & & & & & & & & & & & \\
\hline 20000 & $\frac{9100}{8000}$ & \begin{tabular}{|l|l|}
0 \\
$\$ 0$
\end{tabular} & $\frac{102}{102}$ & $\frac{10}{10}$ & $\frac{182}{782}$ & $\frac{100-39}{p 0.79}$ & $\frac{10000}{12000}$ & $\frac{50000}{5000}$ & $\frac{9600}{2100}$ & $\frac{100 \%}{1000}$ & & $-\frac{10 \%}{10>}$ & & 2000 & 8100 & 1200 & $\frac{660}{660}$ & 99 & 9 & S6617218 & 5879618 & S6/SLI8 & Sp: $65665+18$ & & S660-56-9L80-10t- \\
\hline 2000 & $\frac{200}{8200}$ & $\frac{10}{50}$ & $\frac{100}{102}$ & $\frac{100}{100}$ & $z B 2$ & $50-79$ & $\varepsilon 1000$ & $\frac{5000}{15000}$ & set: & $100>$ & & $10>$ & & $500^{\circ}>$ & & $\frac{200}{200}$ & $\begin{array}{ll}E E^{\prime} \\
\varepsilon 6^{\prime} 0\end{array}$ & $\frac{9}{19}$ & $\frac{10}{01}$ & $\frac{566128}{661278}$ & $\frac{5699 / 8}{56 / 91 / 8}$ & $\frac{565 / 18}{56 / 51 / 8}$ & $\begin{array}{l}08.65 / 1 / 8 \\
08: 715601 / 8\end{array}$ & & 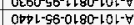 \\
\hline$\varepsilon 00^{\circ}$ & 2200 & 50 & 802 & 50 & 104 & $+0-35$ & $\varepsilon 1000$ & 5000 & $\angle E: O$ & $600>$ & & $10>$ & & $500=$ & & 200 & 560 & & 9 & $96 / p / 8$ & 961688 & 961878 & $0 \varepsilon: 6$ seres & & $0860-66-8080-101-\psi$ \\
\hline 5000 & 5000 & 50 & 102 & 10 & $2 \theta L$ & 50.39 & $p 1000$ & 9000 & 5960 & 1000 & & $|0\rangle$ & & $500=$ & & 200 & $86^{\circ} 0$ & & 2 & $\frac{6 / 7 t+18}{10}$ & 5680 & $\overline{G E / R / 3}$ & 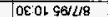 & & $0601-56-\angle 000-101-Y$ \\
\hline $10-3 s$ & $\begin{array}{c}5000 \\
5000\end{array}$ & 50 & $i z$ & 50 & 82 & $10 \cdot 32$ & 50000 & 2000 & 6000 & $1.00>$ & & $60>7$ & & 2000 & 200 & 200 & $E 60$ & & or & $\frac{96+1 / 8}{18}$ & Seros & $56 / 2 / 3$ & $08: 696178$ & & $0 E G-G G-b 000-10 L-Y$ \\
\hline$+0-79$ & $\frac{95000}{1000}$ & 10 & 602 & +0 & 182. & $+0-3 \varepsilon$ & 90000 & 2000 & 9000 & $100 \%$ & & $\begin{array}{ll}10>1 \\
0>1\end{array}$ & & 2000 & 1200 & 200 & 860 & & or & $56 / 71 / 8$ & $5 \in 1818$ & $96 / 8 / 3$ & of:9t 56/z/8 & & $08+1-c 6-8000-101-Y$ \\
\hline $200^{\circ} 0$ & 1200 & 10 & 902 & 10 & $\varepsilon B L$ & $20-9 \varepsilon$ & 80000 & 5000 & Bitso & 1000 & & $10>$ & & 2000 & 5000 & $\frac{200}{200}$ & $86^{\circ} 0$ & & 01 & $\frac{50 / 18}{56 / 1 / 9}$ & $96 / 1 / 8$ & $\frac{56 h 18}{56 / L 8}$ & 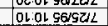 & $\mid$ & 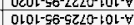 \\
\hline 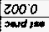 & 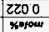 & $\frac{p 0}{s=0}$ & $\frac{802}{x+004}$ & $\frac{0}{40.000}$ & 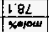 & 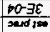 & 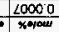 & $\frac{5000}{5000=0}$ & 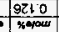 & 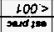 & मुका & 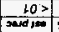 & Trovert & \begin{tabular}{|l|l|}
2000 \\
$300+1 / 60$
\end{tabular} & 5000 & 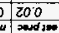 & 580 & & $\angle L$ & s6/pto & Sark & $96 / \mathrm{k} / \mathrm{g}$ & LE.ph S618ULS & $970 \%$ & $25 \mathrm{Pr}-56-81.50-01-4$ \\
\hline & 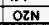 & & 20 & & $z \mathrm{~N}$ & & & & & & ZaH & & & & & 다에 & & & & рэноवश & PazאIFu & рамарәт & awIL addurs & 897 & gal 라durs \\
\hline
\end{tabular}




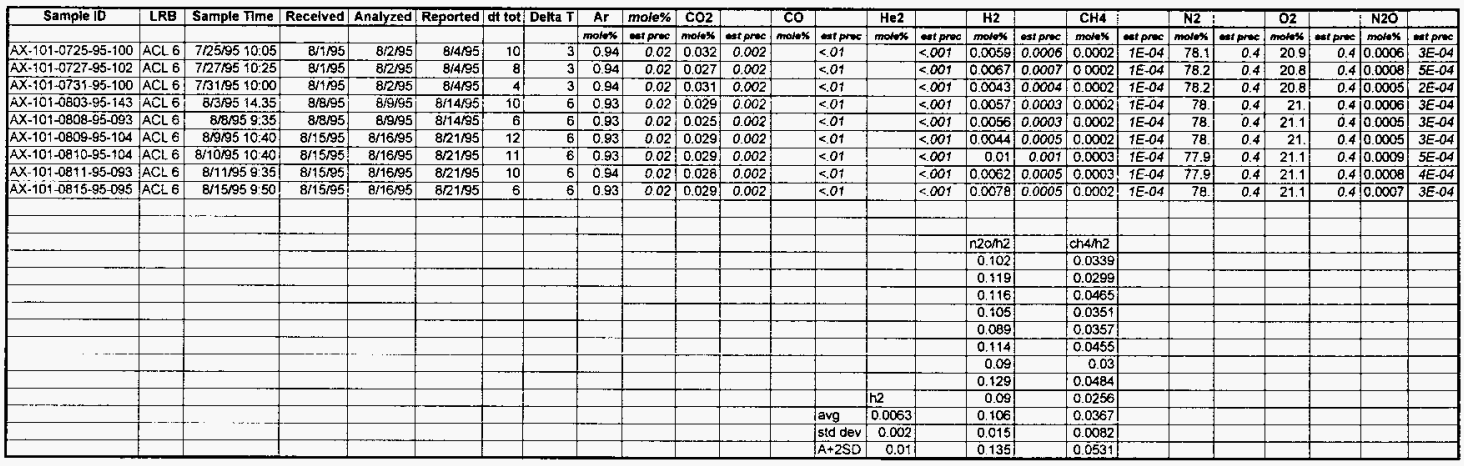


1

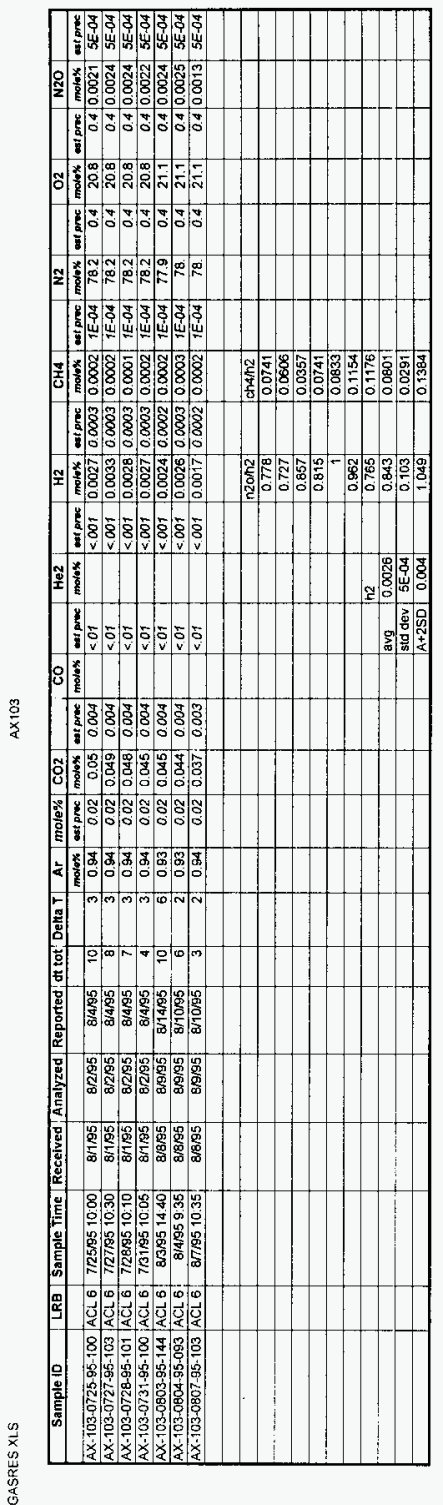




\begin{tabular}{|c|c|c|c|c|c|c|c|c|c|c|c|c|c|c|c|c|c|c|c|c|c|c|c|c|c|}
\hline Sample id & LRB & Sample Time & Received & Analyzed & Reported & de tof & Defta T & $\overline{A r}$ & mode\% & $\mathrm{CO2}$ & & $\mathrm{CO}$ & & $\mathrm{He2}$ & & H2 & & $\mathrm{CH} 4$ & & N2 & & 02 & & N2O & \\
\hline & & & & & & & & moinx & errator & motest & $\operatorname{miprc}$ & motex $x$ & est proce & molex & estprect & molox & est proc & molox & \begin{tabular}{|l|} 
est proce \\
$3 E$ ed
\end{tabular} & motex & est proc & molex & estpres & $\frac{\operatorname{mos} x}{0.007}$ & 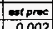 \\
\hline BY-103-0922-95-140 & $\mathrm{ACL} 6$ & $9 / 22951400$ & $9 / 26105$ & $9 / 26195$ & $8 / 27 / 95$ & 4 & 1 & 0.94 & 0.02 & 0.007 & 0.002 & & 2.01 & & $<.001$ & 0.023 & 0.001 & 0.0004 & $2 E-04$ & 78.1 & 0.4 & 20.9 & 0.4 & 0.007 & 0.002 \\
\hline$B Y-103-1002-95-142$ & ACL 6 & $102 / 951420$ & $10 / 10 \% 5$ & $90 / 10 / 95$ & $10 / 13 / 95$ & 90 & 3 & 0.94 & 0.02 & 0.006 & 0.0006 & & $<01$ & & 5001 & 0013 & 0.001 & 0.0003 & $\frac{-2 E-04}{1 E-04}$ & 78 & 0.4 & 21 & 0.4 & 0.0022 & $5 E-04$ \\
\hline$B Y-103-1009-95-143$ & $\mathrm{ACL} 6$ & $10 / 9 / 951430$ & $10 / 10 / 95$ & $10 / 10 / 95$ & $10 / 13 / 95$ & 3 & 3 & 0.94 & 0.02 & 0.004 & 0.002 & & $<.01$ & & $<.001$ & 0.02 & 0.001 & 0.0003 & 1E-04 & $7 \overline{8}$. & 0.4 & 21. & 0.4 & 0.0025 & SE-04 \\
\hline IK-103-EY-1 & ACL6 & $3 / 271962: 00$ & $3 / 2896$ & $3 / 2896$ & $3 / 28 / 96$ & 1 & 0 & 0.94 & 0.02 & 0.021 & 0.001 & & 8.01 & & $<001$ & 0.0066 & 0.0003 & & $<.001$ & 78.0 & 0.4 & 210 & 0.4 & 0.002 & $2 E+04$ \\
\hline \multirow[t]{12}{*}{ TK-103-EY-2 } & $A C L 6$ & $3 / 27 / 962.00$ & $3 / 28196$ & $3 / 28 / 96$ & $3 / 28 / 96$ & 1 & 0 & 0.93 & 0.02 & 0.021 & 0.001 & & $<.01$ & & $<.001$ & 0.0069 & 0.0003 & & $<.007$ & 77.9 & 0.4 & 21.1 & 0.4 & 0.002 & $2 E-04$ \\
\hline & & & & & & & & & & & & & & & & & & & & & & & & & \\
\hline & & & & & & & & & & & & & & & & & & & & & & & & & \\
\hline & & & & & & & & & & & & & & & & n2om2 & & की 4 h2 & & & & & & & \\
\hline & & & & & & & & & & & & & & & & 0.304 & & 0.0174 & & & & & & & \\
\hline & & & & & & & & & & & & & & & & 0.169 & & 0.0231 & & & & & & & \\
\hline & & & & & & & & & & & & & & & & 0.125 & & 0.015 & & & & & & & \\
\hline & & & & & & & & & & & & & & & & 0.303 & & 0 & & & & & & & \\
\hline & & & & & & & & & & & & & & h2 & & 0.29 & & 0 & & & & & & & \\
\hline & & & & & & & & & & & & & avg & 0.0139 & & 0.238 & & 0.0185 & Exclude & 5 all the & 0 points & & & & \\
\hline & & & & & & & & & & & & & std der & 0.007 & & 0085 & & 0.0044 & & & & & & & \\
\hline & & & & & & & & & & & & & $A+2 S D$ & 0.029 & & 0.408 & & 0.0268 & & & & & & & \\
\hline
\end{tabular}




\begin{tabular}{|c|c|c|c|c|c|c|c|c|c|c|c|c|c|c|c|c|c|c|c|c|c|c|c|c|c|}
\hline Sample lo & LRE & Sample Time & Received & Analyzed & Reported & dit tot & Defta T & Ar & mafe\% & $\mathrm{CO} 2$ & & $\mathrm{CO}$ & & $\mathrm{He} 2$ & & $\mathrm{H} 2$ & & $\mathrm{CH}_{4}$ & & N2 & & 02 & & N2O & \\
\hline & AC6 & & & $=0005$ & 90705 & & & monts & ost proce & melow & estanes & molex & 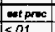 & mohe & setproce & molate & $=0 \operatorname{sen} x$ & $\frac{m+a t s}{0002}$ & $\frac{m \text { tprocit }}{2 E-04}$ & molex & $\theta$ etproc & movex & stpresc & $\begin{array}{l}\text { matex } \\
0.114\end{array}$ & otpresc \\
\hline$\frac{B Y-106-0922-95-141}{8 Y-106-1002-65-142}$ & $\frac{A C L 6}{A C L 6}$ & $\frac{9 / 22 / 95+4: 10}{10 / 2 / 95+4: 25}$ & $\begin{array}{r}9 / 26 / 95 \\
10 / 10 / 95\end{array}$ & $\begin{array}{r}\frac{9 / 26 / 95}{10 / 10,95} \\
\end{array}$ & $\begin{array}{r}9 / 27 / 95 \\
10 / 13 / 95\end{array}$ & $\begin{array}{r}4 \\
10\end{array}$ & $\frac{1}{3}$ & $\begin{array}{r}0.93 \\
0.94\end{array}$ & $\begin{array}{l}0.02 \\
0.02 \\
\end{array}$ & 0.0090 & 0.002 & & $\frac{1<01}{<01}$ & & 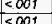 & 0.111 & 0.005 & \begin{tabular}{|l|l|}
0.002 \\
0001
\end{tabular} & $2 E-04$ & 77.8 & \begin{tabular}{|l|}
0.4 \\
\end{tabular} & 21.0 & +-0.4 & 0.114 & -0.005 \\
\hline $8 Y-106-1002-65-142$ & $\begin{array}{ll}A C L \\
A C L & 5 \\
\end{array}$ & 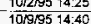 & $\frac{1001 / 1095}{101095}$ & $\frac{1001095}{1014095}$ & $\frac{10013395}{101395}$ & $\frac{10}{3}$ & 3 & $\begin{array}{ll}0.94 \\
0.94\end{array}$ & $\frac{0.02}{0.02}$ & 0.0050 & 0.002 & & $<01$ & & $\frac{<.001}{<001}$ & $\begin{array}{l}0.052 \\
0.01 \\
\end{array}$ & 0.003 & 0.0012 & $5 E-04$ & 77,9 & 0.4 & 21.0 & 0.4 & 0.041 & 0.002 \\
\hline $\begin{array}{l}E Y-106-1009-95-144 \\
T K-106-B Y-1\end{array}$ & $\operatorname{Acc} 6$ & $\frac{10919594: 40}{327}$ & $\frac{101 / 1090}{3 / 28 / 96}$ & $\frac{10 / 28 / 96}{3 / 2 / 96}$ & $3 / 28196$ & 1 & 30 & 094 & 002 & & & & |<.01 & & $<.001$ & 0.027 & 0.001 & 0.0005 & 3E--04 & 78.0 & 0.4 & 21.0 & 0.4 & 0.0017 & $5 E-a 4$ \\
\hline $\begin{array}{l}\text { TK-106-BY-1 } \\
\text { TK-106-BY } 2\end{array}$ & $\mathrm{ACL} 6$ & & & & & & & 0.94 & 0.02 & 0.0033 & 0.0005 & & $<.01$ & & $<001$ & 0.0051 & 0.0003 & & $<001$ & 77.9 & 0.4 & 21.1 & 0.4 & 0.0041 & $5 E-04$ \\
\hline TK-106-BY 2 & ACCL 6 & $3 / 27 / 962: 00$ & $3 / 28 / 96$ & $3 / 2896$ & $3 / 28 / 96$ & 1 & 0 & 0.94 & 0.02 & $0.00 \overline{34}$ & 0.0005 & & $<01$ & & $<.001$ & 0.005 & 0.0003 & & $<001$ & 77.9 & 0.4 & 21.1 & 0.4 & 0.0034 & $5 E-04$ \\
\hline & & & & & & & & & & & & & & & & & & & & & & & & & \\
\hline$---\cdots$ & & & & & & & & & & & & & & & & & & & & & & & & & \\
\hline & & & & & & & & & & & & & & & & n20 2 & & $c h 4 / 2$ & & & & & & & \\
\hline & & & & & & & & & & & & & & & & 9.027 & & 0.018 & & & & & & & \\
\hline & & & & & & & & & & & & & & & & 0.788 & & 0.0231 & & & & & & & \\
\hline & & & & & & & & & & & & & & & & 0.081 & & 0.0238 & & & & & & & \\
\hline & & & & & & & & & & & & & & & & 0.804 & & 0 & & & & & & & \\
\hline & & & & & & & & & & & & & & $\ln 2$ & & 0.68 & & & & & & & & & \\
\hline & & & & & & & & & & & & & avg & 0.0388 & & 0.676 & & 0.0216 & Excludes & 5 all the & e points & & & & \\
\hline & & & & & & & & & & & & & stod dev & 0.045 & & 0.356 & & 0.0032 & & & & & & & \\
\hline & & & & & & & & & & & & & $A+2 S D$ & 0.128 & & $1.38 \mathrm{~g}$ & & 0.0279 & & & & & & & \\
\hline
\end{tabular}




\begin{tabular}{|c|c|c|c|c|c|c|c|c|c|c|c|c|c|c|c|c|c|c|c|c|c|c|c|c|c|}
\hline Sample ID & LRB & Sample Time & Recelved & Analyzed & Reported: & att tot & | Defta T & Ar & mole\% & $\mathrm{CO} 2$ & & co & & $\mathrm{Me2}$ & & $\mathrm{H} 2$ & & $\mathrm{CH} 4$ & & N2 & & 02 & & N20 & \\
\hline & & & & & & & & maiex & extprece & matex & mipure & motes $x$ & $m i p=c$ & molex & menowe & malox & etproce & moros & estpence & molex: & estprect & molex & extposes & $\operatorname{monx}$ & extprect \\
\hline BY-109-0922-95-141 & $A C L 6$ & $9 / 22 / 9514: 15$ & 9/2E/95 & $9 / 26 / 95$ & 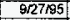 & 4 & 1 & 0.93 & 0.02 & 0.003 & 0.001 & & $<.01$ & & $<.001$ & 0.0154 & 0.0008 & 0.0002 & TE-04 & 779 & 0.4 & 21.1 & 0.4 & 0.004 & 0.001 \\
\hline BY-109-1002-95-143 & $\mathrm{ACL} 6$ & $10 / 2 / 951430$ & $10 / 10 / 95$ & $10 / 10 / 95$ & S0/13/95 & 10 & 3 & 0.94 & 0.02 & & $<005$ & & $<.01$ & & $<001$ & 0.009 & 0.0005 & 0.0004 & $2 E-04$ & 779 & 0.4 & 21.1 & 0.4 & 0.0009 & $5 E-04$ \\
\hline EY-109-1009-95-143 & $\mathrm{ACL} 6$ & $10 / 9 / 9514.35$ & $10 / 10 \% 95$ & $10 / 10 / 95$ & $10 / 13 / 95$ & 3 & 3 & 0.94 & 0.02 & & $<, 005$ & & $<.01$ & & $<.001$ & 0.01 & 0.0005 & 0.0004 & $2 E-04$ & 78. & 0.4 & 21.1 & 0.4 & 0.0007 & $4 E-04$ \\
\hline TK-109-BY-1 & $\overline{A C L} \bar{B}$ & $327 \% 962.00$ & $3 / 28 / 96$ & $3 / 28 / 96$ & $3 / 28 / 96$ & 1 & 0 & 0.94 & 0.02 & 0.0057 & 0.0006 & & $<.04$ & & $<.001$ & 0.001 & 0.0003 & & $<.001$ & 779 & 0.4 & 21.1 & 0.4 & & $<.0005$ \\
\hline \multirow{12}{*}{ TK-109-EY-2 } & ACL 6 & $3 / 27 / 962.00$ & $3 / 28 / 66$ & $3 / 28 / 96$ & $3 / 28 / 96$ & 1 & 0 & 0.94 & 0.02 & 0.0025 & 0.0003 & & $<.01$ & & $<.001$ & 0.0015 & 0.0003 & & $<.001$ & 779 & 0.4 & 21.2 & 0.4 & & $<, 0005$ \\
\hline & & & & & & & & & & & & & & & & & & & & & & 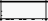 & & & \\
\hline & & & & & & & & & & & & & & & & & & & & & & & & & \\
\hline & & & & & & & & & & & & & & & & $\ln 20 / 2$ & & ch $4 \pi-72$ & & & & & & & \\
\hline & & & & & & & & & & & & & & & & 0.26 & & 0.013 & & & & & & & \\
\hline & & & & & & & & & & & & & & & & 0.1 & & 0.0444 & & & & & & & \\
\hline & & & & & & & & & & & & & & & & 0.07 & & 0.04 & & & & & & & \\
\hline & & & & & & & & & & & & & & & & 0 & & 0 & & & & & & & \\
\hline & & & & & & & & & & & & & & h2 & & 0 & & 0 & & & & & & & \\
\hline & & & & & & & & & & & & & avg & 0.0074 & & 0.143 & & 0.0325 & Exclude & the all & II o points & & & & \\
\hline & & & & & & & & & & & & & std dev & 0.006 & & 0.102 & & 0.017 & & & & & & & \\
\hline & & & & & & & & & & & & & $A+2 S D$ & 0.02 & & 0.347 & & 0.0665 & & & & & & & \\
\hline
\end{tabular}


量

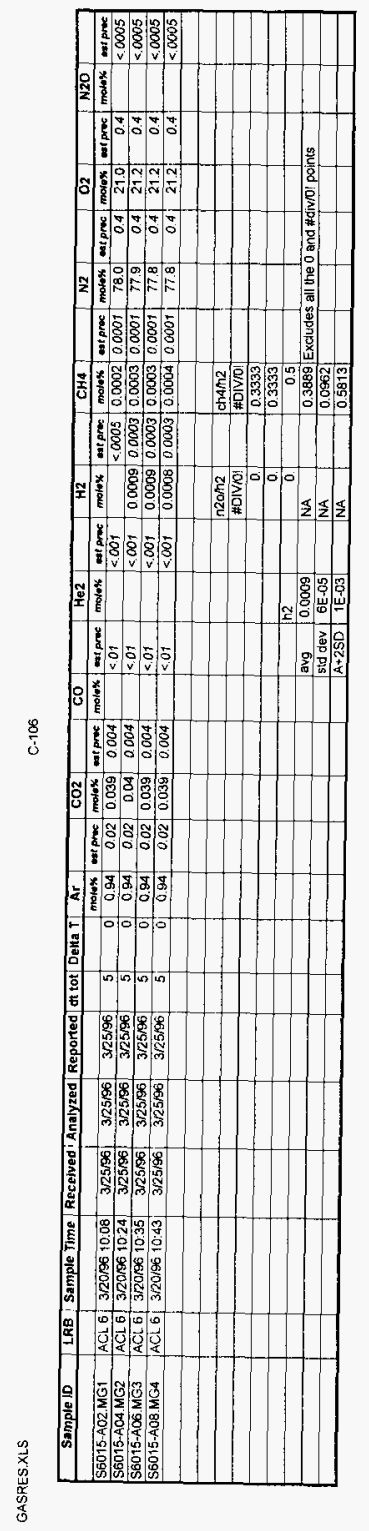




\begin{tabular}{|c|c|c|c|c|c|c|c|c|c|c|c|c|c|c|c|c|c|c|c|c|c|c|c|c|c|}
\hline Sample ID & LRE & Sample Time & Recelved & Analyzed & Reported & de tot & Delta T & $\mathrm{Ar}$ & mole\% & $\mathrm{CO} 2$ & & $\mathrm{CO}$ & & $\mathrm{He}_{2}$ & & $\mathrm{H} 2$ & & $\mathrm{CH} 4$ & & N2 & & 02 & & $\mathrm{N2O}$ & \\
\hline & & & & & & & & manolex & ext pros & molex & est proce & molos & est proc & matek & estproc & motex & ast precec & mofos & $\operatorname{cost\text {prec}}$ & molex & ext prect & molex & est proce & motos & $=0 \operatorname{son}$ \\
\hline S-102-0505-95-090 & ACL 6 & $5 / 5 / 959.05$ & 8/8/95 & $8 / 9 / 95$ & 8/44/95 & 101 & 6 & $\begin{array}{l}6 \\
6\end{array}$ & 0.02 & 0.008 & 0.002 & & $<.01$ & & $<.001$ & 0.03 & 0.003 & 0.0004 & $2 E-04$ & 78.0 & 0.4 & 21.0 & 0.4 & 0.021 & 0.002 \\
\hline S-102-0804-95-144 & $\mathrm{ACl} 6$ & $8 / 40514: 40$ & 8/8/95 & $8 / 9 / 95$ & $8 / 14 / 95$ & g & 6 & 0.93 & 0.02 & & $<.005$ & & $<.01$ & & $<.001$ & 0.06 & 0.003 & 0.0004 & $2 E-04$ & 77.8 & 0.4 & 21.1 & 0.4 & $\overline{0} .041$ & 0.005 \\
\hline S-102-0607-95-095 & ACL 6 & $8 / 7959.50$ & $8 / 2 / 25$ & $8 / 9 / 95$ & $8 / 14 / 95$ & 7 & 6 & 0.94 & 0.02 & 0.03 & 0.002 & & c.01 & & 5.001 & 0.028 & 0.003 & 0.0004 & $2 E-04$ & 77.8 & 0.4 & 21.2 & 0.4 & 0.021 & 0.002 \\
\hline S-102-0807-95-151 & $A C L$ & $8 / 70515: 40$ & arats & $8 / 9755$ & $8 / 14 / 95$ & 6 & 6 & 0.94 & 0.02 & 0.024 & 0.002 & & $<09$ & & $<.001$ & 0.041 & 0.004 & 0.0005 & $2 E-04$ & 77.9 & 0.4 & 21.1 & 0.4 & 0.028 & 0.003 \\
\hline S-102-0808-95-093 & ACL 6 & $8 / 8 / 95930$ & Quers & $8 / 965$ & $8 / 14 / 95$ & हा & 6 & 0.94 & 0.02 & & $\times 005$ & & $<01$ & & $<.001$ & 0.075 & 0.004 & 0.0007 & $3 E-04$ & 77.8 & 0.4 & 21.1 & 0.4 & 0.056 & 0.003 \\
\hline S-102-0808-95-144 & ACL 6 & $8 / 8 / 95 \quad 14: 40$ & $8 / 15 / 95$ & $8 / 15 / 96$ & $8 \longdiv { 2 1 / 9 5 }$ & 12 & 6 & 0.94 & 0.02 & 0.0042 & 0.0005 & & $<.09$ & & $<.001$ & 0.072 & 0.004 & 0.0008 & $4 E-04$ & 77.8 & 0.4 & 21.1 & 0.4 & 0.051 & 0.005 \\
\hline S-102-0609-95-095 & ACL 6 & $8 / 9 / 959.55$ & $8 / 15 / 95$ & $8 / 15 / 95$ & $8 / 21 / 95$ & 12 & 6 & $\begin{array}{ll}0.94 \\
0.94\end{array}$ & 0.02 & 0.0042 & 0.0005 & & 501 & & $<.001$ & 0.07 & 0.004 & 0.0009 & $4 E-04$ & 77.9 & 0.4 & 210 & 0.4 & 0.049 & 0.005 \\
\hline S-102-0810-95-095 & $A C L 6$ & $8 / 10 / 959: 55$ & $8 / 15 / 95$ & $8 / 15 / 95$ & $8 / 21 / 95$ & 11] & 6 & 0.94 & 0.02 & 0.0039 & 0.0005 & & $<.04$ & & $<001$ & 0.075 & 0.004 & 0.001 & $4 E-04$ & 77.9 & 0.4 & 210 & 0.4 & 0.053 & 0.005 \\
\hline S-102-0810-95-144 & ACL 6 & $8 / 1000514: 40$ & $8 / 15 / 25$ & $8 / 15 / 95$ & $8 / 21 / 95$ & $10:$ & 6 & 0.94 & 0.02 & 0.0041 & 0.0005 & & $<01$ & & 6001 & 0076 & 0004 & 0.0009 & $4 E-04$ & 780 & 0.4 & 209 & 0.4 & 0.054 & 0.005 \\
\hline S-102-0811-95-140 & ACL 6 & $8 / 10 / 9514: 00$ & $8 / 15$ ros & 8/15/95 & $8 / 21 / 95$ & 10 & 6 & 0.94 & 0.02 & 0.0037 & 0.0005 & & $<01$ & & $<.001$ & 0.075 & 0.004 & 0.001 & $5 E-04$ & 77.9 & 0.4 & 21.0 & 0.4 & 0.053 & 0.005 \\
\hline S-102 Drill String ?- & ACL 6 & $1 / 12 / 9620: 30$ & $1 / 115 / 96$ & $1 / 15 / 96$ & $1 / 16 / 96$ & 3 & & 0.293 & 0.006 & & $<.01$ & & $<01$ & & $<.001$ & 2.69 & 0.05 & 0.021 & 0.001 & 89.3 & 0.1 & 6.1 & 0.1 & 1.61 & 0.03 \\
\hline MT Hughey 2/14/96 & ACL 6 & $2 / 14 / 9612: 00$ & $2 / 44 / 96$ & $2 / 16 / 96$ & $2 / 20 / 96$ & 6! & & 0.125 & 0.006 & & $<.001$ & & $<.01$ & & $\angle .001$ & 2.14 & 0.04 & & $<.001$ & 95.2 & 0.06 & 2.4 & 0.05 & 0.174 & 0.003 \\
\hline & & & & & & & & & & & & & & & & & & & & & & & & & \\
\hline & & & & & & & & & & & & & & & & & & & & & & & & & \\
\hline & & & & & & & & & & & & & & & & n2om2 & & का $4 m 2$ & & & & & & & \\
\hline & & & & & & & & & & & & & & & & 07 & & 0.0133 & & & & & & & \\
\hline & & & & & & & & & & & & & & & & 0.6833 & & 0.0067 & & & & & & & \\
\hline & & & & & & & & & & & & & & & & 0.75 & & 0.0143 & & & & & & & \\
\hline & & & & & & & & & & & & & & & & 0.8829 & & 0.0122 & & & & & & & \\
\hline & & & & & & & & & & & & & & & & 0.7467 & & 0.0093 & & & & & & & \\
\hline & & & & & & & & & & & & & & & & 0.7083 & & 0.0111 & & & & & & & \\
\hline & & & & & & & & & & & & & & & & 0.7 & & 0.0129 & & & & & & & \\
\hline & & & & & & & & & & & & & & & & 0.7067 & & 0.0133 & & & & & & & \\
\hline & & & & & & & & & & & & & & & & 0.7105 & & 0.0118 & & & & & & & \\
\hline & & & & & & & & & & & & & & & & \begin{tabular}{|l|}
0.7067 \\
0506
\end{tabular} & & 0.0133 & & & & & & & \\
\hline & & & & & & & & & & & & & & & & 0.5985 & & 0,0078 & & & & & & & \\
\hline & & & & & & & & & & & & & & h2 & & 0.0813 & & & & & & & & & \\
\hline & & & & & & & & & & & & & avg & 0.0602 & & 0.7095 & & 0.0118 & Excludes & is all the & 0 points & and las & st two d & points & \\
\hline & & & & & & & & & & & & & sid dev & 002 & & 0.0226 & & 0.0023 & & & & & & & \\
\hline & & & & & & & & & & & & & $A+2 S D$ & 0.099 & & 0.755 & & $0.0164 \mid$ & & & & & & & \\
\hline
\end{tabular}


WHC-SD-WM-TI-753 REV 0

$\stackrel{8}{\mathrm{~S}}$

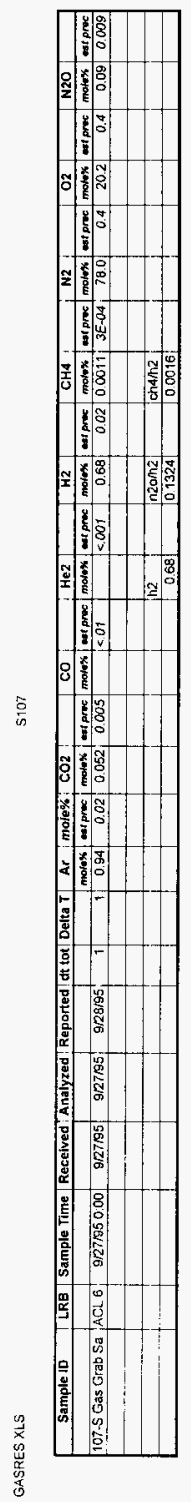

B-19 
WHC-SD-WM-TI-753 REV 0

魷

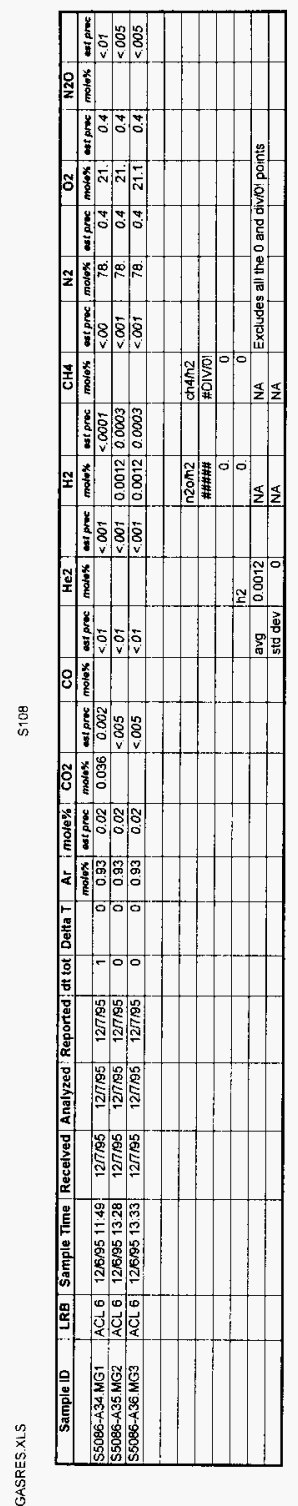




\begin{tabular}{|c|c|c|c|c|c|c|c|c|c|c|c|c|c|c|c|c|c|c|c|c|c|c|c|c|c|}
\hline Sample ID & LRB & Sample Time & Recelved & Analyzed & Reported & de tot & Delta T & Ar & mole\% & $\mathrm{CO} 2$ & & CO & & Mez & & H2 & & $\mathrm{CH4}$ & & N2 & & 02 & & $\mathrm{N2O}$ & \\
\hline 50080340 & $\overline{016}$ & & & & & & & mavex & ext proc & molex & 0 est proce & $\operatorname{mos} x$ & $\alpha \sin x$ & $\operatorname{molex} x$ & 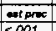 & movex & astprect & moles: & estanoc| & mats & astpose & molex & sstpioc & molex & arpanac \\
\hline S5085-A34.MG1 & PCL 6 & $1215 / 9511.09$ & $1218 / 95$ & $12 / 6 / 95$ & 12/5/95 & 1 & 0 & 0.93 & 0.02 & 0.038 & 0.002 & & $<.01$ & & 8.001 & 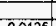 & 50005 & & $<.001$ & 78.1 & 0.4 & 20.9 & 0.4 & + & $<.001$ \\
\hline S5085-A35.MG2 & \begin{tabular}{|l}
$A C L L$ \\
$A C L 6$
\end{tabular} & $12 / 5 / 9511: 10$ & $\frac{12 / 6 / 95}{12(8 / 95}$ & $-126 / 95$ & 121695 & 1 & 0 & 0.93 & 0.02 & 0.0036 & 0.0004 & & $<.01$ & 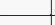 & $<001$ & 0.0125 & 0.0004 & & $<.001$ & 78 & 0.4 & 211 & 04 & 0.0016 & $5 E-04$ \\
\hline & & $12 / 5=5,17.14$ & & 12,6195 & $12 / 6 / 95$ & & & 0.93 & 0.02 & 0.0032 & 0.0004 & & $<.07$ & & $<.001$ & 0.0124 & 0.0004 & & $<.001$ & 78. & 0.4 & 21.1 & 0.4 & {$[0.0012$} & EE-04 \\
\hline & & & & & & & & & & & & & & & & & & & & & & & & & \\
\hline & & & & & & & & & & & & & & & & n20/m2 & & का $4 / m 2$ & & & & & & & \\
\hline & & & & & & & & & & & & & & & & \#OIVIo! & & \#DIVIO & & & & & & & \\
\hline & & & & & & & & & & & & & & & & 0.128 & & 0 & & & & & & & \\
\hline & & & & & & & & & & & & & & $n_{2}$ & & 0.0968 & & 0 & & & & & & & \\
\hline & & & & & & & & & & & & & avg & 0.0125 & & 0.1124 & & NA & Exclude: & sall the & 0 and tod & divfor $p c$ & & & \\
\hline & & & & & & & & & & & & & stc dev & $7 E-05$ & & 0.0221 & & INA & & & & & & & \\
\hline & & & & & & & & & & & & & $A+2 S D$ & 00126 & & 0.1565 & & $N A$ & & & & & & & \\
\hline
\end{tabular}




\begin{tabular}{|c|c|c|c|c|c|c|c|c|c|c|c|c|c|c|c|c|c|c|c|c|c|c|c|c|c|}
\hline Sample ID & LRB & Sample Time: & Recelved & Analyzed & Reported & attor: & Delía T & Ar & mole\% & $\mathrm{CO} 2$ & & co & & He2 & & $\mathrm{H}_{2}$ & & $\mathrm{CH}_{4}$ & & \begin{tabular}{|l|} 
N2 \\
\end{tabular} & & 02 & & N2O & \\
\hline & & & & & & & & molex & 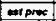 & $\operatorname{mosex}$ & est proce & motox & ostipoec & movos & exteroce & moress & ostproc & morox & esiproes & moiex & estproce & maiox & $\Leftrightarrow t$ proce & motex & 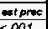 \\
\hline S-111-0711-95-150 & ACL & $7 / 11 / 9515: 05$ & $7 / 18995$ & 7/19/95 & $7 / 25 / 95$ & 13 & 7 & 0.94 & 0.02 & 0.008 & 0,003 & & $<.07$ & & $<, 001$ & 0.0053 & 0.0005 & & $<0005$ & 78 & 0.4 & 21. & 0.4 & & $<.001$ \\
\hline S-111-0714-95-101 & ACLE & $7 \longdiv { 1 4 / 9 5 1 0 \cdot 1 0 }$ & $7 / 18 / 95$ & $7 / 49 / 95$ & $7 / 25 / 95$ & 11 & & 0.94 & 0.02 & 003 & 0.002 & & $<01$ & & $<001$ & 0.0016 & 0.0002 & & $<.0005$ & 78 & 0.4 & 21.1. & 0.4 & & $<.001$ \\
\hline S-111-0717-95-103 & ACL 6 & $7 / 17 / 9510.35$ & $7 / 18 / 95$ & $7 / 19 / 95$ & $7 / 25 / 95$ & 8 & 7 & 0.94 & 0.02 & 0.031 & 0.002 & & $<.01$ & & $<.001$ & & $<0005$ & & $<.0005$ & 78. & 0.4 & 21.1 & 0.4 & & $<.001$ \\
\hline $\mathrm{S}-111-0 / 25-95-142$ & ACLE & $7 / 25 / 9514: 20$ & $8 / 195$ & $8 / 3 / 95$ & 8/4/35 & 9) & 3 & 0.94 & 0.02 & & 8.005 & & 5.04 & & $<.001$ & 0.0085 & 0.0005 & 0.0002 & 1E-04 & 78 & 0.4 & 21.1 & 0.4 & & $<.001$ \\
\hline $5 \cdot 111-0727-95-145$ & $A C L E$ & $7 / 27 / 9514: 55$ & $8 / 1 / 95$ & $8 / 3 / 95$ & $8 / 4 / 95$ & 7 & 3 & 0.95 & 0.02 & 0.031 & 0.002 & & $<.01$ & & $<001$ & $0.00+3$ & 0.0003 & 0.0003 & $1 E-04$ & 78. & 0.4 & 21.1 & 0.4 & & 4.005 \\
\hline S-111-0731-95-145 & ACL 6 & $7 / 39 / 951450$ & $8 / 1 / 95$ & $8 / 3 / 95$ & $8 / 4 / 95$ & 3 & & 0.95 & 0.02 & 0.042 & 0.003 & & $<.01$ & & $<001$ & & $<0005$ & 0.0002 & 1E.04 & 78 & 0.4 & 21.1 & 0.4 & & $<.005$ \\
\hline S-111-0803-95-102 & $A C L E$ & $8 / 5 / 9510.20$ & $8 / 695$ & 8/9/85 & $8 / 14 / 95$ & 11. & 6 & 0.94 & 0.02 & & $<005$ & & $c .01$ & & $<001$ & 0.0077 & 0.0004 & 0.0002 & $1 E-04$ & 78. & 0.4 & 21.1 & 0.4 & 0.0017 & SE- 04 \\
\hline 5-111-0804-95-144 & $\mathrm{ACL} 6$ & $8 / 499514.45$ & $8 / 6,95$ & $8 / 2 / 95$ & $8 / 14 / 95$ & 9 & 6 & 0.94 & 0.02 & 0.033 & 0.002 & & 2.01 & & $\frac{2001}{<00}$ & 0.0005 & 0.0003 & $\mid$\begin{tabular}{|l|l|}
0.0002 \\
\end{tabular} & IE-04 & 779 & 04 & 21.1 & 0.4 & & $<.005$ \\
\hline S-111-0807-95-094 & ACL 6 & 877959.45 & $8 / 8995$ & 8ngro5 & 8/14/95 & 7 & 6 & 0.94 & 0.02 & & $<.005$ & & $<.01$ & & $<.001$ & 0.021 & 0.001 & 0.0003 & $1 E-04$ & 78. & 0.4 & 21.1 & 0.4 & 0.0038 & $5 E \cdot 04$ \\
\hline & & & & & & & & & & & & & & & & & & & & & & & & & \\
\hline & & & & & & & & & & & & & & & & & & & & & & & & & \\
\hline & & & & & & & & & & & & & & & & $n 20 / 2$ & & $\operatorname{con} 4 m 2$ & & & & & & & \\
\hline & & & & & & & & & & & & & & & & 0. & & 0 & & & & & & & \\
\hline & & & & & & & & & & & & & & & & \#DIVR! & & HDIVI & & & & & & & \\
\hline & & & & & & & & & & & & & & & & 0 & & 0.0235 & & & & & & & \\
\hline & & & & & & & & & & & & & & & & 0. & & 0.2308 & & & & & & & \\
\hline & & & & & & & & & & & & & & & & \#DIV/O! & & HEDIVIOS & & & & & & & \\
\hline & & & & & & & & & & & & & & & & 0.2208 & & 0.026 & & & & & & & \\
\hline & & & & & & & & & & & & & & & & 0. & & 0.4 & & & & & & & \\
\hline & & & & & & & & & & & & & & $\mathrm{h}_{2}$ & & 0.181 & & 0.0143 & & & & & & & \\
\hline & & & & & & & & & & & & & $\mathrm{g} \times \mathrm{g}$ & 0.0066 & & 0.2009 & & 0.1339 & Exclude & s the 0 e & and \#div/ & O! points & & & \\
\hline & & & & & & & & & & & & & std dev & 0.0071 & & 0.0282 & & 0.1719 & & & & & & & \\
\hline & & & & & & & & & & & & & $A+2 S D$ & 0.020 & & 0.2572 & & 0.4827 & & & & & & & \\
\hline
\end{tabular}




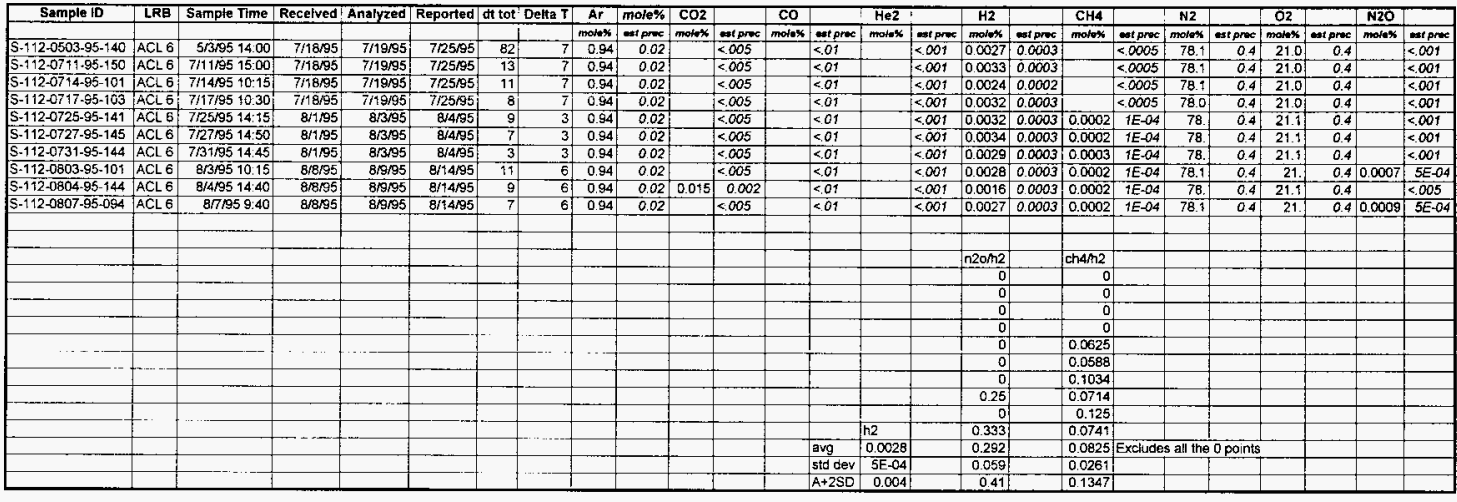




\begin{tabular}{|c|c|c|c|c|c|c|c|c|c|c|c|c|c|c|c|c|c|c|c|c|c|c|c|c|c|}
\hline Sample ID & iLRB & Sample rime & 年ceived & Analyzed & Reported & & & Al & & & & $C_{0}$ & & $\mathrm{H}_{\mathrm{H} 2} \mathrm{z}$ & & $\mathrm{H}_{2}$ & & $\mathrm{CH}_{4}$ & & N2 & & 02 & & & \\
\hline SX'104-0602-95-100 & ACL 6 & 627951020 & 6 & 6/895 & 6/19/55 & & & $\frac{m a b x}{0.94}$ & $\frac{\text { etpresco }}{0.02}$ & monts & $=0$ & moles & \begin{tabular}{|l} 
etpreac \\
cot
\end{tabular} & modex $x$ & 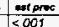 & $\frac{\operatorname{mothx}}{0.0008}$ & extposer & $\mid$ & 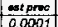 & matex & $\begin{array}{c}\operatorname{exproc} \\
04\end{array}$ & moles & 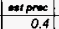 & & 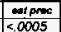 \\
\hline sx-101-06066.95-093 & ACL 6 & $6,619599.30$ & 6FA & 6,6195 & 69905 & 3 & & $\begin{array}{l}0.94 \\
0.94 \\
\end{array}$ & $\frac{0.02}{0.02}$ & \begin{tabular}{|l|l|}
0.043 \\
0.042 \\
\end{tabular} & \begin{tabular}{|l|}
0.002 \\
0.002 \\
\end{tabular} & & $\frac{0.01}{<.01}$ & & $\frac{.001}{<.001}$ & $-\frac{0.0008}{0.0005}$ & $\mid 0.00032$ & & $\begin{array}{l}\frac{0.0001}{<.0005} \\
\end{array}$ & $\frac{778}{779}$ & 0.4 & $\frac{21.2}{21.2}$ & $\begin{array}{c}0.4 \\
0.4 \\
\end{array}$ & & $\frac{5.0005}{<.0005}$ \\
\hline$(-101-1609-95-104$ & ACL 6 & $6 / 9 / 951045$ & $6 / 13 / 95$ & 6/13/95: & $5 / 4695$ & & & \begin{tabular}{l|l|}
3 & 0.94 \\
\end{tabular} & 0.02 & 0.041 & 0.002 & & $<.01$ & & $<.001$ & & $<.0005$ & 5.00002 & 0.0001 & 780 & 0.4 & & 0.4 & & .0005 \\
\hline $\begin{array}{l}S X-F 01-0612-95-14 \\
S X-101-0616-95-134\end{array}$ & \begin{tabular}{|l|} 
ACLL 6 \\
$A C L 6$ \\
\end{tabular} & 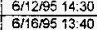 & $-\frac{61131395}{602015}$ & $\frac{6 / 13195}{6 / 2195}$ & $\frac{6,16195}{6027255}$ & \begin{tabular}{|l|}
-3 \\
5 \\
\end{tabular} & & \begin{tabular}{l|l|}
3 & 0.95 \\
2 & 0.93 \\
\end{tabular} & +0.02 & \begin{tabular}{|l|}
0.042 \\
0.033
\end{tabular} & \begin{tabular}{|l|l|}
0.002 \\
0.002 \\
\end{tabular} & & $\frac{8.01}{501}$ & & $\begin{array}{c}5.001 \\
5001 \\
\end{array}$ & .00005 & \begin{tabular}{|l|}
0.0003 \\
$<005$
\end{tabular} & 30.0002 & $\mid 0.0001$ & 780 & 04 & 21.0 & 0.4 & & $<.0005$ \\
\hline$\frac{5 x-110 .-06616-95-134}{5 x-101-0620-95-094}$ & ACL B & $6201859: 45$ & $6 / 20195$ & | & 6 & 2 & & $\begin{array}{ll}2 & 0.93 \\
2 & 0.93 \\
\end{array}$ & $\begin{array}{l}0.02 \\
0.02 \\
\end{array}$ & $\begin{array}{l}0.033 \\
0.033 \\
\end{array}$ & \begin{tabular}{|l|}
0.002 \\
0.002 \\
\end{tabular} & & \begin{tabular}{|l|l|}
$<04$ \\
$<.04$
\end{tabular} & & $\begin{array}{l}\frac{4.001}{<.001} \\
<.001\end{array}$ & & $\begin{array}{l}<.0005 \\
<<005 \\
\end{array}$ & & $\mid \begin{array}{l}0.0001 \\
k 0005\end{array}$ & 78.0 & 0.4 & \begin{tabular}{|l|}
21.0 \\
2110
\end{tabular} & $\begin{array}{l}0.4 \\
0.4 \\
\end{array}$ & & $<.0005$ \\
\hline$x \times-101-0622-95-102$ & ACL 6 & $6222 / 9510.25$ & $6 / 27795$ & $6 / 2895$ & $6 / 29 / 95$ & 7 & & 0.93 & 0.02 & 0.035 & \begin{tabular}{|l|l|}
0.002 \\
\end{tabular} & & $\frac{0.04}{<.01}$ & & $\frac{0.007}{<.001}$ & 0.0007 & \begin{tabular}{|l|l|}
0.00003 \\
\end{tabular} & & 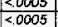 & $\begin{array}{r}-780 \\
-78.2 \\
\end{array}$ & $\frac{0.4}{0.4}$ & $\begin{array}{l}211.0 \\
20.9\end{array}$ & $\begin{array}{l}0.4 \\
0.4\end{array}$ & & $\begin{array}{l}<.0005 \\
<.0005\end{array}$ \\
\hline 27.95-102 & & & & $6 / 28,195$ & $6 / 29 / 95$ & 2 & & 0.94 & & & & & $<.01$ & & $<.001$ & & & & $\frac{.00005}{<.0005}$ & 78.2 & & & & & $\frac{5.0005}{<0005}$ \\
\hline & & $6 / 30959.25$ & $7 / 1495$ & & & & & & $0.02 \quad-25$ & $\frac{0.033}{0.033}$ & $\frac{0.002}{0.002}$ & & <की & & $<001$ & & $<0005$ & & $\frac{1001}{2001}$ & 780 & 0.4 & $\frac{2.4}{21.1}+3$ & 0.94 & & $\frac{4.0005}{50005}$ \\
\hline SK-104-0707-95-102 & ACL 6 & $7 \pi m 5510.20$ & $7111 / 95$ & $7 / 14495$ & $7118 \times 5$ & 11 & & 7. 0.94 & 0.02 & 0.034 & 0.002 & & $<01$ & & 8.001 & & $<.0005$ & & $<.001$ & 77.9 & & & 0.4 & & $<.0005$ \\
\hline$x-101-0911-95-150$ & ACL 6 & g/7 17p5 15:00 & 912205 & 9/1395 & 9/14/95 & 2 & & 0.94 & 0.02 & 0.035 & 0.002 & & $<.01$ & & 5.004 & & $<.0005$ & 0.0002 & 0.0001 & 77.9 & & 21.1 & 0.4 & & $\alpha .0$. \\
\hline $5 x-101-0915-95-094$ & ACL 6 & $9 / 151959.45$ & & $9 / 20,95$ & 9/21/95 & & & 0.94 & 0.02 & 0.033 & 0.002 & & $<.04$ & & .001 & & $<.0005$ & & $<.0005$ & 78.0 & & 21.1 & 0.4 & & $<.0005$ \\
\hline$\frac{5 x-101.0919-95-094}{S x}$ & $A C L 6$ & $9 / 9959: 45$ & 9/19/95 & 9 & 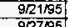 & 2 & & 0.94 & 0.02 & 0.031 & 0.002 & & $<.01$ & & 5.001 & & $\times 0005$ & $\mid 0.0002$ & 0.0001 & 779 & 0.4 & 21.1 & 0.4 & & $<.0005$ \\
\hline 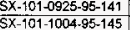 & $\mid \begin{array}{l}\text { ACC. } 6 \\
\text { ACL6 } 6\end{array}$ & \begin{tabular}{|l|}
$3 / 25 / 95514: 15$ \\
$10 / 4 / 95$ \\
\end{tabular} & $\frac{9,26195}{10 / 1095}$ & $\begin{array}{r}9266955 \\
1010195 \\
\end{array}$ & 912735 & & & 0.94 & 0.02 & 0.033 & 0.002 & & $<<01$ & & 5.001 & 0.0010 & 0.0003 & 0.0002 & 0.0001 & 779 & 0.4 & 21.1 & 0.4 & & $<.0005$ \\
\hline $241-5 X-101-1$ & \begin{tabular}{|l|}
$A C L L$ \\
$A C L$
\end{tabular} & \begin{tabular}{|l|l}
$32005613: 00$ \\
\end{tabular} & $3 / 2106$ & $\frac{7017 / 90}{3 / 2196}$ & $\frac{7017 / 956}{3 / 21966}$ & $\frac{8}{0}$ & & 0.94 & 0.02 & $\frac{0.035}{0.038}$ & \begin{tabular}{|l|l|}
0.002 \\
0.002 \\
\end{tabular} & & $\frac{61}{<01}$ & & $\frac{2.001}{<.001}$ & & $\frac{<.0005}{<.005}$ & 0.00011 & $\mid 0.0001$ & 78.1 & $\frac{0.4}{0.4}$ & $\frac{21.0}{20.8}$ & $\frac{0.4}{0.4}$ & & $\frac{5.0005}{<0005}$ \\
\hline $241-S X-101-2$ & ACL 6 & $3 / 2019613: 00$ & $3 / 2196$ & $3 / 21965$ & $3 / 21 / 96$ & 0 & & 0.95 & 0.02 & 0.036 & 0.002 & & $<.09$ & & $<.001$ & & $<.0005$ & & $\alpha .001$ & 78.0 & 0.4 & 21.0 & 0.4 & & $\frac{5.0005}{<.0005}$ \\
\hline & & & & & $\ldots$ & & & & & & & & & & & & & $\ldots \ldots+. .$. & & -3 & & & & & \\
\hline & & & & & & & & & & & & & & & & 2002 & & thath? & & & & & & & \\
\hline & & & & & & & & & & & & & & & & (1) & & 0.25 & & & & & & & \\
\hline & & & & & & & & & & & & & & & & > & & (1) & & & & & & & \\
\hline & & & & - $\cdots$ & & & & & & & & & & & & Murvor 0 & & 04 & & & & & & & \\
\hline & & & & & & & & & & & & & & & & \#OIVOI & & HDIVIVI & & & & & & & \\
\hline & & & & & & & & & & & & & & & & Folvre! & & \#DIVIV! & & & & & & & \\
\hline & & & & & & & & & & & & & & & & FDIVIOP! & & \#OIVR: & & & & & & & \\
\hline & & & & & & & & & & & & & & & & FDVIVI & & | & & & & & & & \\
\hline & & & & & & & & & & & & & & & & Filvo! & & WOIVE! & & & & & & & \\
\hline & & & & & & & & & & & & & & & & FDIV/O1 & & 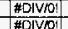 & & & & & & & \\
\hline & & & & & $\ldots$ & & & & & & & & & & & 0 & & 02 & & & & & & & \\
\hline & & & & & & & & & & & & & & & & \#Divio! & & \#DIVIOI & & & & & & & \\
\hline & & & & & & & & & & & & & & & & FDive! & & EDIVO! & & & & & & & \\
\hline & & & & & & & & & & & & & lavg & 00007 & & NA & & $\mid \begin{array}{l}\mid+2833 \\
0.28 \\
\end{array}$ & Exciude & $\begin{array}{l}\text { Sal the } \\
\text { S }\end{array}$ & 0 and \#d & & nt5 & & \\
\hline & & & & & & & & & & & & & stid der & $2 E-04$ & & $\mathrm{NA}$ & & 0 & & (n) & & & & & \\
\hline & & & & & & & & & & & & & $\left.\right|_{A+2 S D}$ & 0.001 & & & & 0.4915 & & & & & & & \\
\hline
\end{tabular}




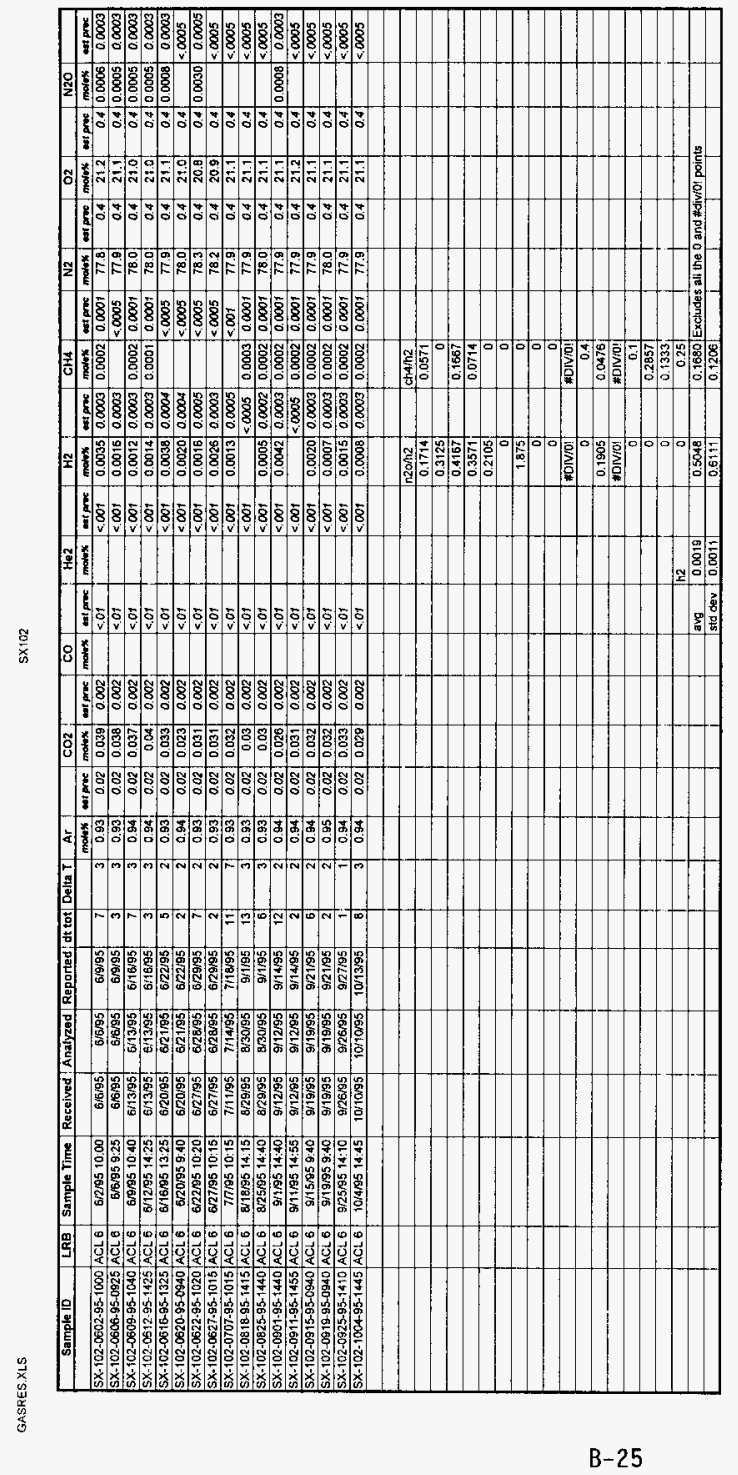


WHC-SD-WM-TI-753 REV 0

象

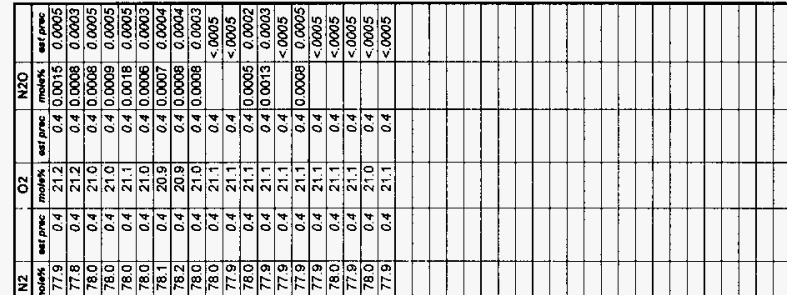
는.

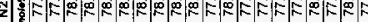

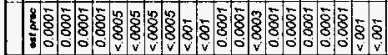

논

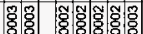

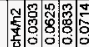

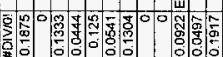

4

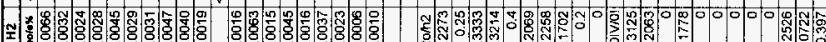

e

\%

초

象

(1)

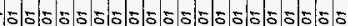

8

$\frac{8}{x}$

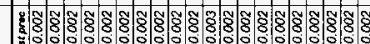

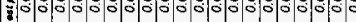

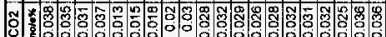

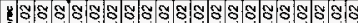

.

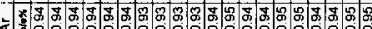

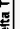

8)लnmonn

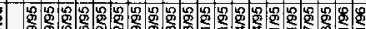

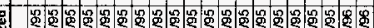

ㄱ.

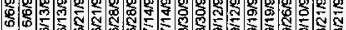

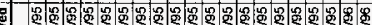

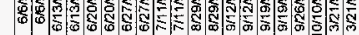

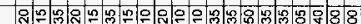

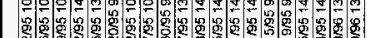

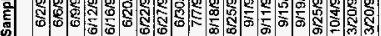

这

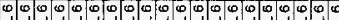

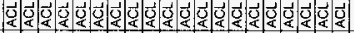

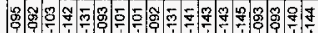

을

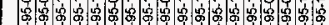

異

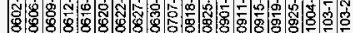

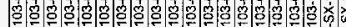

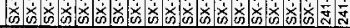

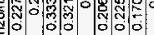

率。

:

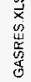




\begin{tabular}{|c|c|c|c|c|c|c|c|c|c|c|c|c|c|c|c|c|c|c|c|c|c|c|c|c|c|}
\hline Sampie Io & LRB & Sample Time & Recelyed & Anatyzed & Reported & de tot & Detta T & Ar & & $\mathrm{CO} 2$ & & $\mathrm{CO}$ & & $\mathrm{He} 2$ & & H2 & & $\mathrm{CH} 4$ & & N2 & & 02 & & $\mathrm{~N} 2 \mathrm{O}$ & \\
\hline & & & & & & & & motex & on proce & mats & atp proc & mainx & $=\tan$ & molox & est proces & $\operatorname{motax} x$ & $\operatorname{monac}$ & molex & estprescects & mows & eatproc & malox & $\operatorname{est}$ proce & matex & estprex \\
\hline$S X-104-0602-95-101$ & ACL 6 & $6 / 2 / 9510: 10$ & 6/6/95 & $6 / 6 / 95$ & $6 / 9 / 95$ & 7 & $\overline{3}$ & 0.94 & 0.02 & 0.042 & 0.002 & & $<01$ & & $<001$ & 0.0009 & 0.0003 & & $<0005$ & 77.9 & 0.4 & 21.1 & 0.4 & & $<0005$ \\
\hline$S X-104-0606-95-100$ & ACL 5 & $6 / 69951000$ & 81595 & $66 / 95$ & 69195 & 3 & 3 & 0.94 & 0.02 & 0.042 & 0.002 & & $<01$ & & 0.001 & & $<0005$ & & -0005 & 77.8 & 0.4 & 212 & 0.4 & & $<0005$ \\
\hline SX-104-0609-95-105 & ACL 6 & $8 / 9 / 95 \quad 10.50$ & $6 / 13 / 95$ & $6 / 13 / 95$ & $6 / 16 / 95$ & 7 & 3 & 0.94 & 0.02 & 0.04 & 0.002 & & $<<01$ & & $<.001$ & 0.0002 & 0.0001 & 0.0002 & 0.0001 & 78.1 & 0.4 & 21.0 & 0.4 & & $<0005$ \\
\hline $5 x-104-0612-95-143$ & ACL 6 & $6 / 12 / 9514: 35$ & $6 / 13 / 95$ & $6 / 13 / 95$ & $6 / 16 / 95$ & 3 & $-\frac{5}{3}$ & 0.94 & 0.02 & 0.042 & 0,002 & & $<01$ & & $<.001$ & 0.0005 & 0.0003 & 0.0002 & 0.0001 & 78.0 & 0.4 & 21.0 & 0.4 & & $<.0005$ \\
\hline $5 X-104-0616-95-132$ & $A C L 6$ & $5 / 15 / 9513.25$ & $6 / 20195$ & $6 / 21 / 95$ & $6 / 22 / 95$ & 5 & 2 & 0.93 & 0.02 & 0.033 & 0.002 & & $<.01$ & & $<.001$ & & $<0,0005$ & & $<.0005$ & 78.0 & 0.4 & 21.0 & 0.4 & & $<0005$ \\
\hline SX-104-0620-95-095 & ACL 6 & $6 \longdiv { 2 0 0 5 9 : 5 0 }$ & $6 / 20195$ & $6 / 21195$ & $6 / 22195$ & 2 & 2 & 0.93 & 0.02 & 0032 & 0002 & & $<01$ & & $<.001$ & 0.0006 & 0.0003 & & $<.0005$ & 76.0 & 0.4 & 21.0 & 0.4 & & $<.0005$ \\
\hline SX-104-0622-95-103 & ACL 6 & $6 / 22 / 951030$ & $6 / 27 / 95$ & $6 / 28 / 95$ & $6 / 29195$ & 7 & 2 & 0.94 & 0.02 & 0.035 & 0.002 & & $<01$ & & $<.001$ & & $<.0005$ & & $<.0005$ & 78.1 & 0.4 & 20.9 & 0.4 & & $<0005$ \\
\hline SX-104-0627-95-102 & ACL 6 & $6 / 27 / 9510.25$ & $6 \longdiv { 2 7 9 5 }$ & $6 / 28 / 95$ & $6 / 29895$ & 2 & 2 & 0.94 & 0.02 & 0.034 & 0.002 & & $<01$ & & $\times 001$ & & $<0005$ & & $<.0005$ & 78.1 & 0.4 & 209 & 0.4 & & $<0005$ \\
\hline SX-104-0630-95-093 & ACL 6 & 630195930 & $7 / 11 / 95$ & $7 / 14 / 95$ & $7 / 18195$ & 18 & $\frac{4}{7}$ & 0.93 & 0.02 & 0.034 & 0.002 & & $<01$ & & $<.001$ & & $<.0005$ & & $<.001$ & 77.9 & 0.4 & 21.1 & 0.4 & & $<.0005$ \\
\hline SX-104-0707:95-102 & ACL 6 & $7 / \pi / 95 \quad 10: 25$ & $7 / 11 / 95$ & $7 / 14 / 95$ & $7 / 18 / 95$ & 11 & 7 & 0.94 & 0.02 & 0.034 & 0.002 & & $<.07$ & & $<.001$ & 0.0007 & 0.0003 & & $<.009$ & 77.9 & 0.4 & 21.1 & 0.4 & & $<.0005$ \\
\hline $5 X-104-0818-95-142$ & ACLO & $8 / 18 / 9514: 20$ & $8 / 29 / 95$ & $8 / 30 / 95$ & $9 / 1 / 195$ & 13 & 3 & 0.94 & 0.02 & 0.028 & 0.002 & & $<01$ & & $<.001$ & 0.0019 & 0.0005 & 0.0002 & 0.0001 & 78.0 & 0.4 & 21.0 & 0.4 & & $<.0005$ \\
\hline SX-104-0825-95-144 & ACLE & $8 / 25 / 95 \quad 14,45$ & $8 / 29 / 95$ & $8 / 30 / 95$ & $9 / 1 / 95$ & 6 & 3 & 0.94 & 0.02 & 0.032 & 0.003 & & $<.01$ & & $<.009$ & & $<.0005$ & 0.0002 & 0.0001 & 78.0 & 0.4 & 21.0 & 0.4 & & $<0005$ \\
\hline SX-104-0901-95-144 & ACL 6 & $9 / 1 / 9514.45$ & $9 / 12 / 95$ & $9 / 43 / 95$ & $9 / 14 / 95$ & 12 & & 0.94 & 0.02 & 0.028 & 0.002 & & $<.01$ & & $<.001$ & 0.0014 & 0.0003 & 0.0002 & $0.000 i$ & 77.9 & 0.4 & 21.1 & 0.4 & & $<0005$ \\
\hline SX-104-0911-95-150 & 4 & $9 / 11 / 951505$ & $9 / 12 / 95$ & $9 / 113 / 25$ & $9 / 14 / 95$ & 2 & $\frac{2}{2}$ & 0.94 & 0.02 & 0.032 & 0.002 & & $<01$ & & $<001$ & & $<0005$ & 0.0002 & 0.0001 & 779 & 0.4 & -21.2 & 0.4 & & $<, 0005$ \\
\hline SX-104-0915-95-095 & ACL 6 & $9 / 15 / 25950$ & $9 / 19 / 95$ & $9 / 20 / 95$ & $9 / 21 / 95$ & 6 & 2 & 0.95 & 0.02 & 0.037 & 0.002 & & $<01$ & & $<.001$ & & .0005 & 0.0002 & 0.0001 & 77.9 & 0.4 & $2 \uparrow 1$ & 0.4 & & $<.0005$ \\
\hline SX+104.0919-95-095 & ACL 6 & $9 / 19 / 95950$ & $9 / 19 / 95$ & 920095 & $9 / 21 / 95$ & 2 & 2 & 0.94 & 0.02 & 0.03 & 0.002 & & $<.01$ & & $<.001$ & 0.0007 & 0.0003 & 0.0001 & 0.0001 & 77.9 & 0.4 & 21.1 & 0.4 & & $<.0005$ \\
\hline $5 X-104-0925-95-142$ & ACL 6 & $9 / 25 / 95 \quad 14: 20$ & $9 / 26 / 95$ & $9 / 26 / 95$ & 9/27/95 & 1 & 1 & 0.94 & 0.02 & 0.031 & 0.002 & & $<.01$ & & $<.001$ & 0.0028 & 0.0003 & 0.0002 & 0.0001 & 77.9 & 0.4 & 21.1 & 0.4 & & $<0,0005$ \\
\hline $5 X-104-1004-95-145$ & ACL 6 & $10 / 4 / 9514: 55$ & $10 / 10 / 95$ & $10 / 10 / 95$ & 70/13/95 & 8 & & 0.94 & 0.02 & 0.032 & 0.002 & & $<.01$ & & $<. \infty 0^{\prime}$ & 0.0005 & 0.0003 & \begin{tabular}{|l|}
0.0001 \\
\end{tabular} & \begin{tabular}{|l|}
0.0001 \\
\end{tabular} & 78.0 & 0.4 & 21.1 & 0.4 & & $<00005$ \\
\hline & & & & & & & & & & & & & & & & & & & & & & & & & \\
\hline & & & & & & & & & & & & & & & & & & & & & & & & & \\
\hline & & & & & & & & & & & & & & & & $120 \mathrm{~m}^{2}$ & & chamin & & & & & & & \\
\hline & & & & & & & & & & & & & & & & 0 & & & & & & & & & \\
\hline & & & & & & & & & & & & & & & & \#DINOA & & \#ONO: & & & & & & & \\
\hline & & & & & & & & & & & & & & & & 0 & & & & & & & & & \\
\hline & & & & & & & & & & & & & & & & 0 & & +0.4 & & & & & & & \\
\hline & & & & & & & & & & & & & & & & HDIVIO! & & FDEVIOT & & & & & & & \\
\hline & & & & & & & & & & & & & & & & 0 & & & & & & & & & \\
\hline & & & & & & & & & & & & & & & & ADIV/O! & & \#CIVIO!! & & & & & & & \\
\hline & & & & & & & & & & & & & & & & \#DIV/O! & & \#DIVIO! & & & & & & & \\
\hline & & & & & & & & & & & & & & & & 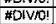 & & ADIVOS & & & & & & & \\
\hline & & & & & & & & & & & & & & & & 0 & & & & & & & & & \\
\hline & & & & & & & & & & & & & & & & 0 & & 0.1053 & & & & & & & \\
\hline & & & & & & & & & & & & & & & & AOIVIO! & & \#DIVIV! & & & & & & & \\
\hline & & & & & & & & & & & & & & & & 0 & & 0.1429 & & & & & & & \\
\hline & & & & & & & & & & & & & & & & ADIV/O! & & ADIVIO! & & & & & & & \\
\hline & & & & & & & & & & & & & & & & \#DIV/o! & & ADIVYO! & & & & & & & \\
\hline & & & & & & & & & & & & & & & & 0 & & 0.1429 & & & & & & & \\
\hline & & & & & & & & & & & & & & & & 0 & & 0.0714 & & & & & & & \\
\hline & & & & & & & & & & & & & & h2 & & 0 & & 0.2 & & & & & & & \\
\hline & & & & & & & & & & & & & avg & 0.0010 & & NA & & 0.2946 & Excludes & s all the & 0 and $\#$ d & divio! por & & & \\
\hline & & & & & & & & & & & & & std dev & 0.0008 & & NA & & 0.329 & & & & & & & \\
\hline & & & & & & & & & & & & & $A+2 S D$ & 0,0026 & & NA & & 0.9526 & & & & & & & \\
\hline
\end{tabular}




\begin{tabular}{|c|c|c|c|c|c|c|c|c|c|c|c|c|c|c|c|c|c|c|c|c|c|c|c|c|c|}
\hline Sample II & LRB & Sample Time & Received & Analyzed & Reported & dit tot & Delta T & Ar & & $\mathrm{CO} 2$ & & $\mathrm{CO}$ & & $\mathrm{He} 2$ & & H2 & & CH4 & & N2 & & $\mathrm{O2}$ & & \multicolumn{2}{|c|}{ N2O } \\
\hline & & & & & & & & moder: & starec & molax & est prex & molox & encerac & moriex & ostprec & molex & $\operatorname{mot}_{\text {prec }}$ & madiex & est procec & mosos: & est proce & molos & atproc & & extproce \\
\hline$S X-105-0602-95-101$ & ACl 6 & $6219510: 15$ & 6/6/95 & $6 / 695$ & 6.9/95 & 7 & 3. & 0.94 & 0.02 & 0.004 & 0.002 & & $<01$ & & $<.001$ & 0.0016 & 0.0003 & & 5.0005 & 77.8 & 0.4 & 21.2 & 0.4 & & $<.0005$ \\
\hline SX-105-0606-95-100 & ACL 6 & $6,6 / 95 \quad 10: 05$ & $6 / 6195$ & $6 / 695$ & 69995 & 3 & 3 & 0.94 & 0.02 & 0.044 & $\begin{array}{ll}0.002 \\
\end{array}$ & & $<.01$ & & $<.001$ & 0.0005 & 0.0002 & & $<0,005$ & 77.9 & 0.4 & 21.2 & 0.4 & & $<.0005$ \\
\hline $5 \times-105-0609-95-105$ & ACL 6 & $699 / 9510: 50$ & $6 / 13 / 95$ & $6 / 13 / 95$ & $6 / 16 / 95$ & 7 & 3 & 0.94 & 0.02 & 0.042 & 0.002 & & $<.01$ & & $<.001$ & 0.0005 & 0.0003 & 0.0002 & 0.0001 & 780 & 0.4 & 21.0 & 0.4 & & $<.0005$ \\
\hline $5 \times-105-0616-95-132$ & $\mathrm{ACL} 6$ & $6 / 16 / 95$ 13:20 & $6 \longdiv { 2 0 1 9 5 }$ & $6 \longdiv { 2 1 / 9 5 }$ & $6 / 2295$ & 5 & 2 & 0.93 & 0.02 & 0.033 & 0.002 & & $<01$ & & 2.001 & 0.0016 & 0.0003 & & $<.0005$ & $780^{\circ}$ & 0.4 & 210 & 0.4 & & $<.0005$ \\
\hline SX-105-0620-95-095 & ACL 6 & $6 / 201959: 55$ & 620195 & $6 / 21 / 95$ & $6 / 22195$ & 2 & 2 & $0 \overline{93}$ & 0.02 & 0.034 & 0.002 & & $<.01$ & & $<.001$ & 0.0008 & 0.0003 & & 5.0005 & 78.0 & 0.4 & 21.0 & 0.4 & & $<.0005$ \\
\hline SX-105-0622-95-103 & ACLE & $6 / 22 / 95 \quad 10: 35$ & $6 / 27 / 95$ & 6,28195 & $6 / 20195$ & 7 & 2 & 0.94 & 0.02 & 0.035 & 0.002 & & $<.07$ & & $<.001$ & & $<.0005$ & & 5.0005 & 78.1 & 0.4 & 20.9 & 0.4 & & $<0005$ \\
\hline SX-105-0627-95-103 & ACL 6 & $6 / 27 / 15590: 30$ & $627 / 95$ & $6 / 28 / 95$ & $6 / 29 / 95$ & 2 & 2 & 0.94 & 0.02 & 0.034 & 0.002 & & $<.01$ & & $<.001$ & 0.0006 & 0.0003 & & 5.001 & 78.2 & 0.4 & 20.9 & 0.4 & & $\leq 0005$ \\
\hline SX-105-0630-95-093 & $A C L 6$ & $6 / 30 / 959.35$ & $7 / 11 / 95$ & $7 / 14 / 95$ & 7/18/95 & 18 & 7 & 0.94 & 0.02 & 0.034 & 0.002 & & $<.07$ & & $<.001$ & 0.0008 & 0.0003 & & $<.001$ & 78.0 & 0.4 & 21.7 & 0.4 & & $<0005$ \\
\hline$S X-105.0707-95-103$ & ACL 6 & $7 / 79590: 30$ & $7 / 11195$ & $7 / 14 / 95$ & $7 / 18 / 95$ & 11 & 7 & 0.94 & 0.02 & 0.034 & 0.002 & & $<01$ & & $<.001$ & 0.0010 & 0.0005 & & $<\infty 1$ & 77.9 & 0.4 & 21.4 & 0.4 & & $<0005$ \\
\hline $5 X-105-0818-95-142$ & $A C L 6$ & $8 / 18 / 95 \quad 14: 25$ & $8 / 29 / 95$ & $8 \sqrt{30 / 95}$ & 9/1/95 & 13 & 3 & 0.93 & 0.02 & 0.03 & 0.003 & & $<.01$ & & $<.001$ & 0.0012 & 0.0005 & 0.0002 & 0.0001 & 77.9 & 0.4 & 21.1 & 0.4 & & $<0005$ \\
\hline$S X-105-0825-95-145$ & ACL 6 & $8 / 25 / 95 \quad 14: 50$ & $829 / 95$ & $8 / 30 / 95$ & 9/1/95 & 6 & 3 & 0.93 & 0.02 & 0.03 & 0.002 & & $<01$ & & $<.001$ & & $<.0005$ & 0.0002 & 0.0001 & 78.0 & 0.4 & 21.1 & 0.4 & & $<0005$ \\
\hline SX-105-0901-95-145 & ACL 6 & 9/4,95 14:50 & $9 / 12 / 95$ & $9 / 13 / 95$ & $9 / 14 / 95$ & 12 & 2 & 0.94 & 0.02 & 0.023 & 0.002 & & $<.01$ & & $<.001$ & 0.0054 & 0.0003 & 0.0002 & 0.0001 & 77.8 & 0.4 & 21.1 & 0.4 & 0.0010 & 0.0003 \\
\hline $5 \times-105-0911-95-15$ & ACLE & $9 / 11 / 95 \quad 15: 10$ & $9 / 12 / 95$ & 9/13/95 & $9 / 1495$ & 2 & 2 & 0.94 & 0.02 & 0.032 & 0.002 & & $<.01$ & & $<.001$ & & $<0005$ & 0.0002 & 0.0001 & 77.9 & 0.4 & 21.1 & 0.4 & & $<.0005$ \\
\hline $5 x-105-0915-95-095$ & ACL 6 & $9 / 45 / 959: 55$ & $9 / 49 / 95$ & $9 / 20 / 95$ & $9 / 21 / 95$ & 6 & 2 & 0.95 & 0.02 & 0.035 & 0.002 & & $<.01$ & & 5.001 & 0.0012 & 0.0003 & 0.0002 & 0.0001 & 77.9 & 0.4 & 21.1 & 0.4 & & $<.0005$ \\
\hline SX-105-0919-95-095 & ACL 6 & $9 / 19 / 959: 55$ & $9 / 19 / 95$ & $9 / 20 / 95$ & $9 / 21 / 95$ & 2 & 2 & 0.95 & 0.02 & 0.032 & 0.002 & & $<.01$ & & $<.001$ & 0.0005 & 0.0003 & 0.0002 & 0.0001 & 77.9 & 0.4 & 21.9 & 0.4 & & $<.0005$ \\
\hline SX-105-0925-95-142 & $A C L 6$ & $9 / 2519514: 25$ & $9 / 26 / 95$ & $9 / 26 / 95$ & $9 / 27 / 95$ & 1 & 1 & 0.94 & 0.02 & 0.034 & 0.002 & & $<01$ & & 5.001 & 0.0021 & 0.0003 & 0.0002 & 0.0001 & 77.9 & 0.4 & 21.1 & 0.4 & & $<.0005$ \\
\hline $5 x-105-1004-95-150$ & ACL 6 & $10 / 4 / 9515: 00$ & $10 / 10 / 95$ & $10 / 10 / 95$ & $10 / 13 / 95$ & 8 & 3 & 0.94 & 0.02 & 0.031 & 0.002 & & $<.01$ & & $<.001$ & 0.0012 & 0.0003 & 0.0002 & 0.0001 & 77.9 & 0.4 & 21.1 & 0.4 & & $<0005$ \\
\hline $241-\mathrm{SX}-105-1$ & ACL 6 & 3/20/966 13:00 & $3 / 21 / 96$ & $3 / 21 / 06$ & $3 / 2496$ & 0 & 0. & 0.95 & 0.02 & 0.036 & 0.002 & & $<01$ & & $<.001$ & & $<0005$ & & $\angle 001$ & 77.9 & 0.4 & 21.1 & 0.4 & & $<0005$ \\
\hline $241-5 \times-105-2$ & ACL 6 & $3 / 20 / 961300$ & $3 / 21 / 96$ & $3 / 21 / 96$ & $3 / 21 / 96$ & 0 & 0 & 0.95 & 0.02 & 0.037 & 0.002 & & $<.01$ & & $<.001$ & & $<0005$ & & 5.001 & 77.8 & 0.4 & 21.1 & 0.4 & & $\leqslant 0005$ \\
\hline & & & & & & & & & & & & & & & & & & & & & & & & & \\
\hline & & & & & & & & & & & & & & & & & & & & & & & & & \\
\hline & & & & & & & & & & & & & & & & $\ln 20 / 22$ & & chr $4 / 72$ & & & & & & & \\
\hline & & & & & & & & & & & & & & & & 0 & & 0 & & & & & & & \\
\hline & & & & & & & & & & & & & & & & -0 & & 0 & & & & & & & \\
\hline & & 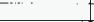 & & & & & & & & & & & & & & $\frac{0}{0}$ & & 0.4 & & & & & & & \\
\hline & & & & & & & & & & & & & & & & 0 & & & & & & & & & \\
\hline & & & & & & & & & & & & & & & & \#OIV/O! & & \#DIVIO: & & & & & & & \\
\hline & & & & & & & & & & & & & & & & 0 & & 0 & & & & & & & \\
\hline & & & & & & & & & & & & & & & & 0 & & 0 & & & & & & & \\
\hline & & & & & & & & & & & & & & & & 0 & & o & & & & & & & \\
\hline & & & & & & & & & & & & & & & & 0 & & 0.1667 & & & & & & & \\
\hline & & & & & & & & & & & & & & & & \#DIV/o! & & \#OIVIO! & & & & & & & \\
\hline & & & & & & & & & & & & & & & & 0.1852 & & 0.037 & & & & & & & \\
\hline & & & & & & & & & & & & & & & & \#DIVIOI & & 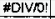 & & & & & & & \\
\hline & & & & & & & & & & & & & & & & 0 & & 0.1667 & & & & & & & \\
\hline & & & & & & & & & & & & & & & & 0 & & 0.4 & & & & & & & \\
\hline & & & & & & & & & & & & & & & & 0 & & 0.0952 & & & & & & & \\
\hline & & & & & & & & & & & & & & & & & & 0.1667 & & & & & & & \\
\hline & & & & & & & & & & & & & & & & \#DIV/0! & & \#DIVIOS: & & & & & & & \\
\hline & & & & & & & & & & & & & & h2 & & 蓜IV/0! & & \#DAVRO & & & & & & & \\
\hline & & & & & & & & & & & & & avg & 0.0014 & & $\mathrm{NA}$ & & \begin{tabular}{|l|}
0.2046 \\
\end{tabular} & Excludes & sall the & 0 and $\# d i$ & INRT! po & ints & & \\
\hline & & & & & & & & & & & & & sto dev & 0.0013 & & NA & & 0.1418 & & & & & & & \\
\hline & & & & & & & & & & & & & $A+2 S D$ & 0.0039 & & & & 0.4883 & & & & & & & \\
\hline
\end{tabular}


WHC-SD-WM-TI-753 REV 0

密

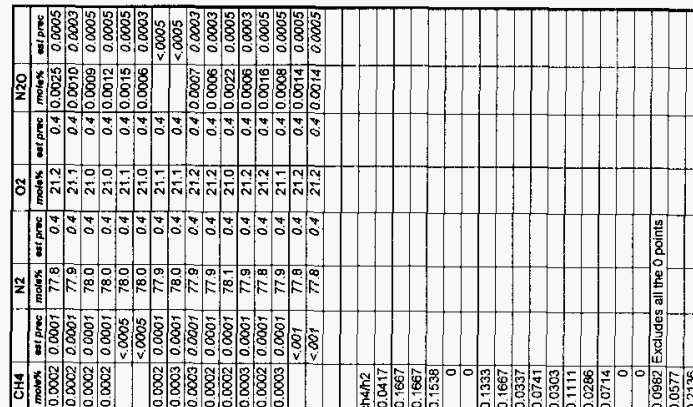

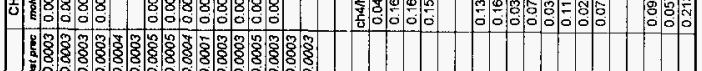

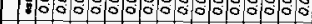

순

地

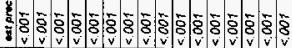

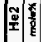

$\frac{1}{2}$

$\frac{8}{x}$

8 )

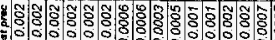

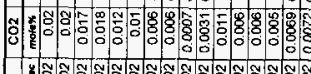

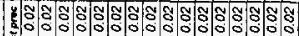

i

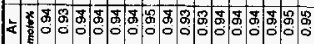

मलनलतनलिक तल लिए

部

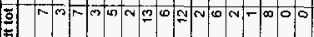

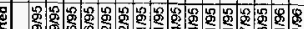

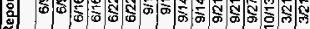

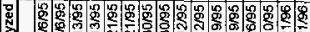

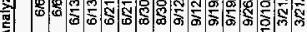

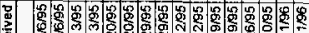

蛋

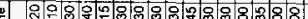

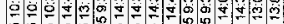

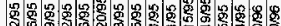

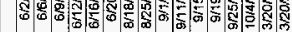

(1) $00 \% 0000 \%$

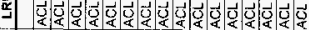

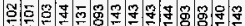

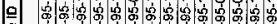

$\circ$

क.

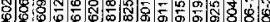

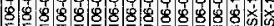

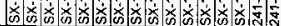




\begin{tabular}{|c|c|c|c|c|c|c|c|c|c|c|c|c|c|c|c|c|c|c|c|c|c|c|c|c|c|}
\hline Sample ID & LRB & Sample Time & Received & Ánälyzed & Reported & de tot & Delta T & Ar & & $\mathrm{CO} 2$ & & $\mathrm{CO}$ & & $\mathrm{He} 2$ & & $\mathrm{H} 2$ & & $\mathrm{CH} 4$ & & N2 & & 02 & & $\mathrm{N2O}$ & \\
\hline & & & & & & & & mosos & extproes & monose & satprese & matex & $\operatorname{matpox} \mid$ & marex & etproce & $\operatorname{matax}$ & estponec & molex & elpract & molex & setpesos & molox & sasterac & monos & wiprece \\
\hline$S X-109-0502-95-102$ & $\mathrm{ACL} 6$ & $6 / 2 / 9510: 20$ & $6 / 6 / 95$ & $6 / 6 \% 5$ & 6909 & 7 & 3 & 0.93 & 0.02 & \begin{tabular}{|l|}
0.041 \\
\end{tabular} & 0.001 & & $<.01$ & & $<.001$ & 0.0015 & 0.0003 & \begin{tabular}{|l|l|}
0.0002 \\
\end{tabular} & 0.0001 & 78.0 & 0.4 & 21.0 & 0.4 & 0.0005 & 0.0003 \\
\hline SX-109-0606-95-101 & ACL $\overline{6}$ & $6 / 6 / 9510: 15$ & $6 / 6 / 95$ & $6 / 6195$ & 69995 & 3 & $\frac{5}{3}$ & 0.94 & 0.02 & 0.04 & 0.002 & & $<.01$ & & $<.001$ & 0.0007 & 0.0003 & 0.0002 & 0.0001 & 779 & 0.4 & $\frac{21,0}{21,1}$ & 0.4 & & 60.0005 \\
\hline$S X-109-0609-95-110$ & ACL 6 & $6 / 9 / 951100$ & $6 / 13 / 95$ & $6 / 13 / 95$ & $6 / 16 / 95$ & 7 & 3 & 0.94 & 0.02 & 0.039 & 0.002 & & $<.01$ & & 5.001 & 0.0006 & 0.0003 & 0.0002 & 0.0001 & 78.0 & 0.4 & 21.0 & 0.4 & & $<.0005$ \\
\hline$S \overline{S X}-109-0612-95-144$ & $A C L 6$ & $6 / 12 / 9519: 00$ & $6 / 13 / 95$ & $6 / 13 / 95$ & $6 / 46 / 95$ & 4 & 3 & 0.94 & 0.02 & 0.039 & 0.002 & & $<.01$ & & 5.001 & 0.0008 & 0.0003 & & $<.0005$ & 78.0 & 0.4 & 21.0 & 0.4 & 0.0003 & 0.0002 \\
\hline$\$ X-109-0825-95-145$ & $\mathrm{ACL} 6$ & $8 / 25 / 95 \quad 14: 55$ & 8/29/95 & $8 / 30 / 95$ & $9 / 1 / 95$ & 6 & 3 & 0.94 & 0.02 & 0.027 & 0.003 & & $<.07$ & & $<.001$ & & $<.0005$ & 0.0001 & 0.0007 & 78.0 & 0.4 & 21.1 & 0.4 & & $\alpha .0005$ \\
\hline$S X-109-0901-95-145$ & $\mathrm{ACL} 6$ & $9 / 1 / 95 \quad 14: 55$ & $9 / 12 / 95$ & M13/95 & 9/14/85 & \$2 & $\overline{2}$ & 0.94 & 0.02 & 0.03 & 0.002 & & $<.01$ & & 5.001 & 0.0017 & 0.0003 & & $<.0005$ & 77.9 & 0.4 & 21.9 & 0.4 & & $<.0005$ \\
\hline $241-5 \times-109-1$ & $A C L E$ & $3 / 20 / 9613.00$ & $3 / 21 / 96$ & $3 / 21 / 96$ & $3 / 21 / 96$ & of & 0 & 0.95 & 0.02 & 0.032 & 0.002 & & $<.07$ & & $<.001$ & 0.0005 & 0,0003 & & $<007$ & 77.9 & 0.4 & 21.9 & 0.4 & & $<0005$ \\
\hline $241-\mathrm{SX}-109-2$ & ACL 6 & $3 / 20 / 9613: 00$ & $3 / 21,96$ & $3 / 21 / 96$ & $3 / 21 / 96$ & of & 0 & 096 & 0.02 & 0.032 & 0.002 & & $<.01$ & & 5.001 & 00006 & 0.0003 & & $<001$ & 779 & 0.4 & 21.1 & 04 & & $<.0005$ \\
\hline & & & & & & & & & & & & & & & & & & & & & & & & & \\
\hline & & & & & & & & & & & & & & & & 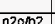 & & 4 & & & & & & & \\
\hline & & & & & & & & & & & & & & & & $\frac{10312}{0.3333}$ & & 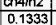 & & & & & & & \\
\hline & & & & & & & & & & & & & & & & 0 & & 0.2857 & & & & & & & \\
\hline & & & & & & & & & & & & & & & & 0 & & 0.3333 & & & & & & & \\
\hline & & & & & & & & & & & & & & & & 0.375 & & & & & & & & & \\
\hline & & & & & & & & & & & & & & & & \#DIVO: & & \#DIVO: & & & & & & & \\
\hline & & & & & & & & & & & & & & & & 0 & & 0 & & & & & & & \\
\hline & & & & & & & & & & & & & & & & 0 & & of & & & & & & & \\
\hline & & & & & & & & & & & & & & $\mathrm{h2}$ & & 0 & & 0 & & & & & & & \\
\hline & & & & & & & & & & & & & avg & 0.0009 & & 0.3542 & & 0.2508 & Exclude & $s$ all the & 0 and $\# 0$ & Yolp & nts & & \\
\hline & & & & & & & & & & & & & std deY & $5 E-04$ & & 0.0295 & & 0.1045 & & & & & & & \\
\hline & & & & & & & & & & & & & $A+2 S S D$ & 0.002 & & 04131 & & 0.4597 & & & & & & & \\
\hline
\end{tabular}


WHC-SD-WM-TI-753 REV 0

1

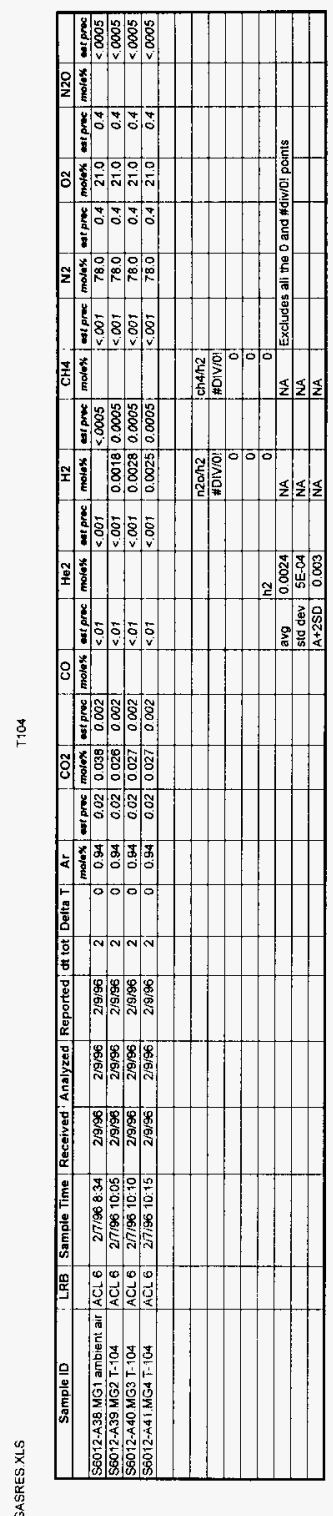




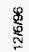

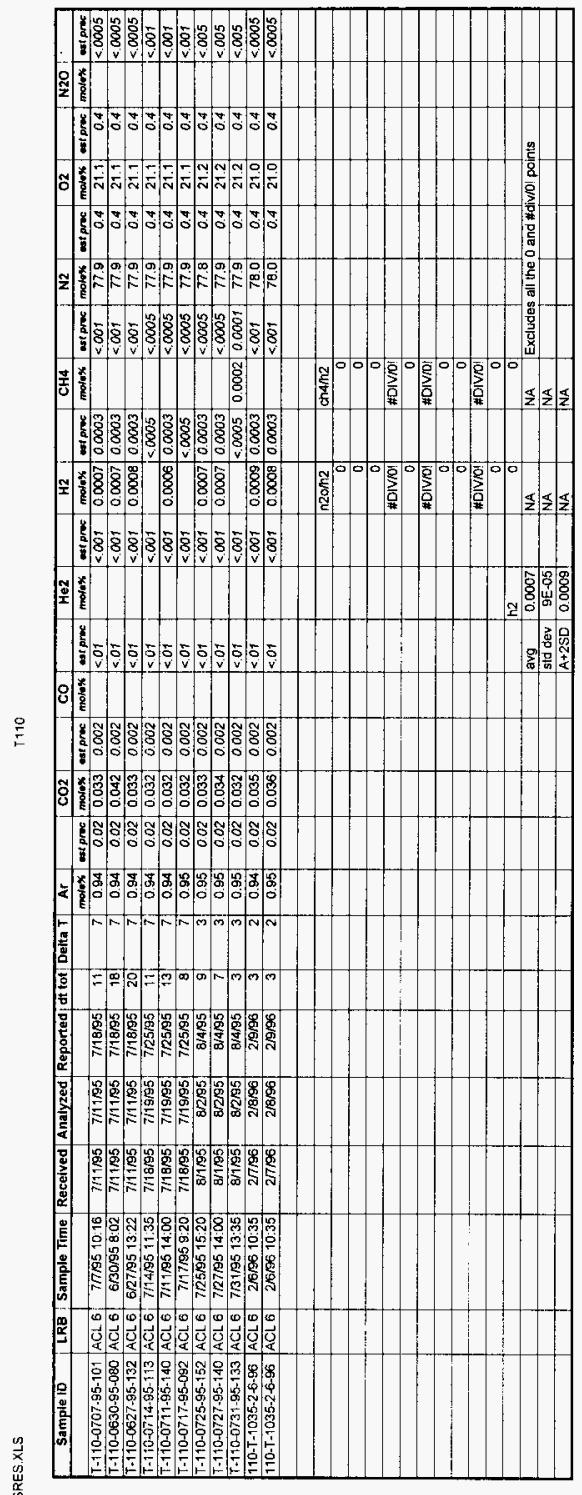




\begin{tabular}{|c|c|c|c|c|c|c|c|c|c|c|c|c|c|c|c|c|c|c|c|c|c|c|c|c|c|}
\hline Sample iD & LRE & Sample Time & Received & Analyzed & Reported & det tot & Deita T & Ar & & $\mathrm{CO}$ & & $\mathrm{CO}$ & & $\mathrm{He2}$ & & $\mathrm{Hz}$ & & CH4 & & N2 & & 02 & & N2O & \\
\hline & & & & & & & & molts & $\operatorname{sentans}$ & maies & $=0$ & moher & sospente & molex & 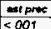 & $\begin{array}{l}\text { molex } \\
00040\end{array}$ & 0.000 & $\frac{\operatorname{mon} x}{0.002}$ & entorect & molex & $=\frac{0.00}{0.4}$ & $\frac{\text { molex }}{20.8}$ & $\frac{-0 \text { enes: }}{0.4}$ & $\frac{\operatorname{mob} x}{0.058}$ & $\frac{0009}{000}$ \\
\hline$U-103-0707-95-110$ & $A C L 6$ & $7 / 7 / 9511.00$ & $7 / 1195$ & 7713135 & $\begin{array}{l}7 / 18 / 155 \\
7 / 18 / 85\end{array}$ & 11. & & \begin{tabular}{|l|}
0.94 \\
0.94
\end{tabular} & 0.02 & 0.009 & \begin{tabular}{|l|}
0.0009 \\
0.0008
\end{tabular} & & $\frac{<.01}{<.01}$ & & $\begin{array}{l}<001 \\
<, 001\end{array}$ & $\left|\frac{0,0840}{0.0780}\right|$ & $\frac{0.002}{0.002}$ & $\begin{array}{r}0.002 \\
0.0019\end{array}$ & $\frac{0.0005}{0.0005}$ & $-\frac{78.1}{780}$ & $\begin{array}{l}0.4 \\
0.4\end{array}$ & $\frac{20.8}{20.8}$ & \begin{tabular}{|l|} 
\\
$\mid$
\end{tabular} & \begin{tabular}{|l|l|}
0.088 \\
0.079
\end{tabular} & $\begin{array}{l}0.009 \\
0.005\end{array}$ \\
\hline $\begin{array}{l}\mathrm{U}-103-0630-95-084 \\
\mathrm{U}-103-0527-95-135\end{array}$ & $\begin{array}{ll}\text { ACL } 6 \\
\text { ACL } 6\end{array}$ & $\begin{array}{r}6 / 30 / 958: 45 \\
6 / 27 / 9513: 55\end{array}$ & \begin{tabular}{|l|}
$7 / 11 / 95$ \\
$7 / 19 / 95$ \\
\end{tabular} & $\begin{array}{l}7 / 13 / 95 \\
7113 / 95\end{array}$ & $\frac{7 / 18 / 85}{7 / 18 / 95}$ & \begin{tabular}{|l|} 
\\
\end{tabular} & & \begin{tabular}{|c|}
+0.54 \\
0.93 \\
\end{tabular} & $\frac{0.02}{0.02}$ & $\frac{0.008}{0.017}$ & $\begin{array}{l}0.008 \\
0002 \\
\end{array}$ & & $<01$ & & $<001$ & $|0.0740|$ & 0.002 & $\mid 0.0021$ & 0.0005 & 778 & $\frac{0.4}{0.4}$ & $\frac{20,8}{211}$ & $\frac{0.4}{0.4}$ & $\begin{array}{l}0.079 \\
0.075 \\
\end{array}$ & $\frac{0.005}{0.005}$ \\
\hline U-103-0503-95-030 & ACL 6 & 53195900 & $7 / 11 / 95$ & $7 / 13 / 95$ & $7 / 18 / 95$ & 76 & 7 & 0.92 & 0.02 & & $<.01$ & & $<.01$ & & $<.001$ & 0.0780 & 0.002 & 0.0021 & 0.0005 & 77.9 & 0.4 & 210 & 0.4 & 0.091 & 0,005 \\
\hline U-103-0717-95-100 & $\mathrm{ACL} 6$ & 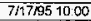 & $7 / 18995$ & $7 / 19 / 95$ & $7 / 25 / 96$ & 8 & & 0.94 & 0.02 & 0.029 & 0.002 & & $<.01$ & & $<001$ & 0.0360 & 0.002 & 0.0008 & 0.0004 & 77.9 & 0.4 & 21.0 & 0.4 & 0.05 & 0.005 \\
\hline U-103-0711-95-145 & $\mathrm{ACl} 6$ & $7 / 41 / 9514.50$ & $7 / 18 / 95$ & $7 / 19 / 95$ & $725 / 95$ & 13 & & 0.94 & 0.02 & & $<.005$ & & $<.01$ & & $<.001$ & 0.0830 & 0.004 & 0.0016 & 0.0005 & 78.0 & 0.4 & 20.9 & 0.4 & 0.124 & 0.006 \\
\hline U-103-0714-95-112 & $\mathrm{ACL} 6$ & $7 / 14 / 9511.25$ & $7 / 1985$ & $7 / 19 / 95$ & $7 / 25 / 95$ & 11 & 7 & 0.94 & 0.02 & 0.02 & 0.002 & & 509 & & $<001$ & 00620 & 0.003 & 0.0013 & 0.0005 & 78.0 & 0.4 & 20.9 & 0.4 & 0.083 & 0.005 \\
\hline U-103-0725-95-150 & ACL 6 & $7 / 25 / 9515: 05$ & $8 / 1 / 195$ & $8 / 3 / 95$ & $8 / 4 / 95$ & 9 & 3 & 0.94 & 0,02 & 0.034 & 0.005 & & $<01$ & & $<\infty$ & 00460 & 0002 & 0,001 & 0.0005 & 778 & 0.4 & 211 & 04 & 0.063 & 0006 \\
\hline $\mathrm{U}-103-0727-95-142$ & $\mathrm{ACL} 6$ & $7 / 27 / 95 \quad 14: 25$ & $8 / 1 / 95$ & $8 / 3795$ & $8 / 4 / 95$ & 7 & 3 & 0.94 & 0.02 & 0.025 & 0.005 & & $<.09$ & & $<.001$ & 0.0440 & 0.002 & 0.0006 & 0.0003 & 77.9 & $\frac{.74}{0.4}$ & $\frac{21.1}{21.1}$ & 0.4 & 0.063 & 0.006 \\
\hline \multirow{17}{*}{ U-103-0731-95-141 } & $\overline{A C L} 6$ & $7 / 3195 \quad 14: 10$ & 8/1/95 & $8 / 3 / 95$ & $8 / 4 / 95$ & 3 & 3 & 0.94 & 0.02 & 0.029 & 0.005 & & $<01$ & & $<001$ & 0.0470 & 0.002 & 0.001 & 0.0005 & 77.9 & 0.4 & 21.1 & 0.4 & 0.066 & 0.006 \\
\hline & & & & & & & & & & & & & & & & & & & & & & & & & \\
\hline & & & & & & & & & & & & & & & & & & & & & & & & & \\
\hline & & & & & & & & & & & & & & & & n20,n2 & & ch $4 m 2$ & & & & & & & \\
\hline & & & & & & & & & & & & & & & & 1.048 & & 0.0238 & & & & & & & \\
\hline & & & & & & & & & & & & & & & & 1.013 & & 0.0244 & & & & & & & \\
\hline & & & & & & & & & & & & & & & & 1.014 & & 0.0284 & & & & & & & \\
\hline & & & & & & & & & & & & & & & & 1.167 & & 0.0269 & & & & & & & \\
\hline & & & & & & & & & & & & & & & & 1.389 & & 0.0222 & & & & & & & \\
\hline & & & & & & & & & & & & & & & & 1.494 & & 0.0193 & & & & & & & \\
\hline & & & & & & & & & & & & & & & & 1.339 & & 0.021 & & & & & & & \\
\hline & & & & & & & & & & & & & & & & 1.37 & & 0.0217 & & & & & & & \\
\hline & & & & & & & & & & & & & & & & 1.432 & & 0.0136 & & & & & & & \\
\hline & & & & & & & & & & & & & & n2 & & 1.404 & & 0.0213 & & & & & & & \\
\hline & & & & & & & & & & & & & avg & 0.0632 & & 1.267 & & 0.0223 & & & & & & & \\
\hline & & & & & & & & & & & & & std dev & 0.0184 & & 0.187 & & 0.0041 & & & & & & & \\
\hline & & & & & & & & & & & & & $A+2 S D$ & 0.1 & & 1.641 & & 0.0305 & & & & & & & \\
\hline
\end{tabular}

$\omega$
$\omega$
$\omega$ 


\begin{tabular}{|c|c|c|c|c|c|c|c|c|c|c|c|c|c|c|c|c|c|c|c|c|c|c|c|c|c|}
\hline Sample ID & LRB & Sample Time & Received & Analyzed & Reported & det tot & Delta T & Ar & & $\mathrm{CO2}$ & & co & & He2 & & $\mathrm{H}_{2}$ & & $\mathrm{CH} 4$ & & N2 & & 02 & & N2O & \\
\hline & & & & & & & & moles & est prece & $\operatorname{matex}$ & 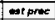 & molex & at proc & motex & ontpresc & molox & est prect & molex & est procec & molox & $=0$ proce & mothex & estprecec & molak & estaros \\
\hline U-105-0630-55-064 & $A C L E$ & $6 / 30 / 958: 40$ & $7 / 11 / 95$ & $7 / 13 / 95$ & $7 / 18 / 95$ & 18 & & 0.94 & 0.02 & 0.007 & 0.0007 & & $<01$ & & $<001$ & 0.050 & 0.001 & $0.00 \div 6$ & 0.0005 & 78.1 & 0.4 & 20.8 & 0.4 & 0.0830 & 0.005 \\
\hline U-105-0707-95-104 & ACLE & $7 / 7 / 9510.40$ & $7 / 11 / 95$ & $7 / 13 / 95$ & $7 / 18 / 95$ & 11 & 7 & 0.93 & 0.02 & 0.006 & 0.0006 & & $<0.01$ & & $<.001$ & $0.0660^{\circ}$ & 0.001 & 0.0024 & 0.0005 & 78.2 & 0.4 & 20.7 & 0.4 & 0.1120 & 0.005 \\
\hline $\mathrm{U}-105-0711-05-14 \overline{4}$ & ACL 6 & $7 / 11 / 95 \quad 14: 45$ & $7118 / 95$ & $7 / 19195$ & $7 / 25 / 95$ & 13 & 7 & 0.94 & 0.02 & & $<005$ & & $<.01$ & & $<0.001$ & 0.0670 & 0.003 & 0.0018 & 0.0005 & 779 & 0.4 & 20.9 & 0.4 & 0.1660 & 0.008 \\
\hline 1. $105-0714-95-112$ & $A C L 6$ & $7114 / 9511.20$ & $7 / 18195$ & $7 / 18 / 95$ & $7 \pi 25 / 95$ & 11 & & 0.94 & 002 & & $<, 005$ & & $<.01$ & & $<.001$ & 0.0570 & 0.003 & 0.0017 & 0.0005 & 77.9 & 0.4 & 20.9 & 0.4 & 0.1670 & 0.008 \\
\hline U- $105-0717-95-095$ & ACL 6 & 71771959.55 & $7 / 18 / 95$ & $7 / 19 / 95$ & $7 / 25195$ & 8 & 7 & 0.94 & 002 & & $<005$ & & $<.04$ & & $<.001$ & 0.0650 & 0.003 & $0.00 \div 7$ & 0.0005 & 77.9 & 0.4 & 20.9 & 0.4 & 0.1620 & 0.008 \\
\hline U-105-1300-2-7-96 & $A C L 6$ & $2 / 79613: 00$ & $2 / 7 / 96$ & $2 / 8 / 86$ & $29 / 96$ & 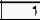 & 2 & 0.95 & 0.02 & 0.061 & $0.00 E$ & & $<.01$ & & $<.001$ & 0.0026 & 0.0003 & & $<.001$ & 780 & 0.4 & 20.9 & 0.4 & 0.0390 & 0.004 \\
\hline \multirow[t]{11}{*}{$U-105-1300-27-96$} & ACLE & $2719613: 00$ & $2 / 796$ & $2 / 8 / 96$ & 20106 & 1 & 2 & 0.94 & 0.02 & & $<005$ & & $<01$ & & $<001$ & 0.0460 & 0.001 & 0.0043 & 0.0003 & 78.1 & 0.4 & 20.8 & 0.4 & 0.1260 & 0.003 \\
\hline & & & & & & & & & & & & & & & & & & & & & & & & & \\
\hline & & & & & & & & & & & & & & & & n2o/n2 & & कर 4 /h2 & & & & & & & \\
\hline & & & & & & & & & & & & & & & & 1.66 & & \begin{tabular}{|l|} 
\\
\end{tabular} & & & & & & & \\
\hline & & & & & & & & & & & & & & & & 1.69697 & & 0.0364 & & & & & & & \\
\hline & & & & & & & & & & & & & & & & 2.47761 & & 0.0269 & & & & & & & \\
\hline & & & & & & & & & & & & & & & & 2.49254 & & 0.0254 & & & & & & & \\
\hline & & & & & & & & & & & & & & & & 2.49231 & & 0.0262 & & & & & & & \\
\hline & & & & & & & & & & & & & & & & 15 & & 0 & & & & & & & \\
\hline & & & & & & & & & & & & & & h2 & & 2.73913 & & $0 . \overline{2883}$ & & & & & & & \\
\hline & & & & & & & & & & & & & Figg & 0.0602 & & 2.25976 & & 0.0292 & Exclude & 5 all the & opoints & and the & bad valv & e data. & \\
\hline$\ldots$. & & & & & & & & & & & & & sid dev & 0.0095 & & 0.46086 & & 0.0042 & & & & & & & \\
\hline & & & & & & & & & & & & & $A+2 S D$ & 0.0792 & & \begin{tabular}{|l|}
3.18148 \\
\end{tabular} & & 0.0376 & & & & & & & \\
\hline
\end{tabular}


㐘

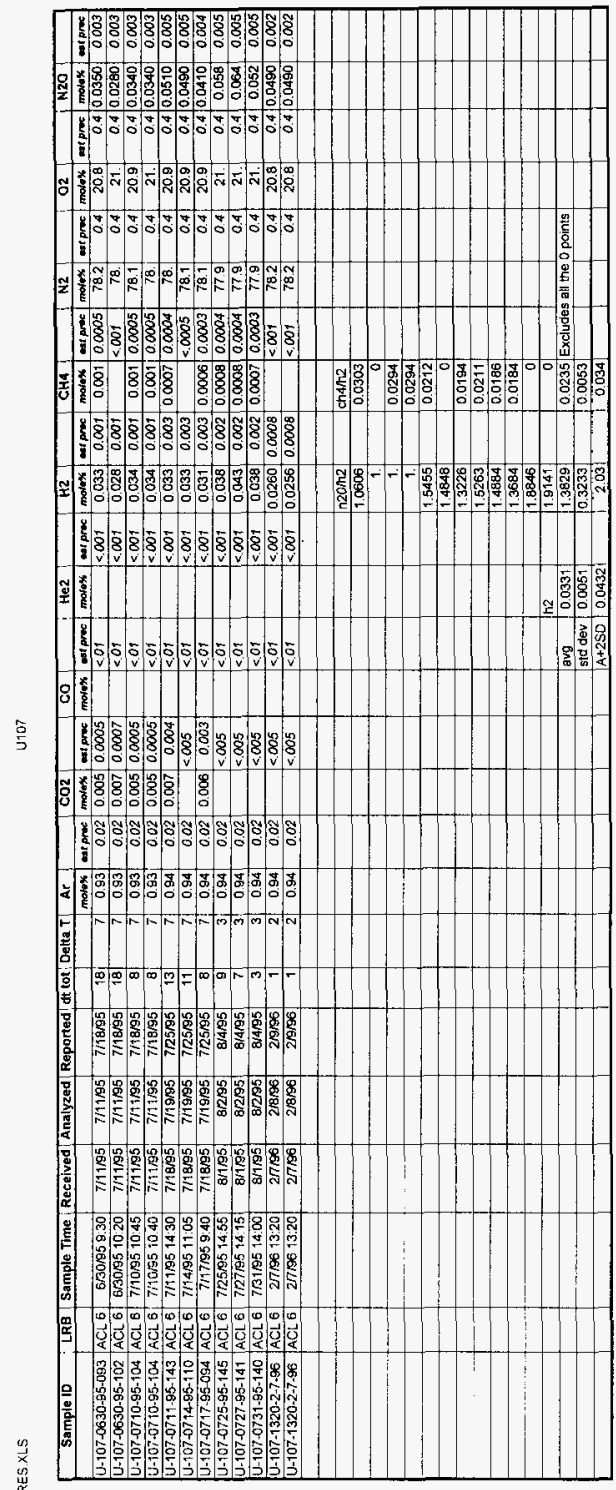




\begin{tabular}{|c|c|c|c|c|c|c|c|c|c|c|c|c|c|c|c|c|c|c|c|c|c|c|c|c|c|}
\hline Sample ID & LRB & Sample Time & Received & Antlyzed & Reported & dt tot & Delta T & Ar & & $\mathrm{CO} 2$ & & Co & & $\mathrm{He2}$ & & H2 & & CH4 & & N2 & & $\mathrm{O} 2$ & & $\mathrm{~N} 2 \mathrm{O}$ & \\
\hline & & & & & & & & molox & estares & moles & cot prec & males & \&i proc & molex & estarsec & motes & ent prece & madex & $=1$ aneck & matex & ext presec & motes & est pros & motex & Esterow \\
\hline U-108-0527-95-1350 & ACL 6 & $6 / 27 / 9513.50$ & $7 / 41 / 95$ & $7 / 14 / 95$ & $7 / 18 / 95$ & 20 & & 0.94 & 0.02 & 0.003 & 00003 & & $<.01$ & & $<=001$ & 0.0430 & 0.001 & 0.0011 & 00005 & 78.1 & 0.4 & 20.9 & 0.4 & 0.0330 & 0.003 \\
\hline $0-108-0630-95-0835$ & ACL 6 & 6/30/95 8:35 & $7 / 11 / 95$ & $7 / 12 / 95$ & $7 / 18 / 95$ & 18 & 7 & 0.94 & 0.02 & 0.004 & 0,0004 & & $<.01$ & & $<<01$ & 0.0410 & 0.001 & 0.0008 & 0.0004 & 78.1 & 0.4 & 20.8 & 0.4 & 0.0310 & 0.003 \\
\hline U-108-0707-95-1050 & ACL 6 & $7 / 7 / 9510.50$ & $7 / 41 / 95$ & $7 / 14 / 95$ & $7 / 118 / 95$ & 11 & 7 & 0.93 & 0.02 & 0.004 & 00004 & & $<01$ & & $<001$ & 0.050 & 0.001 & 0.001 & 0.0005 & 78.1 & 0.4 & 20.9 & 04 & 0.0360 & 0.003 \\
\hline U-108-07+1-95-1435 & $\mathrm{ACl} \theta$ & $7 / 11 / 9514: 35$ & $7 / 18 / 95$ & $7 / 19 / 95$ & $7 / 25 / 95$ & 13 & 7 & 0.94 & 0.02 & & $<.005$ & & $<.01$ & & $<009$ & 0.0470 & 0.005 & 0.001 & 0.0005 & 78.0 & 0.4 & 20.0 & 0.4 & 0.0530 & 0.005 \\
\hline U-100-0714-95-1110 & ACL 6 & $7 / 14 / 9511: 10$ & $7 / 18 / 95$ & $7 / 19 / 95$ & $725 / 95$ & 11 & 7 & 093 & 0.02 & & $<005$ & & $<01$ & & $<001$ & 00450 & 0.004 & 00008 & 00004 & 780 & 04 & 20.9 & 0.4 & $\mid 0.0510$ & 0.005 \\
\hline U-108-0717-95-0945 & ACL 6 & $7 / 17 / 959: 45$ & 711895 & $7 / 19 / 95$ & $7 / 25 / 95$ & 8 & 7 & 0.93 & 0.02 & 0.005 & 0.003 & & $<.01$ & & $<.001$ & 0.0430 & 0.004 & 0.0018 & 0.0009 & 78.0 & 0.4 & 20.9 & 0.4 & 0.0450 & 0.004 \\
\hline U-108-0725-95-1500 & $\mathrm{ACL} 6$ & $7 / 25 / 95$ 15:00 & $8 / 1 / 95$ & $8 / 2 / 95$ & $8 / 4 / 95$ & 9 & 3 & 0.95 & 0.02 & 0.021 & 0.005 & & $<01$ & & $<001$ & 0.021 & 0.001 & 00005 & 00002 & 779 & 0.4 & 21.1 & 0.4 & 0.016 & 0.005 \\
\hline U-106-0727-95-1430 & $A C L 6$ & $7 / 27 / 9514: 30$ & $3 / 1 / 95$ & $8 / 2 / 95$ & $8 / 4 / 95$ & 7 & & 0.95 & 0.02 & 0.023 & 0.005 & & $<.01$ & & $<.001$ & 0.024 & 0.001 & 0.0005 & 0.0002 & 77.9 & 0.4 & 21.1 & 0.4 & 0.018 & 0.005 \\
\hline U-108-0731-95-1405 & ACL 6 & $7 / 31 / 9514: 05$ & $8 / 1 / 95$ & $8 / 2 / 95$ & $8 / 495$ & 3 & 3 & 0.95 & 0.02 & 0.026 & 0.005 & & $<01$ & & $<.001$ & 0.018 & 0.001 & $\mid 0.0004$ & 0.0002 & 77.9 & 0.4 & 21.1 & 0.4 & 0.014 & 0.005 \\
\hline$\overline{\mathrm{J}}-100-0911-95-1410$ & ACL 6 & $9 / 11 / 9514: 10$ & $9 / 12 / 95$ & $9 / 12 / 95$ & $9 / 14 / 95$ & 2 & 2 & 0.93 & 0.02 & 0.005 & 0.002 & & $<01$ & & $<.001$ & 0.049 & 0.001 & $\mid 0.0007$ & 0.0002 & 779 & 0.4 & 21 & 0.4 & 0.053 & 0.005 \\
\hline U-108-0911-95-14t0) & ACL 6 & $9 / 11 / 95$ 14:10 & $9 / 12 / 95$ & $9 / 12 / 95$ & $9 / 14 / 95$ & 2 & $\frac{2}{2}$ & 0.94 & 0.02 & 0.005 & 0.002 & & $<.01$ & & $<001$ & 0.048 & 0.001 & \begin{tabular}{|l|}
0.0008 \\
\end{tabular} & 0.0002 & 78.1 & 0.4 & 20.9 & 0.4 & 0.055 & \begin{tabular}{|l|}
0.005 \\
\end{tabular} \\
\hline U-108-0918-95-0930 & $\mathrm{ACL} 6$ & $9 / 18 / 959: 30$ & $9 / 19 / 95$ & $9 / 20 / 95$ & $9 / 21 / 95$ & 3 & & 0.95 & 0.02 & 0.034 & 0.002 & & $<.01$ & & $<001$ & & $<.0005$ & 0.0002 & 0.0001 & 77.9 & 0.4 & 21.1 & 04 & & $<0005$ \\
\hline U. $108-0918-9509301$ & $\mathrm{ACL} 6$ & $9 / 18 / 959: 30$ & $9 / 19 / 95$ & $9 / 20 / 95$ & $9 / 21 / 95$ & 3 & 2 & 0.96 & 0.02 & 0.037 & 0.002 & & $<.01$ & & $<, 001$ & 0.0008 & 0,0003 & 0.0001 & 0.0001 & 77.9 & 0.4 & 21.1 & 0.4 & & $<0005$ \\
\hline U-108-1315-2-7-961 & ACL 6 & $2 7 \longdiv { 9 6 } 1 3: 15$ & $2 \pi / 96$ & 21896 & 29196 & 1 & 2 & 0.95 & 0.02 & 0011 & 0.002 & & $<01$ & & $<001$ & 00296 & 00000 & & $<001$ & 781 & 04 & 20.9 & 04 & 0.0370 & 0.003 \\
\hline U-108-1315-2-7.962 & ACL 6 & $2 \pi / 9613.15$ & $27 / 96$ & $2 / 8 / 96$ & $2 / 996$ & t & & 0.95 & 0.02 & 0.026 & 0.002 & & $<.01$ & & $<001$ & 0.0145 & 0,0006 & & $<.001$ & 78.0 & 0.4 & 21.0 & 0.4 & 0.0120 & 0.003 \\
\hline & & & & & & & & & & & & & & & & & & & & & & & & & \\
\hline & & & & & & & & & & & & & & & & & & & & & & & & & \\
\hline & & & & & & & & & & & & & & & & ก20M2 & & ch4m2 & & & & & & & \\
\hline & & & & & & & & & & & & & & & & 07674 & & 00256 & & & & & & & \\
\hline & & & & & & & & & & & & & & & & 0.7561 & & 0.0195 & & & & & & & \\
\hline & & & & & & & & & & & & & & & & 0.72 & & 0.02 & & & & & & & \\
\hline & & & & & & & & & & & & & & & & 1.1277 & & 0.0213 & & & & & & & \\
\hline & & & & & & & & & & & & & & & & 1.1333 & & 0.0178 & & & & & & & \\
\hline & & & & & & & & & & & & & & & & 10465 & & 0.0419 & & & & & & & \\
\hline & & & & & & & & & & & & & & & & 0.7619 & & 0.0238 & & & & & & & \\
\hline & & & & & & & & & & & & & & & & 075 & & 0.0208 & & & & & & & \\
\hline & & & & & & & & & & & & & & & & 0.7778 & & 0.0222 & & & & & & & \\
\hline & & & & & & & & & & & & & & & & 1.0816 & & 0.0143 & & & & & & & \\
\hline & & & & & & & & & & & & & & & & \begin{tabular}{|l|}
1.1458 \\
\end{tabular} & & 0.0167 & & & & & & & \\
\hline & & & & & & & & & & & & & & & & \#DIVIN! & & \#Divo! & & & & & & & \\
\hline & & & & & & & & & & & & & & & & 0 & & 0.125 & & & & & & & \\
\hline & & & & & & & & & & & & & & & & 1.25 & & 0 & & & & & & & \\
\hline & . & .. & & & & & & & & & & & & $\mathrm{h} 2 \mathrm{2}$ & & 08276 & & 0 & & & & & & & \\
\hline & & & & & & & & & & & & & javg & 0.0339 & & 0.9343 & & 0.0307 & Exchudes & Is all the & 0 and \#Ci & divol poin & ints & & \\
\hline & & & & & & & & & & & & & sid dev & 0.0157 & & 0.196 & & 0.0305 & & & & & & & \\
\hline & & & & & & & & & & & & & $\mathrm{A}+2 \mathrm{SD}$ & $\mid 0.0653$ & & 13262 & & 0.0917 & & & & & & & \\
\hline
\end{tabular}




\begin{tabular}{|c|c|c|c|c|c|c|c|c|c|c|c|c|c|c|c|c|c|c|c|c|c|c|c|c|c|}
\hline Sample ID & LRB & Sample Time & Received & Analyzed & Reported & Det tor & Delta T & Ar & & $\mathrm{CO} 2$ & & Co & & Hez & & $\mathrm{H} 2$ & & CH4 & & N2 & & 02 & & N2O & \\
\hline & & & & & & & & molex & ertaresc & moins & $\operatorname{ent} p$ & moles & entpose & molex & wetpore & moves & etpmect & moles & est prac & molox & expore & manas: & est posec & motax & estpresc \\
\hline U-109-0707-95-105 & ACL 6 & $7 / 79510.55$ & $7 / 11 / 95$ & $7 / 12 / 95$ & $7 / 18 / 95$ & 11 & 7 & 0.94 & 0.02 & 0005 & 00005 & & $<.01$ & & $<.001$ & 0.0460 & 0.001 & 0.0011 & 0.0005 & 78.1 & 0.4 & 20.9 & 0.4 & 0.0390 & 0.004 \\
\hline U-109-0711-95-144 & $A C L-6$ & $7 / 11 / 951440$ & $7 / 18 / 95$ & $7 / 19 / 95$ & $7 / 25 / 95$ & 13 & 7 & 0.94 & 0.02 & 0.008 & 0.0008 & & $<0 t$ & & $<.001$ & 0.0410 & 0.004 & 0.0000 & 0.0004 & 78.1 & 0.4 & 20.9 & 0.4 & 0.0460 & 0.005 \\
\hline $\mathrm{U}-109-0714-95-11 t$ & ACLE & $7 / 14 / 9511: 15$ & $7 / 18 / 95$ & $7 / 19 / 95$ & $7 / 25 / 95$ & 11 & & 0.93 & 0.02 & & $<005$ & & $<.01$ & & $<.001$ & 0.0420 & 0.004 & 0.0007 & 0.0003 & 78.0 & 0.4 & 20.9 & 0.4 & 0.0520 & 0.005 \\
\hline $0 .+09-0717-95-095$ & ACLE & $7 / 17959.50$ & $7 / 11895$ & $7 / 19 / 95$ & $7725 / 95$ & 8 & 7 & 0.93 & 0.02 & & $\times .005$ & & 5.01 & & 5,001 & 0.0390 & 0.004 & 0.0007 & 0.0004 & 78.1 & 0.4 & 20.9 & 0.4 & 0.0470 & 0005 \\
\hline 100 & $\overline{A C L}$ & 1228795000 & $12 / 2899$ & $12228 \overline{85}$ & $12 / 28 \sqrt{95}$ & 0 & $\overline{0}$ & 0.87 & 0.02 & 0061 & 0.006 & & & & $<.001$ & 1.440 & 0.03 & 0.006 & 0.003 & 78.2 & 0.4 & 19.2 & 0.4 & 0.280 & 0.02 \\
\hline U109 & AC. 6 & $1 / 49660.00$ & $1 / 496$ & $1 / 4 / 56$ & $1 / 4 / 96$ & 0 & 0 & 0.005 & 0.001 & & $<.01$ & & $<.01$ & & 5.001 & 6.20 & 0.1 & 0.08 & 0.01 & 883 & 0.1 & .047 & 0.004 & 5.30 & 0.1 \\
\hline Quill Rod Truck \#3 & ACL 6 & $1 / 17 / 96000$ & $1 / 17 / 96$ & $1 / 17196$ & $1 / 177 / 96$ & 0 & 0 & 0.18 & 0.004 & & $<.005$ & & $<.07$ & & $<.001$ & 0.650 & 0.07 & 0.011 & 0.02 & 94.9 & $0.0 \overline{8}$ & 3.860 & 0.08 & 0.4230 & 0.009 \\
\hline U-109-1330-2-7-96 & ACL 6 & $2 \pi / 96 \quad 13.30$ & $27 / 96$ & $218 / 96$ & $2 / 9 / 96$ & 1 & 2 & 0.94 & 0.02 & & $<.005$ & & $<.01$ & & $<0.01$ & 0.0212 & 0.0006 & & $<001$ & 781 & 0.4 & 20.9 & 0.4 & 0.0273 & 0.0009 \\
\hline \multirow{16}{*}{ U-109-1330-2-7-96 } & ACL 6 & $2 / 10613: 30$ & $27 / 96$ & $2 / 8 / 56$ & 29906 & 1 & 2 & 0.94 & 0.02 & & $<005$ & & $<.07$ & & $<.001$ & 10.0215: & 0.0006 & & $<001$ & 781 & 0.4 & 20.9 & 0.4 & 0.0272 & 0.0009 \\
\hline & & & & & & & & & & & & & & & & & & & & & & & & & \\
\hline & & & & & & & & & & & & & & & & & & & & & & & & & \\
\hline & & & & & & & & & & & & & & & & $\ln 20 \mathrm{O} 2$ & & ch4m2 & & & & & & & \\
\hline & & & & & & & & & & & & & & & & 0.8478 & & 0.0239 & & & & & & & \\
\hline & & & & & & & & & & & & & & & & 1.122 & & 0.0195 & & & & & & & \\
\hline & & & & & & & & & & & & & & & & 1.2381 & & 00167 & & & & & & & \\
\hline & & & & & & & & & & & & & & & & 1.2059 & & 0.0179 & & & & & & & \\
\hline & & & & & & & & & & & & & & & & 0.1944 & & 0.0042 & & & & & & & \\
\hline & & & & & & & & & & & & & & & & 0.8548 & & 0.0129 & & & & & & & \\
\hline & & & & & & & & & & & & & & & & 0.6508 & & 0.0169 & & & & & & & \\
\hline & & & & & & & & & & & & & & & & 1.2877 & & & & & & & & & \\
\hline & & & & & & & & & & & & & & h2 & & 1.2651 & & 0 & & & & & & & \\
\hline & & & & & & & & & & & & & avg & 0.0351 & & 1.161 & & 0.0195 & Excludes & is the dat & ta labelec & $u-109$ & and the & quili rod & data \\
\hline & & & & & & & & & & & & & std dev & 0.0109 & & 0.1639 & & 0.0032 & & & & & & & \\
\hline & & & & & & & & & & & & & $A+2 S D$ & 0.0569 & & 1.499 & & 0.0259 & & & & & & & \\
\hline
\end{tabular}


WHC-SD-WM-TI-753 REV 0

This page intentionally left blank. 
WHC-SD-WM-TI-753 REV 0

\section{APPENDIX C}

SLURRY GAS COMPOSITIONS 
WHC-SD-WM-TI-753 REV 0

This page intentionally left blank.

C-2 


\section{APPENDIX C}

\section{SLURRY GAS COMPOSITIONS}

Direct measurements do not exist for all species comprising the released slurry gas compositions in any of the tanks. The released slurry gas compositions must be inferred from tank headspace concentration data. The released slurry gas compositions were developed using the data from Appendix B. While Appendix A also contains useful information, the Appendix $B$ data has multiple sets of data for each tank. In addition, the data collected is on tanks that are declared to be under the flammable gas unreviewed safety question. Therefore, the data reported in Appendix $B$ is highly pertinent.

The sample analysis provided tank headspace concentrations for hydrogen, methane, and nitrous oxide. The available data was converted to released slurry gas compositions, assuming that these three species make up the non-soluble portion of the slurry gas. The following equation represents the model used in converting the measured concentrations into a slurry gas composition.

$$
x_{\mathrm{ns}, \mathrm{H}_{2}}+x_{\mathrm{ns}_{2} \mathrm{CH}_{4}}+x_{\mathrm{ns}, \mathrm{N}_{2} \mathrm{O}}=1
$$

This model is based on the assumption that the species ratio obtained from the tank headspace measurements are the same for the gas that exists in the waste and will be released by a gas release event. This is considered a good assumption if the mass transfer from the waste surface is negligible (the gases are non-soluble) and the species ratios do not change with time or location in the waste.

To calculate a released slurry gas composition for each tank, the data from Appendix B was used to calculate the average, standard deviation, and average plus two standard deviations for each of the following: hydrogen, the ratio of nitrous oxide to hydrogen, and the ratio of methane to hydrogen. The average plus two standard deviations are the values that were used in deriving the gas compositions.

The gas monitoring performed in the tank farms (see Appendix A) shows that almost all the tanks produce ammonia. Unfortunately, very limited data is available on ammonia in the tanks of interest. It should also be noted that ammonia is soluble in the tank waste. Therefore, ammonia is expected to be present in the release gas because of two mechanisms: a constituent of the generated gas and the gas released because of mass transfer (i.e., as waste from a higher pressure zones moves into a lower pressure zone, the saturation value changes and ammonia is off-gassed). 
The ammonia fraction in the release gas is important in determining the safety envelope. The presence and amount of ammonia affects the safety analyses in the following major areas:

- Ammonia is a more energetic fuel than hydrogen.

- Ammonia affects the lower flammability limit of the mixture. When expressed in terms of hydrogen concentration only, the lower flammability limit decreases with increasing ammonia content.

- Ammonia is corrosive and toxic.

For this analysis, an ammonia concentration of $15 \%$ was chosen. This was based on the value chosen by LANL (1995) for the mixer pump safety assessment.

0ther gases are present in the slurry gas too. One of the gases that should be present is nitrogen. Laboratory experiments on simulated Tank 241-SY-101 waste and on real waste from Tank 241-SY-103 show that nitrogen is produced in the range from 20 to $40 \%$ depending on the temperature. It should also be noted that, the retained gas sampler results from tank 241-AW-101 indicate that there was at least $20 \%$ nitrogen in the slurry gas for that tank. No information exists for single-shell tank waste, however, it is conservative to assume that $20 \%$ nitrogen is present.

It is also likely that water vapor will exist in the slurry gas. An upper bound of $2.5 \%$ is expected. However, the water vapor content is also conservatively set to zero. See Appendix E.

Thus, the final composition is given by the following model.

$$
X_{\mathrm{ns}, \mathrm{H}_{2}}+X_{\mathrm{ns}, \mathrm{CH}_{4}}+X_{\mathrm{ns}, \mathrm{N}_{2} \mathrm{O}}+X_{\mathrm{s}, \mathrm{NH}_{3}}+X_{\mathrm{ns}, \mathrm{N}_{2}}=1
$$

For example, for Tank 241-AN-103, the hydrogen concentration plus two standard deviations is 0.018 mole percent. The ratio of nitrous oxide to hydrogen (plus two standard deviations) is 0.086 . The ratio of methane to hydrogen is 0 . Thus, hydrogen is 0.018 mole percent, nitrous oxide is 0.0015 mole percent $(0.018 * 0.086)$ and methane is 0 mole percent. The total is 0.0195 $(0.018+0.0015+0)$. Normalizing the composition for these gases gives

$$
\begin{aligned}
& 1=x_{\mathrm{ns}, \mathrm{H}_{2}}+x_{\mathrm{ns}_{2} \mathrm{CH}_{4}}+x_{\mathrm{ns}, \mathrm{N}_{2} \mathrm{O}} \\
& 1=\frac{0.018}{0.0195}+\frac{0.0015}{0.0195}+\frac{0}{0.0195} \\
& 1=0.921+0.079+0
\end{aligned}
$$


To complete the released slurry gas composition, ammonia is set at 0.15 and nitrogen at 0.20 and the gas composition is renormalized. That is

$$
\begin{aligned}
& \mathrm{l}=X_{\mathrm{ns}, \mathrm{H}_{2}}+X_{\mathrm{ns}, \mathrm{N}_{2} \mathrm{O}}+X_{\mathrm{ns}, \mathrm{CH}_{4}}+X_{\mathrm{s}, \mathrm{NH}_{3}}+X_{\mathrm{ns}_{2} \mathrm{~N}_{2}} \\
& 1=0.60+0.05+0+0.15+0.20
\end{aligned}
$$

Thus, the released slurry gas composition for Tank $241-\mathrm{AN}-103$ is $60 \%$ hydrogen, $5 \%$ nitrous oxide, $0 \%$ methane, $15 \%$ ammonia and $20 \%$ nitrogen.

The data for each tank, where monitoring data exists, is given in the following spreadsheet pages. Also calculated were the lower flammability limit for each gas composition (both the total mixture and the hydrogen concentration at mixture lower flammability limit).

The lower flammable limit for the mixture is calculated using Le Chatlier's rule.

$$
\mathrm{LFL}_{\text {mixture }}=\frac{1}{\frac{X_{\mathrm{H}_{2}}}{\mathrm{LFL}_{\mathrm{H}_{2}}}+\frac{X_{\mathrm{CH}_{4}}}{\mathrm{LFL}_{\mathrm{CH}_{4}}}+\frac{X_{\mathrm{NH}_{3}}}{\mathrm{LFL}_{\mathrm{NH}_{3}}}}
$$

For example, to calculate the mixture lawer flammability limit for tank 241-AN-103, the flammable gases (no inerts) need to be normalized. For Tank 241-AN-103, the normalized concentrations are $80 \%[60 /(60+0+15)]$ hydrogen, $0 \%[0 /(60+0+15)]$ methane, and $20 \%[15 /(60+0+15)]$ ammonia. Using these in Le Chatlier's rule gives:

$$
\begin{aligned}
L F L_{\text {mixture }} & =\frac{1}{\frac{0.8}{4.0}+\frac{0}{5.5}+\frac{0.2}{15}} \\
& =4.69
\end{aligned}
$$

If the only species being monitored for was hydrogen (i.e., a hydrogenspecific monitor is being used), the hydrogen concentration at the mixture lower flammability limit is useful. This is calculated by taking the total mixture lower flammability limit and multiplying by the volume fraction of hydrogen in the slurry gas when compared to only the flammable constituents $\left(X_{\text {hydrogen }}+X_{\text {mefhane }}+X_{\text {ammonia }}=1\right)$. That is, if the total mixture lower flammability 1 imit were $3.5 \%$ and the volume fraction of hydrogen in the slurry 
gas when compared to only the flammable constituents were $50 \%$, then the hydrogen concentration at the mixture lower flammability limit is $1.75 \%$ hydrogen. For Tank 24l-AN-103, the hydrogen concentration at mixture lower flammability limit is found by multiply the normalized hydrogen concentration times the lower flammability limit. This gives $3.75 \%(0.8 * 4.69)$ hydrogen.

Earlier analysis (Sherwood 1995) developed a hydrogen concentration at the mixture lower flammability 1 imit of $2.5 \%$ hydrogen and $25 \%$ of the hydrogen concentration at the mixture lower flammability limit as $0.625 \%(6,250 \mathrm{ppm})$ hydrogen. This was based on a generic slurry gas composition and was developed to provide one monitoring value for all tanks regardless of the unique composition in the tank. A review of the calculated values in the spreadsheet pages indicates this value is still bounding, except for Tank 241-SX-104, where the hydrogen concentration at the mixture lower flammability limit is $2.16 \%$ hydrogen and one quarter of the hydrogen concentration at the mixture lower flammability limit is $0.5394 \%(5,394 \mathrm{ppm})$ hydrogen. 


\begin{tabular}{|c|c|c|c|c|c|c|c|c|c|c|c|c|c|c|c|c|c|c|c|c|}
\hline & A & $\bar{B}$ & $\bar{C}$ & $\bar{D}$ & $\bar{E}$ & $F$ & $G$ & $\mathrm{H}$ & 1 & $\mathrm{~J}$ & $\mathrm{~K}$ & $\bar{L}$ & $M$ & $\mathrm{~N}$ & 0 & $P$ & $Q$ & $\mathbf{R}$ & $\mathbf{s}$ & $\mathrm{T}$ \\
\hline 1 & & & & & & & & & & & & & & & & Total & $\mathrm{H}_{2}$ & & & Equiv. \\
\hline 2 & & \multicolumn{3}{|c|}{$\mathrm{H} 2$} & \multicolumn{3}{|c|}{$\mathrm{N} 2 \mathrm{O} / \mathrm{H} 2$} & \multicolumn{3}{|c|}{$\mathrm{CH} 4 / \mathrm{H} 2$} & \multicolumn{5}{|c|}{ Raleased Slumy Gas Composition } & Mixture & Conc @ & Stored Gas & Headspace & Fuel \\
\hline 3 & DST & Average & Sto. Dev & $\bar{A}+2 \mathrm{SD}$ & \begin{tabular}{|l|} 
Average \\
\end{tabular} & Std.Dev. & $A+2 S D$ & Average & Std. Dey. & $A+2 S D$ & $\mathrm{H}_{2}$ & $\mathrm{~N} 2 \mathrm{O}$ & $\mathrm{CH} 4$ & $\mathrm{NH3}$ & $\mathrm{N} 2$ & LFL & LFL & \begin{tabular}{l|l} 
(scm) \\
\end{tabular} & (m3) & W/Air \\
\hline 4 & AN-103 & $5.4 E-03$ & $63 \mathrm{E}-03$ & $1.8 \mathrm{E}-02$ & $6.7 E-02$ & $9.3 E-03$ & $8.6 \mathrm{E}-02$ & $\mathrm{NA}$ & NA & & $60 \%$ & $5 \%$ & $0 \%$ & $15 \%$ & $20 \%$ & 4.69 & 3.75 & 641 & 1717 & $80 \%$ \\
\hline 5 & AN-104 & $5.8 E-03$ & $3.2 E-03$ & $1.2 \mathrm{E}-02$ & $1.5 \mathrm{E}-01$ & $2.2 \mathrm{E}-02$ & $1.9 \mathrm{E}-01$ & NA & NA & & $55 \%$ & $10 \%$ & $0 \%$ & $15 \%$ & $20 \%$ & 4.75 & 3.73 & 320 & 1321 & $74 \overline{\%}$ \\
\hline 6 & AN-105 & $\overline{1.6 E-02}$ & $2.2 E-02$ & $6.0 \mathrm{E}+02$ & $1.7 \mathrm{E}-01$ & $4.6 E-02$ & $2.6 \mathrm{E}-01$ & NA & NA. & & $52 \%$ & $13 \%$ & $0 \%$ & $15 \%$ & $20 \%$ & 4.79 & 3.71 & 397 & 1024 & $71 \%$ \\
\hline 7 & $A N-107$ & & & & & & & & & & & & & & & & & & 1328 & \\
\hline 8 & AW-101 & B.5E-02 & $1.1 \mathrm{E}-01$ & 31E-01 & $7.9 \mathrm{E}-02$ & $1.4 \mathrm{E}-01$ & $3.5 \mathrm{E}-01$ & $9.3 E-63$ & $1.1 \mathrm{E}-03$ & $1.2 \mathrm{E}-02$ & $48 \%$ & $17 \%$ & $1 \%$ & $15 \%$ & $20 \%$ & 4.85 & 3.66 & 229 & 1065 & $69 \%$ \\
\hline 9 & $A W-104$ & & & & & & & & & & & & & & & & & 150 & 1083 & \\
\hline 10 & AिY-107 & & & & & & & & & & & & & & & & & 34 & 1759 & \\
\hline 11 & 5Y-101 & $29 \mathrm{E}-0 \mathrm{03}$ & $21 \mathrm{E}-03$ & $7.1 \mathrm{E}-03$ & $7.7 \mathrm{E}-01$ & $3.4 E-01$ & $1.4 \mathrm{E}+00$ & NA & NA & & $31 \%$ & $27 \%$ & $1 \%$ & $15 \%$ & $25 \%$ & 5.24 & 3.51 & 551 & 1032 & $53 \%$ \\
\hline 12 & $5 Y .103$ & $2.4 E-02$ & $4.4 \mathrm{E}-02$ & 1. $1 \mathrm{E}-01$ & $4.8 \mathrm{E}-01$ & $2.5 \mathrm{E}-01$ & $97 \mathrm{E}-01$ & $4.8 \mathrm{E}-02$ & $7.1 \mathrm{E}-02$ & $7.9 \mathrm{E}-01$ & $30 \%$ & $20 \%$ & $2 \%$ & $17 \%$ & $31 \%$ & 5.43 & 3.35 & 119 & 2514 & $58 \%$ \\
\hline 13 & & & & & & & & & & & & & & & & & & & & \\
\hline 14 & SST & & & & & & & & & & & & & & & & & & & \\
\hline 75 & A-101 & $1.1 E-01$ & $4.3 \mathrm{E}-02$ & 2. OE-01 & $1.6 E-01$ & 1.3E-C2 & $1.9 E-01$ & $9.4 E-03$ & $3.4 E-03$ & $16 \mathrm{E}-02$ & $54 \%$ & $10 \%$ & $1 \%$ & $15 \%$ & $20 \%$ & 4.76 & 3.68 & 130 & 1224 & $77 \%$ \\
\hline 46 & $A-103$ & & & & & & & & & & & & & & & & & 102 & 3349 & \\
\hline 17 & Ax-101 & $6.3 \mathrm{E}-03$ & $1.8 E-03$ & $9.8 \mathrm{E}-03$ & 1.1E-01 & $1.5 \mathrm{E}-02$ & $1.4 E-01$ & $3.7 E-02$ & $8.2 E-03$ & $5.3 \mathrm{E}-02$ & $55 \%$ & $7 \%$ & $3 \%$ & $15 \%$ & $20 \%$ & 4.76 & 3.59 & - & 1886 & $84 \%$ \\
\hline 18 & $A x-103$ & $2.6 E-03$ & $4.8 \mathrm{E}-04$ & $3.6 \mathrm{E}-03$ & $8.4 E-01$ & $1.0 \mathrm{E}-01$ & $1.0 E+\infty$ & $8.0 E-02$ & $2.9 E-02$ & $1.4 E-\overline{01}$ & $30 \%$ & $31 \%$ & $4 \%$ & $15 \%$ & $20 \%$ & 5.28 & 3.21 & - & & $63 \%$ \\
\hline 19 & $8 X \cdot 107$ & & & & & & & & & & & & & & & & & 122 & 1933 & \\
\hline 20 & $8 Y-101$ & & & & & & & & & & & & & & & & & 266 & 3165 & \\
\hline 21 & 8 Y-102 & & & & & & & & & & & & & & & & & $\because$ & 2933 & \\
\hline 22 & $8 Y .103$ & $1.4 E-02$ & $7.5 E-03$ & 2.9E-02 & $2.4 E-01$ & $8.5 E-02$ & 4.1E-01 & $1.8 \mathrm{E}-02$ & $4.1 \mathrm{E}-03$ & $2.7 \mathrm{E}-02$ & $45 \%$ & $18 \%$ & $1 \%$ & $15 \%$ & $20 \%$ & 4.89 & 3.60 & - & 2529 & $69 \%$ \\
\hline 23 & $8 \overline{-105}$ & & & & & & & & & & & & & & & & & 183 & 2322 & \\
\hline 24 & $\overline{B Y-106}$ & $39 \mathrm{E}-02$ & $4.5 E-02$ & $1,3 \mathrm{E}-01$ & $6.8 \mathrm{E}-01$ & $3.6 E-01$ & $1.4 \mathrm{E}+\infty \mathrm{O}$ & $2.2 \mathrm{E}-02$ & $3.2 E-03$ & $2.8 E-02$ & $27 \%$ & $37 \%$ & $1 \%$ & $15 \%$ & $20 \%$ & 5.42 & 3.42 & - & 1432 & $49 \%$ \\
\hline 25 & $B Y-109$ & $7 \overline{4 E-03}$ & $6.1 \mathrm{E}-03$ & $2.0 \mathrm{E}-02$ & $1.4 \mathrm{E}-01$ & $1.0 E-0$ & $3.5 \mathrm{E}-01$ & $3.2 \mathrm{E}-02$ & $1.7 \mathrm{E}-02$ & $6.7 E-02$ & $46 \%$ & $15 \%$ & $3 \%$ & $15 \%$ & $20 \%$ & 4.89 & 3.51 & - & 2746 & $76 \%$ \\
\hline 26 & $\begin{array}{l}-104 \\
\end{array}$ & & & & & & & & & & & & & & & & & 30 & 2296 & \\
\hline 27 & $c-105$ & $8.7 \overline{\mathrm{E}}-04$ & $5.8 \mathrm{E}-05$ & $9.8 \mathrm{E}-04$ & NA & NA & & $3.9 \mathrm{E}-01$ & $9.6 \mathrm{E}-02$ & $5.8 \mathrm{E}-01$ & $41 \%$ & $0 \%$ & $24 \%$ & $95 \%$ & $20 \%$ & 4.98 & 256 & & 2372 & $140 \%$ \\
\hline 28 & $C-107$ & & & & & & & & & & & & & & & & & 5 & 2296 & \\
\hline 29 & S-101 & & & & & & & & & & & & & & & & & 138 & 2380 & \\
\hline 30 & S-102 & $60 \mathrm{E}-02$ & $20 \mathrm{E}-02$ & $99 E-02$ & $7.1 E-01$ & $23 E-02$ & $75 E-01$ & $1.2 \mathrm{E}-02$ & $2.3 E-03$ & $1.6 \mathrm{E}-02$ & $37 \%$ & $28 \%$ & $1 \%$ & $15 \%$ & $20 \%$ & 5.08 & $\overline{356}$ & 608 & 1924 & $58 \%$ \\
\hline 31 & $5-103$ & & & & & & & & & & & & & & & & & 256 & 2961 & \\
\hline 32 & S-105 & & & & & & & & & & & & & & & & & 120 & 2412 & \\
\hline 33 & S-106 & & & & & & & & & & & & & & & & & 808 & 2197 & \\
\hline 34 & $5-107$ & $6.8 \mathrm{E}-01$ & & $6 \mathrm{BE} \cdot 01$ & $1.3 E-01$ & & $1.3 \mathrm{E}-01$ & $1.6 \mathrm{E}-03$ & & $16 \mathrm{E}-03$ & $57 \%$ & $8 \%$ & $0 \%$ & $15 \%$ & $20 \%$ & 4.72 & 3.73 & 77 & 2543 & $77 \%$ \\
\hline 35 & s.108 & $1.2 \mathrm{E}-03$ & & $1.2 \mathrm{E}+03$ & NA & NA & & NA & NA & & $65 \%$ & $0 \%$ & $0 \%$ & $15 \%$ & $20 \%$ & 4.64 & 3.77 & & 2268 & $85 \%$ \\
\hline 36 & $\overline{5-109}$ & & & & & & & & & & & & & & & & & 447 & 2256 & \\
\hline 37 & $5-110$ & $1.2 \mathrm{E}-02$ & $7.1 \mathrm{E}-05$ & $1.3 \mathrm{E}-\mathrm{C} 2$ & $1.4 \mathrm{E}-01$ & $2.2 \mathrm{E}-02$ & $1.6 \mathrm{E}-01$ & NA & NA & & $56 \%$ & $9 \%$ & $0 \%$ & $15 \%$ & $20 \%$ & 4.73 & 3.73 & & 2510 & $76 \%$ \\
\hline $3 \overline{8}$ & S-111 & $6.6 \mathrm{E}-03$ & $7.1 \mathrm{E}-03$ & $2.1 \mathrm{E}-02$ & $2.0 E-01$ & $2.8 \mathrm{E}-02$ & $2.6 \mathrm{E}-01$ & $1.4 \mathrm{E}-01$ & $\mid 1.7 \mathrm{E}-01$ & $4.8 E-01$ & $37 \%$ & $10 \%$ & $18 \%$ & $15 \%$ & $20 \%$ & 5.05 & 2.68 & 466 & 1938 & $197 \%$ \\
\hline 39 & S-112 & $2.8 \mathrm{E}-0 \mathrm{~S}$ & $5,3 E-04$ & $3.9 \mathrm{E}-03$ & $2.9 E-01$ & $5.9 E-02$ & $4, \bar{E}-01$ & $8.3 E-02$ & $2.6 \mathrm{E}-02$ & 1.3E-01 & $42 \%$ & $17 \%$ & $6 \%$ & $15 \%$ & $20 \%$ & 4.96 & 3.33 & & 2005 & $81 \%$ \\
\hline 40 & SX-101 & $70 \mathrm{E}-04$ & $2.1 \mathrm{E}-04$ & $1.1 \mathrm{E}-03$ & NA & NA & & $2.8 \mathrm{E}-01$ & $1.0 E-01$ & $4.9 E-01$ & $44 \%$ & $0 \%$ & $21 \%$ & $15 \%$ & $20 \%$ & 4.94 & 2.69 & 56 & 3152 & $134 \%$ \\
\hline 41 & SX-102 & T. GE-O3 & $1.1 \mathrm{E}-03$ & $4.2 E-03$ & $5.0 E-01$ & $6.1 E-01$ & $1.7 \mathrm{E}+\infty$ & $1,7 E-01$ & $1.2 \mathrm{E}-01$ & $4.1 \mathrm{E}-01$ & $21 \%$ & $36 \%$ & $6 \%$ & $15 \%$ & $20 \%$ & 5.61 & 2.63 & 386 & 2865 & $69 \%$ \\
\hline 42 & $5 x-103$ & 3 . 1E-03 & $1.7 \mathrm{E}-03$ & $6.5 E-03$ & $2.5 E-01$ & $7.2 \mathrm{E}-02$ & $4.0 E-01$ & $92 \mathrm{E}-02$ & $5.0 \mathrm{E}-02$ & 4.9E-01 & $41 \%$ & $16 \%$ & $8 \%$ & $55 \%$ & $20 \%$ & 4.98 & 3.20 & 673 & 2393 & $87 \%$ \\
\hline 43 & $5 x-104$ & $1.0 \mathrm{E}-03$ & $8.0 E-04$ & $2.6 \mathrm{E}-03$ & $\mathrm{NA}$ & $\mathrm{NA}$ & & $2.9 \mathrm{E}-01$ & $3.3 \mathrm{E}-01$ & $9.5 \mathrm{E}-01$ & $33 \%$ & $0 \%$ & $32 \%$ & $15 \%$ & $20 \%$ & 5.11 & 2.13 & & 2591 & $958 \%$ \\
\hline 44 & $5 X-105$ & $1.4 \mathrm{E}-03$ & $1.3 \mathrm{E}-03$ & $3.9 E-03$ & NA & NA & & $2.0 E-01$ & $1.4 E-01$ & 4.9E-01 & $44 \%$ & $0 \%$ & $21 \%$ & $15 \%$ & $20 \%$ & 4.94 & 2.70 & & 2357 & $134 \%$ \\
\hline 45 & $5 X-106$ & $3.4 E-03$ & $2.4 \mathrm{E}-03$ & $8.1 \mathrm{E} .03$ & $4.6 \mathrm{E}-01$ & $2.7 \mathrm{E}-01$ & $9.9 E-01$ & $9.8 \mathrm{E}-02$ & $5.8 E-02$ & $2.1 E-01$ & $30 \%$ & $29 \%$ & $6 \%$ & $15 \%$ & $20 \%$ & 5.27 & 3.06 & 266 & 2813 & $70 \%$ \\
\hline 46 & $5 \times-109$ & $9.1 \mathrm{E}-04$ & $4.8 E-04$ & $1.9 \mathrm{E}-03$ & $3.5 \mathrm{E}-01$ & $2.9 \mathrm{E}-02$ & 4.1 E-01 & $2.5 \mathrm{E}-01$ & $1.0 \mathrm{E}-01$ & $4.6 \mathrm{E}-01$ & $35 \%$ & $14 \%$ & $16 \%$ & $15 \%$ & $20 \%$ & 5.10 & 2.70 & & 3896 & $107 \%$ \\
\hline 47 & T-104 & $2.4 \mathrm{E}-03$ & $5.1 E-04$ & $3.4 \mathrm{E}-03$ & NA & NA & & $N A$ & & & $65 \%$ & $0 \%$ & $0 \%$ & $15 \%$ & $20 \%$ & 4.64 & 3.77 & - & 1458 & $85 \%$ \\
\hline 48 & $\overline{\mathrm{I}-140}$ & $7.4 \mathrm{E} \Omega 4$ & $9.2 \mathrm{E}-05$ & $9.2 \mathrm{E}-04$ & NA & NA. & & NA & & & $65 \%$ & $0 \%$ & $0 \%$ & $15 \%$ & $20 \%$ & 4.64 & 3.77 & $\bar{r}$ & 1555 & $85 \%$ \\
\hline 49 & $7 x-102$ & & & & & & & & & & & & & & & & & 175 & 3209 & \\
\hline 50 & $\overline{D x-111}$ & & & & & & & & & & & & & & & & & 179 & 2652 & \\
\hline 51 & $7 x-112$ & & & & & & & & & & & & & & & & & 511 & 1594 & \\
\hline 52 & $7 X+113$ & & & & & & & & & & & & & & & & & 242 & 1814 & \\
\hline 53 & $7 X-115$ & & & & & & & & & & & & & & & & & 297 & 1985 & \\
\hline 54 & $U-102$ & & & & & & & & & & & & & & & & & 272 & 9821 & \\
\hline 55 & $\mathrm{U}-103$ & $5.3 \mathrm{E}-02$ & $18 \mathrm{E}-02$ & 1.0E-01 & 1. $3 E+00$ & $\overline{\overline{9} \mathrm{E}-01}$ & $9.6 E+00$ & $2.2 E-02$ & $4.1 E-03$ & $3.0 \mathrm{E}-02$ & $24 \%$ & $40 \%$ & $1 \%$ & $15 \%$ & $20 \%$ & 5.54 & 3.36 & 303 & 1448 & $47 \%$ \\
\hline 56 & $0-105$ & $6.0 \mathrm{E}-02$ & $9.5 \mathrm{E}-03$ & $7.9 \mathrm{E}-02$ & $2.3 E+\infty 0$ & $46 \mathrm{E}-01$ & $3.2 \mathrm{E}+00$ & $2.9 E-02$ & $4.2 \mathrm{E}-03$ & $3.8 \mathrm{E}-02$ & $15 \%$ & $49 \%$ & $1 \%$ & $15 \%$ & $20 \%$ & 6.24 & 3.10 & 209 & 1619 & $37 \%$ \\
\hline 57 & U-106 & & & & & & & & & & & & & & & & & 41 & 2381 & \\
\hline 58 & U-107 & $3.3 E-02$ & $5.1 E-03$ & $4.3 \mathrm{E}-02$ & $1.4 E+\infty$ & $3.2 \mathrm{E}-01$ & $2.0 E+\infty 0$ & $2.3 \mathrm{E}-02$ & $5.3 \mathrm{E}-0 \mathrm{3}$ & $3.4 E-02$ & $21 \%$ & $43 \%$ & $1 \%$ & $15 \%$ & $20 \%$ & $5 . \overline{3}$ & $3 . \overline{2} 9$ & 184 & 1693 & $43 \%$ \\
\hline 59 & $0-108$ & \begin{tabular}{|l|}
$3.4 E-02$ \\
\end{tabular} & $1.6 E-02$ & $6.5 \mathrm{E}-02$ & $9.3 E-01$ & $2.0 E-01$ & $1.3 E+00$ & $3.1 \mathrm{E}-02$ & $3.0 E-02$ & $9.2 E-02$ & $27 \%$ & $36 \%$ & $2 \%$ & $15 \%$ & $20 \%$ & 5.40 & 3.27 & 271 & 1456 & $55 \%$ \\
\hline 60 & U-109 & $3.5 E-02$ & $1.18-02$ & $5.7 \mathrm{E}-02$ & $1.2 E+\infty 0$ & $1.6 \mathrm{E}-01$ & $1.5 \mathrm{E}+00$ & $2.0 E-02$ & $3.2 \mathrm{E}-03$ & $2.6 \mathrm{E}-02$ & $26 \%$ & $38 \%$ & $1 \%$ & $15 \%$ & $20 \%$ & 5.47 & 3.40 & 215 & 1473 & $48 \%$ \\
\hline
\end{tabular}


WHC-SD-WM-TI-753 REV 0

This page intentionally left blank. 
WHC-SD-WM-TI-753 REV 0

\section{APPENDIX D}

ADIABATIC BURN DATA

D-1 
WHC-SD-WM-TI-753 REV 0

This page intentionally left blank.

D-2 


\section{APPENDIX D}

\section{ADIABATIC BURN DATA}

The adiabatic burn pressures were calculated for each of the tanks that have slurry gas compositions (see Appendix C) and estimates of retained gas volumes. The following chemical reactions are assumed to take place.

$$
\begin{aligned}
& \mathrm{H}_{2}+\frac{1}{2} \mathrm{O}_{2} \rightarrow \mathrm{H}_{2} \mathrm{O}(\mathrm{g}) \\
& \mathrm{NH}_{3}+\frac{3}{4} \mathrm{O}_{2} \rightarrow \frac{1}{2} \mathrm{~N}_{2}+\frac{3}{2} \mathrm{H}_{2} \mathrm{O}(\mathrm{g}) \\
& \mathrm{CH}_{4}+2 \mathrm{O}_{2} \rightarrow \mathrm{CO}_{2}+2 \mathrm{H}_{2} \mathrm{O}(\mathrm{g})
\end{aligned}
$$

Note, it is assumed that nitrous oxide does not participate in the burn. This is a good assumption for a well-mixed tank. This assumption breaks down for subsurface burns and localized burns, where the principal oxidizer may be nitrous oxide. This is a potential non-conservatism.

The release fraction of the retained gas is an important parameter. As discussed in Section 3.1.1.2 and 3.1.2.2, release fractions range up to approximately $50 \%$ of the stored gas. Studies at PNL (Reid 1996) indicate that an earthquake could cause the release of $50 \%$ to nearly all of the retained gas volume in the tank. Nakayama and Vogt (1996) also indicate that the ignition of a single, large bubble $(10 \mathrm{~cm})$ under the waste surface may cause the release of nearly all of the retained gas volume. Because the parameter is largely unknown, a parametric analysis was performed with the release fraction ranging from $5 \%$ to $100 \%$.

The first step used in calculating the adiabatic burn pressure in the spreadsheet is to take the headspace volume (see Appendix C) and calculate the total number of moles of oxygen and nitrogen (the two principal gases in air) that exist in the tank headspace. Next, the number of moles of each of the reactants (hydrogen, methane, and ammonia) are calculated for the entire volume of retained gas (see Appendix C). The number of moles of oxygen (the only oxidizer considered) required for complete combustion of varying release amounts of slurry gas (from $5 \%$ to $100 \%$ ) was calculated. This was done to see if any of the tanks were oxygen limited. No tanks were identified as oxygen limited. Thus, it was shown that complete burns of up to $100 \%$ of the released slurry gas could occur.

The next step in calculating the adiabatic burn pressure was to determine the number of moles of products formed during combustion. These products are water, carbon dioxide, and nitrogen. Their reaction products will absorb heat from the combustion and tend to lower the final pressure that is reached. 
The total energy released by the burns is calculated. The energy is based on the unique gas composition for each of the tanks and the following combustion energies in Table D-1.

Table D-1. Combustion Energies.

\begin{tabular}{|c|c|}
\hline Reaction & Combustion Energy (kcal/mole) \\
\hline $\mathrm{H}_{2}+0.5 \mathrm{O}_{2} \rightarrow \mathrm{H}_{2} \mathrm{O}(\mathrm{g})$ & {$[-57.8]-[0+0]=-57.8$} \\
\hline $\mathrm{NH}_{3}+0.75 \mathrm{O}_{2} \rightarrow 0.5 \mathrm{~N}_{2}+1.5 \mathrm{H}_{2} \mathrm{O}(\mathrm{g})$ & {$\left[1.5^{\star}(-57.8)+0\right]-$} \\
\hline $\mathrm{CH}_{4}+2 \mathrm{O}_{2} \rightarrow \mathrm{CO}_{2}+2 \mathrm{H}_{2} \mathrm{O}(\mathrm{g})$ & {$[-11.0+0]=-75.7$} \\
\hline
\end{tabular}

The temperature that the dome space reaches is calculated using the following formula.

$$
\text { Energy } \left._{\text {burn }}=\left(\sum \text { (Moles }\right)_{i}(\text { MolecularWeight })_{i}(\text { SpecificHeat })_{i}\right) \Delta T
$$

where the sum is over n-components (air, water vapor, carbon dioxide, and nitrogen). By assuming an initial temperature, $T_{i}$, for the tank headspace, the final headspace temperature is $T_{i}+\Delta T$. The assumed temperature is $313 \mathrm{~K}$ $\left(40^{\circ} \mathrm{C}\right)$ which is fairly close to the measured tank headspace temperature in all tanks. Table D-2 provides the data used for the above equation.

Table D-2. Parameters used to Calculate the Final Temperature.

\begin{tabular}{|c|c|c|}
\hline Constituent & $\begin{array}{c}\text { Molecular Weight } \\
\text { (g/mole) }\end{array}$ & $\begin{array}{c}\text { Specific Heat } \\
\text { (cal } / \mathrm{g} \cdot \mathrm{K})\end{array}$ \\
\hline Air & 28.987 & 0.2403 \\
\hline Water & 18 & 1 \\
\hline Carbon Dioxide & 44 & 0.2021 \\
\hline Nitrogen & 28 & 0.2490 \\
\hline
\end{tabular}



formula.

The final pressure in the tank was then calculated using the following

$$
\frac{P_{f}}{P_{i}}=\frac{n_{f} T_{f}}{n_{i} T_{i}}
$$

where $\mathrm{n}$ is the number of moles in the tank headspace, $\mathrm{T}$ is the temperature in the headspace and the subscripts $f$ and $i$ represent final and initial, respectively. The final pressure calculated using this method is the absolute pressure. To get to gauge pressure, one atmospheric pressure must be subtracted from this number. The spreadsheets give the final gauge pressure in kilopascals $(\mathrm{kPa})$. Those entries in bold type are pressures that exceed the onset of structural failure. The onset of structural failure is at $312 \mathrm{kPa}$ (45.3 psig) for double-shell tanks and $76 \mathrm{kPa}$ (11 psig) for singleshe11 tanks.

\section{KEY PARAMETERS AND ASSUMPTIONS-ACCIDENT ANALYSIS WITHOUT CONTROLS.}

1. Gas Composition-Monitoring data from the head space is used to obtain the slurry gas estimate. This is based on the assumption that the species ratios obtained from the head space measurements are the same as for the gas bubbles that exist in the waste. That is, the mass transfer from the waste surface is negligible and the species ratios do not change with time or bubble location. The noncondensible species of interest are not very soluble in the waste. Consequently, the mass transfer effects are expected to be smal1. Continuous monitoring data for nitrous oxide and hydrogen are available for Tank 241-SY-101. This data encompasses both gas release events and the time periods between events. The data show that the ratios during steady state releases are close to the same as those during events. Thus, the assumption made to base the slurry gas composition on head space measurements is reasonable.

There is one gas that is soluble in the waste; ammonia. Thus, the assumption made above is not a good assumption for ammonia.

Instead, ammonia was set at a constant value. In this modeling, the value chosen was $15 \%$ of the slurry gas released. This is consistent with measurements in Tank 241-SY-101. A sensitivity study on the effect of ammonia was conducted, i.e., $10 \%$ and $20 \%$ values were used. These did not significantly affect the calculated temperature or pressure from the burn. Since ammonia is a good fuel, the pressure and temperature would be affected if the value becomes larger than $20 \%$.

The slurry gas compositions developed do not contain nitrogen. Since data was not available on the amount of nitrogen present in the slurry gas except for a very few tanks (241-SY-101 and 241-SY-103) and since it is highly dependent on tank temperature and tank chemistry, a simplifying assumption was made that there 
and tank chemistry, a simplifying assumption was made that there was $20 \%$ nitrogen in the slurry gas. To determine the effect, a slurry gas composition with $0 \%$ nitrogen was compared to a slurry gas composition with $20 \%$ nitrogen. The final gauge pressure was 11 to $21 \%$ (depends on the remaining gas constituents) higher with $0 \%$ nitrogen.

2. Gas Release Volumes-The amount of gas released from single-shell tanks has not been well quantified. Current estimates for singleshell tanks indicate that $~ 50 \%$ of the stored gas volume may be released during some events. For most tanks, significant adiabatic isochoric complete combustion pressures were calculated starting at releases of $10 \%$ of the stored gas.

The amount of gas released from double-shell tanks has not been well quantified. Calculations for 241-SY-101 indicate that $\sim 50 \%$ of the stored gas volume was released during some events. Data on historical releases in other double-shell tanks support smaller quantities of gas are released. For most tanks, significant adiabatic isochoric complete combustion pressures were calculated starting at releases of $10 \%$ of the stored gas.

Seismic events are also capable of releasing gas from the waste. Current estimates indicate that $50 \%$ to nearly all of the gas could be released by a seismic event. A range of release volumes ranging from $5 \%$ to $100 \%$ were calculated (WHC-SD-WM-TI-753).

3. Retained Gas Volumes-The gas volumes were calculated using a surface level variation with atmospheric pressure technique (WHC-SD-WM-ER-526, Evaluation of Hanford Tanks for Trapped Gas). These gas volumes are best estimate volumes, i.e., all parameters chosen for the calculation were average or 50-percentile values. These volumes are not considered bounding retained gas volumes and could vary by a factor of two. The effect of releasing and burning more gas is found in key parameter 5. In addition, the methodology assumes that gas is retained in the tank by hydrostatic pressure. It does not account for strength of the material. Thus, tanks that have strong waste matrices may not exhibit any changes in level with barometric pressure changes and still have significant volumes of retained gas. Other tanks may have moderately strong waste matrices that are weakly affected by barometric pressure. These tanks would be calculated as having only small amounts of retained gas when in fact they may also have significant retained gas volumes.

4. Calculated Pressures Pressures calculated are adiabatic isochoric complete combustion pressures. Dynamic effects are not accounted for. The 241-SY-101 dynamic analysis showed that the burn caused a dynamic amplification in the pressure. The amplification factor is in the range of 1.2 to 2 . This means that the tank will be harmonically excited by the burn and will experience damage similar to what would happen at pressures 1.2 to 2 times larger than those calculated. 
In addition, the nitrous oxide was not used as an oxidizer in the calculations. For a well-mixed tank, this is a good assumption since there is no mechanism to make the fuel burn preferentially with nitrous oxide rather than oxygen and oxygen is the predominant oxidizer in the well-mixed tank. However, this assumption is clearly non-conservative for local burns where the burn would occur before the slurry gas mixture was mixed with the air in the headspace. It is also non-conservative for subsurface ignition events. Ignoring the nitrous oxide reduces the calculated pressures by $0 \%$ to $22 \%$ (depending on the tank and how much nitrous oxide is in the slurry gas).

The effects of higher pressure include different tank response (i.e., dome failure with collapse into the tank or total destruction of the dome) and more material being released. These effects are discussed in key parameter 5.

5. Released Material-The amount of waste material released to the environment is a function of the size of the burn. The consequences reported in Section 5.8.1 are for burns that obtain pressures that just equal the internal structural pressure limits of the tank. If all the other parameters involved in how much material is entrained remain the same (such as the surface area of the tank, the radius of the tank, the density of the waste material, etc.) then the only parameter that changes is flame front velocity. For the largest burns, the flame front velocity could be 6 times larger than what was used. The empirical entrainment equation used is functionally dependent on the square of the flame front velocity. Thus, the amount of material that is entrained from the largest burns can be larger by a factor of 36 . Larger burns are documented in Sections 5.8.2 and 5.8.3.

For accidents were there is debris impacting the surface, the amount of released material could also be increased by debris from the dome impacting the waste surface. Based upon the calculations in WHC-SD-WM-CN-051 (1996) an additional $3.8 \mathrm{~L}$ of respirable material will exit the tank because of the dome collapse.

The type of material released also plays a major role. This analysis used double-shell tank 1 iquids or aging waste facility 1iquids (WHC-SD-WM-SARR-037 1996), depending upon the accident scenario. No solids were accounted for. This is because of data obtained from the tank that had the most vigorous rollover-type gas release events (Tank 241-SY-101). The core sampling of

Tank 241-SY-101 indicated that the crust, the convective layer, and the nonconvective layer were chemically the same (WHC-SD-WM-DTR-026 1992). WHC-SD-WM-DTR-026 (1992) indicates that transuranics were higher in the material from the lower layers of the tank. The very bottom layer of the tank did not participate in any of the rollovers (as evidenced by three temperature trees in the waste). However, it can be postulated that a gas release event (complete rollover or partial rollover) in a double-shell tank (or aging waste facility tank) may bring some of these solids (which contain a larger percentage of the transuranics) to the surface of the tank. Thus, 
it is possible that some fraction of the material suspended could be solids. Assuming a split of $95 \%$ liquids with $5 \%$ solids would cause the calculated radiological consequences to increase by a factor of $\sim 5$ for double-shell tanks and a factor of 60 for aging waste facility tanks. This analysis used single-shell tank solids (WHC-SD-WM-SARR-037 1996) for the single-shell tank deflagration. Radiological consequences cannot be increased by any other choice of waste material for the single-shell tank deflagrations. The doublecontained receiver tank uses a $5 \%$ single-shell tank solids and $95 \%$ single-shell tank liquids (WHC-SD-WM-SARR-037 1996) source term. Five percent solids was chosen based upon discussions with operations and consideration of the low flow rates during salt well pumping (ranging from $0.19 \mathrm{~L} / \mathrm{min}$ to $19 \mathrm{~L} / \mathrm{min}[0.05$ to $5 \mathrm{gal} / \mathrm{min}]$ ). A change in the split of solids and liquids to $67 \% 1$ iquids with $33 \%$ solids would cause the calculated radiological consequences to increase by a factor of 4 for double-contained receiver tanks. 


\begin{tabular}{|c|c|c|c|c|c|c|c|c|c|c|c|c|c|c|c|c|}
\hline & $\mathrm{U}$ & $\mathrm{v}$ & $w$ & $\bar{x}$ & \begin{tabular}{l|l}
$Y$ & \\
&
\end{tabular} & 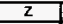 & $\mathbf{A A}$ & $\mathbf{A B}$ & $A C$ & AD & $\mathrm{AE}$ & AF & AG. & AH & Al & Ad \\
\hline 1 & & \multicolumn{2}{|c|}{ Headspace } & & Siurry Gas & & & & & & & & & & & \\
\hline 2 & & 02 & N2 & $\mathrm{H} 2$ & $\begin{array}{ll}\mathrm{CH} 4 \\
\end{array}$ & $\mathrm{NH3}$ & \multicolumn{10}{|c|}{ moles of $\mathrm{O} 2$ needed for combustion } \\
\hline$\overline{3}$ & DST & (moles) & (moles) & (moles) & (moles) & (moles) & $5 \%$ & $10 \%$ & $15 \%$ & $20 \%$ & $25 \%$ & $30 \%$ & $40 \%$ & $50 \%$ & $75 \%$ & $100 \%$ \\
\hline 4 & AN-103 & $1.6 \mathrm{E}+04$ & $6.0 E+04$ & $1.7 E+04$ & $\overline{0.0 E+00}$ & $43 E+03$ & $5.9 E+02$ & $1.2 \mathrm{E}+03$ & $1.8 E+03$ & $2.4 E+03$ & $3.0 \mathrm{E}+03$ & $36 E+03$ & $47 E+03$ & $599+03$ & $8.5 E+03$ & $1.2 \mathrm{E}+04$ \\
\hline 5 & AN-104 & $12 E+04$ & $46 E+04$ & $7.9 E+03$ & $0.0 E+00$ & $\overline{2}$. $\mathrm{iE}+03$ & $2.8 E+02$ & $5.5 E+02$ & $8.3 E+02$ & $1.9 \mathrm{E}+03$ & $1.4 \mathrm{E}+03$ & $9.7 \mathrm{E}+03$ & $2.2 E+03$ & $2.8 \mathrm{E}+03$ & $4.2 \mathrm{E}+03$ & $5.5 \mathrm{E}+03$ \\
\hline 6 & AN-10.5 & $9.5 \mathrm{E}+03$ & $3.5 E+04$ & $9.2 \mathrm{E}+03$ & $0.0 E+\infty 0$ & $2.7 \mathrm{E}+03$ & $3.3 E+02$ & $6.6 E+02$ & $9.9 E+02$ & $9.3 \mathrm{E}+03$ & $9.7 E+03$ & $2.0 E+03$ & $2.6 \mathrm{E}+03$ & $3.3 E+03$ & $5.0 \mathrm{E}+03$ & $6.6 \mathrm{E}+03$ \\
\hline 7 & $\overline{A N-107}$ & 1.2E+04 & $4.6 \mathrm{E}+04$ & & & & & & & & & & & & & \\
\hline 8 & AW-101 & $9.9 E+03$ & $3.7 E+04$ & $49 E+03$ & $5.6 E+01$ & $1.5 \mathrm{E}+03$ & $1.9 \mathrm{E}+\mathrm{C2}$ & $3.7 \mathrm{E}+02$ & $5.6 \mathrm{E}+02$ & $7.4 \mathrm{E}+02$ & $9.3 E+02$ & $11 E+03$ & $1.5 \mathrm{E}+03$ & $19 \mathrm{EE}+03$ & $2.8 \mathrm{E}+0.3$ & $3.7 \mathrm{E}+03$ \\
\hline 9 & $A W-104$ & $1.0 E+04$ & $3.8 \mathrm{E}+04$ & & & & & & & & & & & & & \\
\hline 10 & AY-101 & $1.6 \mathrm{E}+04$ & $6.1 \mathrm{E}+04$ & & & & & & & & & & & & & \\
\hline 11 & SY-101 & $9.6 \mathrm{E}+03$ & $3.6 E+04$ & $7.8 \mathrm{E}+03$ & $1.3 E+02$ & $3.7 \mathrm{E}+03$ & $3.5 \mathrm{E}+\mathrm{C} 2$ & $6.9 \mathrm{E}+02$ & $1.0 E+03$ & 1. $4 \mathrm{E}+03$ & 1.7E+03 & $2.1 \mathrm{E}+03$ & $\overline{2} .8 \bar{E}+03$ & $3.5 \mathrm{E}+03$ & $5.2 \mathrm{E}+03$ & $6.9 \mathrm{E}+03$ \\
\hline 12 & SY-103 & $2.3 E+04$ & $8.7 E+04$ & $1.6 \mathrm{E}+03$ & $8.5 E+01$ & $9.0 \mathrm{E}+02$ & $8.2 \mathrm{E}+01$ & $1.6 \mathrm{E}+02$ & $2.5 E+02$ & $3.3 \mathrm{E}+02$ & $4.1 \mathrm{E}+02$ & $4.9 \mathrm{E}+02$ & $6.6 \mathrm{E}+02$ & $8.2 E+02$ & $1.2 \mathrm{E}+03$ & $1.6 E+03$ \\
\hline 13 & & & & & & & & & & & & & & & & \\
\hline 14 & SST & & & & & & & & & & & & & & & \\
\hline 15 & $\mathrm{~A}-101$ & 1.1E+04 & $4.2 \mathrm{E}+04$ & $3.2 \mathrm{E}+03$ & $5.15+01$ & $8.7 E+02$ & $1.2 \mathrm{E}+02$ & $2.3 E+02$ & $3.5 E+02$ & $4.7 \mathrm{E}+02$ & $5.8 E+02$ & $7.0 E+02$ & $9.3 E+02$ & $1.2 \mathrm{E}+\mathrm{O3}$ & $1.8 \mathrm{E}+03$ & $2.3 \mathrm{E}+03$ \\
\hline 16 & $A-103$ & $3.1 E+04$ & $1.2 \mathrm{E}+05$ & & & & & & & & & & & & & \\
\hline 17 & AX-101 & $1.8 \mathrm{E}+04$ & $6.5 \mathrm{E}+04$ & & & & & & & & & & & & & \\
\hline 18 & $A X-103$ & $\overline{0} 0 \mathrm{E}+00$ & $0.0 \mathrm{E}+00$ & & & & & & & & & & & & & \\
\hline 19 & $B X-107$ & $1.8 \mathrm{E}+04$ & $6.7 \mathrm{E}+04$ & & & & & & & & & & & & & \\
\hline 20 & BY-101 & $2.9 \mathrm{E}+04$ & $1,1 \mathrm{E}+05$ & & & & & & & & & & & & & \\
\hline 21 & $8 Y-102$ & $2.7 \mathrm{E}+04$ & $1.0 \mathrm{E}+05$ & & & & & & & & & & & & & \\
\hline 22 & $8 Y-103$ & $2.4 \mathrm{~F}+04$ & $8.8 E+04$ & & & & & & & & & & & & & \\
\hline 23 & BY-105 & $2.2 \mathrm{E}+04$ & $8.0 E+04$ & & & & & & & & & & & & & \\
\hline 24 & $B Y-106$ & $1.3 E+04$ & $5.0 E+04$ & & & & & & & & & & & & & \\
\hline 25 & BY-109 & $2.6 \mathrm{E}+04$ & $9.5 E+04$ & & & & & & & & & & & & & \\
\hline 26 & C-104 & $2.1 E+04$ & $8.0 E+04$ & & & & & & & & & & & & & \\
\hline 27 & $\mathrm{C}=106$ & $2.2 E+04$ & $8.2 E+04$ & & & & & & & & & & & & & \\
\hline 28 & $C-107$ & $2.1 E+04$ & $8.0 E+04$ & & & & & & & & & & & & & \\
\hline 29 & S-101 & $2.2 \mathrm{E}+04$ & $8.2 E+04$ & & & & & & & & & & & & & \\
\hline 30 & S-102 & $1.8 \mathrm{E}+04$ & $6.7 E+04$ & $1.0 E+04$ & $1.6 \mathrm{E}+02$ & $4.1 \mathrm{E}+03$ & 4. $2 E+02$ & $8.4 E+02$ & $1.3 E+03$ & $1.7 \mathrm{E}+03$ & $2.1 E+03$ & $2.5 \mathrm{E}+03$ & $3.4 \mathrm{E}+03$ & $4.2 \mathrm{E}+03$ & $6.3 E+03$ & $8.4 E+03$ \\
\hline 31 & $S+103$ & $2.8 \mathrm{E}+04$ & $10 \mathrm{E}+05$ & & & & & & & & & & & & & \\
\hline 32 & S-105 & $2.2 E+04$ & $8.4 E+04$ & & & & & & & & & & & & & \\
\hline 33 & S-106 & $2.0 \mathrm{E}+04$ & $76 E+04$ & & & & & & & & & & & & & \\
\hline 34 & $5-107$ & $2.4 E+04$ & $8.8 E+04$ & & & & & & & & & & & & & \\
\hline 35 & $5-108$ & $2.1 E+04$ & $7.9 E+04$ & & & & & & & & & & & & & \\
\hline 36 & $5-109$ & $2.1 E+04$ & $7.8 E+04$ & & & & & & & & & & & & & \\
\hline 37 & $5-110$ & $2.3 E+04$ & $8.7 E+04$ & & & & & & & & & & & & & \\
\hline 38 & S-111 & $4.8 E+04$ & $6.7 E+04$ & $78 \mathrm{E}+03$ & $\overline{3.7 \mathrm{E}+03}$ & $3 . \overline{1} E+03$ & $69 \mathrm{E}+02$ & $94 \mathrm{E}+0 \overrightarrow{3}$ & $24 \mathrm{E}+03$ & $27 \mathbf{E}+03$ & $3.4 E+03$ & $4: E+03$ & $5.5 \mathrm{E}+03$ & $6.9 E+03$ & $1.0 \mathrm{E}+04$ & $1.4 E+04$ \\
\hline 39 & S-112 & $1.9 \mathrm{E}+04$ & $6.9 E+04$ & & & & & & & & & & & & & \\
\hline 40 & SX-101 & $2.9 \mathrm{E}+04$ & $1.1 \mathrm{E}+05$ & $1.1 E+03$ & $5.3 \mathrm{E}+02$ & $3.7 E+02$ & $9.5 E+01$ & $1.9 \mathrm{E}+02$ & $28 \mathrm{E}+02$ & $3.8 \mathrm{E}+0.2$ & $4.7 \mathrm{E}+02$ & $5.7 E+02$ & $7.6 \mathrm{E}+02$ & $9.5 \mathrm{E}+02$ & $1.4 E+03$ & $1.9 E+03$ \\
\hline 41 & $5 X-102$ & $2.7 \mathrm{E}+04$ & $9.9 E+04$ & $36 E+03$ & $1.5 E+03$ & $2.6 E+03$ & $3.3 E+02$ & $6.6 \mathrm{E}+02$ & $1.0 E+03$ & $1.3 E+03$ & $1.7 \mathrm{E}+03$ & $2.0 E+03$ & $2.7 E+03$ & 3. $3 \mathrm{E}+03$ & $5.0 \mathrm{E}+03$ & $6.6 E+03$ \\
\hline 42 & $5 X-103$ & $2.2 \mathrm{E}+04$ & $8.3 E+04$ & 1. $2 \mathrm{E}+04$ & $2.3 \mathrm{E}+03$ & $4.5 E+03$ & $7,1 \mathrm{E}+02$ & $1.4 \mathrm{E}+03$ & $2.1 \mathrm{E}+03$ & $2.9 \mathrm{E}+03$ & $3.6 \mathrm{E}+03$ & $4,3 E+03$ & $5.7 E+03$ & $7.1 \mathrm{E}+03$ & $1.1 \mathrm{E}+04$ & $1.4 E+04$ \\
\hline 43 & $5 x-104$ & $2.4 E+04$ & $9.0 E+04$ & & & & & & & & & & & & & \\
\hline 44 & $5 X-105$ & $2.2 \mathrm{E}+04$ & $8.2 E+04$ & & & & & & & & & & & & & \\
\hline 45 & $5 x-106$ & $2.6 \mathrm{E}+04$ & $9.7 E+04$ & $3.5 E+03$ & $7.5 E+02$ & $1.8 \mathrm{E}+03$ & $2.3 \mathrm{E}+02$ & $4.6 \mathrm{E}+02$ & $6.9 E+02$ & $9.2 \mathrm{E}+\mathrm{C} 2$ & $1.1 \vec{E}+03$ & 1.4E+03 & $1.8 \mathrm{E}+03$ & $23 \mathrm{E}+03$ & $3.4 E+03$ & $4.6 E+03$ \\
\hline 46 & $5 X-109$ & $3.6 \mathrm{E}+0.4$ & 1.4E+05 & & & & & & & & & & & & & \\
\hline 47 & 0.104 & $1.4 E+04$ & $5.1 E+04$ & & & & & & & & & & & & & \\
\hline 48 & T-110 & $1.5 \mathrm{E}+04$ & $5.7 \mathrm{E}+04$ & & & & & & & & & & & & & \\
\hline 49 & $7 x-102$ & $3.0 E+04$ & $1.1 \mathrm{E}+05$ & & & & & & & & & & & & & \\
\hline 50 & $\overline{7 X-111}$ & $2.5 \vec{E}+04$ & $9.2 E+04$ & & & & & & & & & & & & & \\
\hline 51 & $7 X-112$ & $1.5 \mathrm{E}+04$ & $5.5 E+04$ & & & & & & & & & & & & & \\
\hline 52 & $\overline{\mid x-113}$ & $1.7 \mathrm{E}+0.4$ & $6.3 E+04$ & & & & & & & & & & & & & \\
\hline 53 & $7 X-115$ & $1.8 \mathrm{E}+04$ & $6.9 E+04$ & & & & & & & & & & & & & \\
\hline 54 & U-102 & $1.7 \mathrm{E}+04$ & $6.3 \mathrm{E}+04$ & & & & & & & & & & & & & \\
\hline 55 & U.103 & $1.3 \mathrm{E}+04$ & $5.0 E+04$ & $33 E+03$ & $1.0 \mathrm{E}+02$ & $2.0 \mathrm{E}+03$ & $1.7 \mathrm{E}+02$ & $3.4 E+C 2$ & $5.1 E+02$ & $6.8 E+02$ & $8.4 E+02$ & $10 E+03$ & $1.4 E+0.3$ & $1.7 \mathrm{E}+03$ & $2.5 E+03$ & $3.4 E+03$ \\
\hline 56 & $U-105$ & $1.5 \mathrm{E}+04$ & $5.6 E+04$ & $1.5 E+03$ & $5.4 E+01$ & $1.4 \mathrm{E}+03$ & $9.4 E+01$ & 1. $9 E+02$ & $2.8 E+02$ & $38 E+02$ & $4.7 E+02$ & $56 \mathrm{E}+02$ & $7.5 \mathrm{E}+02$ & $9.4 E_{2}+02$ & $1.4 E+03$ & $1.9 E+03$ \\
\hline 57 & U.706 & $2.2 \mathrm{E}+04$ & $8.3 E+04$ & & & & & & & & & & & & & \\
\hline 58 & U.107 & $1.6 \mathrm{E}+04$ & $5.9 \mathrm{E}+04$ & $18 E+03$ & $5.9 E+01$ & $\{.2 E+03$ & $96 E+01$ & $1 . \mathrm{GE}+02$ & $2.9 E+02$ & $3 \overline{8 E}+02$ & $4.8 \mathrm{E}+02$ & $58 \mathrm{E}+02$ & $7.7 \mathrm{E}+02$ & $9.6 \mathrm{E}+02$ & $1.4 \bar{E}+03$ & $1.9 E+03$ \\
\hline $5 \hat{9}$ & U.108 & $1.4 \mathrm{E}+04$ & $5.0 E+04$ & $3.3 E+03$ & 3. $. E+02$ & $9.8 E+03$ & $1.8 E+02$ & $3.6 \mathrm{E}+02$ & $5 . \overline{4 E+02}$ & $7.2 \bar{E}+02$ & $9.0 \mathrm{E}+02$ & $1.1 \mathrm{E}+03$ & $9.4 E+03$ & $1.8 E+03$ & $2.7 \mathrm{E}+03$ & $3.6 E+03$ \\
\hline 60 & U.109 & $1.4 \mathrm{E}+04$ & $5.1 \mathrm{E}+04$ & $2.5 E+03$ & $6.4 E+01$ & $1.4 E+03$ & $1.2 \mathrm{E}+\mathrm{O} 2$ & $2.5 E+02$ & $3.7 \mathrm{E}+02$ & $4.9 E+022$ & $6.1 \mathrm{E}+02$ & $7.4 \mathrm{E}+02$ & $9.8 \mathrm{E}+02$ & $1.2 \mathrm{E}+03$ & $1.8 \mathrm{E}+03$ & $2.5 \mathrm{E}+03$ \\
\hline
\end{tabular}




\begin{tabular}{|c|c|c|c|c|c|c|c|c|c|c|c|c|c|c|c|c|c|c|c|c|c|}
\hline & AK & AL & AM & AN & $A O$ & $A P$ & $A Q$ & $\overline{A R}$ & AS & AT & $A U$ & AV & AW & $A x$ & $A Y$ & $A Z$ & BA & BB & $\mathrm{BC}$ & $\mathrm{BD}$ & BE \\
\hline$\frac{1}{2}$ & & & & & moles of & 420 prod & ced by $\mathrm{con}$ & thustion & & & & & & & & & uced by c & mbustion & & & \\
\hline \begin{tabular}{|l}
3 \\
\end{tabular} & DST & $5 \%$ & $10 \%$ & $15 \%$ & $20 \%$ & $25 \%$ & $30 \%$ & $40 \%$ & $50 \%$ & $75 \%$ & $100 \%$ & $5 \%$ & $10 \%$ & $15 \%$ & $20 \%$ & $25 \%$ & $30 \%$ & $40 \%$ & $50 \%$ & $75 \%$ & \\
\hline 4 & AN-103 & $1.2 \mathrm{E}+03$ & $2.4 E+03$ & \begin{tabular}{|l|l|}
$3.6 E E+03$ \\
\end{tabular} & $\frac{4.7 E+03}{4.75}$ & $59 \mathrm{gE+03}$ & $7.1 E+03$ & $9.5 E+03$ & $\frac{1.2 E+04 \mid}{104}$ & $18 E+[D 4$ & $24 E+04$ & $0,0 \mathrm{~F}+\infty$ & $0 \mathrm{DE+ \infty}$ & $00 E+\infty 0$ & $0,0 E+\infty$ & 0,0 & 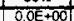 & $0,0 E+\infty$ & $O O E+\infty C$ & $0,0=+00$ & $00 \mathrm{E}+\infty$ \\
\hline 5 & AN-104 & $5.5 E+02$ & 1. $\mathrm{E} E+03$ & $1.7 E+03$ & $22 \mathrm{E}+03$ & $28 E+03$ & $3.3 \mathrm{E}+03$ & $4.4 E+03$ & $5.5 \mathrm{E}+03$ & $8.3 \mathrm{E}+03$ & 1.11E+04 & $0.0 E+\infty$ & $0.0 E+00$ & $0.0 E+\infty$ & $0.0 \tilde{E}+\infty$ & $0.0 E+\infty$ & $0.0 E+00$ & $10 E+\infty$ & $\overline{D E+D C}$ & $0.0 E+00$ & $0.0 E+00$ \\
\hline 6 & AN-105 & $6.6 E+02$ & $1.3 E+03$ & $2.0 E+03$ & $2.6 E+03$ & $3.3 E+03$ & $4.0 E+03$ & $5.3 E+03$ & $6.6 E+03$ & \begin{tabular}{|l|}
$9.9 E+C 3$ \\
\end{tabular} & $1.3 E+04$ & $0.0 \varepsilon+\infty$ & $0.0 E+\infty$ & $0.0 E+00$ & $0.0 \mathrm{E}+\infty$ & $0.0 E+\infty$ & $0.0 E+00$ & $0.0 E+\infty$ & $0.0 E+00$ & $0.0 \mathrm{E}+00$ & $0.0 E+00$ \\
\hline$\frac{7}{8}$ & $A N-107$ & 7 & 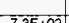 & 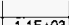 & 10507 & 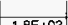 & & & & & & & & & & & & & & & \\
\hline 9 & $\frac{\mid W-101}{A W-104}$ & $3.7 E+02$ & $13 t+02$ & $1.1 \mathrm{1}+03$ & $1,1 E+03$ & $1.8 E+63$ & $2.2 E+03$ & $2.96+03 \mid$ & $3 . t E+0.35$ & $3.5 E+03$ & $7.3 E+03$ & $2.8 E+\infty$ & $5.6 E+\infty 0$ & $84 E+\infty 0$ & 1.1E+0? & $1.4 E+01$ & $1.7 E+01$ & $2.2 E+01$ & $2.8 \mathrm{E}+01$ & $4.2 E+01$ & $5.6 E+01$ \\
\hline 90 & AY-107 & & & & & & & & & & & & & & & & & & & & \\
\hline \begin{tabular}{|l}
11 \\
12
\end{tabular} & $5 y-101$ & $6.8 E+02$ & \begin{tabular}{|l|l|}
$1.4 E+03$ \\
\end{tabular} & $2.0 E+03$ & $2.7 E+03$ & $\begin{array}{r}3.4 E+03 \\
705+0 ?\end{array}$ & \begin{tabular}{|l|l|} 
\\
\end{tabular} & $5.4 E+03$ & $6.8 E+03$ & $1.0 E+04$ & $1.4 E+04$ & $65 E+\infty$ & $1.3 \mathrm{E}+01$ & $1.9 \mathrm{E}+01$ & $26 E+01$ & $3.2 E+01$ & $3.9 E+01$ & $5.2 E+01$ & $6.5 E+01$ & $9.7 \mathrm{E}+01$ & $1.3 E+02$ \\
\hline$\frac{12}{13}$ & $5 Y-103$ & $1.6 \mathrm{E}+02$ & $3.1 \mathrm{E}+02$ & \begin{tabular}{|l|l|} 
& $47 \mathrm{E}+02$ \\
\end{tabular} & & $7.8 \mathrm{E}+02$ & \begin{tabular}{|l|l|} 
\\
\end{tabular} & $1.3 E+03$ & $\mid 1.6 \mathrm{E}+03\}$ & $2.3 \mathrm{E}+03$ & $3.1 \mathrm{E}+03$ & $42 E+\infty$ & $8.5 E+00$ & $1.3 \mathrm{E}+01$ & $1.7 E+01$ & $2.1 E+01$ & $2.5 E+01$ & $3.4 \mathrm{E}+01$ & $4.2 E+01$ & $64 \mathrm{E}+01$ & $8.5 E+01$ \\
\hline . & SST & & & & & & & & & & & & & & & & & 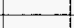 & & & \\
\hline 15 & A-101 & $2.3 E+02$ & $46 E+02$ & $6.9 E+02$ & $9.1 E+02$ & $1.1 \mathrm{E}+03$ & $1.4 E+03$ & $1.8 E+03$ & $23 E+03$ & $3.4 \mathrm{E}+\mathrm{C3}$ & $4.6 E+03$ & $25 \mathrm{E}+\infty \mathrm{CO}$ & $5.1 E+00$ & $7.6 E+00$ & $1.0 \mathrm{E}+01$ & $1.3 \mathrm{E}+01$ & $1.5 E+01$ & $2.0 \mathrm{E}+01$ & $2.5 E+01$ & $3.8 \mathrm{E}+01$ & $5.1 \mathrm{E}+01$ \\
\hline 16 & $\begin{array}{l}A-103 \\
x-101\end{array}$ & & & & & & & & & & & & & & & & & & & & \\
\hline 16 & $A X-101$ & & & & & & & & & & & & & & & & & & & & \\
\hline$\frac{18}{19}$ & $\frac{x X-103}{B X-107}$ & & & & & & & & & & & & & & & & & & & & \\
\hline 20 & $\frac{B X+0 T}{B Y-101}$ & & & & & & & & & & & & & & & & & & & & \\
\hline$\sqrt{21}$ & $B Y-102$ & & & & & & & & & & & & & & & & & & & & \\
\hline$[22$ & $8 Y-103$ & & & & & & & & & & & & & & & & & & & & \\
\hline 23 & $8 Y-105$ & & & & & & & & & & & & & & & & & & & & \\
\hline 24 & & & & & & & & & & & & & & & & & & & & & \\
\hline 25 & $\overline{B Y-109}$ & & & & & & & & & & & & & & & & & & & & \\
\hline 26 & C-104 & & & & & & & & & & & & & & & & & & & & \\
\hline 27 & E-106 & & & & & & & & & & & & & & & & & & & & \\
\hline 28 & $\begin{array}{l}-107 \\
-107\end{array}$ & & & & & & & & & & & & & & & & & & & & \\
\hline \begin{tabular}{|l|}
29 \\
30
\end{tabular} & $\frac{5-101}{\mathbf{S}-102}$ & $8.2 E+02$ & $1.6 \vec{E}+03$ & $2.5 \mathrm{E}+03$ & $3 \cdot \overline{3} \bar{E}+03$ & $41 E+03$ & $4 \mathrm{gE}+03$ & $6.6 E+03$ & $8.2 E+03$ & $1.2 E+04$ & $1.6 E+04$ & $8.1 E+\infty$ & $1.6 E+01$ & $2.4 E+01$ & $3.3 E+01$ & $4.1 E+01$ & $4.9 E+01$ & $6.5 E+01$ & $8.1 E+01$ & $1.2 E+02$ & $1.6 E+02$ \\
\hline 31 & $\frac{5-103}{5}$ & & & & & & & & & & & & & & & & & & & & \\
\hline$\frac{32}{33}$ & $\frac{15-105}{s-106}$ & & & & & & & & & & & & & & & & & & & & \\
\hline 34 & S-107 & & & & & & & & & & & & & & & & & & & & \\
\hline 35 & & & & & & & & & & & & & & & & & & & & & \\
\hline & & & & & & & & & & & & & & & & & & & & & \\
\hline 37 & $\frac{5-110}{5.140}$ & $20=03$ & $20=03$ & $305+03$ & $405=0$ & $50=03$ & $50 \mathrm{E}+0 x$ & $80=03$ & 105004 & $15=0$ & $20=01$ & $105+02$ & 37807 & $565+02$ & $70 \mathrm{E}+07$ & 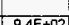 & 14103 & 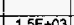 & $10=03$ & $28 E-D^{3}$ & $37 E+03$ \\
\hline 39 & s-1 & & & & & & & & & & & & & & & & & & & & \\
\hline$\overline{40}$ & & $1.4 \mathrm{E}+02$ & $2.7 E+02$ & $4.1 \mathrm{E}+02$ & $5.4 \mathrm{E}+02$ & $6.8 E+02$ & $\overline{82 E+02}$ & $1.1 \mathrm{E}+03$ & $1.4 E+03$ & $\overline{2.0 E+03}$ & $2.7 E+03$ & $2.7 \mathrm{E}+01$ & $5.3 E+01$ & $8.0 \mathrm{E}+01$ & $\frac{1.9 E+02}{1.9}$ & $1.3 E+02$ & $1.6 E+02$ & +02 & $2.7 E+02$ & $40 \mathrm{OE}+02$ & $5.3 E+02$ \\
\hline & $5 x-102$ & $52 \mathrm{E}+02$ & $10 \mathrm{EE}+03$ & $4.6 \mathrm{E}+03$ & $2.1 E+03$ & $26 E+03$ & $31 \mathrm{E}+03$ & \begin{tabular}{|c|c|}
$4.2 E+03$ \\
\end{tabular} & $5.2 \mathrm{E}+103$ & $8.6 E+03$ & $1.0 E+04$ & $73 E+01$ & $\frac{1.5 E+02}{10}$ & $\frac{2.2 E+02}{20}$ & $2.9 E+02$ & $3.5 E+02$ & $4.4 E+02$ & $5.8 E+02$ & $7.3 E+02$ & $1.1 E+03$ & $1.5 E+03$ \\
\hline & $5 x-$ & $1.2 E+03$ & $2.4 \mathrm{E}+03$ & $3.6 E+03$ & $4.8 \mathrm{E}+03$ & $6.0 \mathrm{E}+03$ & $7,1 \mathrm{E}+03$ & $9.5 E+03$ & $1.2 \mathrm{E}+04$ & $1.8 \mathrm{E}+04$ & $2.4 E+04$ & $1.2 \mathrm{E}+02$ & $2.3 E+02$ & $3.5 E+02$ & $4.7 \mathrm{E}+02$ & $5.9 E \div 02$ & $7.0 E+02$ & $9.4 \mathrm{E}+\overline{02}$ & $1.2 \mathrm{E}+03$ & $1 . \overline{E E}+03$ & $2.3 \mathrm{E}+03$ \\
\hline 4 & & & & & & & & & & & & & & & & & & & & & \\
\hline 44 & & & & & & & & & & & & & & & & & & & & & \\
\hline 45 & $5 x$ & $3.8 \mathrm{E}+02$ & $77 \mathrm{E}+02$ & $1.2 E+03$ & $1.5 \mathrm{E}+03$ & $1.9 \mathrm{E}+03$ & $2 \cdot 3 \mathbf{E}+03$ & $3.1 \mathrm{E}+03$ & $3.8 \mathrm{E}+03$ & $5.8 \mathrm{E}+03$ & $7.7 E+03$ & $3.7 \mathrm{E}+01$ & $7.5 E+01$ & 1.1.E+ +02 & $1.5 \mathrm{E}+02$ & $1.9 E+02$ & $2.2 E+02$ & $3.0 E+02$ & $3.7 E+02$ & $5.6 E+02$ & $7.5 E+02$ \\
\hline 46 & $5 X \cdot 109$ & & & & & & & & & & & & & & & & & & & & \\
\hline & & & & & & & & & & & & & & & & & & & & & \\
\hline & & & & & & & & & & & & & & & & & & & & & \\
\hline & & & & & & & & & & & & & & & & & & & & & \\
\hline & & & & & & & & & & & & & & & & & & & & & \\
\hline & & & & & & & & & & & & & & & & & & & & & \\
\hline & & & & & & & & & & & & & & & & & & & & & \\
\hline & & & & & & & & & & & & & & & & & & & & & \\
\hline & & +02 & $\begin{array}{l}E+02 \\
+02\end{array}$ & & $E+03$ & $E+03$ & $2.0 E+03$ & $2.6 \mathrm{E}+03$ & 3.3E+03 & & $6.6 E+03$ & $5.0 E+00$ & 1.0E +01 & $1.5 \mathrm{E}$ & & $2.5 \mathrm{E}+01$ & $8.0 E+01$ & 4. $0 E+01$ & 5.0E+01 & $7.5 \mathrm{E}+01$ & $1.0 E+02$ \\
\hline & & $1.8 \mathrm{E}+02$ & $3.7 \mathrm{E}+02$ & $55 E+02$ & $7.3 \mathrm{E}+02$ & $9.1 E+02$ & $1.1 \mathrm{E}+03$ & $1.5 \mathrm{E}+03$ & $1.8 E+03$ & $2.7 \mathrm{E}+03$ & $3.7 \mathrm{E}+03$ & $2.7 E+\infty 0$ & $5.4 E+00$ & $8.1 \mathrm{E}+\infty 0$ & 1.1. $1 E+01$ & 1.3E+01 & $1.6 \mathrm{E}+01$ & $2.2 E+01$ & $2.7 \overline{7 E}+01$ & $4.0 E+011$ & $5.4 E+01$ \\
\hline & & & & & & & $1115+03$ & $15 E+03$ & $19 E+03$ & & & & $5.9 E+\infty$ & $89 E++C$ & $12 E+C 1$ & $1.5 E+91$ & $18 \mathrm{E}+01$ & $24 E+01$ & & & \\
\hline & j-108 & +02 & & & & & $2.0 \mathrm{E}$ & $2.5 E+03$ & $3.3 \mathrm{E}$ & $4.9 E+C 3$ & $6.6 \varepsilon+03$ & $1.5 E+01$ & $3.0 E+01$ & & & & & & $1.5 \mathrm{E}+02$ & & \\
\hline & 109 & & & & & & & & & & & & & & & & & Et & $3.2 E+0$ & $4 \mathrm{BE}+0$ & \\
\hline
\end{tabular}




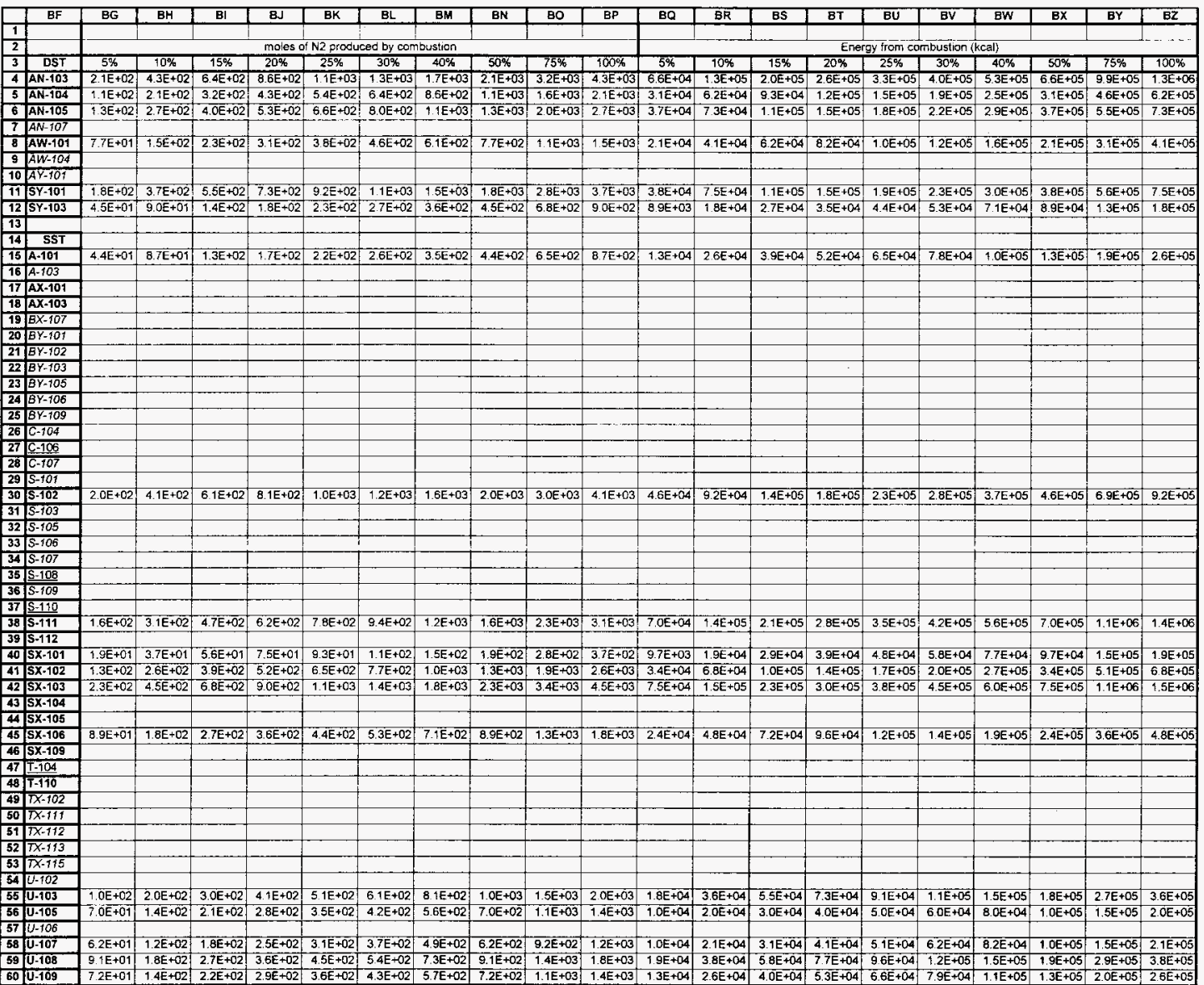




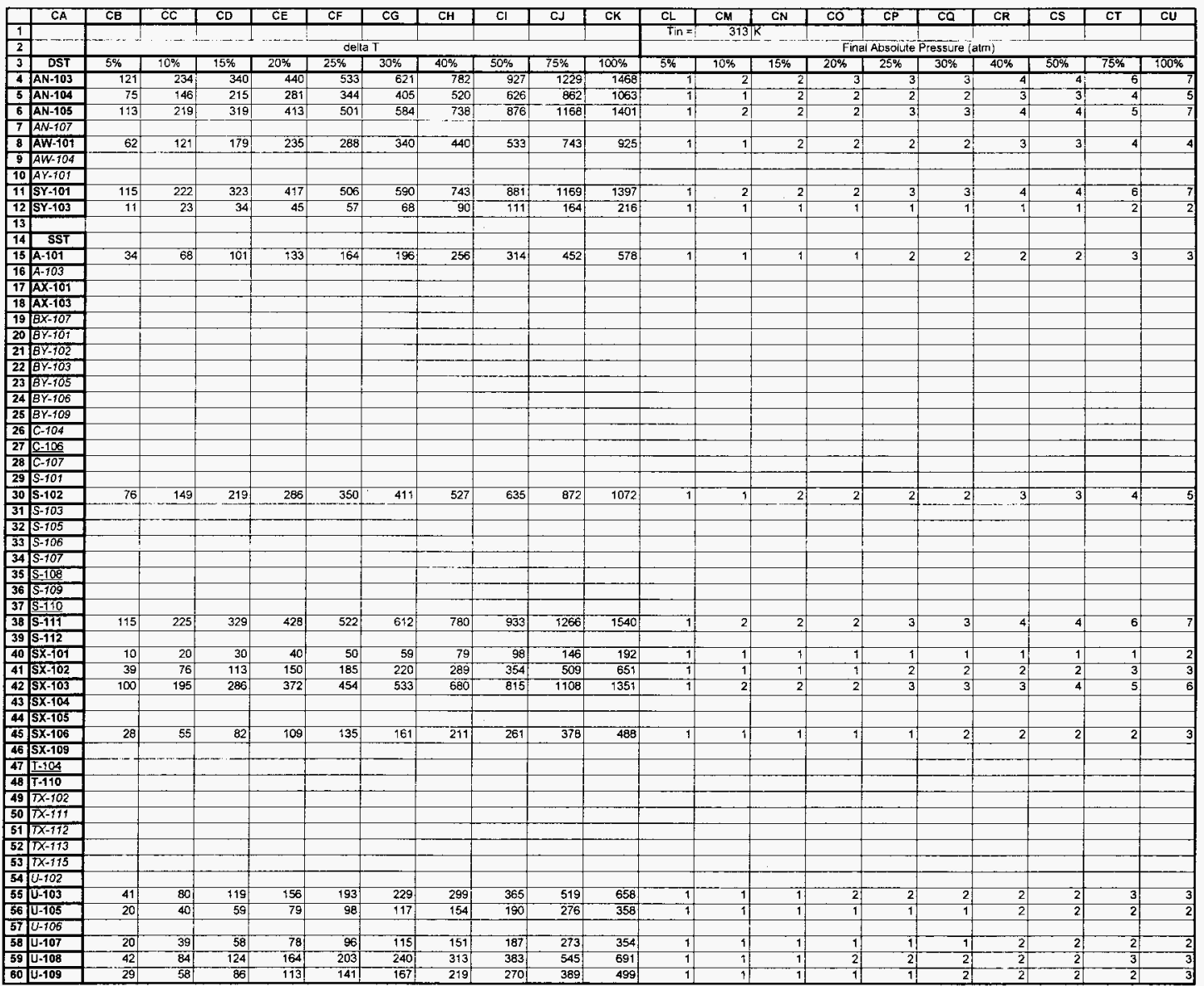


WHC-SD-WM-TI-753 REV 0

8
8
8
8

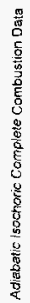

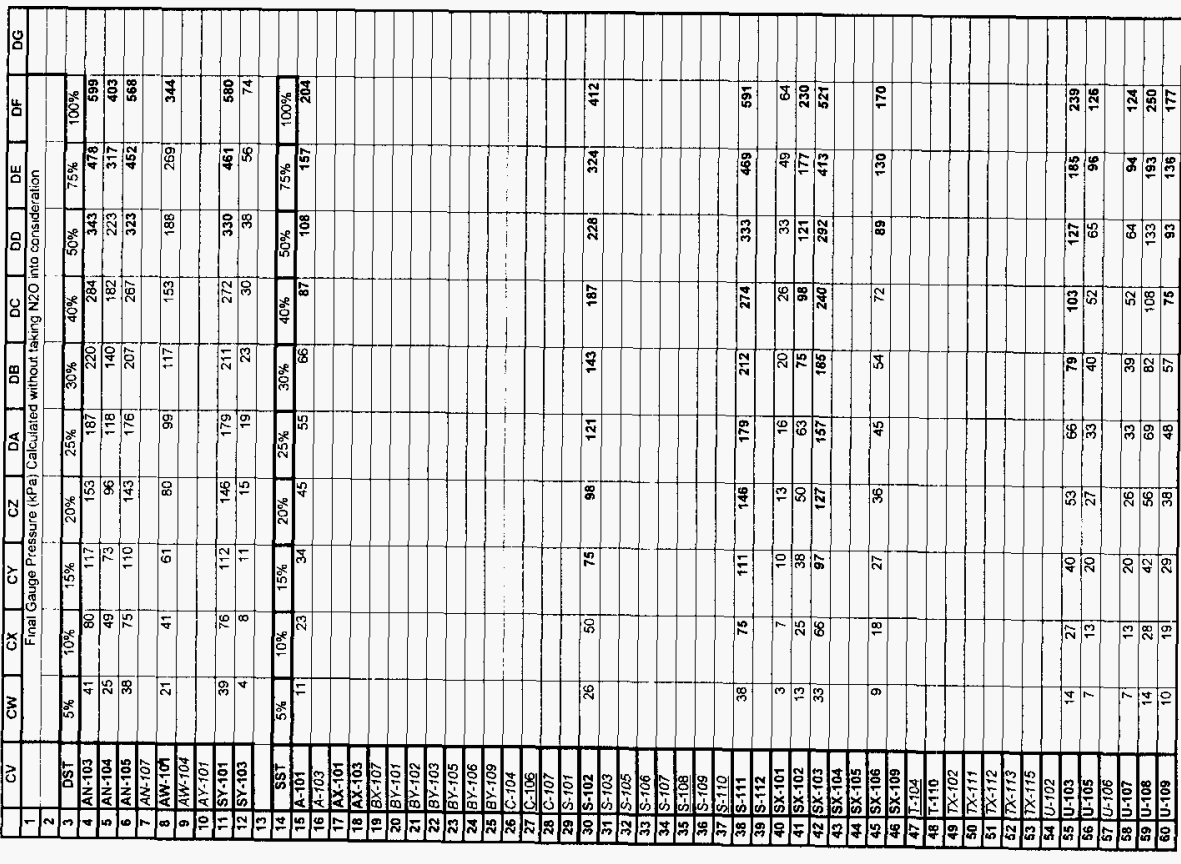

D-13 
DST Pressure as a Function of Released Gas Quantity

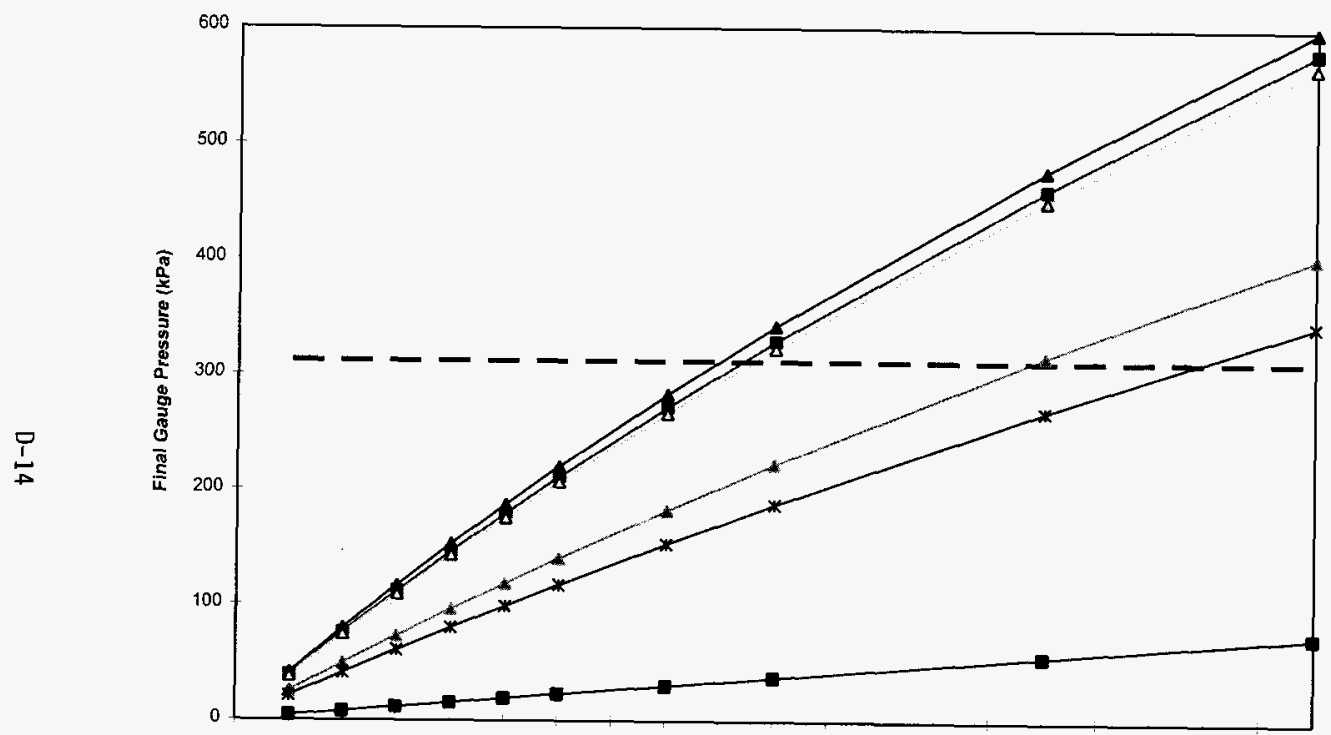

$\longrightarrow \mathrm{AN}-103$

$\rightarrow$ SY-101

$\triangle$ AN-105

$\rightarrow$ AN-104

* AW-10

- -ISFP

$\Rightarrow-$ SY-103

$\begin{array}{lllllllllllllllllllllllllllll}0 \% & 5 \% & 10 \% & 15 \% & 20 \% & 25 \% & 30 \% & 35 \% & 40 \% & 45 \% & 50 \% & 55 \% & 60 \% & 65 \% & 70 \% & 75 \% & 80 \% & 85 \% & 90 \% & 95 \% & 100 \%\end{array}$ $\%$ Slurry Gas Released 
SST Pressure as a Function of Release Gas Quantity

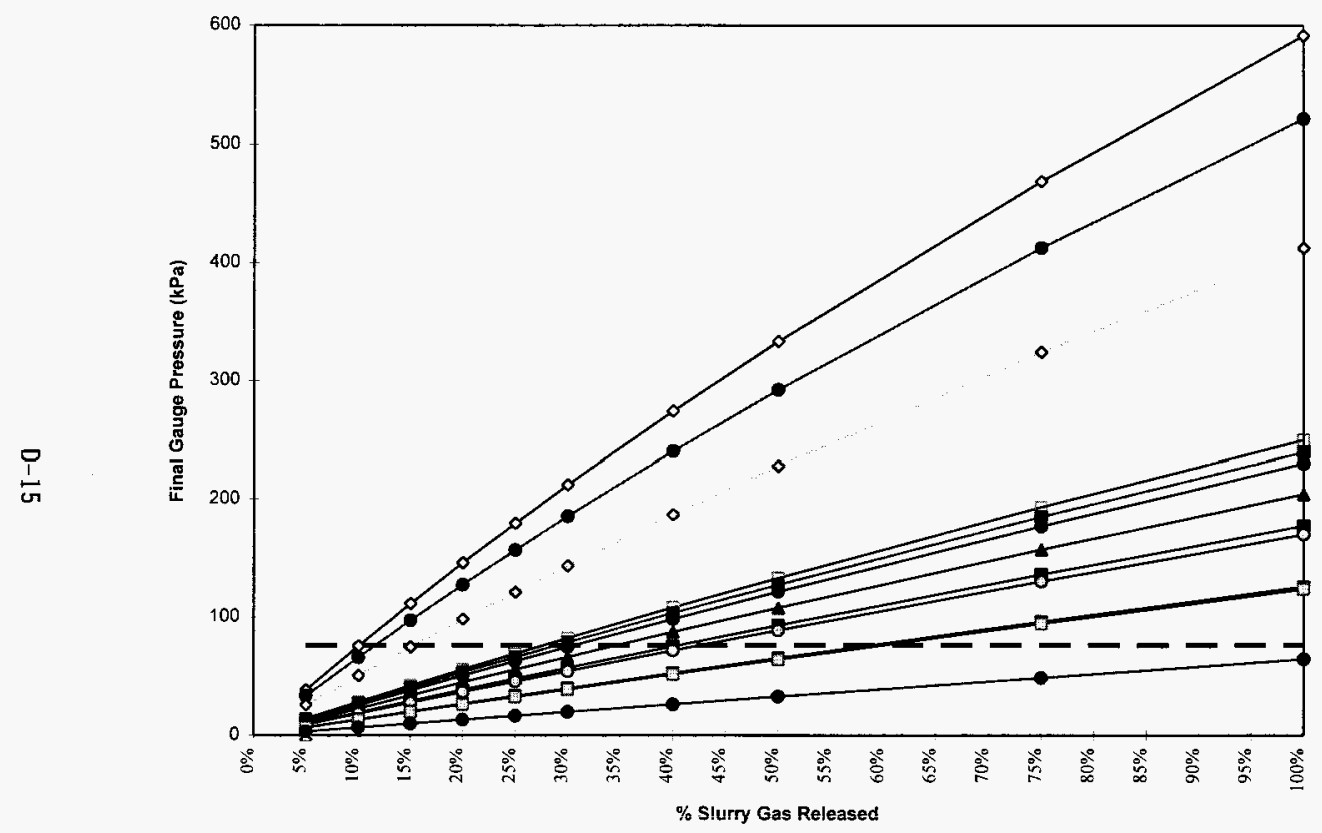




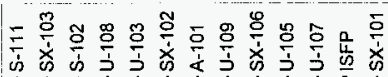

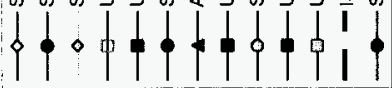

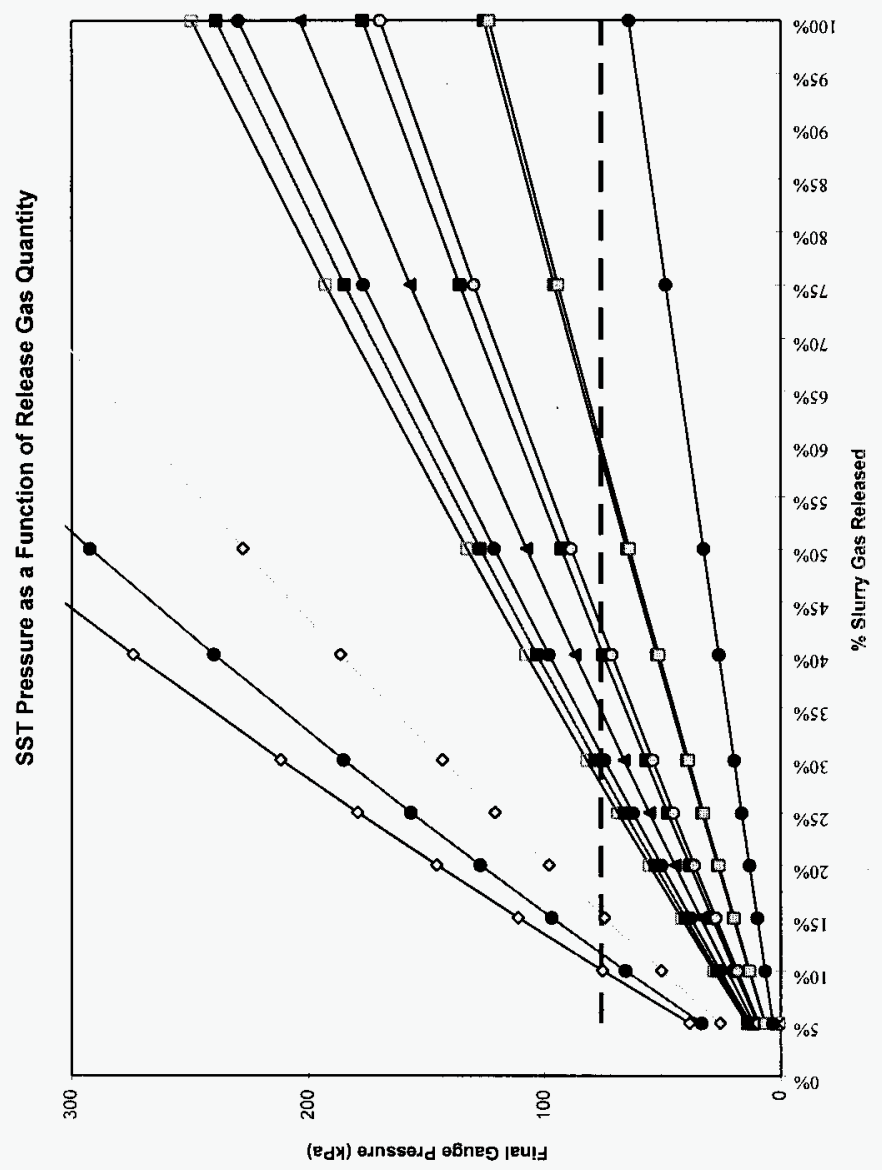



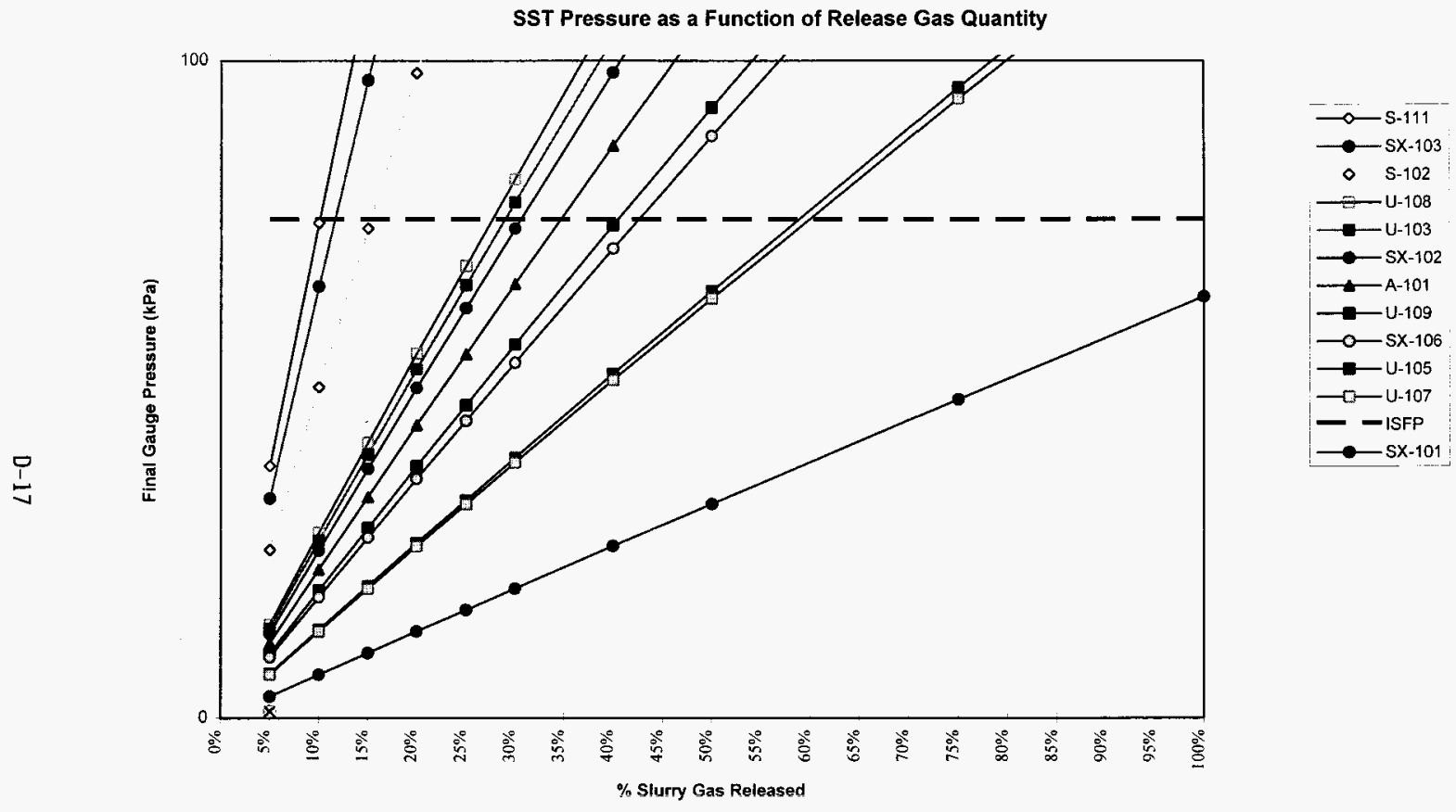
SST Pressure as a Function of Release Gas Quantity

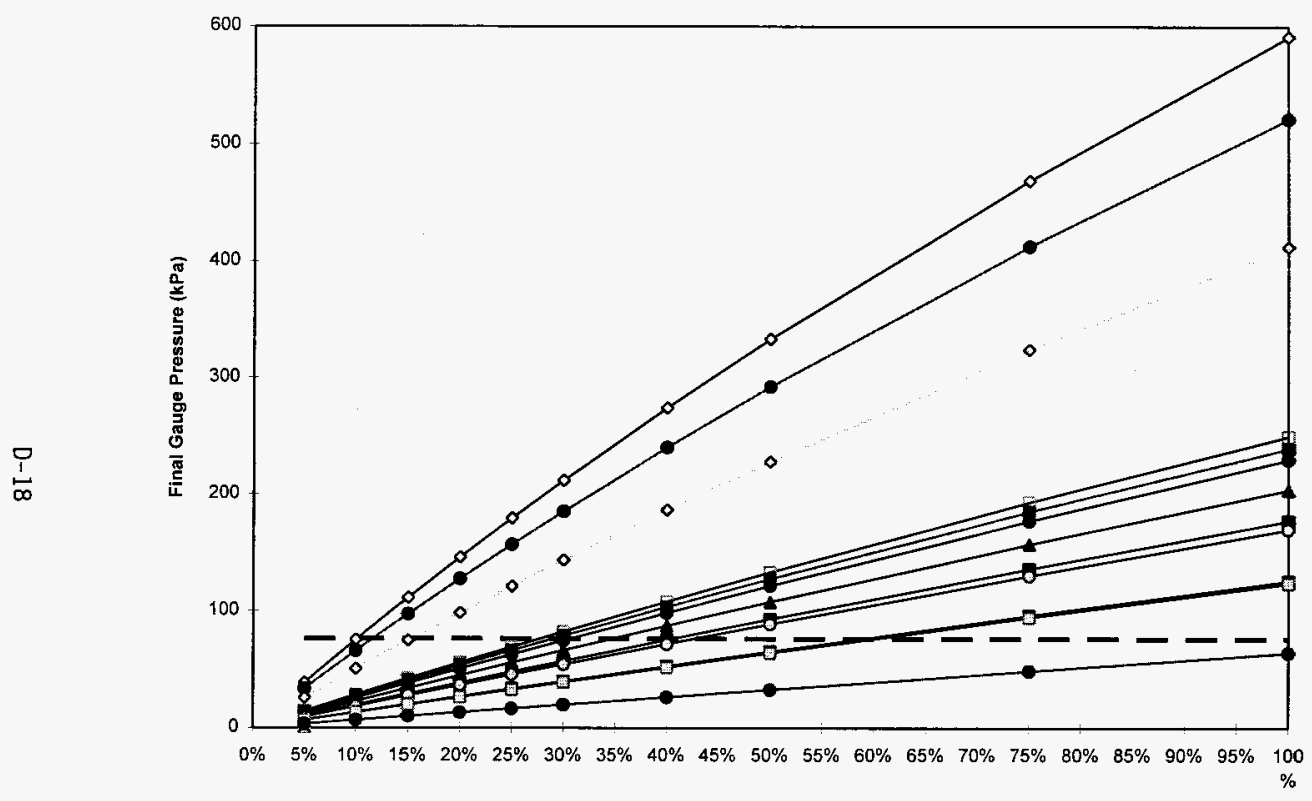

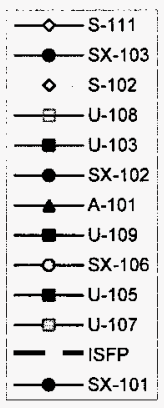



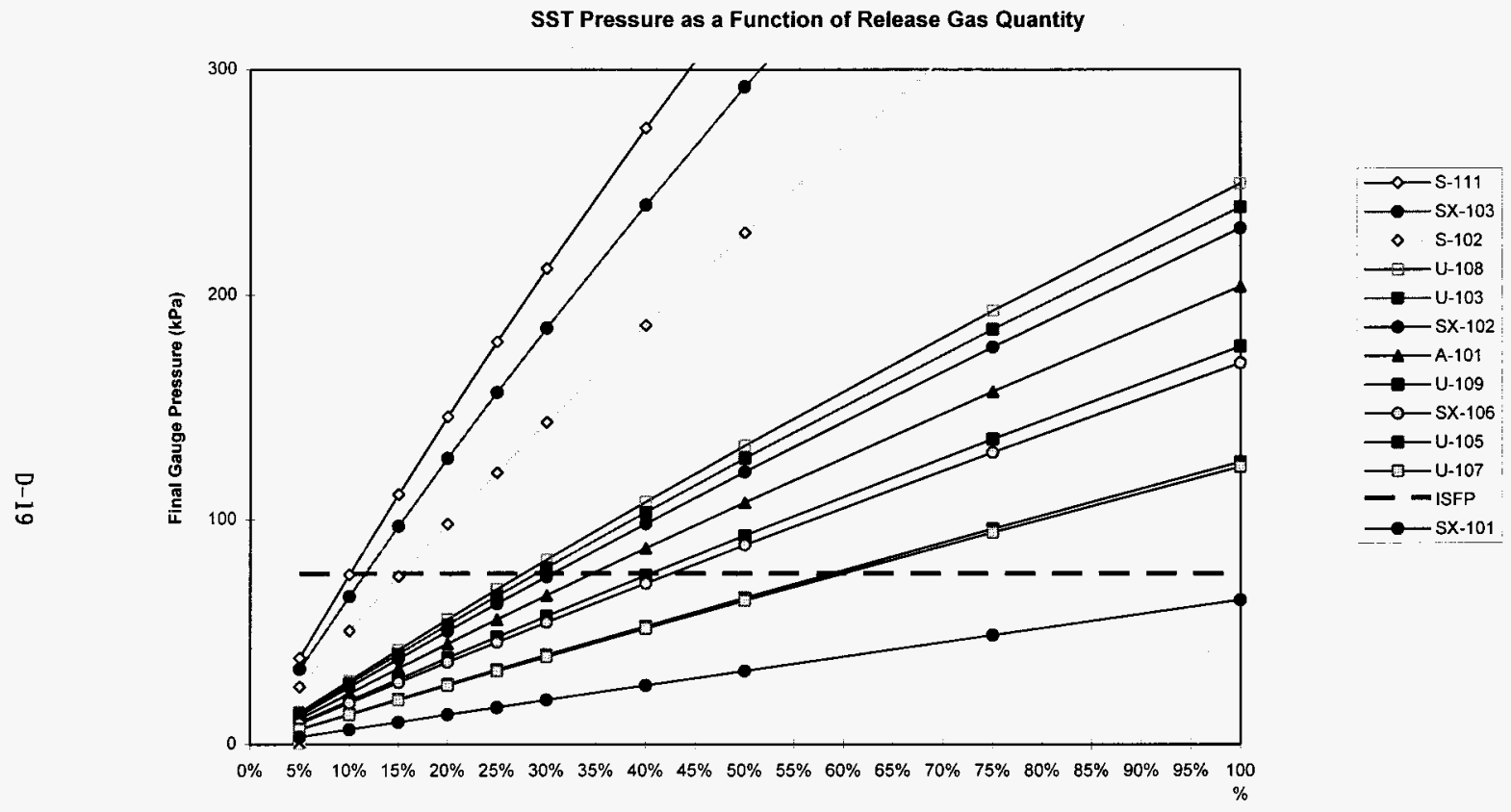

\% Silurry Gas Reieased 

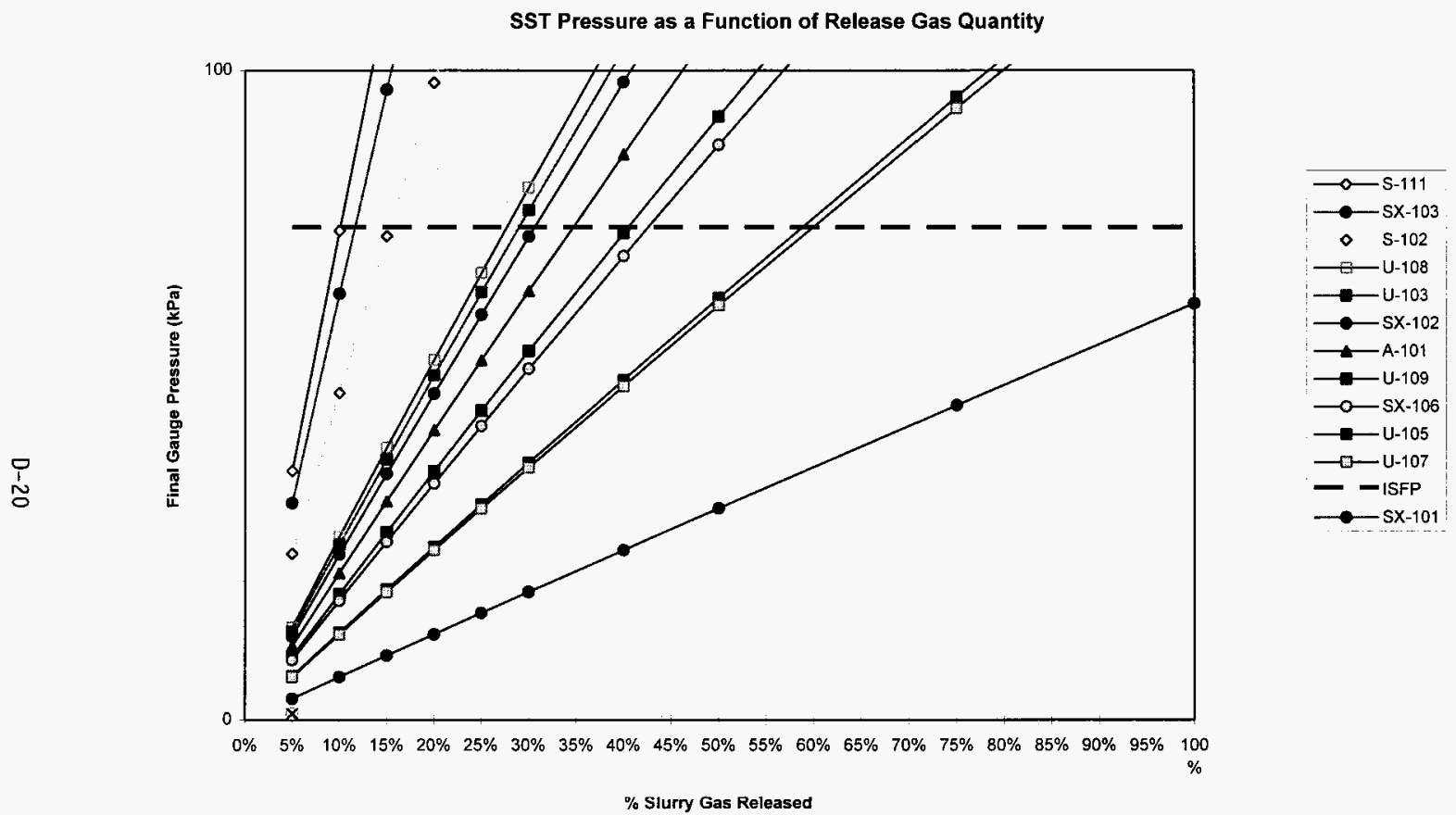


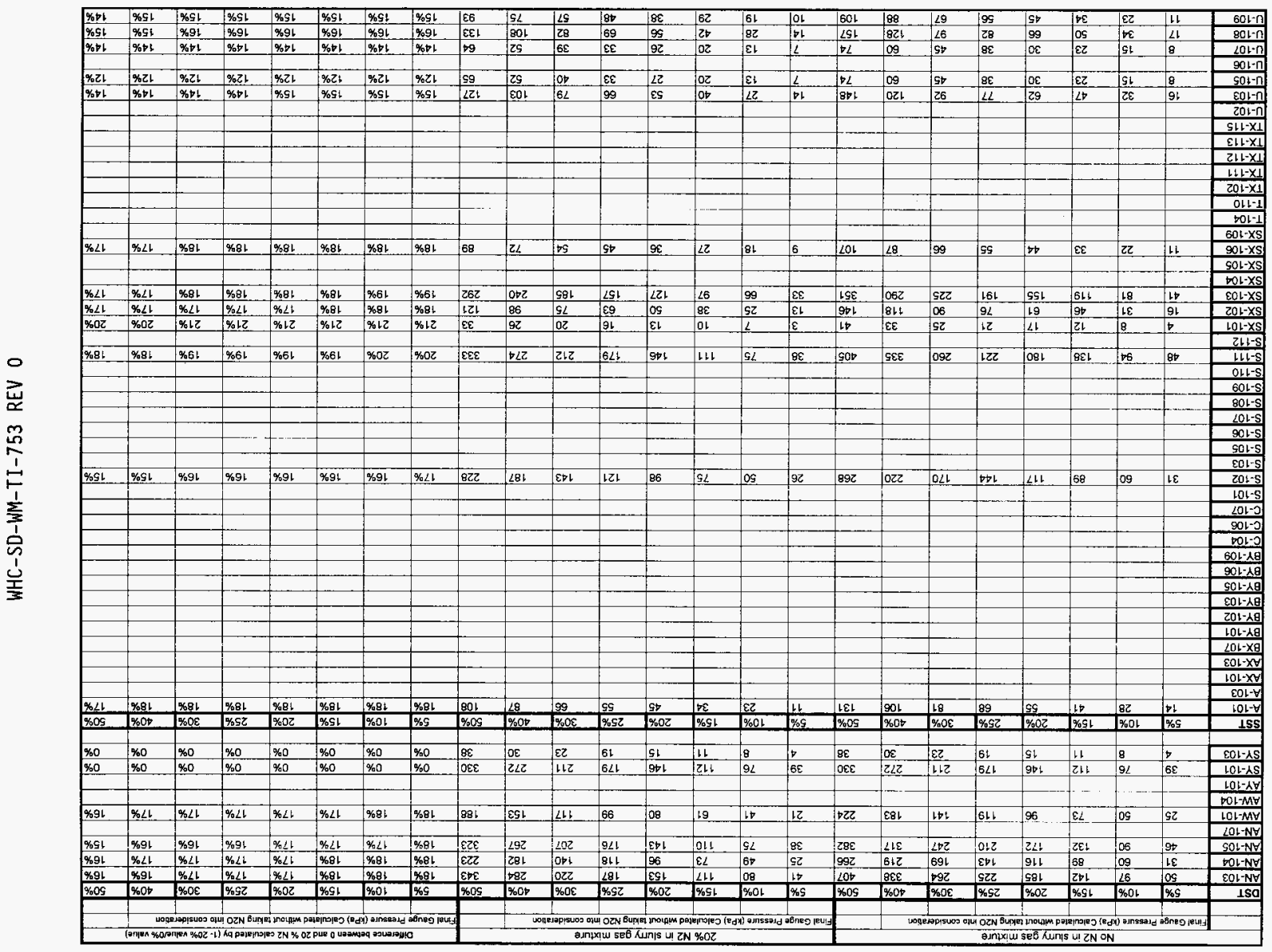




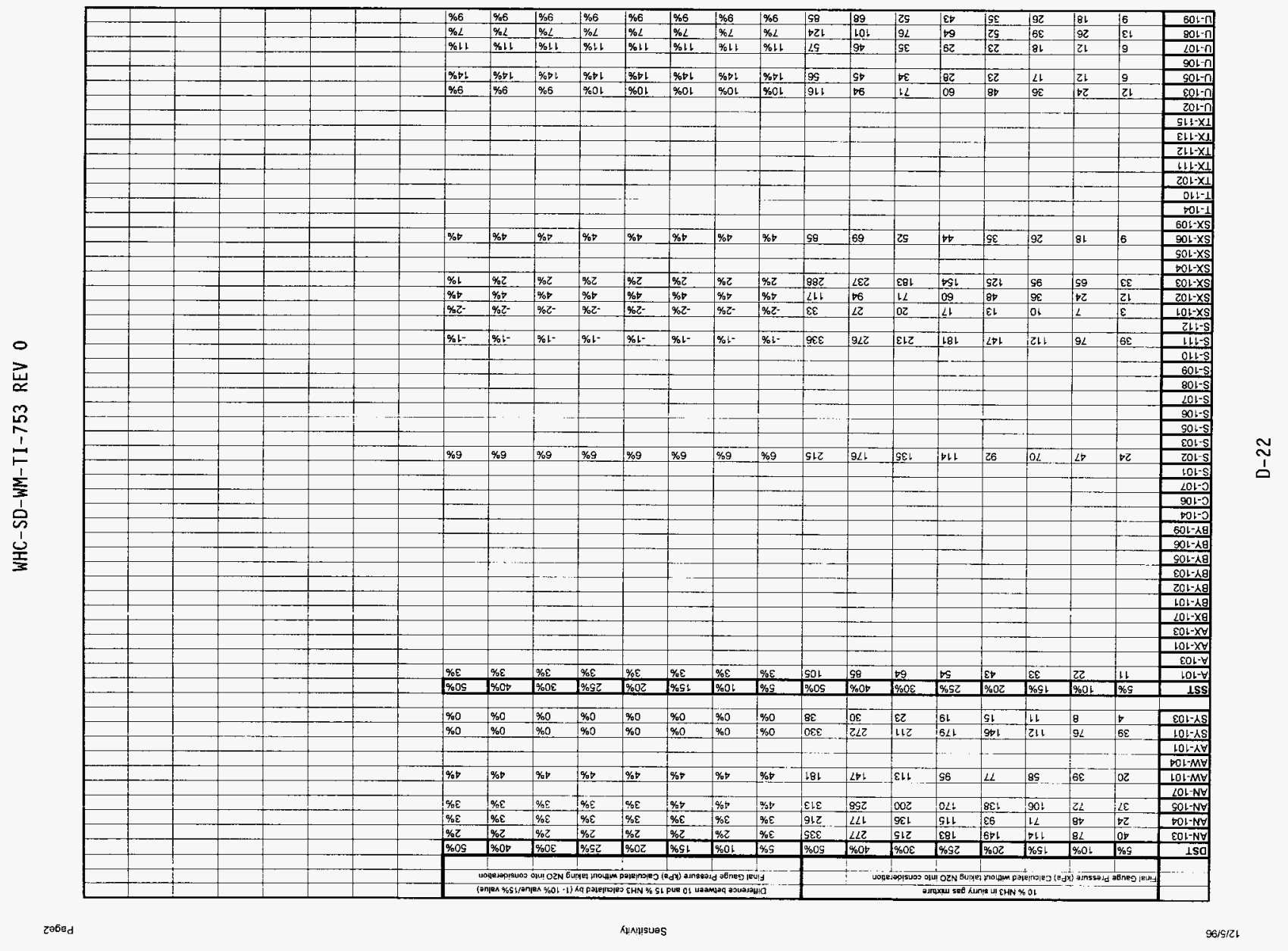




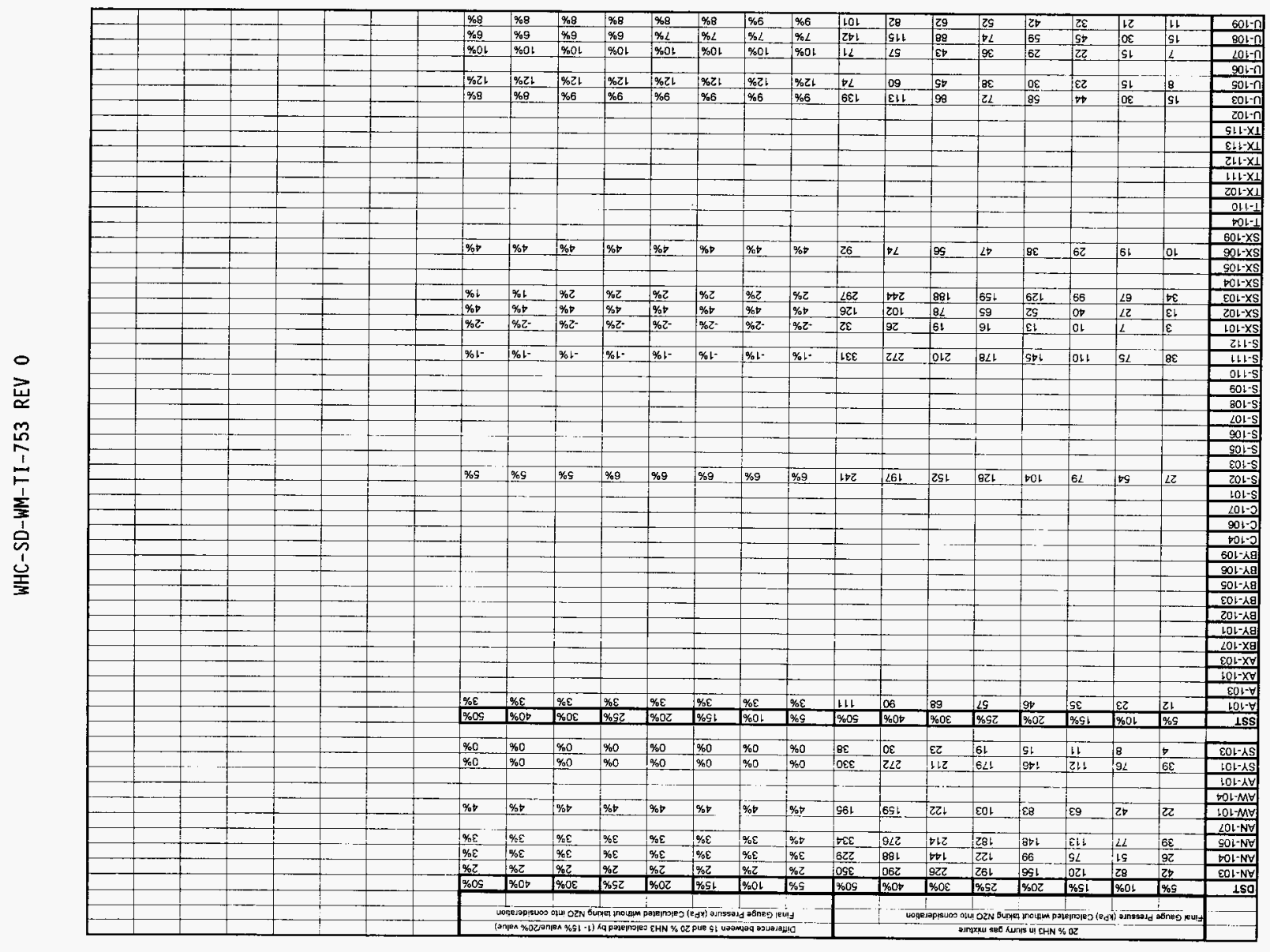


WHC-SD-WM-TI-753 REV 0

This page intentionally left blank. 
WHC-SD-WM-TI-753 REV 0

\section{APPENDIX E}

COMMENTS ON FLAMMABILITY LIMITS AND HUMIDITY 
WHC-SD-WM-TI-753 REV 0

This page intentionally left blank.

$E-2$ 
Received: by ccmail from fepl.rl.gov

From jeshep@galcit.caltech.edu@fepo

$X$-Envelope-From: jeshepegalcit.caltech .eduefepo

Received: by fepl.rl.gov (5.51/5.17.rl-1)

id AA09158; Tue, 16 Jan 96 11:14:42 PST

Received: from znd by kelvin.galcit.caltech.edu with SMTP

(8.6.7/DEI:4.45) id LAA14159; Tue, 16 Jan 1996 11:12:52 -0800

Date: Tue, 16 Jan $199611: 12: 52-0800$

Message-Id: <199601161912. LAA14159@kelvin.galcit.caltech.edu>

X-Sender: jeshep@absolute (Unverified)

Mime-Version: 1.0

Content-Type: text/plain; charset="us-asci $i "$

To: kemal poiumbre.ta52.1an1.gov, Gerald D Jerry Johnsonerl.gov, bōb white@lumbre.ta52.lan1.gov, Nörton G McDuffieerl.gov

From: jeshep@galcit.caltech.edu@fepo (Joe Shepherd)

Subject: Flammability Limits and Humidity

X-Mailer: <Windows Eudora Version 2.0.2>

Some Comments on Flammability Limits and Humidity 16 January 1996

To:

Jerry Johnson Gerald D Jerry Johnsonerl.gov

Norton McDuffie Norton G-McDuffie@rl.gov

Bob White bob_whitêlumbre.ta52.1anl.gov

Kemal Pasamehmetoglu kemāl_p@lumbre.ta52.1an1.gov

From: Joe Shepherd, Caltech

Gentlemen:

I have being following the recent e-mail about flammability limits and humidity that has been forwarded to me by Bob White. After discussing this with Kemal, he suggested that I should provide my own perspective.

First, I think that it is important to recognize that the significance of the humidity effect will depend strongly on the initial temperature. At room temperature $(295-298 \mathrm{~K})$ there appears to be little effect on the mixtures of interest to us. The main reason is that at $295 \mathrm{~K}, 100 \%$ humidity corresponds to a mole fraction of $.026(2.6 \%)$. The effect of water vapor on flammability for the mixtures of interest appears to be mainly thermodynamic, so a very slight change (increase) in the LFL would be expected since the increased heat capacity of water over nitrogen or oxygen would result in a lower energy content and flame temperature. The effect is exceedingly slight and for some gases like hydrogen, there is no measured effect on the LFL of humidity (Coward and Jones, p. 16). At $40 \mathrm{C}$, the maximum fraction of water would be $.08(8 \%)$. This may give a measurable change in the LFL if the mixture was saturated, however nominal conditions in the tanks are $20 \%$ relative humidity so the effect would comparable in magnitude to that at $295 \mathrm{~K}$, i.e., negligible. However, there may be an effect on the flammability of the release mixture itself before mixing with the air in the tank space. But as I discuss below, I think that this will be slight. 
There are some issues of interpretation connected with humidity effects on flammability. It is important to keep these in mind when considering the data.

1. Historically, the effect of humidity, small variations in initial temperature and pressure have been neglected in reporting flammability limits (see p.3, Coward and Jones). The main reason is that these effects are too small to be quantified using the classical flammability apparatus (2" diam tube) and technique. There is substantial intrinsic scatter in the measurement and it is essentially non-quantitative in nature. That is, the criterion for determining flame propagation is subjective in nature, and will vary with the observer and the ignition source.

2. In many cases, such as the detonation experiments of Lucker (and others discussed below), the results are extremely apparatus dependent and the so-called "limits' do represent any intrinsic flammability or detonation limit but simply reflect the limitations of the experiment.

3. It is difficult to dispense gases and measure concentration with the necessary precision to quantify this effect using typical instrumentation found in engineering laboratories. We can in our laboratory measure partial pressure changes as small as $2 * 10^{\wedge}-4$ bar which translates to an accuracy of . $02 \%$ in composition for a single component. But as the errors accumulate when multiple components are introduced into a mixture, the net error on the composition of mixtures will increase up to 0.05 to $0.1 \%$.

4. There will be an effect of initial temperature. Experiments over a range of initial temperatures show that the LFL decreases with increasing temperature with a fixed gas composition. For example, in hydrogen, the LFL for downward propagation decreases from $9 \%$ to $8.8 \%$ as the temperature increases from 20 to $100 \mathrm{C}$ (Coward and Jones, p. 18). When measuring the effect of humidity at elevated temperatures (as done in the BoM tests for WHC), the temperature effect has to be independently considered.

5. The compositions that are reported from older humid experiments are often corrected to a dry mixture basis! That is, the LFL fuel composition is computed for a hypothetical mixture which has the same amount. air, fuel and dituent but the water vapor has been removed. This tends to exaggerate any humidity effect that may be present.

6. The limit of interest for safety considerations is probably that associated with turbulent combustion with an ignition source characteristic of the safety concern, i.e., frictional sparks in the present case. The difference between those limits and the usually quiescent electric spark-initiated LFL is much greater than any difference that might be produced by humidity at room temperature. Unfortunately, these considerations are seldom reflected in realistic error bounds on LFL composition. Keeping this in mind, some measured variations at room temperature are: 
Methane-air LFL $5.24 \%$ (humid) or $5.32 \%$ (humid, reported on a dry basis), $5.22 \%$ (dry) (Coward and Jones)

Ammonia-air LFL $15.95 \%$ (humid - not clear how this was computed) $15.15 \%$ (dry) (Fenton, et a1.)

Hydrogen-air LFL $4.0 \%$ (humid) or $4.1 \%$ dry basis

$4.0 \%$ (dry) (upward propagation, Coward and Jones)

7. As mentioned by Chuck Stewart of PNL, there has been a very substantial amount of work on explosion limits (deflagration and detonation) of steam diluted hydrogen-air mixtures at elevated temperatures. The review paper of mine that he refers to has over 72 references to experiments with hydrogen-air-steam mixtures. As Chuck points out, the LFL of hydrogen-air-steam mixtures appears to be essentially independent of the steam concentration up to a rather high level of dilution, when the composition is expressed on a true basis (\% of total mixture, including the steam). This experimental result for hydrogen-air-steam mixtures is expected to carry over to the more complex mixtures that characterize the GREs as long as there are no significant chemical interactions between water vapor and the other components such as NH3 and N2O. We do not expect this to be the case based on our review of the existing data. The BoM experiments show no significant effect of about $50 \%$ humidity at $54 \mathrm{C}$ on the flammability limits of equimolar H2-N20 in air (Figs. 35 and 37 of WHC-SD-WM-ES-219).

\section{References}

H.F. Coward and G.W. Jones "Limits of Flammability of Gases and Vapors" Bulletin 503 BoM.

A.S. Khan, R.D. Kelley, K.S. Chapman, and D.L. Fenton "Flammability Limits of Ammonia-Air Mixtures" ASHRAE Transactions, Vol. 101, Pt. 2, 1995.

Joseph 
WHC-SD-WM-TI-753 REV 0

This page intentionally left blank.

$E-6$ 
WHC-SD-WM-TI-753 REV 0

\section{APPENDIX F}

WASTE TANK VENTILATION SYSTEM WASTE MATERIAL ACCUMULATIONS

F-1 
WHC-SD-WM-TI-753 REV 0

This page intentionally left blank.

$$
F-2
$$




\begin{tabular}{|c|c|c|c|c|c|c|c|c|c|c|c|c|c|}
\hline \multicolumn{5}{|c|}{ WHC-SD-WM-SARR-037 } & \multirow{2}{*}{\multicolumn{3}{|c|}{$\begin{array}{c}\text { SX, C- } 106 \\
\text { SST Solids on a } 3 \times 3 \text { Array of } \\
24 \times 24 \times 12 \text { Filters }\end{array}$}} & \multicolumn{6}{|c|}{ SSTs with Passive Breather Filters } \\
\hline & \multirow{2}{*}{$\begin{array}{c}\text { SsT Soinds } \\
(\mathrm{Bq} / \mathrm{L})\end{array}$} & \multirow{2}{*}{$\frac{\text { SST Liquids }}{(\mathrm{Bq} / \mathrm{L})}$} & \multirow{2}{*}{\begin{tabular}{|c|} 
DST Liquids \\
(Bq/L)
\end{tabular}} & \multirow{2}{*}{\begin{tabular}{|c|} 
AWF Liquids \\
$(\mathrm{Bq} / \mathrm{L})$ \\
\end{tabular}} & & & & \multicolumn{3}{|c|}{ SST Solids on a $24 \times 24 \times 12$ Filter } & \multicolumn{3}{|c|}{ SST Solids on a $12 \times 12 \times 12$ Filter } \\
\hline & & & & & (Ci) & $(\mathrm{Bq})$ & (L) & (Ci) & $(8 q)$ & (L) & (Ci) & $(\mathrm{Bq})$ & (L) \\
\hline $\operatorname{Co6} 0$ & $4.2 \mathrm{E}+08$ & $9.5 \mathrm{E}+06$ & $7.0 \mathrm{E}+06$ & $7.7 E+05$ & & & & & & & & & \\
\hline Sr90 & $1.6 \mathrm{E}+12$ & 1.1E+10 & $4.6 E+09$ & $5.6 \mathrm{E}+09$ & 0.4840 & $1.8 \mathrm{E}+10$ & 0.011 & 0.4840 & $1.8 E+10$ & 0.011 & 0.4840 & $1.8 \mathrm{E}+10$ & 0.011 \\
\hline Y 90 & $1.6 \mathrm{E}+12$ & 1. $1 E+10$ & $4.6 \mathrm{E}+09$ & $5.6 \mathrm{E}+09$ & 0.4840 & $1.8 \mathrm{E}+10$ & 0.011 & 0.4840 & $1.8 \mathrm{E}+10$ & 0.011 & 0.4840 & $1.8 E+10$ & 0.011 \\
\hline Cs137 & $1.0 \mathrm{E}+11$ & $2.2 \mathrm{E}+10$ & $5.9 \mathrm{E}+10$ & $8.8 \mathrm{E}+10$ & 0.0303 & $1.1 \mathrm{E}+09$ & 0.011 & 0.0303 & $1.1 \mathrm{E}+09$ & 0.011 & 0.0303 & $1.1 E+09$ & 0.011 \\
\hline Eu154 & $5.8 \mathrm{E}+09$ & $2.4 \mathrm{E}+09$ & $4.2 \mathrm{E}+07$ & $0.0 \mathrm{E}+00$ & 0.0017 & $6.3 E+07$ & 0.011 & 0.0017 & $6.3 \mathrm{E}+07$ & 0.011 & 0.0017 & $6.3 \mathrm{E}+07$ & 0.011 \\
\hline Np237 & $3.0 E+07$ & $0.0 \mathrm{E}+00$ & $2.3 \mathrm{E}+05$ & $9.2 \mathrm{E}+04$ & & & & & & & & & \\
\hline Pu238 & $1.9 \mathrm{E}+08$ & $9.2 \mathrm{E}+04$ & $1.8 \mathrm{E}+06$ & $2.8 \mathrm{E}+03$ & & & & & & & & & \\
\hline Pu239 & $4.4 \mathrm{E}+08$ & $3.6 \mathrm{E}+07$ & $7.7 \mathrm{E}+06$ & $1.2 \mathrm{E}+06$ & & & & & & & & & \\
\hline Pu241 & $3.2 \mathrm{E}+09$ & $2.6 E+08$ & $1.8 \mathrm{E}+07$ & $3.4 \mathrm{E}+05$ & & & & & & & & & \\
\hline Am241 & $2.3 \mathrm{E}+08$ & $4.2 \mathrm{E}+07$ & $3.4 \mathrm{E}+07$ & 1.1E+06 & & & & & & & & & \\
\hline \multirow[t]{2}{*}{$\mathrm{Cm} 244$} & $2.3 \mathrm{E}+06$ & $4.2 E+05$ & $1.2 \mathrm{E}+05$ & $1.1 \mathrm{E}+04$ & & & & & & & & & \\
\hline & & & & TOTAL & 1.00 & $3.7 E+10$ & 0.011 & 1.00 & $3.7 \mathrm{E}+10$ & 0.011 & 1.00 & $3.7 \mathrm{E}+10$ & 0.011 \\
\hline \multicolumn{5}{|c|}{ MicroShield Calculated Dose for HEPA (mSv/hr) } & & & 0.257 & & & 1.77 & & & 4.75 \\
\hline & & \multicolumn{3}{|c|}{ HEPA Operating Limit (mSv/hr) } & & & 2 & & & 2 & & & 2 \\
\hline & & & & OL/CD & & & 7.782 & & & 1.12994 & & & 0.42105 \\
\hline & & \multicolumn{3}{|c|}{ HEPA Loading to give OL (L) } & & & 0.08725 & & & 0.01267 & & & 0.00472 \\
\hline & & & \multicolumn{2}{|c|}{$1 \%$ Reiease $(\mathrm{L})$} & & & 0.00087 & & & 0.00013 & & & 4.7E-05 \\
\hline & 1 & & \multicolumn{2}{|c|}{1} & & & & & & & & & \\
\hline \multicolumn{5}{|c|}{ MicroShield Calculated Dose for Prefilter ( $\mathrm{mSv} / \mathrm{hr})$} & & & 0.34 & & & No Prefilter & & & No Prefilter \\
\hline & \multicolumn{4}{|c|}{ Prefilter Operating Limit (mSv/hr) } & & & 2 & & & & & & \\
\hline & & & & OL/CD & & & 5.88235 & & & & & & \\
\hline & & \multicolumn{3}{|c|}{ Prefilter Loading to give $\mathrm{OL}(\mathrm{L})$} & & & 0.06595 & & & & & & \\
\hline & & & \multicolumn{2}{|c|}{$1 \%$ Release $(\mathrm{L})$} & & & 0.00066 & & & & & & \\
\hline & & & & & & & & & & & & & \\
\hline & \multicolumn{4}{|c|}{ Volume Released from One Filter Bank (L) } & & D & 3.06E-03 & & $\mathbf{P}$ & 1.27E-04 & & $\mathbf{P}$ & 4.72E-05 \\
\hline \multicolumn{5}{|c|}{ Number of Parallel Banks Operating at the Same Time } & & & 2 & & & 1 & & & 1 \\
\hline & & \multicolumn{3}{|c|}{ TOTAL RELEASED (L) } & & & 6.13E-03 & & & 1.27E-04 & & & $4.72 \mathrm{E}-05$ \\
\hline & & & & & & & & & & & & & \\
\hline & \multicolumn{13}{|c|}{ D = Two HEPAs, a Prefilter, and another volume equal to the prefilfer for stuff coming out of the ventilation ducting } \\
\hline & $=$ & $2^{*} \mathrm{HEPA}$ Volun & $m e+2^{*}$ Prefilt & ter Volume & & & & & & & & & \\
\hline & $P=$ & Passive breath & her HEPA, no & prefilter, no se & and HEPA, & and no appre & ciable ventilat & in ducting & & & & & \\
\hline & $=$ & 1*HEPA Volun & & & & & & & & & & & \\
\hline & $\mathbf{A}=$ & Two (2) HEPA & Is, no prefilter & but there are & (2) de-en & trainers and $n$ & naterial in the & entilation du & Jcting (1) & & & & \\
\hline & $=$ & 5*HEPA Volun & & & & & & & & & & & \\
\hline & $\mathrm{C}=$ & Two HEPAs, a & a prefilter, a lo & ow efficiency fil & r(treated a & is a prefilter), & and another $\mathrm{vc}$ & ume equal to & to the prefilter $\mathrm{f}$ & for material in & ve vent. duct & & \\
\hline & $=$ & 2*HEPA Volun & $m e+3^{*}$ Prefilte & er Volume & & & & & & & & & \\
\hline
\end{tabular}




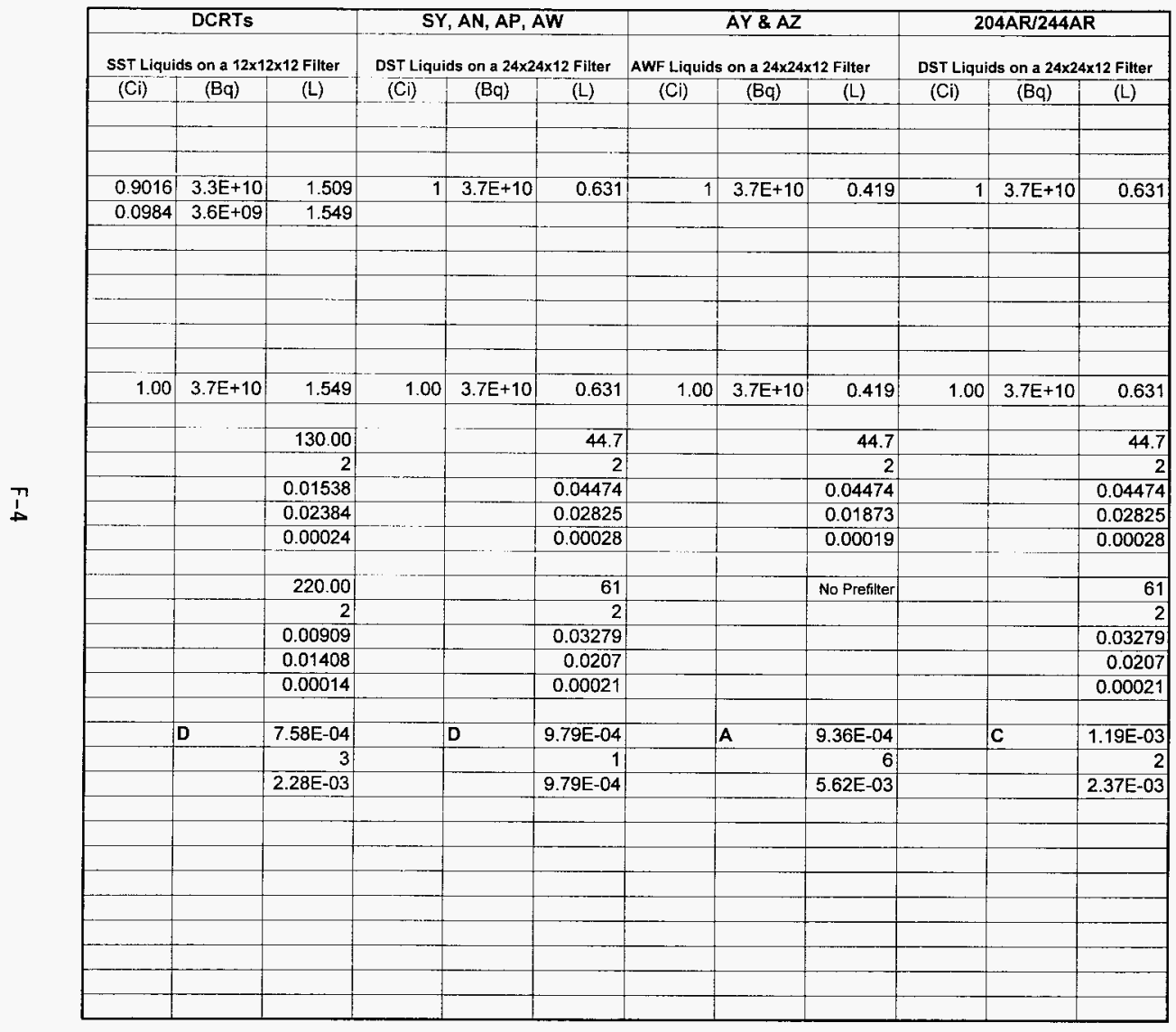


WHC-SD-WM-TI-753 REV 0

APPENDIX G

RADIOLOGICAL AND TOXICOLOGICAL CONSEQUENCES 
WHC-SD-WM-TI-753 REV 0

This page intentionally left blank. 
WHC-SD-WM-TI-753 REV 0

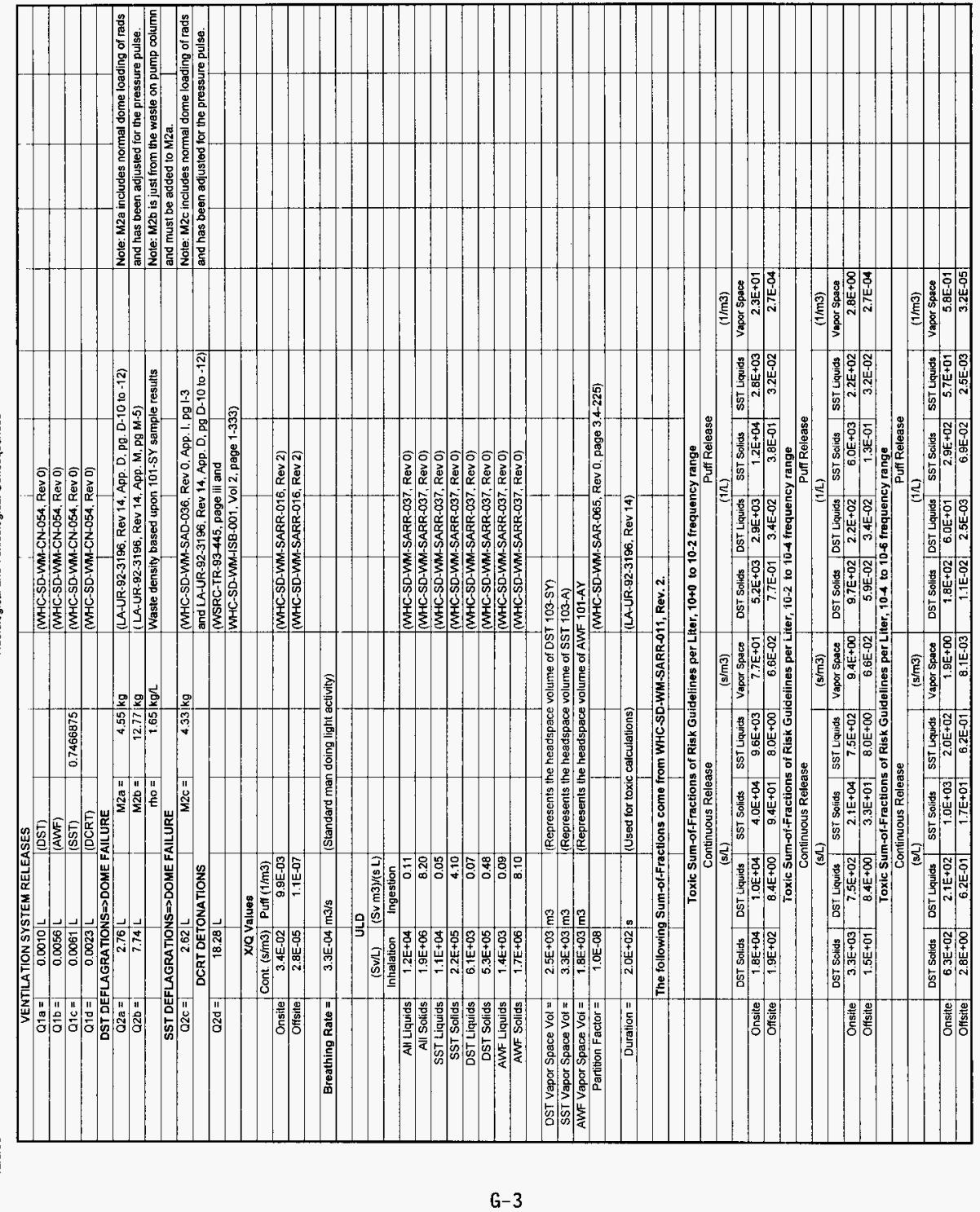




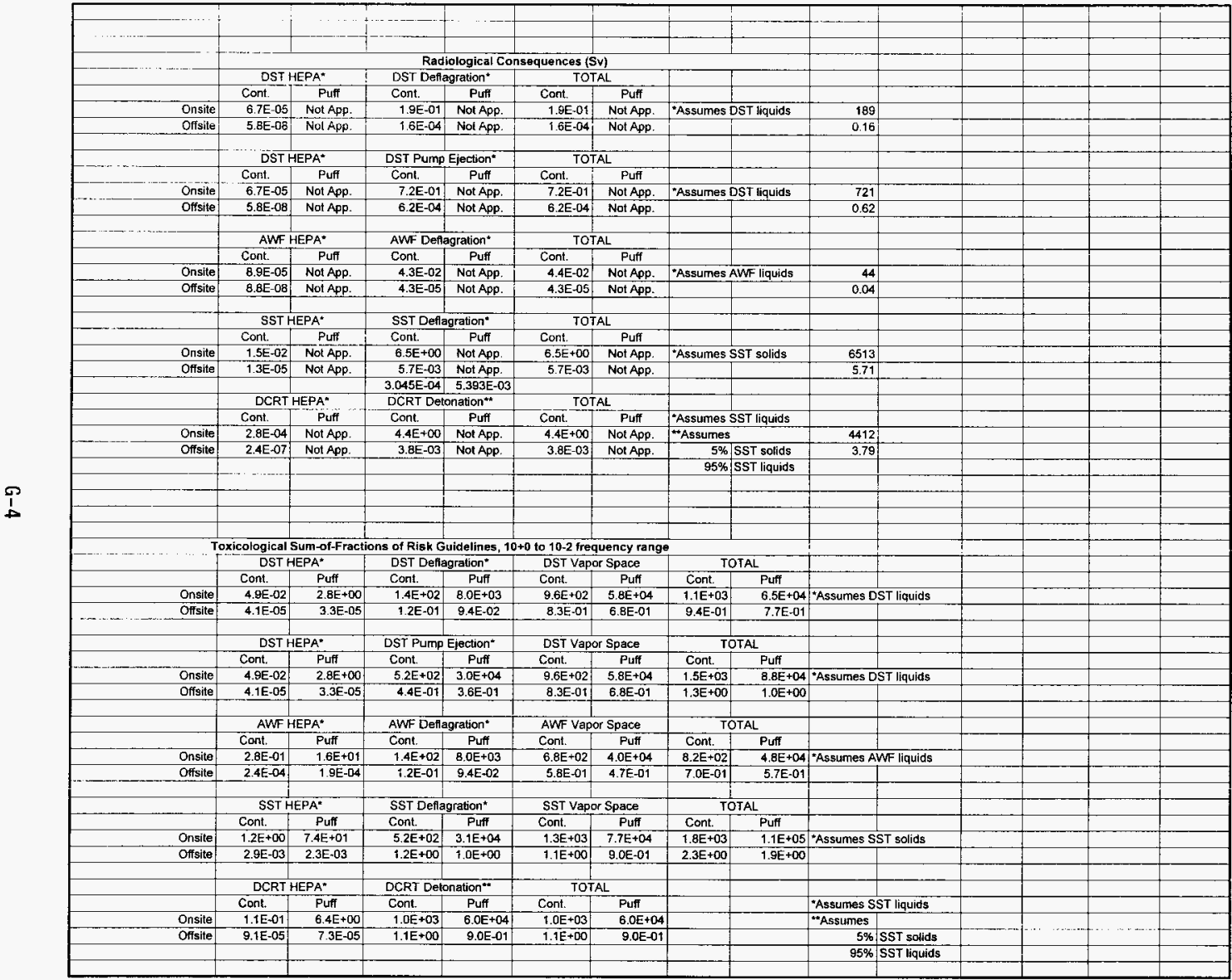




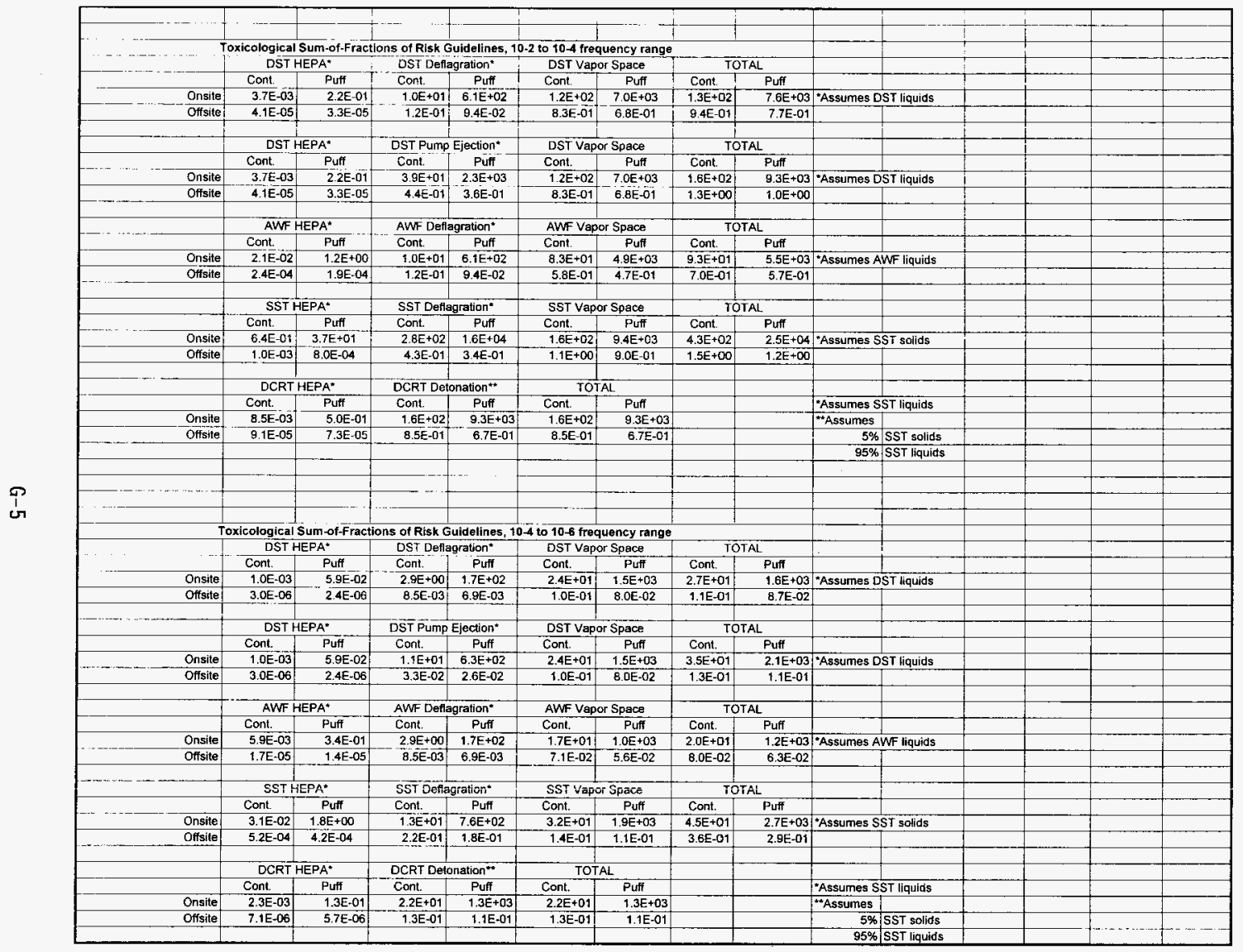


WHC-SD-WM-TI-753 REV 0

This page intentionally left blank. 
WHC-SD-WM-TI-753 REV 0

\section{APPENDIX H \\ CHECKLIST FOR PEER REVIEW}

H-1 


\section{WHC-SD-WM-TI-753 REV 0}

This page intentionally left blank. 


\section{CHECKLIST FOR PEER REVIEW}

Document Reviewed: WHC-SD-WM-TI-753, Rev. 0, Summary of Flammable Gas Hazards and Potential Consequences in Tank Waste Remediation System Facilities at the Hanford Site

Scope of Review: Appendix D, adiabatic pressure calculations

$\frac{\text { Yes }}{\text { No }}$ [ []

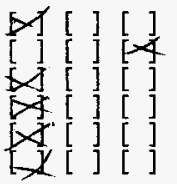

bX [ ] [ ]

[][]$\times[$

$\infty[$ ] [ ]

$\left[\begin{array}{lll}{[} & {[} & k] \\ {[} & {[} & {[}\end{array}\right]$

[X] [ ]

[][]$\times[$

QJ [ ] [ ]

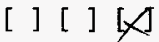

[ ] [ $\mathbb{X}^{*}$
Previous reviews complete and cover analysis, up to scope of this review, with no gaps.

Problem completely defined.

Accident scenarios developed in a clear and logical manner.

Necessary assumptions explicitly stated and supported.

Computer codes and data files documented.

Data used in calculations explicitly stated in document.

Data checked for consistency with original source information as applicable.

Mathematical derivations checked including dimensional consistency of results.

Models appropriate and used within range of validity or use outside range of established validity justified.

Hand calculations checked for errors. Spreadsheet results should be treated exactiy the same as hand calculations.

Software input correct and consistent with document reviewed.

Software output consistent with input and with results reported in document reviewed.

Limits/criteria/guidelines applied to analysis results are appropriate and referenced. Limits/criteria/guidelines checked against references.

Safety margins consistent with good engineering practices.

Conclusions consistent with analytical results and applicable limits.

Results and conclusions address all points required in the problem statement.

Format consistent with appropriate NRC Regulatory Guide or other standards

Review calculations, comments, and/or notes are attached.

Document approved.
Bob M. Marusich (CMVhormoln $9 / 30) 96$

Reviewer (Printed Name and Signature)
Date

* Any calculations, comments, or notes generated as part of this review should be signed, dated and attached to this checklist. Such material should be labeled and recorded in such a manner as to be intelligible to a technically qualified third party. 


\section{CHECKLIST FOR PEER REVIEW}

Document Reviewed: WHC-SD-WM-TI-753, Rev. 0, Summary of Flammable Gas Hazards and Potential Consequences in Tank Waste Remediation System Facilities at the Hanford Site

Scope of Review: Sections 1-5

$\frac{\text { Yes No }}{\text { [ ] [ ] }[\mathrm{X}]}$ *

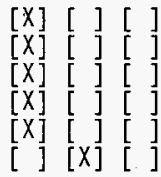

$[X][$ ] [ ]

[ ] [ ] $[X]$

[X] [ ] [ ]

[ ] [ ] $[\mathrm{X}]$

[ ] $[X]$ [ ]

$[x][][]$

[X] [ ] [ ]

[ ] [ ] $[\mathrm{X}]$

[ ] [X] *

[X] [ ] [ ] Document approved. For sections reviewed. review, with no gaps.

Problem completely defined.

Computer codes and data files documented. applicable. of resuits. range of established validity justified. treated exactly the same as hand calculations. document reviewed. against references. limits. For sections reviewed. statement. For sections reviewed. standards

Previous reviews complete and cover analysis, up to scope of this

Accident scenarios developed in a clear and logical manner.

Necessary assumptions explicitly stated and supported.

Data used in calculations explicitiy stated in document.

Data checked for consistency with original source information as

Mathematical derivations checked including dimensional consistency

Models appropriate and used within range of validity or use outside

Hand calculations checked for errors. Spreadsheet results should be

Software input correct and consistent with document reviewed.

Software output consistent with input and with results reported in

Limits/criteria/guidelines applied to analysis results are appropriate and referenced. Limits/criteria/guidelines checked

Safety margins consistent with good engineering practices.

Conclusions consistent with analytical results and applicable

Results and conclusions address all points required in the problem

Format consistent with appropriate NRC Regulatory Guide or other

Review calculations, comments, and/or notes are attached.

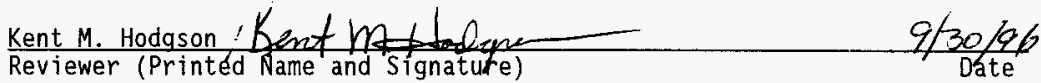

* Any calculations, comments, or notes generated as part of this review should be signed, dated and attached to this checklist. Such material should be labeled and recorded in such a manner as to be intelligible to a technically qualified third party. 


\section{CHECKLIST FOR PEER REVIEW}

Document Reviewed: WHC-SD-WM-TI-753, Rev. 0, Summary of Flammable Gas Hazards and Potential Consequences in Tank Waste Remediation System Facilities at the Hanford Site

Scope of Review: Radiological and toxicological consequences

$\frac{\text { Yes } N o-N A}{[][][]}$

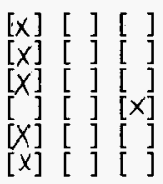

[X] [ ] [ ]

[x] [ ] [ ]

[X] [ ] [ ]

$[x][][]$

[X] [ ] [ ]

$\left[\begin{array}{lll}{[x]} & {[} & {[x]}\end{array}\right]$

[X] [ ] [ ]

[ ] [ ] [X]

[ ] $[X]$ *
Previous reviews complete and cover analysis, up to scope of this review, with no gaps.

Problem completely defined.

Accident scenarios developed in a clear and logical manner.

Necessary assumptions explicitly stated and supported.

Computer codes and data files documented.

Data used in calculations explicitly stated in document.

Data checked for consistency with original source information as applicable.

Mathematical derivations checked including dimensional consistency of results.

Models appropriate and used within range of validity or use outside range of established validity justified.

Hand calculations checked for errors. Spreadsheet results should be treated exactly the same as hand calculations.

Software input correct and consistent with document reviewed.

Software output consistent with input and with results reported in document reviewed.

Limits/criteria/guidelines applied to analysis results are appropriate and referenced. Limits/criteria/guidelines checked against references.

Safety margins consistent with good engineering practices.

Conclusions consistent with analytical results and applicable 1 imits.

Results and conclusions address all points required in the problem statement.

Format consistent with appropriate NRC Regulatory Guide or other standards

[X] [ ] [ ] Document approved.

* Any calculations, comments, or notes generated as part of this review should be signed, dated and attached to this checklist. Such material should be labeled and recorded in such a manner as to be intelligible to a technically qualified third party. 
WHC-SD-WM-TI-753 REV 0

This page intentionally left blank. 


\section{DISTRIBUTION SHEET}

\begin{tabular}{|c|c|c|c|c|c|}
\hline \multirow{2}{*}{$\begin{array}{l}\text { To } \\
\text { Distribution }\end{array}$} & \multirow{2}{*}{\multicolumn{3}{|c|}{$\begin{array}{l}\text { From } \\
\text { RJ Van Vleet }\end{array}$}} & \multicolumn{2}{|l|}{ Page 1 of 2} \\
\hline & & & & \multicolumn{2}{|c|}{ Date $12 / 06 / 1996$} \\
\hline \multicolumn{4}{|l|}{ Project Title/Work Order } & \multicolumn{2}{|c|}{ EDT No. 619405} \\
\hline \multicolumn{4}{|c|}{$\begin{array}{l}\text { WHC-SD-WM-TI-753, Rev. } 0 \text {, Summary of Flammable Gas Hazard and } \\
\text { Potential Consequences in Tank Waste Remediation System } \\
\text { Facilities at the Hanford Site }\end{array}$} & \multicolumn{2}{|l|}{ ECN No. } \\
\hline Name & MSIN & $\begin{array}{l}\text { Text } \\
\text { With All } \\
\text { Attach. }\end{array}$ & Text Only & $\begin{array}{l}\text { Attach./ } \\
\text { Appendix } \\
\text { Only }\end{array}$ & $\begin{array}{c}\text { EDT/ECN } \\
\text { Only }\end{array}$ \\
\hline
\end{tabular}

Project Hanford Manaqement Company (76)

Central Files

H. Babad

S. A. Barker

N. F. Barilo

W. B. Barton

R. E. Bauer

J. L. Blackwell

D. R. Bratzel

J. G. Burton

R. J. Cash

M. L. Dexter

R. A. Dodd

G. L. Dunford

W. G. Farley

G. W. Gault

R. L. Guthrie

D. W. Hamilton

G. N. Hanson

J. P. Harris

R. C. Hill

G. D. Johnson

N. W. Kirch

C. E. Leach

D. S. Leach

J. W. Lentsch

E. J. Lipke

R. M. Marusich

W. H. Meader

D. M. Ogden

R. E. Raymond

R. W. Reed

S. H. Rifaey

W. E. Ross

G. W. Ryan

G. R. Sawtelle

R. L. Schlosser

0. M. Serrano

E. R. Siciliano

D. B. Smet

P. L. Smith
A3-88 X

S7-14

R2-11

R3-01

R2-11

S7 -14

A2-34

S7-14

S7-01

S7-14

$\mathrm{R} 1-51$

S5-07

A2-34

A3-37

A3 -37

A3-37

S7-12

S5-05

S2-48

Rl-51

S7-14

R2-11

R1-49

A3-34

S7-14

A2-34

A3-34

S8-05

HO-34

S7-12

S5-07

$\mathrm{R} 1-56$

S5-07

A3-37

A3-37

$\mathrm{R} 1-56$

R2-54

HO-31

N1-46

R3-08

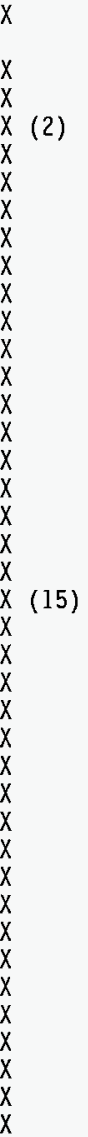


DISTRIBUTION SHEET

\begin{tabular}{|c|c|c|c|c|c|}
\hline To & \multirow{2}{*}{\multicolumn{3}{|c|}{$\begin{array}{l}\text { From } \\
\text { RJ Van Vleet }\end{array}$}} & \multicolumn{2}{|l|}{ Page 2 of 2} \\
\hline Distribution & & & & \multicolumn{2}{|c|}{ Date $12 / 06 / 1996$} \\
\hline \multicolumn{4}{|l|}{ Project Title/Work Order } & \multicolumn{2}{|c|}{ EDT No. 619405} \\
\hline \multicolumn{4}{|c|}{$\begin{array}{l}\text { WHC-SD-WM-TI-753, Rev. 0, Summary of Flammable Gas Hazard and } \\
\text { Potential Consequences in Tank Waste Remediation System } \\
\text { Facilities at the Hanford Site }\end{array}$} & \multicolumn{2}{|l|}{ ECN No. } \\
\hline Name & MSIN & $\begin{array}{l}\text { Text } \\
\text { With All } \\
\text { Attach. }\end{array}$ & Text Only & $\begin{array}{l}\text { Attach./ } \\
\text { Appendix } \\
\text { Only }\end{array}$ & $\begin{array}{c}\text { EDT/ECN } \\
\text { Only }\end{array}$ \\
\hline
\end{tabular}

S. M. Stahl

R. P. Tucker

R. J. Van Vleet

K. A. White

J. R. White

J. H. Wicks

S. U. Zaman

Pacific Northwest National Laboratory
A3-37

T4-00

A3-34

S5-09

H5-09

R2 -50

R3-08

(6)
M. E. Brewster
J. W. Brothers
P. A. Gauglitz
L. R. Pederson
C. W. Stewart
P. D. Whitney

Los Alamos National Laboratory

D. R. Bennett

S. Eisenhawer

W. L. Kubic

K. Pasamehmetog $1 \mathrm{u}$

E. Rodriguez

J. Spore
K9-62

K9-20

P7-41

K7-15

K7-15

$\mathrm{K} 5-12$

\section{U.S. Department of Energy - Richland Field Office (11)}
M. H. Campbel1
K. 0 . Chen
J. M. Gray
C. A. Groendyke
R. R. McNulty
G. W. Rosenwald

$57-73$

$\begin{array}{ll}K 575 & X \\ K 575 & X \\ K 575 & X \\ K 575 & X \\ K 575 & X \\ K 575 & X\end{array}$

$x$
$x$
$x$
$X$
$x$
$X$

(6)

S7-54

S7-54

S7-54

S7-51

S7-54 